MUNIR MACHADO DE SOUSA SABAG

AS OBRAS ITALIANAS NÃO EDITADAS DOS WINCHESTER PARTBOOKS (GB-WCc MS 153): UM ESTUDO ENTRELAÇADO DOS PROCESSOS DE TRANSCRIÇÃO E INTERPRETAÇÃO

São Paulo

2020 
MUNIR MACHADO DE SOUSA SABAG

\title{
AS OBRAS ITALIANAS NÃO EDITADAS DOS \\ WINCHESTER PARTBOOKS (GB-WCc MS 153): UM \\ ESTUDO ENTRELAÇADO DOS PROCESSOS DE \\ TRANSCRIÇÃO E INTERPRETAÇÃO
}

\author{
Versão Corrigida \\ (versão original disponível na Biblioteca da ECA/USP)
}

Tese apresentada à Escola de Comunicações e Artes da Universidade de São Paulo para a obtenção do título de Doutor em Artes junto ao Programa de Pósgraduação em Música.

Área de Concentração: Processos de Criação Musical

Linha de Pesquisa: Questões Interpretativas

Orientador: Prof. Dr. Marco Antonio da Silva Ramos

São Paulo

2020 
Autorizo a reprodução e divulgação total ou parcial deste trabalho, por qualquer meio convencional ou eletrônico, para fins de estudo e pesquisa, desde que citada a fonte.

Catalogação na Publicação

Serviço de Biblioteca e Documentação

Escola de Comunicações e Artes da Universidade de São Paulo

Dados inseridos pelo(a) autor(a)

Sabag, Munir Machado de Sousa

As obras italianas não editadas dos Winchester Partbooks

(GB-WCC MS 153): um estudo entrelaçado dos processos de

transcrição e interpretação / Munir Machado de Sousa Sabag ;

orientador, Marco Antonio da Silva Ramos. -- São Paulo,

2020

291 p.: il.

Tese (Doutorado) - Programa de Pós-Graduação em Música -

Escola de Comunicações e Artes / Universidade de São Paulo.

Bibliografia

Versão corrigida

1. Polifonia Renascentista 2. Winchester Partbooks 3.

Villanella 4. Notação mensural branca 5. Estudos de

performance I. Ramos, Marco Antonio da Silva II. Título.

CDD 21.ed. - 780

Elaborado por Alessandra Vieira Canholi Maldonado - CRB-8/6194 
SABAG, Munir M. S. As obras italianas não editadas dos Winchester Partbooks (GBWCc MS 153): um estudo entrelaçado dos processos de transcrição e interpretação. 2020. 291 f. Tese (Doutorado em Artes) - Escola de Comunicações e Artes da Universidade de São Paulo. São Paulo, 2020.

Aprovado em:

Banca Examinadora

Prof. Dr.

Instituição:

Julgamento:

Prof. Dr.

Instituição:

Julgamento:

Prof. Dr.

Instituição:

Julgamento:

Prof. Dr.

Instituição:

Julgamento:

Prof. Dr.

Instituição:

Julgamento: 


\section{AGRADECIMENTOS}

Ao Prof. Dr. Marco Antonio da Silva Ramos pela orientação segura desta pesquisa, pela longa amizade, pelo constante encorajamento e por compartilhar generosamente o olhar experiente e agudo que tem sobre a música.

À Profa. Dra. Susana Cecília Almeida Igayara de Souza, líder do GEPEMAC, pela oportunidade de participar deste grupo como pesquisador e pela orientação do Trabalho de Conclusão de Curso que foi, há alguns anos, o embrião desta pesquisa.

Ao Programa de Pós-Graduação em Música da ECA-USP pela estrutura oferecida aos estudantes e pelo apoio financeiro concedido para participação na 47th MedRen Conference 2019 Basel.

A todo o Comunicantus: Laboratório Coral da ECA-USP pelo ambiente saudável e estimulante; ao Everton da Cruz, em particular, por sua eficiência e disponibilidade para todo o necessário.

Aos queridos integrantes e ex-integrantes do Madrigal Comunicantus, que se dedicaram a ensaiar semanalmente parte do repertório tratado neste texto: Ana Maria Graciano Figueiredo, Camilla Liberali da Silva Ramos, Camila Lohmann, Cecilia Busato, Débora Diniz, Denise Cocareli, Erika Scarpinella, Fernanda Moura, Filipe Fonseca, Flávio Moreira, Giovanna Elias, Giselle Cota, Gustavo Alves, Joaquim Sanches, Julia Chicote, Lucas Torres, Lucienne Coltri, Marcelo Recski, Marcia Malaquias, Marcio Giachetta Paulilo, Martha Monteiro, Raquel Neves, Silvestre Lonardelli, Vera Marta Takayama, Vinicius Penteado, Vinicius Pontes e Willians Rodrigues.

A Fernanda Moura pelo trabalho de técnica vocal gentilmente realizado junto ao Madrigal Comunicantus em 2019.

Ao colega Marcelo Recski pela participação ativa no Madrigal Comunicantus e pelas importantes reflexões compartilhadas sobre questões de performance.

Aos Drs. Fernando Cardoso e Elam Rotem pela disposição demonstrada para examinar e discutir exemplos de musica ficta.

À Profa. Dra. Martha Monteiro (IME-USP) pelas discussões a respeito do tópico das proporções. 
Aos professores Dr. Jorge de Almeida e Dra. Maria Cecilia Casini (FFLCH-USP) pela enorme gentileza com que revisaram os textos italianos e suas traduções.

Ao Dr. Magnus Williamson (University of Newcastle), pela preciosa oportunidade de aprendizado e prática de transcrições no projeto Tudor Partbooks.

Aos colegas Carolina Andrade, Denise Cocareli e Filipe Fonseca pelo companheirismo acadêmico e constante solicitude.

Ao professor Roberto Rodrigues pelo auxílio na etapa preparatória ao ingresso neste programa.

A todos os meus coralistas externos à Universidade por haverem compreendido e respeitado as exigências diárias que esta pesquisa representaria.

A Karin Riske, Leonardo Blecher e Ana Assumpção pela amizade e constante apoio.

À minha família, que não hesitou em apoiar mais esta iniciativa e novamente me perdoou inúmeras ausências.

A Marcia Hentschel - interlocutora incansável e inspiradora - não apenas pelas incontáveis e profundas discussões a respeito do conteúdo deste texto, mas sobretudo pela infinita paciência e carinho que teve comigo durante o período de sua elaboração. 


\section{RESUMO}

SABAG, Munir M. S. As obras italianas não editadas dos Winchester Partbooks (GBWCc MS 153): um estudo entrelaçado dos processos de transcrição e interpretação. 2020. 291 f. Tese (Doutorado em Artes) - Escola de Comunicações e Artes da Universidade de São Paulo. São Paulo, 2020.

Neste trabalho apresentamos um estudo de aspectos notacionais e interpretativos de obras vocais em italiano pertencentes aos Winchester Partbooks, manuscritos flamengos datados da década de 1560 e hoje localizados na Winchester College Warden and Fellows Library (Winchester, Inglaterra). Os manuscritos, disponibilizados digitalmente em 2016, constituem um conjunto de quatro volumes (discantus, altus, tenor e bassus) e contêm 107 peças seculares a três e quatro vozes, das quais 81 são formas vocais italianas, 16 são chansons francesas e 10 são peças inglesas adicionadas por um escriba posterior. Após uma discussão preliminar das fontes e das formas musicais nelas presentes, descrevemos o processo através do qual pudemos identificar 41 obras em italiano (villanellas, em sua maioria) ainda não editadas em notação moderna - e estas foram selecionadas para transcrição como parte deste trabalho. Em virtude das importantes diferenças estruturais entre a notação musical moderna e a notação mensural branca do século XVI, discutimos os aspectos rítmicos deste sistema através de exposições teóricas e possíveis aplicações ao repertório em questão. $\mathrm{O}$ tópico das inflexões ficta - isto é, as alterações cromáticas não notadas nas fontes originais e possivelmente acrescentadas a suas edições modernas - é abordado através da exposição do sistema hexacordal e do exame de casos específicos aos quais podem ser aplicadas. Em seguida abordamos alguns aspectos interpretativos através da discussão do uso de fontes originais para a performance deste repertório. No capítulo final, apresentamos o texto musical através de transcrições em formato de partitura, que contêm também os textos italianos e suas respectivas traduções para o português. As discussões teóricas e editoriais, assim como as reflexões a respeito da performance, são entremeadas por exemplos extraídos do corpus sob consideração, caracterizando a pesquisa como um estudo entrelaçado envolvendo musicologia, edição e interpretação.

Palavras-chave: Winchester Partbooks. Polifonia Renascentista. Villanella. Transcrição musical. Notação mensural branca. Interpretação. Estudos de performance. 


\begin{abstract}
SABAG, Munir M. S. The Unedited Italian Works from the Winchester Partbooks (GB-WCc MS 153): an Interlaced Study of the Transcription and Interpretation Processes. 2020. 291 f. Thesis (Doctor of Arts) - Escola de Comunicações e Artes da Universidade de São Paulo. São Paulo, 2020.
\end{abstract}

In this work we present a study of notational and interpretative aspects of Italiantexted works belonging to the Winchester Partbooks - Flemish manuscripts dated from the 1560s and now located at the Winchester College Warden and Fellows Library (Winchester, England). The manuscripts, made available online in 2016, constitute a set of four volumes (discantus, altus, tenor and bassus) and contain 107 three- and fourvoiced secular pieces, 81 of which are Italian vocal forms, 16 are French chansons and 10 are English pieces added by a later scribe. Following a preliminary discussion regarding the sources and the musical forms therein, we describe the process through which we were able to single out 41 Italian-texted works (mostly villanellas) not yet edited in modern notation and these were selected for transcription as part of this work. Due to the important structural differences between modern musical notation and the 16th-century white mensural notation, we discuss rhythmic aspects of this system through theoretical expositions and possible applications to the repertoire in question. The topic of ficta inflections - i. e., chromatic alterations not notated in the original sources and possibly added to their modern editions - is approached through the exposition of the hexachordal system and examination of specific cases to which they may be applied. We later approach some interpretative aspects through the discussion of the use of original sources for the performance of this repertoire. In the final chapter we present the musical text through transcriptions in score format, which contain the Italian texts and their translations to Portuguese. The theoretical and editorial discussions, as well as the thoughts on performance, are interspersed with examples drawn from the corpus under consideration, characterizing the research as an interlaced study involving musicology, edition and interpretation.

Keywords: Winchester Partbooks. Renaissance Polyphony. Villanella. Musical Transcription. White Mensural Notation. Interpretation. Performance Studies. 


\section{LISTA DE FIGURAS}

Figura 1 - Início das composições de Nola e Willaert de Madonn'io non lo so (colagem) (NOLA, 1930, p. 13; WILLAERT, 1930, p. 18).

Figura 2 - Início das composições de Nola e Willaert de Cingari simo (colagem) (NOLA, 1936, p. 13; WILLAERT, 2015, p. 1)...

Figura 3 - Início do refrão das composições de Nola e Donato de Chi la gagliarda (colagem) (NOLA, 1983, p. 35; DONATO, 2014, p. 2).

Figura 4 - Início das composições de Nola e Willaert de O dolce vita mia che t'haggio fatto (colagem) (NOLA, 1949, p. 86; WILLAERT, 1949, p. 88).

Figura 5 - Capa da encadernação da parte do discantus. ..........................................34

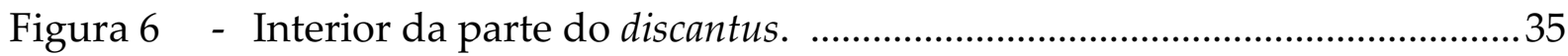

Figura 7 - Primeira página das canções italianas (discantus). ..................................36

Figura 8 - Primeira página das chansons francesas (discantus). ..............................37

Figura 9 - Primeira página das canções inglesas (discantus). ...................................37

Figura 10 - Modelo da ficha do protocolo de identificação para os Winchester Partbooks.

Figura 11 - Formas usuais das figuras e pausas em publicações impressas no século XVI.

Figura 12 - Formas manuscritas das figuras e pausas extraídas dos Winchester Partbooks.

Figura 13 - Exemplos de ligaduras (HEYDEN, 1540, p. 45).

Figura 14 - Ligaduras binárias em notação mensural branca (APEL, 1953, p. 90).

Figura 15 - Representações esquemáticas das regras de ligaduras (APEL, 1953, p. 92).

Figura 16 - Valores das figuras em posições iniciais, médias ou finais em ligaduras exemplificadas no tratado Scintille di Musica (LANFRANCO, 1533, p. 38).

Figura 17 - Valores das figuras expressos em número de semibreves para exemplos extraídos de $A$ Plain and Easy Introduction to Practical Music (MORLEY, 1608, p. 10-11).

Figura 18 - Exemplo de ligadura cum opposita proprietate no tenor da peça Non posso far, cor mio, de Hubert Waelrant (Winchester Partbooks, n. 38).

Figura 19 - Mensurações da longa, brevis e semibrevis. 59

Figura 20 - Diagramas das relações entre as figuras mensurais em diferentes combinações de tempus e prolatio (MORLEY, 1608, p. 15-16).

Figura 21 - Perfeições nos níveis tempus e prolatio.

Figura 22 - Imperfeição $a$ parte post e a parte ante em tempus perfectum. 
Figura 23 - Pausas notadas em diferentes alturas em tempus perfectum (APEL, 1953, p. 111).

Figura 24 - Notação de pausas na peça Fiamenga fredda, core di diamante, de Adrian Tubal (Winchester Partbooks, n. 15), escrita em tempus imperfectum cum prolatione imperfecta.

Figura 25 - Exemplos de imperfeição ad partem e ad partes em prolatio perfecta

Figura 26 - Coloração em prolatio perfecta e prolatio imperfecta.

Figura 27 - Exemplos das regras de imperfeição da brevis em tempus perfectum (APEL, 1953, p.108).

Figura 28 - Alteração da semibrevis em tempus perfectum.

Figura 29 - Valores temporais (expressos em número de breves) de longae e breves em tempus perfectum (STAINER, 1900, p. 220).

Figura 30 - Uso do punctus divisionis (STAINER, 1900, p. 220).

Figura 31 - Exemplo de tempus imperfectum cum prolatione imperfecta (Winchester Partbooks, n. 31) e transcrição moderna realizada pelo presente autor sem redução de valores. .74

Figura 32 - Exemplo de tempus perfectum cum prolatione imperfecta e transcrição moderna de Alec Harman (MORLEY; HARMAN, 1952 , p. 51) modificada para $\diamond=\mathbf{O}$ (sem redução de valores). .74

Figura 33 - Exemplo de tempus imperfectum cum prolatione perfecta e transcrição moderna de Alec Harman (MORLEY; HARMAN, 1952, p. 36) modificada para $\boldsymbol{\nabla}$ (sem redução de valores).

Figura 34 - Exemplo de tempus perfectum cum prolatione perfecta (APEL, 1953, p. 143), versão mensural com decodificação das ligaduras e transcrição moderna de John Stainer (STAINER; STAINER, 1898, p. 50-51) modificada para $\diamond=\mathbf{O}$ (sem redução de valores).

Figura 35 - Associação dos sinais de mensuração com tactus igual e tactus desigual segudo a teoria musical dos séculos XV e XVI (ZARLINO, 1573, Lib. III, p. 144).

Figura 36 - Início da transcrição do discantus das peças Ecco la stagion novella (Winchester Partbooks, n. 5) e Mort'è pietà, de Hubert Waelrant (Winchester Partbooks, n. 13), realizada pelo presente autor.

Figura 37 - Agrupamentos irregulares de semiminimae no início da peça Tanto sai fare cogli innamorati, de Adrian Tubal (Winchester Partbooks, n. 39).

Figura 38 - Duas possíveis transcrições do início da peça Conza lavezzi siam, de Hubert Waelrant (Winchester Partbooks, n. 43).

Figura 39 - Agrupamentos rítmicos em diferentes vozes da peça La manza mia si chiama Saporita, de Adrian Tubal (Winchester Partbooks, n. 16). ........91

Figura 40 - Proporções do genus multiplex (ZARLINO, 1589, lib. I, cap. XXIIII). 
Figura 41 - Proporções do genus superparticulare (ZARLINO, 1589, lib. I, cap. XXVI).

Figura 42 - Proporções do genus superpartiens (ZARLINO, 1589, lib. I, cap. XXVII).

Figura 43 - Proporções do genus multiplex superparticulare (ZARLINO, 1589, lib. I, cap. XXVIII).

Figura 44 - Proporções do Genus multiplex superpartiens. (ZARLINO, 1589, lib. I, cap. XXIX).

Figura 45 - Proporções aplicadas à semibrevis. 102

Figura 46 - Exemplo de Vicente Lusitano para proportio dupla (LUSITANO, $1558, f .10 v)$ e transcrição moderna realizada pelo presente autor. .....103

Figura 47 - Exemplo de Vicente Lusitano para proportio tripla (LUSITANO, $1558, f .10 v)$ e transcrição moderna realizada pelo presente autor. .....103

Figura 48 - Exemplo de Vicente Lusitano para proportio quadrupla (LUSITANO, $1558, f .10 v)$ e transcrição moderna realizada pelo presente autor. .....104

Figura 49 - Exemplo de Vicente Lusitano para proportio sesquitertia (LUSITANO, 1558, f. 11r) e transcrição moderna realizada pelo presente autor. .......104

Figura 50 - Exemplo de Thomas Morley para proportio tripla em tempus perfectum e transcrição de Alec Harman (MORLEY; HARMAN, 1952, p. 51-52) modificada para $\diamond=\mathbf{O}$ (sem redução de valores). 105

Figura 51 - Exemplo de Vicente Lusitano para proportio sesquialtera (LUSITANO, $1558, f .11 r$ ) e transcrição moderna realizada pelo presente autor. 106

Figura 52 - Exemplos de Adriano Banchieri para o uso de proportio sesquialtera através de notas coloridas (BANCHIERI, 1614, p. 31).

Figura 53 - Transcrição do exemplo de Adriano Banchieri (BANCHIERI, 1614, p. 31) para o uso de proportio sesquialtera através de notas coloridas, realizada pelo presente autor.

Figura 54 - Interpretações do sinal 3 como tripla ou sesquialtera ...............................109

Figura 55 - Interpretação alternativa do sinal 3. .....................................................110

Figura 56 - Convenções editoriais para transcrições de mudanças métricas e coloração.

Figura 57 - Início do discantus da peça anônima Ecco la stagion novella (Winchester Partbooks, n. 5) e transcrição moderna realizada pelo presente autor.

Figura 58 - Alterações métricas na peça anônima Ecco la stagion novella (Winchester Partbooks, n. 5) e transcrição moderna realizada pelo presente autor.

Figura 59 - Alterações métricas no discantus da peça Tri ciechi siamo, de Hubert Waelrant (Winchester Partbooks, n. 18).

Figura 60 - Transcrição de alterações métricas na peça Tri ciechi siamo, de Hubert Waelrant (Winchester Partbooks, n. 18), realizada pelo presente autor. 
Figura 61 - Alterações métricas na peça Tri ciechi siamo, de Giovane da Nola (NOLA, 1545, n. 1).

Figura 62 - Alterações métricas no discantus da peça O Dio, che fosse quella costumanza, de Hubert Waelrant (Winchester Partbooks, n. 10).

Figura 63 - Transcrição de alterações métricas na peça O Dio, che fosse quella costumanza, de Hubert Waelrant (Winchester Partbooks, n. 10), realizada pelo presente autor.

Figura 64 - Alterações métricas no discantus da peça Conza lavezzi siam, de Hubert Waelrant (Winchester Partbooks, n. 43).

Figura 65 - Transcrição de alterações métricas na peça Conza lavezzi siam, de Hubert Waelrant (Winchester Partbooks, n. 43), realizada pelo presente autor.

Figura 66

- Alterações métricas no discantus da peça L'amanza mia si chiama saporita, de Adrian Tubal (Winchester Partbooks, n. 16).

Figura 67 - Transcrição de alterações métricas na peça L'amanza mia si chiama saporita, de Adrian Tubal (Winchester Partbooks, n. 16), realizada pelo presente autor.

Figura 68 - Alterações métricas no altus da peça Non t'arricordi, de Hubert Waelrant (Winchester Partbooks, n. 45).

Figura 69 - Transcrição de alterações métricas na peça Non t'arricordi, de Hubert Waelrant (Winchester Partbooks, n. 45), realizada pelo presente autor.

Figura 70 - Scala musicalis ou gamut (QUERCU, 1509, f. 3r).

Figura 71 - Detalhes do gamut destacando as alturas a la mi re e Gamma ut (QUERCU, 1509, f. 3r).

Figura 72 - Ilustrações da mão guidoniana em tratados dos séculos XV a XVII (RAMIS DE PAREIA, 1482, f. 2v; QUERCU, 1509, f. 2r; LUSITANO, 1558, f. 2v; ZACCONI, 1596, f. 15v; BANCHIERI, 1614, p. 3; PENNA, 1679, p. 5).

Figura 73 - Sequência das alturas representadas na mão guidoniana (PENNA, 1679, p. 5).

Figura 74 - Ampliação do gamut usando-se as costas da mão (VANNEO, 1533, f. 9v,10v).

Figura 75 - Detalhe da mão ilustrada por Penna indicando quadrum e b molle (PENNA, 1679, f. 5).

Figura 76 - Posições dos hexacordes duros (hard), naturais (natural) e moles (soft) no gamut transposto (cantus mollis) (ROUTLEY, 1985, p. 62), com solmização acrescentada pelo presente autor.

Figura 77 - Pontos de mutação para solmização hexacordal em movimento ascendente e descendente em cantus durus e em cantus mollis (GUMPELZHAIMER, 1591, f. Cr, Cijr). 
Figura 78 - Solmização hexacordal e pontos de mutação para movimento ascendente e descendente em cantus durus (BARNETT, 2002, p. 410). 130

Figura 79 - Solmização hexacordal e pontos de mutação para movimento ascendente e descendente em cantus mollis (BARNETT, 2002, p. 410).

Figura 80 - Alturas solmizadas com a sílaba $f a$ acima dos hexacordes, garantindo intervalos de um semitom com as notas adjacentes.

Figura 81 - Alturas solmizadas com a sílaba $f a$ acima dos hexacordes, garantindo intervalos de um semitom com as notas adjacentes (sistema transposto).

Figura 82 - Parte original do altus e compassos 15-19 da transcrição da peça Madonna mia per te son quasi morto, de Hubert Waelrant (Winchester Partbooks, n. 51).

Figura 83 - Possíveis inflexões ficta em consonâncias imperfeitas em progressões para consonâncias perfeitas (ROUTLEY, 1985, p. 66). .....137

Figura 84 - Inflexões ficta nas cláusulas subsemitonum modi (ROUTLEY, 1985, p. 67).

Figura 85 - Trecho original do discantus e compassos 14-17 da transcrição da peça Deh, perchè abbandonasti me, de Adrian Tubal (Winchester Partbooks, n. 42).

Figura 86 - Trechos originais do discantus, altus e tenor e compassos 30-35 da transcrição da peça Mill'anni sono ch'io non t'haggio vista, de Hubert Waelrant (Winchester Partbooks, n. 29).

Figura 87 - Trechos originais do altus e bassus e compassos 62-68 da transcrição da peça Deh, perchè abbandonasti me, de Adrian Tubal (Winchester Partbooks, n. 42).

Figura 88 - Inicipit precedendo a transcrição moderna da peça Donna, voi siete bella, de Adrian Tubal (Winchester Partbooks, n. 17).

Figura 89 - Impressão em formato choirbook (LIBRO PRIMO DE LA CROCE, 1531, fol. xiiiv, ix $r$ )

Figura 90 - Madrigal Comunicantus em apresentação realizada em 29/11/2019 no Espaço das Artes ECA-USP (Foto: Filipe Fonseca)

Figura 91 - Fac-símile do início da parte do discantus da peça Fiamenga fredda, core di diamante, de Adrian Tubal (Winchester Partbooks, n. 15)

Figura 92 - Transcrição da parte do discantus da peça Fiamenga fredda, core di diamante, de Adrian Tubal (Winchester Partbooks, n. 15), utilizando-se figuras e claves modernas.

Figura 93 - Fac-símile do início da parte do altus da peça Fiamenga fredda, core di diamante, de Adrian Tubal (Winchester Partbooks, n. 15)

Figura 94 - Transcrição da parte do altus da peça Fiamenga fredda, core di diamante, de Adrian Tubal (Winchester Partbooks, n. 15), utilizando-se figuras e claves modernas. 
Figura 95 - Fac-símile do início da parte do tenor da peça Fiamenga fredda, core di diamante, de Adrian Tubal (Winchester Partbooks, n. 15)

Figura 96 - Transcrição da parte do tenor da peça Fiamenga fredda, core di diamante, de Adrian Tubal (Winchester Partbooks, n. 15), utilizando-se figuras e claves modernas.

Figura 97 - Fac-símile do início da parte do bassus da peça Fiamenga fredda, core di diamante, de Adrian Tubal (Winchester Partbooks, n. 15)

Figura 98 - Transcrição da parte do bassus da peça Fiamenga fredda, core di diamante, de Adrian Tubal (Winchester Partbooks, n. 15), utilizando-se figuras e claves modernas.

Figura 99 - Primeiras páginas da transcrição em partitura da peça Fiamenga fredda, core di diamante, de Adrian Tubal (Winchester Partbooks, n. 15).

Figura 100 - Acentuações observadas nas leituras em partes separadas ou em partitura para um trecho do discantus da peça Fiamenga fredda, core di diamante, de Adrian Tubal (Winchester Partbooks, n. 15).

Figura 101 - Exemplo do possível uso do Mensurstrich em um trecho da peça Fiamenga fredda, core di diamante, de Adrian Tubal (Winchester Partbooks, n. 15).

\section{LISTA DE EXEMPLOS}

Exemplo 1 - Início da transcrição do madrigal anônimo Pace non trovo (Winchester Partbooks, n. 4) sem redução de valores, realizada pelo presente autor.

Exemplo 2 - Transcrição do início da peça Sta' costante, cor mio, ch'io t'amo ogn'hora, de Hubert Waelrant (Winchester Partbooks, n. 35) sem redução de valores.

Exemplo 3 - Compassos 22-29 da transcrição da peça Fiamenga fredda, core di diamante, de Adrian Tubal (Winchester Partbooks, n. 15).

Exemplo 4 - Compassos 4-9 da peça Tri ciechi siamo, de Hubert Waelrant (Winchester Partbooks, n. 18).

Exemplo 5 - Compassos 1-5 da peça I dolci sguardi tuoi, alta signora, de Hubert Waelrant (Winchester Partbooks, n. 36).

Exemplo 6 - Compassos 5-9 da peça O Dio che fosse quella costumanza, de Hubert Waelrant (Winchester Partbooks, n. 10).

Exemplo 7 - Compassos 15-18 da peça La manza mia si chiama saporita, de Adrian Tubal (Winchester Partbooks, n. 10).

Exemplo 8 - Compassos 29-32 da peça I dolci sguardi tuoi, alta signora, de Hubert Waelrant (Winchester Partbooks, n. 36). 
Exemplo 9 - Compassos 21-28 da peça Tanto sai fare con li innamorati, de Adrian Tubal (Winchester Partbooks, n. 39).

Exemplo 10 - Compassos 39-43 da peça Donna voi siete bella, de Adrian Tubal (Winchester Partbooks, n. 17).

Exemplo 11 - Compassos 18-23 da peça Mill'anni sono ch'io non t'haggio vista, de Hubert Waelrant (Winchester Partbooks, n. 29).

\section{LISTA DE TABELAS}

Tabela 1 - Lista das peças dos Winchester Partbooks (FORNEY, 1999, p. 56-58)...39

Tabela 2 - Peças italianas selecionadas para transcrição. ...........................................44

Tabela 3 - Número de peças italianas por compositor. ...............................................45

Tabela 4 - Detalhamento dos processos sofridos pelas figuras originais no exemplo de tempus imperfectum cum prolatione perfecta. ..........................75

Tabela 5 - Detalhamento dos processos sofridos pelas figuras originais no exemplo de tempus perfectum cum prolatione perfecta. ...............................77

Tabela 6 - Ocorrências de sinais de mensuração diferentes de $\mathbf{C}$ nas peças selecionadas para transcrição na presente pesquisa. .84

Tabela 7 - Quantidades comparadas em proporção, termos das divisões e nomenclaturas das proporções do genus multiplex exemplificadas por Zarlino.

Tabela 8 - Quantidades comparadas em proporção, termos das divisões e nomenclaturas das proporções do genus superparticulare exemplificadas por Zarlino.

Tabela 9 - Quantidades comparadas em proporção, termos das divisões e nomenclaturas das proporções do genus superpartiens exemplificadas por Zarlino.

Tabela 10 - Quantidades comparadas em proporção, termos das divisões e nomenclaturas das proporções do genus multiplex superparticulare exemplificadas por Zarlino.

Tabela 11 - Quantidades comparadas em proporção, termos das divisões e nomenclaturas das proporções do genus multiplex superpartiens exemplificadas por Zarlino. 


\section{LISTA DE ABREVIATURAS}

$\begin{array}{lll}\text { WPB } & - & \text { Winchester Partbooks } \\ L & - & \text { longa } \\ B & - & \text { brevis } \\ S & - & \text { semibrevis } \\ M & - & \text { minima } \\ \text { Sm } & - & \text { semiminima } \\ F & - & \text { fusa } \\ S f & - & \text { semifusa }\end{array}$




\section{SUMÁRIO}

1 INTRODUÇÃO

2 AS FORMAS VOCAIS LIGEIRAS DO RENASCIMENTO E OS WINCHESTER PARTBOOKS.

2.1 RELAÇÕES ENTRE O MADRIGAL E AS FORMAS VOCAIS LIGEIRAS

2.2 WINCHESTER PARTBOOKS (WINCHESTER COLLEGE WARDEN AND FELLOWS LIBRARY, MS 153)

2.2.1 Seleção de peças para análise: o protocolo de identificação do material .38

3 WINCHESTER PARTBOOKS: TRANSCRIÇÃO À LUZ DA TEORIA .48

3.1 TRATAMENTO DE ELEMENTOS RÍTMICOS …………………………….....50

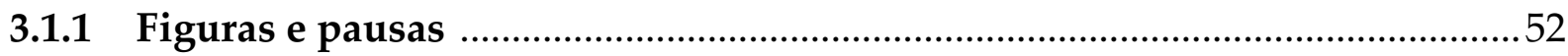

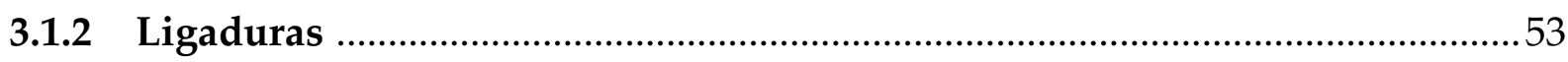

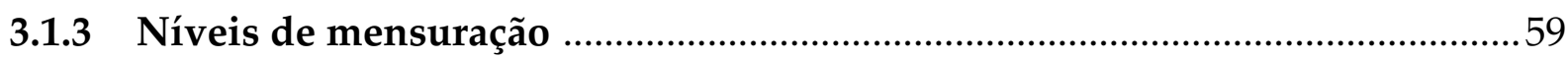

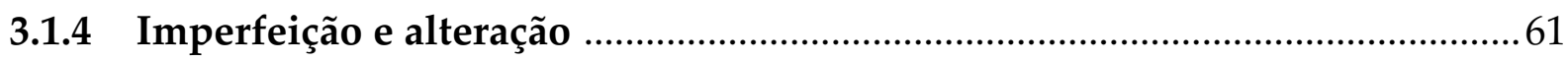

3.1.5 Punctus divisionis e punctus additionis ........................................................70

3.1.6 Exemplos das mensurações principais ……………………………………......71

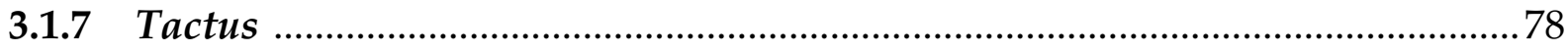

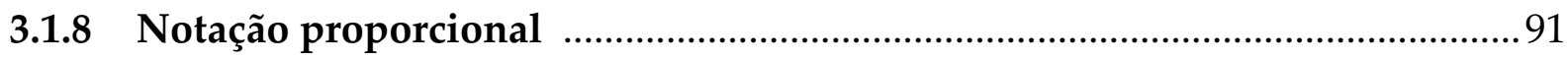

3.1.8.1 As proporções como entidades matemáticas .......................................................91

3.1.8.2 Aplicação das proporções à música mensural .....................................................101 
3.1.9 Relações entre metros binários e ternários nos Winchester Partbooks

3.2 TRATAMENTO DOS ACIDENTES E MUSICA FICTA 120

3.2.1 Gamut guidoniano e sistema hexacordal 120

3.2.2 Convenções para a aplicação de inflexões ficta 132

3.2.2.1 Mi contra fa 132

3.2.2.2 Fa super la 134

3.2.2.3 Cadentia 137

3.2.2.4 Subsemitonum modi 139

3.2.2.5 Tierce de picardie 140

3.2.3 Interpretação de acidentes escritos 141

3.3 ALGUMAS CONSIDERAÇÕES SOBRE PERFORMANCE 150

3.3.1 Partbooks e partituras 152

3.3.2 Relato de caso: Madrigal Comunicantus 155

3.3.2.1 Constituição do grupo 156

3.3.2.2 Experiência com leitura em partbooks 159

4 TRANSCRIÇÕES DAS PEÇAS SELECIONADAS 171

4.1 PACE NON TROVO (WPB, n. 4) 173

4.2 ECCO LA STAGION NOVELLA (WPB, n. 5)

4.3 IO CHE TROPP' ALT' AMOR VOLSI SEGUIRE (WPB, n. 7) 180

4.4 TU SEI LA CAUSA DE LA MORTE MIA (WPB, n. 9) 182

4.5 O DIO CHE FOSSE QUELLA COSTUMANZA (WPB, n. 10) 184 


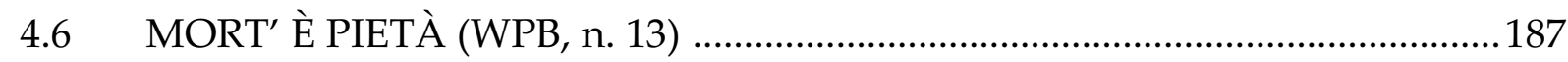

4.7 FIAMENGA FREDDA, CORE DI DIAMANTE (WPB, n. 15) …………….......190

4.8 LA MANZA MIA SI CHIAMA SAPORITA (WPB, n. 16) …………………......193

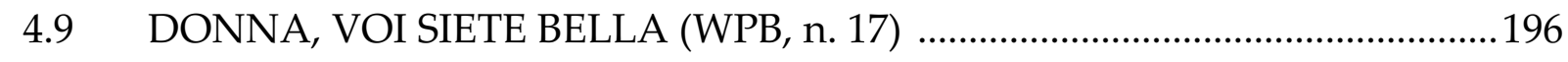

4.10 TRI CIECHI SIAMO (WPB, n. 18) …………………………………….......199

4.11 PASCHINO, BELLO PASCHINO (WPB, n. 22) ................................................203

4.12 MILL'ANNI SONO CH'IO NON T'HAGGIO VISTA (WPB, n. 29) ...............206

4.13 NON T'HO POSSUTO MAI, DONNA, MOSTRARE (WPB, n. 31) ................209

4.14 CHIAMO LA MORT' OGN'HOR (WPB, n. 34) …………………………....212

4.15 STA' COSTANTE, COR MIO, CH'IO T'AM' OGN'HORA (WPB, n. 35). .....214

4.16 I DOLCI SGUARDI TUOI, ALTA SIGNORA (WPB, n. 36) ............................216

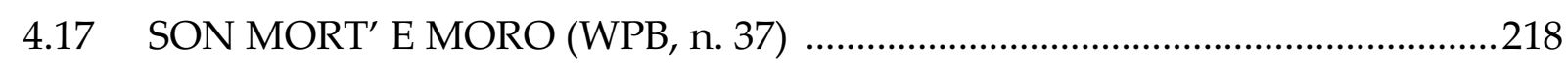

4.18 NON POSSO FAR, COR MIO, CHE PUR NON PIANGA (WPB, n. 38) .......220

4.19 TANTO SAI FARE CON L'INNAMORATI (WPB, n. 39) ………………….....223

4.20 AMAR DIVERS' AMANTI (WPB, n. 40) …………………………………....225

4.21 DEH PERCHÈ ABBANDONASTI ME (WPB, n. 42) ……….............................228

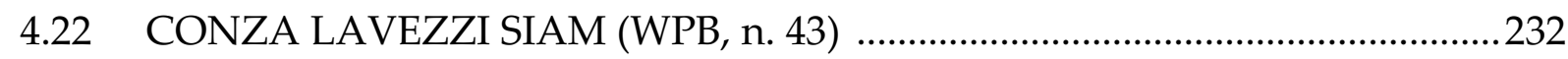

4.23 MADONN' HABBI PIETÀ DEL MIO MARTIRE (WPB, n. 44) ........................2235

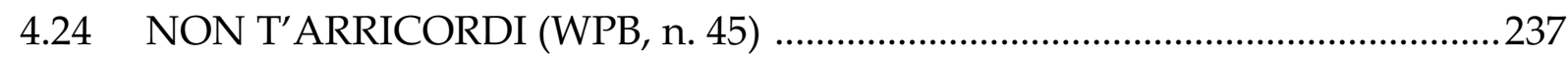

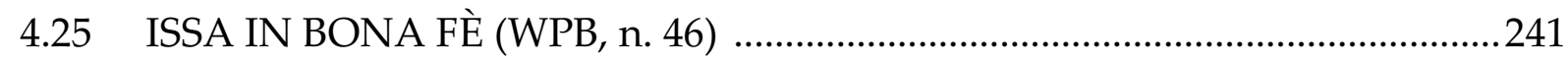

4.26 QUANTI NE VEDI, TUTT' A TE LI TIRI (WPB, n. 50) …………………….....24

4.27 MADONNA MIA, PER TE SON QUASI MORTO (WPB, n. 51) .....................247 
4.28 IN TUTTO VUOI CH'IO MOR' O TRADITORA (WPB, n. 52) ........................250

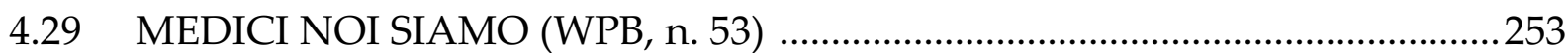

4.30 PORT' ACQUA' L CRIN E PIGLIA VENT' IN RETE (WPB, n. 54) ................255

4.31 ME BISOGNA SERVIR QUESTA CRUDELE (WPB, n. 55) ............................258

4.32 LA BELLA MONICELLA VAD’ A MESSA (WPB, n. 56) ................................261

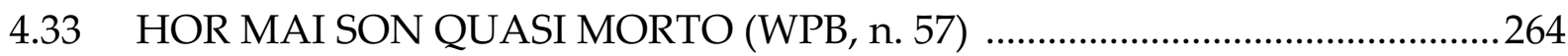

4.34 SON MOLTI GIORNI, AHIMÈ, CH'IO PERS' IL CORE (WPB, n. 58) ...........267

4.35 VORRIA E NON VORRIA QUESTO VI DIRE (WPB, n. 62) ..........................270

4.36 OGNIUNO SAPP' HORMAI LA PENA MIA (WPB, n. 63) .............................272

4.37 FORSI PERCHÈ CORE MIO BELL' AHIMÈ (WPB, n. 39) ..............................274

4.38 QUELL' HORA DESIATA SEMPR' ASPETTO (WPB, n. 65) ..........................277

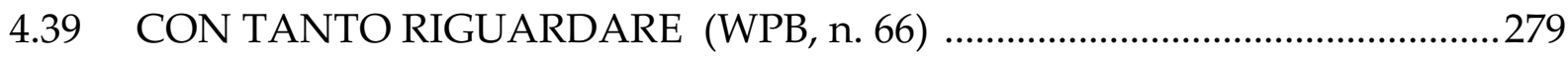

4.40 A D'ALTRE LO VUOI DARE 'STE PASSATE (WPB, n. 80) ...........................281

4.41 SE BEN DA VOI MADDON' I FIA LONTANO (WPB, n. 81) .........................283

5 CONSIDERAÇÕES FINAIS: UM ESTUDO ENTRELAÇADO ..................286

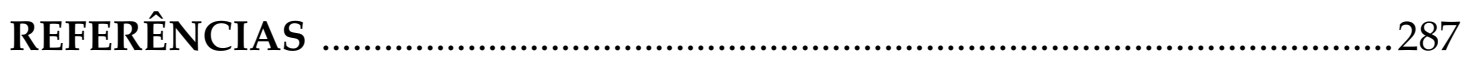




\section{INTRODUÇÃO}

A pesquisa apresentada neste texto trata de questões interpretativas relacionadas à música vocal secular do Renascimento europeu, com ênfase no madrigal e em algumas de suas formas correlatas. Os dois principais propósitos da investigação foram: (i) compreender as relações existentes entre a notação original da música renascentista, os diferentes processos de transcrição para a notação moderna e as questões interpretativas envolvidas em sua performance; e (ii) possibilitar, através de análise de fontes originais e esforços de transcrição, o acesso de intérpretes não necessariamente especializados no repertório do Renascimento a peças que não fazem parte do repertório canônico associado a este período. Diante destes objetivos, a pesquisa foi iniciada por estudos de repertório através dos quais se buscou examinar fontes musicais dos séculos XVI e XVII - além de edições modernas e gravações - com a finalidade de identificar e selecionar novas obras de interesse para transcrição e análise. Diversas varreduras foram realizadas entre fontes primárias (livros de madrigais e antologias publicadas até o início do século XVII) visando-se à identificação de obras ainda não editadas em notação moderna e preferencialmente exequíveis também por grupos não especializados. Conforme discutiremos no próximo capítulo, estas buscas permitiram a localização de um conjunto de manuscritos flamengos datados da década de 1560, os Winchester Partbooks, que contêm 41 peças italianas a quatro vozes (villanelle, em sua maioria) aparentemente nunca publicadas em notação moderna - e estas constituem o objeto central da presente pesquisa.

A possibilidade de se realizar este tipo de investigação no Brasil é relativamente recente e inteiramente devida às iniciativas dos principais museus, universidades e bibliotecas europeias e norte-americanas que têm digitalizado partes de seus acervos musicais e tornado possível a consulta a um número crescente de manuscritos e edições dos séculos XV, XVI e XVII. Uma busca pelo termo "madrigali" em títulos de coleções disponíveis para visualização completa, realizada em março de 2015 nos 
principais repositórios digitais de música antiga ${ }^{1}$, nos retornou ao menos 1000 resultados - número que não incluía as publicações de gêneros seculares contemporâneos como a canzonetta, a villanella, a chanson ou o Lied; paralelamente, o contínuo crescimento do volume de fontes secundárias relacionadas a este repertório (transcrições, análises e gravações) pode ser observado em projetos abertos de colaboração como IMSLP (Internet Music Score Library Project), CPDL (Choral Public Domain Library), assim como no circuito comercial de edições e registros fonográficos. Nossa percepção deste prodigioso volume de materiais originais disponíveis para investigação foi, sem dúvida, um dos fatores que declancharam esta pesquisa.

Sob o ponto de vista da musicologia e dos estudos de repertório, a polifonia vocal do Renascimento tem sido objeto de vastas e aprofundadas investigações. São notáveis, para os madrigais italianos e ingleses, os estudos - possivelmente ainda não superados em sua abrangência - publicados em meados do século XX, The Italian Madrigal (EINSTEIN, 1949) e The Elizabethan Madrigal: a Comparative Study (KERMAN, 1962). A obra de Einstein, editada em três volumes, aborda cada um dos subgêneros do madrigal italiano e as formas ligeiras a ele relacionadas, fornecendo transcrições (em claves antigas) de 97 das peças citadas em seu texto. O estudo de Kerman, embora não inclua edições completas, é claramente apoiado no monumental trabalho de transcrição da música renascentista inglesa realizado por Edmund Fellowes (18701951) e posteriormente revisto por Thurston Dart (1921-1971), abarcando o período iniciado com a influência musical italiana na Inglaterra e encerrado com a última geração de seus próprios madrigalistas. Ambas as obras inspiraram grande parte das investigações posteriores e possuem inegável influência sobre o que se tornou o repertório renascentista canônico durante a segunda metade do século XX. Consideramos importante notar, contudo, que qualquer estudo geral ou específico

\footnotetext{
${ }_{1}$ As bases de dados consultadas para esta busca foram Museo internazionale e biblioteca della musica di Bologna (www.bibliotecamusica.it), Münchener DigitalisierungsZentrum (http://www.digitalesammlungen.de), Royal Holloway Repository (https://repository.royalholloway.ac.uk), Library of Congress (www.loc.gov), Biblioteca Digital Hispánica (bdh.bne.es), Bibliothèque Nationale de France (http://gallica.bnf.fr) e IMSLP (www.imslp.org).
} 
necessariamente privilegia determinadas obras em detrimento de outras. $\mathrm{O}$ comentário do compositor e historiador da música Charles Burney (1726-1814) sobre sua pesquisa em música do Renascimento, publicado ainda no século XVIII em um dos volumes de A General History of Music (1776-89), é bastante ilustrativo deste ponto; após tratar da música de períodos anteriores em sua obra, Burney relata:

Apesar de havermos chegado àquele período em que as produções da imprensa diminuirão consideravelmente o trabalho de pesquisa, a dificuldade de encontrar material será apenas substituída pela [dificuldade] de seleção; e o folhear da música antiga, depois que ela é encontrada, é realizado com muito mais esforço do que o de obras literárias da mesma idade: por serem publicadas e preservadas em partes individuais, estas partes devem primeiramente ser colocadas em tal estado em que o olho possa comparar suas diversas relações em um olhar; ou, para usar a linguagem dos músicos, elas precisam ser colocadas em partitura antes que suas belezas ou defeitos possam ser descobertos, e isso, pela dificuldade da notação obsoleta e pela falta de barras [de compasso], torna-se um processo muito lento. Mas estando determinado a não falar de música com a qual eu não esteja familiarizado, ou da qual eu não consiga fornecer espécimes, eu transcrevi em partitura muitos volumes, não apenas da mesma época, mas às vezes do mesmo autor, para selecionar as melhores produções que posso, para meu trabalho, ou ao menos para qualificar-me para julgar as habilidades e recursos de cada compositor. Das produções de cada período eu tentei procurar exemplos das obras daqueles que eram os principais favoritos de seus contemporâneos, com a finalidade de colocar isto em poder dos críticos de composição para que comparem excelência musical, e construam suas opiniões de superioridade baseados nos trabalhos em si, e não em sistema, conjetura ou preconceito. (BURNEY, 1935, p. 705, tradução nossa²

\footnotetext{
${ }^{2}$ No original: "Though we are arrived at that period when the productions of the press will considerably diminish the labour of research; yet the dificulty of finding materials will be now only changed to that of selection; and the perusal of old music, after it is found, is attended with much more trouble than literary works of equal antiquity: for being published and preserved in single parts, these parts must previously be put to such a state, that the eye may compare their several relations at one glance; or, to use the language of Musicians, they must be scored, before their beauties or defects can be discovered, and this, from the difficulty of obsolete notation, and the want of bars, is rendered a very slow process. But being determined to speak of no music with which I am unacquainted, or of which I am unable to furnish specimens, I have transcribed in Partitura, or Score, many volumes, not only of the same age, but sometimes of the same author, in order to select the best productions I am able, for my work, or at least to qualify myself to judge each composer's abilities and resources. Of the production of each period I have endeavoured to procure examples from the works of those who were the chief favourites of their contemporaries, in order to put it in the power of critics in composition to compare musical excellence,
} 
Os desafios descritos pelo historiador não diferem, em sua essência, daqueles enfrentados na pesquisa aqui apresentada. Além de lidar com as dificuldades técnicas de transcrição, Burney se depara com o natural problema da escolha das peças a serem estudadas ou publicadas, e ao mesmo tempo em que procura se eximir da responsabilidade do julgamento, admite a existência da crítica vinda de sua própria parte, de seus contemporâneos e do leitor renascentista. Este tipo de juízo - e a consequente seleção de conjuntos de obras consideradas importantes por determinados grupos de pessoas em certos momentos - normalmente implica no estabelecimento de repertórios canônicos que, ainda que justificados, inevitavelmente deixam lacunas para posterior investigação.

Apesar de a música renascentista encontrar-se extensamente documentada no que se refere a publicações em notação moderna, existem diversas razões para se acreditar que a disciplina da edição admita novos esforços. Primeiramente, as possibilidades de acesso às fontes primárias tendem a aumentar com o desenvolvimento dos projetos de digitalização dos grandes museus e bibliotecas; as iniciativas de transcrição, por sua vez, passaram por transformações metodológicas importantes ao longo do século XX, resultando em publicações de caráter enormemente diversificado. Parece-nos razoável, portanto, a suposição de que a edição musical nem sempre tenha atendido às necessidades dos intérpretes ou correspondido às expectativas de alguns grupos deles. O musicólogo Willi Apel afirma em The Notation of Polyphonic Music: 900-1600 que “a notação, longe de ser um mero desafio intelectual, é, em todos os seus vários estágios, a expressão perfeita da música que ela representa" (APEL, 1953, p. 86, tradução nossa ${ }^{3}$ ); em virtude da perda das antigas tradições interpretativas da polifonia vocal do século XVI, contudo, a escrita original deste repertório exige uma variedade de inferências por parte do performer atual: aspectos musicais importantes como acentuação e fraseado, por exemplo, não

and build their opinions of superiority upon the works themselves, and not upon system, conjecture or prejudice."

${ }^{3}$ No original: "notation, far from being merely an intellectual puzzle, is in all its various stages the perfect expression of the music it represents." 
eram indicados através de dispositivos notacionais específicos, mas são percebidos por intérpretes e editores através da observação de contornos melódicos, da horizontalidade do contraponto, e principalmente da íntima relação entre música e texto - esta última francamente atestada por composições como o madrigal. As constantes mudanças nas tradições interpretativas observadas em registros fonográficos da polifonia do Renascimento ao longo dos séculos XX e XXI, por sua vez, tornam a demonstrar que as relações entre o texto musical impresso e a performance estão sujeitas a permanente revisão.

No capítulo 2 abordamos inicialmente as relações existentes entre o madrigal e duas das formas ligeiras a ele relacionadas, a villanella e a canzonetta. Estes gêneros são discutidos não apenas por sua evidente importância musicológica, mas sobretudo pelo fato de serem eles os mais frequentes nas fontes tratadas na presente investigação; a discussão destas formas é apoiada na literatura sobre a música secular do Renascimento e ilustrada através de exemplos do tratamento conferido pelos mestres madrigalistas no norte da Itália ao material musical proveniente do sul da península, as canzone villanesche alla napolitana (seção 2.1). Os Winchester Partbooks, manuscritos flamengos hoje localizados na Winchester College Warden and Fellows Library da cidade britânica de Winchester, contêm abundantes exemplos destes gêneros ligeiros e são descritos na seção 2.2, na qual relatamos também os processos que levaram à definição do corpus a ser efetivamente transcrito e analisado neste trabalho.

O capítulo 3 constitui um texto introdutório ao sistema de escrita musical do Renascimento e a possíveis questões interpretativas a ele relacionadas. Alguns dos tópicos abordados dialogam de maneira direta com aspectos filológicos ou analíticos da musicologia e por esta razão são discutidos através de referências a tratados e outras fontes musicais dos séculos XVI e XVII, assim como a estudos mais recentes a respeito do repertório deste período. As questões interpretativas - entre as quais se incluem problemas relacionados à transcrição da música vocal renascentista para a notação moderna - são discutidas, sempre que possível, utilizando-se exemplos extraídos das peças selecionadas para transcrição como parte desta tese. Destinado 
sobretudo ao intérprete não especialista na notação musical do Renascimento, o texto contém uma discussão inicial a respeito do tratamento de aspectos rítmicos (seção 3.1), realizada através da apresentação dos fundamentos da notação mensural branca, sistema de escrita utilizado para a notação da música polifônica durante o período 1450-1600, aproximadamente. A exposição prossegue com a abordagem de aspectos relacionados ao tratamento de alturas e acidentes em edições modernas (seção 3.2), onde as ocorrências de musica ficta - isto é, de inflexões cromáticas não necessariamente notadas nas fontes originais - são discutidas através da apresentação do sistema hexacordal e das convenções possivelmente utilizadas para a aplicação de tais alterações. Por fim, uma discussão a respeito do uso de fontes originais e edições modernas para a execução deste repertório é realizada considerando-se depoimentos de intérpretes e professores, assim como nosso próprio relato de experiências desenvolvidas junto a um ensemble vocal (seção 3.3).

O capítulo 4 consiste nas transcrições em notação moderna do conjunto de 41 peças selecionadas. Este texto musical constitui a parte mais extensa do presente trabalho e sua elaboração foi resultado do exame dos manuscritos originalmente confeccionados segundo a prática notacional do século XVI - isto é, em partes separadas, sem barras de compasso, com frequentes ambiguidades rítmicas e indicação incompleta de acidentes (sob a ótica da notação atual). As transcrições são apresentadas em formato de partitura, onde o material musical referente a cada peça é precedido da reprodução dos textos italianos acompanhados de suas respectivas traduções para o português, além de incipits musicais que indicam as claves originais e as primeiras notas correspondentes a cada parte (discantus, altus, tenor e bassus). Para a revisão dos poemas e de suas traduções - igualmente desafiadores em razão da ortografia não normatizada, da ausência de pontuação, do uso de expressões napolitanas e do frequente double entendre - contamos com o precioso auxílio dos professores Dr. Jorge de Almeida e Dra. Maria Cecilia Casini (FFLCH-USP). 


\section{AS FORMAS VOCAIS LIGEIRAS DO RENASCIMENTO E OS WINCHESTER PARTBOOKS}

A expressão mais elaborada da música vocal secular do século XVI manifestouse através do gênero denominado madrigal. De origem fiorentina, este tipo de composição não-estrófica era baseado em textos de teor sério - em geral refletindo a voga Petrarquista iniciada na Itália nos anos 1530 - e exibia, em seu apogeu, uma sofisticada estrutura polifônica a cinco ou mais vozes e uma estreitíssima relação textomúsica. Diversos madrigalistas importantes, contudo, dedicaram-se paralelamente à composição de formas vocais menos complexas, mais próximas das tradições orais e da improvisação, e produziram um vasto repertório de canções que até hoje são frequentemente executadas pelos mesmos intérpretes devotados ao primeiro gênero. Iniciaremos este texto abordando as relações entre o madrigal e uma destas formas correlatas - a canzone villanesca alla napoletana (ou villanella, como passou a ser denominada na segunda metade do século XVI) - através de exemplos apoiados na literatura musicológica, e em seguida descreveremos a pesquisa que possibilitou a identificação deste repertório em um conjunto de manuscritos flamengos, os Winchester Partbooks (Winchester College Warden and Fellows Library, MS 153), tornando possível a transcrição de 41 peças aparentemente nunca editadas em notação moderna como parte desta pesquisa.

\subsection{RELAÇÕES ENTRE O MADRIGAL E AS FORMAS VOCAIS LIGEIRAS}

Embora mereça especial consideração musicológica devida ao rico repertório a ela associado, a villanella não foi o primeiro exemplo de música vocal ligeira no século XVI. Nas décadas iniciais do cinquecento, a antiga frottola do século XV já se havia simplificado através de formas como a villotta, o quodlibet, a mascherata, ou ainda como a tedesca, a greghesca, a moresca e a ebraica - estas últimas utilizando textos de temática rústica e frequentemente obscena, em inequívoca associação com a commedia dell'arte. 
A partir da década de 1540 a música ligeira foi alimentada por uma enorme quantidade de novos materiais temáticos provenientes do sul da Itália: as canzoni villanesche alla napoletana, cujos principais mestres foram Giovan Tommaso di Maio (ca.1490-ca.1563) e Giovan Domenico da Nola (ca.1510-1592). A canzone villanesca, ou simplesmente napoletana, alcançou imediata popularidade no norte da península itálica e foi abordada em Veneza por diversos compositores, entre os quais Francesco Corteccia (1502-1571), Perissone Cambio (ca.1520-ca.1562), Baldassare Donato (ca.15251603) e o flamengo Adrian Willaert (ca.1490 -1562).

A oposição entre as formas ligeiras e o madrigal foi extensamente discutida por vários dos musicólogos que estudaram a música vocal do Renascimento (EINSTEIN, 1949; REESE, 1954; ROCHE, 1990; HAAR, 2006) e todos eles reconhecem a existência de uma relação importante - ainda que antagônica - entre o gênero sério do madrigal e as formas musicais mais simples, sobretudo pelo fato de estas últimas haverem sido cultivadas por madrigalistas tão importantes quanto Adrian Willaert, Roland de Lassus (1532-1594), e, algumas décadas depois, por Luca Marenzio (1553-1599) e Claudio Monteverdi (1567-1643). Alfred Einstein inicia sua abordagem do assunto afirmando que

a música vocal mais ligeira do Cinquecento encontra-se em uma relação peculiar, em enfática oposição, ao madrigal, que é quase sempre sentimental, elegíaco e sério, nunca ultrapassando os limites da arte elevada, mesmo quando chega a ter um tom mais leve. Mas esta oposição não é de forma alguma uma oposição da música aristocrática à música folclórica, nem mesmo à música "popular". Seria totalmente errado opor esta música ao gênero elevado e sério do madrigal. E seria igualmente errado ver nela um protesto nacional contra o polifonismo dos mestres do Norte. A villanella, a villotta, e o restante dessas formas, quaisquer que sejam seus nomes, absolutamente não representam arte popular. Elas foram cultivadas pelos flamengos e pelos franceses na Itália tanto quanto pelos próprios italianos e eram pretendidos para o mesmo público do madrigal (EINSTEIN, 1949, v. 1, p. 340, tradução nossa'1).

\footnotetext{
${ }^{1}$ No original: "The lighter vocal music of the Cinquecento stands in a peculiar relationship, in emphatic opposition, to the madrigal, which is almost always sentimental, elegiac, and serious, never overstepping the limits of high art even when it strikes a lighter note. But this opposition is not at all an opposition of aristocratic music to folk music, not even to 'popular' music. It would be entirely wrong
} 
Com efeito, a existência de inter-relações entre estas formas torna-se bastante clara ao se observar não apenas as diferenças, mas sobretudo as influências de um gênero sobre outro. Gustave Reese afirma que a villanesca trouxe leveza ao madrigal, e que este ocasionalmente emprestou à primeira um caráter levemente polifônico (REESE, 1954, p. 443), propiciando o surgimento de um novo gênero - a canzonetta que se encontra em uma posição intermediária entre a simplicidade crua da canção napolitana e a artificialidade e o engenho próprios do madrigal.

Em suas origens napolitanas, a villanesca era arranjada para apenas três partes e exibia as melodias originais - rústicas e angulares - na voz superior. Segundo Einstein, a escrita a três vozes típica desta forma pode ser explicada pela prática dos cantores ao se acompanharem ao alaúde - já que estes omitiam a voz do contralto e colocavam as outras duas em tablatura como acompanhamento - ou ainda pela técnica de improvisação do século XV, em que três partes eram de fato a norma (EINSTEIN, 1949, p. 357). Ainda nas palavras do autor, os compositores Francesco Corteccia e Adrian Willaert "trataram as produções de [Giovan Domenico da] Nola como presentes da natureza caídos do céu" (EINSTEIN, 1949, p. 78, tradução nossa²), pois foram utilizadas como cantus prius facti para um grande número de novas composições. $\mathrm{O}$ musicólogo James Haar acrescenta que, em Veneza, estas peças de temáticas rudes e anti-Petrarquistas "eram selecionadas, polidas para se remover elementos rústicos e arranjadas para quatro vozes (com a melodia original do soprano agora no tenor)" (HAAR, 2006, p. 232, tradução nossa ${ }^{3}$. Com efeito, os arranjos de Adrian Willaert para as villanesche Madonn'io non lo so e Cingari simo, de Giovan da Nola, ilustram a escrita

to oppose this music to the high-serious genre of the madrigal. And it would be equally wrong to see in it a national protest against the polifonismo of the northern masters. The villanella, villotta, and the rest of these forms, whatever their names, do not represent popular art at all. They were cultivated by the Netherlanders and Frenchmen in Italy quite as much as by the Italians themselves and they were intended for the same public as was the madrigal."

${ }^{2}$ No original: "treated Nola's productions as gifts of nature fallen from the sky."

${ }^{3}$ No original: "were picked up, dusted off to remove rusticities, and arranged for four voices (with the original soprano melody now in the tenor)." 
a quatro vozes típica do norte da Itália, onde as melodias originais foram rearmonizadas e aparecem na parte do tenor (figs. 1 e 2).

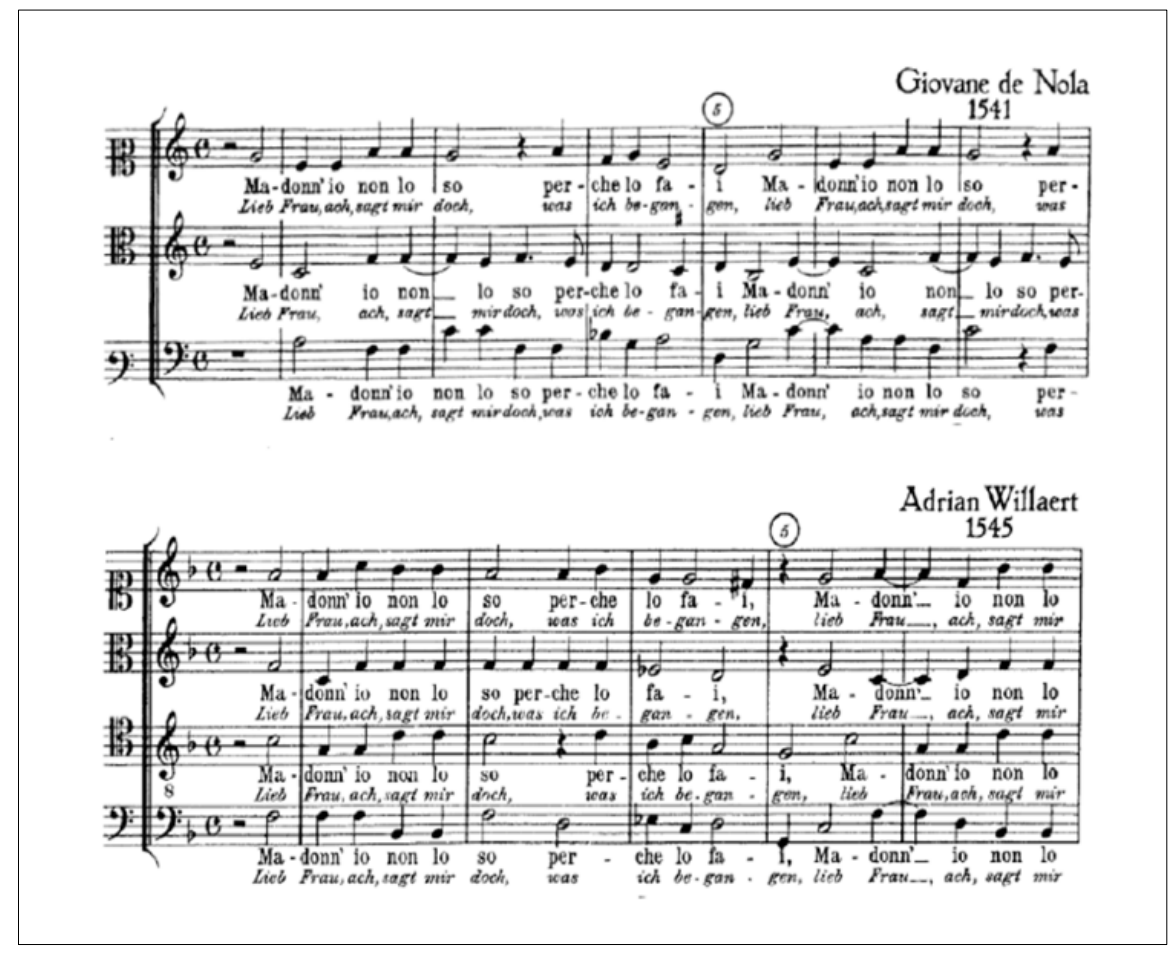

Figura 1. Início das composições de Nola e Willaert de Madonn'io non lo so (colagem) (NOLA, 1930, p. 13; WILLAERT, 1930, p. 18).

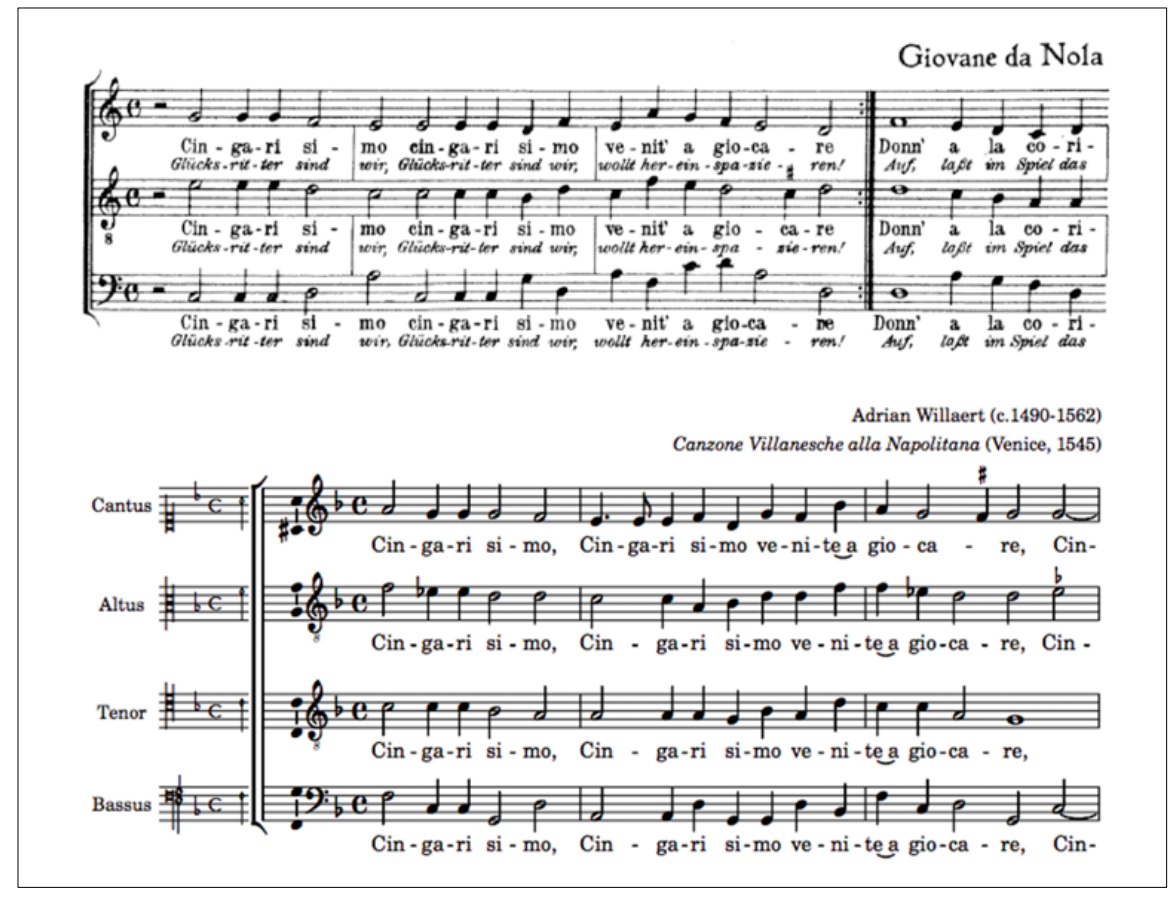

Figura 2. Início das composições de Nola e Willaert de Cingari simo (colagem) (NOLA, 1936, p. 13; WILLAERT, 2015, p. 1). 
A forma poética preferida dos compositores napolitanos era o strambotto toscano (poema de esquema rímico A-B-A-B-A-B-C-C), onde cada dístico A-B - em geral composto de versos heptassílabos ou hendecassílabos - era ampliado adicionando-se um refrão de métrica menos rigorosa. Nos manuscritos e edições do século XVI é comum encontrar-se apenas a primeira parte do texto (A-B-refrão) alinhada às notas e os outros versos exibidos separadamente, de modo que a primeira estrofe de uma villanesca possui, em geral, a forma ternária $A:\|B\|:$ refrão :\|. Um exemplo desta estrutura tripartida pode ser observado na célebre villanella Chi la gagliarda, donne, vo' imparare, composta por Baldassare Donato e inspirada pela composição homônima de Nola. Neste caso, Jerome Roche salienta que Donato utiliza a melodia original como cantus prius factus apenas no início da peça, e na terceira parte ("tan tan tan ta...") toma somente seu padrão rítmico e o estende a uma maior escala (ROCHE, 1990, p. 97). Neste refrão (fig. 3), pode-se ainda observar na escrita de Donato o "polimento" apontado por James Haar, através do qual se evitam as quintas paralelas presentes no original de Nola, assim como em um grande número de composições napolitanas deste gênero.

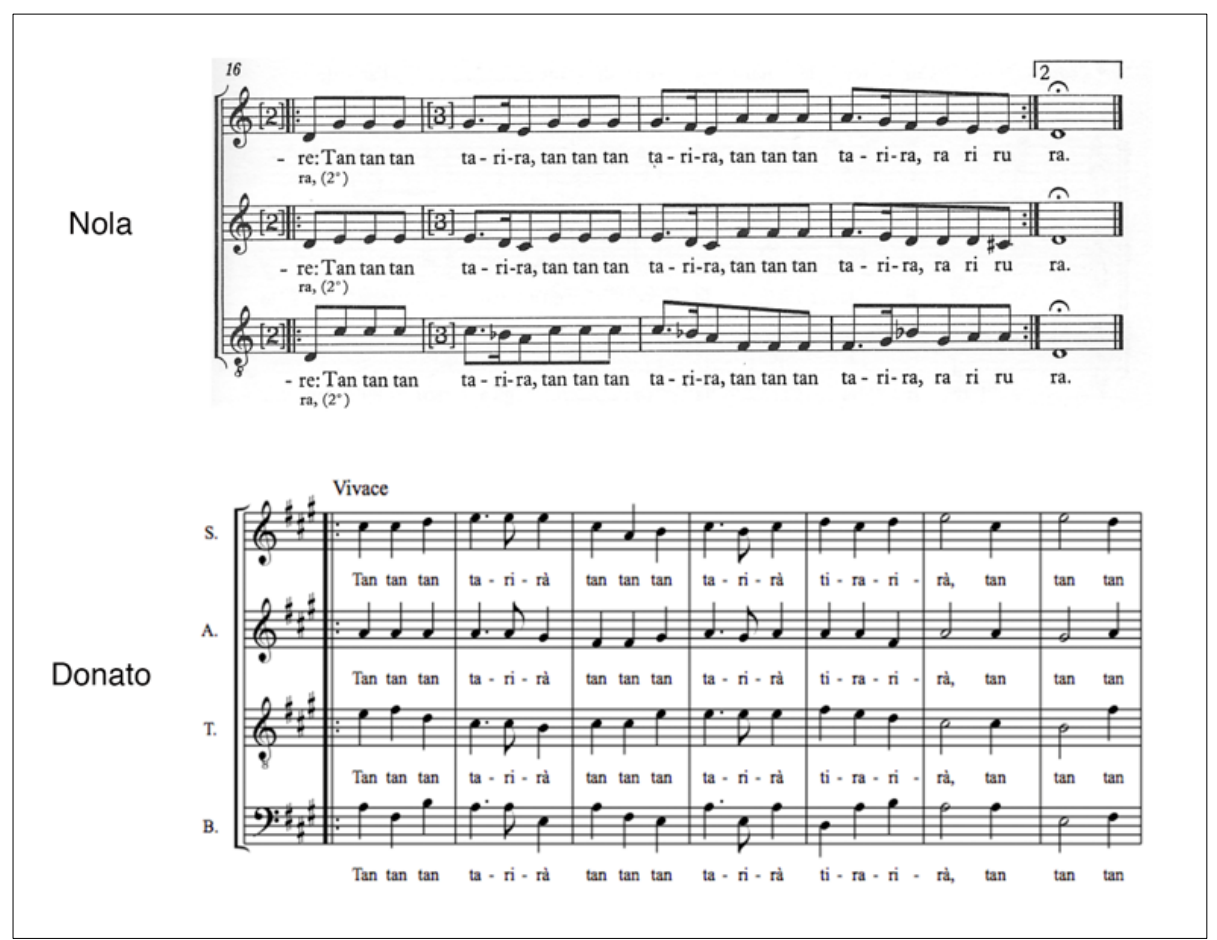

Figura 3. Início do refrão das composições de Nola e Donato de Chi la gagliarda (colagem) (NOLA, 1983, p. 35; DONATO, 2014, p. 2). 
Uma evidência adicional das importantes relações existentes entre a villanesca e o madrigal pode ainda ser observada através das frequentes paródias literárias e musicais feitas pelos compositores napolitanos sobre temáticas madrigalescas. Einstein (1949, vol. 1, p. 373), ao discutir a paródia na villanella, afirma que esta última zomba do madrigal e toma uma direção agressiva em direção a ele. Exemplos concretos deste conflito são o uso de versos iniciais de poemas de Petrarca seguidos de textos jocosos, a imitação impertinente da polifonia sacra, ou ainda suspensões caricaturais alla madrigalesca como as exibidas no início da versão de Nola para O dolce vita mia che t'haggio fatto (fig. 4). Neste exemplo, o posterior arranjo de Willaert preserva a melodia original e foi editado por Einstein com a importante informação de que o cantus prius factus encontra-se na parte do tenor.

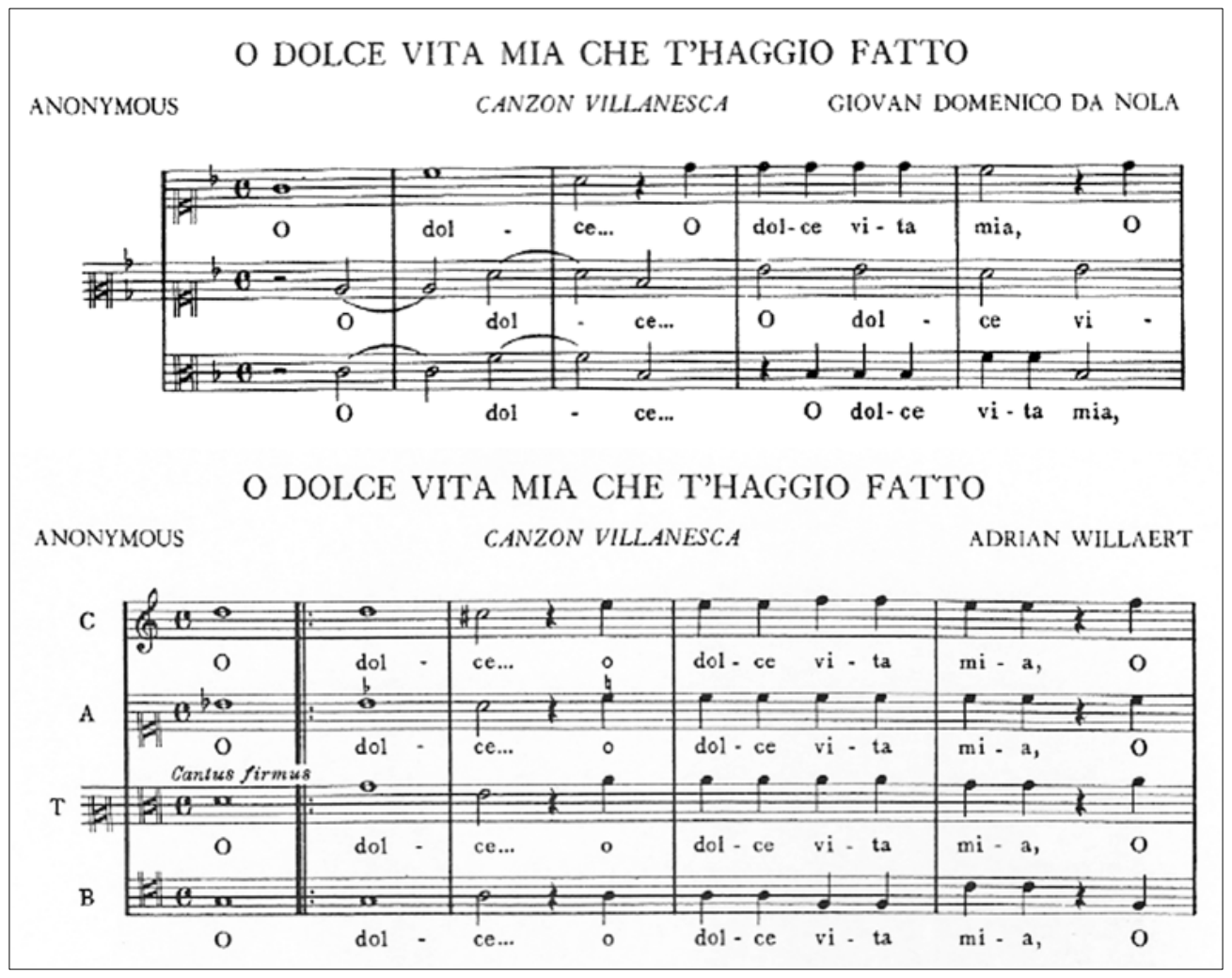

Figura 4. Início das composições de Nola e Willaert de $O$ dolce vita mia che t'haggio fatto (colagem) (NOLA, 1949, p. 86; WILLAERT, 1949, p. 88). 


\subsection{WINCHESTER PARTBOOKS (WINCHESTER COLLEGE WARDEN AND FELLOWS LIBRARY, MS 153)}

Conforme destacado anteriormente, a identificação de fontes primárias da música vocal do Renascimento foi um dos objetivos centrais desta pesquisa de repertório, edição e análise musical orientadas para a performance. Os elementos de interesse prático e pedagógico, definidos a priori como pontos importantes da investigação, direcionaram as primeiras buscas de material para as formas vocais ligeiras do século XVI, das quais a canzone villanesca alla napoletana, discutida na seção anterior, constitui um dos mais importantes exemplos. A villanesca foi estudada em grande profundidade pela musicóloga Donna Cardamone-Jackson (1937-2009), que produziu importantes edições e analisou exaustivamente seu repertório sob perspectivas formais, textuais, históricas e sociais em algumas dezenas de publicações. Cardamone lecionou na Universidade de Minnesota de 1969 a 2007 e se aposentou devido a um grave problema de saúde que enfrentou a partir de 2006; o site da instituição aponta entre suas atividades de pesquisa do período 2004-2005, entretanto, um projeto nunca concretizado: a edição das canções em dialetos italianos dos Winchester Partbooks para as A-R Editions (UNIVERSITY OF MINNESOTA), o que nos motivou a procurar por estes volumes e a verificar a possível adequação de seu repertório à presente pesquisa.

Os Winchester Partbooks são manuscritos de origem flamenga datados da década de 1560 e atualmente fazem parte do acervo da Winchester College Warden and Fellows Library, na cidade britânica de Winchester, estando catalogados nesta biblioteca como MS 153. Seus quatro volumes foram disponibilizados em fevereiro de 2016 no repositório digital DIAMM (Digital Image Archive of Medieval Music) ${ }^{4}$ e lá estão catalogados segundo as denominações das vozes correspondentes a cada parte, a saber: discantus, altus, tenor e bassus (WINCHESTER PARTBOOKS, [entre 1564 e

\footnotetext{
${ }^{4}$ www.diamm.ac.uk
} 
1566]). Embora se saiba que os partbooks pertençam ao Winchester College desde o século XVIII, sua trajetória anterior ainda não pôde ser completamente determinada. No estudo mais recente que pudemos encontrar a respeito da coleção, a musicóloga Kristine Forney (1999, p. 50-51) conjeturou que os volumes fossem provenientes de Antuérpia e que tivessem sido encomendados pelo rei Erik XIV da Suécia como um presente para a rainha Elizabeth I, embora cite estudos anteriores que propõem que tenham sido originalmente confeccionados para amadores, encadernados para um mercador inglês, ou ainda sido presentes de um dignitário flamengo. Pode-se afirmar, de qualquer modo, tratar-se de itens inequivocamente luxuosos, pois suas encadernações são ornamentadas com ouro, fios de seda e brasões pintados a mão (fig. 5) e seu interior exibe a música em caligrafia cuidadosa e iniciais capitulares de rebuscada ornamentação (fig. 6).

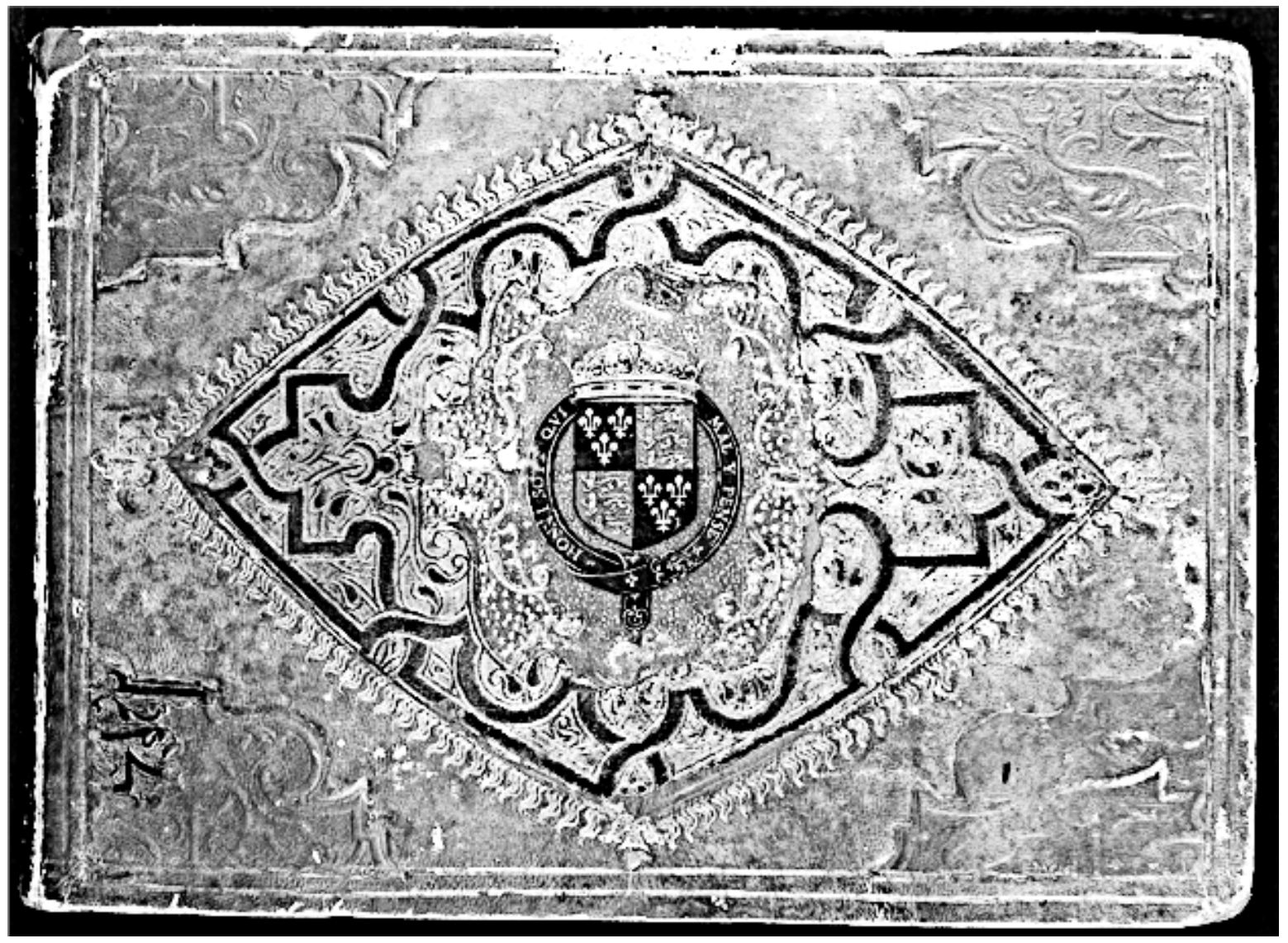

Figura 5. Capa da encadernação da parte do discantus. 


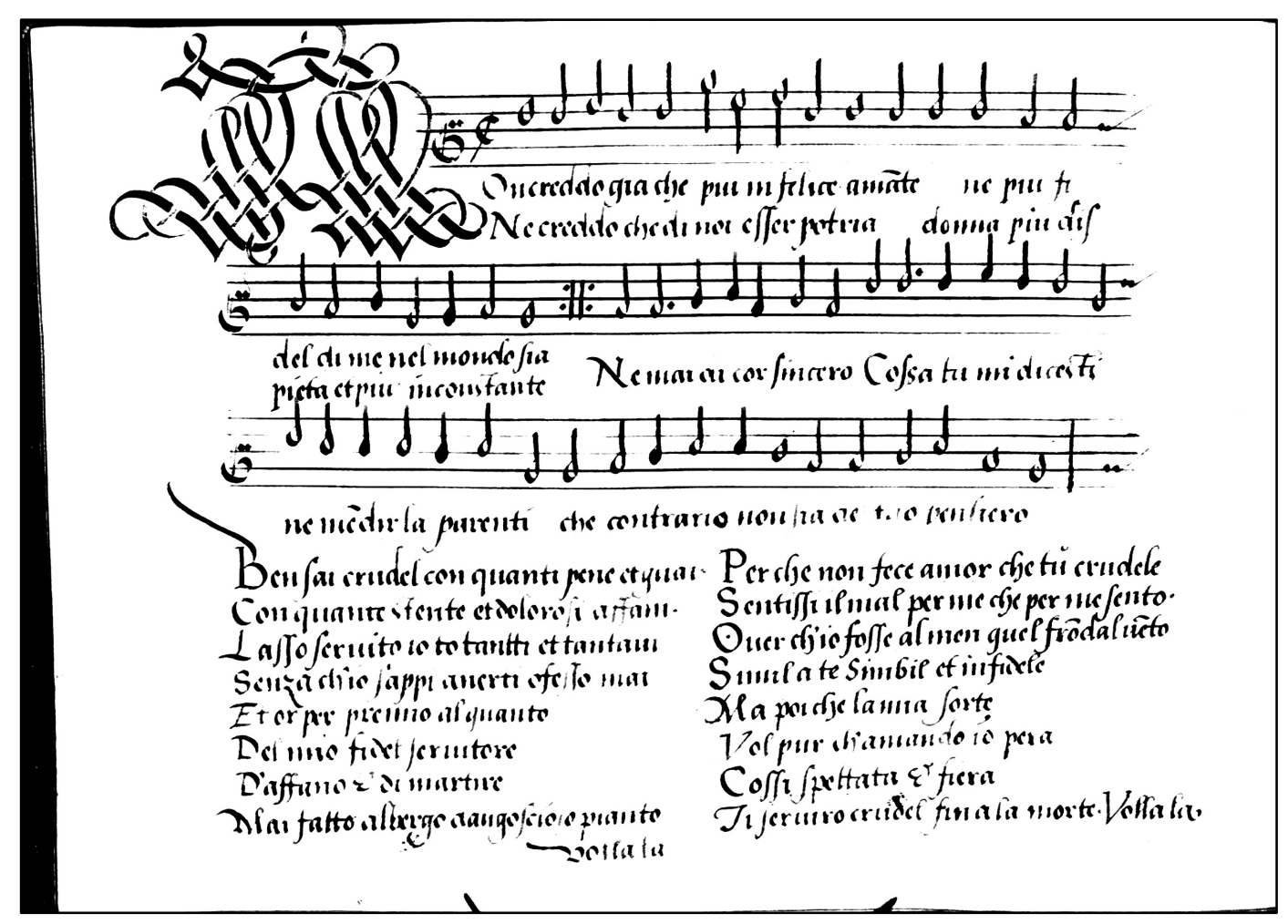

Figura 6. Interior da parte do discantus.

Os Winchester Partbooks contêm um conjunto de 107 peças seculares, das quais 81 são formas vocais com texto em italiano, 16 são chansons francesas e 10 são peças inglesas adicionadas por um escriba posterior. Entre os compositores presentes na coletânea incluem-se grandes mestres como Roland de Lassus (1532-1594), Philippe Verdelot (1480-1530), Jacques Arcadelt (1507-1568), Baldassare Donato (ca.1530-1603), Adrian Willaert (ca.1490-1562), Hubert Waelrant (ca.1517-1595), Pierre Certon (ca.15151572) e Claudin de Sermisy (ca.1490-1562), além de autores menos celebrados como o flamengo Adrian Tubal (ca.1525-?) - ou nomes ainda mais obscuros como Briaco e Caldarino, a quem se atribuem algumas peças da coleção.

Embora o repertório contido nos Winchester Partbooks esteja dividido nestes três subconjuntos de idiomas claramente delimitados, as canções com textos em italiano ou dialeto napolitano não são, em sua totalidade, de autoria de compositores italianos. Entre as 81 peças escritas no idioma, apenas 25 puderam ser de fato atribuídas a italianos nativos (Azzaiolo, Donato, Nasco, Briaco, Caldarino e Lambertini), enquanto 7 permanecem anônimas e 49 exibem nos manuscritos os 
nomes dos franco-flamengos Hubert Waelrant, Roland de Lassus, Philippe Verdelot, Adrian Tubal, Adrian Willaert e Jacques Arcadelt - alguns dos quais se interessaram pela canzone villanesca e produziram arranjos a quatro vozes das melodias rústicas provenientes do sul da Itália, conforme discutido na seção 2.1. As 16 chansons francesas estão representadas na coleção através de obras de Lassus, Waelrant e de uma geração de compositores provavelmente já falecidos à época da confecção dos mansucritos, entre os quais Pierre Sandrin (ca.1490 - após 1561), Claudin de Sermisy e Pierre Certon. As 10 peças inglesas, por sua vez, possuem autoria atribuída a Thomas Ford (1580-1648) e naturalmente foram adicionadas por um copista posterior em páginas não utilizadas dos cadernos originais. As diferenças de caligrafia entre este terceiro subconjunto e os anteriores podem ser observadas nas figuras 7, 8 e 9, que exibem a primeira página de música de cada um deles.

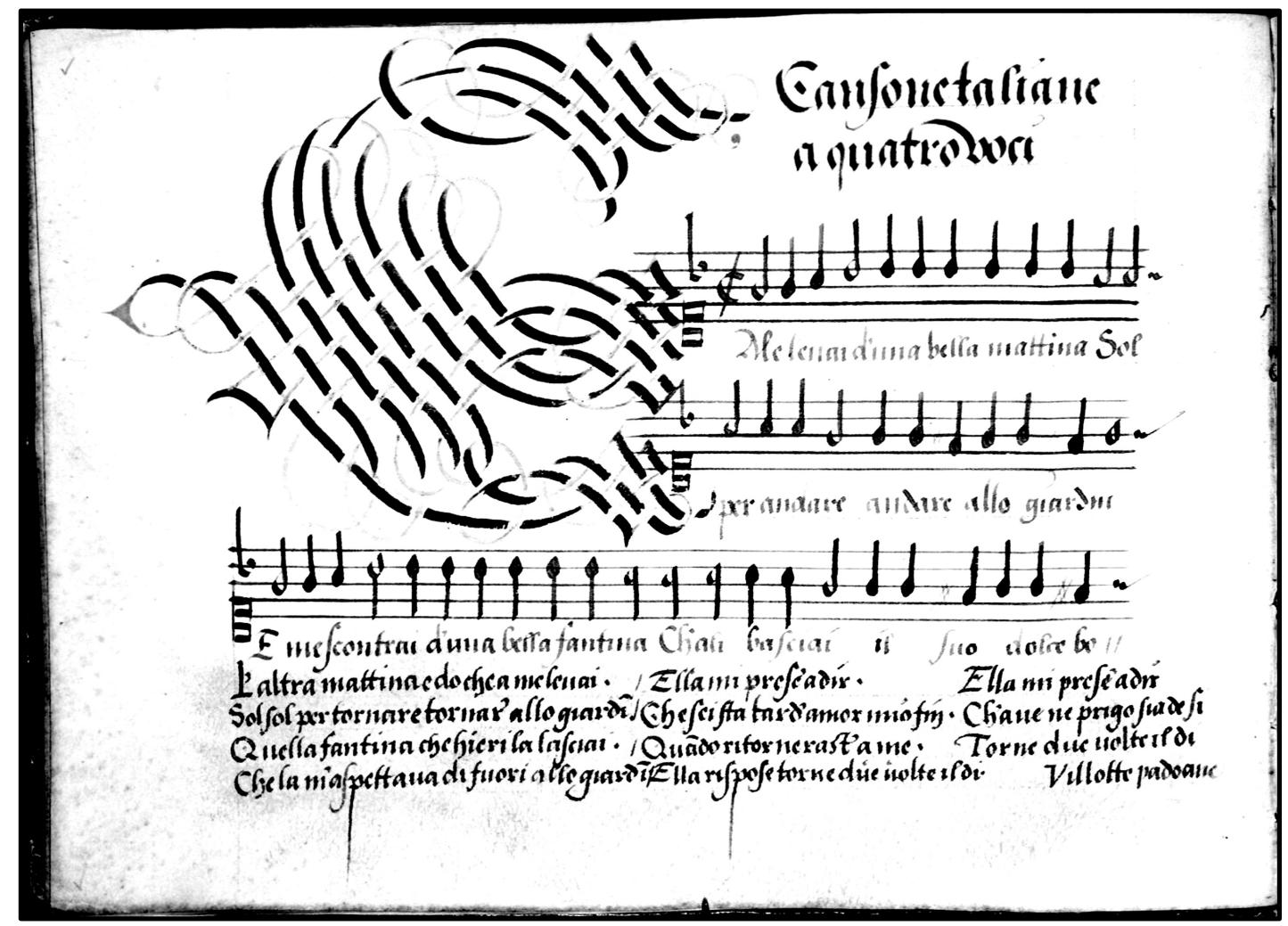

Figura 7. Primeira página das canções italianas (discantus). 


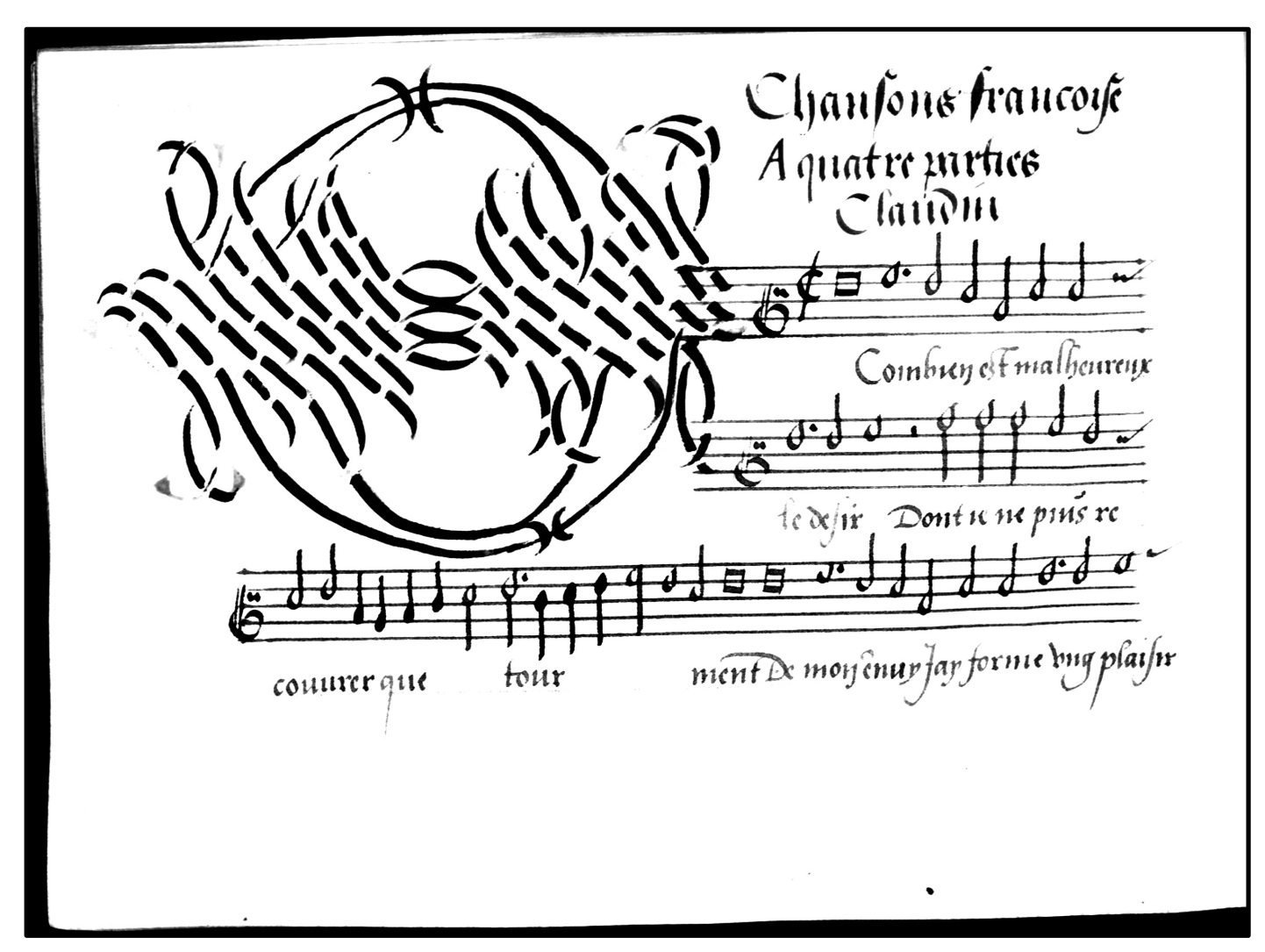

Figura 8. Primeira página das chansons francesas (discantus).

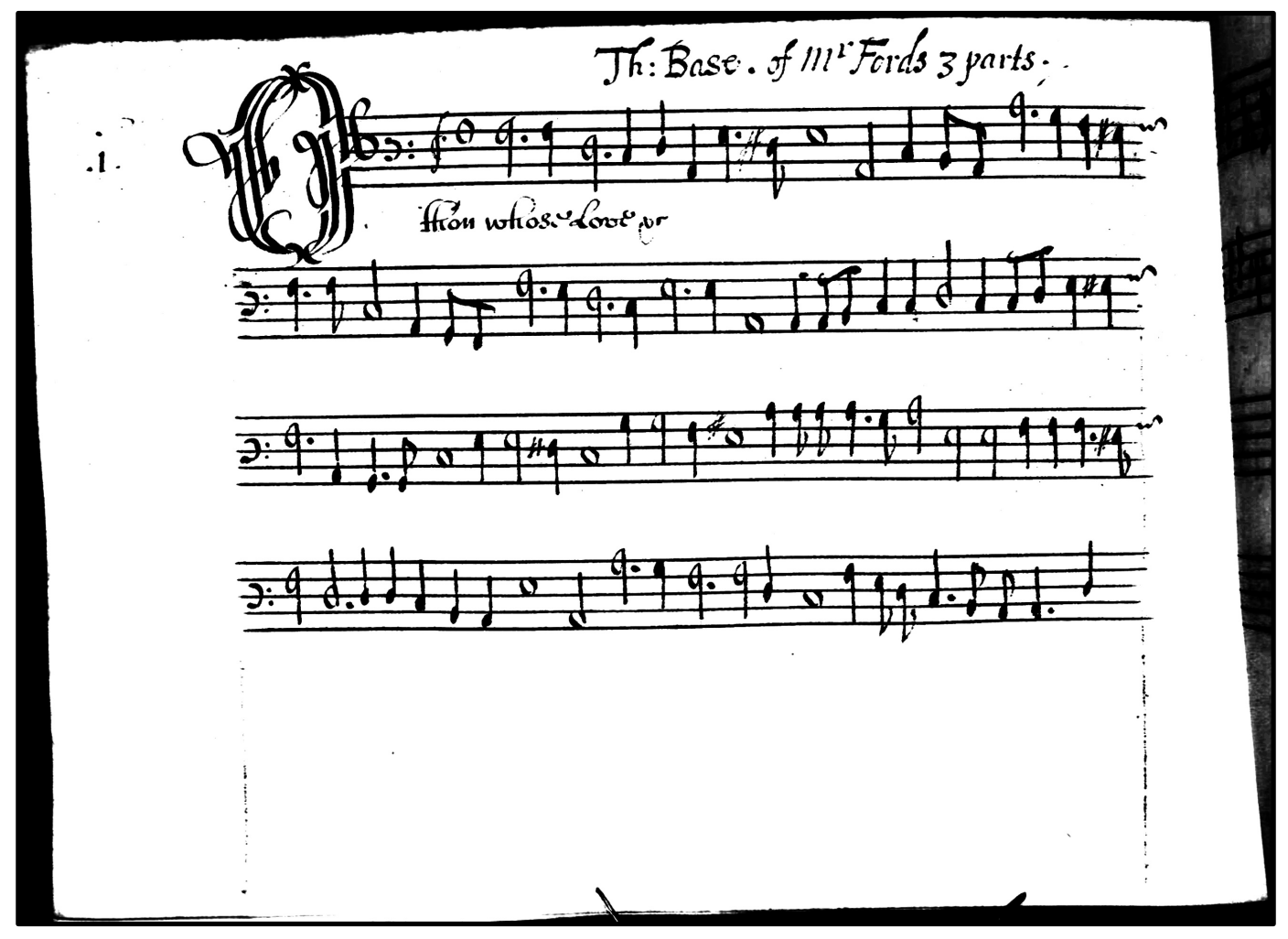

Figura 9. Primeira página das canções inglesas (discantus). 


\subsubsection{Seleção de peças para análise: o protocolo de identificação de material}

Com o objetivo de identificar peças ainda não editadas em notação moderna nestes volumes, procedemos a seu exame detalhado e realizamos pesquisas blibliográficas e documentais que revelaram que: (i) o conjunto completo das chansons francesas já foi transcrito por Janet Ritterman em sua tese de doutorado (RITTERMAN, 1977), embora esta não tenha sido publicada; (ii) as peças italianas e inglesas nunca foram editadas como conjuntos, sendo necessárias pesquisas individuais para se avaliar o interesse musicológico e a viabilidade do uso das transcrições eventualmente produzidas neste trabalho.

A tabela 1, publicada no estudo de Kristine Forney (1999, p. 56-58), contém a relação completa das peças contidas no MS 153, além de suas atribuições de autoria e eventuais correspondências com outras fontes. Os compositores anotados entre colchetes não estão apontados nos manuscritos e o processo que levou a sua identificação, assim como às concordâncias com publicações catalogadas no RISM (Répertoire International des Sources Musicales), não é descrito pela autora. Consideramos interessante notar o fato apontado por Forney (1999, p. 55) de apenas as atribuições a compositores franco-flamengos estarem anotadas nos manuscritos - o que, segundo a musicóloga, reforça a hipótese de estes serem originários de Antuérpia. Com efeito, mediante a observação das imagens disponíveis no repositório digital DIAMM, pudemos notar que o copista evitou a identificação de autores italianos ao longo de toda a coleção, mesmo em sequências de obras muito provavelmente retiradas de importantes publicações venezianas como o Secondo Libro de Villotte del Fiore, de Filippo Azzaiolo; dentre as obras provavelmente copiadas desta fonte (nos 67 a 79), o escriba não deixou, entretanto, de apontar o nome de Jacques Arcadelt para uma peça isolada (n. 69), enquanto para as outras reservou apenas atributos gerais relacionados a suas formas, como "villotta" (nos 73, 75, 78 e 79), "napolitana" (no 72 e 
74), “todesca” (n. 71) e "venetiana" (n. 76). Os números restantes desta sequência (67, 68, 70 e 77), sendo madrigais, não receberam qualquer observação do copista.

TABLE 1

Contents of the Winchester Part Books

\begin{tabular}{|c|c|c|}
\hline Incipit & Composer & Concordance* \\
\hline 1. E mi levai d'una bella mattina & [Azzaiolo] & $1557^{18}$ \\
\hline 2. No, no, no, no gia mai non cange & & ** \\
\hline 3. Non credo gia che piu infelice amante & & $* *$ \\
\hline 4. Pace non trov'et non ho da far guerra & & \\
\hline 5. Ecco la stagion novella & & \\
\hline 6. Ia passa il tiempo lo tiempo es passado & & \\
\hline 7. Io ch' tropp' alt'amor volti seguire & & \\
\hline 8. Stava la gentil dama all'ombra & & \\
\hline 9. Tu sei la causa de la morte mia & Waelrant & $15^{6}{ }_{5}$ Waelrant \\
\hline 10. O Dio che fosse quella costumanza & Waelrant & ${ }_{15} 6_{5}$ Waelrant \\
\hline 11. Se pur ti guardo dolce anima mia & Waelrant & \\
\hline 12. Vita della mia vita quanto gran tort & Verdelot & $1533^{2}$ \\
\hline 13. Mort' e pieta l'amor la torte sia & Waelrant & ${ }^{1} 5^{6} 5$ Waelrant \\
\hline 14. Aldi dolce ben mio & [Azzaiolo] & $1557^{18}$ \\
\hline 15. Fiamenga fredda core di dimante & Tubal & \\
\hline 16. La manza mia si chiama & Tubal & \\
\hline 17. Donna voi sete bella/E non cortese & Tubal & \\
\hline 18. Tri ciechi siamo povr' innamorati & Waelrant & \\
\hline 19. Li nostri preti han questa buon'usanza & [Donato] & $155^{\circ}$ Donato \\
\hline 20. Madonna mia famme bon'offerta & Willaert & ${ }^{1} 545^{20}$ \\
\hline 21. Vecchie letrose non valete niente & Willaert & $1545^{20}$ \\
\hline 22. Paschino bello paschino/Deh toccha & Waelrant & \\
\hline $\begin{array}{l}\text { 23. Et quand'a fatto l'ovo la mattina la mia } \\
\text { galina }\end{array}$ & Willaert & {$\left[\mathrm{C}^{1} 55^{\circ}\right]^{19}$} \\
\hline 24. Madonna mia pieta chiam et vita & Lassus & $1555^{19}$ \\
\hline 25. Tu sei madonna mia ch'io t'am'et vogli & Lassus & $1555^{19}$ \\
\hline 26. La cortesia voi donne predicate & Lassus & $1555^{19}$ \\
\hline 27. Tu traditora m'hai puost'a sto core & Lassus & $1555^{19}$ \\
\hline 28. Sto core mio se fosse di diamante & Lassus & $1555^{19}$ \\
\hline 29. Mill'anni sono ch'io non t'haggio vista & Waelrant & ${ }_{15} 6_{5}$ Waelrant \\
\hline 3o. Occhi lucent' assai piu che le stelle & [Donato] & {$\left[\mathrm{c} 155^{\circ}\right]^{19}$} \\
\hline 31. Non t'ho possuto mai donna mostrare & Waelrant & ${ }_{15} 6_{5}$ Waelrant \\
\hline 32. Se sai ch'io t'amo et piu che me t'honoro & [Donato] & {$\left[\mathrm{C} 155^{\circ}\right]^{19}$} \\
\hline 33. O dolce vita mia, non mi far guerra & [Donato] & {$\left[\mathrm{Cl}_{55} \mathrm{O}^{19}\right.$} \\
\hline 34. Chiamo la mort'ogn'hor che me ne leva & Waelrant & ${ }_{15} 6_{5}$ Waelrant \\
\hline 35. Sta' constante cor mio, che t'am'ogn'hora & Waelrant & ${ }_{15} 65$ Waelrant \\
\hline 36. I dolci squardi toi, alta signora & Waelrant & ${ }_{15} 65$ Waelrant \\
\hline 37. Son mort'e moro/E pur credo morire & Waelrant & ${ }_{15} 65$ Waelrant \\
\hline $\begin{array}{l}\text { 38. Non posso far cor mio, che pur non } \\
\text { pianga }\end{array}$ & Waelrant & 1565 Waelrant \\
\hline
\end{tabular}

Tabela 1. Lista das peças dos Winchester Partbooks (FORNEY, 1999, p. 56-58). 
39. Tanto sai fare con l'inamorati

40. Amar divers'amanti

41. O quant amore sempre t'ho portato

42. Deh per ch'abbandonasti me

43. Conza lavezzi siam s'havesti rotto madonna

44. Madonn' habbi pieta del mio martire

45. Non ta recordi/E quando mi decevi

46. Issa in bona fe quando sei bella

47. Che t'haggio fatto che m'hai tolte core

48. Da l'horto se ne vien la vilanella

49. Vorrei che tu cantassi una canzone

50. Quanti ne vedi tutt'a te li tiri

51. Madonna mia per te son quasi morto

52. In tutto voi ch'io mor'o traditora

53. Medici noi siamo o donne belle

54. Port'acq'al crin'e piglia vent'in rete

55. Me bisogna servir questa crudele

$5^{6}$. La bella monicella ved'a messa

57. Hor mai son quasi morto e tu n'ol credit

58. Son molti giorni, ahime, ch'io persi

59. Gentil madonna del mio cor

6o. Chi passa per sta strada'e non sospira beato

61. Vorria morire per uscir da guai

62. Vorria e non vorria questo no dire

63. Ogniuno sapp'hor mai la pena mia

64. Forsi perche core mio bell'hayme

65. Quell' hora desiata sempr'aspetto

66. Con tanto riguardare

67. Stanco e solingo

68. Anchor che col partire

69. Perche la vit'e breve

7o. Pastorella d'amor non fuggir

71. Bernarde non puo stare

72. O vilanella quand'a l'acqua vai

73. E levaime d'una bella mattina

74. Girometta senza te

75. Mille gentil salute

76. Bona via faccia barca

77. Vita de la mia vita

78. Ch'il credera s'il dico

79. O pur donne belle

8o. A d'altre lo voi dare

81 . Se ben da voi madonn'i fia lontano
Tubal

Waelrant

[Donato] [C1550 $]^{19}$

Tubal

Waelrant

Waelrant

Waelrant

[Nasco] $\quad 15^{6} 5$ Nasco

[Nasco] 1565 Nasco

[Azzaiolo] $\quad{ }_{1557^{19}}$

[Azzaiolo] $1557^{19}$

Waelrant $\quad 1565$ Waelrant

Waelrant $\quad 1565$ Waelrant

Waelrant $\quad{ }_{5} 6_{5}$ Waelrant

Waelrant

Waelrant $\quad 1565$ Waelrant

Waelrant $\quad{ }_{5} 6_{5}$ Waelrant

Waelrant

Waelrant

Waelrant $\quad{ }_{5} 6_{5}$ Waelrant

[Azzaiolo] ${ }_{1557^{18}}$

[Azzaiolo] $\quad{ }_{1557^{18}}$

Waelrant $\quad 1585^{19}$

Waelrant

Waelrant

Waelrant

Waelrant

Waelrant

[Briaco] $1559^{19}$

[Caldarino] $1559^{19}$

Archadelt $1559^{19 * * *}$

[Ganassi] $1559^{19}$

[Azzaiolo] $1559^{19}$

[Azzaiolo] $1559^{19}$

[Azzaiolo] $1559^{19}$

[Azzaiolo] $\quad 1559^{19}$

[Azzaiolo] $\quad 1559^{19}$

[Azzaiolo] $1559^{19}$

[Lambertini] $1559^{19}$

[Azzaiolo] $1559^{19}$

[Azzaiolo] $\quad{ }^{1559^{19}}$

Waelrant

Waelrant

Tabela 1 (cont.). Lista das peças dos Winchester Partbooks (FORNEY, 1999, p. 56-58). 
82. O thou whose love I prize

Mr. Ford

83 . O how my Soule is ravished

[Ford]

84 . Who ever smelt the breath

[Ford]

85 . Go wounded Soule

[Ford]

86. My love is like a Garden

[Ford]

87 . What curious Face is this

[Ford]

88. Come forth my deare

[Ford]

89 . Now sleepe my love

[Ford]

9o. What greater Joy

[Ford]

91. Strike thou the Anvil

[Ford]

92. O combien est malheureux le desir

Claudin

93. Bon jour mon cueur

Lassus

1541

94. Au pres de vous secretement

[Jacotin/

1564 Lassus

Sermisy]

95. Je fille quant Dieu ne donne de quoy

96. La la la je ne loz se dire

Gosse

$15^{2} 8^{3}$

97. Tant que vivray en aige flourissant

[Certon]

$1545^{8}$

98. Le volez vous bien dame que je couche

[Claudin]

$1528^{3}$

99. Il me souffit de tous des maulx

10o. Pour ung plaisir que si peu dure

Waelrant

[Sermisy] $15^{2} 9^{3}$

[Sermisy] $\quad 153^{6}$

101. Celle qui ma tant pourmenez

[Sermisy] $15^{2} 9^{3}$

102. Doulce memoire en plaisir consomez

Sandrin $\quad 1528^{11}$

103. Vous perdes temps de ma dire mal d'elle

[Sermisy] $\quad 1528^{3}$

104. Dont vient cela belle je vous supplie

[Sermisy] $1528^{3}$

105. Se je ne voy m'amye je mourray de doleur

[Willaert] 1560 Willaert

106. Ce faulx amour d'arc et de fleische

Lassus $\quad 1562$ Lassus

107. Une bergiere ung jour au champs estoit

Passereau/ $1545^{10}$

[Marle]

*first printed concordance

** served as basis for sonnets by Sidney

***cites basis for source rather than first printed concordance

Tabela 1 (cont.). Lista das peças dos Winchester Partbooks (FORNEY, 1999, p. 56-58). 
Diante do grande volume de material exibido nos partbooks, foi necessário estabelecer um recorte para sua abordagem, assim como um protocolo de identificação de peças para uma tomada sistemática de decisões quanto à possível produção de transcrições de cada uma delas. A presente investigação foi concentrada no conjunto de peças com textos em italiano ${ }^{5}$ e estabelecemos um protocolo que consiste em uma série de perguntas referenciais através das quais se puderam confirmar as informações de Forney, compará-las com aquelas fornecidas no repositório digital DIAMM, eventualmente atualizá-las e incluir novos dados relacionados a cada peça. O modelo da ficha contendo os itens de interesse está apresentado na figura 10.

A aplicação do protocolo às 81 peças italianas dos Winchester Partbooks permitiu identificar um total de 41 obras para as quais as respostas aos itens $5 a, 5 c, 7 a$, $7 \mathrm{~b}$ e 7c foram todas negativas - isto é, para as quais não se encontraram quaisquer transcrições, edições modernas, gravações ou registros em video - e estas foram selecionadas para transcrição como parte da presente pesquisa (tab. 2). A tabela 3 resume as informações referentes ao número de peças selecionadas de cada autor, assim como o número total de composições atribuídas a cada um deles nos partbooks.

\footnotetext{
${ }^{5}$ Conforme destacado nas páginas 38-39, as eventuais indicações de formas como villotta, napoletana, tedesca, etc. por parte do copista não são consistentes para a totalidade do corpus selecionado. No presente texto, portanto, não trataremos de tais classificações e discutiremos características gerais da villanella e da canzonetta enquanto formas vocais ligeiras.
} 


\section{PROTOCOLO PARA IDENTIFICAÇÃO DO MATERIAL DOS WINCHESTER PARTBOOKS}

\section{Numeração da peça nos partbooks:}

\section{Incipit:}

a) segundo Forney:

b) segundo DIAMM:

\section{Nome do compositor:}

a) segundo Forney:

b) segundo DIAMM:

\section{Concordâncias com outras fontes:}

a) Primeira concordância impressa com outras fontes segundo Forney:

b) Obteve-se acesso ao fac-símile?

c) Identificaram-se outras concordâncias?

d) Em caso afirmativo ao item (c), obteve-se acesso ao fac-símile?

\section{Material em notação moderna:}
a) Identificou-se alguma transcrição?
b) Em caso afirmativo ao item (a), obteve-se acesso ao material?
c) Identificou-se alguma edição publicada?
d) Em caso afirmativo ao item (c), obteve-se acesso ao material?
6. Estudos acadêmicos:
a) Identificaram-se publicações acadêmicas que citem a peça?
b) Em caso afirmativo ao item (a), obteve-se acesso ao material?
c) Identificou-se outro tipo de texto que cite a peça (programas de concerto, críticas, etc.)?

\section{Registros fonográficos ou em video:}
a) Identificaram-se gravações comerciais em LP ou CD?
b) Identificaram-se gravações disponíveis em plataformas digitais de música (Spotify, Apple Music, etc.)?
c) Identificaram-se registros em video da execução da peça?

\section{Outros Comentários:}

Transcrever? ( ) Sim ( ) Não

Figura 10. Modelo da ficha do protocolo de identificação para os Winchester Partbooks. 


\begin{tabular}{|c|c|c|}
\hline $\mathrm{n}^{\mathbf{0}}$. & incipit & compositor \\
\hline 04 & Pace non trovo & anônimo \\
\hline 05 & Ecco la stagion novella & anônimo \\
\hline 07 & Io che tropp' alt' amor volsi seguire & anônimo \\
\hline 09 & Tu sei la causa de la morte mia & Waelrant \\
\hline 10 & O Dio che fosse quella costumanza & Waelrant \\
\hline 13 & Mort' è pietà & Waelrant \\
\hline 15 & Fiamenga fredda, core di diamante & Tubal \\
\hline 16 & La manza mia si chiama Saporita & Tubal \\
\hline 17 & Donna, voi siete bella & Tubal \\
\hline 18 & Tri ciechi siamo & Waelrant \\
\hline 22 & Paschino, bello Paschino & Waelrant \\
\hline 29 & Mill' anni sono ch'io non t'haggio vista & Waelrant \\
\hline 31 & Non t'ho possuto mai, donna, mostrare & Waelrant \\
\hline 34 & Chiamo la mort' ogn'hor & Waelrant \\
\hline 35 & Sta' costante, cor mio, ch'io t'am' ogn'hora & Waelrant \\
\hline 36 & I dolci sguardi toi, alta signora & Waelrant \\
\hline 37 & Son mort' e moro & Waelrant \\
\hline 38 & Non posso far, cor mio, che pur non pianga & Waelrant \\
\hline 39 & Tanto sai fare con l'innamorati & Tubal \\
\hline 40 & Amar divers' amanti & Waelrant \\
\hline 42 & Deh perchè abbandonasti me & Tubal \\
\hline 43 & Conza lavezzi siam & Waelrant \\
\hline 44 & Madonn' habbi pietà del mio martire & Waelrant \\
\hline 45 & Non t'arricordi & Waelrant \\
\hline 46 & Issa in bona fè & Nasco \\
\hline 50 & Quanti ne vedi, tutt' a te li tiri & Waelrant \\
\hline 51 & Madonna mia, per te son quasi morto & Waelrant \\
\hline 52 & In tutto voi ch'io mor' o traditora & Waelrant \\
\hline 53 & Medici noi siamo & Waelrant \\
\hline 54 & Port' acqua'l crin e piglia vent' in rete & Waelrant \\
\hline 55 & Me bisogna servir questa crudele & Waelrant \\
\hline 56 & La bella monicella vad' a messa & Waelrant \\
\hline 57 & Hor mai son quasi morto & Waelrant \\
\hline 58 & Son molti giorni, ahimè, ch'io pers' il core & Waelrant \\
\hline 62 & Vorria e non vorria questo vi dire & Waelrant \\
\hline 63 & Ogniuno sapp' hormai la pena mia & Waelrant \\
\hline 64 & Forsi perchè core mio bell' ahimè & Waelrant \\
\hline 65 & Quell' hora desiata sempr' aspetto & Waelrant \\
\hline 66 & Con tanto riguardare & Waelrant \\
\hline 80 & A d'altre lo voi dare 'ste passate & Waelrant \\
\hline 81 & Se ben da voi madonn' i fia lontano & Waelrant \\
\hline
\end{tabular}

Tabela 2. Peças italianas selecionadas para transcrição. 


\begin{tabular}{|l|c|c|}
\hline Compositor & $\begin{array}{c}\text { Peças } \\
\text { italianas no } \\
\text { MS 153 }\end{array}$ & $\begin{array}{c}\text { Peças selecionadas } \\
\text { para transcrição }\end{array}$ \\
\hline (anônimo) & 7 & 3 \\
\hline Jacques Arcadelt & 1 & - \\
\hline Filippo Azzaiolo & 14 & - \\
\hline [Il Conte di] Briaco & 1 & - \\
\hline Giovanni Francesco Caldarino & 1 & - \\
\hline Baldassare Donato & 5 & - \\
\hline Alfonso Ganassi & 1 & - \\
\hline Giovan Tomaso Lambertini & 1 & - \\
\hline Roland de Lassus & 5 & - \\
\hline Giovanni Nasco & 2 & 5 \\
\hline Adrian Tubal & 5 & - \\
\hline Philippe Verdelot & 1 & 32 \\
\hline Hubert Waelrant & 34 & - \\
\hline Adrian Willaert & 2 & - \\
\hline Adrian Willaert / (Tiberio Fabrianese) & 1 & \\
\hline
\end{tabular}

Tabela 3. Número de peças italianas por compositor.

Examinando individualmente as concordâncias apontadas por Forney em seu estudo (itens $4 \mathrm{a}$ e $4 \mathrm{~b}$ do protocolo) e procurando também por outras correspondências (itens $4 \mathrm{c}$ e $4 \mathrm{~d}$ ), pudemos observar alguns fatores dignos de nota. Primeiramente, verificamos que entre as 40 peças com transcrições disponíveis em notação moderna (e portanto não selecionadas para transcrição nesta pesquisa), apenas quatro delas ( $\mathrm{n}^{\circ \mathrm{s}}$. $2,3,6,8)$ não constam em outras fontes do século XVI, e estas foram transcritas em artigos acadêmicos que citam diretamente os Winchester Partbooks (FABRI, 1970, p. 238-253; CARDAMONE, 1995, p. 91-93); para as outras 36 peças não selecionadas, as concordâncias apontam para fontes impressas que contêm conjuntos de repertório maiores e mais bem conhecidos, sugerindo que a maioria de suas edições modernas 
não tenha sido produzida a partir dos manuscritos de Winchester. Os exemplos mais importantes destas publicações renascentistas são: (i) os dois volumes de Filippo Azzaiolo onde se encontram as célebres villote del fiore ${ }^{6}$, que contêm não somente as 14 peças de sua autoria no MS 153, mas também aquelas atribuídas a Briaco, Caldarino, Ganassi e Lambertini - o que aponta para o fato muito provável de estas publicações terem sido fontes para a confecção dos próprios partbooks; (ii) o "Opus I" de Lassus7, que contém suas cinco obras italianas na coleção; (iii) o primeiro livro de villanesche de Donato $^{8}$, que contém as cinco peças de sua autoria e uma atribuída a Hubert Waelrant, que será discutida a seguir.

As 35 peças de Hubert Waelrant presentes nos Winchester Partbooks fazem com que este compositor seja, sem dúvida, o mais bem representado na coleção. De acordo com a pesquisa de Forney (tab. 1), as composições a ele atribuídas possuem primeiras concordâncias com apenas duas fontes: $1585^{19}$ (1 peça) e 1565 Waelrant (17 peças), enquanto os 17 títulos restantes são apontados pela autora como sendo unica de Winchester. Ao aplicarmos o protocolo de identificação à totalidade destas obras, pudemos confirmar ambas as correspondências e verificar que a primeira delas $\left(1585^{19}\right)$ é uma das grandes antologias de música vocal do Renascimento, Symphonia Angelica ${ }^{9}$, organizada pelo próprio compositor em Antuérpia aproximadamente duas décadas após a confecção do MS 153. Esta coleção foi bastante estudada no âmbito da musicologia e suas obras foram repetidamente editadas em notação moderna, não consistindo, portanto, em objeto de interesse direto para esta pesquisa.

O estudo da segunda concordância, por outro lado, fornece dados mais interessantes. 1565 Waelrant corresponde aos volumes editados em Veneza por

\footnotetext{
${ }^{6}$ Il primo libro de villotte alla Padoana com alcune Napolitane a quattro voci intitolate villotte del fiore (Veneza: Antonio Gardano, 1557) e Il secondo libro de villotte de del fiore, alla padoana com alcune Napolitane e madrigali a quattro voci (Veneza: Antonio Gardano, 1559), ambos com várias reimpressões por Gardano e Scotto. ${ }^{7}$ Le quatoirsiesme livre a quatre parties contenant dizhuyct chansons italiennes, six chansons francoises, $\mathcal{E}$ six motets (Antuérpia: Tielman Susato, 1555)

${ }^{8}$ Il primo libro di canzon villanesche alla napolitana a quattro voci (Veneza: Antonio Gardano, 1554)

9 Symphonia Angelica di diversi eccelentissimi musici a IIII. V. et VI. Voci, nuovamente raccolta per Huberto Waelrant (Antuérpia: Pierre Phalèse \& Jean Bellère, 1585)
} 
Girolamo Scotto e intitulados Le canzon napolitane a quattro voce (WAELRANT, 1565), cuja parte do alto encontra-se disponível digitalmente na Bayerische Staatsbibliothek; até onde pudemos verificar, esta parte é a única que não foi perdida, e sugerimos aqui a hipótese de ser esta a razão para não havermos encontrado qualquer edição moderna ou registro de execução das 17 peças que exibem esta concordância - e estas foram, naturalmente, selecionadas para transcrição no presente trabalho.

Por fim, entre os outros 17 títulos atribuídos a Waelrant e apontados por Forney como unica em Winchester, apenas um (n. 98: Le volez vous dame que je couche) não faz parte do conjunto de formas italianas e portanto não foi tratado devido ao recorte da pesquisa. Para os 16 restantes, a aplicação do protocolo foi realizada e permitiu a obtenção de um novo dado que atualiza o estudo da autora: a peça Se pur ti guardo (nº. 11), atribuída a Waelrant nos manuscritos e sem correspondências indicadas na tabela 1, pôde ser localizada nas edições de 1551 e 1558 do Primo libro de canzon villanesche de Donato, exibindo, na primeira delas, atribuição a um "incerto autore" (DONATO, 1551, fol. 148). As quatro vozes da peça foram verificadas separadamente para garantir tratar-se da mesma obra, e embora o esclarecimento de sua autoria requeira novas investigações, podemos afirmar com segurança que está diminuído de 17 para 16 o número de unica de Hubert Waelrant no MS 153. As 15 peças italianas sem concordâncias, assim como as 17 mencionadas no parágrafo anterior, foram transcritas como parte da pesquisa e serão tratadas nos próximos capítulos. 


\section{WINCHESTER PARTBOOKS: TRANSCRIÇÃO À LUZ DA TEORIA}

Conforme destacamos anteriormente, o objeto central desta pesquisa consiste em um subconjunto delimitado de obras contidas nos volumes manuscritos intitulados Winchester Partbooks (GB-WCc MS 153) - isto é, no corpus constituído por suas 41 peças italianas que não se encontravam editadas em notação moderna no princípio desta investigação. Em virtude das importantes diferenças estruturais entre a escrita musical do século XVI e aquela praticada atualmente, a transcrição destas peças para a notação moderna identifica-se com um dos objetivos aqui propostos, nomeadamente a ampliação do repertório acessível aos intérpretes não especializados na notação musical do Renascimento. A importância desta função editorial é salientada pelo musicólogo Thomas Schmidt-Beste ao afirmar que

afinal, os editores são supostamente os especialistas, e editar significa "traduzir" a música para os usuários, tanto intérpretes como acadêmicos, tornando-a acessível àqueles para quem é impraticável ou impossível trabalhar diretamente com as fontes. É um pouco como dublar um filme em língua estrangeira - em princípio todos concordamos que algo é perdido no processo, mas seria cruel negar o prazer da experiência cinematográfica a qualquer pessoa que não seja poliglota. Por esta razão, nós convertemos partbooks e choirbooks para o formato de partitura; por esta razão nós convertemos notação mensural para notação moderna e adicionamos barras de compasso; por esta razão nós adicionamos musica ficta; e por esta razão nós transcrevemos o texto da escrita gótica para caracteres romanos (SCHMIDT-BESTE, 2013, p. 108-109, tradução nossa ${ }^{1}$ ).

Uma avaliação crítica dos processos editoriais por parte dos usuários de edições modernas deste repertório, contudo, pode requerer uma série de reflexões a respeito

\footnotetext{
${ }^{1}$ No original: "after all, the editors are allegedly the experts, and editing is about "translating" music for users, both performers and scholars, making it accessible to those for whom it is impossible or impracticable to work directly from the sources. It is rather like dubbing a foreign-language movie - in principle, we all agree that something is lost in the process, but it would seem harsh to refuse the enjoyment of the cinematic experience to anybody who is not a polyglot. For this reason, we convert partbooks and choirbooks into score format; for this reason we convert mensural notation into modern notation and add barlines; for this reason we add musica ficta; and for this reason we transcribe the text from Gothic bookhand into Roman typeface."
} 
de seus aspectos notacionais, além de uma clara distinção entre o material original e as possíveis intervenções dos editores - o que nem sempre constitui uma tarefa fácil para o leitor não especializado, conforme aponta Bernard Thomas no artigo intitulado Renaissance Music in Modern Notation:

Para fazer o melhor uso de qualquer edição o intérprete precisa saber exatamente o que é original e o que não é. Mas a menos que ele esteja realmente envolvido em edição ou em arranjo, é difícil para ele adquirir o hábito de pensar nesses termos, e eu suspeito fortemente que a maioria dos intérpretes realmente não têm ideia de até que ponto eles estão sendo influenciados pelas muitas decisões aparentemente triviais tomadas pelo editor (ou pela casa editora) antes que a música chegue ao público (THOMAS, 1977, p. 4, tradução nossa²).

Por esta razão, explicitamos nosso processo editorial no presente capítulo através da abordagem dos tópicos potencialmente mais problemáticos do antigo sistema de notação; o texto foi estruturado em três seções principais, a saber: (i) a discussão de aspectos rítmicos, realizada através da exposição dos fundamentos da notação mensural branca e da exemplificação de transcrições de peças extraídas do corpus sob consideração (seção 3.1); (ii) a discussão de aspectos relacionados aos acidentes possivelmente acrescentados em notação moderna - isto é, a musica ficta - através da exposição do sistema hexacordal e das possíveis inflexões cromáticas a se aplicarem às peças transcritas na pesquisa (seção 3.2); e (iii) algumas reflexões a respeito da utilização de fontes originais, diferentes tipos de transcrições e seus possíveis efeitos sobre a performance deste repertório (seção 3.3). Para esta última discussão consideramos depoimentos de professores e intérpretes, assim como nosso próprio relato de experiência desenvolvido junto ao Madrigal Comunicantus, ensemble vocal constituído no âmbito do Comunicantus: Laboratório Coral da ECA-USP.

\footnotetext{
${ }^{2}$ No original: "To make the best use of any edition the performer needs to know exactly what is original and what is not. But unless he is actually involved in editing or arranging, it is difficult for him to get into the habit of thinking in these terms, and I strongly suspect that the majority of performers really have no idea to what extent they are being influenced by the many apparently trivil decisions taken by the editor (or the publisher) before the music reaches the public."
} 


\subsection{TRATAMENTO DE ELEMENTOS RÍTMICOS}

Embora a notação musical moderna possua múltiplas semelhanças com aquela praticada durante o Renascimento, os atuais editores do repertório polifônico dos séculos XV e XVI são constantemente confrontados com questões importantes relacionadas a seus aspectos rítmicos. Os processos de transcrição da notação mensural branca para a notação moderna exigem não apenas que se tomem decisões relativas às durações de figuras isoladas, mas frequentemente requerem avaliações de seus significados em contextos musicais mais amplos - ora especificados através dos antigos sinais de mensuração e proporção, ora determinados a partir das relações entre diferentes vozes, ora inferidos através de tradições documentadas em escritos teóricos ou nas próprias fontes musicais do Renascimento. O sistema mensural nunca chegou a ser totalmente livre de inconsistências ou conflitos, e por esta razão os intérpretes modernos - incluindo-se os ensembles especializados em performances baseadas em fac-símiles - obrigam-se a realizar alguma espécie de análise rítmica do material musical impresso ou manuscrito por meio de uma interpretação criteriosa das fontes originais ou ainda através de uma avaliação crítica dos processos editoriais adotados nas transcrições.

Em sua recente publicação intitulada Tactus, Mensuration and Rhythm in Renaissance Music - possivelmente o mais abrangente estudo já realizado a respeito do ritmo na música renascentista - a musicóloga Ruth DeFord afirma que

a notação mensural não foi um sistema único, unificado, mas uma coleção de práticas diversas que variaram com a época, o lugar, o gênero e o compositor. Ela era frequentemente inconsistente, mesmo em um repertório estreitamente definido. Teóricos discordavam sobre aspectos importantes dela e frequentemente faziam objeções às práticas notacionais dos compositores, mesmo quando concordavam uns com os outros. Os principais pontos de discordância entre os teóricos eram as maneiras corretas de notar certas mensurações e proporções, e as relações das diferentes mensurações umas com as outras. Alguns teóricos do século XVI também adotaram atitudes 
dogmáticas sobre tactus que estavam em desacordo com as práticas da maioria dos intérpretes (DEFORD, 2015, p. 3-4, tradução nossa ${ }^{3}$ ).

Com efeito, os reflexos desta diversidade de práticas podem ser abundantemente observados nas fontes musicais dos séculos XV e XVI e também nas edições modernas da polifonia renascentista. As eventuais complexidades do antigo sistema não impedem, entretanto, que intérpretes não especializados na notação mensural possam se beneficiar do conhecimento das linhas gerais de sua estrutura. Em particular, (i) a determinação do tactus (pulso) a se adotar na performance de peças específicas; e (ii) o estabelecimento de relações entre ritmos binários e ternários dentro de uma mesma obra - algo notadamente frequente no repertório vocal do século XVI - permeiam grande parte da discussão sobre os aspectos rítmicos da música do Renascimento e constituem problemas centrais para sua interpretação. Esta seção inicia-se, portanto, com um panorama teórico destinado ao intérprete não especialista onde são apresentados os elementos notacionais básicos, a terminologia e as principais mensurações em uso durante o século XVI; em seguida são discutidos tópicos mais complexos como a notação proporcional e as relações temporais entre seções binárias e ternárias de uma mesma peça. A exposição apoia-se tanto em escritos do Renascimento quanto na literatura musicológica dos séculos XX e XXI e inclui, sempre que possível, referências explícitas a exemplos extraídos dos Winchester Partbooks, que constituem o repertório efetivamente tratado na presente pesquisa.

\footnotetext{
${ }^{3}$ No original: "Mensural notation was not a single, unified system, but a collection of diverse practices that varied with time, place, genre and composer. It was often inconsistent even within a narrowly defined repertoire. Theorists disagreed about important aspects of it, and they often objected to the notational practices of composers even when they agreed with each other. The principal subjects of disagreement among theorists were the proper ways of notating certain mensurations and proportions and the relationships of different mensurations to each other. Some sixteenth-century theorists also adopted dogmatic attitudes about tactus that were at odds with the practices of most performers."
} 


\subsubsection{Figuras e pausas}

A partir da segunda metade do século XV os escribas gradualmente abandonaram a antiga prática de preencher de preto as cabeças de todas as figuras musicais, inaugurando o que hoje se denomina notação mensural branca, sistema que foi utilizado para a escrita da música polifônica até o início do século XVII. Em The Notation of Polyphonic Music: 900-1600, Willi Apel afirma que esta alteração foi resultado de fatores externos como a maior dificuldade de se realizar o preenchimento em papel fino se comparado ao antigo pergaminho, além da economia de esforço e tempo envolvidos no processo anterior (APEL, 1953, p. 87). Por volta de 1450, portanto, as figuras musicais assumiram um aspecto mais próximo do atual e recebiam denominações das quais também derivam aquelas utilizadas presentemente. Em notação moderna, contudo, a mensuração de qualquer figura é sempre assumida como sendo binária $(|\mathbf{|}|=\mathbf{=}=\mathbf{o}, \mathbf{o}=d d$, etc. $)$ enquanto o sistema utilizado durante o Renascimento poderia envolver medidas binárias $(\xi=\diamond \diamond, \diamond=\downarrow \downarrow$, etc.) ou ternárias $(\sharp=\diamond \diamond \diamond, \diamond=\downarrow \downarrow \downarrow$, etc.) de alguns valores.

Os teóricos dos séculos XV e XVI se referiam às figuras por seus nomes latinos ou vernáculos a depender do idioma em que escrevessem seus tratados; neste texto, porém, empregaremos consistentemente as denominações latinas para designar as figuras antigas (brevis, semibrevis, minima, etc.), evitando assim que estas sejam confundidas com as modernas (breve, semibreve, mínima, etc.), que pertencem a um sistema de mensuração distinto e por esta razão podem carregar diferentes significados musicais. A seguir apresentamos as formas das figuras mais comumente encontradas em publicações impressas do século XVI (fig. 11), bem como exemplos manuscritos extraídos das fontes examinadas neste trabalho (fig. 12). As diferentes formas das pausas de maxima e longa exibidas na primeira ilustração, que podem cobrir dois ou três espaços do pentagrama, correspondem às mensurações binárias ou ternárias da longa (modus perfectus e modus imperfectus, respectivamente), relações que serão consideradas mais detalhadamente na seção 3.1.4. 


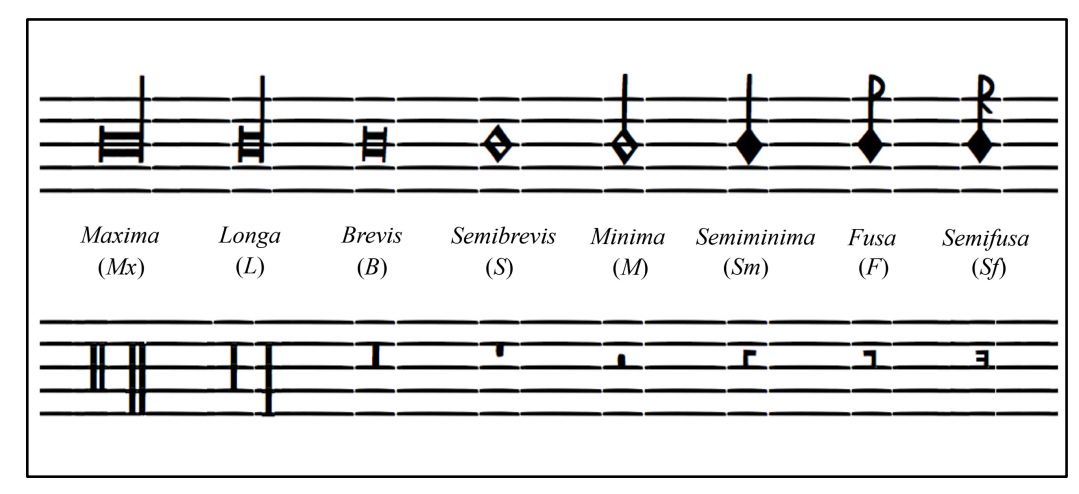

Figura 11. Formas usuais das figuras e pausas em publicações impressas no século XVI.

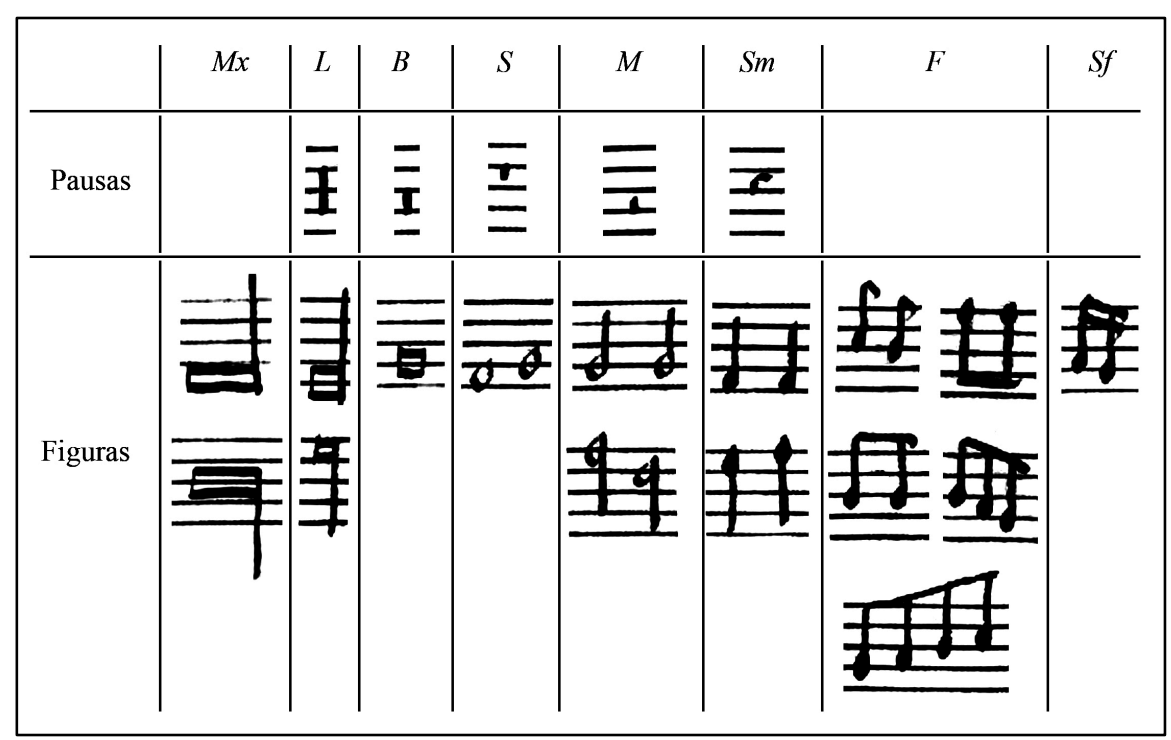

Figura 12. Formas manuscritas das figuras e pausas extraídas dos Winchester Partbooks.

\subsubsection{Ligaduras}

As figuras do sistema mensural podem aparecer conectadas umas às outras, formando conjuntos denominados ligaduras (fig. 13). Na música vocal, costuma-se considerar que elas pressuponham melismas, isto é, todas as suas notas são normalmente associadas a uma única sílaba. Embora estas estruturas já houvessem caído em relativo desuso durante o período considerado nesta pesquisa, elas foram discutidas pela maioria dos teóricos que trataram da música mensural no século XVI e ocasionalmente ocorriam em peças manuscritas ou editadas, possivelmente como 
demonstrações de erudição por parte dos compositores, editores e escribas. As origens destes conjuntos de figuras remontam à notação neumática do canto gregoriano, em que um único símbolo pode expressar simultaneamente (i) a duração de vários sons, e (ii) os movimentos melódicos existentes entre eles. Os neumas mais simples que descrevem saltos ascendentes ou descendentes denominam-se, respectivamente, podatus ( e clivis ( ) ambos expressam uma sequência rítmica do tipo $B L$ - isto é, um som breve seguido de um longo. Durante a Idade Média esta sucessão de durações era considerada própria (por iniciar-se com uma B) e perfeita (por finalizar-se com uma $L)$, configurando as formas que se denominavam cum proprietate et cum perfectione, enquanto sequências diferentes desta (sine proprietate e/ou sine perfectione) eram expressas através de modificações das formas perfeitas correspondentes. Na figura 14, extraída de The Notation of Polyphonic Music: 900-1600, Apel ilustra as ligaduras binárias compostas pelas quatro diferentes combinações de breves e longae (formas cum-cum, sine-cum, cum-sine e sine-sine), além daquelas cum opposita proprietate (c. o. p.), que denotam duas semibreves e são as únicas através das quais se expressam valores menores do que a brevis.

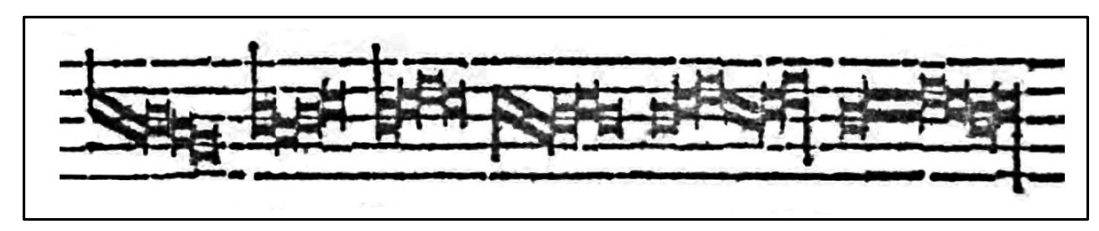

Figura 13. Exemplos de ligaduras (HEYDEN, 1540, p. 45).

\begin{tabular}{|c|c|c|c|}
\hline \multirow[t]{2}{*}{ Symbol } & \multicolumn{2}{|c|}{ Form } & \multirow[t]{2}{*}{ Value } \\
\hline & desc. & asc. & \\
\hline cum-cum & 円 & (9) 的 & $B L$ \\
\hline sine-cum & 8 & (a) ही & $L L$ \\
\hline cum-sine & $A$ & $q(p)$ & $B B$ \\
\hline sine-sine & $\theta$ & q & $L B$ \\
\hline c.o.p. & 46 & $4 b$ & $S S$ \\
\hline
\end{tabular}

Figura 14. Ligaduras binárias em notação mensural branca (APEL, 1953, p. 90). 
A determinação dos valores das figuras em ligaduras compostas por mais de duas notas exige a observação de um conjunto de regras que foram apresentadas pela maioria dos tratadistas que abordaram estas estruturas. Thomas Morley, em particular, afirma em A Plain and Easy Introduction to Practical Music que uma ligadura "é uma combinação ou costura de duas ou mais notas, alterando (através de sua localização e ordem) o valor das mesmas" (MORLEY, 1597, p. 19, tradução nossa4) e não deixa de comentar as formas oblíquas $(\unrhd, \oslash)$ - que indicam apenas as duas notas cujas alturas localizam-se em suas extremidades - no diálogo entre o mestre e seu discípulo Philomathes:

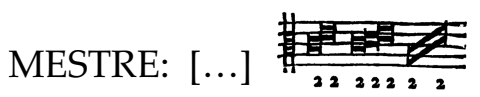

PHILOMATHES: Mas interrompendo seu discurso sobre ligaduras: quantas notas deve conter esse caractere que você escreveu por último?

MESTRE: Duas.

PHILOMATHES: E onde elas se localizam? Porque eu pensei que devesse ser escrito assim: pois ele se estende de $A$ la mi re até $E$ la $m i .^{5}$

MESTRE: As notas se localizam no início e no final, como neste exemplo supracitado: a primeira localiza-se em A la mi re, a última em Ela mi.

(MORLEY, 1597, p. 10, tradução nossa' ${ }^{6}$

Independentemente de tomar parte em uma porção reta ou oblíqua de uma ligadura, cada figura tem seu valor determinado a depender de sua posição dentro do conjunto (initialis, media ou finalis), da direção de sua haste (caso possua uma) e dos intervalos

\footnotetext{
${ }^{4}$ No original: "it is a combination or knitting together of two or more notes, altering (by their situation and order) the value of the same."

${ }^{5}$ No exemplo, A la mi re e E la mi referem-se às atuais alturas Lá3 e Mi4, respectivamente.

${ }^{6}$ No original: "Ma: [...] notes doeth that charecter conteine which you have set downe last? / Ma: Two. / Phi: Where doe they stande? for I thought it should have beene set thus, because it stretcheth from A la mi re, to E la mi. / $M a$ : The notes stand at the beginning and the ende, as in this example aforesaide:the first standeth in A la mi re, the last in E la mi."
} 
melódicos que mantém com as notas adjacentes; alguns teóricos (entre eles Morley) organizaram suas declarações sobre ligaduras a partir da presença ou ausência de hastes, enquanto outros optaram por discutir separadamente os casos das notas iniciais, médias ou finais, por exemplo. De todo modo, os resultados são equivalentes e na presente exposição reproduzimos o conciso resumo apresentado por Apel em seu texto:

A. Regras sobre o significado das hastes.

1. Uma nota com uma haste descendente à direita é $L$;

2. Uma haste ascendente à esquerda da nota inicial faz daquela nota e da próxima uma $S$ cada.

3. Uma inicial com uma haste descendente de seu lado esquerdo é $B$.

B. Regras para notas não contempladas em A.

4. Todas as notas intermediárias são $B$.

5. Uma nota inicial em posição descendente (isto é, seguida de uma nota mais grave) e uma nota final em posição descendente (isto é, precedida de uma nota mais aguda) são $L$.

6. Uma inicial em posição ascendente e uma final em posição ascendente são $B$.

7. Uma nota final em posição oblíqua é $B$.

(APEL, 1953, p. 91-92, tradução nossa7)

\footnotetext{
${ }^{7}$ No original: "A. Rules about the meaning of the tails. 1. A note with a downward tail to the right is $L$. 2. An ascending tail to the left of the initial note makes that note and the following one a $S$ each. 3. An initial with a downward tail to its left side is B. / B. Rules for notes not covered under A. 4. All middle notes are B. 5. An initial note in descending position (i.e., followed by a lower note) and a final note in descending position (i.e., preceded by a higher note) are $L$. 6 . An initial in ascending position and a final in ascending position are B. 7. A final note in oblique form is B."
} 
Estas convenções também foram colocadas pelo autor sob a forma de uma representação esquemática (fig. 15), o que permite realizar facilmente uma decodificação visual de ligaduras ocorrentes no repertório quando necessário. Com este propósito reproduzimos adicionalmente alguns exemplos fornecidos no tratado Scintille di Musica, de Giovanni Lanfranco (fig. 16) - que tratou separadamente as initiales, mediae e finales - e outros extraídos da própria Introduction de Morley (fig. 17), onde os números correspondem à quantidade de semibreves que totalizam o valor de cada figura (semibrevis: 1; brevis: 2; longa: 4).

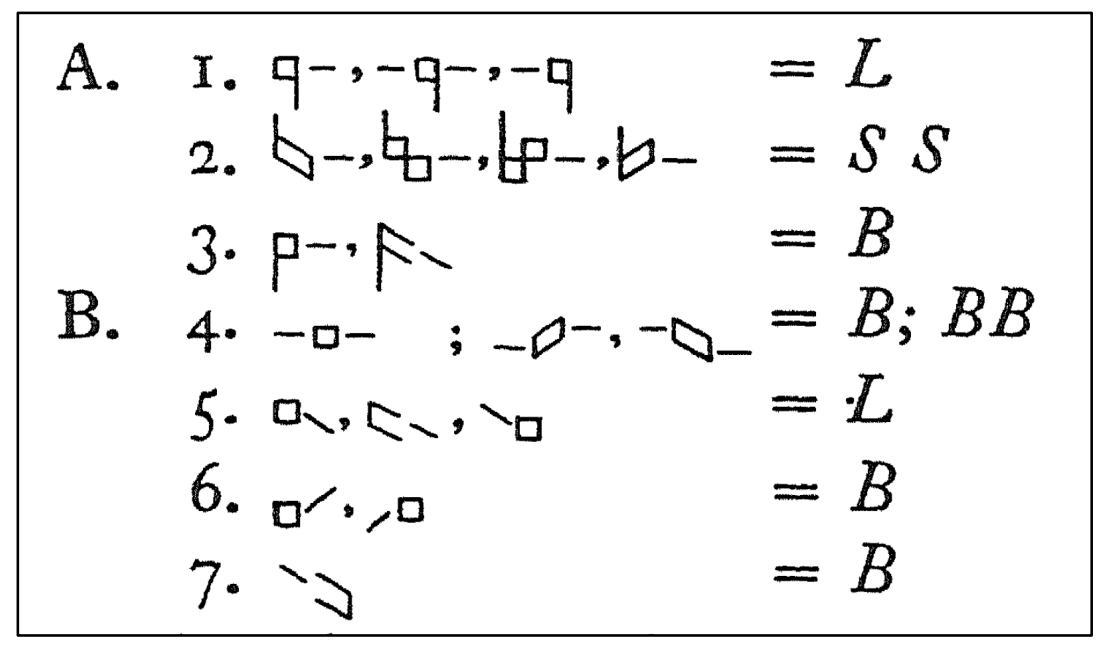

Figura 15. Representações esquemáticas das regras de ligaduras (APEL, 1953, p. 92).

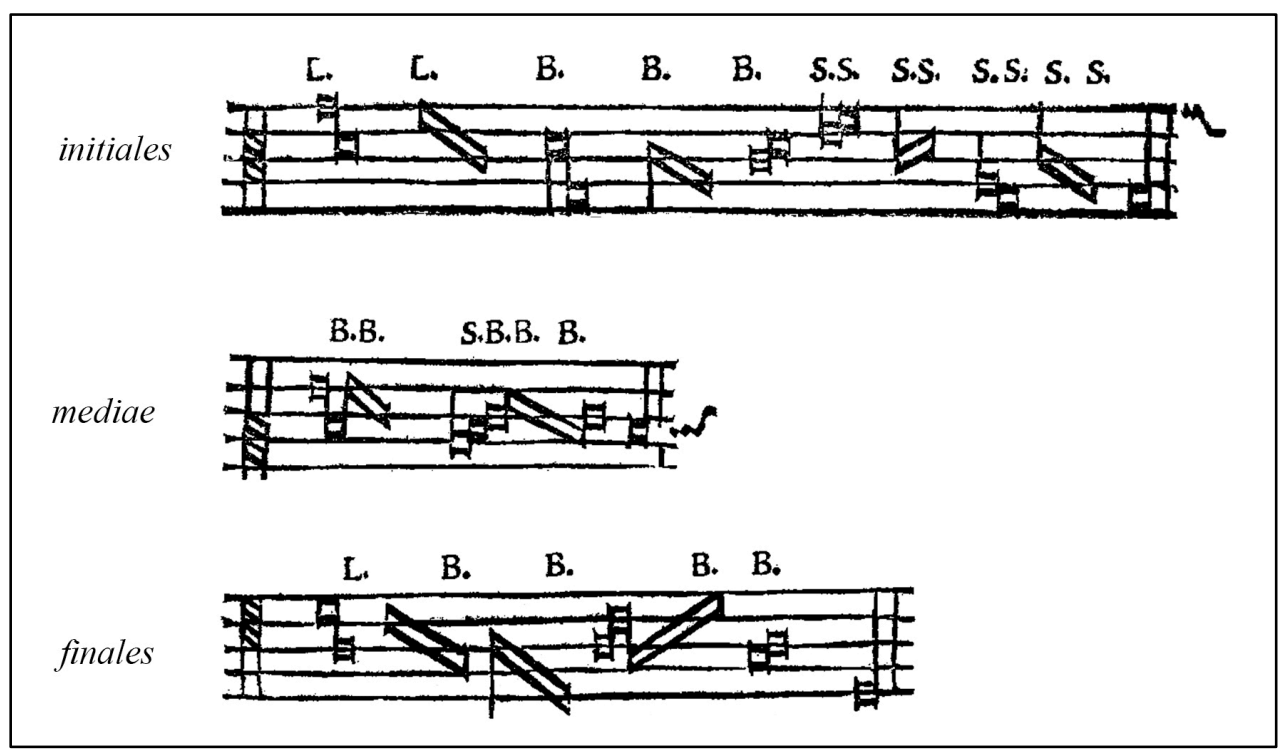

Figura 16. Valores das figuras em posições iniciais, médias ou finais em ligaduras exemplificadas no tratado Scintille di Musica (LANFRANCO, 1533, p. 38). 


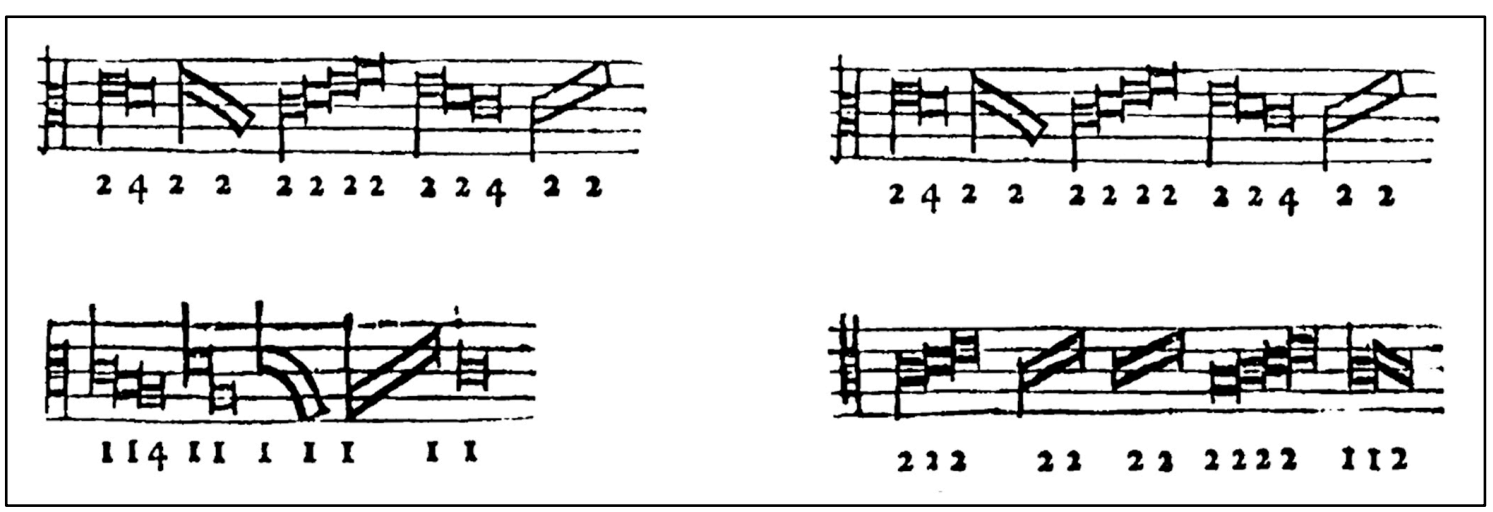

Figura 17. Valores das figuras expressos em número de semibreves para exemplos extraídos de A Plain and Easy Introduction to Practical Music (MORLEY, 1608, p. 10-11).

Em edições modernas do repertório originalmente escrito em notação mensural, trechos em ligaduras são normalmente indicados através de colchetes sobre as notas em questão. Nas peças selecionadas para transcrição neste trabalho, esta convenção foi aplicada à única ocorrência do uso destas estruturas (ligadura cum opposita proprietate, denotando duas semibreves), observada no tenor da peça Non posso far, cor mio (Winchester Partbooks, n. 38), de Hubert Waelrant (fig. 18).

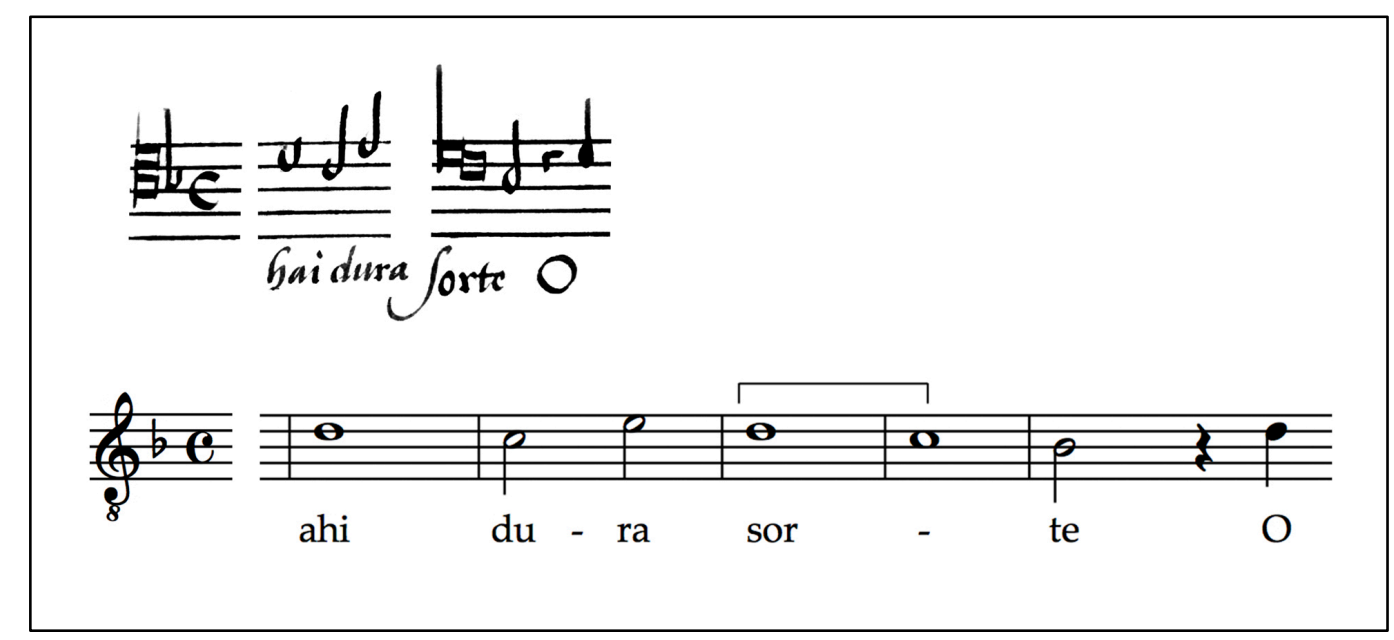

Figura 18. Exemplo de ligadura cum opposita proprietate no tenor da peça Non posso far, cor mio, de Hubert Waelrant (Winchester Partbooks, n. 38). 


\subsubsection{Níveis de mensuração}

Assim como na notação musical moderna, as figuras do sistema mensural são ordenadas de acordo com uma hierarquia de valores temporais que permite determinar precisamente suas durações relativas quando são comparadas umas às outras. Na linguagem musical do final da Idade Média e do Renascimento, o termo mensuração indica a correspondência existente entre o valor temporal de uma figura e aquele de um certo número de figuras da próxima espécie hierarquicamente inferior isto é, "mensuração binária da brevis" significa a equivalência da duração da brevis à de duas semibreves, enquanto "mensuração ternária da semibrevis" indica a correspondência entre o valor da semibrevis e o de três minimae, por exemplo.

As mensurações binárias são denominadas imperfeitas e as ternárias perfeitas; alguns dos níveis de mensuração recebem nomes particulares que eram utilizados correntemente pelos teóricos e compositores, a saber: modus (mensuração da longa), tempus (mensuração da brevis) e prolatio (mensuração da semibrevis) (fig. 19).

\begin{tabular}{|c|c|}
\hline $\begin{array}{l}\text { modus perfectus } \\
\qquad \begin{array}{|}\mathbf{日} \\
\mathbf{日}\end{array}\end{array}$ & $\begin{array}{l}\text { modus imperfectus } \\
\mathbf{日}=\mathbf{日} \text { 日 }\end{array}$ \\
\hline $\begin{array}{l}\text { tempus perfectum } \\
\mathbf{H}=\diamond \diamond \diamond\end{array}$ & $\begin{array}{c}\text { tempus imperfectum } \\
\mathbf{H}=\diamond \boldsymbol{\diamond}\end{array}$ \\
\hline $\begin{array}{l}\text { prolatio perfecta } \\
\boldsymbol{\nabla}=\boldsymbol{\downarrow} \downarrow\end{array}$ & $\begin{array}{l}\text { prolatio imperfecta } \\
\diamond=\downarrow \downarrow\end{array}$ \\
\hline
\end{tabular}

Figura 19. Mensurações da longa, brevis e semibrevis.

Mensurações de valores menores do que a semibrevis não recebem denominações especiais e são sempre imperfeitas; a mensuração da maxima (denominada modus major) é normalmente imperfeita, salvo em casos muito complexos e encontrados apenas em períodos anteriores ao tratado nesta pesquisa. No repertório polifônico do século XVI, os valores mais largos do sistema (maxima e longa) são normalmente 
subdivididos de forma binária, razão pela qual modus major e modus serão supostos imperfeitos na presente exposição; os níveis tempus e prolatio, por sua vez, serão discutidos em diferentes exemplos e designam-se através dos sinais de mensuração $\odot$ (tempus perfectum cum prolatione perfecta), ๔ (tempus imperfectum cum prolatione perfecta), O (tempus perfectum cum prolatione imperfecta) e C(tempus imperfectum cum prolatione imperfecta). As relações entre os valores mensurais em cada um destes casos estão esquematicamente representadas na figura 20, uma colagem de diagramas apresentados por Thomas Morley no tratado A Plain and Easy Introduction to Practical Music, onde se pode observar a subdivisão binária da longa (modus imperfectus) em qualquer das quatro combinações.

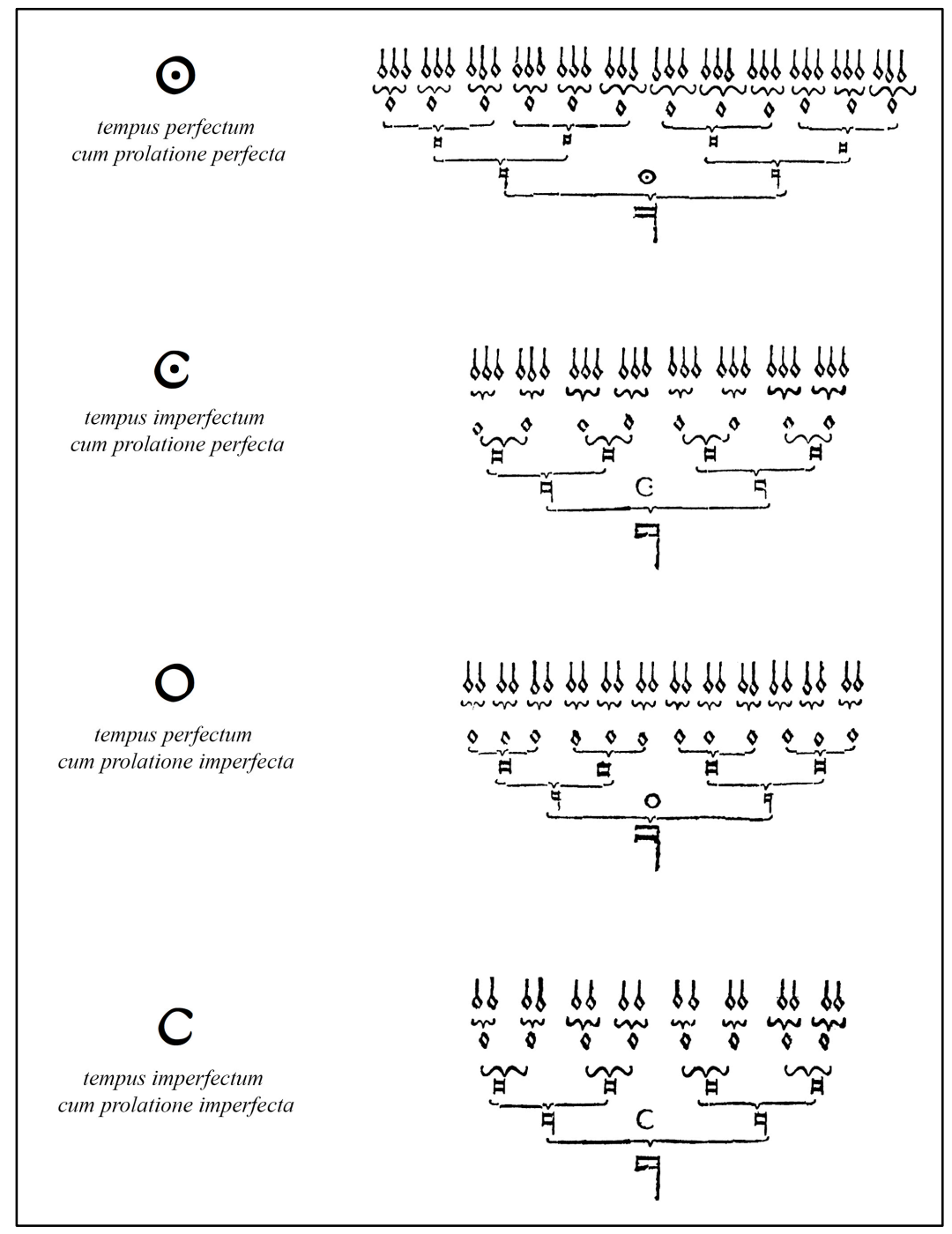

Figura 20. Diagramas das relações entre as figuras mensurais em diferentes combinações de tempus e prolatio (MORLEY, 1608, p. 15-16). 
Embora a construção da polifonia renascentista não seja, em geral, baseada em padrões regulares de acentuação métrica, as subdivisões da brevis e da semibrevis ilustradas acima sugerem uma associação dos antigos sinais de mensuração $\odot$, ๔', O e C com as atuais fórmulas utilizadas para compassos ternários compostos, binários compostos, ternários simples e binários simples, respectivamente; por esta razão, em transcrições modernas com redução de valores 1:4 $\left(\bullet_{\bullet} \cdot\right)$, normalmente se observam

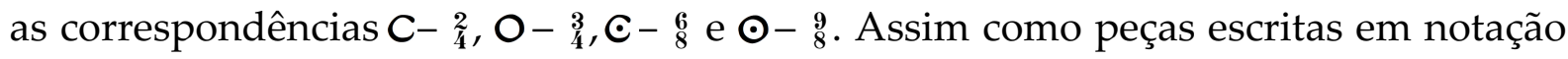
moderna sob as fórmulas de compasso ${ }_{4}^{3}$ ou ${ }_{8}^{6}$ tendem a exibir grupos ternários de semínimas ou colcheias, a música escrita em tempus perfectum ou prolatio perfecta organiza-se analogamente em grupos de três semibreves ou três minimae. Na linguagem mensural, estes agrupamentos são denominados perfeições; uma perfeição no nível tempus equivale, portanto, a um grupo de figuras que somam o valor de três semibreves, enquanto no nível prolatio as perfeições constituem conjuntos que totalizam o valor de três minimae (fig. 21).

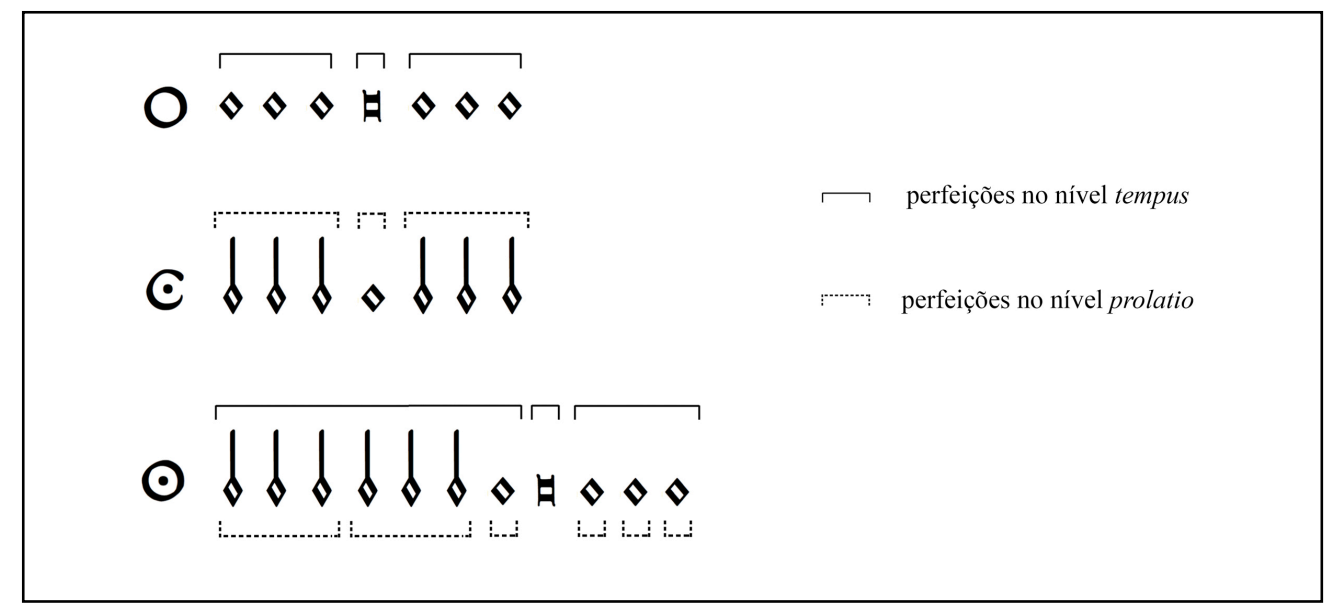

Figura 21. Perfeições nos níveis tempus e prolatio.

\subsubsection{Imperfeição e alteração}

Diferentemente das mensurações imperfeitas (e da notação moderna), em que as relações entre os valores das figuras são binárias e fixas $(\sharp=\diamond, \diamond=\downarrow \downarrow$, etc. $)$, as 
mensurações perfeitas admitem que relações ternárias como $\sharp=\diamond \diamond \bullet \bullet \bullet=\downarrow \downarrow \downarrow$ sejam ocasionalmente alteradas para $\sharp=\diamond$ ou $\diamond=\downarrow \downarrow$ para permitir que determinados grupos de figuras formem perfeições. Como um exemplo, a notação do segundo compasso do trecho $\frac{3}{2}$ o. $\mid$ o $d \mid$ o. || em prolatio perfecta seria impossível caso a relação entre a semibrevis e a minima fosse invariavelmente interpretada como ternária, pois nesta mensuração não há figura com valor equivalente ao de duas minimae. A solução para este problema é a notação do exemplo em questão como $O \diamond \diamond \downarrow \diamond$, porém a segunda semibrevis, como se vê, perde um terço de seu valor temporal, que passa a ser ocupado pela minima seguinte, de modo que o agrupamento $\downarrow \downarrow$ torna-se uma perfeição. O processo sofrido por esta semibrevis em prolatio perfecta é denominado imperfectio (imperfeição). A imperfeição de uma figura pode ser ocasionada por uma figura seguinte a ela (imperfectio a parte post), como no exemplo citado, ou, em algumas situações, pela figura imediatamente anterior (imperfectio a parte ante). $\mathrm{O}$ mecanismo se opera de maneira análoga nos níveis tempus e modus: em tempus perfectum a imperfeição da brevis pode ser causada pela semibrevis (fig. 22), enquanto em modus perfectus uma longa torna-se

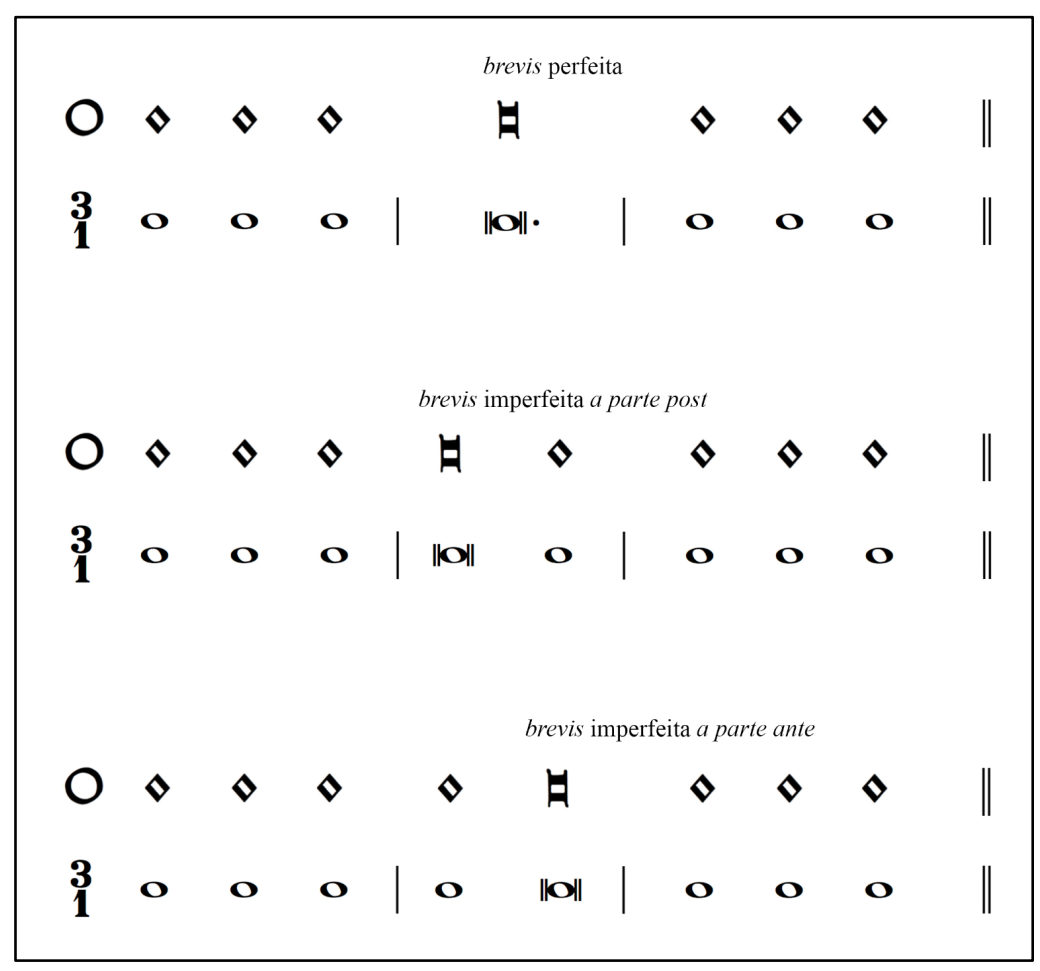

Figura 22. Imperfeição a parte post e a parte ante em tempus perfectum. 
eventualmente imperfeita pela ação da brevis. Ambos os tipos de imperfectio podem ser ocasionados não apenas por uma única figura, mas também por grupos de figuras menores que totalizem o valor desta, ou ainda por pausas de valores equivalentes; as próprias pausas, contudo, nunca se tornam imperfeitas e sua notação em mensurações perfeitas deve ser adaptada às estruturas das perfeições. Na mensuração O, por exemplo, pausas de semibrevis consecutivas devem ser escritas na mesma linha do pentagrama se pertencem a uma mesma perfeição, enquanto pausas pertencentes a perfeições distintas são notadas em linhas diferentes. A importância desta distinção pode ser observada nas transcrições realizadas por Apel para dois exemplos em tempus perfectum com redução de valores 1:4 ( $\bullet \cdot \cdot$ ) (fig. 23): no caso (a), supõe-se que a primeira pausa de semibrevis pertença à mesma perfeição da brevis anterior, que se torna imperfeita a parte post; no caso (b), contrariamente, a primeira pausa de semibrevis deve pertencer à mesma perfeição da pausa seguinte, o que impossibilita seu agrupamento com a primeira brevis, que se mantém perfeita.

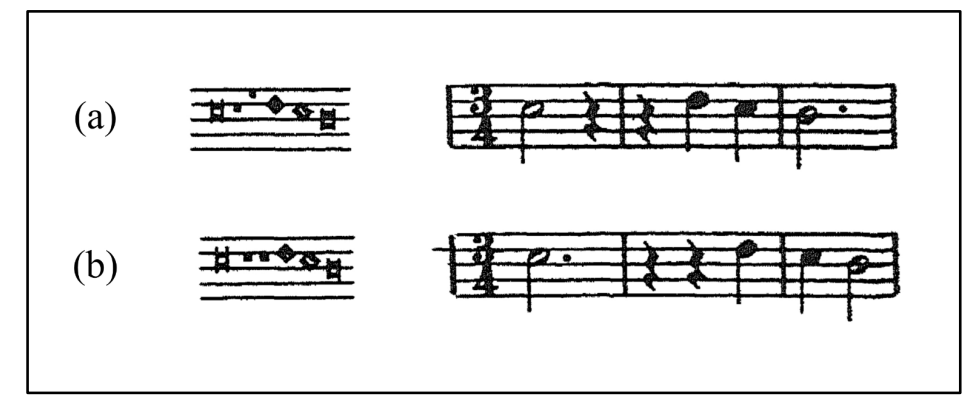

Figura 23. Pausas notadas em diferentes alturas em tempus perfectum (APEL, 1953, p. 111).

Em mensurações imperfeitas, embora a posição das pausas não exerça influência sobre os valores das figuras da maneira discutida acima, sua notação também costuma adaptar-se a estruturas mensurais - baseadas, neste caso, em algum valor binário. Um exemplo pode ser observado no discantus da peça Fiamenga fredda, core di diamante, do compositor flamengo Adrian Tubal, escrita sob o sinal de mensuração C (fig. 24); no trecho correspondente aos compassos 17-19 de nossa transcrição sem redução de valores, o silêncio com valor de duas semibreves é notado 
como pausa de minima + pausa de semibrevis + pausa de minima, de maneira similar ao que ocorre em notação moderna sob a fórmula de compasso c. Apesar de barras de compasso não serem empregadas na notação da música do Renascimento, este exemplo demonstra a importância estrutural atribuída pelo compositor aos grupos com valores equivalentes ao de uma semibrevis nesta mensuração. Conforme discutiremos na seção 3.1.7, esse valor temporal é o tactus teórico da peça em questão.

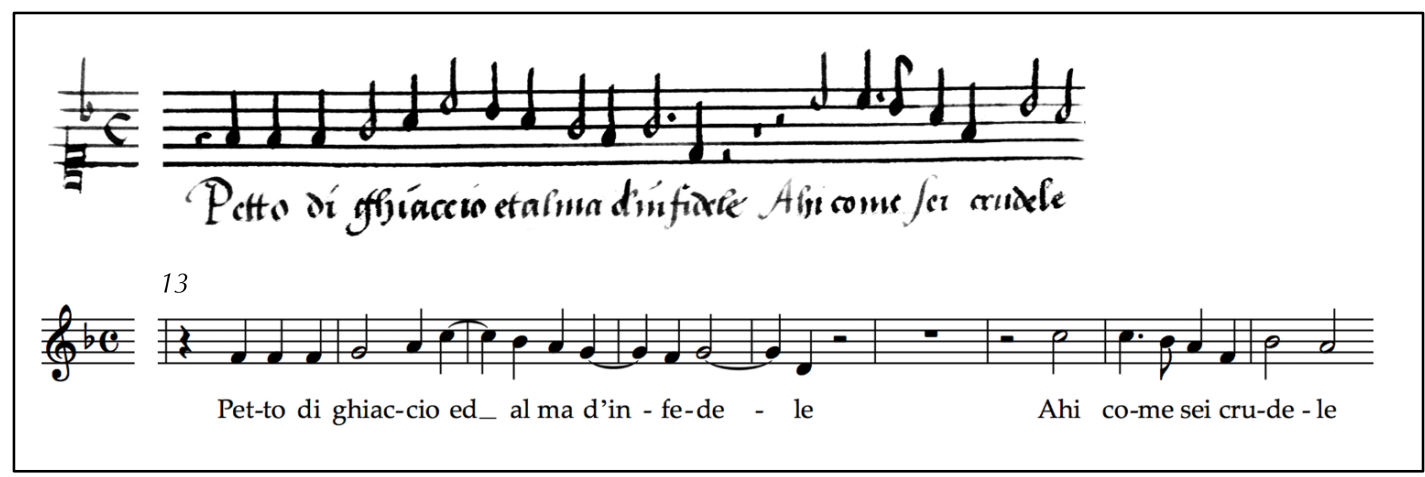

Figura 24. Notação de pausas na peça Fiamenga fredda, core di diamante, de Adrian Tubal (Winchester Partbooks, n. 15), escrita em tempus imperfectum cum prolatione imperfecta.

O processo de imperfeição pode se aplicar também a diferentes partes de uma única figura, o que se denomina imperfectio ad partem (singular) ou ad partes (plural). Nos casos em que uma figura é teoricamente subdividida em duas partes perfeitas, cada uma destas pode, por sua vez, se tornar imperfeita pela figura de espécie imediatamente inferior à sua. Como um exemplo, uma longa em modus imperfectus cum tempore perfecto é composta de duas breves perfeitas que podem se tornar imperfeitas pela ação de semibreves; se apenas uma destas breves sofre imperfeição, o mecanismo é denominado imperfectio ad partem, enquanto as situações em que ambas são afetadas configuram a forma plural imperfectio ad partes. Assim como o mecanismo de imperfeição do todo (imperfectio ad totum), discutido anteriormente, as imperfeições das partes também podem ocorrer em diferentes níveis de mensuração; em prolatio perfecta, por exemplo, é possível a imperfeição ad partem (ou ad partes) da brevis pela minima (fig. 25). 


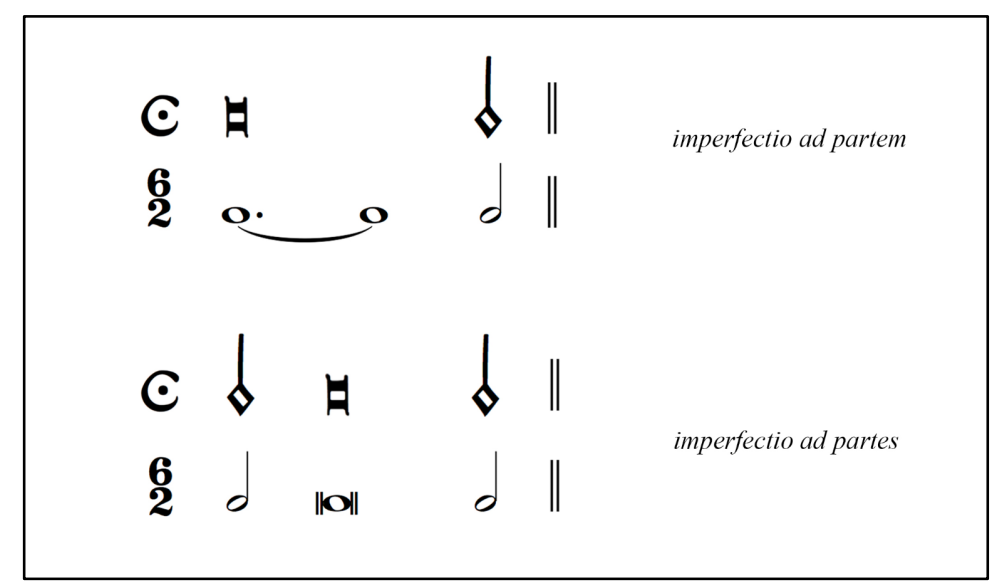

Figura 25. Exemplos de imperfeição ad partem e ad partes em prolatio perfecta.

Thomas Morley afirma que a imperfeição (ad totum) é "a retirada da terça parte do valor de uma nota perfeita, e é feita de três maneiras - por nota, pausa ou cor" (MORLEY, 1597, p. 24, tradução nossa ${ }^{8}$ ). Este terceiro processo é chamado de coloração e consiste em se preencher de preto a cabeça de uma figura, fazendo com que ela perca um terço de seu valor original. Em tempus perfectum, por exemplo, a coloração das breves tem o efeito perfecta a coloração das semibreves significa $\bullet \bullet \diamond \diamond$ (hemiolia prolationis ou hemiolia minor). A aplicação da coloração a figuras perfeitas torna-as, portanto, imperfeitas. Trechos coloridos em mensurações perfeitas frequentemente denotam mudanças de acentuação, que podem ser transcritas em notação moderna através de mudanças nas fórmulas de compasso, a critério de cada editor (figs. 26a, 26b). A coloração de figuras em mensurações imperfeitas, por outro lado, não está associada ao processo de imperfeição e invariavelmente envolve grupos ternários ${ }^{9}$, normalmente transcritos como quiálteras (fig. 26c).

\footnotetext{
${ }^{8}$ No original : "the taking away of the third part of a perfect note's value, and is done three manner of ways - by note, rest or colour."

${ }^{9}$ Em sua detalhada análise destes processos em diferentes mensurações, Apel (1953, p. 127) distingue as colorações aplicadas a figuras imperfeitas ou perfeitas através das denominações "triplet-coloration" e "courante-coloration", respectivamente. O uso destes termos, segundo o autor, justifica-se pelo fato de a mudança métrica ${ }_{4}^{6}-3$, frequentemente implicada no segundo caso, ser característica das courantes de suítes barrocas.
} 


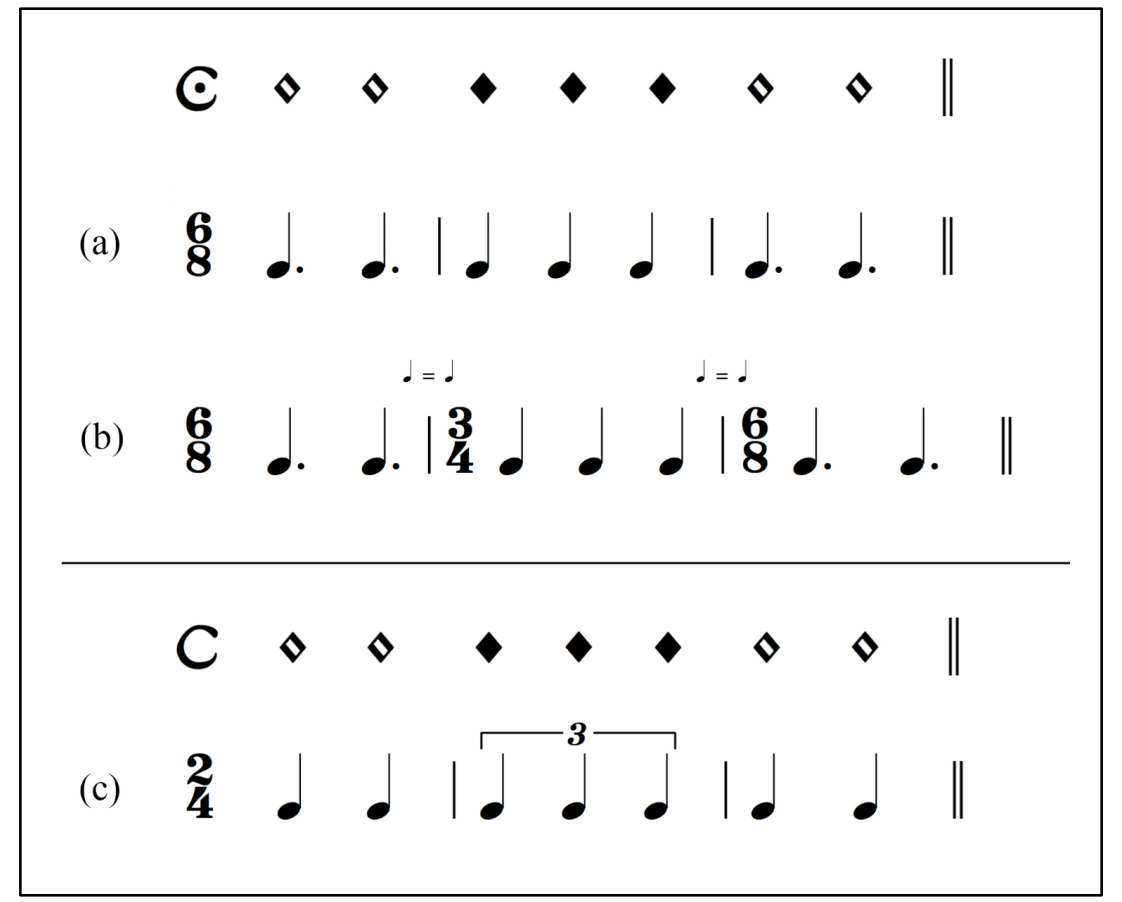

Figura 26. Coloração em prolatio perfecta e prolatio imperfecta.

A coloração pode ainda ser aplicada a uma ou mais notas de ligaduras retas ou oblíquas ( $|,| \downarrow=\bullet$ ) ou mesmo a uma parte de uma única figura ( $\mathbf{q}$, por exemplo), significando que esta é composta de uma parte perfeita e uma imperfeita $(\boldsymbol{+}+\mathbf{)}$. Apel denomina este processo meia coloração (half-coloration) (APEL, 1953, p. 142-144). Em edições modernas, trechos originalmente coloridos são normalmente indicados através de colchetes interrompidos $(\ulcorner\neg \neg)$ sobre as notas envolvidas.

Ao executar a música escrita em mensurações perfeitas, o intérprete é responsável por reconhecer os agrupamentos ternários que constituem as sucessivas perfeições e aplicar os mecanismos de imperfeição às figuras adequadas. Um conjunto de convenções relativas a estes processos foi discutido por diversos teóricos medievais e renascentistas e era observado pela maioria dos compositores destes períodos; Apel as resumiu em cinco regras práticas para o caso particular da mensuração 0 , fornecendo em seguida exemplos (fig. 27) da aplicação de cada uma delas. Apesar de haverem sido formuladas para tempus perfectum - e tratarem, portanto, apenas da imperfeição da brevis - as convenções se operam de maneira análoga quando aplicadas à semibrevis em prolatio perfecta ou à longa em modus perfectus: 
1. Uma brevis é perfeita se seguida de outra brevis ou de uma pausa de brevis;

2. Uma brevis é perfeita se for seguida de duas ou três semibreves;

3. Uma brevis é imperfeita se seguida ou precedida de uma ou de mais de três semibreves;

4. Se tanto imperfectio a parte post e a parte ante são admissíveis, a primeira tem preferência;

5. Uma pausa de brevis nunca pode se tornar imperfeita; entretanto, uma pausa de semibrevis pode causar imperfeição de uma nota.

(APEL, 1953, p. 108, tradução nossa $)^{10}$

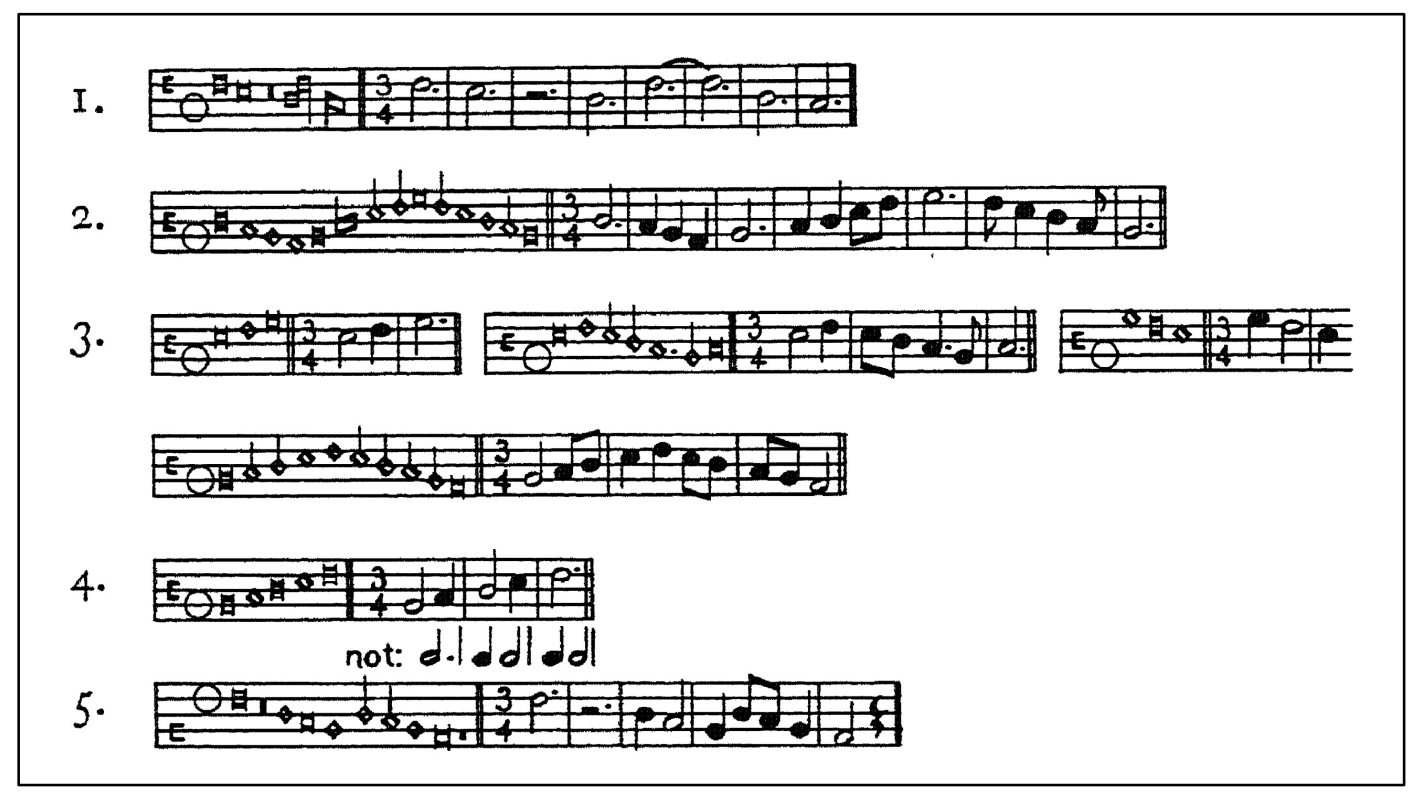

Figura 27. Exemplos das regras de imperfeição da brevis em tempus perfectum (APEL, 1953, p.108).

A primeira convenção enunciada por Apel corresponde à regra "similis ante similem non potest imperfici" ("igual antes de igual não pode ser imperfeita", frequentemente abreviada como "similis ante similem"), uma das mais importantes do sistema mensural. Esta prescrição, quase nunca violada pelos compositores, tem uma

${ }^{10}$ No original: " 1 . $A B$ is perfect if followed by another $B$ or by a $B$-rest / 2 . A $B$ is perfect if followed by two or three $S$ / 3. A $B$ is imperfect if followed or preceded by one or by more than three $S$. / 4 . If both imperfectio $a$ p. $p$. and $a p$. $a$. are admissibile, the former takes preference. / 5. A B-rest can never be imperfected; however a $S$-rest may cause imperfection of a note." 
consequência importante sobre a notação de uma das figurações rítmicas já discutidas anteriormente: no terceiro exemplo da figura 22 (pág. 62), agora reproduzido na parte superior da figura 28, a figura rítmica o $\|\mathbf{O}\|$ presente no segundo compasso da transcrição é notada como $\boldsymbol{\sharp}$ (brevis imperfeita a parte ante) e a perfeição seguinte inicia-se com uma semibrevis; se esta nova perfeição, contudo, for iniciada por uma brevis, a regra similis ante similem não permitirá a imperfeição da figura anterior, fazendo-se necessário algum outro mecanismo para expressar o ritmo em questão. A solução mensural para este caso é a expressão do iambo através de duas semibreves, duplicando-se o valor temporal da última delas (fig. 28, segundo exemplo). Este processo é denominado alteratio (alteração) e ocorre para "alinhar" a próxima brevis (ou outra figura de valor maior) ao início de uma nova perfeição quando há a impossibilidade de se expressar o mesmo ritmo através de imperfectio a parte ante. Em tempus perfectum, a alteração ocorre tipicamente em situações nas quais o início de um grupo de duas semibreves coincide com o início de uma perfeição, sendo particularmente frequente o caso $\sharp \diamond \diamond \sharp$, em que a primeira brevis, segundo a regra 2 de Apel, deve se manter perfeita.

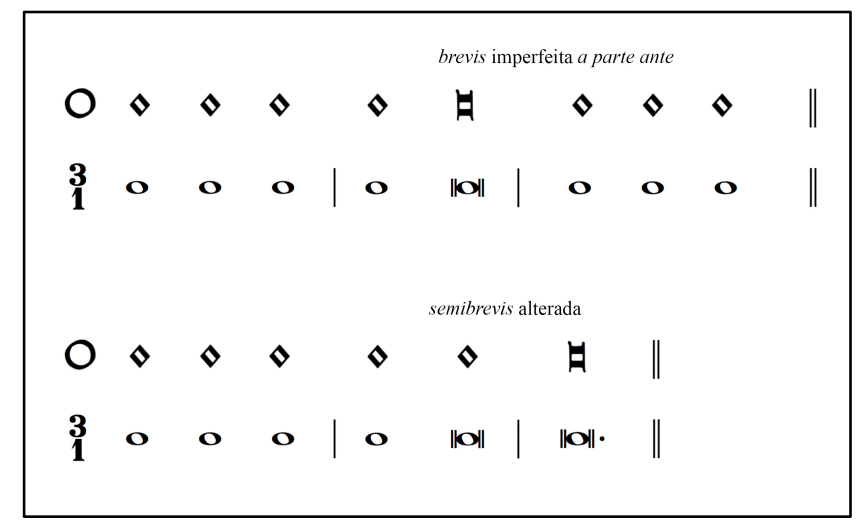

Figura 28. Alteração da semibrevis em tempus perfectum.

Assim como a imperfeição, a alteração pode ocorrer em diferentes níveis mensurais. A figura 29, extraída do artigo The Notation of Mensurable Music, de John Stainer, exemplifica em modus perfectus os efeitos de ambos os processos e foi acrescida de nossas indicações da ocorrência de cada caso. A aplicação das regras de imperfeição 


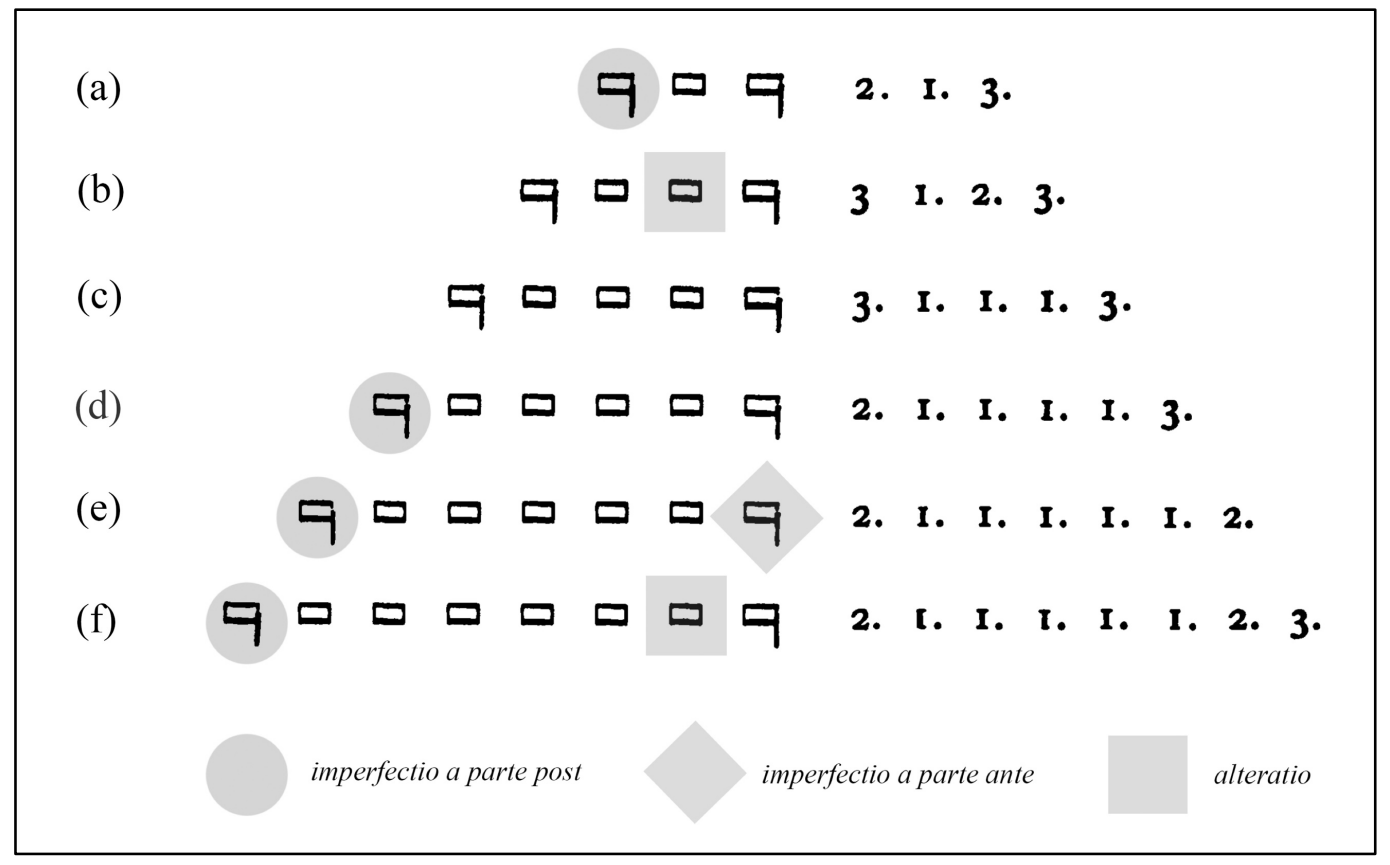

Figura 29. Valores temporais (expressos em número de breves) de longae e breves em tempus perfectum (STAINER, 1900, p. 220).

enunciadas por Apel (adaptadas para modus perfectus) e do mecanismo de alteração permite confirmar as resoluções fornecidas pelo autor para todos os exemplos ilustrados na figura. A primeira longa de cada sequência deve ser imperfeita a parte post, com exceção dos casos em que seja seguida de duas ou três breves (exemplos (b) e (c), respectivamente); a perfeição da longa nestas duas situações corresponde à regra 2 de Apel, que resulta de duas considerações: (i) um conjunto de três breves constitui naturalmente uma perfeição; (ii) um conjunto de duas breves também equivale a uma perfeição se a segunda tem seu valor duplicado por alteratio. Em qualquer destes casos, portanto, não haveria motivo para que a primeira longa se tornasse imperfeita. Nas demais situações, supõe-se sua imperfeição a parte post, conforme a regra 3 de Apel, segundo a qual a longa deve ser imperfeita se seguida de uma ou mais de três breves. Uma vez que o valor da primeira longa de cada sequência esteja definido (e consequentemente a primeira prefeição esteja estabelecida), as perfeições seguintes (caso existam) são reconhecidas como grupos sucessivos de três breves; quando se esgotam estes agrupamentos, as últimas perfeições de cada sequência são definidas a depender das figuras restantes: nos casos (a), (c) e (d) resta apenas uma longa, que se 
mantém perfeita e constitui a última perfeição; nos casos (b) e (f) o grupo final é $\sharp \sharp 甘$, onde a segunda brevis é alterada e a longa se mantém perfeita; no caso (e) resta o grupo $\forall 日$, onde a longa se torna imperfeita a parte ante.

\subsubsection{Punctus divisionis e punctus additionis}

A primeira sequência apresentada por Stainer (longa-brevis-longa) foi resolvida nos valores 2-1-3 por imperfectio a parte post aplicada à primeira longa (e não nos valores 3-1-2 por imperfectio a parte ante aplicada à segunda longa) devido à regra 4 de Apel, segundo a qual imperfectio a parte post deve ter preferência sobre imperfectio a parte ante. A notação do ritmo 3-1-2 através das mesmas figuras é, contudo, possível por meio do dispositivo notacional denominado punctus divisionis (ponto de divisão). A função deste ponto é dividir a música em perfeições, delimitando as fronteiras de cada uma delas. No caso em questão, a inserção do punctus após a primeira longa permite forçar sua perfeição, fazendo com que a sequência $L-B-L$ resulte no ritmo 3-1-2. A figura 30, uma colagem de duas outras sequências extraídas do artigo de Stainer, ilustra a situação discutida e contém um exemplo adicional onde o punctus causa a imperfeição da primeira longa e evita a alteração da segunda brevis. O punctus divisionis aplica-se somente à musica escrita em mensurações perfeitas e pode ter diferentes consequências locais, como a perfeição ou alteração das figuras a ele adjacentes, razão pela qual os teóricos ocasionalmente utilizavam denominações específicas como punctus perfectionis ou punctus alterationis, entre outras. Sua função delimitadora, entretanto, permanece a mesma em qualquer destes casos.

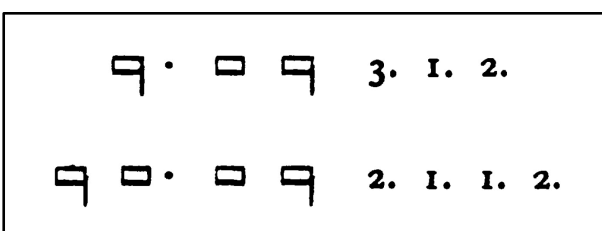

Figura 30. Uso do punctus divisionis (STAINER, 1900, p. 220). 
Ruth DeFord (2015, p. 41) afirma que a terminologia mais simples para descrever os puncti do sistema mensural é aquela segundo a qual estes são classificados em apenas dois tipos, a saber: punctus divisionis e punctus additionis. Este último corresponde ao ponto de aumento da notação moderna (uma figura pontuada é acrescida de metade de seu valor original) e se aplica, portanto, apenas a figuras imperfeitas. Eventuais ambiguidades entre os dois tipos de puncti ocorrentes em peças escritas em mensurações perfeitas podem ser eliminadas através da colocação do punctus divisionis em alturas diferentes da cabeça da figura anterior, ao contrário do punctus additionis (e do atual ponto de aumento), que aparece imediatamente à direita da cabeça da figura afetada. Embora este procedimento nem sempre seja adotado pelos escribas, o contexto musical permite distinguir os dois tipos de puncti na maior parte dos casos; ambiguidades mais problemáticas podem ocorrer em peças escritas na mensuração $\odot$, onde os próprios puncti divisionis podem delimitar perfeições relativas a dois níveis diferentes (tempus e prolatio) e ter suas funções eventualmente confundidas. Estas situações, contudo, são extremamente raras.

\subsubsection{Exemplos das mensurações principais}

Apesar de os teóricos do Renascimento haverem discutido as diferentes mensurações do sistema e tratado casos relativamente complexos de suas aplicações, a música vocal do século XVI - mesmo quando é subdividida de forma ternária raramente foi escrita utilizando-se os sinais de mensuração perfeita da maneira prevista pela teoria. A maior parte da polifonia quinhentista foi notada sob mensurações imperfeitas e ritmos ternários eram expressos através de uma variedade de símbolos que, embora relacionados aos antigos sinais de mensuração perfeita, nunca chegaram a ser empregados de forma consistente e constituíram fonte de importantes discordâncias, tanto entre teóricos quanto entre compositores. Thomas 
Morley, antes mesmo de apresentar as primeiras mensurações na Introduction, lamenta este cenário no diálogo entre o mestre e Philomathes:

MESTRE: Aqueles que nestes trezentos anos escreveram a arte da música colocaram os modos ${ }^{11}$ de maneira diferente daquela que, ou foram, ou são ensinados agora na Inglaterra.

PHILOMATHES: E qual foi a razão para isso?

MESTRE: Embora seja difícil atribuir a causa, ainda assim nós podemos conjecturar que, apesar de os grandes mestres que se destacaram em tempos passados terem sido, sem dúvida, maravilhosamente hábeis no conhecimento [da arte da música], tanto na especulação quanto na prática, desde sua morte o conhecimento da arte decaiu, e um tipo mais ligeiro ou superficial de conhecimento veio em seu lugar, de forma que hoje em dia é assim, se eles [os modernos] conhecem o modo comum e alguns triplos, nada mais procuram.

(MORLEY, 1597, p. 12, tradução nossa ${ }^{12}$ )

Diversos aspectos relacionados aos ritmos "triplos" a que Morley se refere serão discutidos nas seções 3.1.8 a 3.1.9, em que abordaremos a notação proporcional, o conceito de tactus e as relações entre ritmos binários e ternários no repertório vocal do século XVI. Na presente seção, contudo, seguimos a tradição dos antigos teóricos e apresentamos exemplos das quatro mensurações principais $(C, \mathbf{O}, \mathbf{C}$ e $\odot$ ) de acordo com a teoria supostamente vigente no período em questão, fornecendo transcrições modernas correspondentes a cada caso. Diferentemente de edições produzidas com propósitos práticos, as transcrições aqui apresentadas não exibem reduções de valores

\footnotetext{
${ }^{11}$ Em inglês, "moods", tratando-se de mensurações (modus major: greater mood ; modus: lesser mood; tempus: time; prolatio: prolation).

${ }_{12}$ No original: "Ma. Those who within these three hundreth yeares haue written the Art of Musicke, have set downe the Moodes otherwise then they eyther haue been or are taught now in England. / Phi. What haue been the occasion of that? / Ma. Although it bee hard to assigne the cause, yet may we coniecture that although the great musicke maisters who excelled in fore time, no doubt weare wonderfully seen in the knowledge therof, aswell in specilation as practise, yet since their death the knowledge of the arte is decayed and a more slight or superficiall knowledge come in steede thereof, so that it is come now adaies to that, that if they know the common Moode and some Triples, they seeke no further."
} 
em relação aos originais, sendo adotada a correspondência $\bullet=\mathbf{o}$; embora esta opção resulte eventualmente em partes modernas de aspecto pouco familiar aos intérpretes atuais, consideramos que a possibilidade de observação de figuras similares nas duas notações supere este inconveniente. O exemplo em C (fig. 31) foi extraído da peça Non t'ho possuto mai, donna, mostrare, de Hubert Waelrant (Winchester Partbooks, n. 31) e a transcrição é de nossa autoria; os exemplos em O (fig. 32) e ๔ (fig. 33) foram extraídos da Introduction de Morley e originalmente transcritos por Alec Harman (com redução de valores 1:2) em sua edição de 1952 deste tratado; o exemplo em $\odot$ (fig. 34) é o início do tenor da peça Vince con lena, de Bartholomeus de Bononia, transcrito por John Stainer na coleção Dufay and his Contemporaries (também com redução de valores 1:2) e posteriormente discutido por Willi Apel em The Notation of Polyphonic Music: 9001600.

A frequência do uso de imperfectio e alteratio nestes trechos varia segundo as qualidades de suas mensurações: ambos os processos são inexistentes em C e ocorrências de imperfectio a parte post são observadas apenas nas duas breves presentes no exemplo em $\mathbf{O}$; os casos $€$ e $\mathbf{O}$, por sua vez, contêm diversas aplicações destes mecanismos e por esta razão adicionamos as tabelas 4 (para o trecho em O) e 5 (para o exemplo em $\odot$ ), onde explicitamos os processos sofridos pelas figuras originais através de correspondências com as figuras modernas das respectivas transcrições. No caso $\odot$, em particular, produzimos adicionalmente uma versão mensural do original de Bononia onde as ligaduras foram decodificadas para facilitar a visualização das correspondências. 


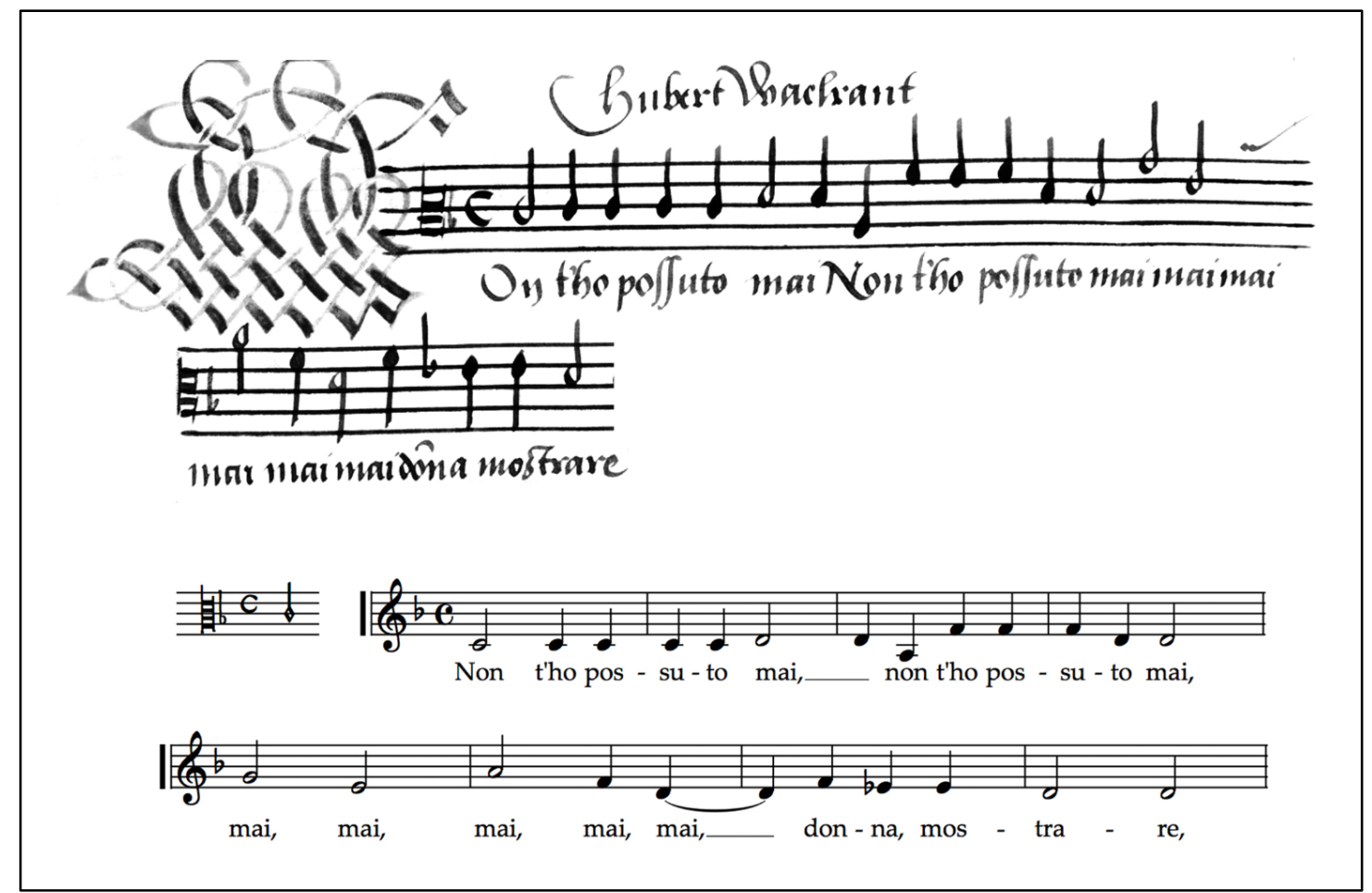

Figura 31. Exemplo de tempus imperfectum cum prolatione imperfecta (Winchester Partbooks, n. 31) e transcrição moderna realizada pelo presente autor sem redução de valores.

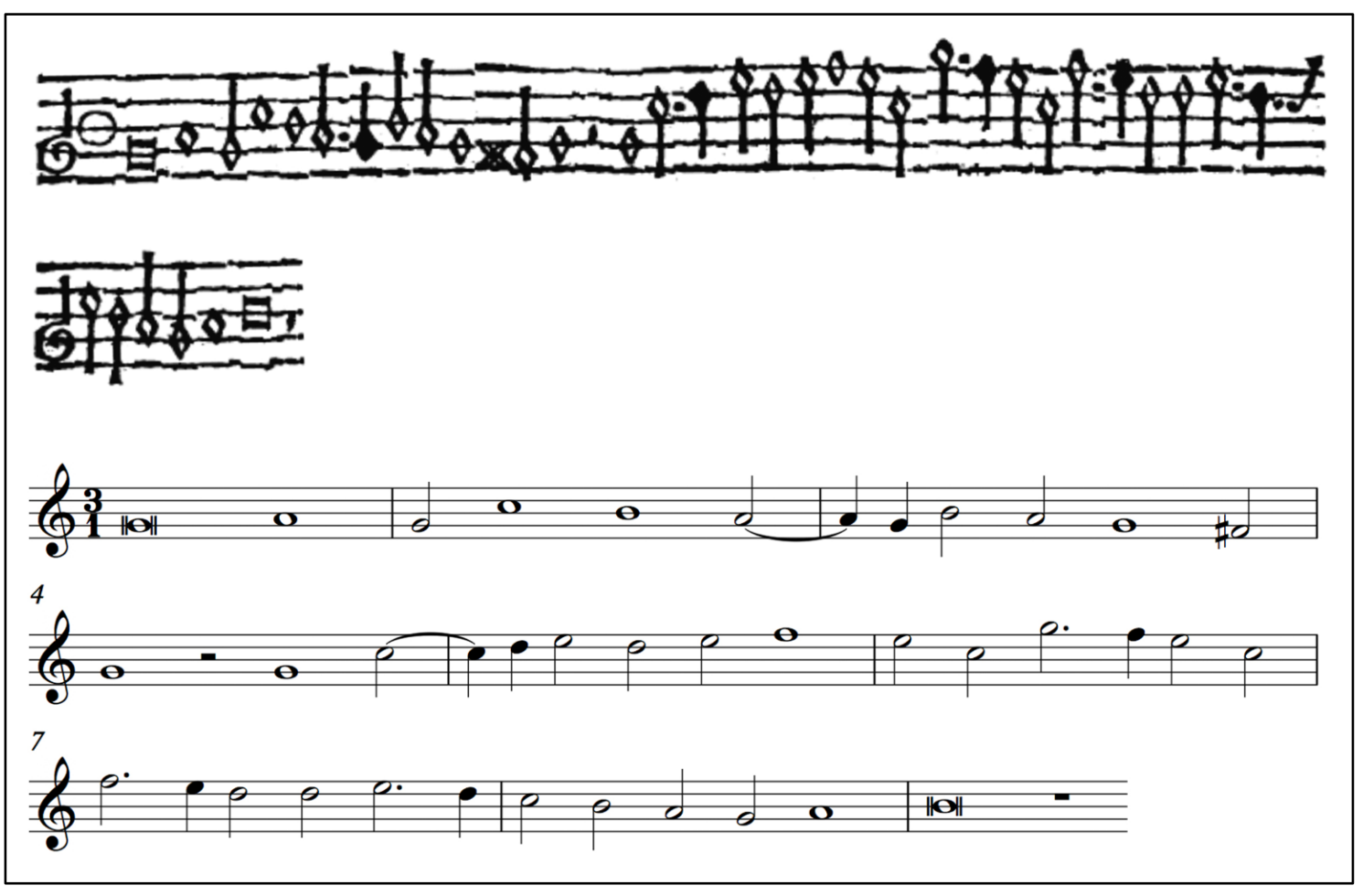

Figura 32. Exemplo de tempus perfectum cum prolatione imperfecta e transcrição moderna de Alec Harman (MORLEY; HARMAN, 1952, p. 51) modificada para $\diamond=\mathbf{o}$ (sem redução de valores). 


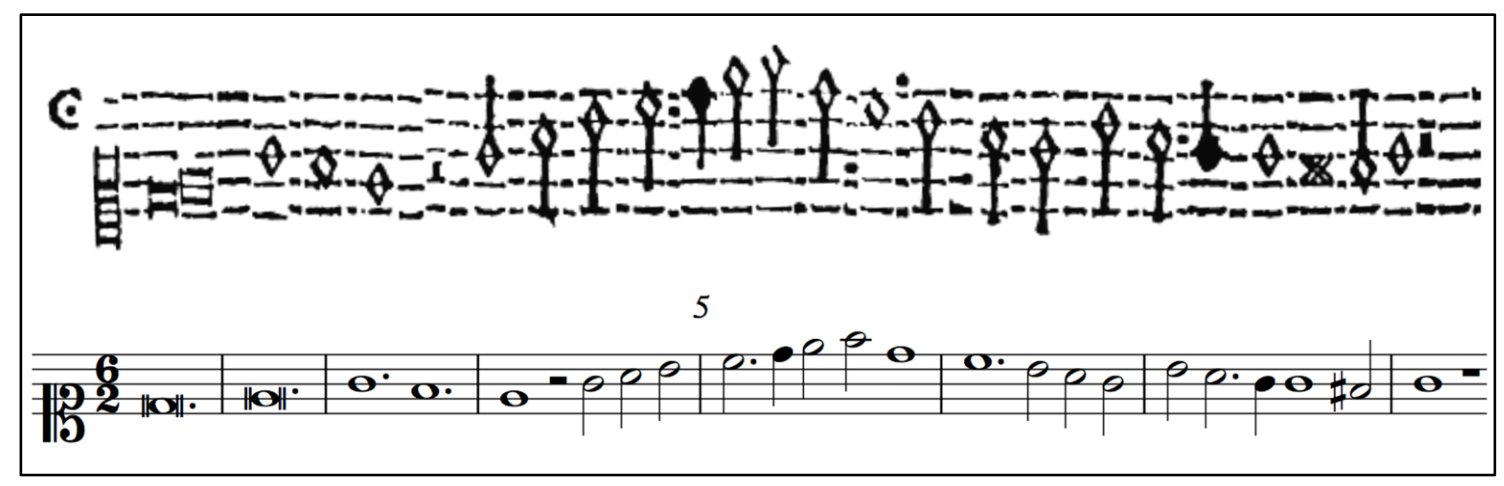

Figura 33. Exemplo de tempus imperfectum cum prolatione perfecta e transcrição moderna de Alec Harman (MORLEY; HARMAN, 1952, p. 36) modificada para $\diamond$ o. (sem redução de valores).

\begin{tabular}{|c|c|c|}
\hline $\begin{array}{l}\text { compasso da } \\
\text { transcrição }\end{array}$ & & figuras correspondentes no original \\
\hline 1 & \multicolumn{2}{|c|}{$B$ (imperfeita) } \\
\hline 2 & \multicolumn{2}{|c|}{$B$ (imperfeita) } \\
\hline \multirow{2}{*}{3} & perfeição 1 & $S$ perfeita ("similis ante similem") \\
\hline & perfeição 2 & $S$ perfeita ("similis ante similem") \\
\hline \multirow[t]{2}{*}{4} & perfeição 1 & $\begin{array}{l}S \text { imperfeita pela pausa de } M \text { seguinte (imperfectio a parte } \\
\text { post) + pausa de } M\end{array}$ \\
\hline & perfeição 2 & $M+M+M$ \\
\hline \multirow[b]{2}{*}{5} & perfeição 1 & $M$ pontuada (punctus additionis) $+S m+M$ \\
\hline & perfeição 2 & $\begin{array}{l}M+M \text { alterada em consequência do punctus divisionis } \\
\text { seguinte }\end{array}$ \\
\hline \multirow{2}{*}{6} & perfeição 1 & $S$ perfeita em consequência do punctus divisionis seguinte \\
\hline & perfeição 2 & $M+M+M$ \\
\hline \multirow{2}{*}{7} & perfeição 1 & $M+M$ pontuada (punctus additionis) $+S m$ \\
\hline & perfeição 2 & $S$ imperfeita pela $M$ seguinte (imperfectio a parte post) $+M$ \\
\hline 8 & \multicolumn{2}{|c|}{$S$ imperfeita pela pausa de $M$ (imperfectio a parte post) + pausa de $M$} \\
\hline
\end{tabular}

Tabela 4. Detalhamento dos processos sofridos pelas figuras originais no exemplo de tempus imperfectum cum prolatione perfecta. 


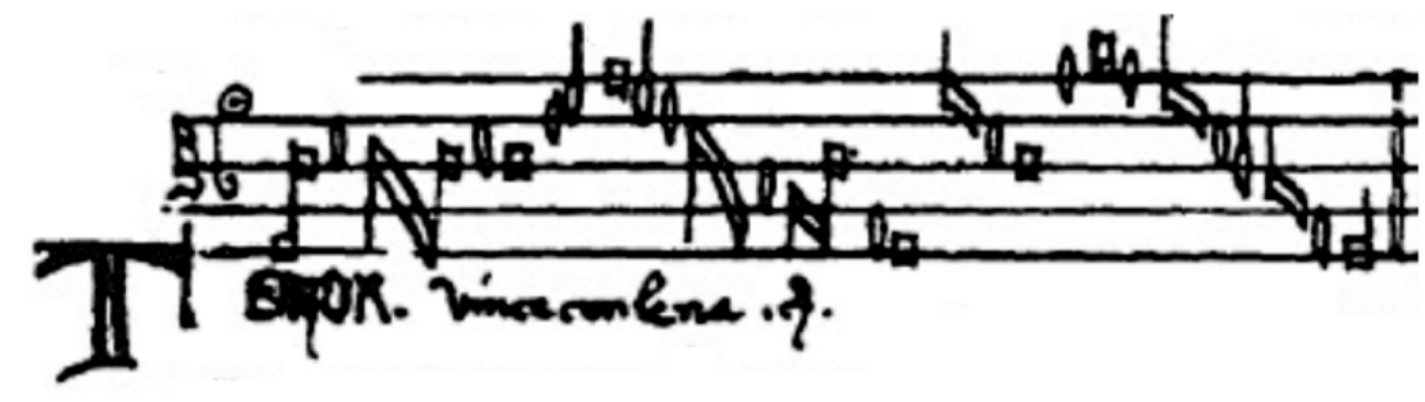

$\odot$
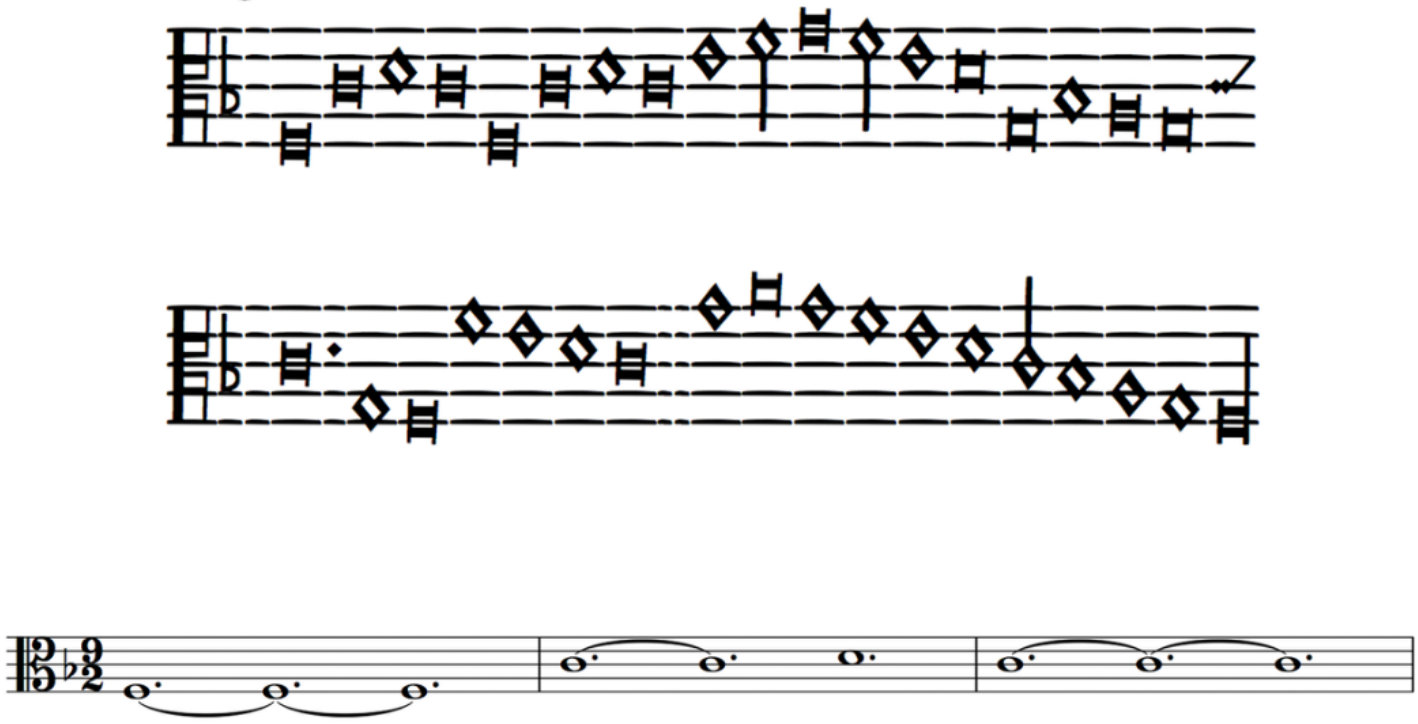

4

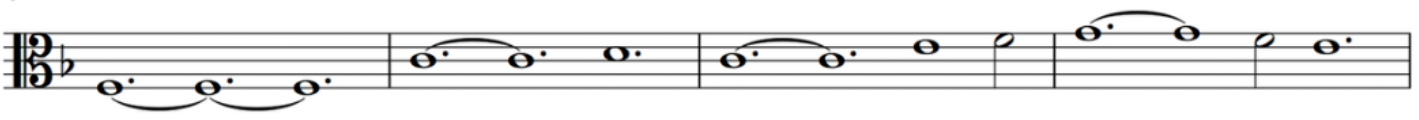

8

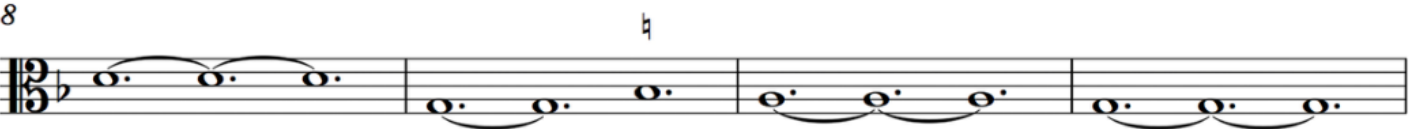

12

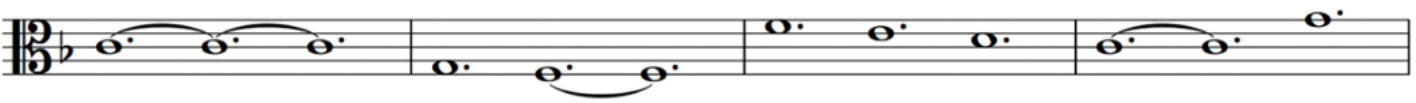

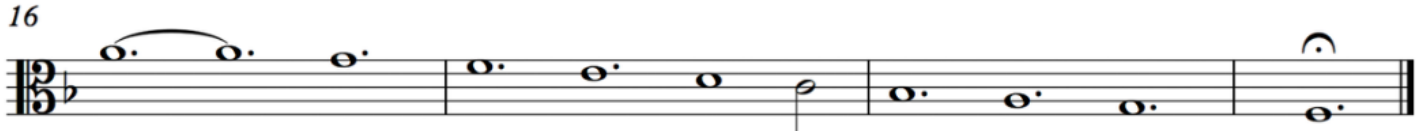

Figura 34. Exemplo de tempus perfectum cum prolatione perfecta (APEL, 1953, p. 143), versão mensural com decodificação das ligaduras e transcrição moderna de John Stainer (STAINER; STAINER, 1898, p. 50-51) modificada para $\diamond=\mathbf{o}$ (sem redução de valores). 


\begin{tabular}{|c|c|c|}
\hline $\begin{array}{l}\text { compasso da } \\
\text { transcrição }\end{array}$ & & figuras correspondentes no original \\
\hline 1 & \multicolumn{2}{|c|}{$\boldsymbol{B}$ perfeita ("similis ante similem") } \\
\hline \multirow{2}{*}{2} & perfeições 1 e 2 & B imperfeita pela $S$ seguinte (imperfectio a parte post - nível tempus) \\
\hline & perfeição 3 & $S$ perfeita (completando a perfeição no nível tempus) \\
\hline 3 & \multicolumn{2}{|c|}{ B perfeita ("similis ante similem") } \\
\hline 4 & \multicolumn{2}{|c|}{$B$ perfeita ("similis ante similem") } \\
\hline \multirow{2}{*}{5} & perfeições 1 e 2 & B imperfeita pela $S$ seguinte (imperfectio a parte post - nível tempus) \\
\hline & perfeição 3 & $S$ perfeita (completando a perfeição no nível tempus) \\
\hline \multirow{2}{*}{6} & perfeições 1 e 2 & B imperfeita pela $S$ seguinte (imperfectio a parte post - nível tempus) \\
\hline & perfeição 3 & $S$ imperfeita pela $M$ seguinte (imperfectio a parte post - nível prolatio) $+M$ \\
\hline \multirow{2}{*}{7} & perfeições 1 e 2 & $B$ imperfeita pela $M$ seguinte (imperfectio ad partem) $+M$ \\
\hline & perfeição 3 & $S$ perfeita (completando a perfeição no nível tempus) \\
\hline 8 & \multicolumn{2}{|c|}{ B perfeita ("similis ante similem") } \\
\hline \multirow{2}{*}{9} & perfeições 1 e 2 & B imperfeita pela $S$ seguinte (imperfectio a parte post - nível tempus) \\
\hline & perfeição 3 & $S$ perfeita (completando a perfeição no nível tempus) \\
\hline 10 & \multicolumn{2}{|c|}{ B perfeita ("similis ante similem") } \\
\hline 11 & \multicolumn{2}{|c|}{ B perfeita ("similis ante similem") } \\
\hline 12 & \multicolumn{2}{|c|}{$B$ perfeita em consequência do punctus divisionis atuando no nível tempus } \\
\hline \multirow{2}{*}{13} & perfeição 1 & $S$ perfeita \\
\hline & perfeições 2 e 3 & B imperfeita pela $S$ anterior (imperfectio a parte ante - nível tempus) \\
\hline \multirow{3}{*}{14} & perfeição 1 & $S$ perfeita ("similis ante similem") \\
\hline & perfeição 2 & $S$ perfeita ("similis ante similem") \\
\hline & perfeição 3 & $S$ perfeita (completando a perfeição no nível tempus) \\
\hline \multirow{2}{*}{15} & perfeições 1 e 2 & B imperfeita pela $S$ seguinte (imperfectio a parte post - nível tempus) \\
\hline & perfeição 3 & $S$ perfeita (completando a perfeição no nível tempus) \\
\hline \multirow{2}{*}{16} & perfeições 1 e 2 & B imperfeita pela $S$ seguinte (imperfectio a parte post - nível tempus) \\
\hline & perfeição 3 & $S$ perfeita (completando a perfeição no nível tempus) \\
\hline \multirow{3}{*}{17} & perfeição 1 & $S$ perfeita ("similis ante similem") \\
\hline & perfeição 2 & $S$ perfeita ("similis ante similem") \\
\hline & perfeição 3 & $S$ imperfeita pela $M$ seguinte (imperfectio a parte post - nível prolatio) $+M$ \\
\hline \multirow{3}{*}{18} & perfeição 1 & $S$ perfeita \\
\hline & perfeição 2 & $S$ perfeita \\
\hline & perfeição 3 & $S$ perfeita \\
\hline 19 & \multicolumn{2}{|l|}{ Longa } \\
\hline
\end{tabular}

Tabela 5. Detalhamento dos processos sofridos pelas figuras originais no exemplo de tempus perfectum cum prolatione perfecta. 


\subsubsection{Tactus}

Independentemente das opções adotadas pelos editores modernos para as reduções dos valores das figuras da notação mensural, a interpretação musical de qualquer obra do repertório renascentista requer o estabelecimento de um pulso que deve corresponder ao valor de alguma das figuras do antigo sistema de escrita. Os teóricos do Renascimento se referiam a esta pulsação através do termo latino tactus ou de alguma de suas traduções em línguas vulgares, como battuta, tatto (em italiano), stroke, tact (em inglês), ou ainda Schlag (em alemão), entre outras. O conceito de tactus foi extensamente discutido tanto no âmbito da musicologia moderna quanto no próprio Renascimento e está frequentemente sujeito a mais de uma interpretação, razão pela qual não são raros os conflitos entre autores que discutiram o termo e suas possíveis aplicações. Com o objetivo de esclarecer eventuais ambiguidades decorrentes de seus diferentes significados, Ruth DeFord faz uma importante distinção entre três possíveis acepções do vocábulo:

O termo "tactus" possui três significados principais: (i) o movimento físico que mede o tempo na performance, ou a unidade de tempo correspondente a este movimento (tactus de performance); (ii) a unidade de tempo que governa a estrutura contrapontística de uma peça (tactus composicional); (iii) a unidade de tempo associada a um sinal de mensuração na teoria musical (tactus teórico). Estas definições nem sempre se aplicam ao mesmo valor em uma peça específica. Algumas das aparentes contradições entre teorias sobre tactus, assim como declarações aparentemente contraditórias sobre o tema em uma única fonte, resultam dos usos do termo com diferentes sentidos (DEFORD, 2015, p. 468, grifos nossos, tradução nossa ${ }^{13}$ ).

\footnotetext{
${ }^{13}$ No original: "The term "tactus" has three primary meanings: (i) the physical motion that measures time in performance, or the unit of time corresponding to that motion (performance tactus); (ii) the unit of time that governs the contrapuntal structure of a piece (compositional tactus); (iii) the unit of time associated with a mensuration sign in music theory (theoretical tactus). These definitions do not always apply to the same value in a particular piece. Some of the apparent contradictions among tactus theories, as well as seemingly contradictory statements about the subject in a single source, result from the uses of the term in different senses."
} 
O teórico e compositor italiano Gioseffo Zarlino (1517-1590), em sua célebre descrição da battuta (em português, "batida") no tratado Istitutioni Harmoniche, compara o tactus ao pulso cardíaco humano devido ao fato de ambos consistirem de movimentos periódicos compostos por duas partes e estabelece uma correspondência entre o par sístole-diástole e seu análogo musical arsis-thesis. Zarlino expõe as motivações para a existência destes movimentos antagônicos afirmando que:

[...] vendo os músicos que, pela diversidade dos movimentos que fazem cantando juntos as partes da canção - por um ser mais veloz ou mais lento que o outro - se poderia gerar alguma confusão, criaram um certo sinal no qual cada cantor deveria se apoiar ao proferir a palavra com medida de tempo veloz ou lenta [...] E imaginaram que fosse bom se tal sinal fosse feito com a mão, para que cada um dos cantores pudesse vê-lo, e fosse regulado em seu movimento à guisa do pulso humano. Depois de dada esta ordem, alguns dos músicos chamaram esse sinal de tactus [...] E realmente me parece que pensaram bem, pois não vejo qual movimento poderiam encontrar, que fosse feito naturalmente e pudesse lhes dar a medida e proporção, que não fosse este. Porque se considerarmos as qualidades que se encontram em um e outro - isto é, no tactus e no pulso, que pelos gregos é chamado sfigmos - encontraremos entre eles muitas correspondências, porque sendo o pulso [...] um certo alargamento e estreitamento, ou melhor, levantamento e abaixamento do coração e das artérias, vem a ser composto de dois movimentos e duas pausas, coisas das quais similarmente o tactus vem a ser composto; [...] E assim como a Medicina chama o primeiro movimento sístole e o segundo diástole, também a Música denomina o battere [positione] thesis e o levare [levatione] arsis. Semelhantemente, assim como o pulso se encontra de duas maneiras, segundo a autoridade dos celebrados princípios da Medicina - isto é, igual e desigual - também o tactus se encontra de duas maneiras, igual e desigual [...] Mas deve-se advertir que consideraram o tactus em duas partes, e tanto à primeira quanto à segunda atribuíram o tempo breve, ou longo, como lhes fosse mais cômodo. É bem verdade que os modernos aplicaram primeiramente ao tactus ora a brevis, ora a semibrevis imperfeitas, fazendo-as iguais ao tempo do pulso dividido em dois movimentos iguais, onde tal tactus se pode verdadeiramente chamar igual; [...] Depois lhe aplicaram ora a brevis com a semibrevis, e ora a semibrevis com a minima, e o dividiram em dois movimentos desiguais, aplicando ao battere [positione] o tempo longo e ao levare [levatione] o breve, colocando-os em proporção dupla. E porque entre o battere [positione] e o levare [levatione] recai a proporção de desigualdade, tal tactus se pode verdadeiramente chamar de desigual. Tendo depois estes músicos tal referência, quando queriam 
dizer o tactus igual, assinalavam suas canções no início com o círculo ou semicírculo inteiros, ou cortados em duas partes por uma linha; e quando queriam dizer o desigual, acrescentavam a tais sinais, ou cifras, o ponto, como se vê nestes exemplos. (ZARLINO, 1589, Lib. III, p. 143-144, tradução nossa ${ }^{14}$ )

Os exemplos fornecidos por Zarlino para tactus igual (battuta equale) e tactus desigual (battuta inequale) estão reproduzidos na figura 35 e foram acrescidos de nossas indicações dos valores mensurais correspondentes a cada um deles de acordo com a teoria musical do período. A citação permite observar que o autor considera separadamente dois diferentes aspectos da battuta: (i) sua subdivisão, que pode ocorrer de forma igual ou desigual; e (ii) sua associação a uma das figuras musicais (brevis ou semibrevis). Ao tratar das subdivisões e dos movimentos fisicamente executados pelo cantor principal para evitar confusões rítmicas, Zarlino evidentemente se refere ao que

\footnotetext{
${ }^{14}$ No original: "[...] i Musici uedendo, che per la diuersità de i mouimenti, che fanno cantando insieme le Parti della cantilena, per esser l'un più ueloce, ò più tardo dell'altro, si poteua generar qualche confusione; ordinarono un certo Segno, dal quale ciascun Cantante s'hauesse da reggere nel proferir la uoce con misura di tempo ueloce, ò tardo [...] Et s'imaginarono che fusse bene, se cotal segno fusse fatto con la mano; accioche ogn'uno de i Cantori lo potesse uedere, \& fusse regolato nel suo mouimento alla guisa del Polso humano. Onde dopoi dato tal'ordine, alcuni de i Musici chiamarono cotal segno Battuta [...] Et ueramente parmi che pensassero bene; percioche non sò uedere, qual mouimento poteuano ritrouare, che fusse fatto naturalmente; \& potesse dare à loro la regola \& proportione, fuori che questo. Percioche se noi consideraremo le qualità, che si ritrouano in uno \& l'altro; cioè, nella Battuta \& nel Polso, che da i Greci è detto $\Sigma \varphi v \gamma \mu$ ó $\varsigma$, ritrouaremo tra loro molte conuenienze; conciosiache essendo il Polso [...] un certo Allargamento \& Ristrengimento; ò pur uogliamo dire Alzamento \& Abbassamento del cuore, \& delle arterie; uiene ad esser composto di due mouimenti, \& di due quiete; dellequali cose similmente la Battuta uiene ad esser composta; [...] Et si come la Medicina chiama il primo mouimento

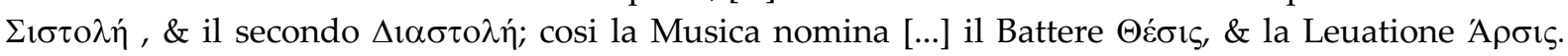
Simigliantemente; si come il Polso si ritroua di due maniere, secondo l'autorità de i commemorati Prencipi della Medicina; cioè, Equale \& Inequale; [...] cosi la Battuta si ritroua di due maniere, Equale \& Inequale; [...] Ma si dè auertire, che considerarono la Battuta in due parti; \& tanto alla prima, quanto alla seconda attribuirono la misura del Tempo breue, ò lungo; come li tornaua più commodo. E' ben uero che i Moderni applicarono primieramente alla Battuta hora la Breue, \& hora la Semibreue imperfette; facendole equali al tempo del Polso distinto in due mouimenti equali; onde cotale Battuta si può ueramente chiamare Equale; [...] Dopoi le applicarono hora la Breue con la Semibreue, \& hora la Semibreue con la Minima, \& la diuisero in due mouimenti inequali, applicando alla Positione il Tempo lungo, \& alla Leuatione il breue, ponendole in Dupla proportione. Et perche tra la Positione \& la Leuatione casca la proportione d'Inequalità, però cotal Battuta si può con uerità chiamare Inequale. Hauendo dopoi essi Musici cotal rispetto, quando intendeuano la Battuta equale, segnauano le lor Cantilene nel principio col Circolo, ò Semicircolo intieri; ouer da una linea in due parti tagliati; \& quando intendeuano l'Inequale aggiungeuano à cotali segni, ò cifere il Punto; come in questi essempi si uede."
} 


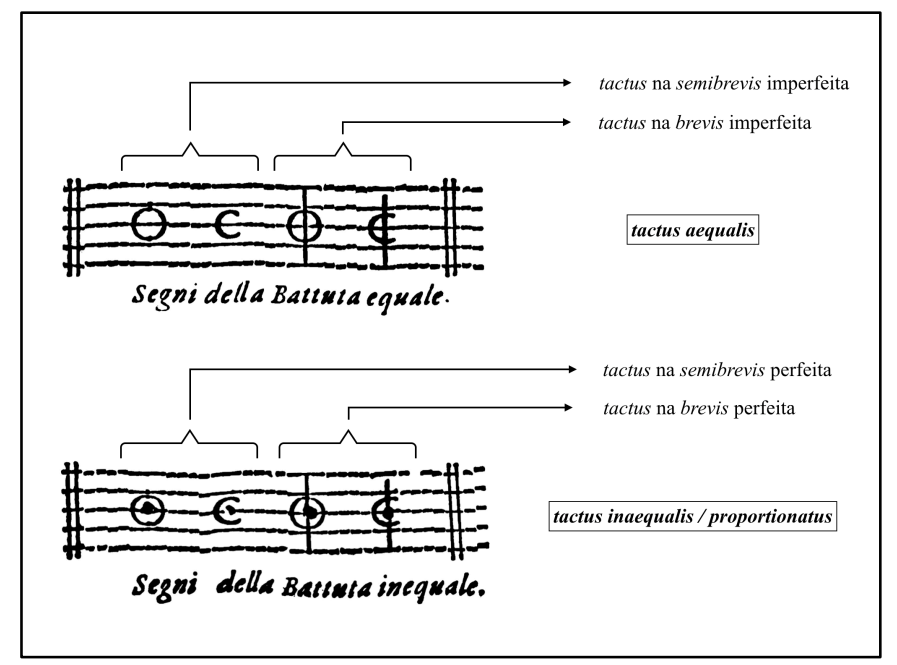

Figura 35. Associação dos sinais de mensuração com tactus igual e tactus desigual segundo a teoria musical dos séculos XV e XVI (ZARLINO, 1573, Lib. III, p. 144).

DeFord define como tactus de performance; ao discutir as associações do pulso com as diferentes figuras (breves e semibreves perfeitas ou imperfeitas), por outro lado, o autor refere-se ao tactus teórico, isto é, à unidade de tempo associada a cada um dos sinais de mensuração. A multiplicidade de usos e significados destes símbolos foi discutida tanto pelos tratadistas do Renascimento quanto por musicólogos dos séculos XX e XXI e constituiu objetos de inúmeras controvérsias; uma análise detalhada da totalidade de suas possíveis interpretações encontra-se além do escopo da presente exposição e neste momento será suficiente observar que "todos os teóricos dos séculos XV e XVI concordam que o tactus de O e C é a semibrevis" (DEFORD, 2015, p. 145, tradução nossa $\left.{ }^{15}\right)$. O comentário de Zarlino a respeito da associação da battuta à brevis (perfeita ou imperfeita) é uma referência às mensurações designadas pelos sinais cortados pelo traço, que teoricamente indicam diminuições - isto é, alterações do tactus original guardando algum tipo de proporção com seu valor anterior. Em particular, o sinal de mensuração \& pode indicar proportio dupla (ver seção 3.1.8) em relação a C, razão pela qual o atual símbolo \& recebe ocasionalmente a denominação "[tactus] alla breve", utilizada até nossos dias.

\footnotetext{
${ }^{15}$ No original: "All theorists of the fifteenth and sixteenth centuries agree that the tactus of $O$ and $c$ is the semibreve"
} 
O tactus composicional, por sua vez, é definido por DeFord (2015, p. 84, 89) como a unidade de tempo que governa a estrutura contrapontística de uma peça - isto é, o valor temporal através do qual se expressam as principais progressões do contraponto em uma composição; esta correspondência pode ser eventualmente confirmada através da observação do tratamento das dissonâncias, cujas durações normalmente correspondem às subdivisões desta unidade. Ao tratar do ictus, isto é, da ênfase ou acento que se pode aplicar a notas em posições métricas importantes, a autora torna esta definição especialmente clara:

Outra questão é se a qualidade do ictus, caso ele exista, se aplica ao tactus de performance ou ao tactus composicional - isto é, se ele é inerente à música ou representado pela natureza do movimento que mede a música. Apesar de estas questões estarem relacionadas logicamente, elas são distintas e não necessariamente idênticas. É possível que o ictus no tactus de performance possa servir apenas para ajudar os intérpretes a colocarem as notas nos lugares corretos, mas não implicar nenhuma ênfase audível nas notas às quais ele corresponde. Alternativamente, o tactus de performance pode não ter uma qualidade íctica, mas a música pode gerar seu próprio sentido de ictus através da localização das dissonâncias, cadências, etc. (DEFORD, 2015, p. 73, tradução nossa ${ }^{16}$ )

Diferentemente do tactus teórico e do tactus de performance, portanto, o tactus composicional é uma unidade necessariamente audível; ainda que uma peça seja notada sob um único sinal de mensuração e mantenha seu tactus teórico inalterado, diferenças na estrutura contrapontística ao longo de sua composição podem permitir a audibilidade de valores mensurais distintos em diferentes momentos. A critério dos

\footnotetext{
${ }^{16}$ No original: "Another issue is whether the quality of the ictus, if it exists, applies to the performance tactus ot the compositional tactus - i. e., whether it is inherent in the music or represented by the nature of the motion that measures the music. Although these questions are logically related, they are distinct and not necessarily identical. It is possible that ictus in the performance tactus might serve only to help performers place the notes in the correct places, but not imply any audible emphasis on the notes to which it corresponds. Conversely, the performance tactus might lack an ictic quality, but the music might generate its own sense of ictus through the placement of dissonances, cadences, etc."
} 
intérpretes, eventuais mudanças no tactus composicional podem ser ou não acompanhadas de alterações correspondentes no tactus de performance.

As abrangentes análises realizadas por DeFord a respeito dos tipos de tactus em diferentes gêneros do repertório vocal do Renascimento incluem considerações sobre a villanesca, a villanella e a canzonetta, formas que constituem objetos de interesse para a presente pesquisa devido à sua significativa frequência nos Winchester Partbooks. Segundo a musicóloga, estes tipos de composição são normalmente notados sob C, e "neste contexto, o sinal representa um tactus composicional sobre a minima e um tactus teórico sobre a semibrevis" (DEFORD, 2015, p. 447, tradução nossa17), o que pudemos efetivamente observar no exame dos manuscritos. As ocorrências de outros sinais de mensuração nas 41 composições transcritas neste trabalho estão indicadas na tabela 6, onde se notam quatro situações (nos 42, 52, 53 e 62) em que uma das quatro vozes exibe o sinal $\downarrow$ - o que sugere uma possível falta de rigor do escriba - e apenas seis casos ( $\mathrm{n}^{\mathrm{os}}$ $4,5,13,18,22$ e 45) em que sinais diferentes de C realmente aparecem em todas as partes. Entre estes últimos, porém, incluem-se o madrigal anônimo Pace non trovo (n. 4), cujo tactus composicional corresponde à semibrevis (ex. 1), e as peças Ecco la stagion novella (n. 5) e Mort'è pietà (n. 13), que possuem caráter francamente ternário com um tactus inaequalis recaindo sobre a semibrevis pontuada (fig. 36). No restante das composições selecionadas para transcrição neste trabalho, o sinal de mensuração é consistentemente $\mathrm{C}$ e o tactus composicional de minima é observado na maioria delas.

Apesar de a semibrevis constituir o tactus teórico desta mensuração, DeFord afirma que este valor

exerce um papel muito menos proeminente nestes gêneros do que no madrigal, frequentemente a ponto de não ter papel absolutamente nenhum na estrutura composicional. Seções repetidas podem ser deslocadas de uma minima em relação às unidades de semibreves da mensuração, e grupos rítmicos dentro de seções são frequentemente

${ }^{17}$ No original: "In this context, the sign represents a compositional tactus on the minim and a theoretical tactus on the semibreve" 


\begin{tabular}{|c|c|c|}
\hline Incipit & compositor & sinais de mensuração \\
\hline Deh, perchè abbandonasti me (n. 42) & Tubal & $\begin{array}{l}\$ \text { discantus } \\
\text { c altus, tenor e bassus }\end{array}$ \\
\hline In tutto vuoi ch'io mor'o traditora (n. 52) & Waelrant & $\begin{array}{l}\oint \text { altus } \\
\text { c discantus, tenor e bassus }\end{array}$ \\
\hline Medici noi siamo o donne belle (n. 53) & Waelrant & $\begin{array}{l}\$ \text { tenor } \\
\text { c discantus, altus e bassus }\end{array}$ \\
\hline Vorria e non vorria questo vi dire (n. 62) & Waelrant & $\begin{array}{l}\oint \text { discantus } \\
\text { c altus, tenor e bassus }\end{array}$ \\
\hline Pace non trovo (n. 4) & anônimo & $\phi$ todas as partes \\
\hline Ecco la stagion novella (n. 5) & anônimo & $\begin{array}{l}3 \text { discantus, altus e bassus } \\
\phi_{3} \text { tenor }\end{array}$ \\
\hline Mort'è pietà (n. 13) & Waelrant & $\phi$ todas as partes \\
\hline Tri ciechi siamo (n. 18) & Waelrant & $\phi$ todas as partes \\
\hline Paschino, bello Paschino (n. 22) & Waelrant & $\phi$ todas as partes \\
\hline Non t'arricordi e quando mi dicevi (n. 45) & Waelrant & $\phi$ todas as partes \\
\hline
\end{tabular}

Tabela 6. Ocorrências de sinais de mensuração diferentes de $C$ nas peças selecionadas para transcrição na presente pesquisa.

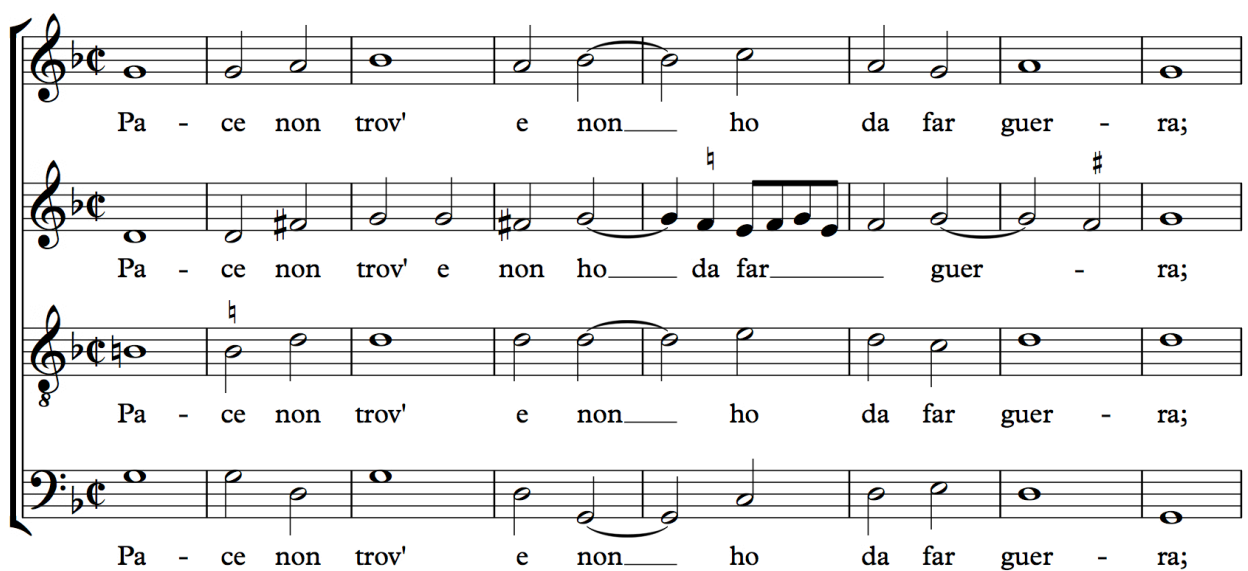

Exemplo 1. Início da transcrição do madrigal anônimo Pace non trovo (Winchester Partbooks, n. 4) sem redução de valores, realizada pelo presente autor. 


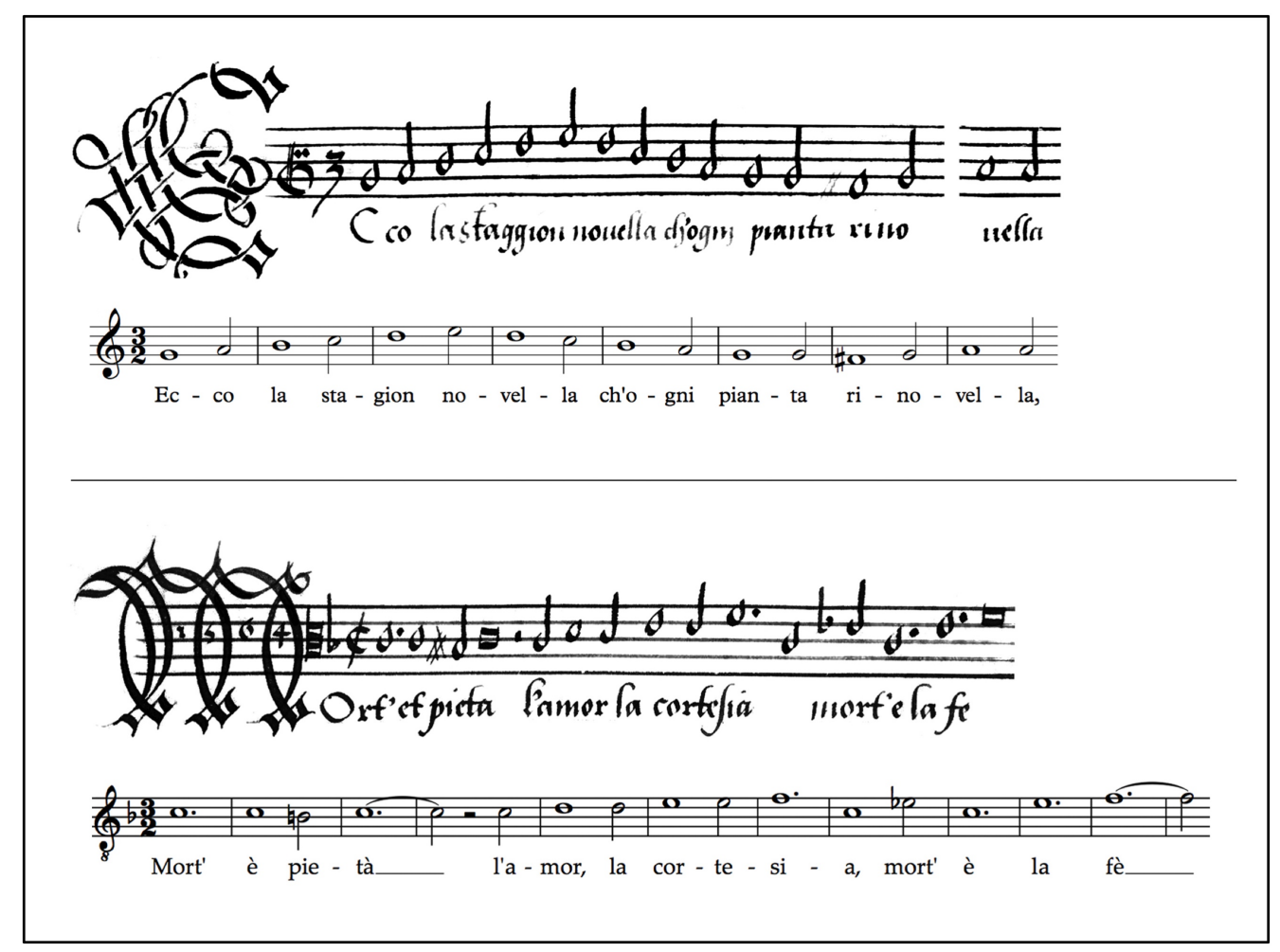

Figura 36. Início da transcrição do discantus das peças Ecco la stagion novella (Winchester Partbooks, n. 5) e Mort'è pietà, de Hubert Waelrant (Winchester Partbooks, n. 13), realizada pelo presente autor.

não relacionadas ao tactus teórico de semibrevis, apesar de o tactus composicional de minima ser sempre significativo (DEFORD, 2015, p. 447-448, tradução nossa $\left.{ }^{18}\right)$.

Com efeito, repetições de trechos com deslocamento de uma minima são frequentes nas villanelle dos Winchester Partbooks, o que confirma a irrelevância estrutural do tactus teórico de semibrevis nestes casos. Um exemplo pode ser observado em nossa transcrição do início da peça Sta' costante, cor mio, ch'io t'amo ogn'hora, de Hubert Waelrant (ex. 2), também publicada em Veneza por Girolamo Scotto em 1565 na coleção Le canzon napolitane a quattro voce (WAELRANT, 1565). A reexposição literal da primeira frase da peça, iniciada na segunda metade do quinto compasso da

\footnotetext{
${ }^{18}$ No original: "plays a much less prominent role in these genres than it does in the madrigal, often to the point of having no role at all in the compositional structure. Repeated sections may be displaced by a minim with respect to the semibreve-units of the mensuration, and rhythmic groups within sections are often unrelated to the theoretical semibreve tactus, though the minim compositional tactus is always significant."
} 

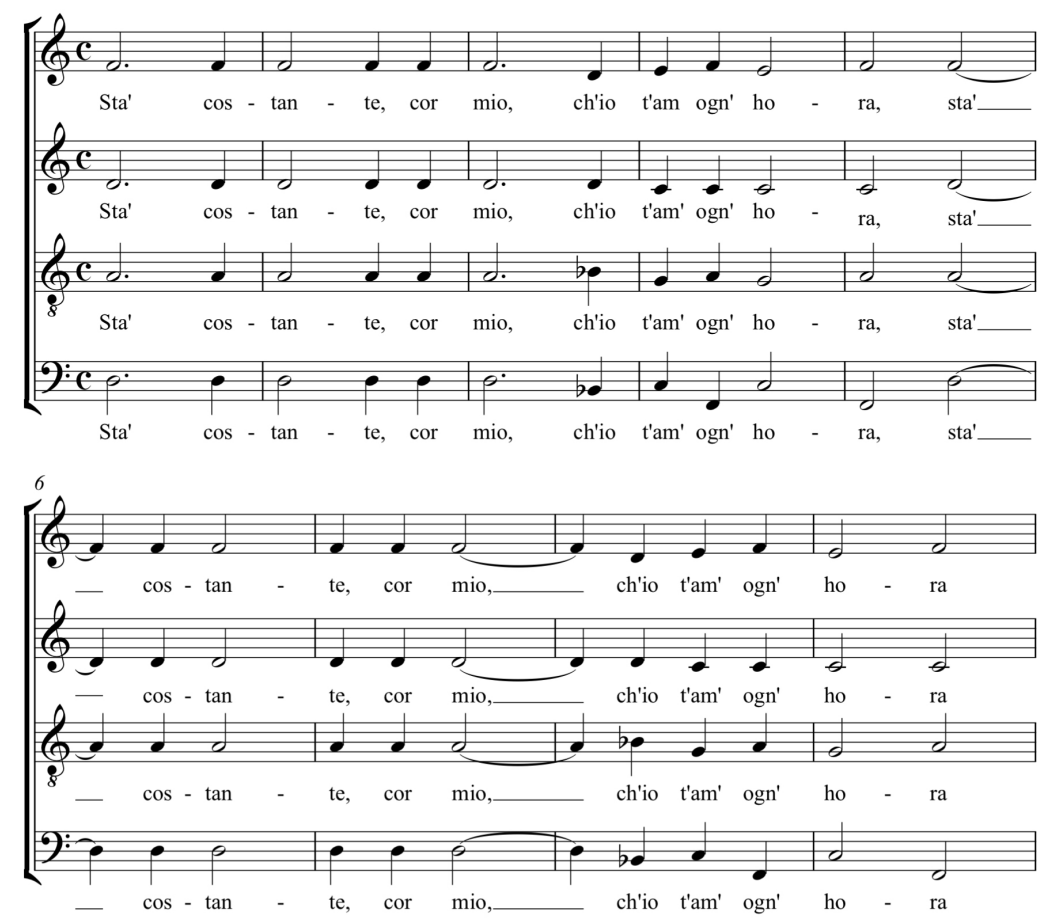

Exemplo 2. Transcrição do início da peça Sta' costante, cor mio, ch'io t'amo ogn'hora, de Hubert Waelrant (Winchester Partbooks, n. 35) sem redução de valores.

transcrição, aparece em uma posição deslocada em relação àquela de sua primeira aparição (tomando-se como referência a estrutura métrica estabelecida pela fórmula de compasso c), o que demonstra não apenas o argumento de DeFord mas também a fragilidade das relações entre as fórmulas de compasso modernas e os antigos sinais de mensuração.

A diferença entre os níveis de relevância do tactus teórico de semibrevis no madrigal e na villanella pode ser claramente apreciada através dos exemplos 1 e 2, onde se observa que algumas minimae de Pace non trovo estão ancoradas em um padrão audível de semibreves, enquanto na villanella Sta costante, cor mio estas figuras soam livremente sem que se criem expectativas quanto a suas posições métricas. O conflito existente entre o tactus teórico de semibrevis e o tactus composicional de minima em villanelle escritas sob o sinal de mensuração C requer uma opção, por parte dos intérpretes, para o estabelecimento de seu tactus de performance. DeFord advoga a adoção da minima para esta unidade, apesar de admitir a interpretação deste repertório 
em andamentos movidos que poderiam estar mais próximos daqueles subentendidos sob $\phi$, onde o tactus composicional seria a semibrevis:

Sendo a maior unidade de tempo que tem algum significado na música, a minima deve funcionar como tactus de performance nessas peças. Considerando a simplicidade e o baixo status da villanesca e da villanella, não é surpreendente que os teóricos quase nunca tenham se dado ao trabalho de mencionar a existência deste tactus. O caráter destas obras sugere um andamento vivo, certamente mais rápido do que os madrigais contemporâneos em $\mathrm{C}$ que exibem textos sombrios e polifonia mais complexa. Se o sinal de mensuração fosse principalmente um indicador de andamento, $\$$ seria mais apropriado para a villanesca e a villanella do que $c$, mas $\$$ implica em um tactus composicional principal na semibrevis (exceto quando aparece erroneamente ou arbitrariamente) e seria, portanto, inapropriado para peças como essas. (DEFORD, 2015, p. 454, tradução nossa ${ }^{19}$ )

Estas mesmas considerações podem ser aplicadas à canzonetta, forma de ocorrência ocasional nos Winchester Partbooks que também foi tratada pela musicóloga em seu estudo. Conforme discutimos na seção 2.1, este tipo de composição exibe diversos elementos que permitem caracterizá-lo como uma forma híbrida entre a villanella e o madrigal. DeFord reafirma esta visão ao descrever o gênero como

um estilo musical diferenciado que se assemelha à villanella em seu caráter leve, forma estrófica e formas internas das estrofes, mas empresta técnicas do madrigal para combinar a música estreitamente à declamação, sintaxe e significado das palavras da primeira estrofe. [...] A mais importante inovação no ritmo da canzonetta é que grupos de duas ou quatro fusae frequentemente carregam sílabas separadas de texto. Padrões rítmicos como a semiminima seguida de duas fusae, todas com sílabas separadas de texto, contribuem para o caráter vivo e

\footnotetext{
${ }^{19}$ No original: "As the largest time unit that has any meaningful role in the music, the minim must function as the performance tactus in these pieces. Considering the simplicity and low status of the villanesca and villanella, it is not surprising that theorists almost never bothered to mention the existence of this tactus. The character of the works suggest a lively tempo, surely faster than the contemporaneous madrigals in $\mathrm{C}$ that feature somber texts and more complex polyphony. If the mensuration sign were primarily an indicator of tempo, $\$$ would be more appropriate to the villanesca and villanella than $C$, but $\$$ implies a principal compositional tactus on the semibreve (except where it appears erroneously or arbitrarily) and would therefore be inappropriate for pieces like these."
} 
fortemente acentuado dos ritmos de canzonetta. (DEFORD, 2015, p. 454-455, tradução nossa ${ }^{20}$ )

A peça Fiamenga fredda, core di diamante, de Adrian Tubal (Winchester Partbooks, n. 15) exibe exemplos claros do uso destas estruturas rítmicas, nos quais se nota adicionalmente o emprego de word-painting (ou "madrigalismos", isto é, gestos musicais que mimetizam o significado do texto): no exemplo 3 pode-se observar a escrita imitativa no trecho "rispond' al mio parlar" ("respondes à minha fala"), assim como a aparente confusão sonora criada pelo contraponto no trecho "niet te verstaen"
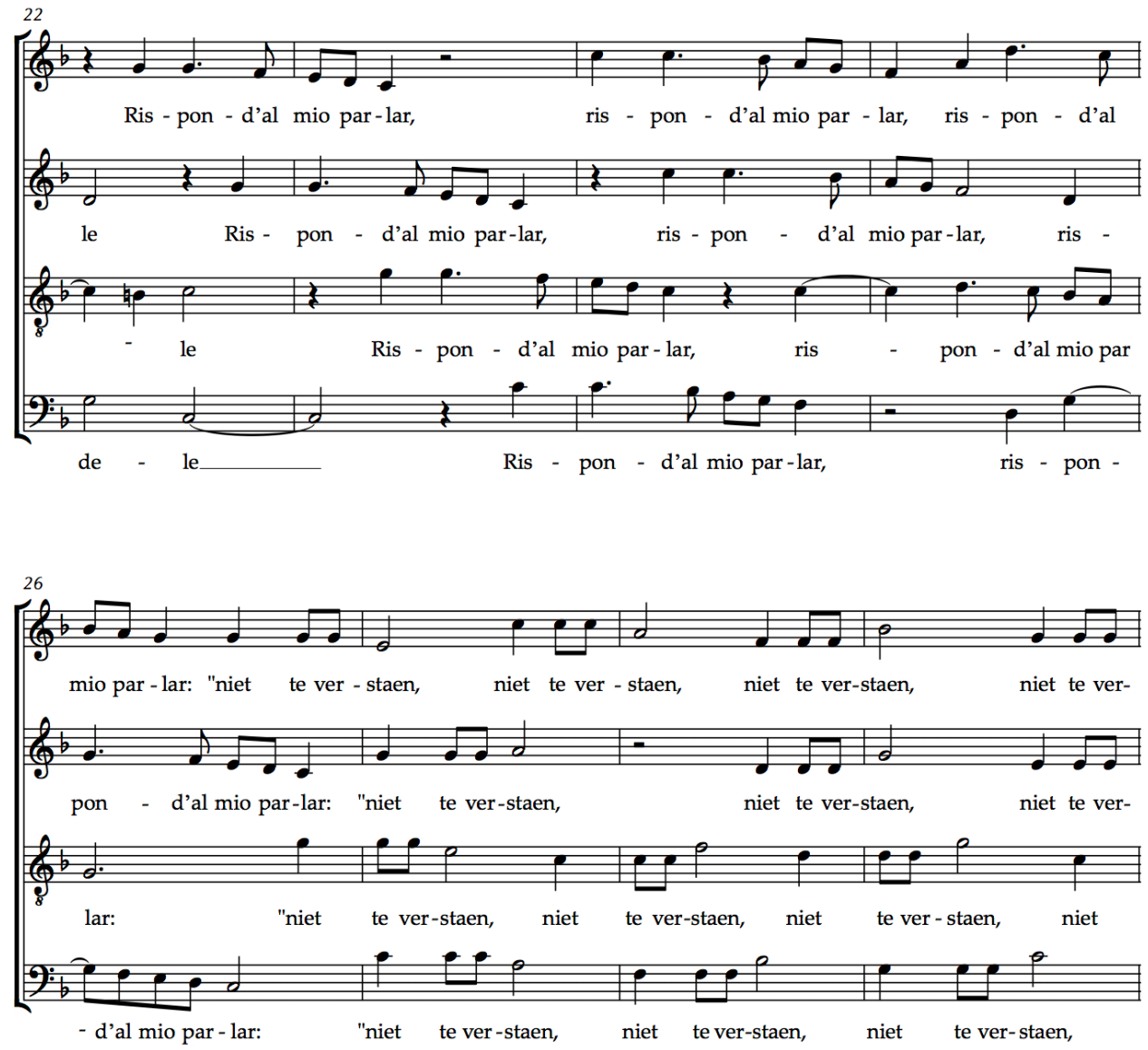

Exemplo 3. Compassos 22-29 da transcrição da peça Fiamenga fredda, core di diamante, de Adrian Tubal (Winchester Partbooks, n. 15).

${ }^{20}$ No original: "The genre is associated with a distinctive musical style that resembles the villanella in its light-hearted character, strophic form, and internal stanza forms, but borrows techniques from the madrigal to match the music closely to the declamation, syntax, and meaning of the words of the first stanza. [...] The most important innovation in the rhythm of the canzonetta is that groups of two or four fusae often carry separate syllables of text. Rhythmic patterns such as the semiminim followed by two fusae, all with separate syllables of text, contribute to the lively and strongly accentual character of canzonetta rhythms." 
("não se entende"). Ainda segundo DeFord (2015, p. 455), a eventual escrita alla madrigalesca observada em trechos de canzonettas pode fazer com que o tactus composicional de minima suba ocasionalmente ao nível da semibrevis; na maior parte dos casos, contudo, a minima mantém sua importância estrutural e permanece uma unidade independente de valores maiores.

As semiminimae ocorrentes nestes tipos de composição, por outro lado, apoiamse no tactus de minima e por esta razão criam efeitos contrastantes quando são agrupadas irregularmente - isto é, quando se chocam com o padrão rítmico binário que governa a composição. Agrupamentos equivalentes a $3+3+2$ ou $3+3+2+2$ semiminimae, particularmente frequentes antes de cadências, requerem mudanças de acentuação e são parte da linguagem que caracteriza a villanella; um exemplo selecionado entre as numerosas ocorrências de situações deste tipo nos Winchester Partbooks pode ser observado no início do altus da peça Tanto sai fare con li innamorati, também de Adrian Tubal (n. 39), onde se nota a configuração 3+3+2+2 (fig. 37):

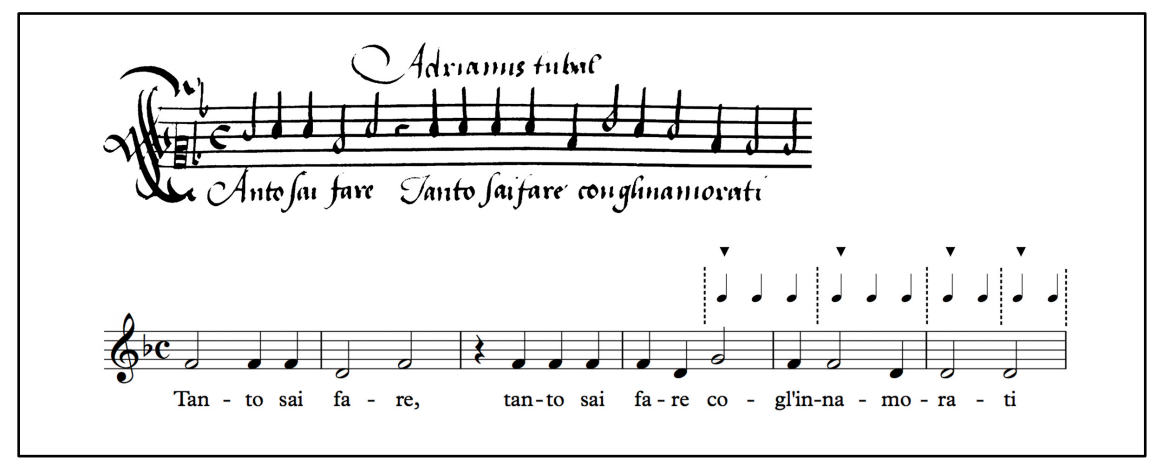

Figura 37. Agrupamentos irregulares de semiminimae no início da peça Tanto sai fare con li innamorati, de Adrian Tubal (Winchester Partbooks, n. 39).

Agrupamentos irregulares como os destacados na figura 37 constituem clichês rítmicos que, por sua frequência, remetem os editores modernos à importante questão do barramento em peças desta natureza. A opção editorial de inserir diferentes fórmulas de compasso modernas - notadamente com o objetivo de sugerir alterações no tactus ao destacar mudanças rítmicas que poderiam passar despercebidas para o intérprete - é bastante comum e frequentemente necessária, sobretudo em edições com 
propósitos exclusivamente práticos; a figura 38 ilustra duas possíveis transcrições do início da villanella intitulada Conza lavezzi siam, de Hubert Waelrant, onde se adota este procedimento no caso (b). Consideramos importante notar, contudo, que tais mudanças de acentuação podem não ocorrer em todas as vozes simultaneamente, o que torna a questão do barramento ainda mais delicada. Nossa transcrição do trecho da peça L'amanza mia si chiama Saporita, de Tubal (fig. 39), ilustra um caso em que as figuras do discantus claramente se agrupam de maneira ternária, enquanto o tenor e o bassus seguem afirmando o tactus composicional de minima. Diante da dificuldade de se expressar todas as nuances rítmicas deste repertório sem que a partitura moderna assuma um aspecto sobrecarregado (através de mudanças nas fórmulas de compasso em partes individuais, por exemplo), optamos por evitar alterações métricas nas presentes transcrições, em uma tentativa de mantê-las tão diplomáticas quanto seja possível.

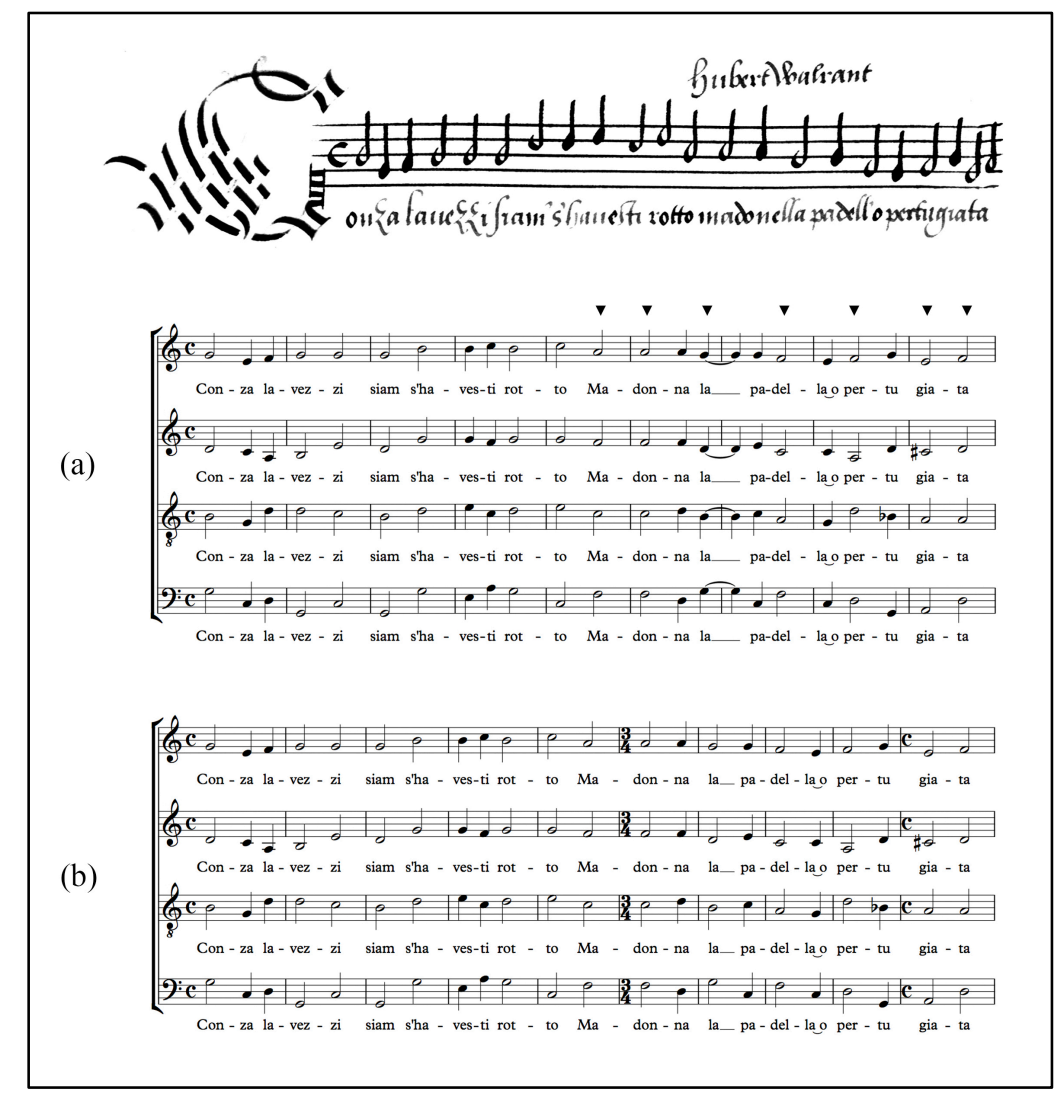

Figura 38. Duas possíveis transcrições do início da peça Conza lavezzi siam, de Hubert Waelrant (Winchester Partbooks, n. 43). 


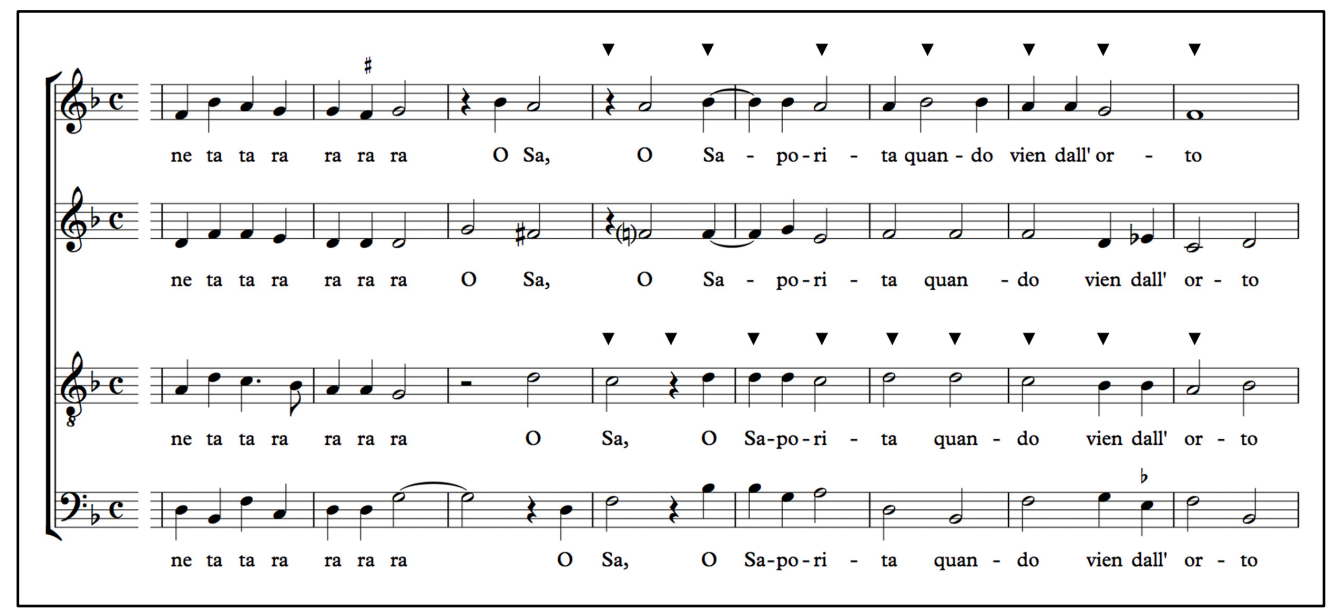

Figura 39. Agrupamentos rítmicos em diferentes vozes da peça L'amanza mia si chiama Saporita, de Adrian Tubal (Winchester Partbooks, n. 16).

\subsubsection{Notação proporcional}

No sistema de notação mensural, as relações entre as durações das figuras musicais eram frequentemente modificadas através do uso de símbolos indicadores de proporção. Nas mensurações consideradas até o momento (C, ๔, O e ๑), o tactus está teoricamente associado à semibrevis e diz-se que as figuras estão em integer valor, isto é, em seus valores integrais; a ocorrência de símbolos diferentes destes em uma composição $\left(\phi, \phi, 3, \frac{3}{2}\right.$ por exemplo), por outro lado, pressupõe que as figuras escritas após estes sinais estejam em notação proporcional, onde o tactus fundamental pode ser alterado segundo regras baseadas em definições matemáticas que foram extensamente discutidas tanto no âmbito teórico quanto em suas aplicações à música mensural.

\subsubsection{As proporções como entidades matemáticas}

Os autores dos tratados musicais do Renascimento - teóricos que certamente possuíam grande familiaridade com a matemática devido à tradição pedagógica medieval que incluía a música no quadrivium ao lado da aritmética, da geometria e da 
astronomia - definiam proporção como uma comparação entre duas quantidades que poderiam ser iguais ou diferentes. O italiano Pietro Aron (1489-1562) inicia sua explanação sobre o tema no tratado Toscanello in Musica afirmando que "como a força dos números é anterior à música, o que se pode compreender por um raciocínio muito simples, [...] resta falar das proporções, que destes números se compõem" (ARON, 1531, lib. II, f. Giiv, tradução nossa ${ }^{21}$ ) e apresenta em seguida suas definições:

[...] diremos proporção quando duas quantidades de um mesmo gênero são comparadas juntas de certa e determinada maneira, isto é, que [...] ou sejam iguais ou sejam desiguais, como aparece nestes números: 3 a 2, 2 a 3, 4 a 3, 5 a 4, e 2 a 2, 3 a 3, 4 a 4, etc. Por isso se nota que todas as quantidades devem ser iguais ou desiguais - se é que é necessário que se faça alguma vez comparação de uma coisa igual a outra, o que gera uma espécie dita proporção racional de igualdade, a qual não vem a propósito ao músico, e portanto desta não falaremos. Mas fazendo comparação de números diferentes, nasce a segunda espécie, dita proporção racional de desigualdade, da qual se ordenam cinco gêneros assim chamados: multiplice, superparticulare, superpartiente, multiplice superparticulare e multiplice superpartiente. (ARON, 1531, lib. II, $f$. Giiv, tradução nossa ${ }^{22}$ )

As proporções racionais de desigualdade - isto é, aquelas através das quais se comparam dois diferentes números inteiros - eram inicialmente classificadas como (a) proporções racionais da desigualdade maior, em que o primeiro número é maior que o segundo, contendo-o um certo número de vezes; e (b) proporções racionais da desigualdade menor, em que o primeiro número é menor que o segundo e está, portanto, nele contido. Cada um destes casos era posteriormente classificado em um dos cinco

\footnotetext{
${ }^{21}$ No original: "Perche la forza de numeri e prima che la musica, como si puo per una semplicissima ragione intendere, $[\ldots]$ resta che parliamo de le proportioni che di questi numeri si compongono"

${ }^{22}$ No original: "[...] diremo proportione quando due quantità dun medesimo genere luna a laltra insieme sono comparate con certa \& determinata habitudine:cioe che [...] ò siano equali ò siano inequali:come appare in questi numeri 3 a 2, 2 a 3, 4 a 3, 5 a 4, \& 2 a 2, 3 a 3, 4 a 4 \&c. Per laqual cosa si notifica che tutte le quantità bisogna siano equali overo inequali: si che è necessario si faccia comparatione alcuna volta dal una equale a laltra:laqual comparatione genera una spetie detta proportione rationale di equalità: la qual non cade in proposito al musico: \& pero di questa non ne parleremo. Ma facendo comparatione di inequale numero, ne nasce la seconda spetie detta proportione rationale di inequalità:de la quale si ordina cinque generi così chiamati. Multiplice. Superparticulare. \& Superpartiente. Multiplice superparticulare. \& Multiplice superpartiente."
} 
gêneros mencionados por Aron, cujas denominações latinas são genus multiplex, genus superparticulare, genus superpartiens, genus multiplex superparticulare e genus multiplex superpartiens. Esta classificação se realizava da mesma maneira para as desigualdades maiores ou menores e provavelmente por este motivo os teóricos costumavam discutir apenas as primeiras, recomendando que se adicionasse o prefixo sub à designação das proporções menores correspondentes (por exemplo, 2:1 denomina-se proportio dupla enquanto 1:2 é proportio subdupla).

Utilizando-se a terminologia da aritmética moderna, a razão para os matemáticos do Renascimento classificarem as proporções em cinco gêneros pode ser compreendida ao se considerar que haja cinco situações possíveis quando se realiza uma divisão entre dois diferentes números naturais onde o dividendo é maior que o divisor: (i) o dividendo contém o divisor um número inteiro de vezes - isto é, o quociente é maior que 1 e o resto da divisão é zero; (ii) o dividendo contém uma vez o divisor mais uma parte alíquota deste último - isto é, o quociente é 1 e o divisor é divisível pelo resto; (iii) o dividendo contém uma vez o divisor mais uma parte não alíquota deste último - isto é, o quociente é 1 e o divisor não é divisível pelo resto; (iv) o dividendo contém o divisor mais de uma vez e também uma parte alíquota deste último - isto é, o quociente é maior que 1 e o divisor é divisível pelo resto; e (v) o dividendo contém o divisor mais de uma vez e também uma parte não alíquota deste último - isto é, o quociente é maior que 1 e o divisor não é divisível pelo resto. Nos casos em que a divisão entre dois números ocorre de acordo com a situação (i), diz-se que ambos estão em uma proporção do genus multiplex; os casos (ii) e (iii) referem-se, respectivamente, aos gêneros superparticulare e superpartiens, enquanto as situações (iv) e (v), sendo combinações das anteriores, correspondem aos gêneros multiplex superparticulare e multiplex superpartiens, respectivamente. A nomenclatura das proporções pertencentes aos diferentes gêneros foi discutida detalhadamente pela maioria dos teóricos renascentistas que trataram deste tema; o italiano Gioseffo Zarlino, em particular, as exemplificou no influente tratado Istitutioni Harmoniche através de ilustrações que permitem observar um número significativo de casos 
particulares e por esta razão foram reproduzidas neste texto acompanhando nossas considerações sobre cada gênero, como veremos a seguir.

(a) Genus multiplex

O genus multiplex é o mais simples entre os cinco gêneros de proporção por envolver dois números naturais tais que um seja múltiplo do outro (isto é, tais que um contenha o outro um número também natural de vezes) e sua nomenclatura requer, portanto, apenas a indicação do fator pelo qual o menor número deve ser multiplicado para resultar no maior. A ilustração de Zarlino (fig. 40) apresenta as denominações das proporções entre dez diferentes quantidades (no exterior da figura) e a unidade (ao centro); cada uma delas está indicada por extenso na tabela 7, onde constam também os termos envolvidos na operação que lhes dá origem.

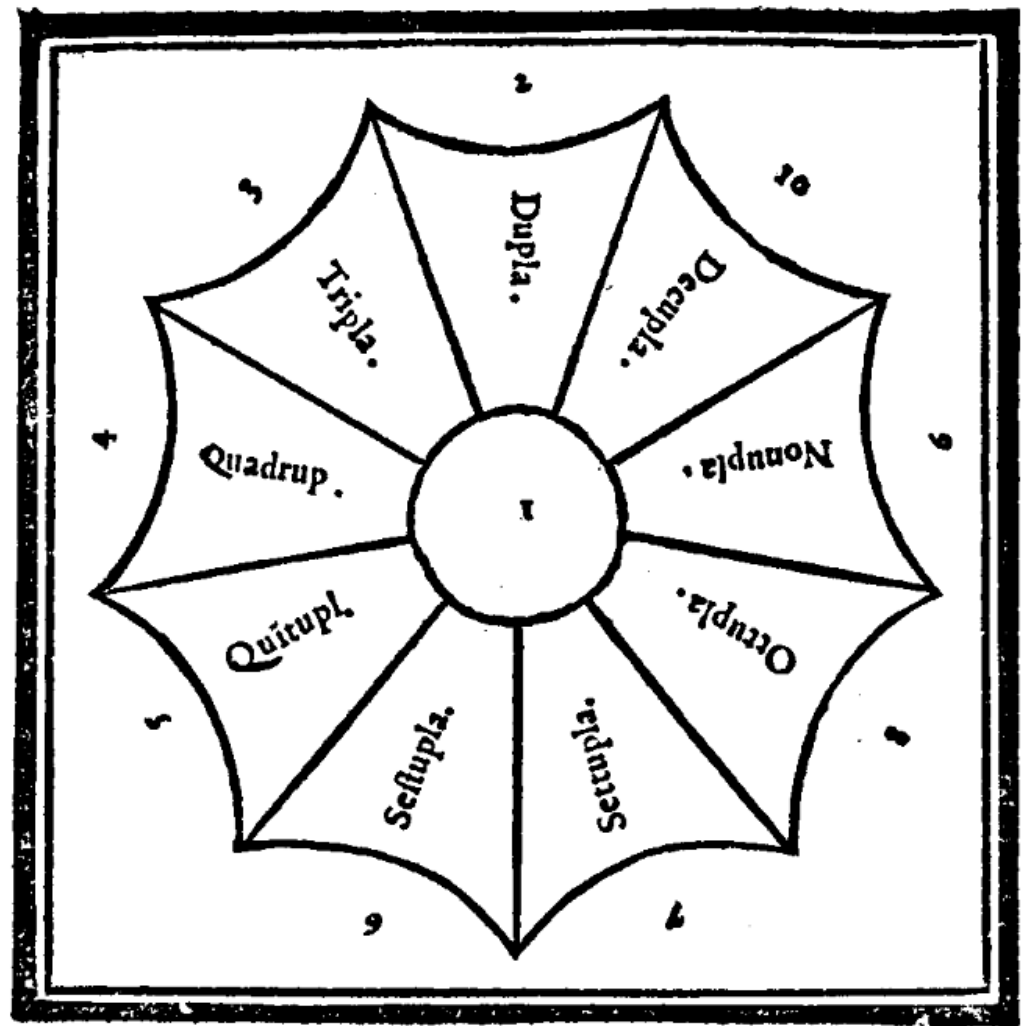

Figura 40. Proporções do genus multiplex (ZARLINO, 1589, lib. I, cap. XXIIII). 


\begin{tabular}{|c|c|c|c|c|c|}
\hline \multicolumn{7}{|c|}{ Genus multiplex } \\
\hline proporção & dividendo & divisor & quociente & resto & nomenclatura \\
\hline $2: 1$ & 2 & 1 & 2 & 0 & dupla \\
\hline $3: 1$ & 3 & 1 & 3 & 0 & tripla \\
\hline $4: 1$ & 4 & 1 & 4 & 0 & quadrupla \\
\hline $5: 1$ & 5 & 1 & 5 & 0 & quintupla \\
\hline $6: 1$ & 6 & 1 & 6 & 0 & sextupla \\
\hline $7: 1$ & 7 & 1 & 7 & 0 & septupla \\
\hline $8: 1$ & 8 & 1 & 8 & 0 & octupla \\
\hline $9: 1$ & 9 & 1 & 9 & 0 & nonupla \\
\hline $10: 1$ & 10 & 1 & 10 & 0 & decupla \\
\hline
\end{tabular}

Tabela 7. Quantidades comparadas em proporção, termos das divisões e nomenclaturas das proporções do genus multiplex exemplificadas por Zarlino.

\section{(b) Genus superparticulare}

Conforme destacamos anteriormente, nas proporções do genus superparticulare se comparam dois números tais que o maior contenha o menor uma única vez e mais uma parte alíquota deste último (em outras palavras, mais uma parte pela qual o número menor seja divisível). Os exemplos fornecidos por Zarlino para este gênero (fig. 41) ilustram estas situações em proporções cujos termos diferem apenas por uma unidade, quantidade que naturalmente constitui parte alíquota de qualquer divisor. As designações de cada proporção estão indicadas na figura em posições que conectam os números que estão sendo comparados e são compostas adicionando-se o prefixo sesqui (que em grego significa "um e meio") ao número menor (2: altera, 3: tertia, 4: quarta, etc.), conforme indicado na tabela 8. Em particular, a denominação latina da proporção 3:2 (sesquialtera) - uma das mais frequentes no repertório polifônico do Renascimento - é provavelmente uma raiz etimológica do substantivo português quiáltera, utilizado até nossos dias. 


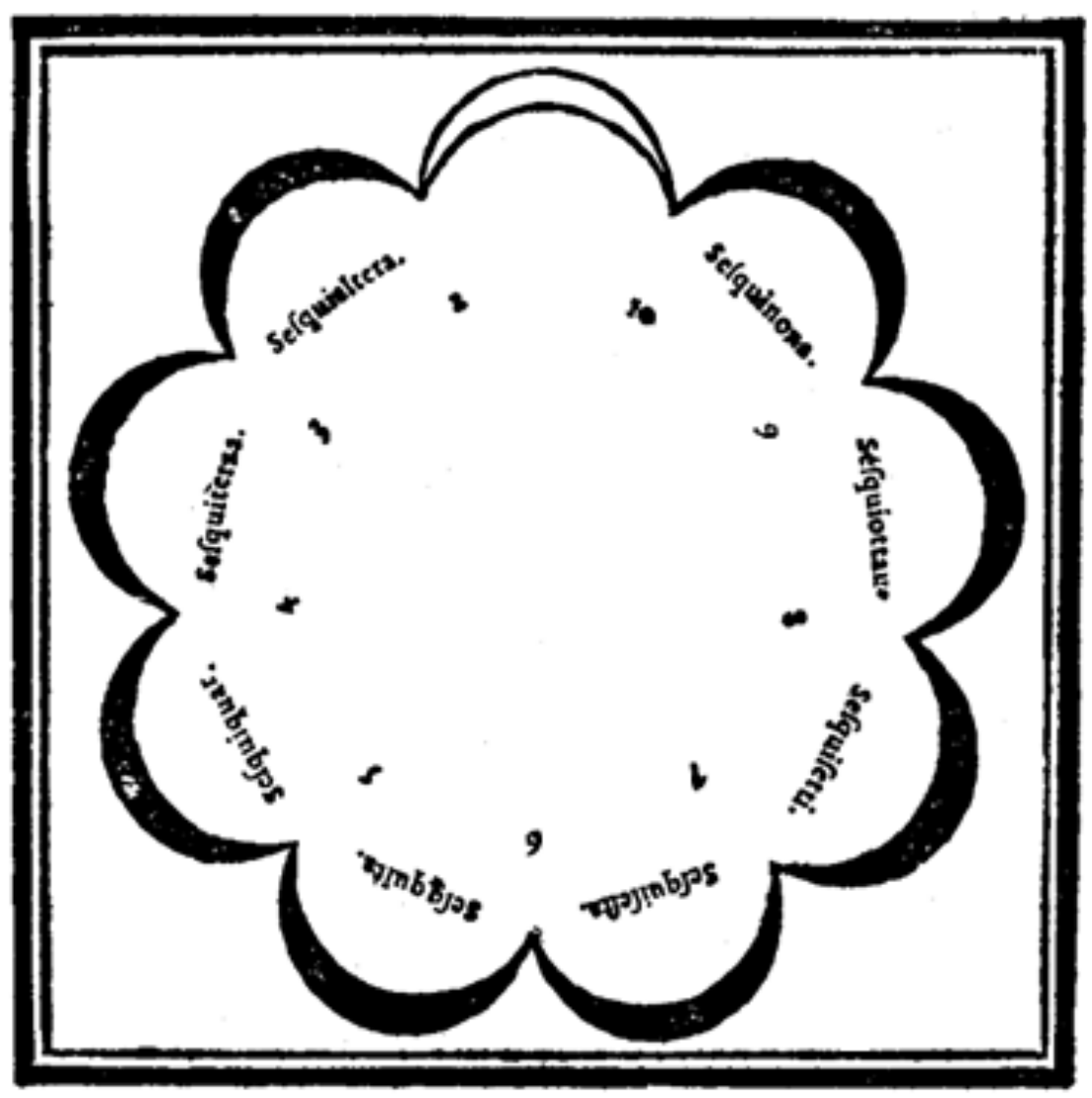

Figura 41. Proporções do genus superparticulare (ZARLINO, 1589, lib. I, cap. XXVI).

\begin{tabular}{|c|c|c|c|c|c|}
\hline \multicolumn{7}{|c|}{ Genus superparticulare } \\
\hline proporção & dividendo & divisor & quociente & $\begin{array}{c}\text { resto } \\
\text { (parte alíquota } \\
\text { do divisor) }\end{array}$ & nomenclatura \\
\hline $3: 2$ & 3 & 2 & 1 & 1 & sesquialtera \\
\hline $4: 3$ & 4 & 3 & 1 & 1 & sesquitertia \\
\hline $5: 4$ & 5 & 4 & 1 & 1 & sesquiquarta \\
\hline $6: 5$ & 6 & 5 & 1 & 1 & sesquiquinta \\
\hline $7: 6$ & 7 & 6 & 1 & 1 & sesquisexta \\
\hline $8: 7$ & 8 & 7 & 1 & 1 & sesquiseptima \\
\hline $9: 8$ & 9 & 8 & 1 & 1 & sesquioctava \\
\hline $10: 9$ & 10 & 9 & 1 & 1 & sesquinona \\
\hline
\end{tabular}

Tabela 8. Quantidades comparadas em proporção, termos das divisões e nomenclaturas das proporções do genus superparticulare exemplificadas por Zarlino. 


\section{(c) Genus superpartiens}

As proporções do gênero superpartiens são aquelas através das quais se comparam dois números naturais tais que o maior contenha o menor uma única vez (isto é, o quociente da divisão é 1) e mais uma quantidade pela qual o número menor não seja divisível. Esta parte não alíquota determina as diferentes espécies deste genus, de modo que a primeira delas compreende os casos em que o resto da divisão é 2 (proporções superbipartiente), como 5:3 (superbipartiente tertias) e 7:5 (superbipartiente quintas); na segunda espécie a parte não alíquota é 3 (proporções supertripartiente), como 7:4 (supertripartiente quartas) e 10:7 (supertripartiente septimas); na terceira espécie, por sua vez, o resto da divisão é 4 (proporções superquadripartiente), como 9:5 (superquadripartiente quintas) e 13:9 (superquadripartiente nonas). A ilustração de Zarlino para este gênero (fig. 42) contém os seis exemplos acima citados - dois para cada espécie, o que se pode verificar através dos arcos que conectam os diferentes números comparados em proporção. A tabela 9 contém estas mesmas quantidades e denominações, além das indicações explícitas dos termos das divisões.

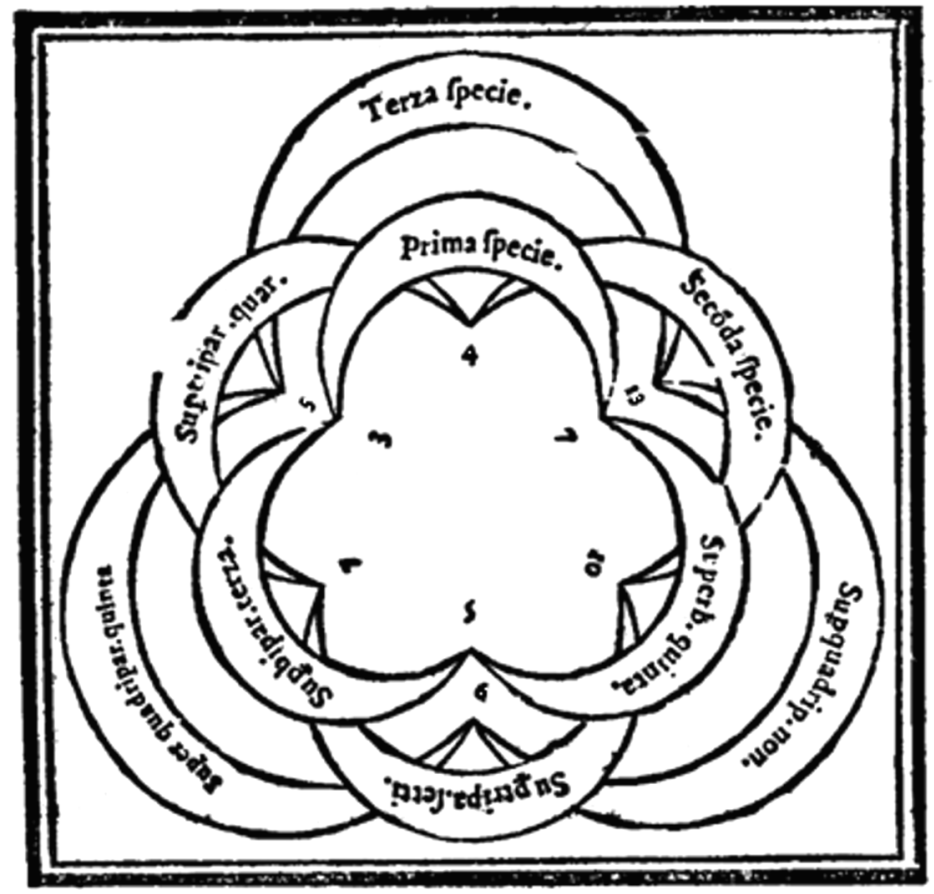

Figura 42. Proporções do genus superpartiens (ZARLINO, 1589, lib. I, cap. XXVII). 


\begin{tabular}{|c|c|c|c|c|c|}
\hline \multicolumn{2}{|c|}{} & & & \multicolumn{5}{c|}{ Genus superpartiens } \\
proporção & dividendo & divisor & quociente & $\begin{array}{c}\text { resto } \\
\text { (parte não alíquota } \\
\text { do divisor) }\end{array}$ & nomenclatura \\
\hline $5: 3$ & 5 & 3 & 1 & 2 & superbipartiente tertias \\
\hline $7: 5$ & 7 & 5 & 1 & 2 & superbipartiente quintas \\
\hline $7: 4$ & 7 & 4 & 1 & 3 & supertripartiente quartas \\
\hline $10: 7$ & 10 & 7 & 1 & 4 & supertripartiente septimas \\
\hline $9: 5$ & 9 & 5 & 1 & 4 & superquadripartiente quintas \\
\hline $13: 9$ & 13 & 9 & 1 & superquadripartiente nonas \\
\hline
\end{tabular}

Tabela 9. Quantidades comparadas em proporção, termos das divisões e nomenclaturas das proporções do genus superpartiens exemplificadas por Zarlino.

(d) Genus multiplex superparticulare

O genus multiplex superparticulare consiste em uma combinação dos dois gêneros anteriores que compõem sua nomenclatura: multiplex pelo fato de o dividendo conter o divisor mais de uma vez e superparticulare pelo fato de o resto da divisão ser uma parte alíquota do divisor. Assim como nos casos multiplex, estas proporções recebem designações referentes ao número de vezes que o número maior contém o menor (dupla, tripla, etc.), e assim como no genus superparticulare, adiciona-se o prefixo sesqui ao divisor (sesquialtera, sesquitertia, etc.). Na ilustração de Zarlino (fig. 43), os números menores - que determinam as diferentes espécies deste gênero - estão no centro da figura e os números maiores na parte externa; os arcos exteriores permitem observar que a primeira espécie compreende as proporções cujo número menor é 2, como 5:2 (dupla sesquialtera), 7:2 (tripla sesquialtera) e 9:2 (quadrupla sesquialtera); a segunda espécie refere-se a proporções onde este divisor é 3, como 7:3 (dupla sesquitertia), 10:3 (tripla sesquitertia) e 13:3 (quadrupla sesquitertia); a terceira espécie, por fim, corresponde aos casos onde o menor número é 4, como 9:4 (dupla sesquiquarta), 13:4 (tripla sesquiquarta) e 17:4 (quadrupla sesquiquarta). A tabela 10 contém os números 
originalmente comparados em proporção e os termos das divisões para os nove exemplos fornecidos na figura de Zarlino.

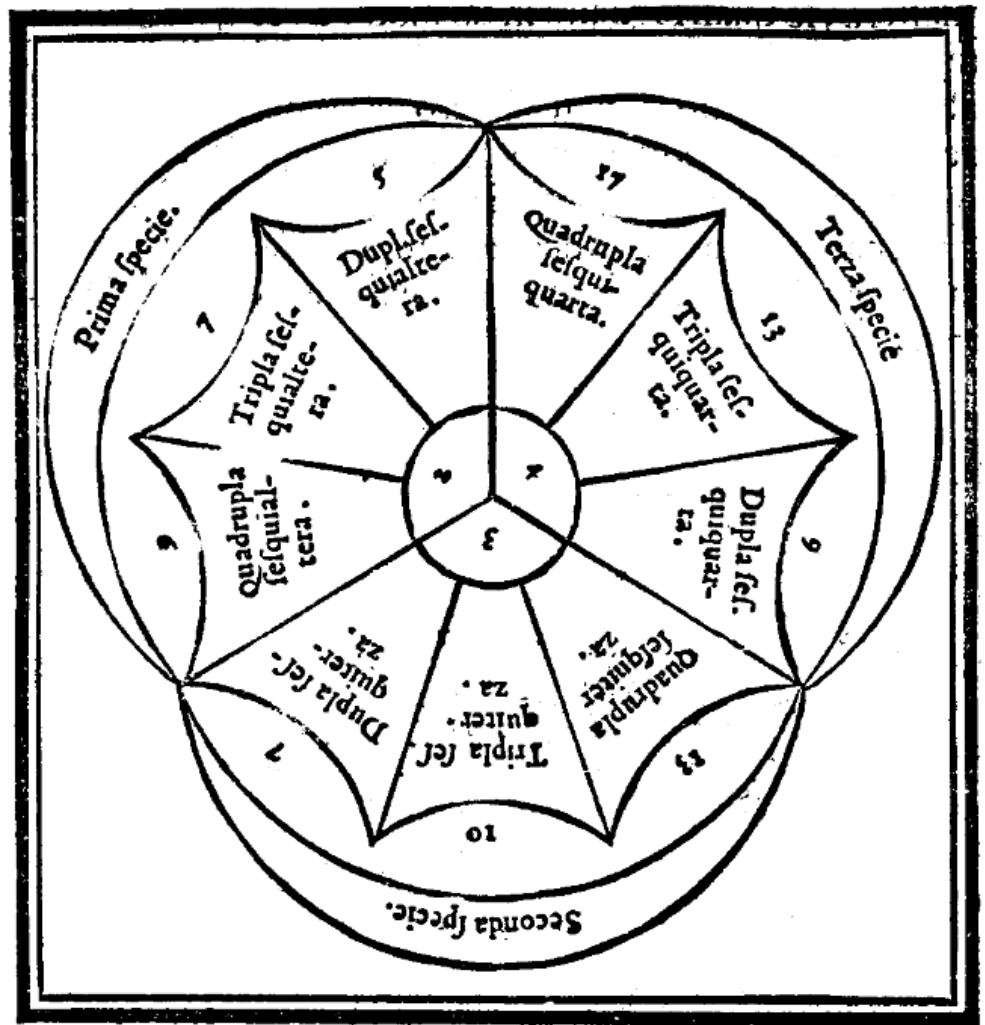

Figura 43. Proporções do genus multiplex superparticulare (ZARLINO, 1589, lib. I, cap. XXVIII).

\begin{tabular}{|c|c|c|c|c|c|}
\hline \multicolumn{6}{|c|}{ Genus multiplex superparticulare } \\
\hline proporção & dividendo & divisor & quociente & $\begin{array}{c}\text { resto } \\
\text { (parte alíquota } \\
\text { do divisor) }\end{array}$ & nomenclatura \\
\hline $5: 2$ & 5 & 2 & 2 & 1 & dupla sesquialtera \\
\hline $7: 2$ & 7 & 2 & 3 & 1 & tripla sesquialtera \\
\hline $9: 2$ & 9 & 2 & 4 & 1 & quadrupla sesquialtera \\
\hline $7: 3$ & 7 & 3 & 2 & 1 & dupla sesquitertia \\
\hline $10: 3$ & 10 & 3 & 3 & 1 & tripla sesquitertia \\
\hline $13: 3$ & 13 & 3 & 4 & 1 & quadrupla sesquitertia \\
\hline $9: 4$ & 9 & 4 & 2 & 1 & dupla sesquiquarta \\
\hline $13: 4$ & 13 & 4 & 3 & 1 & tripla sesquiquarta \\
\hline $17: 4$ & 17 & 4 & 4 & 1 & quadrupla sesquiquarta \\
\hline
\end{tabular}

Tabela 10. Quantidades comparadas em proporção, termos das divisões e nomenclaturas das proporções do genus multiplex superparticulare exemplificadas por Zarlino. 


\section{(e) Genus multiplex superpartiens}

Assim como o gênero multiplex superparticulare, o genus multiplex superpartiens combina características dos dois casos que lhe dão origem. Nestas proporções, portanto, o número maior contém o menor mais de uma vez (propriedade multiplex) e mais uma parte não alíquota deste último (propriedade superpartiens); sua nomenclatura define-se, como no caso anterior, através de uma simples combinação das designações utilizadas nos gêneros originais: a porção relativa a multiplex especifica o número de vezes que o número maior contém o menor (dupla em 8:3, tripla em 15:4, por exemplo), enquanto a porção referente a superpartiens diz respeito a este divisor e à sua parte não alíquota restante na divisão (em 8:3, superbipartiente tertias especifica que o resto 2 é parte não alíquota do divisor 3; em 15:4, supertripartiente quartas especifica que o resto 3 é parte não alíquota de do divisor 4, por exemplo). A ilustração de Zarlino (fig. 44) fornece nove diferentes casos classificados em espécies

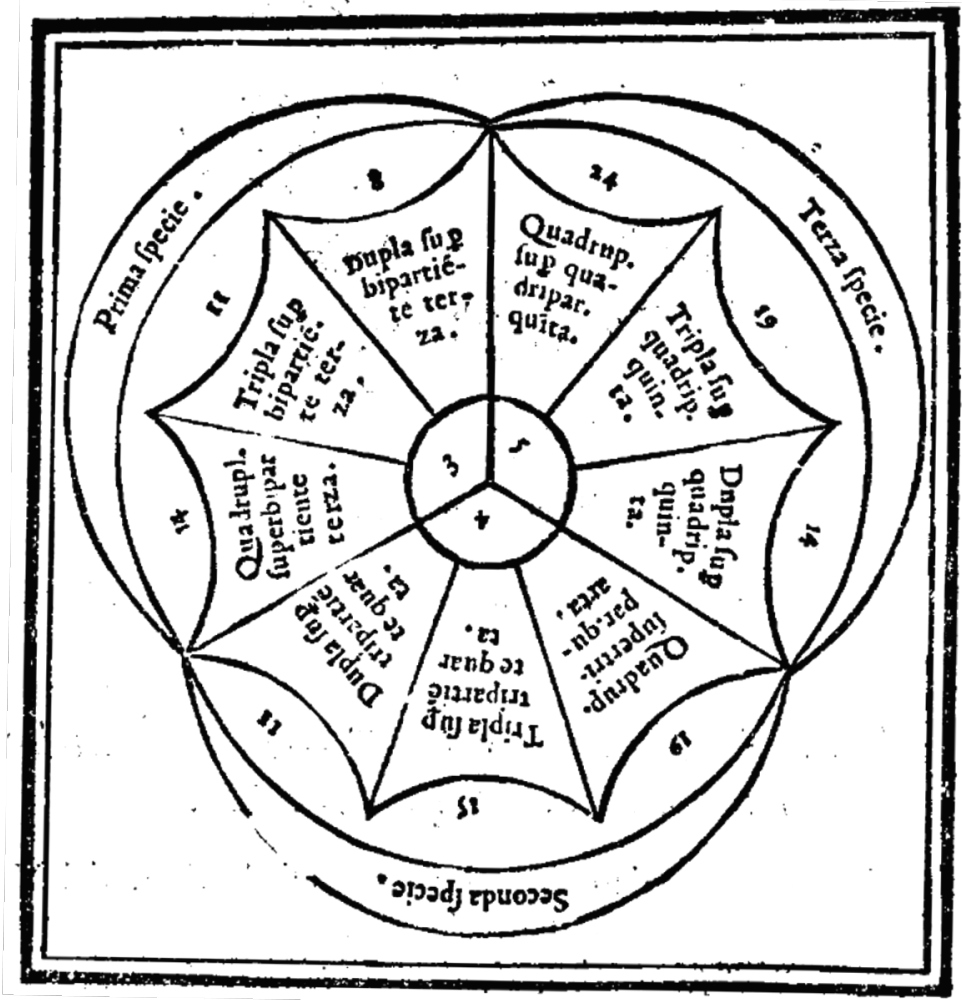

Figura 44. Proporções do Genus multiplex superpartiens. (ZARLINO, 1589, lib. I, cap. XXIX) 
de acordo com o número menor (3, 4 ou 5, ao centro) e a tabela 11 contém a especificação de todos os termos das operações correspondentes.

\begin{tabular}{|c|c|c|c|c|c|}
\hline \multicolumn{3}{|c|}{ Genus multiplex superpartiens } \\
\hline proporção & dividendo & divisor & quociente & $\begin{array}{c}\text { resto } \\
\text { (parte não alíquota } \\
\text { do divisor) }\end{array}$ & nomenclatura \\
\hline $8: 3$ & 8 & 3 & 2 & 2 & dupla superbipartiente tertias \\
\hline $11: 3$ & 11 & 3 & 3 & 2 & tripla superbipartiente tertias \\
\hline $14: 3$ & 14 & 3 & 4 & 2 & quadrupla superbipartiente tertias \\
\hline $11: 4$ & 11 & 4 & 2 & 3 & dupla supertripartiente quartas \\
\hline $15: 4$ & 15 & 4 & 3 & 3 & tripla supertripartiente quartas \\
\hline $19: 4$ & 19 & 4 & 4 & 3 & quadrupla supertripartiente quartas \\
\hline $14: 5$ & 14 & 5 & 2 & 4 & dupla superquadripartiente quintas \\
\hline $19: 5$ & 19 & 5 & 3 & 4 & tripla superquadripartiente quintas \\
\hline $24: 5$ & 24 & 5 & 4 & 4 & quadrupla superquadripartiente quintas \\
\hline
\end{tabular}

Tabela 11. Quantidades comparadas em proporção, termos das divisões e nomenclaturas das proporções do genus multiplex superpartiens exemplificadas por Zarlino.

\subsubsection{Aplicação das proporções à música mensural}

Conforme destacamos anteriormente, uma proporção é definida na linguagem dos teóricos do Renascimento como uma comparação entre quaisquer duas quantidades de uma mesma natureza. Nas aplicações deste conceito à música mensural, as quantidades comparadas identificam-se com o número de figuras que se executam em um determinado intervalo de tempo e uma nova quantidade das mesmas figuras que devem ocupar um intervalo de igual duração após a ocorrência de um sinal indicador de notação proporcional. As proporções constituem um tópico especialmente complexo da notação mensural branca pois eram indicadas através de uma grande variedade de símbolos - alguns dos quais ocasionalmente se confundiam com os próprios sinais de mensuração - que não chegaram a ser empregados de forma única e consistente durante o Renascimento, estando frequentemente sujeitos a 
interpretações ambíguas. Diversos tratadistas não se furtaram a discutir casos proporcionais de excessiva complexidade, embora tais considerações possuíssem caráter francamente especulativo; um exemplo das eventuais extravagâncias dos teóricos neste sentido é comentado por Willi Apel, que afirma que Franchinus Gafurius (1451-1522), no tratado Practica Musicae, "não hesita em explicar proporções que requerem uma diminuição na razão de 9:23" (APEL, 1953, p. 145, tradução nossa ${ }^{23}$ ). Os casos mais comumente encontrados nas fontes musicais do século XVI, entretanto, não incluem proporções matematicamente complexas, sendo as mais frequentes a dupla (2:1), a tripla (3:1), a sesquialtera (3:2) e a sesquitertia (4:3). Nas palavras de Zarlino, “[...] por mais que tais espécies [de proporções] possam ser infinitas, a Música [...] não recebe o infinito, mas se contenta com uma parcela que seja finita e mais próxima da simplicidade, para que possa dar boa conta daquilo que opera" (ZARLINO, 1589, Lib. I, cap. XXIIII, tradução nossa²4).

Quando indicadas através de dois números naturais $m$ e $n$ sob a forma $\underset{n}{m}$, as proporções estabelecem uma correspondência entre a duração de $n$ figuras notadas antes do sinal e a duração de $m$ figuras escritas após sua ocorrência. Os cinco casos mais simples de proporções aplicadas à semibrevis estão apresentados de forma esquemática na figura 45, onde os grupos de figuras à direita das indicações

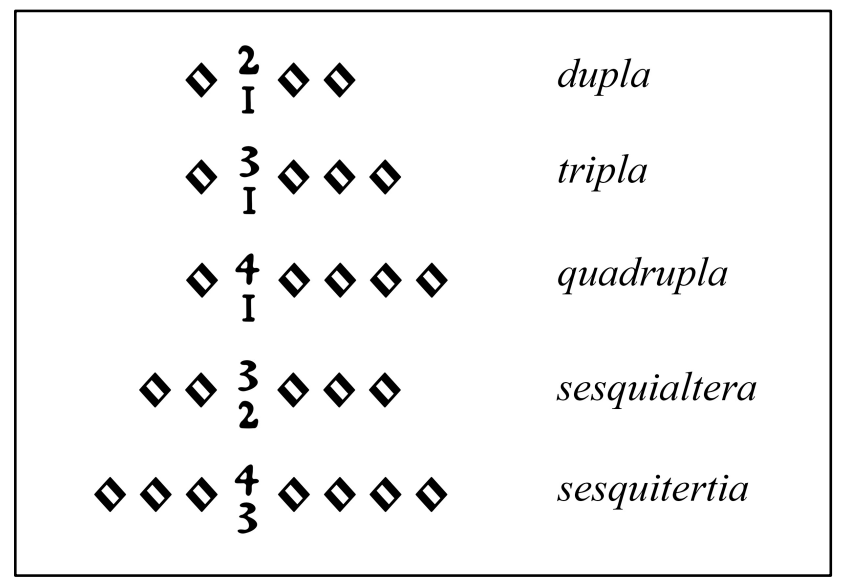

Figura 45. Proporções aplicadas à semibrevis.

\footnotetext{
${ }^{23}$ No original: "does not hesitate to explain proportions calling for a diminution in the ratio of 9:23." ${ }^{24}$ No original: "[...] quantunque tali Specie possino essere infinite ; nondimeno la Musica [...] non riceue l'Infinito; ma si contenta d'una particella, che sia finita, \& più uicina alla semplicità; acciò possa dar buon conto di quello, che opera"
} 
proporcionais devem ter a mesma duração daqueles à esquerda. Exemplos das proporções dupla, tripla, quadrupla e sesquitertia extraídos do tratado Introduttione facilissima de Vicente Lusitano, acompanhados de nossas transcrições modernas (figs. 46, 47, 48 e 49), ilustram o uso destes dispositivos notacionais; Lusitano apresenta cada exemplo através de duas vozes, onde a parte superior exibe as ocorrências proporcionais e a voz inferior permanece em integer valor, constituindo assim uma referência segura para a verificação da correta interpretação dos sinais.

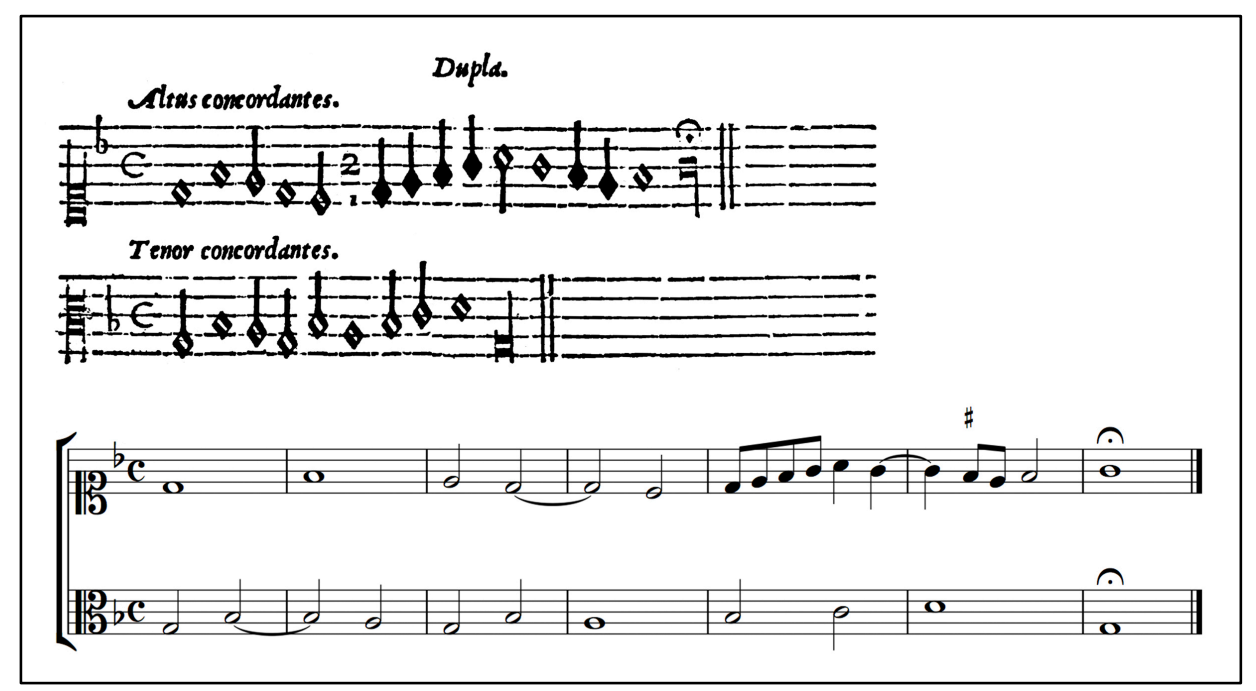

Figura 46. Exemplo de Vicente Lusitano para proportio dupla (LUSITANO, 1558, $f$. $10 v)$ e transcrição moderna realizada pelo presente autor.

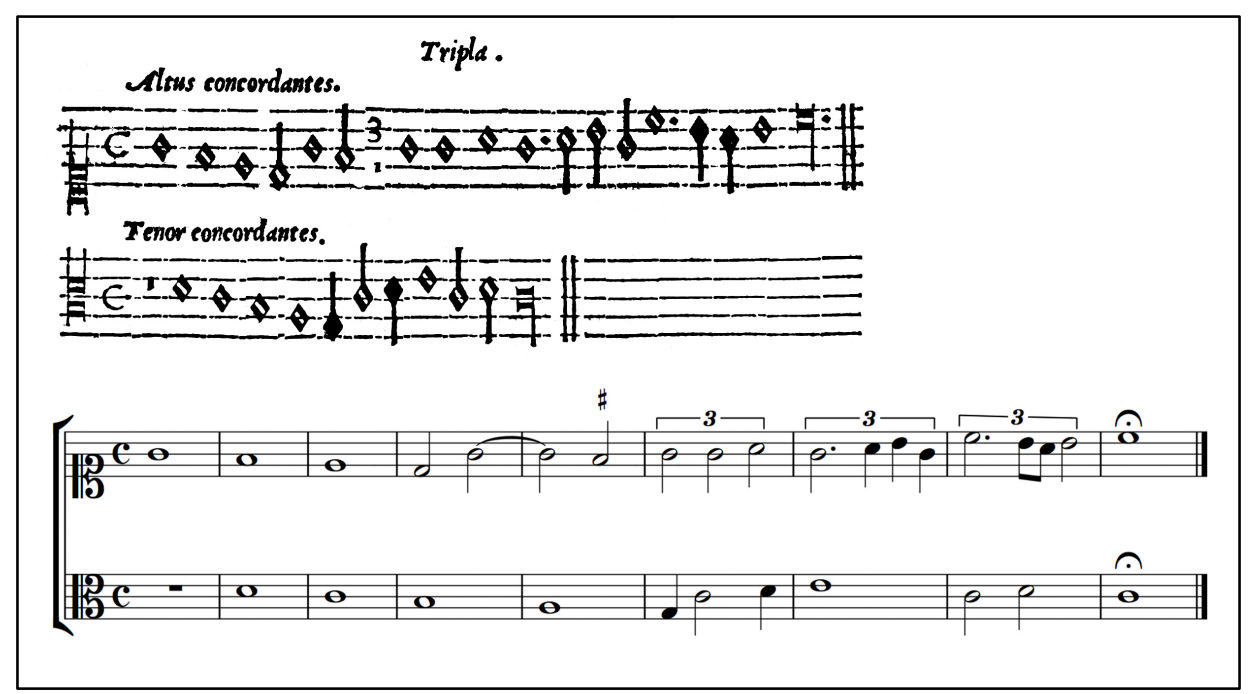

Figura 47. Exemplo de Vicente Lusitano para proportio tripla (LUSITANO, 1558, $f$. $10 v)$ e transcrição moderna realizada pelo presente autor. 


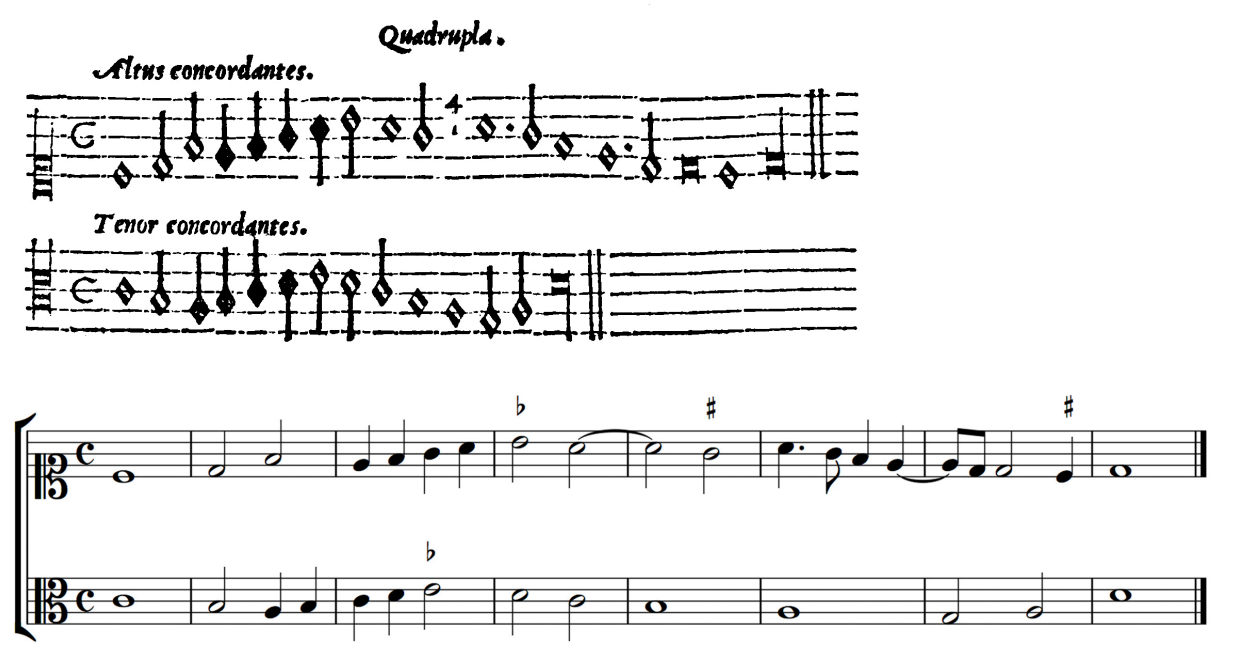

Figura 48. Exemplo de Vicente Lusitano para proportio quadrupla (LUSITANO, 1558, $f .10 v)$ e transcrição moderna realizada pelo presente autor.

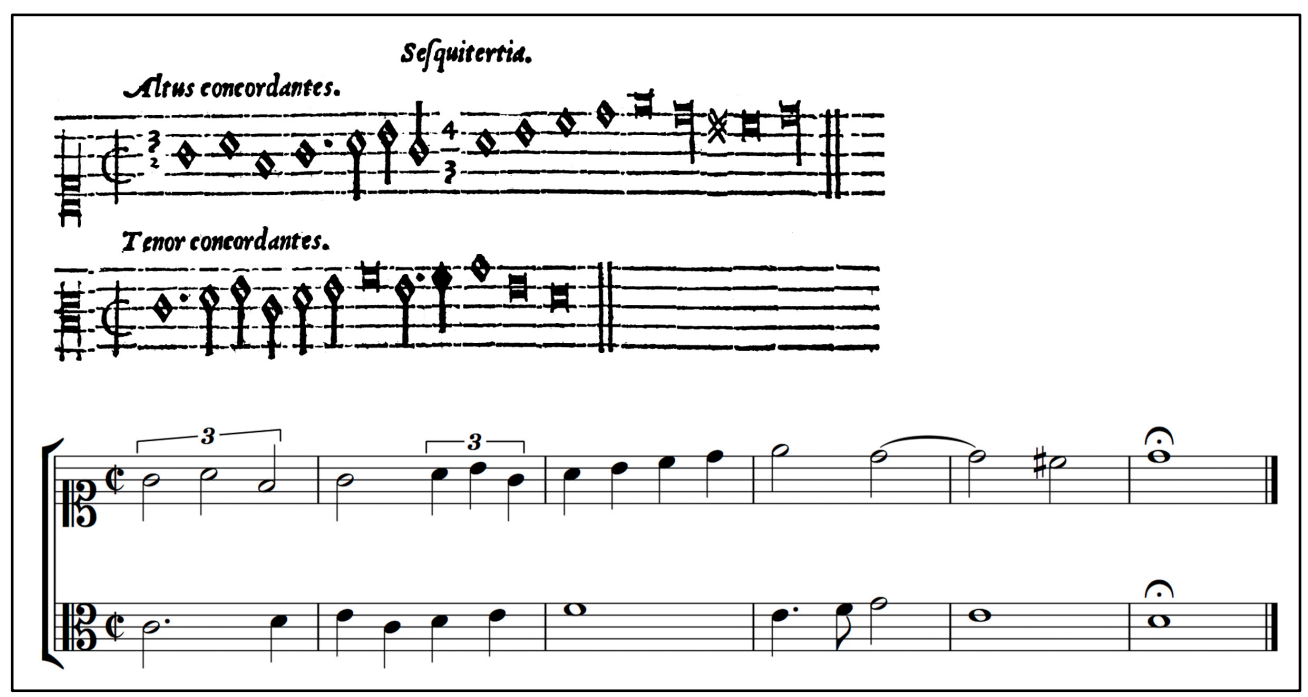

Figura 49. Exemplo de Vicente Lusitano para proportio sesquitertia (LUSITANO, 1558, $f$.

$11 r$ ) e transcrição moderna realizada pelo presente autor.

Indicações proporcionais do tipo ${ }_{n}^{m}$ podem ainda ocorrer sucessivas vezes ao longo de uma composição; se seus efeitos forem considerados cumulativos, o uso da razão inversa $\underset{m}{n}$ tem como consequência lógica o cancelamento da proporção anterior - isto é, uma aumentação subdupla (1:2) ocorrendo após proportio dupla (2:1), por exemplo, deve resultar em integer valor. $\mathrm{O}$ uso deste mecanismo pode ser observado no exemplo fornecido por Morley para proportio tripla e na respectiva transcrição de Alec Harman, originalmente realizada com redução de valores 1:2 (fig. 50). A 
musicóloga Anna Maria Busse Berger (2002, p. 649) afirma que esta interpretação foi introduzida pelo teórico Johannes Tinctoris (ca.1435-1511), um dos grandes reformadores do sistema de notação mensural no século XV. Segundo Busse Berger, “antes de Tinctoris, duas proporções sucessivas, mesmo quando eram indicadas através de frações, não eram cumulativas. Ao invés disso, a segunda era relacionada ao sinal de mensuração inicial." (BERGER, 2002, p. 649, tradução nossa ${ }^{25}$ ). No século XVI, contudo, uma proporção anterior normalmente só se pode considerar cancelada quando seguida de um novo sinal de mensuração.

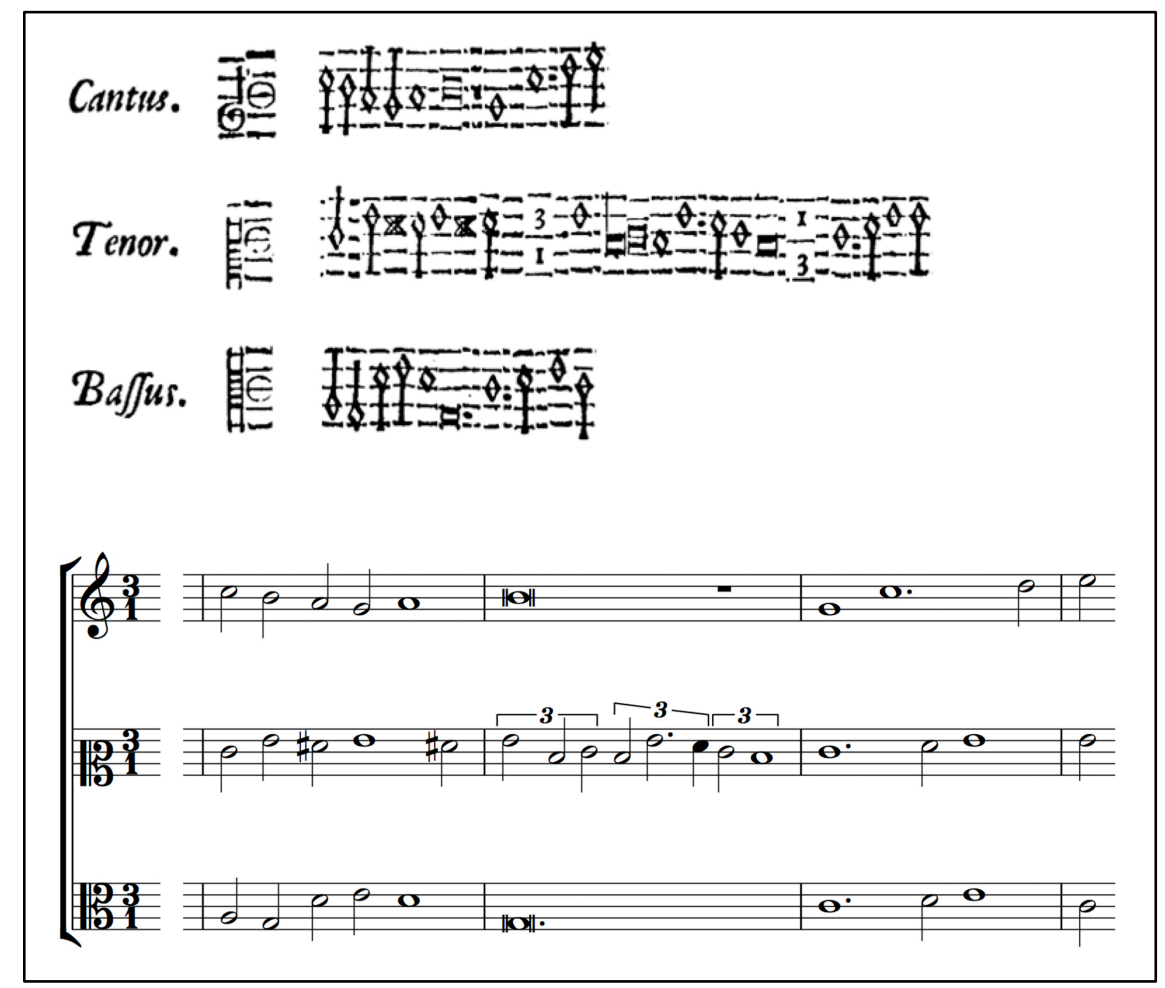

Figura 50. Exemplo de Thomas Morley para proportio tripla em tempus perfectum e transcrição de Alec Harman (MORLEY; HARMAN, 1952, p. 51-52) modificada para $\diamond=\mathbf{o}$ (sem redução de valores).

As proporções tripla (3:1) e sesquialtera (3:2) são as mais habitualmente utilizadas no repertório polifônico quinhentista devido à frequente justaposição de trechos com subdivisões rítmicas binárias e ternárias em uma mesma peça durante este período. Estas relações, como veremos adiante, não eram necessariamente notadas segundo a

25 No original: "Before Tinctoris, two successive proportions, even when they were indicated by fractions, were not cumulative. Instead the second was related to the initial mensuration sign." 
teoria, o que frequentemente resulta em ambiguidades relativas ao tactus a ser adotado após suas indicações. O exemplo de Lusitano para proportio sesquialtera (fig. 51) ilustra o uso de ${ }_{2}^{3}$ de acordo com a definição teórica, segundo a qual três semibreves após o indicador proporcional devem ter a mesma duração de duas semibreves em integer valor.

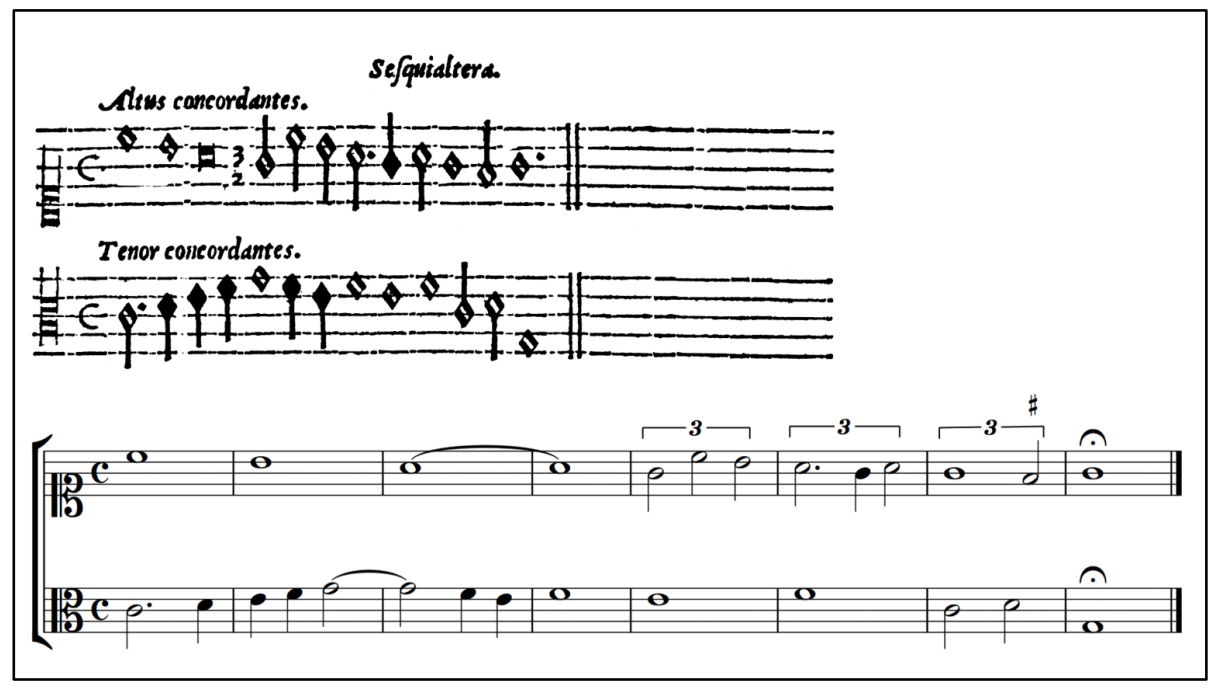

Figura 51. Exemplo de Vicente Lusitano para proportio sesquialtera (LUSITANO, 1558, $f$.

$11 r$ ) e transcrição moderna realizada pelo presente autor.

A proporção sesquialtera também era comumente expressa através da coloração das notas envolvidas, pois a equivalência $\bullet \bullet=\diamond \diamond$ constitui uma maneira alternativa de representar a relação 3:2. O teórico e compositor italiano Adriano Banchieri (15681634), em sua Cartella Musicale, a discute apresentando dois exemplos de seu uso através de notas coloridas nas mensurações por ele denominadas tempo maggior perfetto ( $\phi$, onde o tactus corresponderia, em rigor, à brevis) e tempo minore perfetto ( $C$, onde o tactus corresponde à semibrevis) (fig. 52). Banchieri aponta a suposta dificuldade de execução do exemplo superior devido ao fato de os compositores de sua época já não utilizarem o tactus teórico de brevis que seria adequado a esta mensuração e comenta o uso do sinal 3 a cada grupo de três figuras coloridas (semibreves pretas no exemplo superior e minimae pretas no exemplo inferior, destacadas na figura), o que se assemelha à prática adotada em notação moderna para a notação de tercinas. Uma 
transcrição possível para o exemplo inferior está apresentada na figura 53. O texto de Banchieri lê-se:

O exemplo superior de Sesqui, Altera no tempo perfetto maggiore não é praticado pelos compositores, e isso acontece porque seria difícil cantálo, e também (como dissemos no terceiro Documento) [porque] se introduziu o uso de cantar ambos os tempi sob uma semibreve por battuta, de modo que encontrando-se Sesqui, Altere sempre se cantam três mínimas negras por battuta sob a semibreve, seja no tempo perfetto maggior ou no tempo perfetto minore, e assim praticam os compositores modernos, e este uso convertido em lei deve ser observado; porque agora se assinala a cada battuta o número 3, podendo-se servir de um [único] no princípio para todos. Este número 3 serve como advertência para o mestre que bate o tactus não alterar o tempo do tactus ordinário, e [para] o cantor igualmente subdividir as três mínimas negras em um tactus (Altera), isto é, alterando-as para que se ouça aquele titubeio (BANCHIERI, 1614, p. 31, tradução nossa ${ }^{26}$ ).

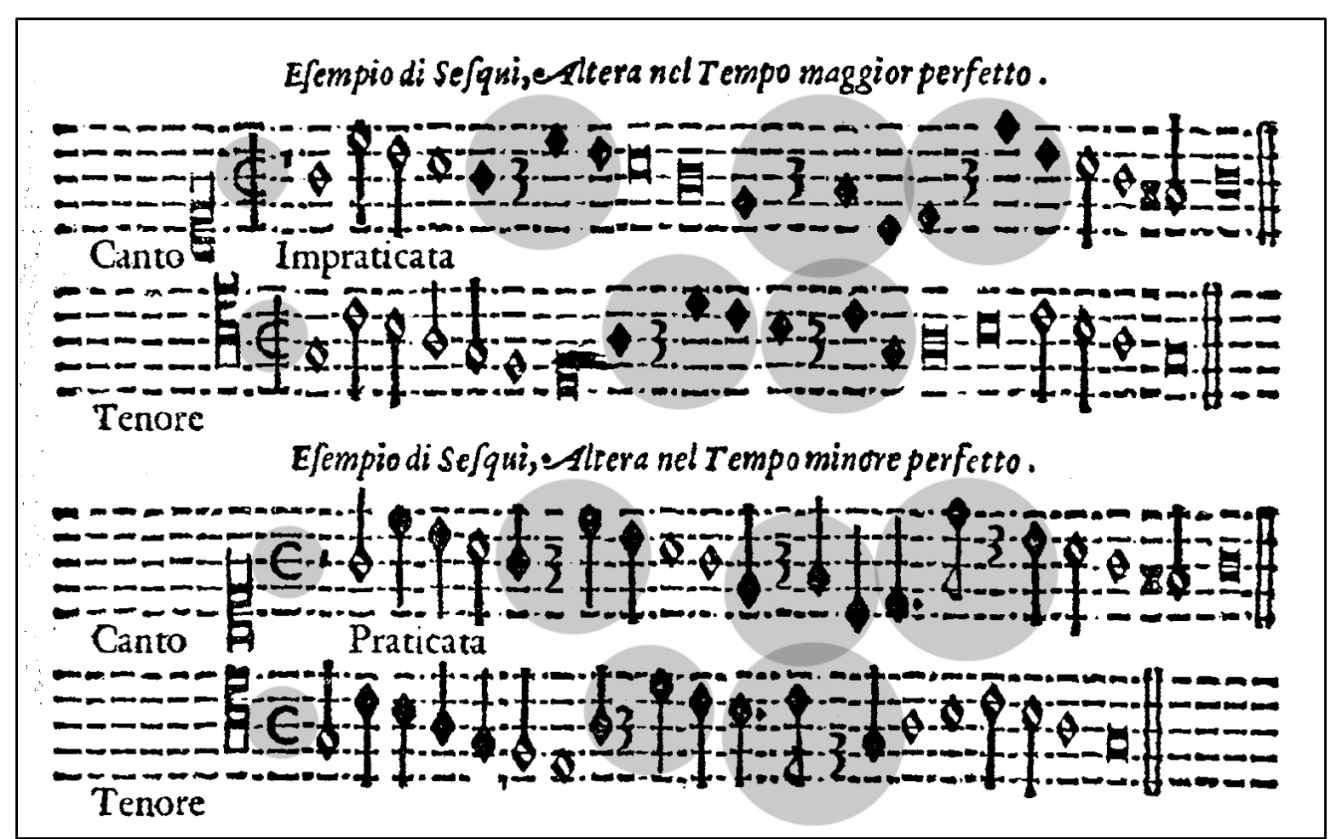

Figura 52. Exemplos de Adriano Banchieri para o uso de proportio sesquialtera através de notas coloridas (BANCHIERI, 1614, p. 31).

\footnotetext{
${ }^{26}$ No original: "L'esempio superiore di Sesqui, Altera nel tempo perfetto maggiore non viene da gli Compositori praticato, \& questo nasce perche saria difficile al cantarla, \& ancora (come detto habbiamo nel terzo Documento) essendosi per uso introdotto cantare amendui gli Tempi sotto una Semibreve per battuta, a tal che trovandosi Sesqui, Altere, sempre si cantano tre minime negre alla battuta sotto la Semibreve, ò sia il tempo perfetto maggiore overo il Tempo perfetto minore da gli Compositori moderni cosi viene praticata, \& quest'uso convertito in legge deve si osservare; perche mò si segni a ciascuna battuta il numero 3. potendosi servire di uno al principio per tutti. Questo numero 3. serve per avertimento al Mastro che batte la battuta non alterare il tempo dalla battuta ordinaria, \& il Cantore parimente compartire le tre minime negre in una battuta (Altera) cioè alterandole acciò si senta quella titubatione."
} 


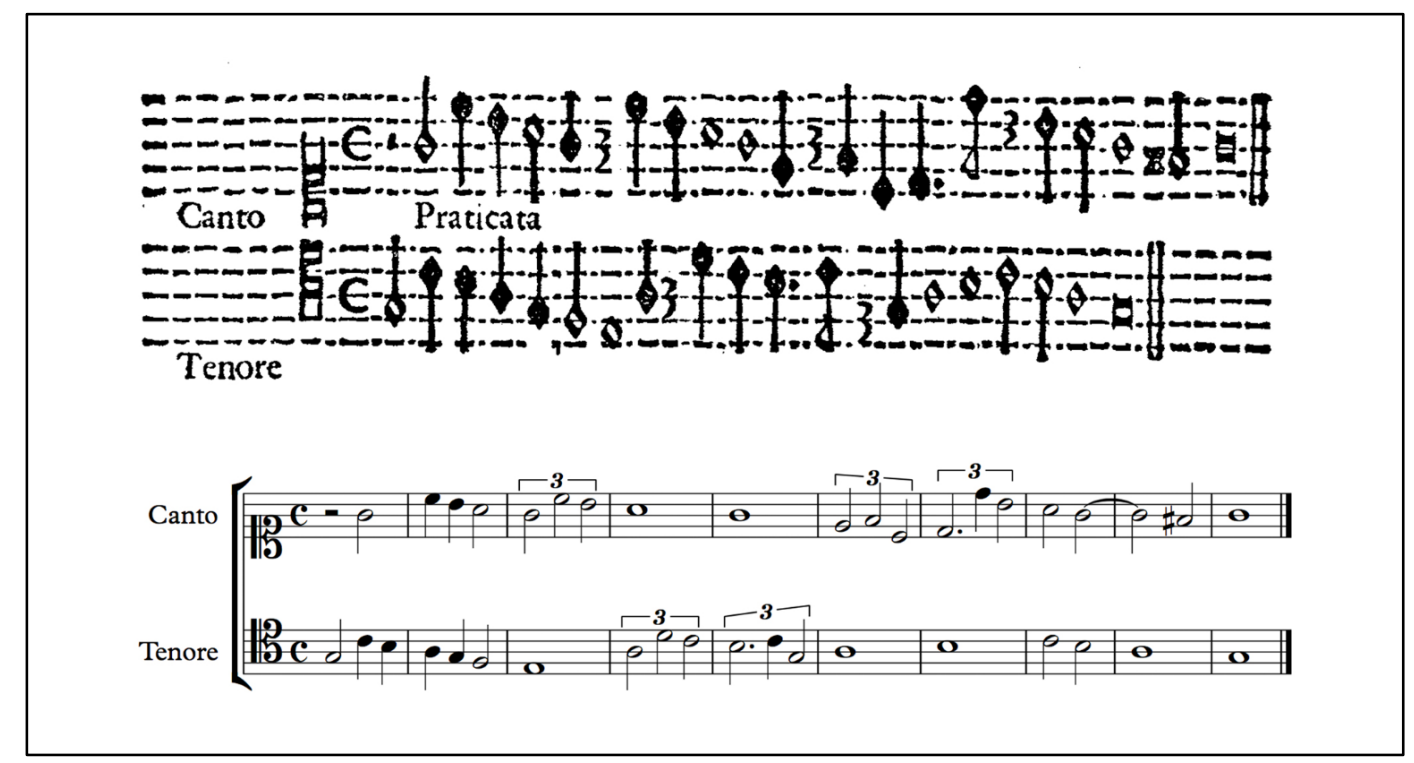

Figura 53. Transcrição do exemplo de Adriano Banchieri (BANCHIERI, 1614, p. 31) para o uso de proportio sesquialtera através de notas coloridas, realizada pelo presente autor.

A notação da sesquialtera da maneira descrita por Banchieri pode ser encontrada em inúmeras composições do século XVI, sobretudo em gêneros de caráter menos polifônico como o balletto, villanesca e a villanella. Diferentemente deste exemplo e daqueles fornecidos por Lusitano, contudo, seções notadas sob 3 ou ${ }_{2}^{3}$ (com ou sem o uso de coloração) nas fontes musicais do período costumam ocorrer simultaneamente em todas as vozes - sem que existam, portanto, partes em integer valor às quais os trechos proporcionais possam ser comparados com segurança - e por este motivo suas relações temporais com trechos anteriores são ocasionalmente ambíguas. Em particular, a frequente utilização do sinal 3 com o significado ${ }_{2}^{3}$ pode resultar em diferenças importantes na interpretação dos trechos proporcionais, o que se pode observar através das transcrições modernas de uma série de minimae agrupadas de forma ternária sob o sinal 3 após um trecho notado sob a mensuração C (fig. 54): no caso (a), três minimae sob 3 são interpretadas como equivalentes a duas minimae sob C (sesquialtera), enquanto a situação $(\mathrm{b})$ corresponde à interpretação de 3 
como um indicador de proportio tripla, em que uma minima em integer valor é considerada equivalente a três minimae após o sinal de proporção.

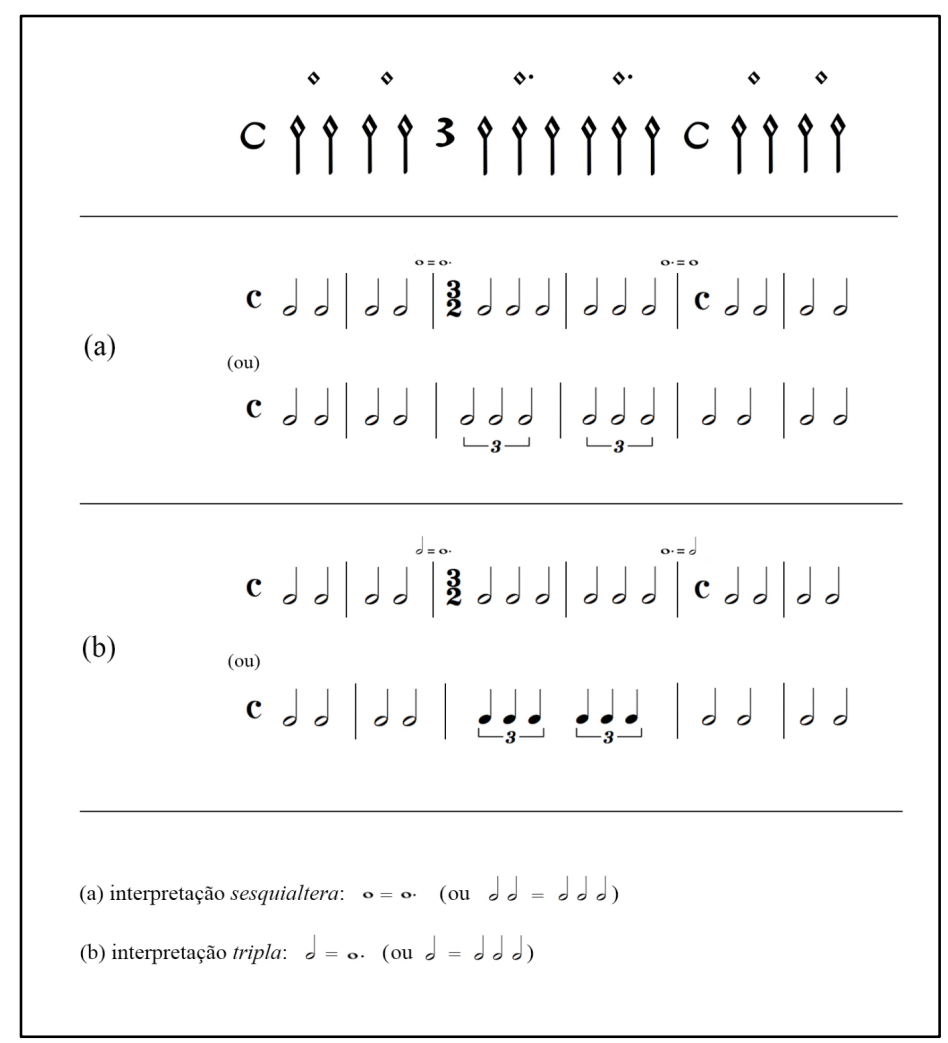

Figura 54. Interpretações do sinal 3 como tripla ou sesquialtera.

A ambiguidade rítmica observada no trecho acima considerado está presente na maioria das ocorrências de seções ternárias em notação mensural, sejam elas indicadas através de sinais equivalentes a $\mathbf{3}$ ou por meio da coloração das figuras envolvidas. A crescente flexibilidade da notação de trechos ternários ao longo do século XVI permite ainda a consideração de outras interpretações, como a equivalência $C \downarrow=3 \downarrow$ (fig. 55) - o que resulta em um andamento intermediário entre os extremos propostos na figura 54 - ou até mesmo a suposição da ausência de qualquer relação proporcional com seções binárias anteriores, conforme afirma Ruth DeFord:

A razão principal para a ambiguidade dos sinais de proporção é que eles servem a dois propósitos distintos: primeiro, para indicar mudanças precisas de andamento, caso em que a música a que eles se aplicam pode ter ou não um caráter métrico ternário; e segundo, para notar o metro ternário, independentemente de sua relação de 
andamento com um metro binário anterior. (DEFORD, 1995, p. 1, tradução nossa' ${ }^{27}$ )

Tripla e sesquialtera usualmente aparecem em todas as vozes e raramente se sobrepõem a outras mensurações no século XVI. Apesar de elas serem chamadas de "proporções", o termo se aplica a elas principalmente no sentido informal através do qual eles designam três semibreves ou três minimae por tactus, sem a necessidade de qualquer relação proporcional com outro sinal. (DEFORD, 2015, p. 171, tradução $\operatorname{nossa}^{28}$ )

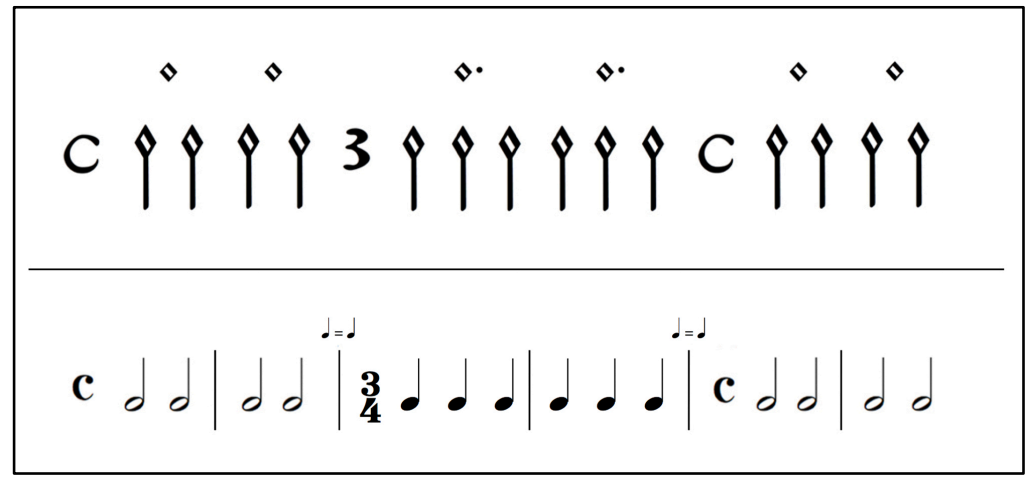

Figura 55. Interpretação alternativa do sinal 3.

As sugestões editoriais para equivalências dos valores de figuras pertencentes a seções binárias e ternárias em publicações modernas representam, portanto, apenas propostas de soluções práticas para os intérpretes, razão pela qual normalmente são indicadas entre colchetes $([\mathbf{o}=\mathbf{o} \cdot]$, por exemplo), assim como trechos originalmente coloridos são notados sob colchetes horizontais interrompidos $(\ulcorner\neg \neg)$ (fig. 56). Ambas as convenções visam a destacar a possibilidade de diferentes soluções interpretativas e foram adotadas em todas as transcrições apresentadas neste texto.

\footnotetext{
${ }^{27}$ No original: "The main reason for the ambiguity of proportional signs is that they serve two distinct purposes: first, to notate precise changes of tempo, in which case the music to which they apply may or may not have ternary metrical character, and second, to notate triple metre, regardless of its tempo rlationship to a preceding duple metre."

${ }^{28}$ No original: "Tripla and sesquialtera usually appear in all voices and rarely overlap with other mensurations in the sixteenth century. Although they are called "proportions", the term applies to them primarily in the informal sense in which they designate three semibreves per tactus without any necessary proportional relation to another sign."
} 


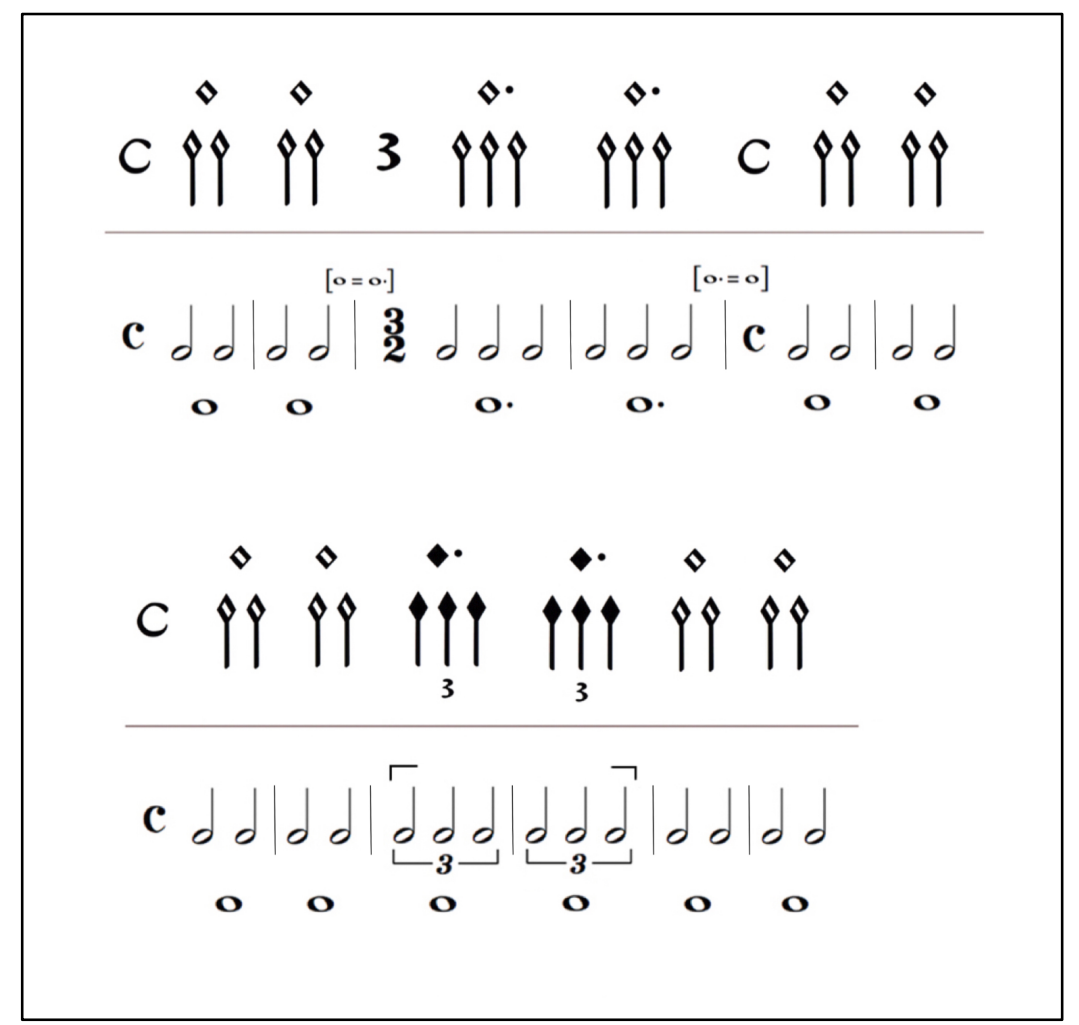

Figura 56. Convenções editoriais para transcrições de mudanças métricas e coloração.

\subsubsection{Relações entre metros binários e ternários nos Winchester Partbooks}

Alternâncias entre metros binários e ternários foram observadas em seis das peças transcritas como parte da presente pesquisa (Winchester Partbooks, no 5, 10, 16, 18, 43 e 45) e estas serão consideradas separadamente a seguir:

(a) Ecco la stagion novella (Winchester Partbooks, n. 5)

Conforme apontado na seção 3.1.8, esta peça anônima inicia-se sob os sinais 3 (no discantus, altus e bassus) e $\$ 3$ (no tenor) - ambos certamente com o mesmo significado - e apresenta escrita homorrítmica com tactus inaequalis recaindo sobre a semibrevis pontuada (fig. 57). Este caso ilustra claramente o uso do símbolo 3 como um sinal de mensuração - pois não há trechos anteriores (ou partes simultâneas em integer 
valor) a serem comparados em proporção - em um período em que já não se utilizavam os antigos sinais indicadores de tempus perfectum ou prolatio perfecta. A mudança métrica ocorrente na transição para o breve trecho binário "sempre il buon tempo mi piacque" (fig. 58) é notada através do sinal $\$$ e a música retorna em seguida a seu fluxo inicial, novamente notada sob 3. Apesar de $\$$ denotar teoricamente um tactus sobre a brevis, há suficientes evidências documentadas a partir da segunda metade do século XVI (entre as quais a declaração de Banchieri) que permitem supor que o tactus de semibrevis também fosse comumente praticado sob este sinal, razão pela qual sugerimos editorialmente as equivalências $[\mathbf{o}=\mathbf{o}]$ e $[\mathbf{o}=\mathbf{0} \cdot]$, que preservam a duração do tactus inicial e aparentemente constituem as soluções mais simples para ambas as transições.

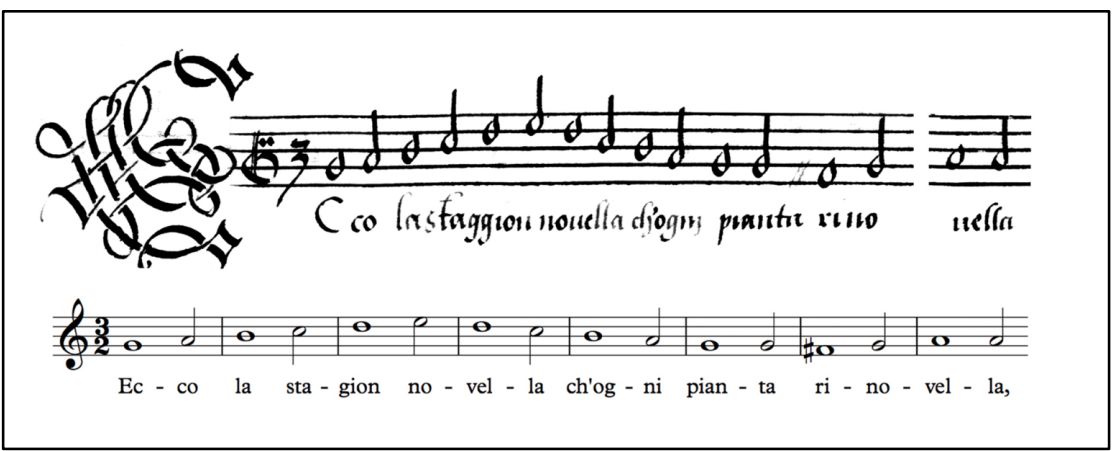

Figura 57. Início do discantus da peça anônima Ecco la stagion novella (Winchester Partbooks, n. 5) e transcrição moderna realizada pelo presente autor.

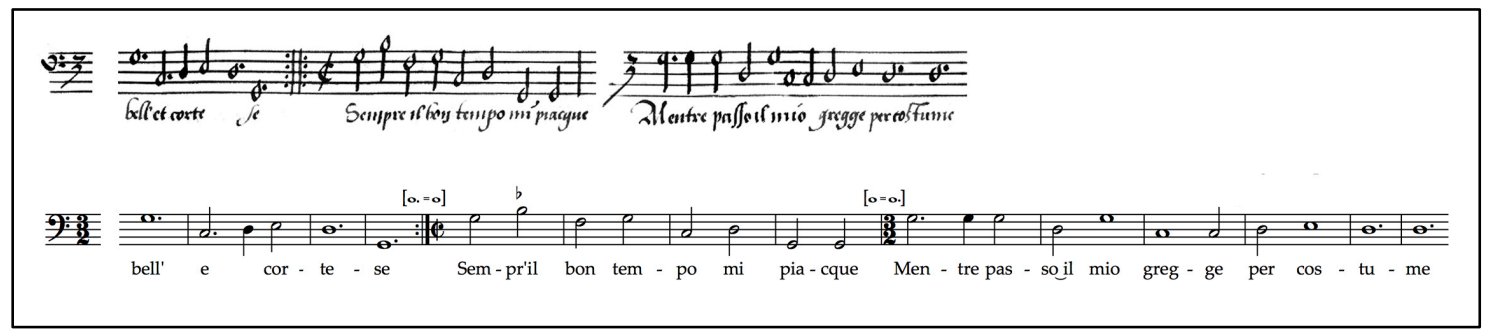

Figura 58. Alterações métricas na peça anônima Ecco la stagion novella (Winchester Partbooks, n. 5) e transcrição moderna realizada pelo presente autor. 
(b) Tri ciechi siamo (Winchester Partbooks, n. 18)

Esta peça de Hubert Waelrant - um arranjo a quatro vozes da mascherata homônima musicada por Giovan da Nola - exibe escrita homorrítmica e inicia-se sob o sinal C em todas as partes, admitindo a adoção da semibrevis como tactus aequalis isto é, como um pulso a ser subdividido igualmente em duas minimae. As alterações rítmicas presentes em cada trecho correspondente ao texto "un' elimosina ai pov'ri orbi" são expressas através de grupos ternários acompanhados do sinal 3, o que se pode observar na reprodução da parte do discantus (fig. 59). Diferentemente do que ocorre

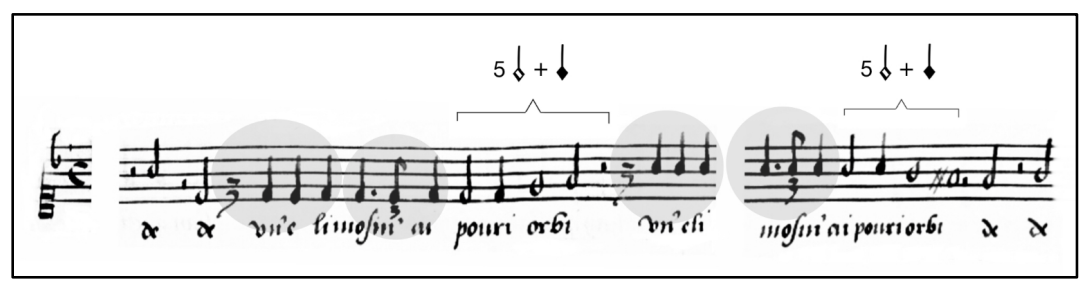

Figura 59. Alterações métricas no discantus da peça Tri ciechi siamo, de Hubert Waelrant (Winchester Partbooks, n. 18).

na peça anterior, contudo, a manutenção do tactus inicial ao longo dos agrupamentos ternários é problemática pois os trechos correspondentes ao texto "pov'ri orbi" não contêm números inteiros de minimae; um tactus constante faria, portanto, com que as posteriores repetições de "un'elimosina" não coincidissem com o início de uma nova battuta e ocasionaria finais de frase sincopados por uma semiminima. Esta possibilidade é consequentemente descartada e a solução proposta na presente transcrição baseia-se na equivalência entre uma minima colorida $(\downarrow)$ pertencente a um dos grupos ternários e uma semiminima ( $\downarrow$ ) anterior ou posterior aos mesmos (fig. 60); esta interpretação é

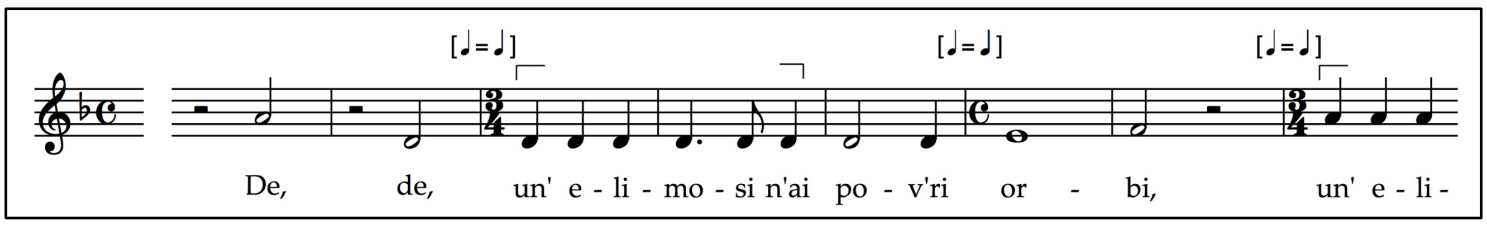

Figura 60. Transcrição de alterações métricas na peça Tri ciechi siamo, de Hubert Waelrant (Winchester Partbooks, n. 18), realizada pelo presente autor. 
observada em diversos registros fonográficos da peça de Nola, que possui escrita rítmica quase idêntica (fig. 61). A transcrição das minimae coloridas através de

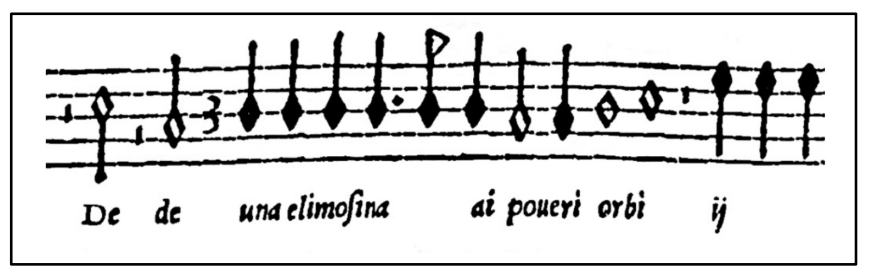

Figura 61. Alterações métricas na peça Tri ciechi siamo, de Giovane da Nola (NOLA, 1545, n. 1).

semínimas modernas, assim como a inserção da fórmula de compasso $\mathbf{4}$ (acompanhada da sugestão $[d=\rfloor]$ ), foram procedimentos editoriais adotados para permitir que a partitura moderna assumisse um aspecto mais próximo dos manuscritos originais. Embora o trecho "pov'ri" ( ل\ ) não tenha sido originalmente notado em coloração, sua evidente estrutura ternária sugeriu que o mantivéssemos sob a indicação métrica $\underset{4}{3}$, razão pela qual optamos por reintroduzir a fórmula $\mathbf{C}$ apenas antes de "orbi". De qualquer forma, o trecho colorido foi notado sob colchetes interrompidos, o que informa as alterações aos intérpretes para que estes possam considerar outras soluções, caso assim o desejem.

(c) O Dio, che fosse quella costumanza (Winchester Partbooks, n. 10)

Esta peça de Hubert Waelrant inicia-se sob o sinal C em todas todas as vozes, exibe escrita homorrítmica e novamente apresenta uma seção ternária notada através do uso de coloração em agrupamentos equivalentes a três minimae coloridas (semibrevis preta + minima preta) (fig. 62). Diferentemente do que ocorre em Tri ciechi siamo, a manutenção do tactus inicial constitui uma efetiva possibilidade para a execução da

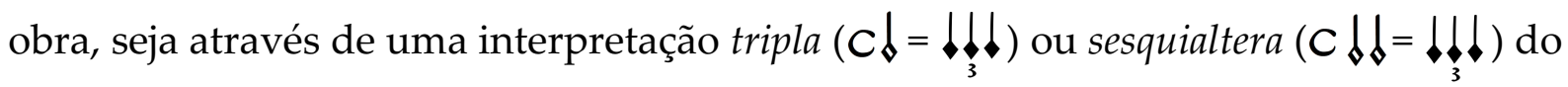
trecho ternário. Apesar de um tactus inalterado não acarretar em problemas métricos do ponto de vista teórico ou estrutural, contudo, é possível que o andamento resultante 
soe excessivamente movido (no caso da interpretação tripla) ou demasiadamente lento (no caso da interpretação sesquialtera); por esta razão sugerimos novamente a solução intermediária $C \downarrow \downarrow \downarrow \downarrow \downarrow \downarrow \downarrow$ (fig. 63) - o que não invalida, naturalmente, qualquer das possibilidades anteriores. Embora esta interpretação equivalha a uma proporção dupla entre a semibrevis branca e a semibrevis preta $(\diamond=\bullet \bullet)$ e requeira uma alteração do tactus no trecho notado em coloração, sua aplicação é musicologicamente viável e está associada a este gênero musical, conforme afirma Ruth DeFord no artigo intitulado Tempo Relationships between Duple and Triple Time in the sixteenth Century:

A evidência discutida até o momento sugere que proporções notadas com sinais de sesquialtera maior poderiam ser interpretadas tanto da maneira como estão escritas, com três semibreves equivalentes a duas do sinal precedente, ou duas vezes mais rápido, com três semibreves equivalentes a uma, e que esta última opção tornou-se cada vez mais comum ao longo do século. Apesar de esta consideração explicar satisfatoriamente muitos exemplos, ela quase certamente não é completa. Existe também evidência de que proporções ternárias não eram sempre estritamente proporcionais às mensurações que as precediam, e que, quando o eram, a proporção era às vezes dupla, ao invés de sesquialtera ou tripla. [...] a semibrevis ou minima na proporção podem ser igualadas, respectivamente, com a minima ou semiminima da mensuração precedente, criando uma proporção dupla entre o sinal ternário e o binário. [...] Fontes práticas provam sem dúvida que esta relação existia, ao menos para proporções notadas em minimae pretas em relação a C; neste caso, a minima preta da proporção é igualada a uma semiminima da notação branca, à qual ela é idêntica em aparência. Esta interpretação era aparentemente mais comum em villanellas, que frequentemente não eram medidas em unidades regulares de semibreves (as durações de seções ou peças inteiras podiam ser um número ímpar de minimae e cadências podiam cair em qualquer minima). (DEFORD, 1995, p. 26-27, 39, 43, 46, tradução nossa29)

\footnotetext{
${ }^{29}$ No original: "The evidence discussed so far suggests that proportions notated with signs of major sesquialtera could be performed either as written, with three semibreves equivalent to two of the preceding sign, or twice as fast, with three semibreves equivalent to one, and that the latter option became increasingly common throughout the century. Although this account satisfactorily explains many examples, it is almost certainly not complete. There is also evidence that ternary proportions were not always strictly proportional to the binary mensurations preceding them, and that when they were, the proportion was sometimes duple, rather than sesquialtera or triple. [...] the semibreve or minim of the proportion may be equated, respectively, with the minim or semiminim of the preceding mensuration, creating a duple proportion between the ternary sign and the binary one [...] Practical sources prove without doubt that this relationship did exist, at least for proportions notated in black
} 


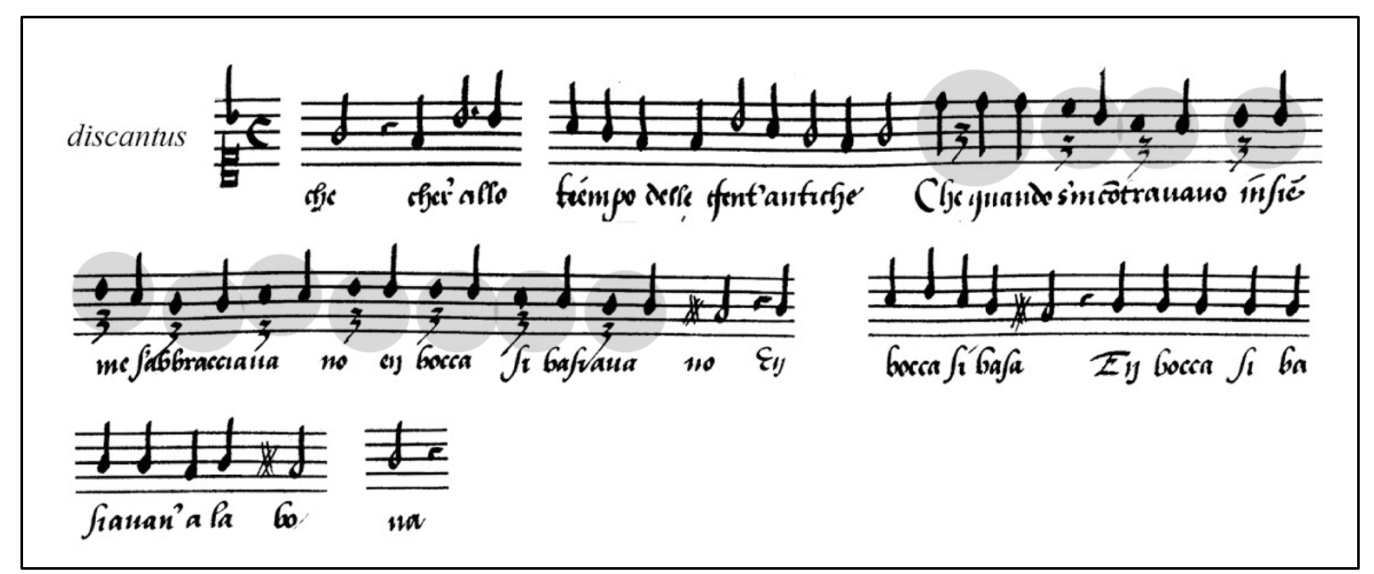

Figura 62. Alterações métricas no discantus da peça O Dio, che fosse quella costumanza, de Hubert Waelrant (Winchester Partbooks, n. 10).
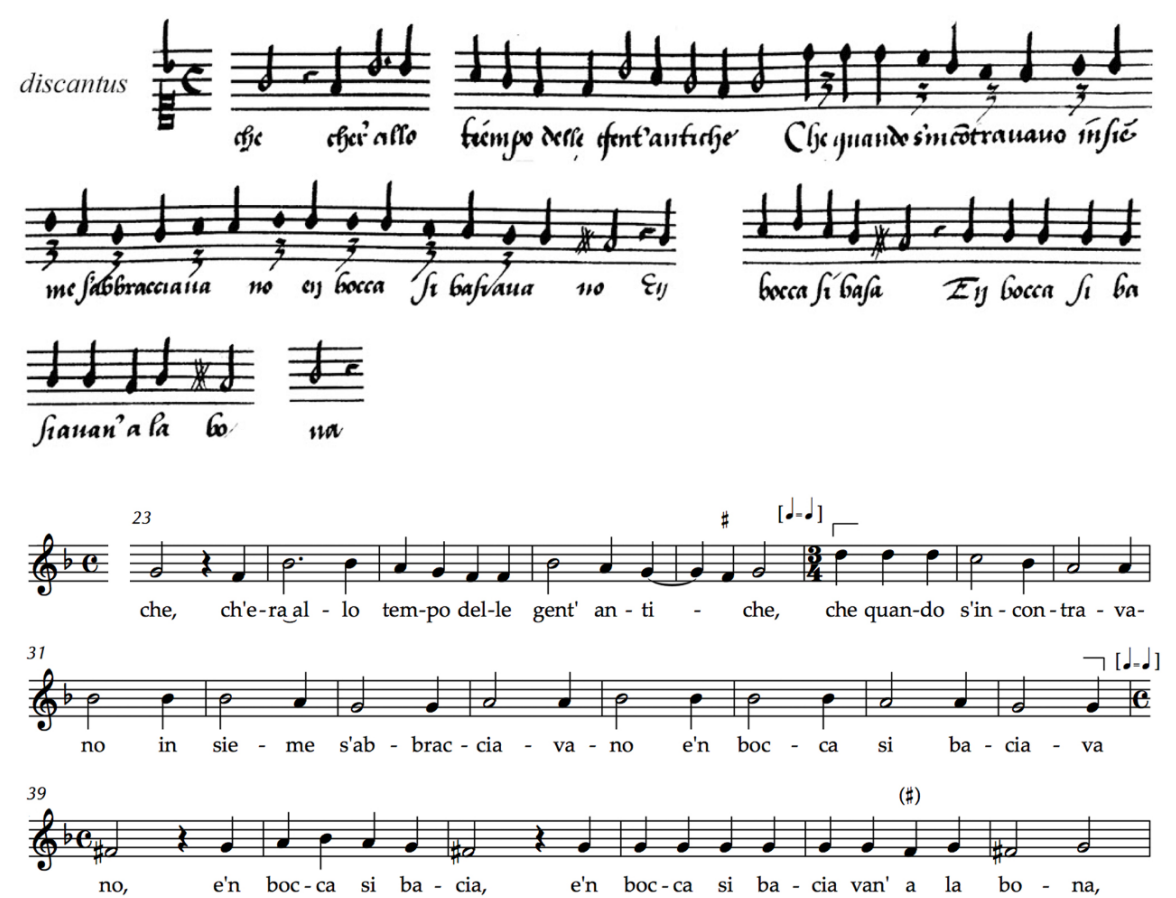

Figura 63. Transcrição de alterações métricas na peça O Dio, che fosse quella costumanza, de

Hubert Waelrant (Winchester Partbooks, n. 10), realizada pelo presente autor.

minims in relation to $C$; in this case, the black minim of the proportion is equated with a semiminim of white notation, to which it is identical in appearance. This interpretation was apparently most common in villanellas, which were often not measured in regular semibreve units at all (the lengths of sections or whole pieces could be an odd number of minims, and cadences could fall on any minim)." 
(d) Conza lavezzi siam (Winchester Partbooks, n. 43)

As considerações realizadas a respeito da peça anterior ( $O$ Dio, che fosse quella costumanza) podem ser aplicadas a esta mascherata do mesmo autor, que possui estrutura igualmente homorrítmica e seção ternária também organizada em grupos equivalentes a três minimae coloridas, o que se pode observar na reprodução do trecho do discantus (fig. 64). As interpretações tripla e sesquialtera do trecho ternário continuam sendo admissíveis como possibilidades teóricas, porém resultam novamente em andamentos que podem ser julgados como demasiadamente movidos ou lentos. A similaridade estrutural entre ambas as peças nos levou a sugerir, portanto, a mesma alternativa discutida no caso anterior, em que a minima colorida é interpretada como sendo equivalente à semiminima anterior à proporção (fig. 65).

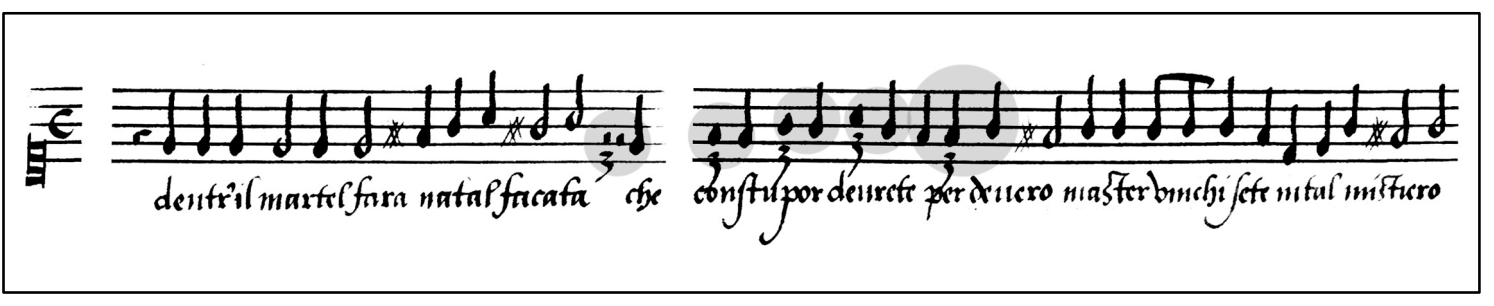

Figura 64. Alterações métricas no discantus da peça Conza lavezzi siam, de Hubert Waelrant (Winchester Partbooks, n. 43).

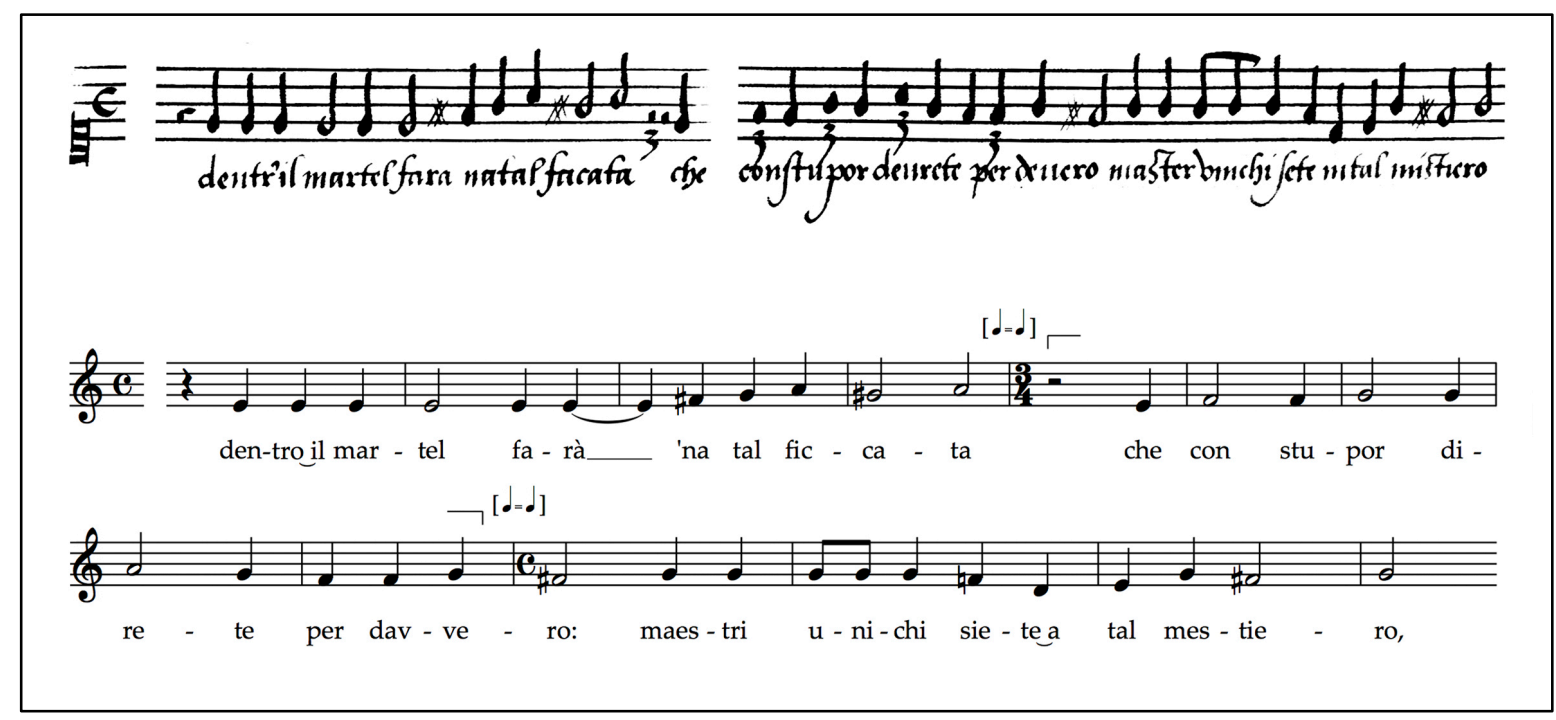

Figura 65. Transcrição de alterações métricas na peça Conza lavezzi siam, de Hubert Waelrant (Winchester Partbooks, n. 43), realizada pelo presente autor. 
(e) L'amanza mia si chiama saporita (Winchester Partbooks, n. 16)

Assim como as três peças anteriores ( $\mathrm{n} \underline{\text { os }}$ 18, 10 e 43), esta villanella do compositor flamengo Adrian Tubal inicia-se sob o sinal C em todas as vozes. Sua escrita é predominantemente homorrítmica e a breve seção ternária é apresentada através de agrupamentos equivalentes a três minimae sem o uso de coloração (fig. 66). As possibilidades de execução deste trecho novamente incluem a manutenção do tactus inicial através das interpretações tripla ( $c \downarrow=3 \downarrow d \downarrow)$ ou sesquialtera $(c \downarrow d=3 \downarrow d \downarrow)$ da proporção, ou ainda - como sugerido nos casos anteriores - o estabelecimento de uma equivalência entre o menor valor relevante antes do sinal $\mathbf{3}$ (a semiminima) e a menor figura ocorrente no trecho ternário (a minima). Assim como nos casos anteriormente discutidos, esta última opção resulta em uma proporção dupla ( $C \downarrow=3 \downarrow \downarrow$ ) que exige a alteração do tactus e representa uma solução de andamento intermediário, havendo sido adotada na presente edição (fig. 67).
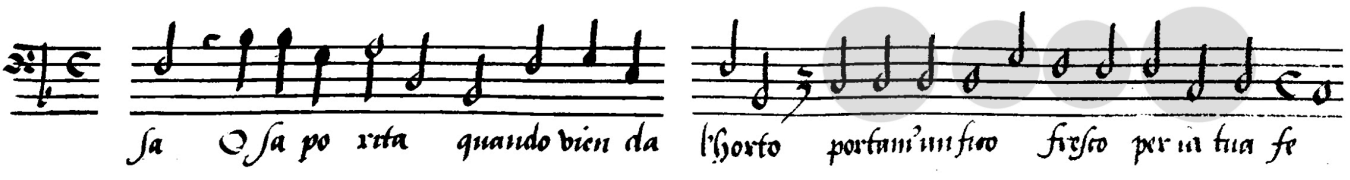

Figura 66. Alterações métricas no discantus da peça L'amanza mia si chiama saporita, de Adrian Tubal (Winchester Partbooks, n. 16).

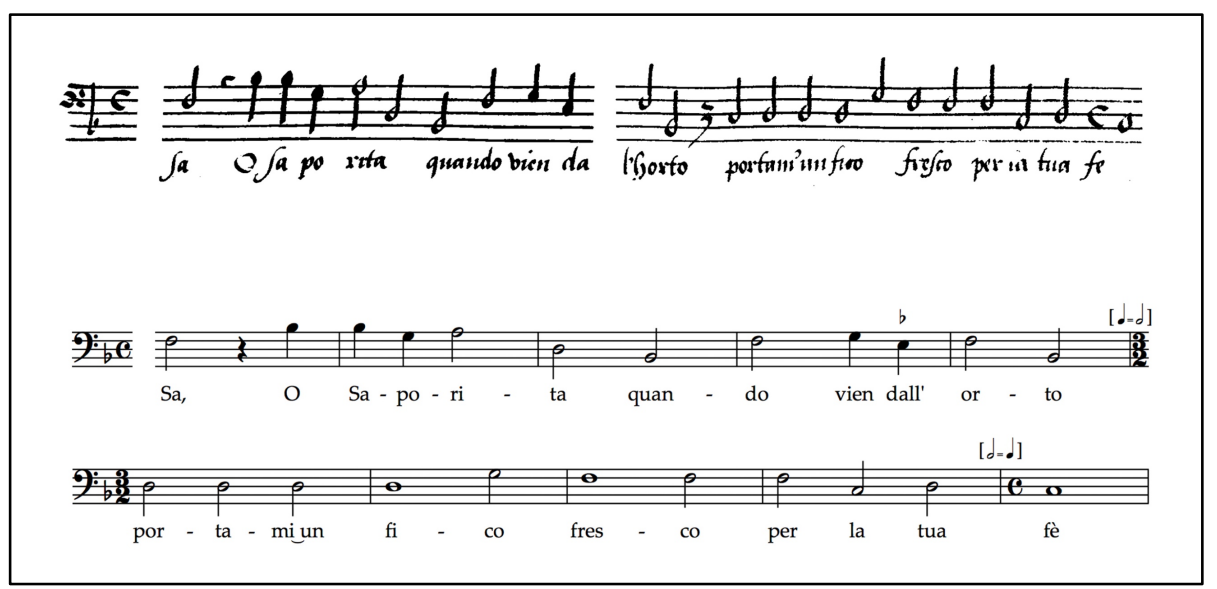

Figura 67. Transcrição de alterações métricas na peça L'amanza mia si chiama saporita, de Adrian Tubal (Winchester Partbooks, n. 16), realizada pelo presente autor. 
(e) Non t'arricordi (Winchester Partbooks, n. 45)

Esta villanella de Hubert Waelrant, cuja textura também é predominantemente homorrítmica, exibe uma seção ternária notada através de grupos equivalentes a três minimae não coloridas, conforme se pode observar na reprodução do trecho do altus (fig. 68). Diferentemente das peças anteriores notadas sob o sinal de mensuração C, onde o menor valor temporal relevante antes das proporções identificava-se com a semiminima, esta composição foi notada sob $\downarrow$ e a colocação do texto no trecho anterior à proporção move-se principalmente através de minimae. A interpretação sugerida nos casos anteriormente considerados - em que as semiminimae iniciais foram igualadas às minimae dos grupos ternários - não possui, portanto, sentido musical na presente situação; a alternativa $\downarrow \downarrow=3 \downarrow$, por sua vez, implicaria em uma seção ternária cujo andamento não parece estar em acordo com suas figurações rítmicas $(\downarrow \downarrow \downarrow)$ ) e tampouco com o texto "abbraciami, giocami, stringimi, baciami" ("abraça-me, brinca comigo, apertame, beija-me") por ser excessivamente lento. A sugestão proposta na presente edição baseia-se, portanto, na manutenção do tactus inicial através da interpretação sesquialtera do sinal 3 (fig. 69).

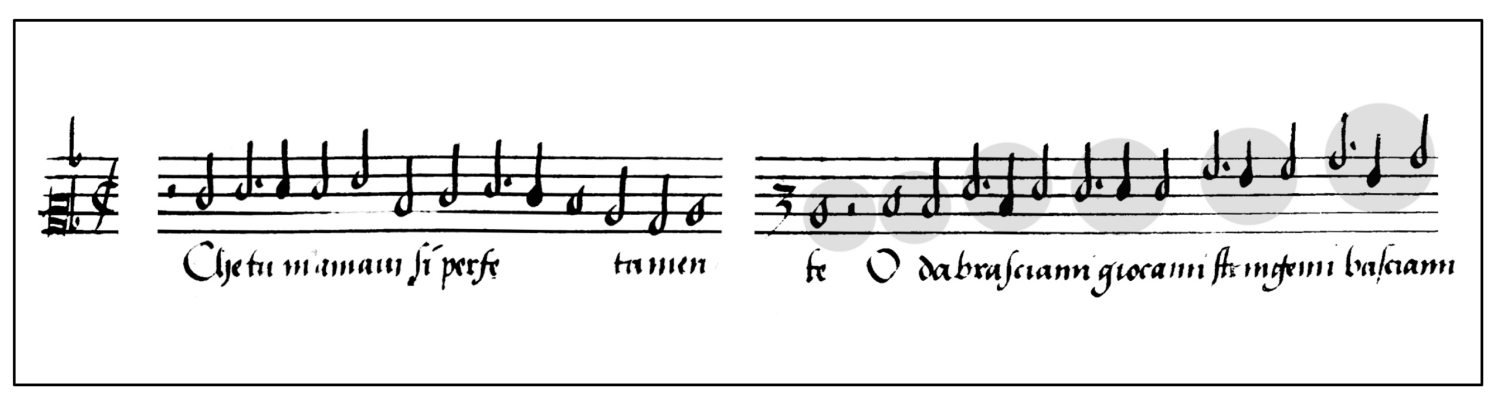

Figura 68. Alterações métricas no altus da peça Non t'arricordi, de Hubert Waelrant (Winchester Partbooks, n. 45). 


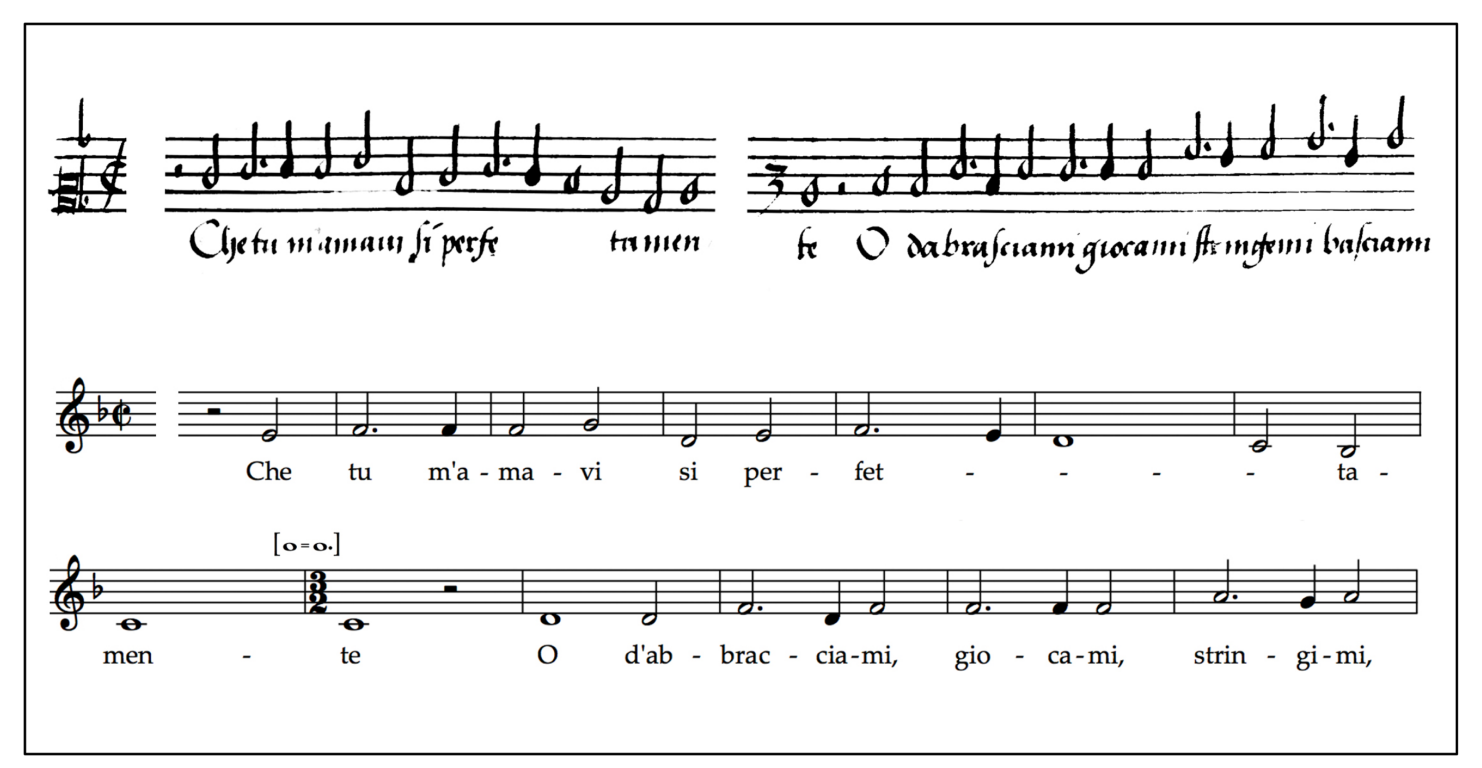

Figura 69. Transcrição de alterações métricas na peça Non t'arricordi, de Hubert Waelrant (Winchester Partbooks, n. 45), realizada pelo presente autor.

\subsection{TRATAMENTO DAS ALTURAS, ACIDENTES E MUSICA FICTA}

Nas edições modernas da música vocal do Renascimento é frequente o emprego da expressão musica ficta como uma referência a alterações cromáticas não notadas explicitamente nas fontes primárias e que hoje podem ser sugeridas editorialmente por uma variedade de razões. Esta acepção, entretanto, não está necessariamente em acordo com aquela pressuposta durante a Idade Média e o Renascimento, segundo a qual as expressões sinônimas musica ficta e musica falsa eram aplicadas pelos teóricos às alturas que estivessem fora da scala musicalis (escala musical, também chamada de gamut), que correspondia, por sua vez, ao âmbito da musica vera (música verdadeira) ou recta (correta). A presente seção compreende uma breve exposição da teoria relacionada a estas inflexões, assim como exemplos de suas aplicações ao repertório tratado nesta pesquisa. 


\subsubsection{Gamut guidoniano e sistema hexacordal}

A organização do gamut, atribuída ao monge Guido d'Arezzo (902-1050), foi representada em um grande número de escritos medievais e renascentistas e neste texto está ilustrada através da figura 70, extraída do tratado Opusculum Musices (1509), de Simon de Quercu (ca.1464-ca.1529). Na figura de Quercu podemos observar à esquerda da escala a classificação das alturas nos registros grave, agudo e superagudo. $\mathrm{Na}$ primeira coluna elas estão representadas em ordem ascendente através de caracteres denominados claves, iniciando-se com a letra grega $\Gamma$ (gama) e seguindo a

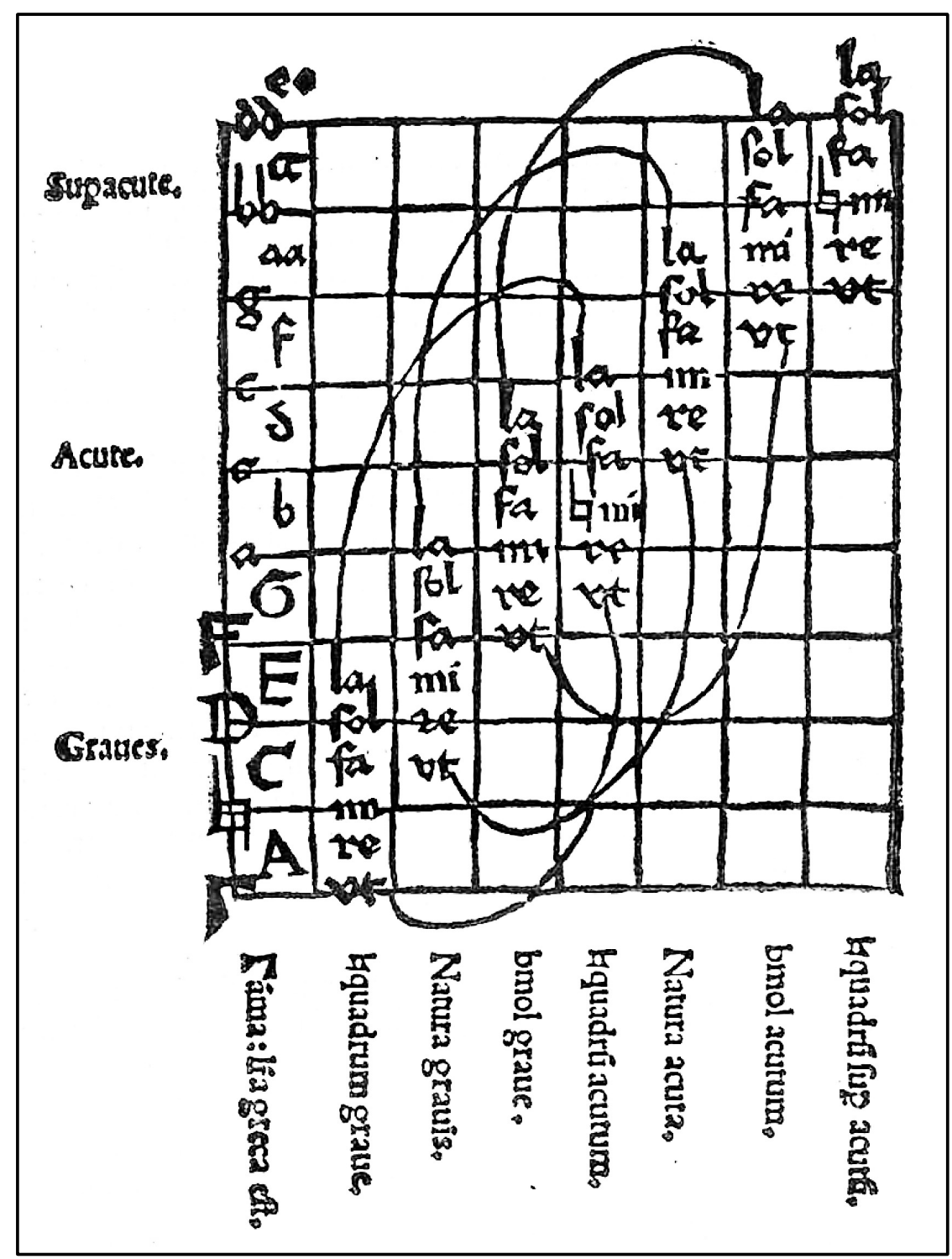

Figura 70. Scala musicalis ou gamut (QUERCU, 1509, f. 3r). 
ordem A - B - C - D - E - F - G com tipos maiúsculos; a próxima oitava (registro agudo) é indicada através de caracteres minúsculos (a, b, c, d, e, f, g) e na porção superior (registro superagudo) normalmente se utilizavam caracteres minúsculos duplicados (aa, bb, cc, dd, ee). As colunas à direita desta contêm indicações das sílabas (voces musicales) com que cada altura poderia ser solmizada a depender do contexto musical do trecho em questão. A estrutura destes conjuntos de seis alturas $(u t, r e, m i$, $f a$, sol, la), denominados hexacordes, é definida de forma que os intervalos melódicos entoados entre uma sílaba e a seguinte sejam de um tom, exceto aquele entre $m i$ e $f a$, que deve ser de um semitom. Os hexacordes iniciam-se nas alturas cujas claves são $\Gamma$, C e F (e em suas oitavas) e são classificados em três diferentes tipos: naturalis, durum e molle. Os hexacordes duros são aqueles iniciados em $\Gamma, \mathrm{G}$ e g, pois contêm o $B$ durum ou quadrum (ou ainda quadratum), de onde deriva a forma moderna $₫$ (solmizado como mi); os hexacordes moles iniciam-se em $\mathrm{F}$ e f e contêm o $B$ molle ou rotundum, que originou a forma $b$ (solmizado como $f a$ ); os hexacordes naturais, por se iniciarem em $C$ e c, não contêm quaisquer das formas de B, b ou bb. Abaixo da escala pode-se observar esta classificação apontada por Quercu em cada um dos registros: quadrum grave, natura gravis, $b$ mol grave, quadrum acutum, natura acuta, $b$ mol acutum e quadrum superacutum. Os teóricos se referiam às alturas por seus nomes completos da maneira com que seriam lidos horizontalmente na escala musical - isto é, iniciados por uma clave e seguidos das possíveis voces para sua solmização - de modo que a altura correspondente à quinta linha de baixo para cima, por exemplo, era chamada de a la mi re (fig. 71). A altura mais grave da escala usual, $\Gamma u t$ - solmizada, em princípio, apenas com a sílaba $u t$ - empresta o nome a todo o sistema (gamma-ut ou gamut).

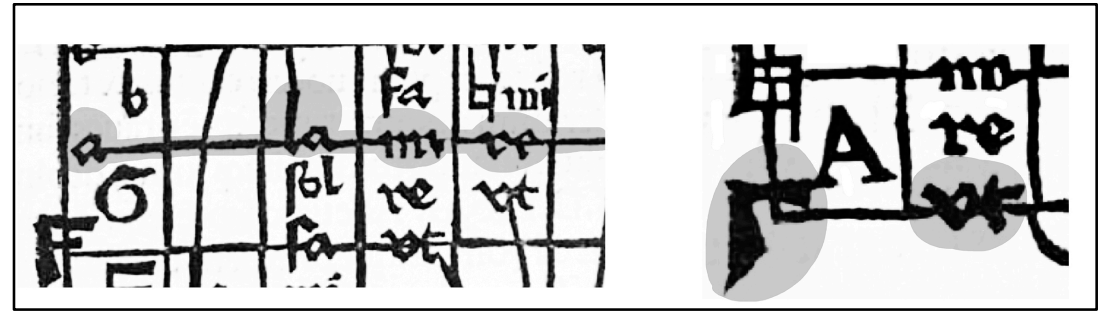

Figura 71. Detalhes do gamut destacando as alturas a la mi re e Gamma ut (QUERCU, 1509, f. 3r). 
A musica vera contida na escala, segundo a tradição pedagógica medieval, poderia também ser representada através do dispositivo didático denominado mão guidoniana, utilizado ao menos desde o século XI no ensino de música para principiantes. O conjunto das vinte alturas que compunham o gamut pode ser mapeado na estrutura de uma mão humana e esta foi ilustrada em diversos tratados musicais da Idade Média, do Renascimento e até mesmo do século XVII - época em que o uso de cromatismos e a emergência do sistema tonal certamente já demandavam alterações suficientes para que o recurso fosse ultrapassado. Na figura 72 apresentamos uma colagem com ilustrações da mão em tratados de Ramis de Pareia (1482), Vicente Lusitano (1558), Ludovico Zacconi (1596), Adriano Banchieri (1614) e Lorenzo Penna (1672), além daquele de Simon de Quercu (1509), de onde havíamos extraído também a figura discutida no parágrafo anterior.

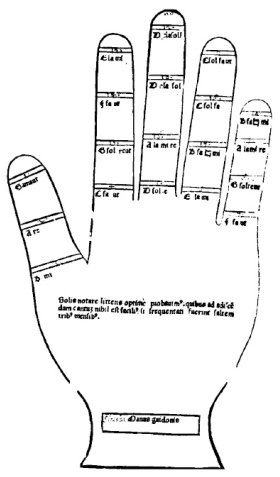

Ramis de Pareia (1482)

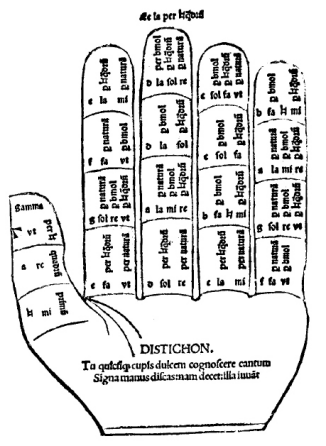

Simon de Quercu (1509)

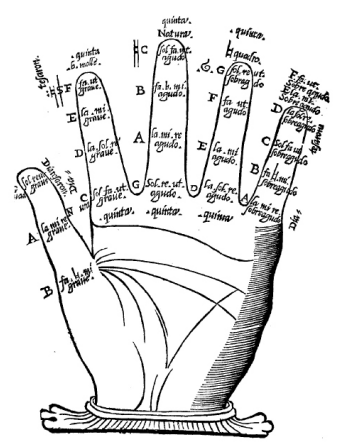

Vicente Lusitano (1558)

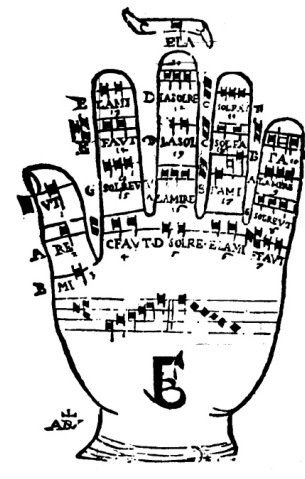

Ludovico Zacconi (1596)

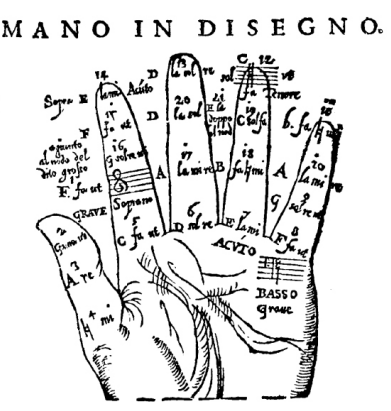

Adriano Banchieri (1614)

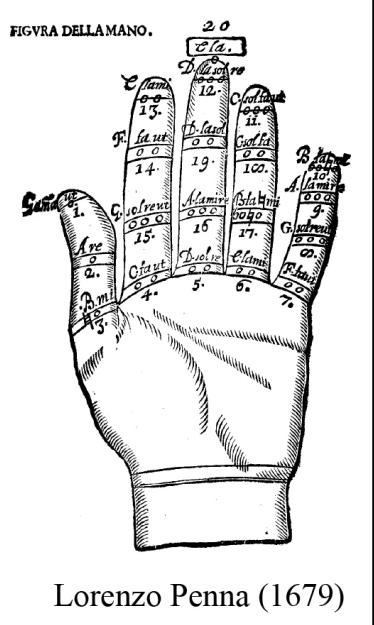

Figura 72. Ilustrações da mão guidoniana em tratados dos séculos XV a XVII (RAMIS DE PAREIA, 1482, f. 2v; QUERCU, 1509, f. 2r; LUSITANO, 1558, f. 2v; ZACCONI, 1596, f. 15v; BANCHIERI, 1614, p. 3; PENNA, 1679, p. 5). 
A correspondência entre as vinte alturas da escala e as articulações dos dedos da mão segue uma distribuição em forma espiral, conforme ilustra a figura 73 (ampliação da mão representada no tratado de Penna acrescida de nossa indicação de direção e sentido): a sequência ascendente iniciada em $\Gamma$ ut e continuada com A re, B mi, C fa ut, D sol re, etc. está distribuída a partir da extremidade do polegar e segue pelas articulações dos outros dedos em um sentido espiral anti-horário, terminando na terceira articulação do dedo médio (n. 19). Além de numerar os passos do gamut, Penna indica uma, duas ou três semibreves para cada altura, relembrando a seu leitor o número de sílabas com que esta pode ser solmizada. A última altura da escala (n. 20) era representada acima da mão por falta de uma vigésima posição.

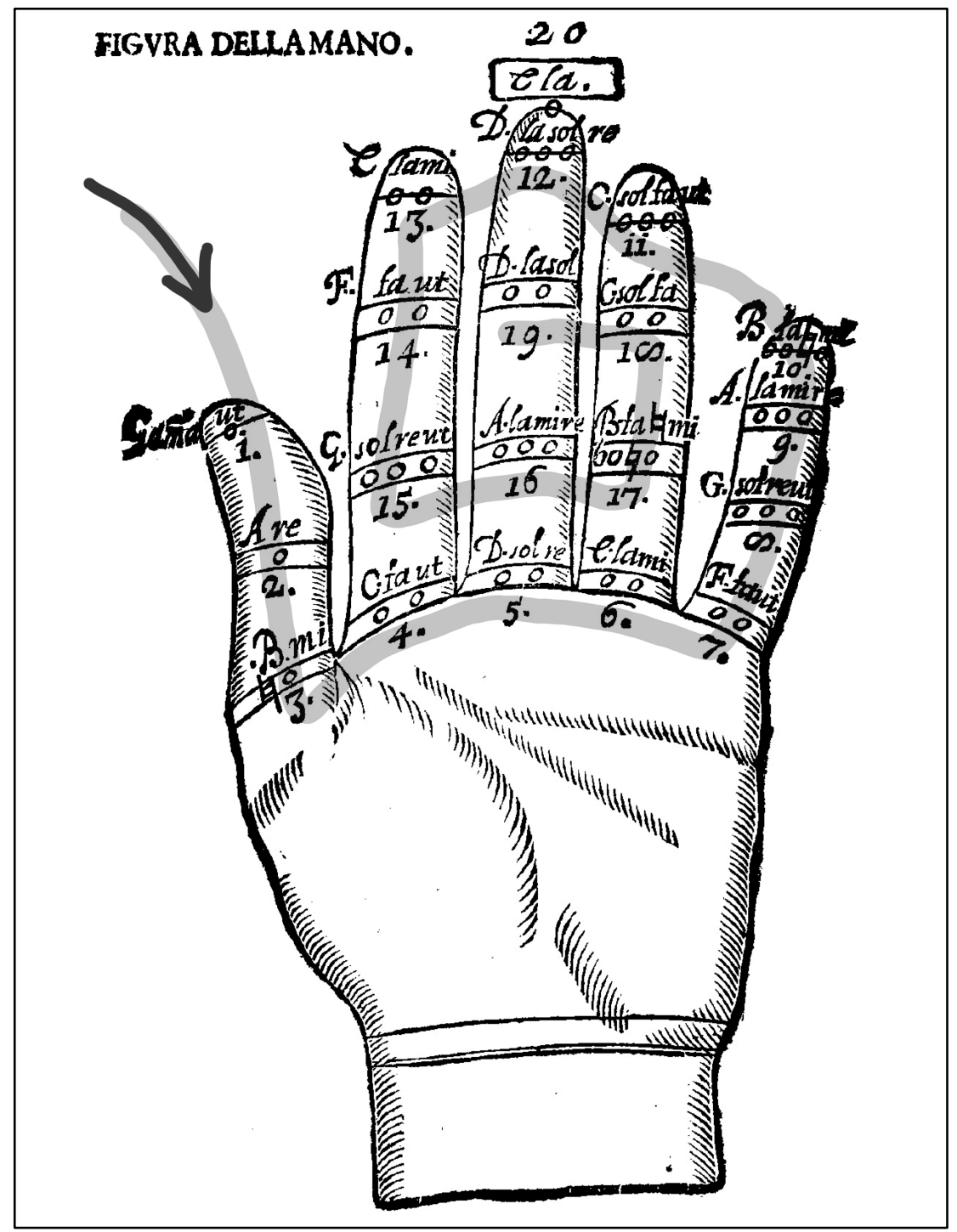

Figura 73. Sequência das alturas representadas na mão guidoniana (PENNA, 1679, p. 5). 
Os limites usuais do gamut, embora tenham sido questionados no âmbito teórico e ultrapassados por inúmeros compositores ao longo do seicento, ainda eram reafirmados como parte da teoria às vésperas do século XVII. Thomas Morley, no tratado A Plain and Easy Introduction to Practical Music (1597), trata do tema de forma bastante clara em um diálogo entre o mestre e seu discípulo Philomathes:

MESTRE: Se você diz que não existe nada abaixo de $\Gamma$ ut você se engana, pois a música não se restringe a amarras determinadas (ainda que os músicos coloquem suas canções dentro de um certo limite). E assim como vocês filósofos dizem que não se pode dar um número tão grande que vocês não deem um maior, e nenhum ponto tão pequeno que vocês deem um menor, assim também não pode existir uma nota tão aguda que vocês não deem uma mais aguda, e nenhuma tão grave que vocês não deem uma mais grave; e portanto tenha em mente aquilo que eu lhe disse a respeito das notas e suas oitavas, pois se você o considerar matematicamente, continua sendo verdade fora da abrangência da escala assim como dentro dela, e assim se pode continuar infinitamente.

PHILOMATHES: Por que então sua escala era feita de vinte notas e não mais?

MESTRE: Porque esse limite era o alcance da maioria das vozes, de forma que abaixo de $\Gamma$ ut a voz parecia um tipo de sussurro, e acima de ee la um tipo de chiado espremido.

(MORLEY, 1597, f. 6-7, tradução nossa) $)^{30}$

\footnotetext{
${ }^{30}$ No original: "Ma. Where as you saie, there is nothing beneath Gam ut, you deceive your selfe : For Musicke is included in no certaine bounds, (though the Musicions do include their songs within a certaine compasse.) And as you Philosophers say, that no number can be given so great, but that you may give a greater. And no poynt so small, but that you may give a smaller. So there can be no note given so high, but you may give a higher. and none so lowe, but that you may give a lower. And therefore call to minde that which I tolde you concerning the keyes and there eightes: for if Mathematically you consider it, it is true as well without the compasse of the Scale, as within : and so may be continued infinitely. / Phi. Why then was your Scale devised of xx. notes and no more? / Ma. Because that compasse was the reach of most voyces : so that under Gam ut the voice seemed as a kinde of humming, and above E la a kinde of constrained skricking."
} 
A visão do mestre neste diálogo também foi discutida por Karol Berger no volume Musica Ficta: Theories of Accidental Inflections in Vocal Polyphony from Marchetto da Padova to Gioseffo Zarlino, onde o autor cita diversos teóricos que consideraram a reprodução dos hexacordes em outras oitavas - entre eles Bartolomeo Ramis de Pareia (ca.14401522), Domingo Marcos Durán (ca.1465-1529) e até mesmo Philippe de Vitry (12911361), ainda no século XIV. Em particular, Adam von Fulda (1445-1505), Georg Rhau (1488-1548) e Angelo da Picitono (ca.1502-1567) atribuíram o fato de os compositores ultrapassarem os limites do gamut à influência de Guillaume Dufay (ca.1397-1474) (BERGER, 1987, p. 13), uma das figuras centrais da Escola de Borgonha no século XV. O teórico italiano Stefano Vanneo (1493-?), também citado por Berger, chegou a considerar em seu tratado Recanetum de musica aurea (1533) as articulações das costas da mão para incluí-las em um gamut mais amplo (fig. 74) e a classificação de alturas externas aos limites habituais como pertencentes ao campo da musica vera ou da musica ficta gerou importantes disputas entre tratadistas ao longo do século XVI.

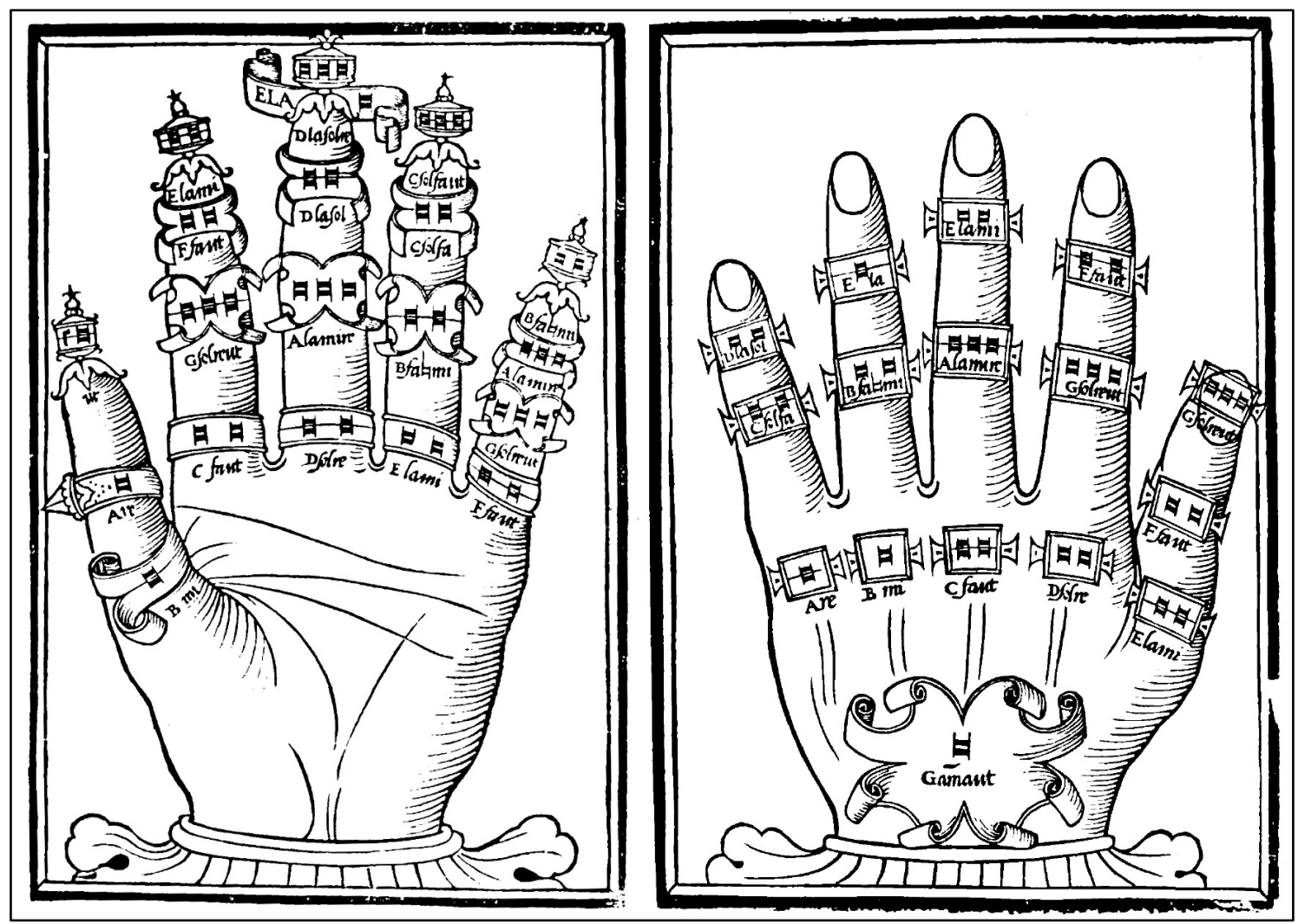

Figura 74. Ampliação do gamut usando-se as costas da mão (VANNEO, 1533, f. 9v,10v). 
Estas considerações sobre a extensão do gamut, embora interessantes do ponto de vista teórico, exercem pouca influência sobre o tratamento dado a ficta nas edições modernas do repertório renascentista, pois normalmente não geram dúvidas nas transcrições para a notação atual e tampouco acarretam em outros problemas editoriais. Algumas alturas pertencentes ao âmbito da musica vera, por outro lado, podem estar relacionadas a ambiguidades importantes enfrentadas hoje por um editor: um exemplo ilustrativo é a opção que este eventualmente precise fazer entre Si3 e Si, 3 (ou Si4 e Si 4 , na oitava superior ${ }^{31}$ ) ao transcrever uma figura originalmente notada sem um sinal de alteração; embora este tipo de problema seja comumente discutido em edições como ficta, consideramos interessante notar que, neste caso, ambas fazem parte do gamut - sendo, portanto, musica vera - e por esta razão sua discussão estaria mais rigorosamente associada à aplicação das regras do contraponto modal do que propriamente à musica ficta no sentido que esta possuía durante a Idade Média e o Renascimento. Na figura 75 destacamos na mão guidoniana as duas alturas em questão (n. 10 e n. 17), as únicas cujas diferentes solmizações correspondem a sons distintos (indicados por bo e Ło), o que é necessário para que seja mantida a estrutura correta dos hexacordes.

O gamut guidoniano poderia ainda ser apresentado em sua forma transposta, que exibe um bemol junto à clave e por esta razão é também chamada de cantus mollis (o sistema não transposto é denominado, por oposição, cantus durus). De maneira análoga ao que ocorre no sistema tonal, onde a adição de um bemol à armadura de clave transpõe a tônica uma quinta abaixo, o gamut transposto também exige que as posições dos hexacordes naturais, duros e moles sejam alteradas para que se mantenham suas estruturas internas - isto é, para que os semitons continuem localizados entre mi e $f a$ em qualquer um deles. No sistema transposto, portanto, Mib passa a fazer parte do sistema de musica recta, enquanto Si 1 , por exemplo, torna-se ficta (fig. 76).

\footnotetext{
${ }^{31}$ Adotamos neste texto o sistema em que o dó central corresponde a Dó4.
} 


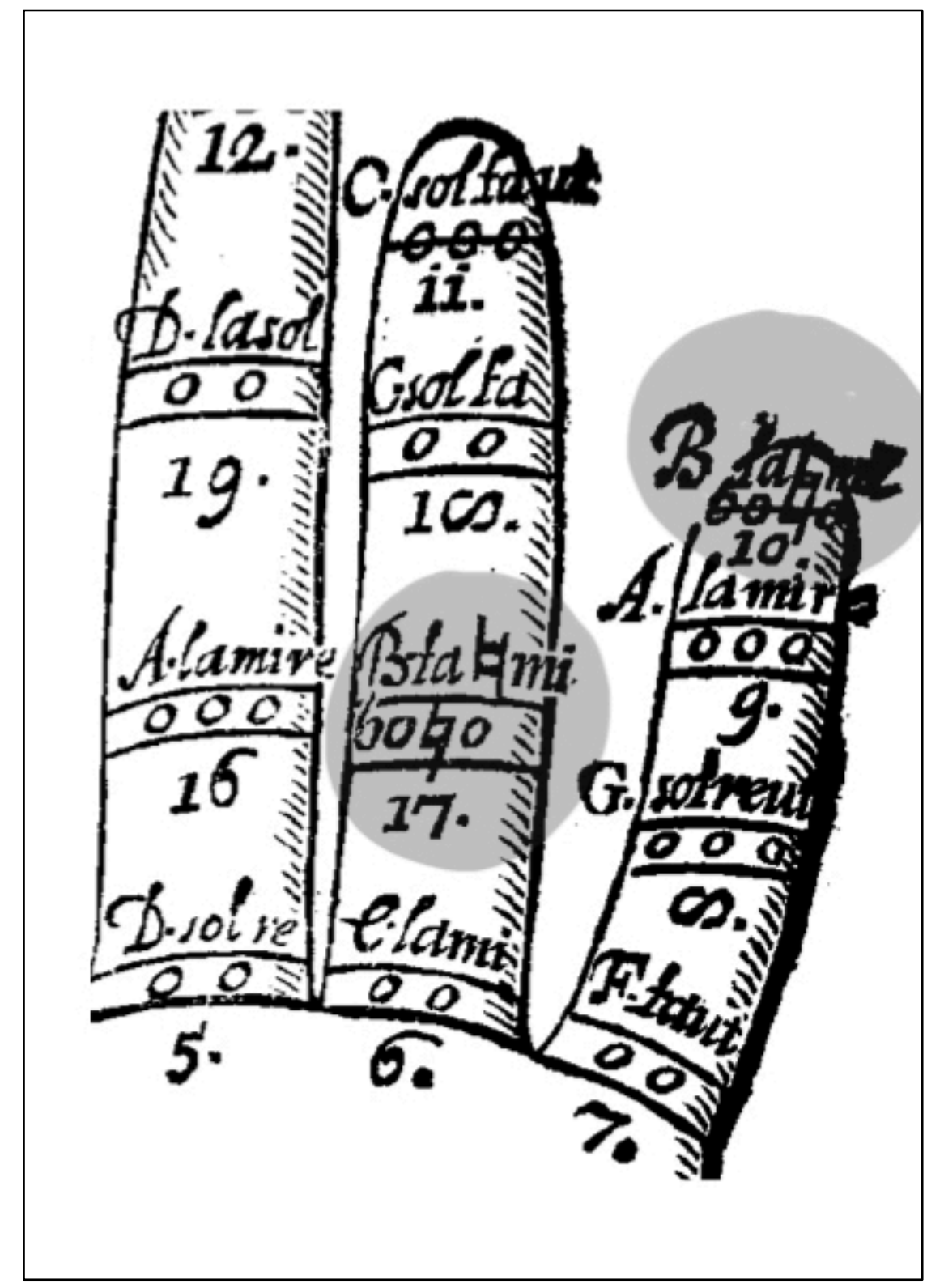

Figura 75. Detalhe da mão ilustrada por Penna indicando $₫$ quadrum e b molle (PENNA, 1679, f. 5).

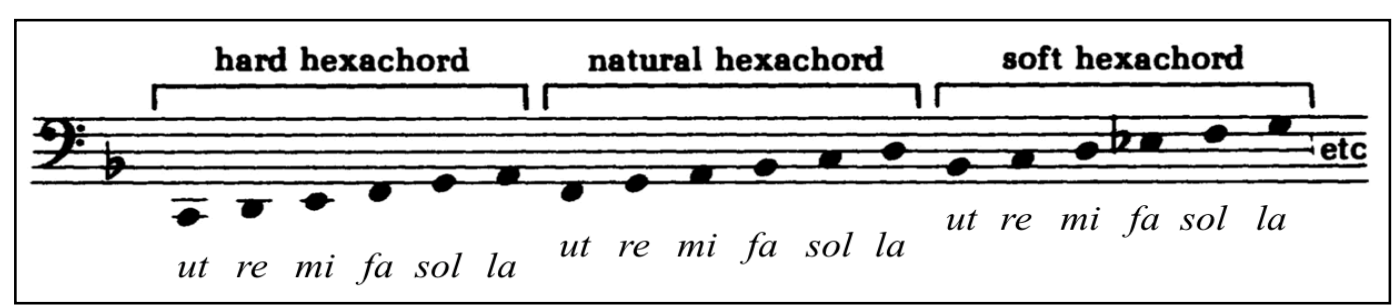

Figura 76. Posições dos hexacordes duros (hard), naturais (natural) e moles (soft) no gamut transposto (cantus mollis) (ROUTLEY, 1985, p. 62), com solmização acrescentada pelo presente autor. 
A solmização de melodias que ultrapassassem o âmbito das seis notas de um hexacorde exigia que se realizassem mutações, isto é, novas alturas deveriam ser solmizadas de acordo com novos hexacordes aos quais os trechos seguintes se adaptassem melhor, ainda que apenas temporariamente, e este processo deveria ser repetido quantas vezes fossem necessárias ao longo da solmização de uma peça. As mutações deveriam ocorrer em algum ponto comum aos dois hexacordes em questão e os teóricos recomendavam que elas se realizassem na sílaba re (do novo hexacorde) quando o movimento fosse ascendente e na sílaba la (do novo hexacorde) quando o movimento fosse descendente. Na figura 77, uma colagem de ilustrações retiradas do Compendium Musicae (1591), de Adam Gumpelzhaimer, estão indicados os pontos de mutação à esquerda para movimento ascendente $(r e)$ e à direita para descendente $(l a)$ em cantus durus e em cantus mollis. As figuras 78 e 79, extraídas do artigo Tonal Organization in Seventeenth Music Theory, de Gregory Barnett, contêm estas mesmas informações, porém exibem explicitamente a solmização, os pontos de mutação (através de figuras preenchidas de preto) e os hexacordes naturais (natural), duros (hard) e moles (soft) para os quais as mutações foram realizadas em cada caso.

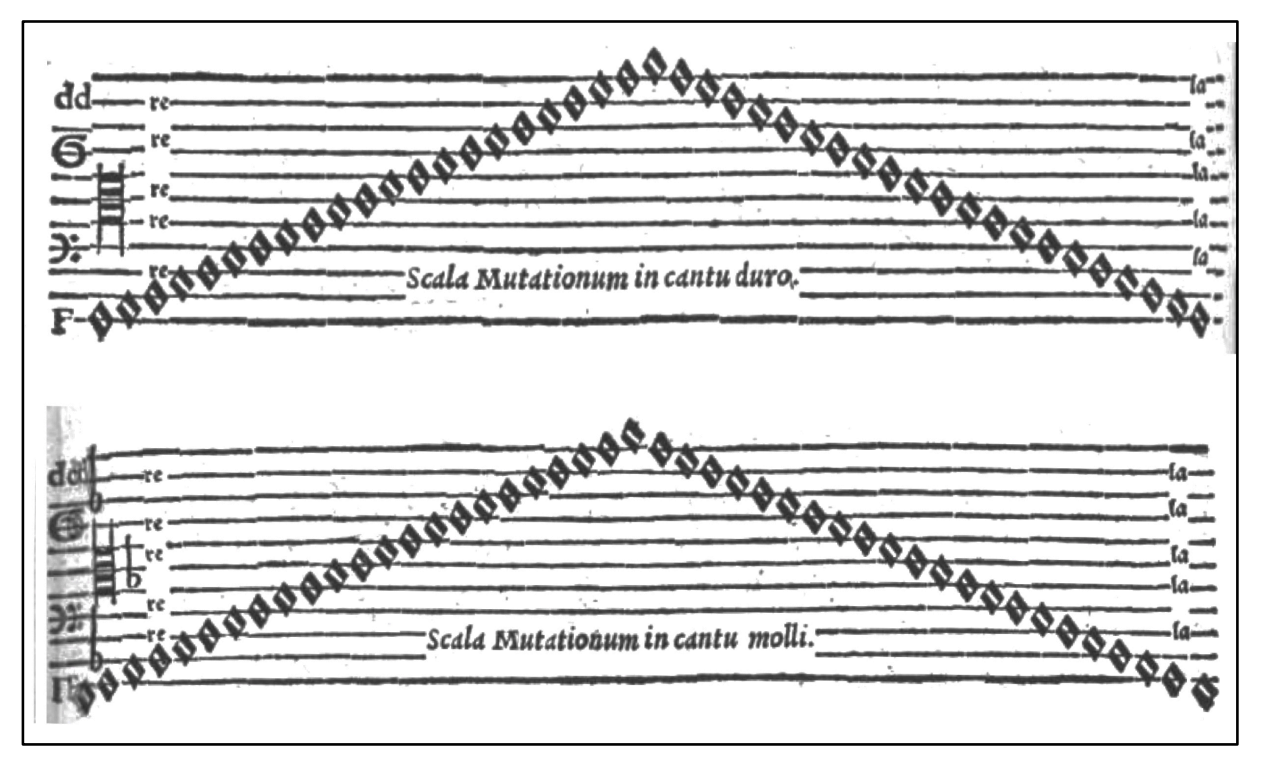

Figura 77. Pontos de mutação para solmização hexacordal em movimento ascendente e descendente em cantus durus e em cantus mollis (GUMPELZHAIMER, 1591, $f$. Cr, Cijr). 


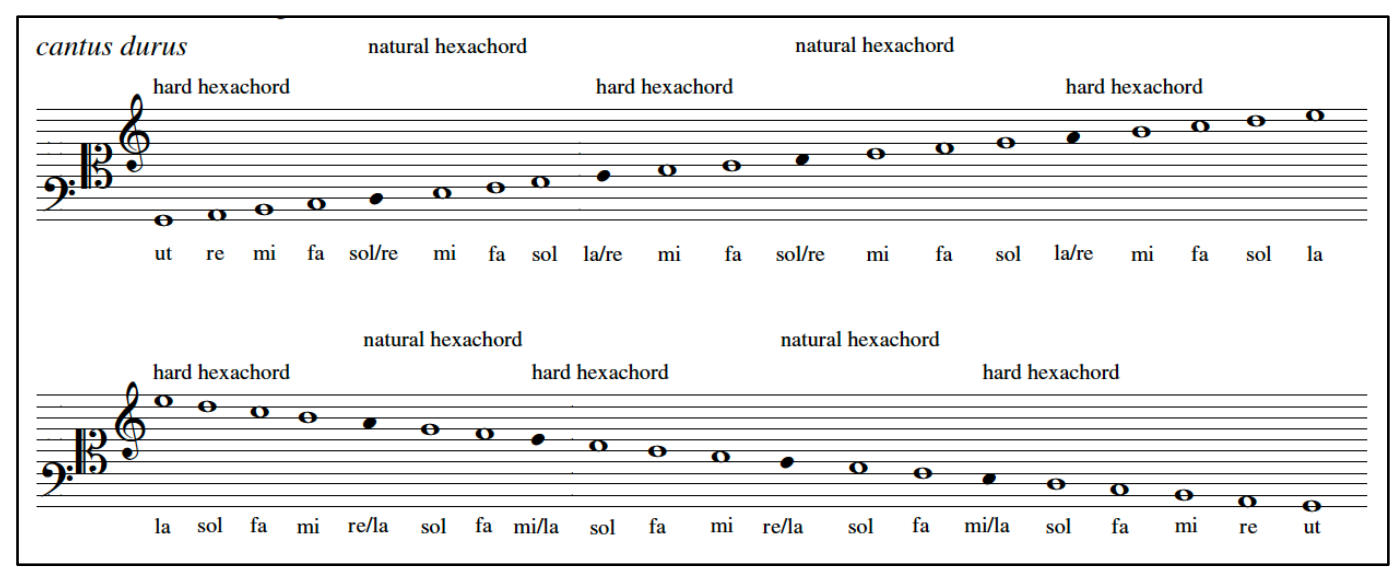

Figura 78. Solmização hexacordal e pontos de mutação para movimento ascendente e descendente em cantus durus (BARNETT, 2002, p. 410).

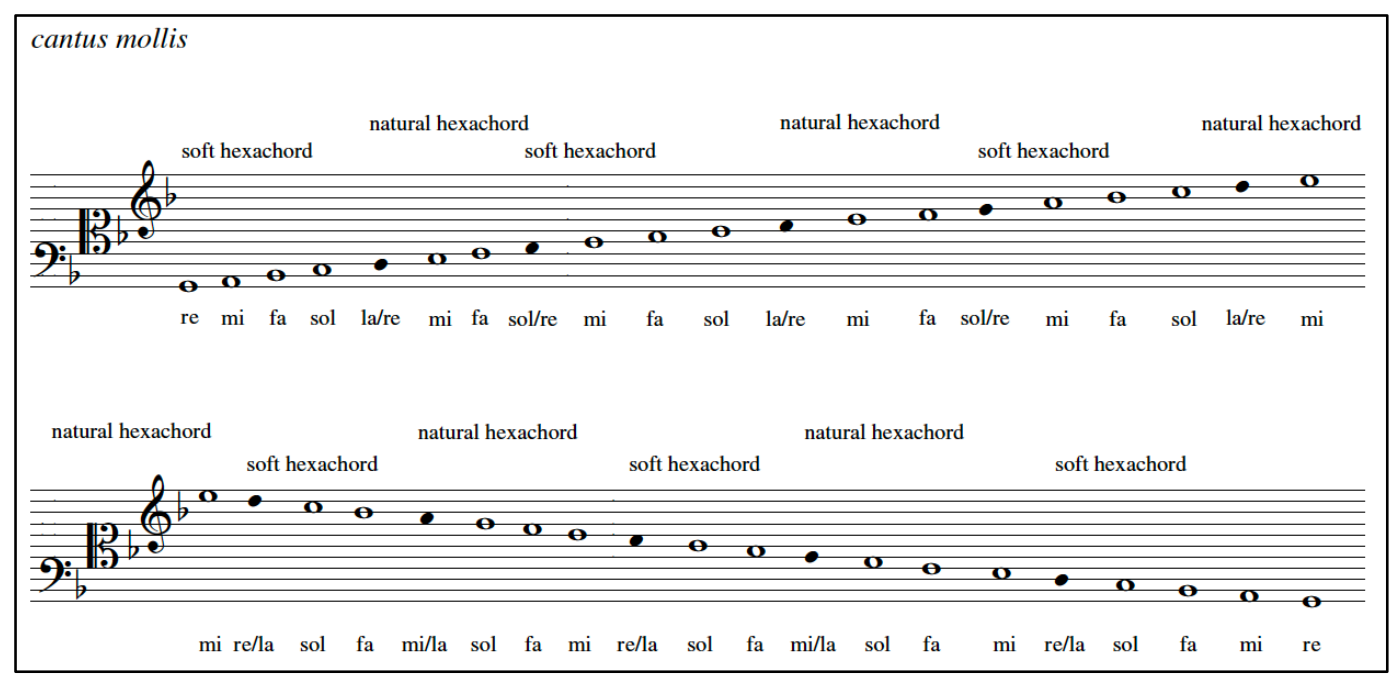

Figura 79. Solmização hexacordal e pontos de mutação para movimento ascendente e descendente em cantus mollis (BARNETT, 2002, p. 410).

Em termos de um teclado moderno, pode-se considerar que as vinte alturas contidas no gamut sejam mapeadas em suas teclas brancas Sol2 a Mi5 ( $\Gamma$ ut a ee $l a)$, adicionando-se eventualmente duas teclas pretas correspondentes a Si, 3 e $\mathrm{Si}, 4$ (b fa e

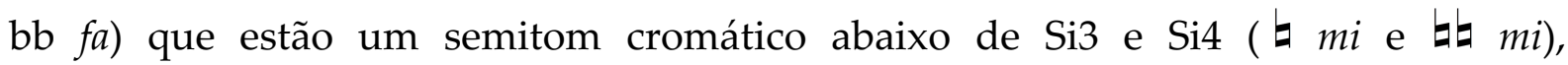
respectivamente. Conforme destacamos anteriormente, todas fazem parte da escala e são, portanto, musica vera; a decisão quanto à solmização de b $f a a^{\prime} m i$ (ou de bb $f a$ a $m i$, na oitava superior) como $f a$ ou $m i$ - e consequentemente quanto à altura a ser entoada nesses casos - deveria ser feita realizando-se as mutações corretas e seguindose regras que impedissem a formação de intervalos melódicos (ou harmônicos, ao se 
considerarem composições polifônicas) aumentados ou diminutos. Tais convenções poderiam exigir, por sua vez, que outras alturas além destas precisassem ser alteradas para se assegurar que outros intervalos se mantivessem perfeitos ao longo de uma composição, eventualmente tendo como consequência o aparecimento de novos sons que realmente não fazem parte do gamut e que não poderiam, portanto, ser solmizados de acordo com a mão guidoniana; estes são alguns dos casos tratados pelos teóricos medievais e renascentistas propriamente como musica ficta.

Aparentemente o mais antigo registro onde se encontra uma justificativa para o emprego de ficta remonta ao século XIII, no Tractatus de discantu (Anônimo 2), onde consta que

a música falsa foi inventada por duas razões, a saber, pela necessidade e pela beleza de uma canção em si. Pela necessidade, pois [de outra forma] não poderíamos ter uma quinta, uma quarta, uma oitava [...]. Pela beleza, como se vê nas canções coroadas ${ }^{32}$ (ANÔNIMO 2, 1874, p. 312, tradução nossa ${ }^{33}$ ).

Estas duas diferentes motivações para as inflexões cromáticas são denominadas causa necessitatis (por causa da necessidade) e causa pulchritudinis (por causa da beleza), termos latinos utilizados correntemente a partir de então. Os teóricos não atribuíam diferenças de importância entre as duas categorias - contrariamente ao que se poderia supor a partir da observação feita no tratado mencionado - e apenas relacionavam causa necessitatis a consonâncias perfeitas (quintas, oitavas e quartas ${ }^{34}$ ) e causa pulchritudinis a consonâncias imperfeitas (terças e sextas), como veremos a seguir.

32 As "canções coroadas", segundo Herlinger, são as canções dos trouvères. (BELDOMANDI, HERLINGER, 1984, p. 81)

${ }^{33}$ No original: "Fuit autem inventa falsa musica propter duas causas, scilicet causa necessitatis, et causa pulchritudinis cantus per se. Causa necessitatis, quia non poteramus habere diapente, diatessaron, diapason [...]; Causa pulchritudinis, ut patet in cantilenis coronatis."

34 No período em questão a classificação do intervalo harmônico de quarta quanto à sua consonância dependia do contexto: ainda que fosse considerado uma dissonância per se no contraponto a duas vozes, poderia se tornar uma consonância quando outros intervalos (quinta ou terça) fossem acrescentados abaixo deste, apoiando-o. (BERGER, 1987, p. 93) 


\subsubsection{Convenções para a aplicação de inflexões ficta}

Nos próximos parágrafos faremos uma exposição das convenções relacionadas ao uso das inflexões de maneira mais específica, tanto sob o ponto de vista teórico como através de exemplos de sua aplicação ao corpus tratado na presente pesquisa. A enunciação dos principais preceitos segue a organização concisa adotada por Nicholas Routley no artigo A Practical Guide to 'musica ficta' (ROUTLEY, 1985), que por sua vez é apoiada na forma com que diversos tratadistas abordaram o tema durante a Idade Média e o Renascimento; referências específicas a respeito de sua aplicação a casos práticos foram extraídas principalmente do texto clássico de Robert Donington, The Interpretation of Early Music (DONINGTON, 1963), acrescidas de estudos musicológicos mais recentes e de nossas próprias observações ao tratar cada exemplo. As convenções para o emprego de ficta foram organizadas por Routley (1985, p. 63-67) através de cinco princípios, dos quais dois estão relacionados a necessitatis e três a pulchritudinis, conforme a discussão que realizaremos nas próximas subseções.

\subsubsection{Mi contrafa}

A primeira convenção relaciona-se à necessidade e é comumente abreviada como mi contra fa; através dela recomenda-se que não se solmizem as sílabas mi e fa simultaneamente em consonâncias perfeitas, o que equivale a dizer que os intervalos harmônicos de quinta, oitava e quarta devem ser mantidos perfeitos (isto é, não aumentados ou diminutos), ao menos nas situações em que coincidem com o tactus e são tratados, portanto, como pontos importantes ao longo de uma composição. Notas de passagem e suspensões, por outro lado, podem justificar o não cumprimento desta regra e, em particular, um trítono ocasionado por uma bordadura imediatamente anterior à conclusão de uma cadência poderia ser até mesmo exigido por causa pulchritudinis em algumas situações. Durante o processo de transcrição do repertório 
examinado neste trabalho encontramos um número significativo de casos em que a ocorrência de mi contra fa teve de ser evitada através da inserção editorial de acidentes em notação moderna. Um exemplo pode ser observado no compasso 6 da peça Tri ciechi siamo, de Hubert Waelrant (ex. 4), onde se encontra a possível ocorrência de uma oitava diminuta entre o bassus e o altus, uma vez que o sinal b está anotado nos manuscritos apenas para este último. Neste caso, contudo, a nota do bassus provavelmente já seria entendida como abaixada devido ao intervalo melódico que mantém com a altura anterior, pois a convenção mi contra fa também opera melodicamente (o cantor evitaria a quarta aumentada entre Sib e Mi inequívoca a solução editorial de acrescentar o acidente em notação moderna.

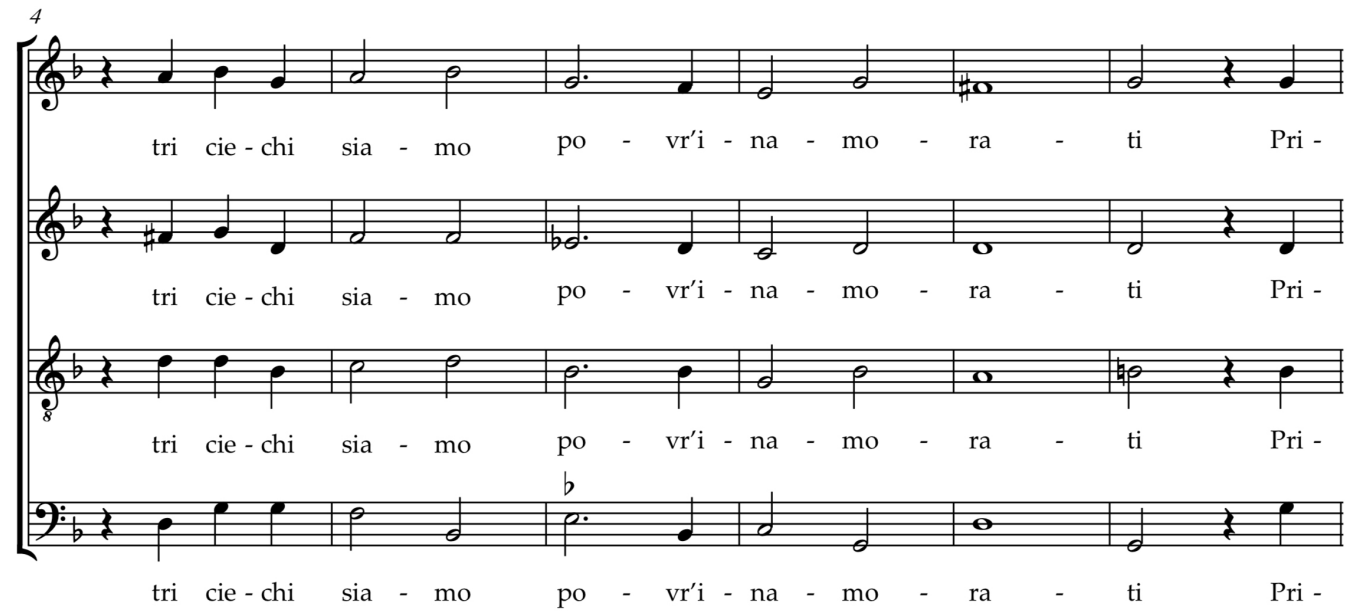

Exemplo 4. Compassos 4-9 da peça Tri ciechi siamo, de Hubert Waelrant

(Winchester Partbooks, n. 18).

A mesma sequência harmônica é observada no primeiro compasso do exemplo 5, extraído da peça peça I dolci sguardi tuoi, alta signora, também de Waelrant; embora o bassus possa novamente evitar a quarta aumentada melódica, o altus não foi advertido como no exemplo anterior e haveria, em princípio, o risco de ocorrência de mi contra fa entre as duas partes (e também entre ambas e o tenor). A solução editorial moderna para ambos os casos é, naturalmente, bastante simples uma vez que se hajam observado as quatro vozes em partitura: no exemplo 4, a adição de um bemol ao bassus 
é justificada não apenas por seu próprio intervalo melódico, mas também pela consonância perfeita que a altura deve formar com o tenor e com o altus; no exemplo 5, o bassus recebe um bemol pela razão melódica e isto tem como consequência a necessidade de adição de um bemol também ao altus para evitar a oitava diminuta, ainda que esta advertência não constasse em sua parte original.

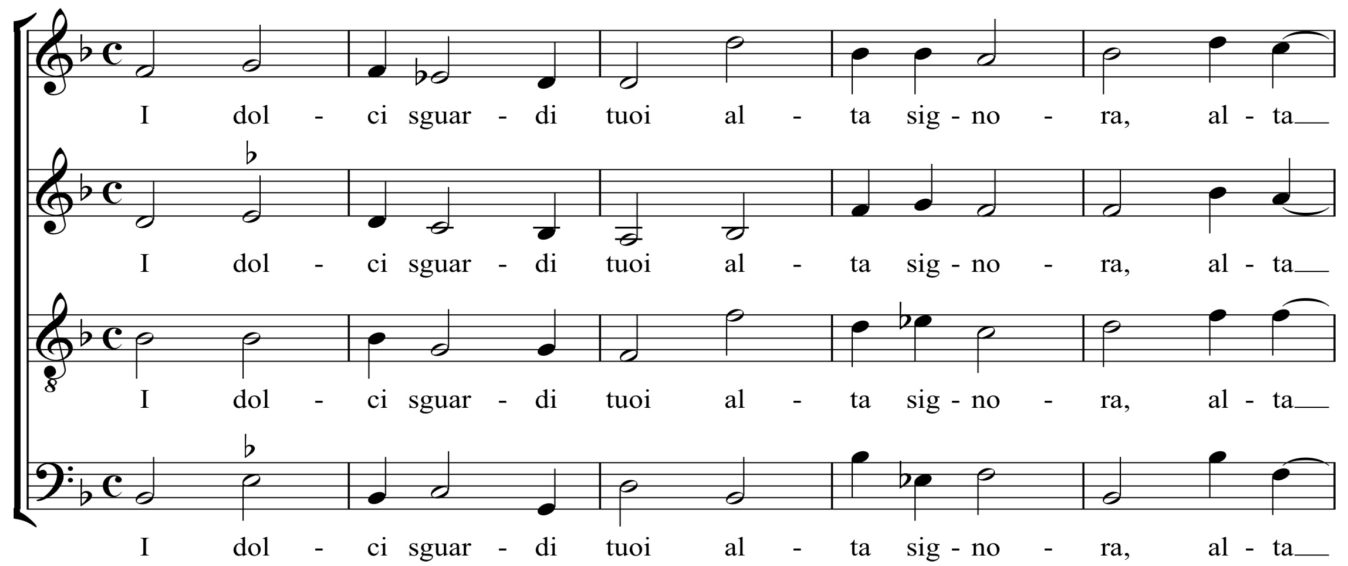

Exemplo 5. Compassos 1-5 da peça I dolci sguardi tuoi, alta signora, de Hubert Waelrant (Winchester Partbooks, n. 36).

\subsubsection{Fa super la}

A próxima convenção relacionada a causa necessitatis é denominada fa super la, ou, em sua forma completa, una nota super la semper est canendum fa (uma nota acima de la sempre é cantada $f a$ ). Nas situações em que uma melodia ascendente ultrapasse o extremo superior de um hexacorde (solmizado como la) e atinja apenas a altura imediatamente seguinte para retornar em seguida ao âmbito inicial, a nota externa ao hexacorde deve estar um semitom (e não um tom) acima da anterior, sendo simplesmente solmizada como fa sem que seja necessário realizar uma mutação (fig. 80). Nos casos dos hexacordes naturais e dos hexacordes duros, as alturas em questão fazem parte do gamut e são, portanto, musica recta; o semitom imediatamente seguinte ao hexacorde mole (modernamente $\mathrm{Mi} b$ ), por outro lado, não encontra sua posição na escala de Guido e exige uma inflexão ficta. No gamut transposto (cantus mollis) a 
convenção se opera de maneira análoga, de modo que neste caso Mib faz parte do sistema recta e altura ficta necessária para satisfazê-la passa a ser Ab (fig. 81).

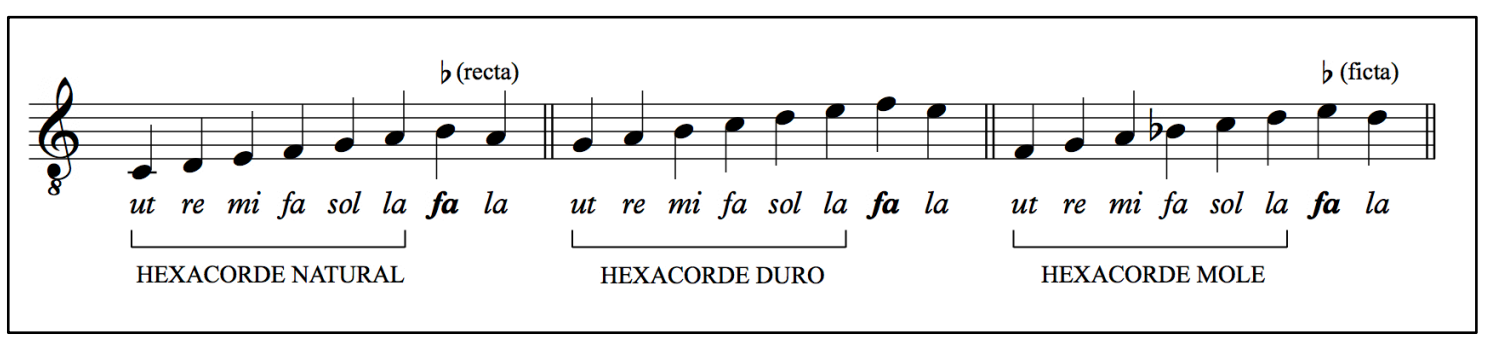

Figura 80. Alturas solmizadas com a sílaba $f a$ acima dos hexacordes, garantindo intervalos de um semitom com as notas adjacentes.

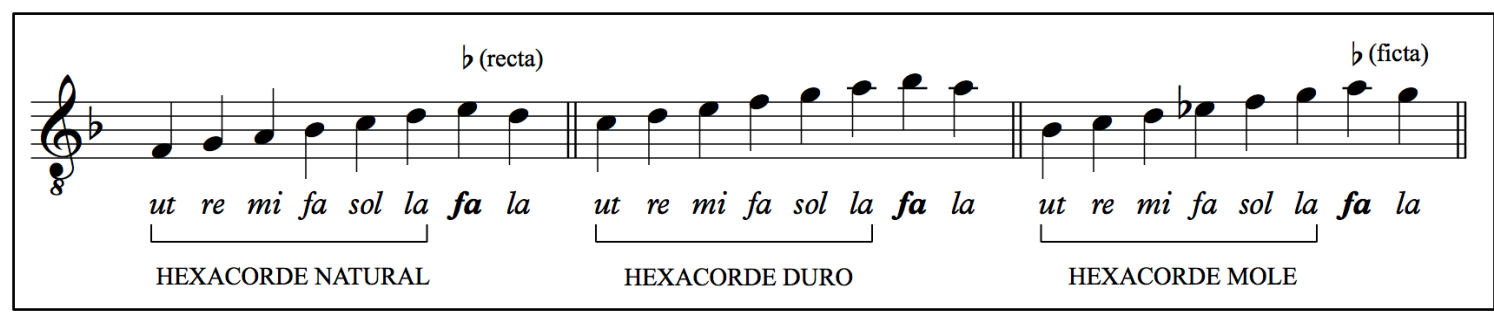

Figura 81. Alturas solmizadas com a sílaba $f a$ acima dos hexacordes, garantindo intervalos de um semitom com as notas adjacentes (sistema transposto).

O objetivo desta prática era evitar trítonos melódicos entre as alturas em questão e o fa de cada hexacorde, e por esta razão a convenção pode ser considerada uma simples extensão da regra mi contra fa; Karol Berger é veemente ao afirmar que “isto não é uma regra separada, mas simplesmente uma das maneiras através das quais a proibição do trítono foi formulada" (BERGER, 1987, p. 77, tradução nossa ${ }^{35}$ ) e condena sua aplicação indiscriminada a situações em que este intervalo não está envolvido, apoiando-se em críticas similares dos tratadistas Georg Rhau, Martin Agricola, Angelo da Picitono e Pietro Aron:

Se nós vamos querer aplicar a regra independentemente da proibição do trítono quando editamos ou executamos a música do século XVI dependerá de querermos seguir a opinião musical mais esclarecida do período ou de imitarmos aquilo que parece ter sido uma prática não sofisticada mas bastante comum. Uma verificação dos acidentes nas

${ }^{35}$ No original: "this is not a separate rule, but merely one of the ways in which the prohibition of the tritone was formulated." 
fontes pode nos ajudar a decidir o que é apropriado para um dado repertório. (BERGER, 1987, p. 79, tradução nossa ${ }^{36}$ )

Com efeito, o exame dos manuscritos de Winchester nos permitiu observar situações onde possíveis ambiguidades a esse respeito já foram solucionadas nas fontes originais. Na figura 82, que contém a parte original do altus e nossa transcrição dos compassos 16-21 da peça Madonna mia, per te son quasi morto, de Hubert Waelrant, o escriba indicou com o sinal $\#$ a semibrevis transcrita no compasso 18 , provavelmente para evitar que esta fosse abaixada em razão de uma aplicação indevida de fa super la.

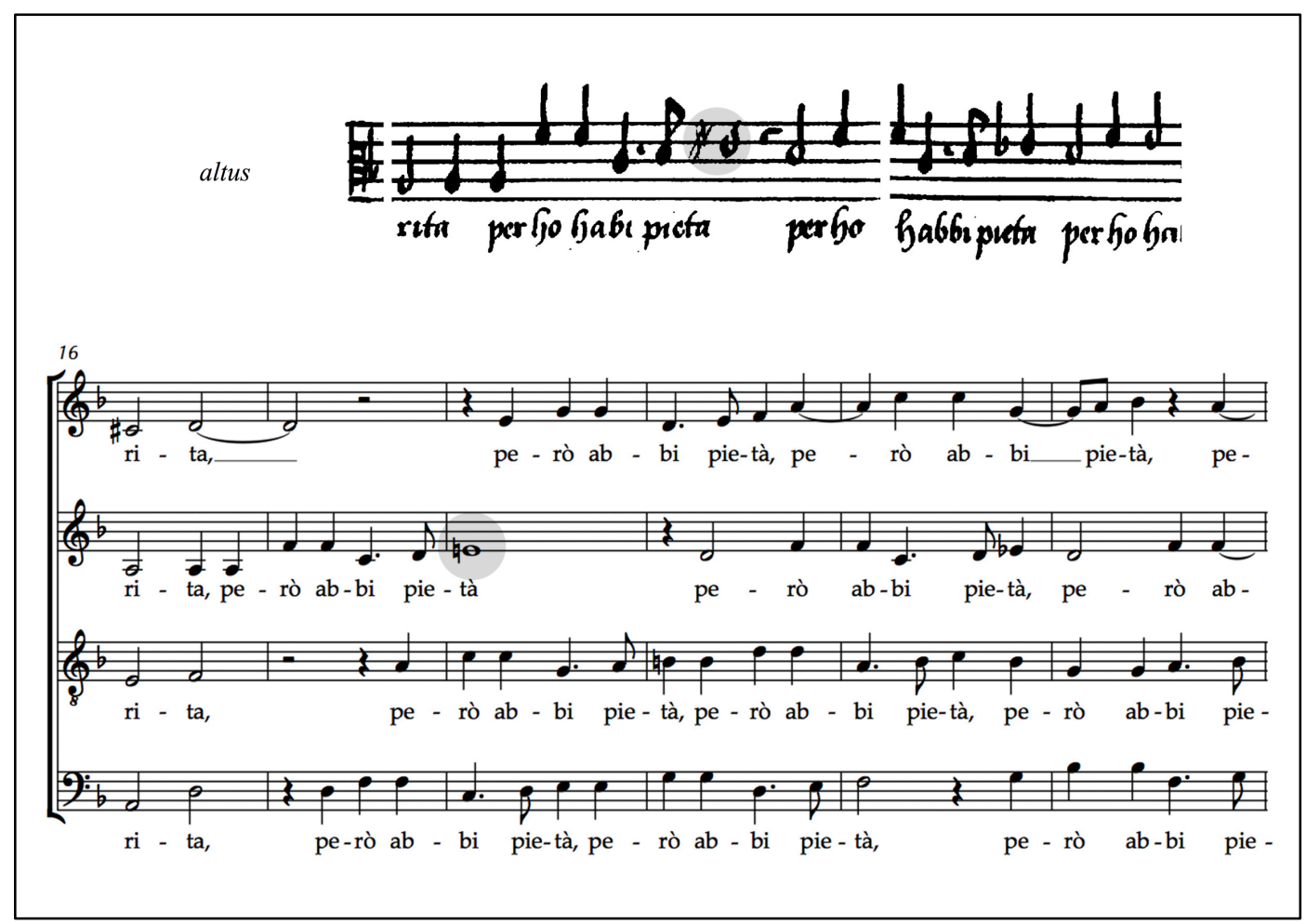

Figura 82. Parte original do altus e compassos 15-19 da transcrição da peça Madonna mia per te son quasi morto, de Hubert Waelrant (Winchester Partbooks, n. 51).

$\mathrm{Na}$ edição das peças abordadas neste trabalho as advertências originais foram conservadas e seguimos o mesmo procedimento editorial adotado pelo musicólogo

\footnotetext{
${ }^{36}$ No original: "Whether we will want to apply the rule independently of the tritone prohibition when editing or performing sixteenth-century music will depend on whether we will want to follow the most enlightened musical opinion of the period or rather imitate what seems to have been an unsophisticated but fairly common practice. An examination of source accidentals may help us to decide what is appropriate for a given repertoire."
} 
John Steele em sua publicação da íntegra dos madrigais a quatro vozes de Luca Marenzio:

Acidentes [relativos a] una nota super la são mantidos. Apesar de não serem estritamente exigidos pelo uso moderno, cantores familiarizados com a música antiga podem ser tentados a aplicar bemóis a notas que deveriam ser deixadas como estão" (STEELE, 1995, p. 187, tradução nossa ${ }^{37}$ ).

\subsubsection{Cadentia}

A terceira convenção apontada por Routley é devida a pulchritudinis por estar relacionada a consonâncias imperfeitas; através dela os teóricos recomendam que uma consonância perfeita deva ser alcançada partindo-se da consonância imperfeita mais próxima, o que requer que uma das vozes execute um movimento melódico de um semitom. A figura 83, extraída do texto do autor, ilustra alguns exemplos com as soluções possíveis nos casos das progressões de: (a) terça para uníssono; (b) sexta para oitava; e (c) terça para quinta. Caso uma das soluções seja parte do sistema recta (como a primeira resolução do exemplo (a) da figura, uma vez que $B$ b faz parte do gamut), os

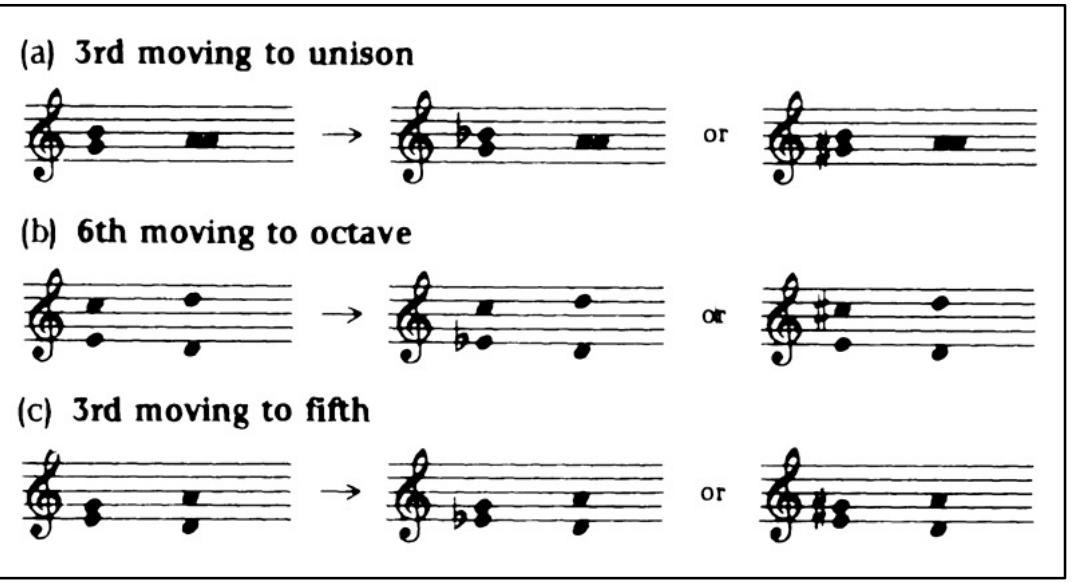

Figura 83. Possíveis inflexões ficta em consonâncias imperfeitas em progressões para consonâncias perfeitas (ROUTLEY, 1985, p. 66).

\footnotetext{
${ }^{37}$ No original: “Una nota supra La accidentals are retained. Even though they are not strictly required by modern usage, singers conversant with early music might be tempted to apply flats to notes that should be left alone."
} 
teóricos recomendam que se dê preferência a esta e não a uma solução ficta, desde que isto não ocasione nenhum outro conflito melódico ou harmônico com outras partes.

Devido à sua ocorrência especialmente frequente em momentos conclusivos de uma composição, esta convenção é comumente abreviada pelos musicólogos como cadentia, o que também faremos ao longo deste texto. Consideramos importante notar, contudo, que o termo latino usado neste contexto não carrega a conotação de término que adquiriu em períodos posteriores; Margaret Bent, após descrever algumas controvérsias anteriores a respeito do uso do vocábulo inglês cadence, opta pela adoção do termo latino como referência a tais progressões, apoiando-se em seu uso feito pelo teórico francês Jacobus de Liège:

\begin{abstract}
Apesar de uma conclusão normalmente requerer uma tal progressão, a progressão não precisa implicar em conclusão. Na época eu não pretendia, como continuo não pretendendo, que "cadência" conotasse nem a definição tonal moderna e nem necessariamente conclusão, mas, de maneira simples e neutra, a progressão de um intervalo imperfeito a um perfeito, seguindo a definição de Jacobus de Liège no século XIV [...] Cadência, portanto, é nada mais e nada menos do que a progressão em duas vozes de um intervalo imperfeito a um perfeito, articulada através de uma progressão de semitom embaixo ou em cima. Eu espero que esses problemas possam ser resolvidos pela palavra latina cadentia (BENT, 2002, p. 14, tradução nossa ${ }^{38}$ ).
\end{abstract}

Um exemplo da necessidade de introdução de um acidente editorial em notação moderna em razão deste tipo de progressão pode ser observado no compasso 7 da peça O Dio che fosse quella costumanza, de Hubert Waelrant (ex. 6). O intervalo harmônico de terça (composta) entre o altus e o bassus é resolvido em uma oitava na segunda semínima do compasso 8, e portanto um movimento melódico de semitom seria esperado em uma das duas partes - isto é, ou o altus executaria o movimento

\footnotetext{
${ }^{38}$ No original: "Although closure usually requires such a progression, the progression need not imply closure. I intended 'cadence' then, as I still do, to connote neither modern tonal definition nor necessarily closure, but, simply and neutrally, the progression of an imperfect to a perfect interval, following the fourteenth-century definition of Jacobus de Liège [...] Cadence, therefore, is no more and no less than the two-part progression of an imperfect to a perfect interval, articulated with a semitone progression above or below. I hope that these problems may be solved by the Latin word cadentia.
} 
descendente Mib - Ré ou o bassus faria o movimento ascendente Dó\#-Ré. Esta última solução, contudo, acarretaria em uma quinta diminuta (composta) com o discantus (além de exigir também a alteração da nota do tenor) e é, portanto, descartada. Neste caso, adicionalmente, ainda que tais choques harmônicos com a voz superior não ocorressem, a primeira solução continuaria sendo preferível devido ao fato de envolver a altura Mib (recta no gamut transposto) e não Dó\# (ficta). Com efeito, a validade de nossa adição editorial do bemol ao altus pôde ser confirmada em uma fortuita repetição posterior do trecho, onde a alteração está indicada explicitamente.

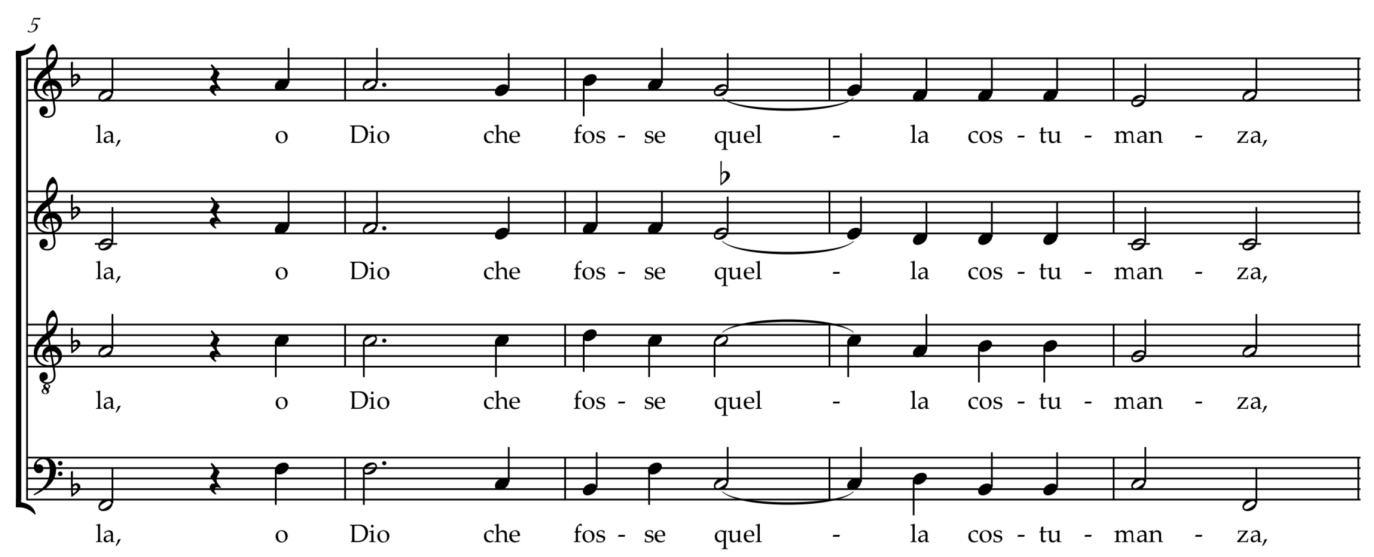

Exemplo 6. Compassos 5-9 da peça O Dio che fosse quella costumanza, de Hubert Waelrant (Winchester Partbooks, n. 10).

\subsubsection{Subsemitonum modi}

A quarta prescrição discutida por Routley é denominada subsemitonum modi (semitom abaixo do modo) e se refere à possível elevação cromática da nota imediatamente inferior à principal em uma bordadura ocorrente durante uma cadência final ou em outros pontos importantes de uma composição (no contexto da música tonal, isto seria equivalente à introdução de sensíveis). Os modos iniciados em Dó, Fá, e Sib (este último no gamut transposto) já contemplam, naturalmente, o semitom em questão; cadências em Ré, Lá e Sol, por outro lado, podem requerer a inflexão, assim como uma conclusão em Dó em cantus mollis (fig. 84). A ocorrência 
deste tipo de figuração melódica é extremamente frequente no repertório polifônico do século XVI, e um exemplo - selecionado entre inúmeros outros - extraído do corpus analisado na presente pesquisa pode ser observado no compasso 18 da peça L'amanza mia si chiama saporita, do compositor flamengo Adrian Tubal (ex. 7). Neste caso, a figuração executada pelo discantus é uma bordadura resolvida na altura para a qual esta voz se dirige (sendo portanto, sua nota principal) e a ela deve-se aplicar a prescrição, elevando-se de um semitom a nota imediatamente anterior à conclusão da cadência.

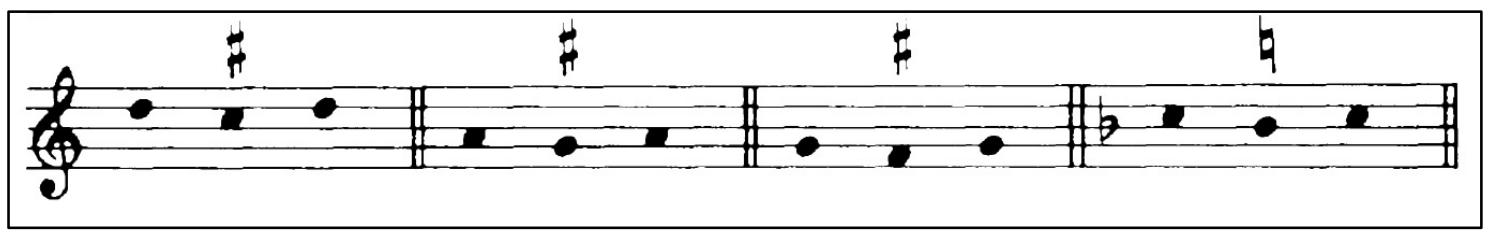

Figura 84. Inflexões ficta nas cláusulas subsemitonum modi (ROUTLEY, 1985, p. 67).

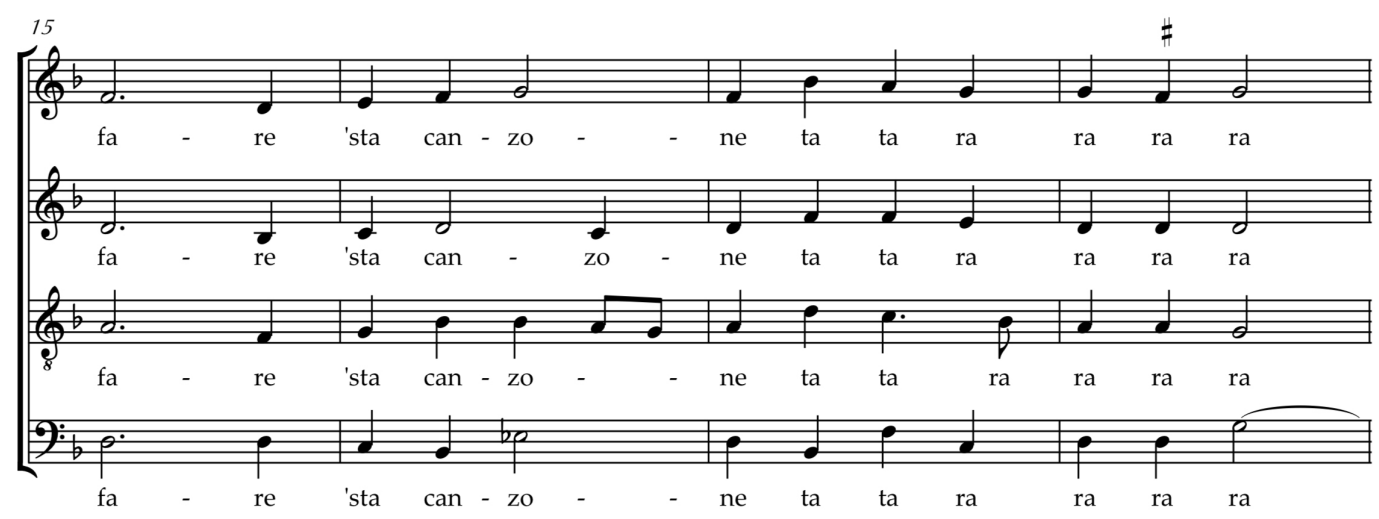

Exemplo 7. Compassos 15-18 da peça L'amanza mia si chiama saporita, de Adrian Tubal (Winchester Partbooks, n. 10).

\subsubsection{Tierce de picardie}

Por fim, a quinta convenção, denominada tierce de picardie, refere-se à eventual alteração cromática da terça de um acorde conclusivo para que este se torne maior, especialmente no final de uma peça, mesmo que isto não esteja indicado explicitamente nos manuscritos ou edições. Routley (1985, p. 67) e Donington (1963, p. 
77-78) destacam os fatos bem conhecidos de os compositores haverem preferido realizar suas conclusões através de acordes sem terça até meados do século XV e de passarem a usar este grau com frequência cada vez maior a partir de então. Após argumentar que a terça menor poderia ser tão incômoda quanto o trítono para os ouvidos medievais em razão da série harmônica, Donington (1963, p. 77) cita diversos tratados dos séculos XVI e XVII (entre eles a Introduction de Thomas Morley) onde constam afirmações categóricas a respeito do uso da terça maior em finais de peças, independentemente das harmonias que os antecedam. No último compasso do exemplo 8 transcrevemos um dos poucos casos em que esta não estava anotada nos manuscritos de Winchester, sendo necessário adicioná-la editorialmente.

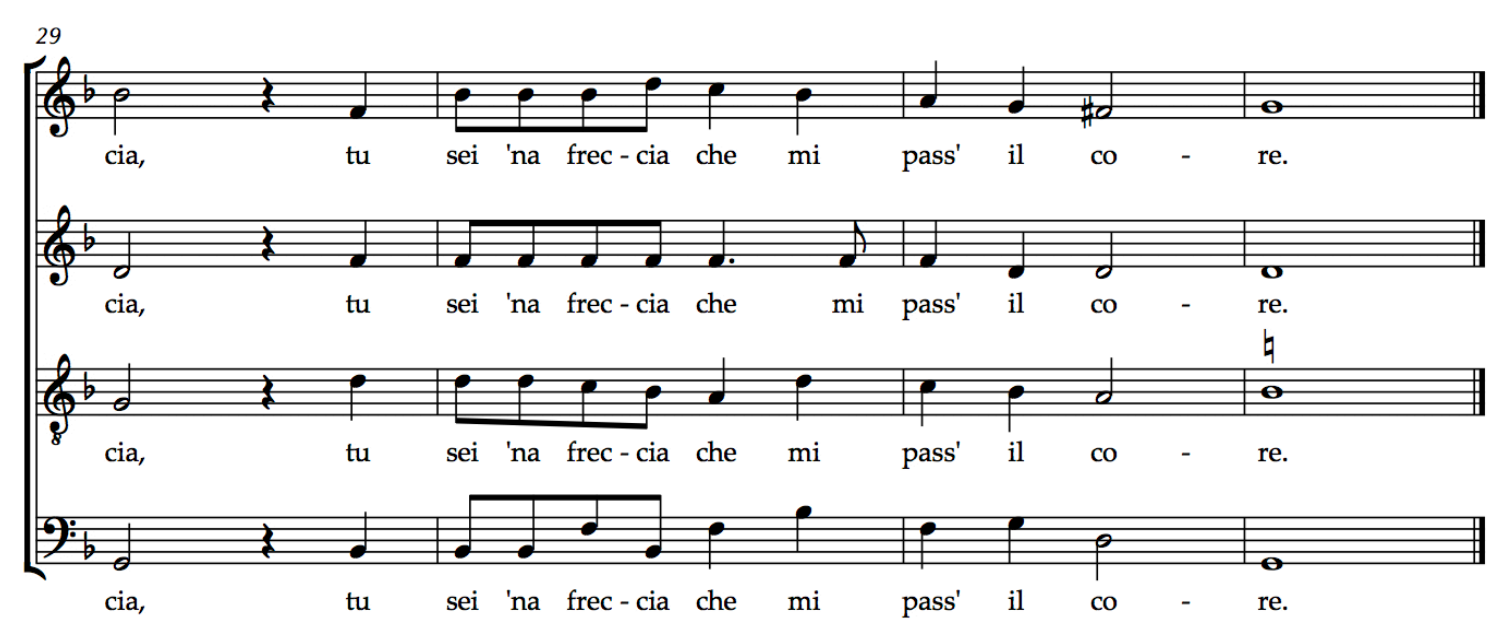

Exemplo 8. Compassos 29-32 da peça I dolci sguardi tuoi, alta signora, de Hubert Waelrant (Winchester Partbooks, n. 36).

\subsubsection{Interpretação de acidentes escritos}

As cinco convenções discutidas nos parágrafos anteriores foram aplicadas por Routley diretamente ao tópico da musica ficta devido ao fato de seu texto se destinar à apresentação de soluções práticas para a introdução, por parte dos editores e 
intérpretes, de acidentes não notados nas fontes primárias em casos específicos. Todas as prescrições, contudo, referem-se a regras gerais do contraponto modal na polifonia do século XVI - cujas consequências podem ser a eventual introdução de ficta em determinados pontos ou, em outros casos, a adoção de soluções recta - e foram justificadas por causa necessitatis ou causa pulchritudinis. Uma outra classe de problemas associados às inflexões, porém, ainda não foi considerada nesta exposição e envolve a extensão da validade dos acidentes já anotados nas fontes originais. Embora esta discussão não esteja necessariamente relacionada aos fundamentos da teoria musical, mas sobretudo aos hábitos e tradições dos escribas e editores do século XVI ao notarem a música polifônica, consideramos que também constitua objeto de interesse pois teve importante papel na orientação das decisões editoriais tomadas ao longo desta pesquisa.

Na notação da música do Renascimento a ausência de barramento com sentido métrico impossibilita a aplicação da atual convenção segundo a qual a vigência de um acidente ocorrente se estende até a próxima mudança de compasso; no século XVI, de maneira geral, um sinal de alteração exerce ação apenas sobre a figura imediatamente à sua direita. Na figura 85 (uma colagem da parte original do discantus com nossa transcrição das quatro vozes da peça Deh, perchè abbandonasti me, de Adrian Tubal), observamos que embora a segunda semínima do discantus no compasso 14 tenha sido alterada, a inflexão certamente não se aplica à primeira semínima do compasso 15; nos casos em que ocorrências subsequentes de uma mesma altura devam ser também alteradas, os sinais de inflexão devem ser repetidos, e isto se pode observar na figura 86 (uma colagem das partes originais do discantus, altus e tenor com nossa transcrição das quatro vozes da peça Mill'anni sono ch'io non t'haggio vista, de Hubert Waelrant), em que cada reiteração está notada explicitamente nos manuscritos. 


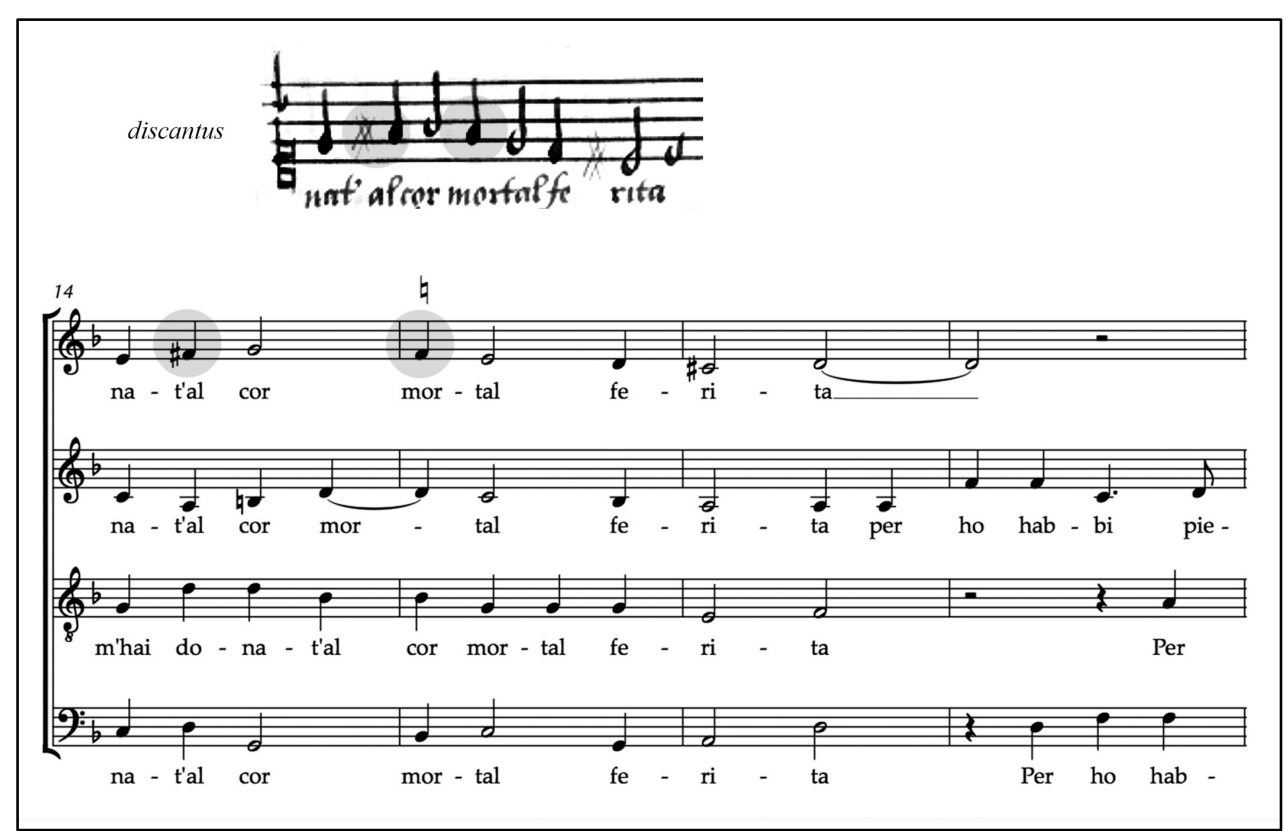

Figura 85. Trecho original do discantus e compassos 14-17 da transcrição da peça Deh, perchè abbandonasti me, de Adrian Tubal (Winchester Partbooks, n. 42).

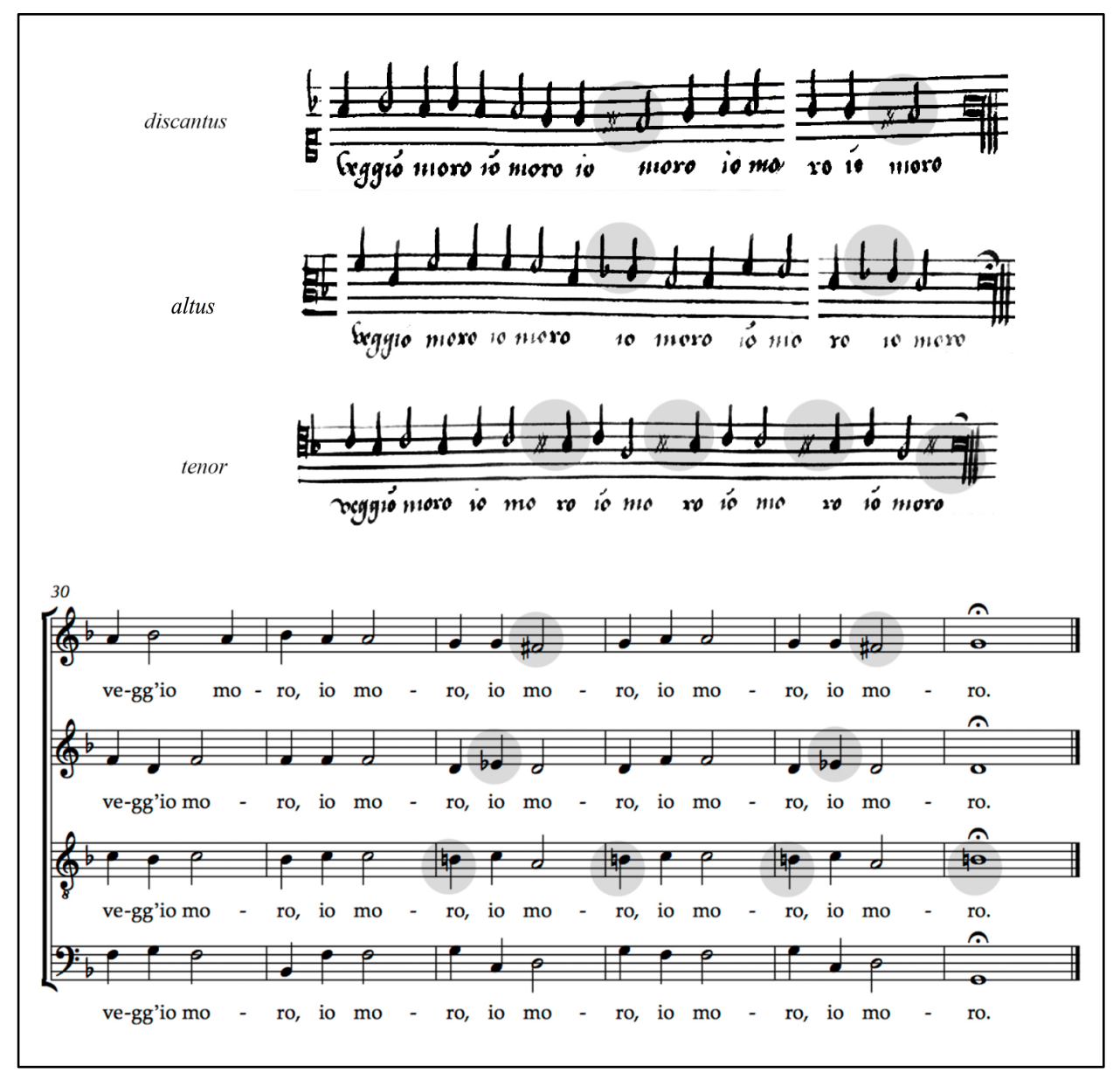

Figura 86. Trechos originais do discantus, altus e tenor e compassos 30-35 da transcrição da peça Mill'anni sono ch'io non t'haggio vista, de Hubert Waelrant (Winchester Partbooks, n. 29). 
A exceção mais comum à regra que determina que a influência de um acidente seja exercida sobre uma única figura é o caso em que sua altura seja repetida imediatamente; nesta situação considera-se, em geral, que as reiterações também estejam sujeitas à mesma inflexão. A figura 87, que contém as partes do altus e do bassus acompanhadas de nossa transcrição da frase final de Deh, perchè abbandonasti me, ilustra a necessidade desta interpretação nos compassos 64-65, evitando não apenas falsas relações nas partes individuais mas também a ocorrência de mi contra fa com o tenor (a última nota do altus, ainda que não seja uma repetição imediata da altura precedente, foi também alterada respeitando-se a convenção tierce de picardie).

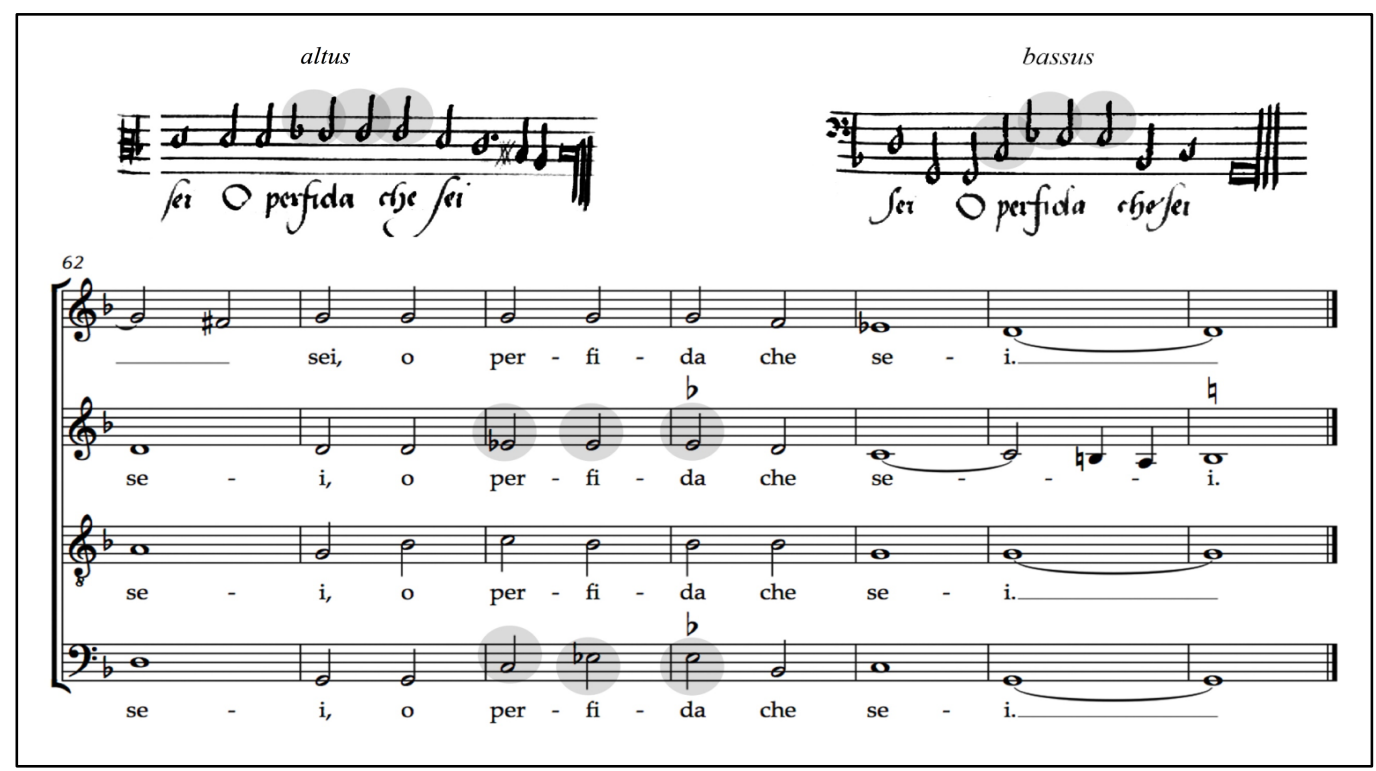

Figura 87. Trechos originais do altus e bassus e compassos 62-68 da transcrição da peça Deh, perchè abbandonasti me, de Adrian Tubal (Winchester Partbooks, n. 42).

Embora esta consideração sobre a influência dos sinais de alteração seja válida na maioria dos casos de alturas repetidas, algumas situações podem admitir - ou exigir - interpretações alternativas. Donington (1963, p. 71) afirma que após uma pausa ou no início de uma nova frase o acidente anterior quase sempre deve ser entendido como cancelado; com efeito, o exemplo 9, extraído da peça Tanto sai fare cogli innamorati, também de Adrian Tubal, demonstra a inevitabilidade da leitura do compasso 24 do altus como Fáa, novamente evitando a ocorrência de mi contra fa com o discantus e com o bassus. 


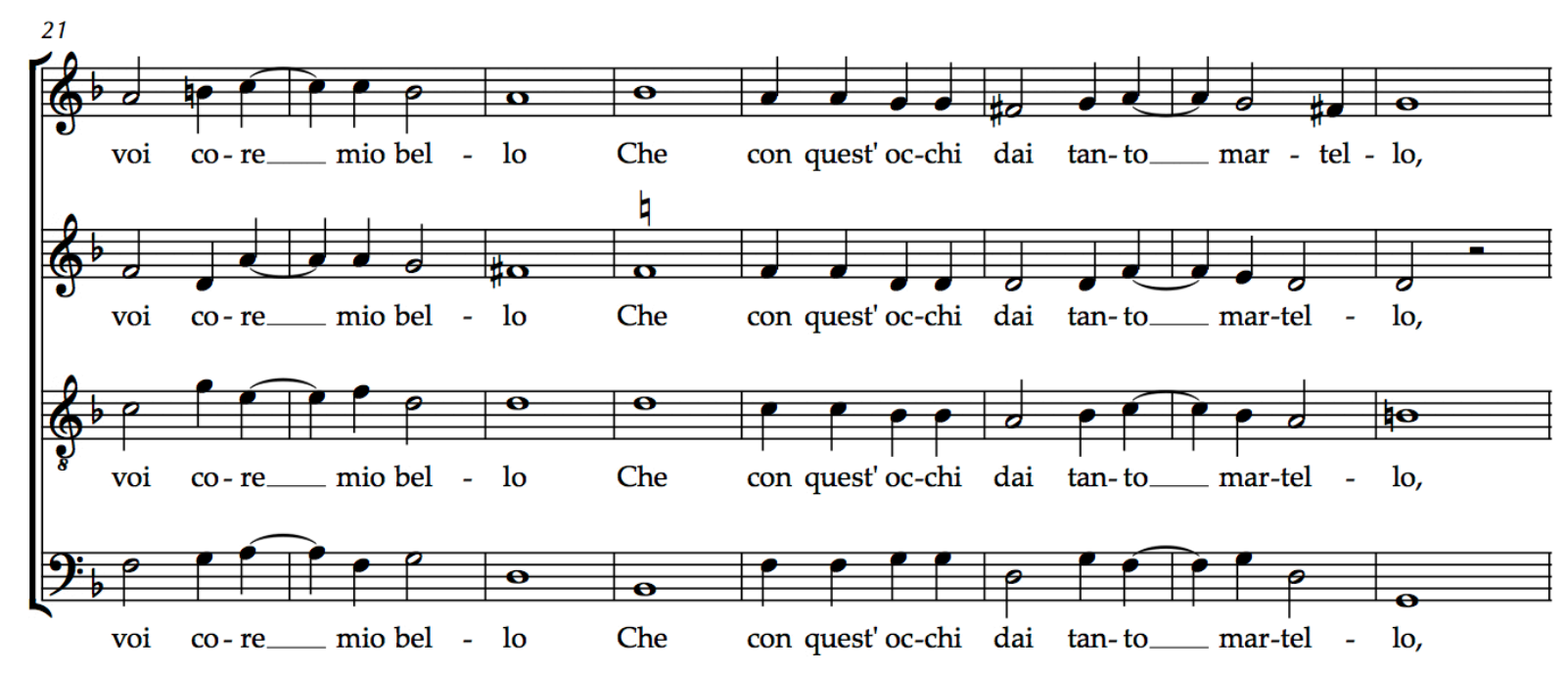

Exemplo 9. Compassos 21-28 da peça Tanto sai fare com li innamorati, de Adrian Tubal (Winchester Partbooks, n. 39).

Nos Winchester Partbooks pudemos ainda observar diversos exemplos do uso de acidentes com ação retroativa - isto é, afetando não apenas a figura imediatamente posterior ao símbolo mas também alguma figura anterior, especialmente em momentos de ornamentação como o ilustrado no compasso 42 do discantus no exemplo 10, extraído da peça Donna, voi siete bella, de Tubal. Embora reste, naturalmente, pouca dúvida quanto à intenção do compositor ou do escriba em casos como este, Donington (1963, p. 71-72) dedica alguns parágrafos à discussão de situações afins e transcreve um exemplo extraído de Lodovico Viadana (ca.1560 - 1627) em que uma nota anterior a um sustenido não está alterada mas a escrita de um baixo contínuo simultâneo exigiria sua alteração; em um segundo exemplo do mesmo compositor, o musicólogo apresenta outra situação em que a nota anterior ao acidente não deveria ser alterada e por esta razão exibe um sinal b de advertência. Ambos os exemplos sugerem fortemente que inflexões desta natureza seriam entendidas tacitamente, e constarão, portanto, nas edições das peças tratadas neste trabalho. 


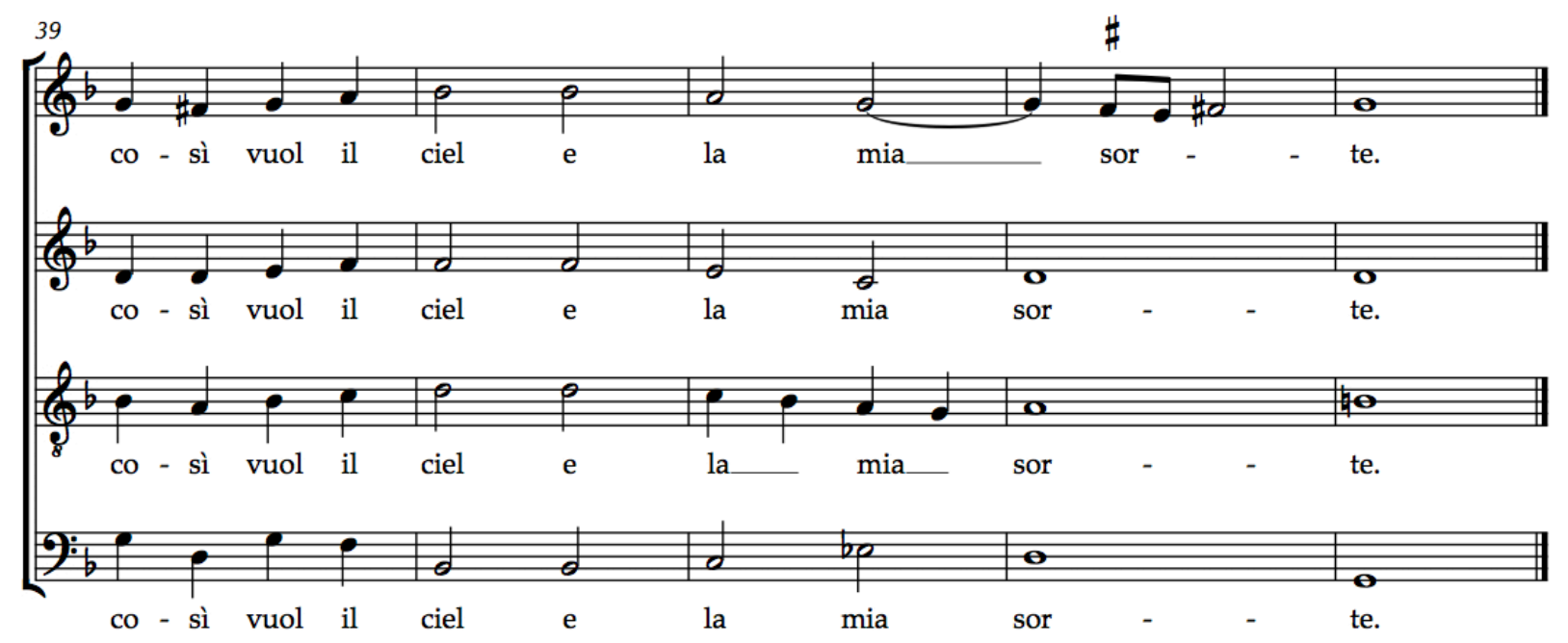

Exemplo 10. Compassos 39-43 da peça Donna voi siete bella, de Adrian Tubal (Winchester Partbooks, n. 17).

Por fim, uma prática adicional observada nos Winchester Partbooks é a ausência de indicação da alteração cromática do grau imediatamente inferior ao subsemitonum modi em uma cadência, ainda que a inflexão deste último esteja indicada explicitamente. O exemplo 11, retirado da peça Mill'anni sono ch'io non t'haggio vista, de Waelrant, ilustra no compasso 20 do discantus esta omissão do escriba e novamente não deixa dúvidas relativas à intenção do compositor, pois o salto de segunda aumentada $B,-C \#$ não seria tolerado e não possuiria, de qualquer forma, sentido musical como parte de uma figura de ornamentação. Ao discutir a ocorrência de casos similares nos manuscritos e edições do século XVI, Donington afirma, utilizando a linguagem tonal, que "onde o sétimo grau de uma escala, com sua função de sensível, é sustenizado ou o foi devido a musica ficta, sua mediante vizinha, o sexto grau da escala, ou o é ou deve se tornar também, se faz parte da cadência." (DONINGTON, 1963, p. 84-85, tradução nossa ${ }^{39}$ ).

\footnotetext{
${ }^{39}$ No original: "Where the seventh degree of the scale, in its function of leading-note, is sharp or has been made so by musica ficta, its neighbouring mediant, the sixth degree of the scale, either is or must be made so too, if it takes part in the cadence;"
} 


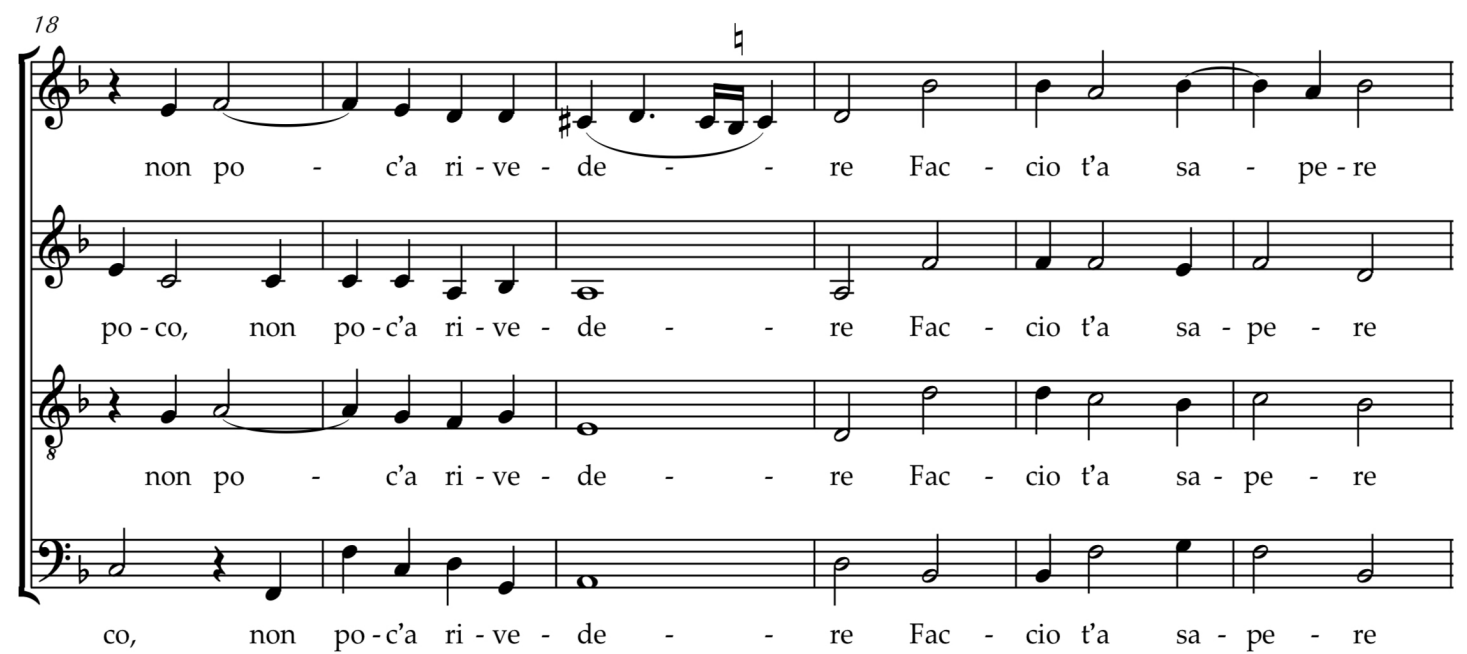

Exemplo 11. Compassos 18-23 da peça Mill'anni sono ch 'io non t'haggio vista, de Hubert Waelrant (Winchester Partbooks, n. 29).

Na maioria dos exemplos discutidos nesta seção as decisões relativas a alterações cromáticas foram orientadas a partir da visão das diferentes vozes alinhadas em partitura; um questionamento mais aprofundado no que se refere à performance de trechos afins nas condições do século XVI (com uso de partes separadas em uma solmização à primeira vista, por exemplo), contudo, inevitavelmente remeteu gerações de musicólogos ao problema de caráter mais geral que trata das inflexões que poderiam ou não ser realizadas pelos cantores de acordo com práticas interpretativas que foram perdidas em períodos posteriores. Donington (1963, p. 74), após reiterar a importância da habilidade dos intérpretes para introduzir acidentes quando necessário, cita diversos teóricos que se preocuparam com este tópico ainda no século XVI - entre eles Pietro Aron, Steffano Vanneo, Gioseffo Zarlino e Thomas Morley - e acaba por destacar eventuais controvérsias sobre o tema através de suas declarações. Em particular, Vanneo afirma em Recanetum de musica aurea (1533) que

os ouvidos são considerados os melhores intérpretes, os que mais podem ajudar, se você observar as partes de um cantor arguto, que quando sente que está produzindo uma progressão dissonante, imediatamente, pouco a pouco e tão discretamente que mal se pode reconhecer e detectar, a abaixa ou a eleva até que uma progressão 
consonante e doce chegue aos ouvidos. (VANNEO, 1533, f. $92 v$ apud DONINGTON, 1963, p. 74, tradução nossa ${ }^{40}$ ).

Esta possibilidade de "correção instantânea" de alturas certamente teve vasta aplicação no repertório vocal do século XVI, não apenas nos inúmeros exemplos em que de fato há erros nas fontes manuscritas ou impressas, mas sobretudo nos casos em que o cantor simplesmente não dispunha, em sua parte, de elementos visuais suficientes para antecipar algum tipo de choque harmônico com outras vozes. A esse respeito Routley argumenta que os cantores realizavam ensaios e que "para aplicar as regras que lidam com as relações entre partes, pelo menos uma execução é necessária até para descobrir o problema" (ROUTLEY, 1985, p. 63, tradução nossa ${ }^{41}$ ). Margaret Bent, ao tratar da performance, acrescenta que "um cantor responderá diferentemente, dependendo do que está ou não acontecendo à sua volta; [...] o que ele faz será afetado pelo que outros cantores fazem, seja em resposta a sinais aurais ou visuais" (BENT, 2002, p. 112, tradução nossa ${ }^{42}$ ) e considera que o sistema não apenas inclua ambos os tipos de sinais, mas também as próprias regras de contraponto:

O que o cantor não faz é "mudar", alterar ou inflexionar notas individuais; [...] Ele não adiciona acidentes, mas "opera a musica ficta", opera o sistema. [...] A dimensão prescritiva da própria notação inclui o sistema não escrito de regras de contraponto compartilhadas pelo compositor e pelo intérprete, das quais o conhecimento compartilhado é presumido por ambos (BENT, 2002, p. 111, tradução nossa ${ }^{43}$ ).

\footnotetext{
${ }^{40}$ A tradução realizada por Donington lê-se: "The ears are considered the best interpreters, which can help you most, if you observe the parts of an accomplished singer, who when he feels that he is producing a dissonant progression, at once little by little and so discretely, that it can scarcely be recognised and detected, either flattens or sharpens it, until a consonant and sweet progression strikes the ears."

${ }^{41}$ No original: "in order to apply the rules that deal with the relationships between parts, at least one sing-through is needed even to discover the problem."

${ }^{42}$ No original: "A singer will respond differently, depending on what is or is not going on around him [...] what he does will be affected by what other singers do, whether in response to visual or aural signals."

${ }^{43}$ No original: "What the singer does not do is 'change', alter, or inflect individual notes; [...] He does not add accidentals, but 'operates musica ficta', operates the system. [...] The prescriptive dimension of the notation itself includes the unwritten system of contrapuntal rules shared by the composer and the performer, shared knowledge of which is presumed by both."
} 
Embora o cenário descrito por Bent seja notadamente elegante e provavelmente verdadeiro na maior parte do tempo, observações como a de Vanneo demonstram que o sistema não seria sempre infalível; teóricos como Aron e Zarlino também discutiram a prática das inflexões ainda no século XVI e criticaram compositores e intérpretes por suas condutas: os primeiros pela falta de clareza na notação e os últimos pelos excessos que frequentemente cometiam ao acrescentar alterações deliberadamente. Nos dias atuais, o adicional problema da perda das antigas tradições interpretativas faz com que casos ambíguos sejam inevitáveis; nestas situações, portanto, a adoção de uma entre as diferentes soluções possíveis por parte do editor ou do intérprete moderno dependerá de sua própria concepção estilística, conforme destaca Routley:

Frequentemente aparecem situações em que os preceitos que governam a musica ficta conflituam-se entre si. Em tais casos, aquilo que um músico francês do século XVIII chamaria de le bon goût - isto é, um conhecimento do estilo combinado com uma compreensão do contexto - decidirá. O bom gosto se desenvolve a partir da experiência na aplicação das regras musicais correntes na Idade Média e no Renascimento, e da familiaridade com exigências práticas (dos cantores). Este é sempre um fator importante ao tomar decisões sobre ficta, e algumas vezes talvez seja o mais importante (ROUTLEY, 1985, p. 69 , tradução nossa $\left.{ }^{44}\right)$.

Encerramos esta seção explicitando nosso processo editorial no que concerne às alturas e suas inflexões. Com o objetivo de facilitar ao intérprete tomadas de decisão quanto a eventuais transposições, transcrevemos todas as obras conservando as alturas originalmente notadas nos manuscritos e indicamos as tessituras de cada parte através de figuras sem haste imediatamente após as claves modernas; as denominações das vozes e as claves originais também foram mantidas nos incipits correspondentes a cada peça (fig. 88). Mantivemos no pentagrama todos os acidentes

\footnotetext{
${ }^{44}$ No original: "Occasions frequently arise when the precepts governing musica ficta conflict with one another. In such cases what the 18th-century French musician would call le bon gout - that is, a knowledge of style combined with an understanding of the context - will decide. Good taste develops from the experience of the application of the musical rules current in the Middle Ages and the Renaissance, and from familiarity with practical (singers') exigencies. It is always an important factor in making decisions about ficta, and may sometimes be the most important."
} 
indicados nas fontes, incluindo advertências que não seriam consideradas necessárias em notação moderna. Todas as alterações indicadas acima do pentagrama são editoriais e foram adicionadas por uma das seguintes razões: (i) para fazer respeitar, através de inflexões recta ou ficta, as regras de contraponto discutidas nesta seção; (ii) para advertir o intérprete a respeito da extensão da validade de um acidente ocorrido anteriormente no pentagrama ou acima dele; e (iii) para solucionar possíveis dúvidas decorrentes de alterações próximas ocorridas em outras vozes. Em qualquer destes casos adotamos a convenção moderna segundo a qual as alterações permanecem válidas até o final de cada compasso, sendo reiteradas (acima do pentagrama) após a barra caso necessário. Em situações consideradas ambíguas - isto é, aquelas para as quais julgamos haver mais de uma solução possível - os acidentes estão indicados acima do pentagrama entre parênteses. Por fim, nos casos em que acreditamos na existência de erros nas fontes, estes foram corrigidos tacitamente nas transcrições e posteriormente apontados nas notas musicológicas referentes a cada peça.

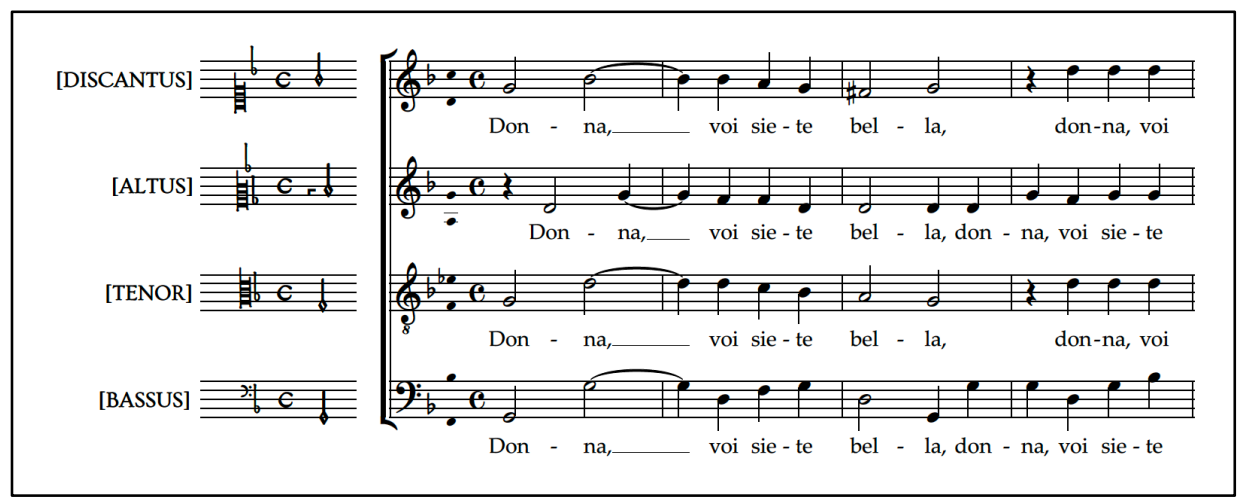

Figura 88. Incipit precedendo a transcrição moderna da peça Donna, voi siete bella, de Adrian Tubal (Winchester Partbooks, n. 17).

\subsection{ALGUMAS CONSIDERAÇÕES SOBRE PERFORMANCE}

As frequentes (e continuamente crescentes) intersecções entre musicologia e performance observadas nas últimas décadas certamente permitem que acadêmicos, editores e intérpretes da música antiga possam se beneficiar mutuamente de seus 
respectivos estudos e práticas. A cooperação entre estes campos aparentemente distintos pode ocorrer não apenas através da exploração conjunta de terrenos comuns a musicólogos e intérpretes, mas também nas situações em que esses papéis se mesclam em figuras como as do pesquisador-editor ou do pesquisador-performer, por exemplo. O musicólogo James Grier, ao considerar a disciplina da edição crítica, propõe uma analogia entre a própria natureza das atividades editoriais e interpretativas ao afirmar que

Intérpretes e editores constantemente tomam decisões em resposta aos mesmos estímulos (notação) baseados nos mesmos critérios (conhecimento da peça e gosto estético). Só os resultados diferem: intérpretes produzem som enquanto editores geram a página escrita ou impressa. (GRIER, 1996, p. 6, tradução nossa ${ }^{45}$ ).

As declarações de Grier, ilustrativas das intersecções acima mencionadas, convidam seus leitores a uma reflexão acerca da efetiva aproximação entre os campos sob consideração e seguramente podem ser aplicadas ao repertório abordado nesta pesquisa; o tratamento editorial de problemas musicológicos relacionados à interpretação da notação rítmica e às possíveis inflexões ficta discutidas neste capítulo, por exemplo, levam em conta a exequibilidade dos resultados, contemplam eventuais ambiguidades, exigem tomadas de decisão e constituem, em última análise, considerações sobre performance em si mesmas.

A presente seção, portanto, fica reservada a alguns aspectos interpretativos ainda não tratados neste texto, a saber: (i) a constituição dos grupos aos quais este repertório pode ser destinado; e (ii) o efeito do uso de materiais em notação original ou moderna por parte de seus intérpretes. Nossa exposição é baseada na literatura sobre estudos de performance da música renascentista e inclui declarações e depoimentos de musicólogos e intérpretes, assim como nosso próprio relato de caso através da descrição do trabalho desenvolvido com o Madrigal Comunicantus, grupo

\footnotetext{
${ }_{45}$ No original: "Performers and editors constantly make decisions in response to the same stimuli (notation) on the basis of the same criteria (knowledge of the piece and aesthetic taste). Only the results differ: performers produce sound while editors generate the written or printed page."
} 
vocal constituído no âmbito do Comunicantus: Laboratório Coral do Departamento de Música da ECA-USP durante o período desta pesquisa. Ao longo das atividades realizadas junto ao madrigal, estivemos interessados nos processos de leitura e apreensão de elementos musicais por parte dos cantores ao lidarem com fac-símiles e edições modernas, sendo observados os efeitos da notação sobre a memorização de melodias, internalização de estruturas rítmicas, domínio do contraponto, consciência harmônica, acentuação e fraseado. Embora os tópicos abordados nesta seção constituam apenas um subconjunto das questões interpretativas confrontadas pelos diretores e demais membros de um ensemble de música antiga, sua discussão reflete parte da prática desenvolvida durante a presente pesquisa, onde as ferramentas musicológicas são orientadas, em última análise, à própria performance.

\subsubsection{Partbooks e partituras}

O final do século XVI foi o período em que se iniciou a transição entre duas tradições notacionais fundamentalmente distintas, denominadas pela musicóloga Anne Smith (2011, p. 4) "cultura de partbooks" e "cultura de partituras". O corpus tratado na presente pesquisa enquadra-se, naturalmente, no primeiro caso e pertence a um período em que a música vocal, com raríssimas exceções, era impressa (ou manuscrita) em partes individuais. O formato denominado choirbook, também ocorrente no século XVI, exibe diferentes vozes em um mesmo volume, porém estas não são alinhadas em partitura (fig. 89) e certamente eram lidas separadamente por cada cantor.

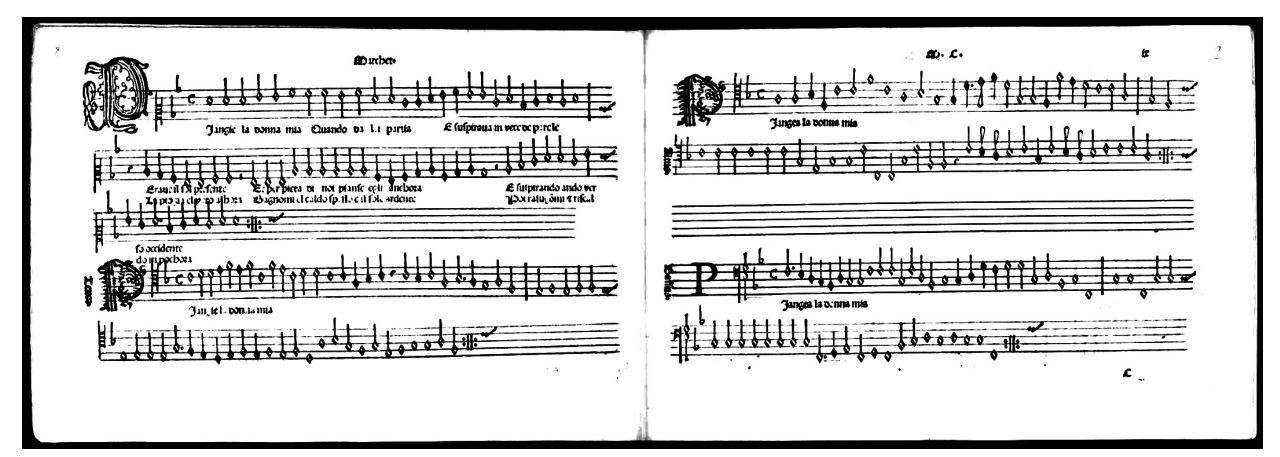

Figura 89. Impressão em formato choirbook (LIBRO PRIMO DE LA CROCE, 1526, fol. xiiiv, ixr) 
As implicações destas diferentes culturas sobre a execução de um repertório cuja construção é baseada no contraponto horizontal - isto é, na sobreposição de linhas melódicas individualmente estruturadas com liberdade rítmica e baseadas sobretudo na declamação do texto - dificilmente serão desprezadas pelo intérprete ou pelo musicólogo interessado em questões de performance da música renascentista. Nos dias atuais, a abordagem deste repertório a partir de fontes originais tem sido cada vez mais frequente por parte de intérpretes especializados e a implementação de uma tal proposta tende a produzir resultados musicais notadamente mais satisfatórios, apesar das possíveis dificuldades encontradas pelos músicos habituados à "cultura de partituras", conforme relatam Anne Smith no volume The Performance of 16th Century Music: Learning from the Theorists (SMITH, 2011) e Alexander Blachly em seu artigo sobre performance na publicação A Performer's Guide to Renaissance Music (KITEPOWELL, 2007):

[...] estou convencida de que nós não chegaremos ao âmago da música se nós não a abordarmos da mesma maneira [que os intérpretes do Renascimento], a partir das partes individuais, permitindo seu fluxo conjunto, sua confluência para criar o todo. Fazer isso significa começar tocando a partir das partes, chegando possivelmente até a memorizá-las. A experiência mostra que o produto é consistentemente de melhor qualidade. [...] Mas após anos ensinando pessoas a ler a partir de fac-símiles, eu acho que a principal razão pela qual nós somos relutantes a fazê-lo é porque nós perdemos nosso senso visual de orientação métrica devido ao fato de não haver barras de compasso. Todos começam imediatamente a se sentir extraordinariamente inseguros e por isso cometem mais erros do que cometeriam normalmente se fossem forçados a tocar em uma clave com a qual não estão acostumados. Ninguém consegue decifrar as pausas, mesmo os sinais sendo basicamente os mesmos da notação de hoje. Nós obviamente determinamos o comprimento das pausas olhando onde estamos no compasso, mais do que olhando para as formas das pausas em si. No início, leva-se frequentemente uma hora inteira para músicos experientes conseguirem tocar uma chanson a quatro partes relativamente simples do começo ao fim. A coisa mais difícil para o professor é conseguir suportar o extremo constrangimento de todos pelo fato de terem tais dificuldades para tocar algo que eles seriam capazes de ler facilmente à primeira vista em notação moderna. Isso 
demonstra o quão longe estamos do ideal do Renascimento." (SMITH, 2011, p. 18-19, tradução nossa ${ }^{46}$ )

O que se pode aprender cantando a partir de partbooks? Eu descobri que cantores experimentam um tremendo entusiasmo quando descobrem pela primeira vez que são capazes de fazer música lendo notação mensural com ligaduras ${ }^{47}$. Ademais, cantar a partir de partbooks liberta os ouvidos da tirania do olho e permite que o som da música - da maneira como ela está acontecendo - sirva de guia para pulso e andamento. Por outro lado, ler a partir dos partbooks torna mais lento o processo de aprendizado, exigindo mais ensaios para preparar a música no nível de concerto. Adicionalmente, uma fotocópia de um fac-símile de um partbook do Renascimento normalmente não é suficiente para a performance. Frequentemente a fotocópia exige tanta edição, principalmente na forma de adição de palavras que estão faltando, que na verdade se está trabalhando com uma edição moderna. Caso alguém possa se dar ao luxo de entrar nesta prática, cantar a partir dos partbooks pode ser um grande benefício para o fraseado, pois o ouvido, seguindo o som das outras vozes, instrui a mente a imitar mais efetivamente do que faz o olho - uma coisa altamente desejável, uma vez que a imitação forma a base subjacente para quase toda a composição do final do século XV e do século XVI. (BLACHLY; KITE-POWELL, 2011, p. 21-22, tradução $\left.\operatorname{nossa}^{48}\right)$

${ }^{46}$ No original: "I am convinced that we will not get at the heart of the music if we do not approach it in the same way, from the individual parts, allowing their flowing together, their confluence to create the whole. To do so means we have to start playing from the parts, often possibly even memorizing them. Experience has shown that the product is consistently of a higher quality" [...] "But after years of teaching people to read from facsimile, I think the main reason we are reluctant to do so is because we lose our visual sense of metric orientation due to the fact that there are no bar lines. Everybody immediately begins feeling extraordinarily insecure and as a result makes even more mistakes than they would make normally if forced to play in an unaccustomed clef. Nobody can decipher the rests, although the signs are basically the same as in today's notation. We obviously determine the length of rests by seeing where we are in the bar, rather than looking at the form of the rests themselves. At the beginning it often takes experienced musicians an entire hour to be able to play through a relatively simple four-part chanson from beginning to end. The hardest thing for the teacher is being able to endure everybody's extreme embarrassment at the fact thar they have such dificulties at playing something that they would be able to sight-read easily the first time through in modern notation. This just points out how far we are from the Renaissance ideal."

${ }^{47}$ Para a definição de ligaduras neste contexto, ver seção 3.1.2.

${ }^{48}$ No original: "What can be learned from singing from partbooks? I have found that singers experience a tremendous thrill when they first find they are able to make music reading mensural notation with ligatures. Moreover, singing from partbooks frees the ear from the tyranny of the eye and allows the sound of the music - as it is happening - to serve as the guide to pulse and tempo. On the other hand, reading from partbooks greatly slows down the learning process, necessitating more rehearsals to prepare music up to concert level. Also, a photocopy of a facsimile of a Renaissance partbook is usually not sufficient for performance. Often the photocopy needs so much editing, primarily in the form of adding missing words, that one is in effect working from a modern edition. If one has the luxury to indulge in the practice, singing from partbooks can be a great boon to phrasing, for the ear, following 
Ambos os musicólogos identificam, portanto, a leitura em partbooks como a situação ideal para uma execução fluida e musical do repertório do Renascimento, apesar de reconhecerem as dificuldades que a notação original pode inicialmente impor aos intérpretes atuais. Com efeito, os cenários descritos por Smith e Blachly foram precisamente aqueles observados em nossa experimentação com a leitura em partes separadas em um ensemble vocal, conforme discutiremos a seguir.

\subsubsection{Relato de caso: Madrigal Comunicantus}

Em maio de 2017, no âmbito do Comunicantus: Laboratório Coral do Departamento de Música da ECA-USP, foi criado o Madrigal Comunicantus, um grupo vocal dedicado ao repertório polifônico do Renascimento. Em atividade até o presente momento, o madrigal iniciou-se com oito integrantes (SSSAAATB) e teve uma formação flexível que se alterou conforme a demanda de interessados e segundo o repertório a ser executado a cada semestre, havendo totalizado dezesseis componentes em dezembro de 2019 (fig. 90). O perfil dos cantores é variado e inclui estudantes do Departamento de Música da ECA-USP, além de coralistas com alguma experiência musical em outras instituições. O grupo realiza um ensaio semanal com duração de duas horas, conduzido pelo doutorando e supervisionado por seu orientador, Prof. Dr. Marco Antonio da Silva Ramos. Embora tenha sido constituído especialmente para os propósitos desta pesquisa e se concentrado inicialmente em peças transcritas e analisadas neste texto, o madrigal dedicou-se também ao repertório vocal

the sound of the other voices, instructs the mind to imitate more effectively than does the eye - a highly desirable thing, in as much as imitation forms the underlying basis for almost all late-fifteenth- and sixteenth-century composition." 
renascentista de maneira mais abrangente, havendo apresentado diversos concertos ao longo de seus três anos de existência.

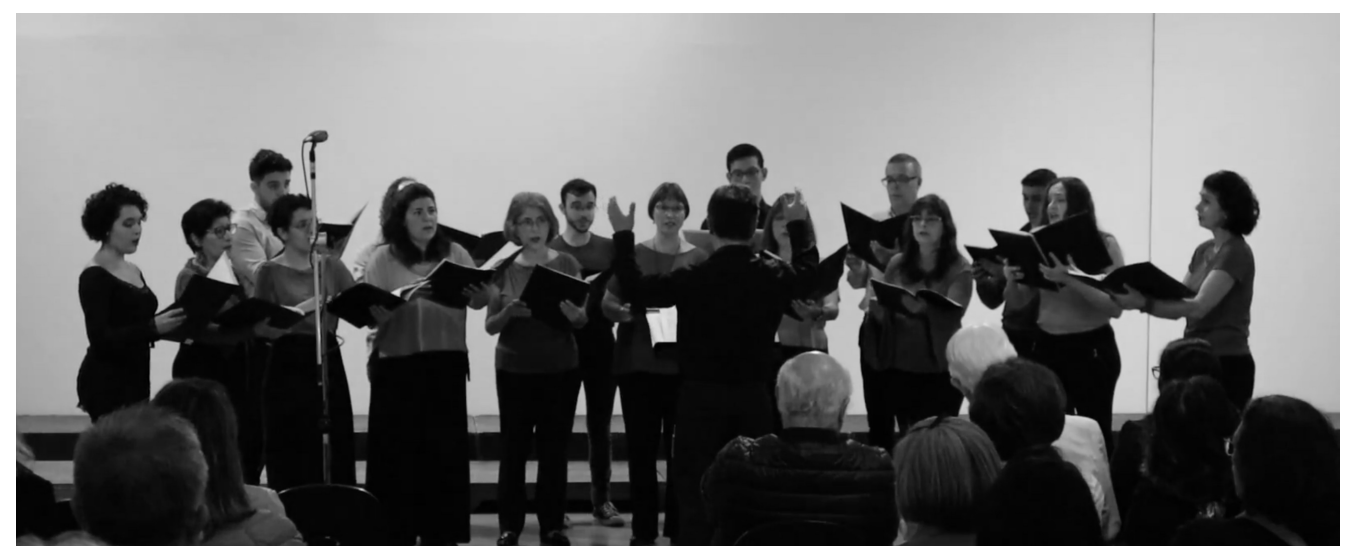

Figura 90. Madrigal Comunicantus em apresentação realizada em 29/11/2019 no Espaço das Artes ECA-USP (Foto: Filipe Fonseca)

\subsubsection{Constituição do grupo}

Embora a música secular do Renascimento seja idealmente executada com apenas um cantor por parte, a implementação de um ensemble vocal dedicado a este repertório em um ambiente onde esta tradição ainda não é consolidada exigiu uma abordagem através da qual diversos integrantes pudessem cooperar na execução de uma mesma linha melódica, contribuindo assim para a segurança de cada cantor e, consequentemente, para a estruturação geral do conjunto. Este procedimento é discutido e justificado pelos musicólogos Alejandro Planchart e Alexander Blachly em seus respectivos artigos sobre performance na publicação A Performer's Guide to Renaissance Music (KITE-POWELL, 2007) ao tratarem de situações bastante semelhantes àquela em que se implementou o Madrigal Comunicantus:

Com cantores jovens e estilisticamente inexperientes, [a escolha de] três a quatro vozes por parte permite que o ensemble produza um som bonito sem perder muita flexibilidade e leveza. Quando eu digo 'sem perder muita flexibilidade' eu quero dizer em termos relativos ao que tais cantores fariam quando cantando um por parte. A flexibilidade do canto a uma voz por parte que se ouve na maioria dos espetaculares ensembles profissionais é baseada em excelente técnica e em anos de 
experiência como cantores solistas e de ensemble por parte de cada um dos membros de um tal conjunto. Também deve ser lembrado que um dos papéis do ensemble de música antiga é proporcionar experiência na interpretação da música antiga a tantos estudantes quando seja praticável dentro do tempo relativamente curto da carreira universitária, já que esta experiência vai criar não apenas intérpretes de música antiga, mas intérpretes 'convencionais' que nunca terão a desconfiança da música antiga que era quase costumeira uma geração atrás. (PLANCHART, KITE-POWELL, 2007, p. 30, tradução nossa ${ }^{49}$ )

Em um ensemble iniciante de música antiga com poucos vocalistas habilidosos (se houver algum), a primeira regra é que a segurança está nos números. Doze ou dezesseis cantores, mesmo que sejam inseguros e estejam experimentando, ainda podem normalmente produzir uma performance agradável e musical de uma chanson de Claudin de Sermisy ou de um madrigal de Verdelot com os quais nenhum quarteto retirado de suas fileiras poderia negociar. Conforme o nível de execução sobe, esta regra diminui em validade, de modo que com intérpretes muito experientes e competentes é mais fácil criar uma performance musicalmente expressiva com apenas um cantor por parte, especialmente em música mais difícil (como madrigais de Giaches de Wert ou Luzzaschi). Naturalmente, o mundo ideal seria aquele em que o ensemble vocal correspondesse ao tamanho e calibre de seu modelo pré-barroco, com um cantor por parte em madrigais e chansons. [...] Um efetivo vocal entre oito e vinte cantores parece ser o tamanho ideal para um ensemble de música antiga, com ensembles menores extraídos do grupo maior quando possível, para música a um cantor por parte. (BLACHLY, KITE-POWELL, 2007, p. 15, tradução nossa ${ }^{50}$ )

${ }^{49}$ No original: “With young and stylistically inexperienced singers, three to four voices to a part allows an ensemble to produce a beautiful sound without losing much flexibility and lightness. When I say "whithout losing much flexibility" I mean this in terms relative to what such singers would do when singing one to a part. The flexibility of one-to-a-part singing one hears in most of the outstanding professional ensembles is predicated on excellent technique and years of experience as solo and ensemble singers on the part of each member of such an ensemble. It also should be remembered that one of the roles of the early music ensemble is to provide experience in performing early music to as many students as practicable within the relatively short time of a college career, as such experience will create not just performers of early music but "mainstream" performers who will never have the distrust of early music that was almost a matter of course a generation ago."

${ }^{50}$ No original: "In a fledgling early music ensemble with few if any skilled vocalists, rule one is that there is safety in numbers. Twelve or sixteen singers, even if they are insecure and tentative, can still usually manage a pleasing and musical performance of a chanson by Claudin de Sermisy or a madrigal by Verdelot that no quartet drawn from their ranks could negotiate. As the level of the execution rises, this rule diminishes in validity, so that with very experienced and competent performers it is easier to create a musically expressive performance with only one singer to a part, especially in more difficult music (such as madrigals by Giaches de Wert or Luzzaschi). Naturally, the ideal world would be for the 
O perfil vocal dos integrantes do Madrigal Comunicantus é diversificado e compreende: (i) jovens estudantes de canto; (ii) regentes corais e estudantes de regência; e (iii) coralistas com experiência baseada majoritariamente em repertórios posteriores ao Renascimento e na interpretação de arranjos corais de música popular brasileira ou estrangeira. As competências relativas à leitura musical são igualmente diversas, variando entre um solfejo eficaz e uma marcada inexperiência com a leitura por parte de alguns participantes, que normalmente compensam essa deficiência através de um maior uso da memória, maior prontidão, concentração e estudo individual fora dos ensaios. Os principais desafios enfrentados pelo doutorando foram, portanto, (i) a construção de uma sonoridade equilibrada a partir de vozes com perfis notadamente distintos, e (ii) a transmissão de conceitos estilísticos a cantores com pouca ou nenhuma familiaridade anterior com o repertório renascentista. A possível diversidade vocal, contudo, não representa uma dificuldade intransponível para o conjunto, conforme observa Planchart:

Ao lidar com cantores jovens, o diretor do ensemble de música antiga frequentemente se deparará com três tipos: (1) a voz não treinada, frequentemente sem vibrato e, com igual frequência, sem foco; (2) a voz treinada com um pequeno vibrato; e (3) a voz treinada onde se pode ouvir o vibrato e um som constantemente produzido com alta pressão de ar. Esta última categoria não tem lugar em um ensemble de música antiga, mesmo quando o ensemble está fazendo música tão tardia quanto Mozart ou Haydn. Das outras duas, uma voz não treinada e sem foco adiciona muito pouco ao ensemble, mas pode ser usada se a pessoa lê muito bem e tem um senso muito bom de ritmo e afinação. Frequentemente estes não-cantores aprendem relativamente rápido como focar suas vozes (e o diretor [do ensemble] de música antiga deve encorajá-los a procurar instrução nisso) e se tornam boas vozes corais. A voz bem focada mas não treinada e a voz treinada com um pequeno vibrato não intrusivo serão os melhores recursos que um diretor [de um ensemble] de música antiga pode ter. (PLANCHART; KITE-POWELL, 2007, p. 31-32, tradução nossa ${ }^{51}$ )

vocal ensemble to match the size and caliber of its pre-Baroque model, with one singer to a part on madrigals and chansons. A vocal component of between eight and twenty singers would seem to be the ideal size for an early music ensemble, with smaller ensembles drawn from the larger group when possible for one-on-a-part music."

${ }^{51}$ No original: "In dealing with young singers the early music director will often face three kinds: (1) the untrained voice, often without a vibrato and equally often without focus; (2) the trained voice with 
Ao longo das atividades do Madrigal Comunicantus, com efeito, pôde-se observar que as vozes mais preparadas dos diferentes naipes contribuíram substancialmente para que estes alcançassem sonoridades satisfatórias sem prejuízo da contribuição dos coralistas com menores competências técnicas. Devido à natural renovação semestral e anual dos estudantes no ambiente universitário, o nível técnico do madrigal apresentou pequenas flutuações, embora a permanência de um núcleo fixo ao longo da maior parte de seu período de existência tenha garantido uma adaptação progressivamente mais eficaz de novos integrantes e uma evolução geral certamente positiva. Nossa experiência aponta, portanto, para uma efetiva possibilidade de abordagem do repertório tratado nesta pesquisa por grupos não especializados, que seguramente podem se beneficiar de sua execução sob a ótica artística e didática.

\subsubsection{Experiência com leitura em partbooks}

Conforme destacado anteriormente, as diferentes formações do grupo e o programa a ser executado em cada semestre foram elementos estreitamente ligados, de modo que a abordagem inicial do repertório - com o qual a maioria dos cantores não possuía familiaridade - foi forçosamente baseada em peças simples através das quais se pudesse iniciar a construção de sua sonoridade. Por razões práticas, as experiências com a leitura em partes separadas restringiram-se a um subconjunto delimitado de peças dos Winchester Partbooks, nomeadamente as cinco composições de autoria do flamengo Adrian Tubal (no 15, 16, 17, 39 e 42).

\footnotetext{
a small vibrato; and (3) the trained voice where one can hear the vibrato and a constant high windpressure tone production. This last category has no place in an early music ensemble, even when the ensemble is doing music as late as Mozart or Haydn. Of the other two, an untrained voice without focus adds very little to an ensemble, but can be used if the person reads very well and has a really good sense of pitch and rhythm. Often such nonsingers manage to learn relatively quickly how to focus their voices (and the early music director should encourage them to seek instruction in this) and become good choral voices. The well-focused but untrained voice and the trained voice with a small unobtrusive vibrato will be the best resources an early music director may have."
} 
O material proposto aos cantores para a leitura da primeira destas peças, a canzonetta Fiamenga fredda, core di diamante, compreendeu fac-símiles das partes individuais (figs. 91, 93, 95 e 97) e transcrições das mesmas partes em claves modernas, porém sem barras de compasso e com espaçamento propositalmente uniforme entre as figuras (figs. 92, 94, 96 e 98). Uma vez que nossos principais objetos de interesse com o experimento foram os efeitos (i) da visão das linhas individuais por parte dos cantores; e (ii) da ausência de barras de compasso, procurou-se minimizar a influência de outros fatores (particularmente as claves antigas e o alinhamento das notas com o texto) sobre a leitura, permitindo-se que cada cantor escolhesse utilizar o fac-símile ou sua respectiva transcrição. A partitura moderna (fig. 99) foi oferecida aos participantes apenas em um momento próximo ao final do ensaio para uma última execução da peça e para a observação de possíveis novas reações dos cantores frente ao material impresso.

Os resultados gerais da experiência revelaram-se em acordo com os já mencionados relatos de Smith e Blachly - isto é, foram necessárias não menos de duas horas de ensaio para a primeira leitura da peça e as principais observações dos cantores durante o ensaio concentraram-se nos pontos naturalmente previstos, a saber: (i) a falta da visão de outras vozes; e (ii) a falta das barras de compasso. Apesar de todos os participantes haverem enfrentado dificuldades iniciais de natureza similar, consideramos interessante notar que a experiência geral parece ter sido percebida diferentemente por alguns cantores, notando-se uma marcada tendência dos participantes com percepção musical mais desenvolvida a considerar vantajosa a leitura em partes separadas. A seção contrapontística da peça (iniciada no final da primeira página da edição moderna), em particular, provocou reações inciais expressas através de depoimentos equivalentes a "sem a grade me perco nas entradas", que posteriormente evoluíram para comentários como "sem a grade sou obrigado a prestar muito mais atenção no que estou ouvindo, principalmente nas entradas". Após um período inicial de adaptação (correspondente à primeira hora de 


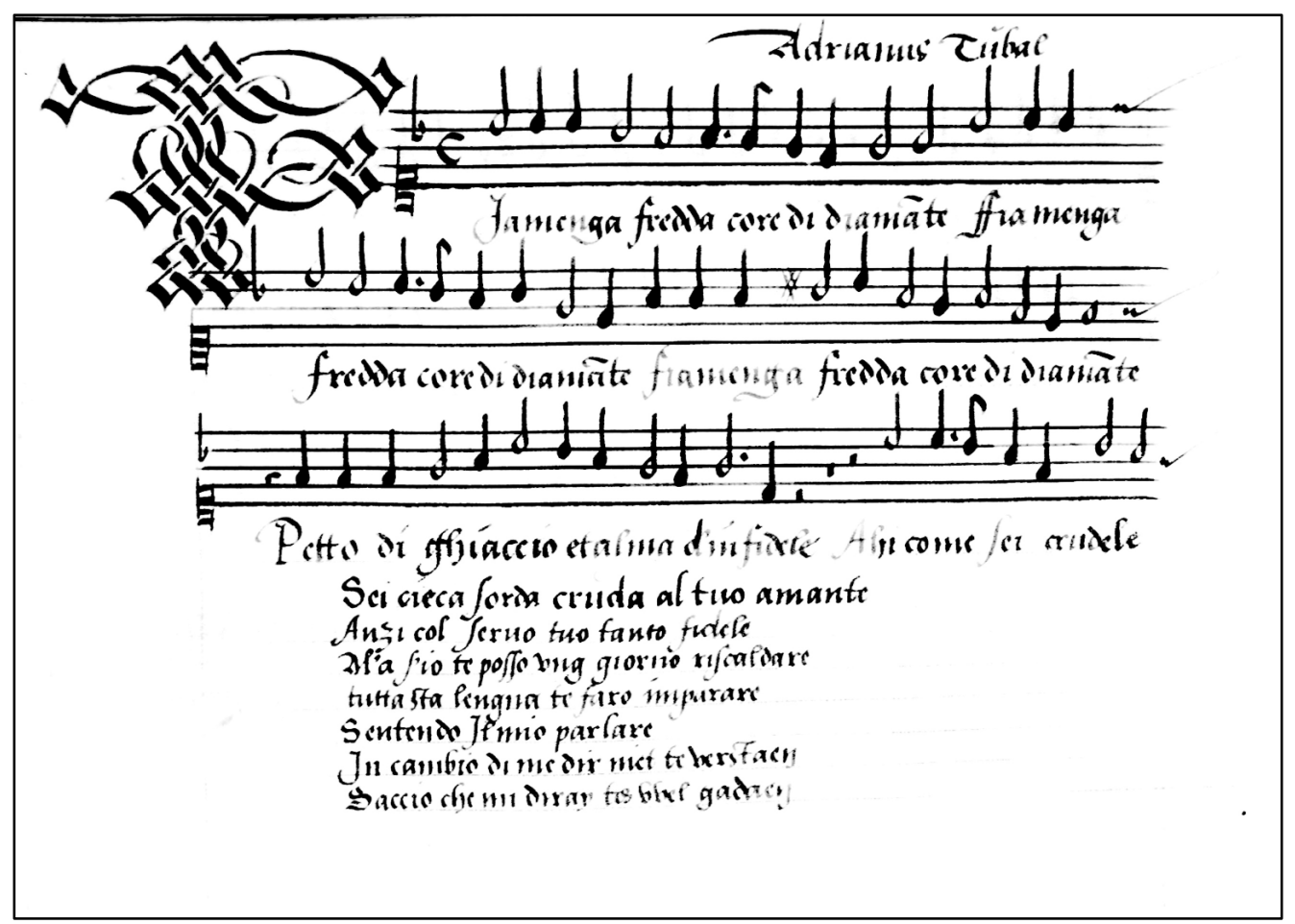

Figura 91. Fac-símile do início da parte do discantus da peça Fiamenga fredda, core di diamante, de Adrian Tubal (Winchester Partbooks, n. 15)

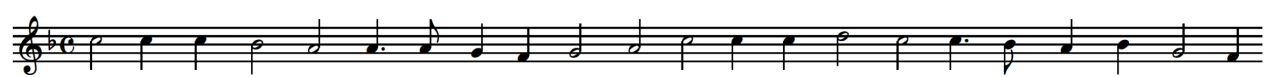

Fia-men - ga fred - da, co - re di dia - man - te, fia - men - ga fred - da, co - re di dia - man - te,

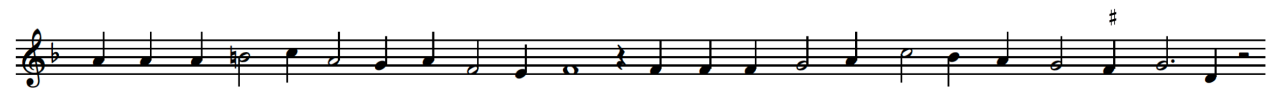

fia - men - ga fred - da, co - re di dia-man - te Pet - to di ghiac cioed al - ma d'in-fe - de - le

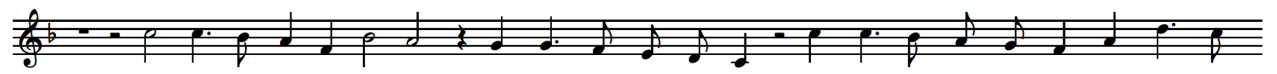

Ahi co - me sei cru-de - le Ris - pon-d'al mio par - lar, ris - pon -d'al mio par - lar, ris - pon - d'al

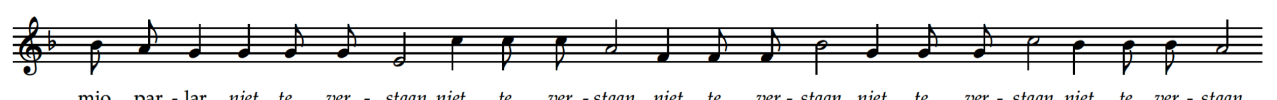

mio par-lar niet te ver - staan, niet te ver-staan, niet te ver-staan, niet te ver-staan, niet te ver-staan
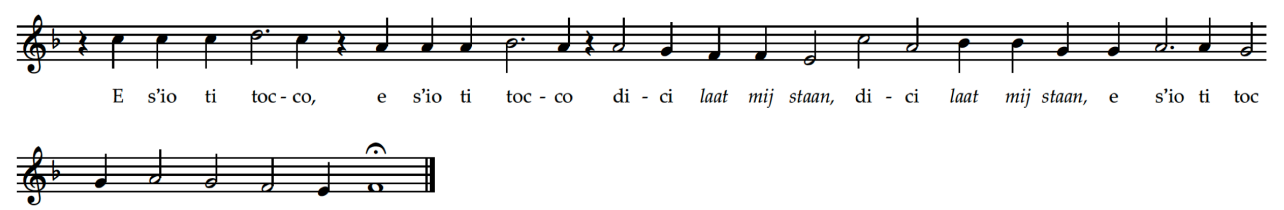

co di - ci laat mij staan.

Figura 92. Transcrição da parte do discantus da peça Fiamenga fredda, core di diamante, de Adrian Tubal (Winchester Partbooks, n. 15), utilizando-se figuras e claves modernas. 


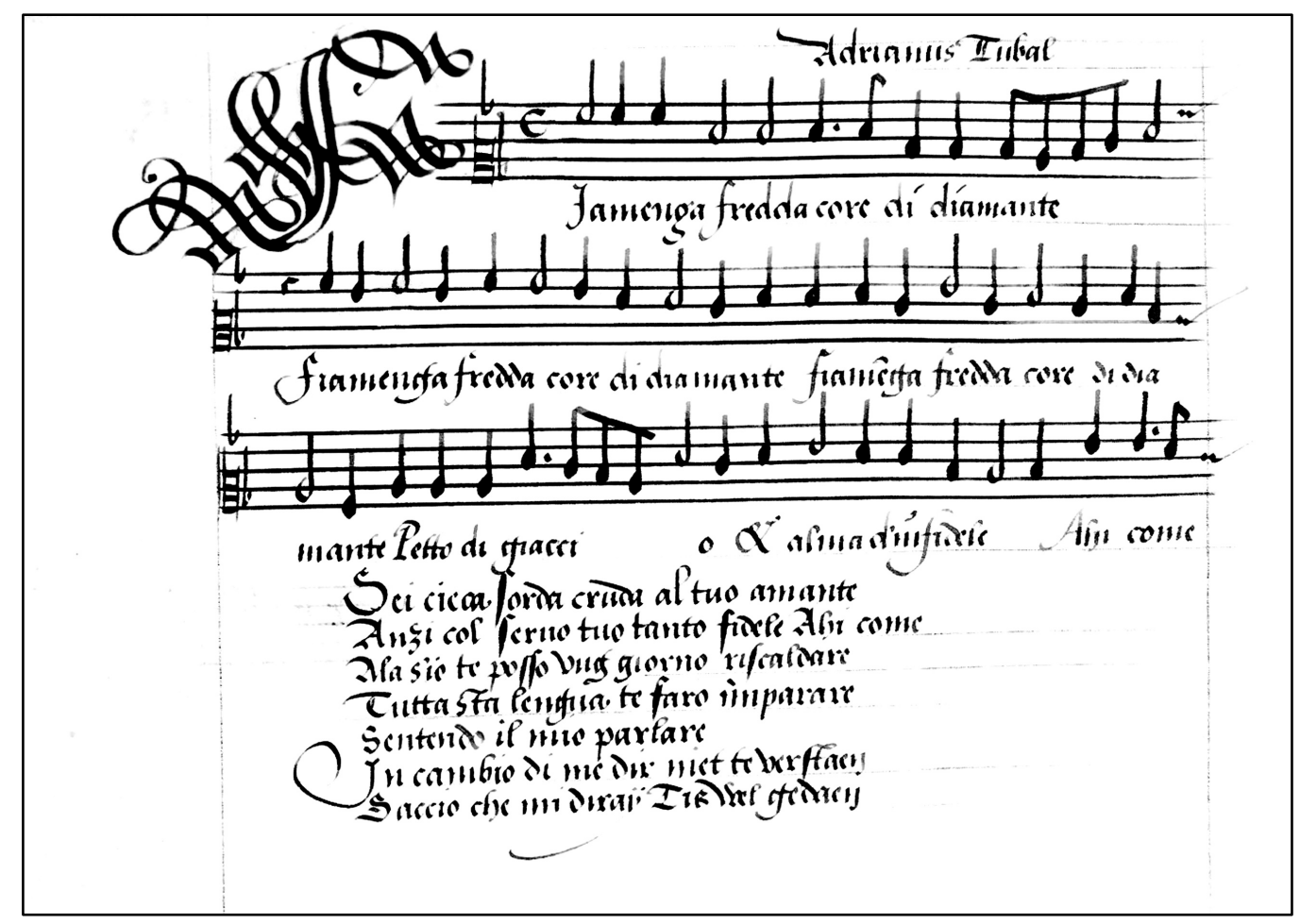

Figura 93. Fac-símile do início da parte do altus da peça Fiamenga fredda, core di diamante, de Adrian Tubal (Winchester Partbooks, n. 15)
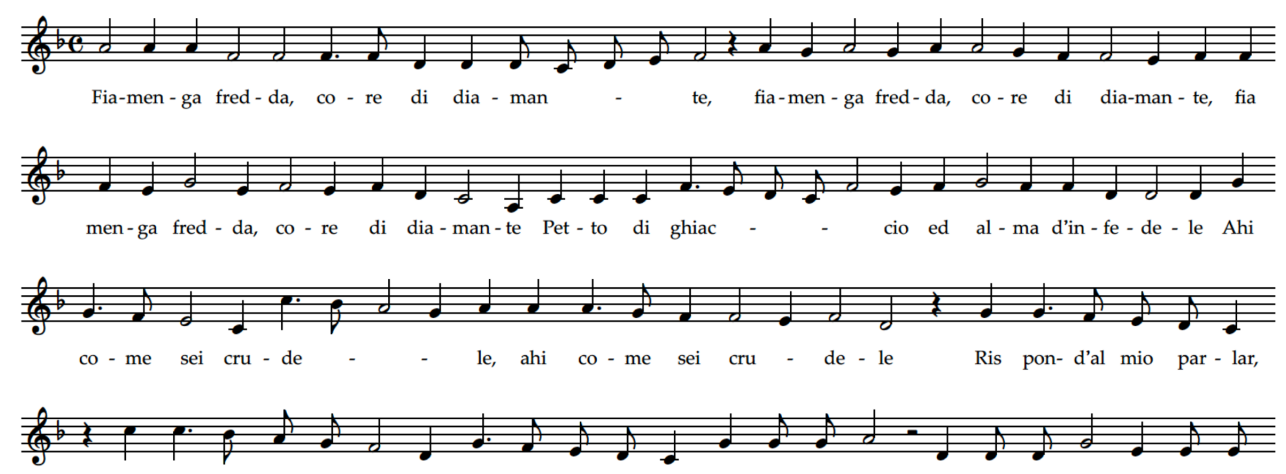

ris - pon-d'al mio par - lar, ris - pon-d'al mio par - lar niet te ver-staan, niet te ver-staan, niet te ver -
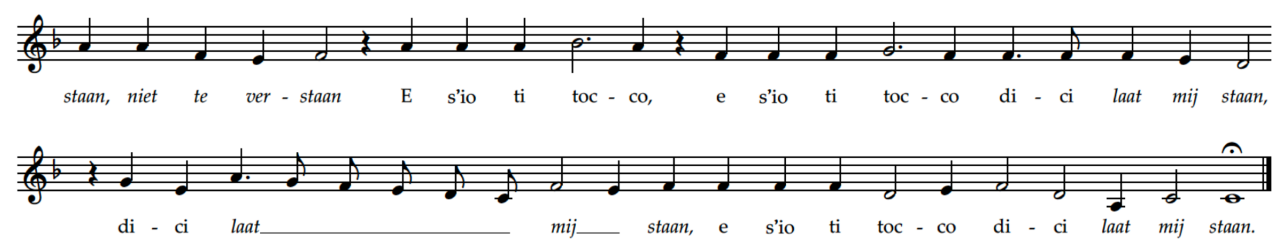

Figura 94. Transcrição da parte do altus da peça Fiamenga fredda, core di diamante, de Adrian Tubal (Winchester Partbooks, n. 15), utilizando-se figuras e claves modernas. 


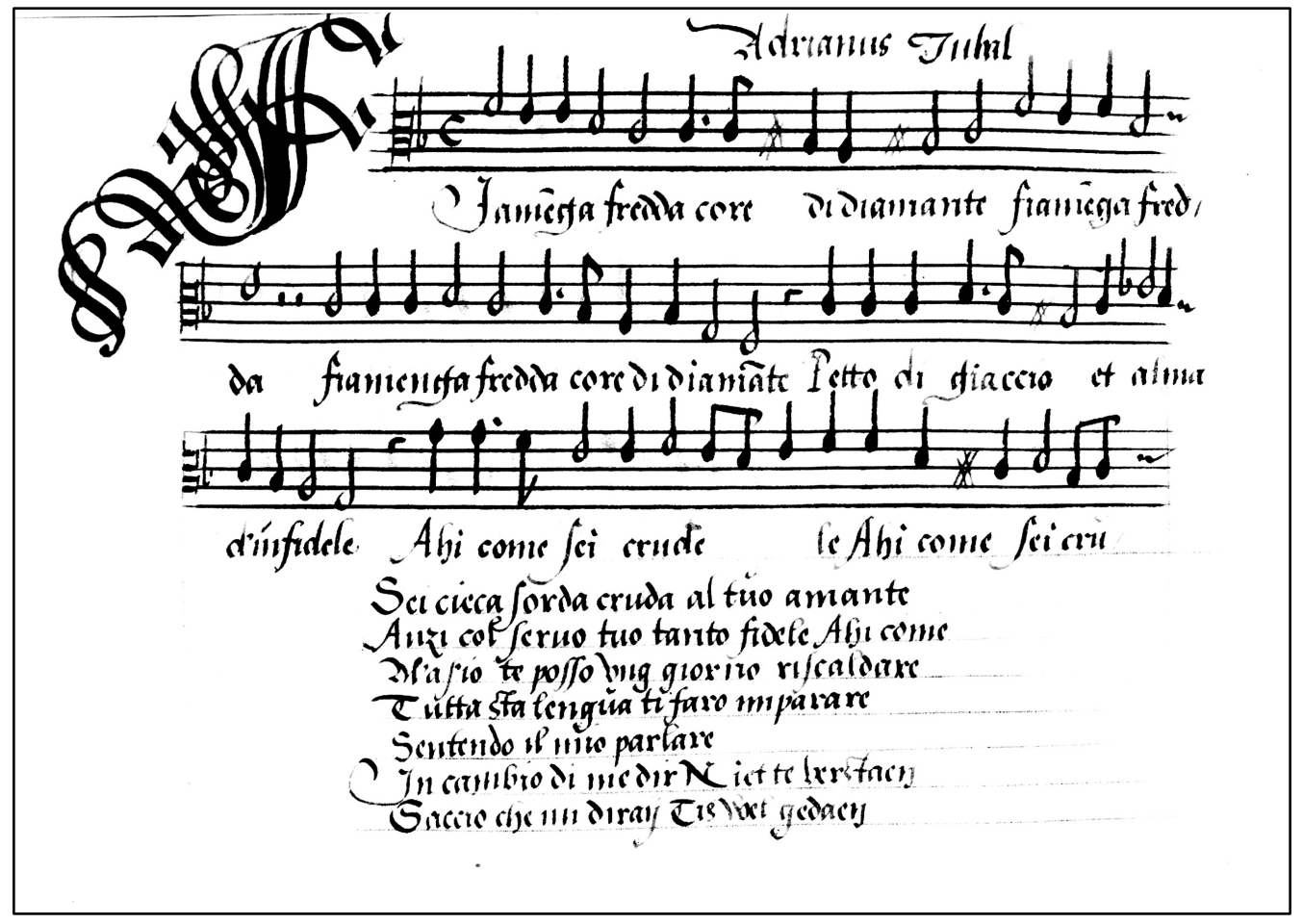

Figura 95. Fac-símile do início da parte do tenor da peça Fiamenga fredda, core di diamante, de Adrian Tubal (Winchester Partbooks, n. 15)

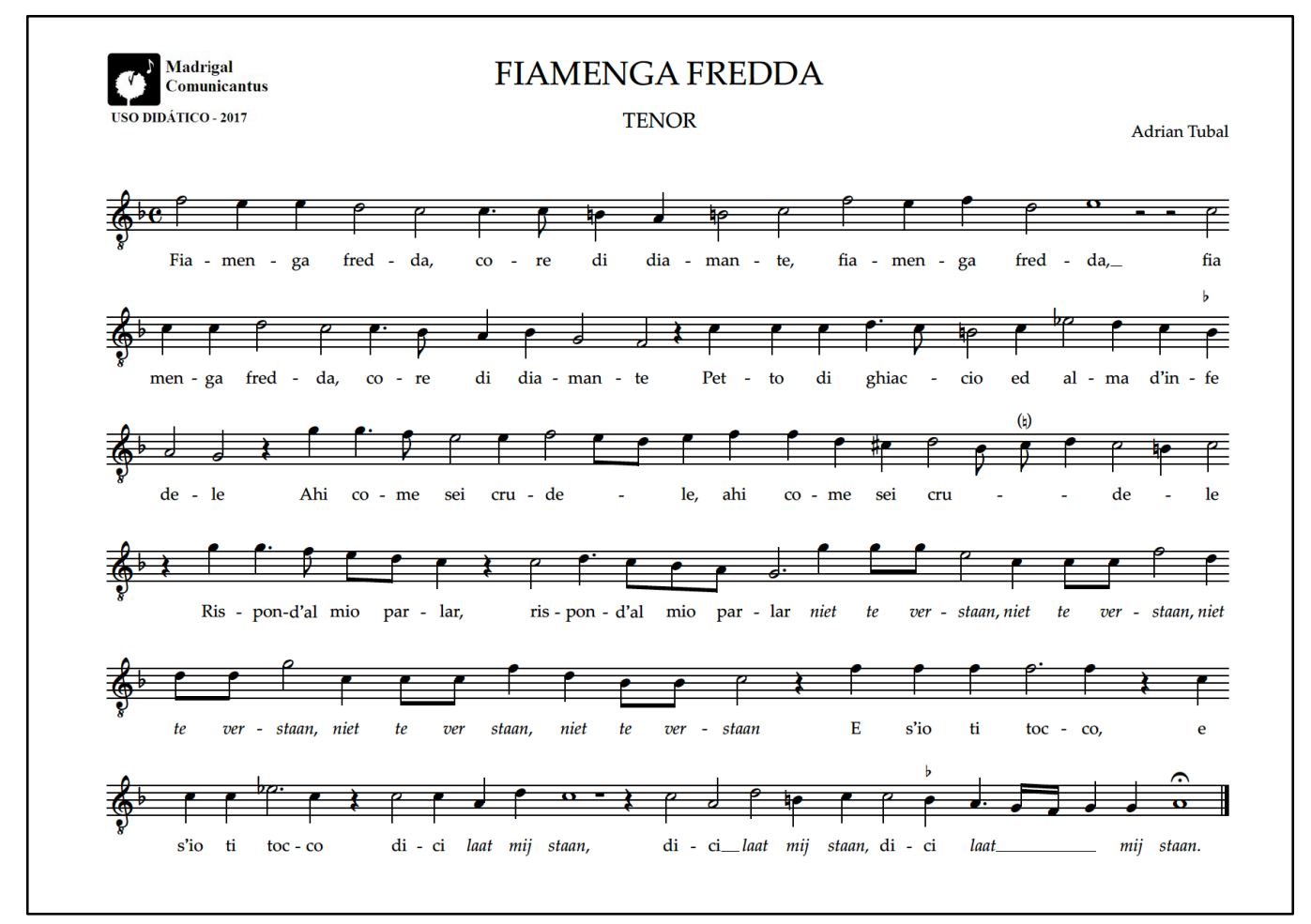

Figura 96. Transcrição da parte do tenor da peça Fiamenga fredda, core di diamante, de Adrian Tubal (Winchester Partbooks, n. 15), utilizando-se figuras e claves modernas. 


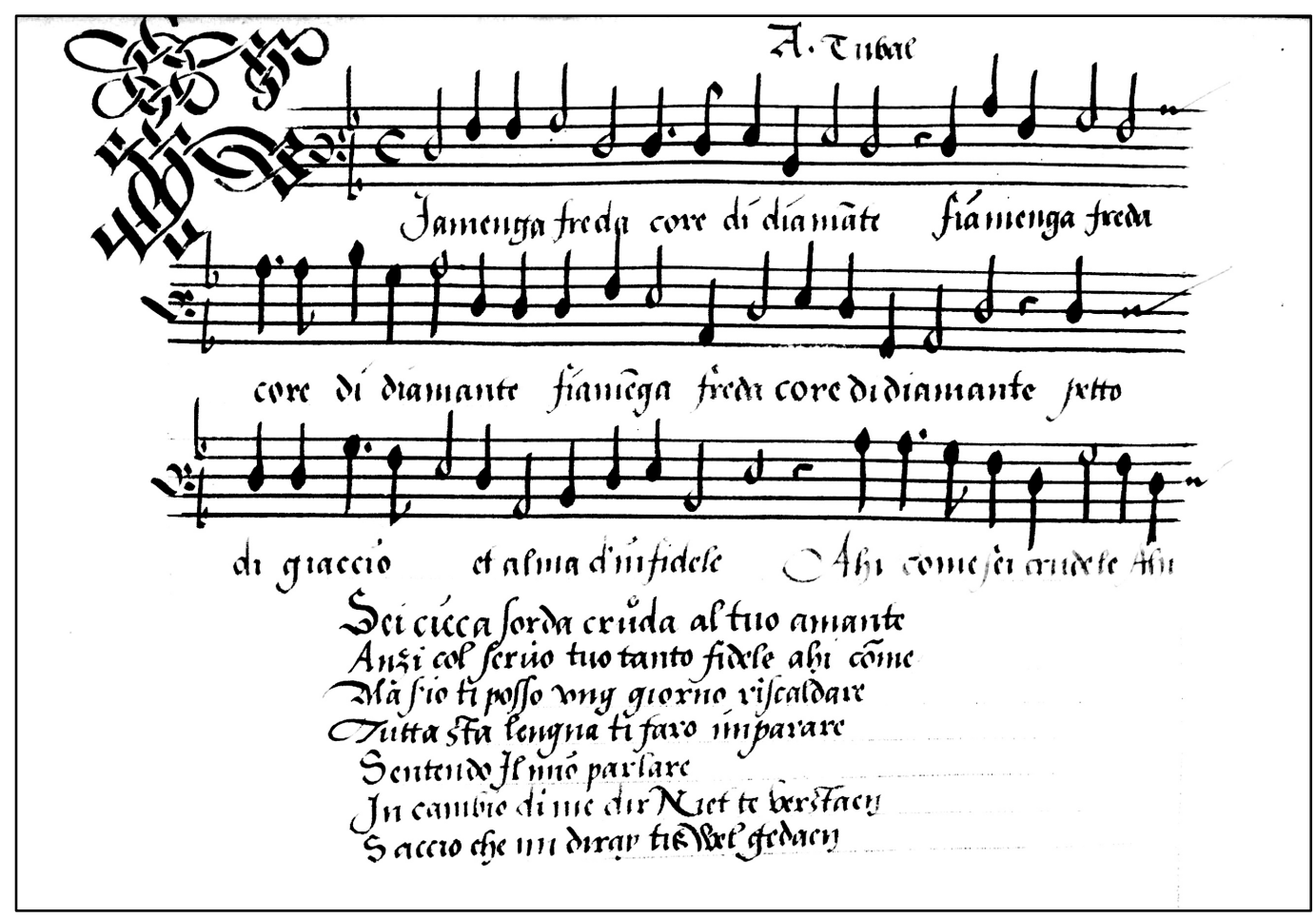

Figura 97. Fac-símile do início da parte do bassus da peça Fiamenga fredda, core di diamante, de Adrian Tubal (Winchester Partbooks, n. 15).

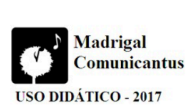

\section{FIAMENGA FREDDA BASSUS}

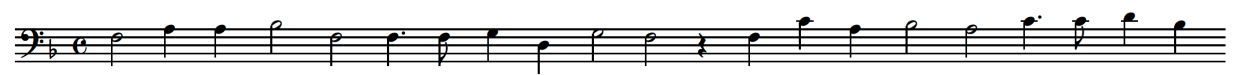

Fia - men - ga fred - da, co - re di dia - man - te, fia - men - ga fred - da, co - re di dia -
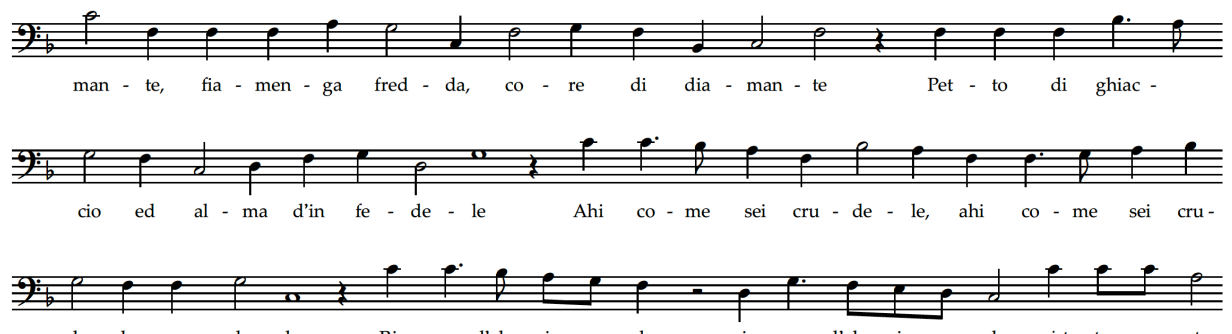

de - le, cru - de - le Ris - pon-d'al mio par - lar, ris - pon d'al mio par - lar niet te ver - staan,
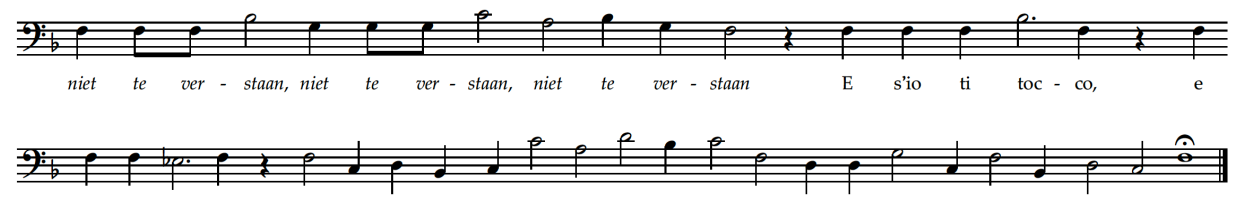

s'io ti toc-co di - ci laat mij staan, di - ci laat mij staan, e s'io ti toc - co di - ci laat mij staan.

Figura 98. Transcrição da parte do bassus da peça Fiamenga fredda, core di diamante, de Adrian Tubal (Winchester Partbooks, n. 15), utilizando-se figuras e claves modernas. 


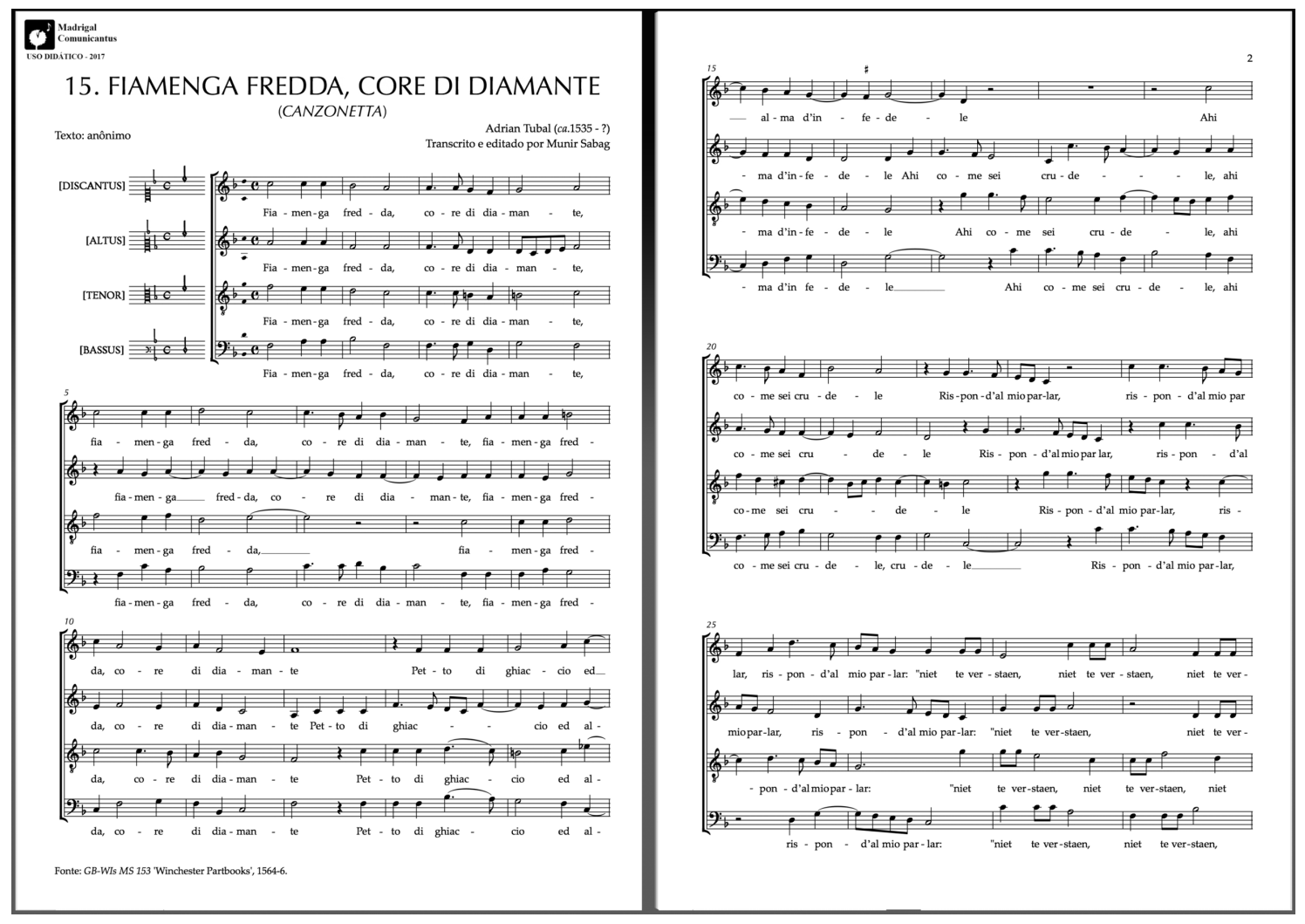

Figura 99. Primeiras páginas da transcrição em partitura da peça Fiamenga fredda, core di diamante, de Adrian Tubal (Winchester Partbooks, n. 15).

ensaio, aproximadamente), a maioria dos cantores - incluindo-se alguns dos que haviam demonstrado alguma relutância inicial ao processo - passou a demonstrar real interesse auditivo nas partes de seus colegas, procurando identificar não apenas a estrutura rítmica do contraponto mas também eventuais dissonâncias e suas respectivas resoluções, o que teve reflexos positivos imediatos no que se refere à afinação do grupo como um todo.

O segundo ponto em questão - isto é, a ausência de barras de compasso também foi percebido inicialmente como uma dificuldade, especialmente na parte do altus, cujo texto apresenta sílabas deslocadas em relação às outras três vozes já no trecho correspondente ao segundo sistema da edição moderna. A seção contrapontística foi igualmente desafiadora para todas as partes em razão das frequentes pausas e síncopas, requerendo insistência e um considerável número de tentativas para que pudesse ser executada. A acentuação correta das sílabas tônicas do 
texto, entretanto, foi rapidamente identificada pelos cantores como guia para o fraseado; este fato tornou-se especialmente claro ao final do ensaio, quando se ofereceu a partitura moderna ao grupo para uma nova execução: a acentuação das sílabas da palavra "rispondi" pelas cantoras da parte do discantus, por exemplo, foi imediatamente realizada de maneira incorreta (fig. 100b, compasso 24), em oposição ao resultado desejável que já havia sido atingido na leitura anterior (fig. 100a).

(a)

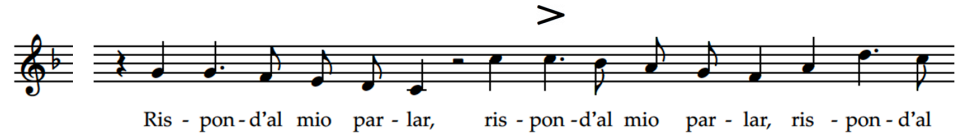

(b)

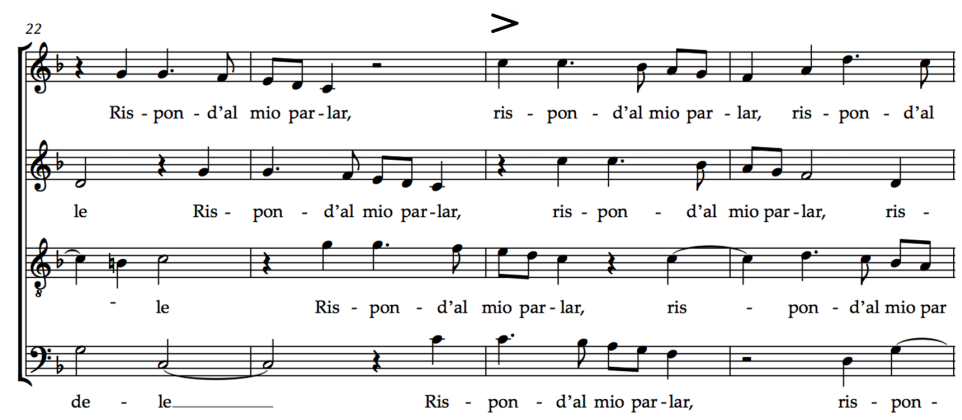

Figura 100. Acentuações observadas nas leituras em partes separadas ou em partitura para um trecho do discantus da peça Fiamenga fredda, core di diamante, de Adrian Tubal (Winchester Partbooks, n. 15).

Esta experiência nos remete novamente ao ponto (já discutido na seção 3.1.8) referente às diferentes possibilidades para o barramento deste repertório em edições modernas. Assim como optamos por evitar mudanças nas fórmulas de compasso em trechos onde os agrupamentos rítmicos se contrapõem ao tactus composicional de uma peça, consideramos impraticável - e provavelmente pouco produtivo - empregar qualquer dispositivo notacional para as inúmeras ocorrências de sílabas tônicas em posições métricas consideradas como "tempos fracos" por intérpretes que analisem (ainda que inconscientemente) este repertório sob óticas posteriores. O próprio uso do Mensurstrich (a barra de compasso que não transpassa o pentagrama), que esteve em 
voga a partir dos anos 1920 (exemplificado na figura 101), é criticado por Blachly em A Performer's Guide to Renaissance Music:

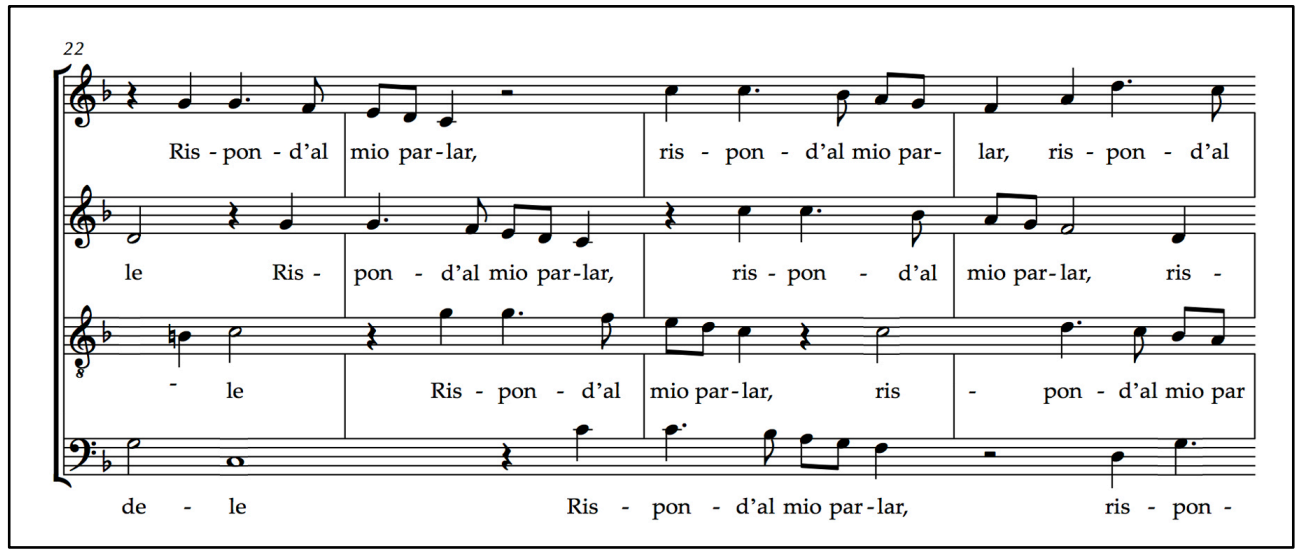

Figura 101. Exemplo do possível uso do Mensurstrich em um trecho da peça Fiamenga fredda, core di diamante, de Adrian Tubal (Winchester Partbooks, n. 15).

Alguns editores então tentaram escrever barras de compasso espaçadas irregularmente para evitar este problema [a acentuação incorreta]. Outros, incluindo alguns intérpretes, fizeram experiências com edições que simplesmente eliminam as barras. Ambas essas abordagens, em minha opinião, são desnecessárias e criam problemas por sua vez. Um coro pode ser ensinado em um tempo relativamente curto que as palavras são os guias corretos para padrões de acentuação. A prática de colocar barras de compasso entre as pautas mas não através delas também me parece um mau compromisso. Tais barras de compasso, que os alemães chamam de Mensurstriche, são feitas para indicar o alinhamento correto das vozes sem exigir que notas longas sejam decompostas nas partes que as constituem quando elas cruzam de um compasso ao próximo. Além das dificuldades impostas para o intérprete quando um "compasso" começa com um espaço em branco representativo daquela porção de uma nota longa de um compasso anterior que cruzou o Mensurstrich e depois termina com uma nota que é "muito longa" (porque ela cruza o próximo Mensurstrich), tais edições devem ser difíceis de revisar, a julgar pelos muitos erros que contêm. Dizer que a fala e a pronúncia correta são os princípios que guiam o fraseado da música do Renascimento é assegurar a primazia da fala sobre a aparente acentuação das barras de compasso. Certamente os cantores da música do Renascimento são tão capazes de dominar as convenções particulares da música que eles interpretam quanto o são os intérpretes de outros repertórios. Aprender a desconsiderar as implicações não pretendidas das barras de compasso modernas não é mais difícil do que aprender o ritmo saltado de uma giga ou a cadência de uma valsa vienense. Assim que um coro permite que as palavras determinem a acentuação, as barras 
de compasso tornam-se meros guias visuais para o conjunto vertical e são invisíveis para todos os outros efeitos. (BLACHLY; KITEPOWELL, 2007, p. 20-21, tradução nossa ${ }^{52}$ )

Na entrevista intitulada There is no such Thing as a Norm ("Não existe essa coisa de norma", em tradução aproximada) concedida a Bernard Sherman e publicada no volume Inside Early Music: Conversations with Performers (SHERMAN, 1997), as declarações do aclamado intérprete e professor Paul Hillier reafirmam alguns dos pontos aqui discutidos, acrescentando sua visão a respeito da validade da abordagem ocasional do material em notação original (ou de adaptações como aquelas produzidas na experiência relatada nesta seção):

A notação moderna coloca um viés na informação que você está recebendo que é muito diferente do que a notação original nos diz. Não é só que a notação antiga normalmente apresenta uma única parte ao invés da partitura. É também, em primeiro lugar, que você não tem barras de compasso que dividem a música com frequência excessiva: você tem uma longa linha sonora, que em notação moderna é quebrada em pequenos segmentos de ${ }_{4}^{4}$, ou ${ }_{2}^{3}$, ou de alguma outra coisa. A barra de compasso não apenas a divide, mas também sugere uma ênfase regular em um beat que é inapropriado para a música na maior parte do tempo. Visualmente, o fluxo da linha e da frase é dificultado por estas barras de compasso. E a segunda coisa que é diferente é a natureza dos valores de figuras que nós usamos, em oposição aos

52 No original: "Some editors have therefore attempted to write irregularly spaced barlines that are intended to avoid this problem. Others, including some performers, have experimented with editions that do away with bar lines altogether. Both of these approaches, in my opinion, are unnecessary and create problems in turn. A choir can be taught in a relatively brief time that the words are the proper guides to stress patterns. The practice of placing bar lines between the staves but not through them also strikes me as a bad compromise. Such bar lines, which the Germans call Mensurstriche, are intended to indicate the proper alignment of voices without requiring longer notes to be broken into constituent parts as they cross from one measure to the next. Quite aside from the difficulties posed for the performer when a "measure" begins with a blank space representative of that portion of a long note from the previous measure which crosses the Mensurstrich, and then ends with a note that is "too long" (because it crosses the next Mensurstrich), such editions must be difficult to proofread, to judge from their many typos. To say that speech and correct pronunciation are the guiding principles of Renaissance phrasing is to assert the primacy of speech rhythm over the apparent bar line stress. Surely, singers of Renaissance music are as able as performers of other repertories to master the particular conventions of the music they perform. Learning to overlook the unintended stress implications of modern bar lines is no more dificult than learning the springing rhythm of a guigue or the lilt of a Viennese waltz. As soon as a choir lets the words determine stress, the bar lines become merely visual guides to vertical ensemble and are to all intents and purposes invisible in other respects." 
originais - tudo isso afeta a maneira com que cantamos a música. Apenas como um exemplo, nós poderíamos considerar um moteto bem conhecido de Byrd, como Ave verum corpus. Olhando para as edições comuns usadas pela maioria dos coros, nós podemos ver imediatamente que o editor respondeu tão bem quanto pôde à demanda da música por um sentido métrico flexível, alternando frequentemente entre fórmulas de compasso binárias e ternárias ao longo da peça. O problema é que há ainda muitas, muitas passagens onde as vozes ou estão em uma mescla de ritmos binários e ternários, ou então têm seus "tempos fortes" ["downbeats"] em momentos diferentes. Nenhum sistema de barramento fará justiça a isso, e o resultado é uma mescla de acentos aparentemente deslocados e síncopas desnecessárias. Mesmo tomando uma linha por vez, o uso de barras de compasso, tão flexível quanto seja, impõe uma resposta definida no lugar da ambiguidade maravilhosamente flexível e expressiva do original. Os céticos argumentarão que o resultado sonoro é basicamente o mesmo em qualquer dos casos, mas eu ouso discordar. Nós ouvimos a mesma sequência abstrata de notas, é claro, e a diferença pode ser bastante sutil em algum dado momento, mas o resultado final é como ver a música através de lentes tingidas. Em última análise, nós perdemos o senso de liberdade rítmica e de fraseado "natural", substituídos por um tipo de segurança inflexível emprestada das convenções de uma época diferente. Seria maravilhoso se as pessoas que querem interpretar a música antiga pudessem usar ou um fac-símile do original ou uma transcrição (conhecida como "diplomática") usando uma adaptação mais legível do estilo original de notação. Pode ser impraticável fazer isso o tempo todo; mas seria uma experiência muito informativa se cantores trabalhassem peças inteiras em notação original uma ou duas vezes e aprendessem os tipos de informação que são transmitidos por tal notação. Às vezes as diferenças são muito sutis; não se deveria insistir nelas com muito peso. Mas então seria possível, eu acho, voltar a usar a notação moderna munido dessa informação e não simplesmente ter ouvido de alguém como eu que o problema com a notação moderna é que ela tem muitas barras de compasso. Uma coisa é dizer isso, e outra é ter a experiência de cantar a música sem as barras de compasso. (SHERMAN, 1997, p. 105-106, tradução nossa ${ }^{53}$ )

\footnotetext{
${ }^{53}$ No original: "Modern notation puts a bias on the information that you're receiving that is very different from what the original notation tells us. It's not only that early notation usually presents a single part by itself rather than a score. It's also, first of all, that you do not have barlines, which divide the music up far too frequently: you get a long line of sound, which in a modern notation is broken up into little segments of $\frac{4}{4}$, or 32 , or something. The barline not only divides it up, it also suggests a regular emphasis on a beat which is inappropriate to the music most of the time. Visually, the flow of the line and phrase is impeded by these barlines. And the second thing that's different is the nature of the note values that we use, as opposed to the originals - all this does affect the way we sing the music. As just one example we might consider a well-known motet by Byrd, such as Ave verum corpus. Looking at the familiar editions used by most choirs, we can see straight away that the editor has responded as well as
} 
Em acordo com as considerações de Hillier, pudemos efetivamente observar no trabalho realizado junto ao Madrigal Comunicantus os benefícios das experiências com a leitura a partir de fac-símiles (ou de suas adaptações) sobre a performance geral do grupo, mesmo quando se executam peças para as quais este material não está disponível.

Reconhecemos, contudo, que as dificuldades relatadas por Smith e Blachly no início desta seção - aliadas algumas vezes a certa relutância por parte dos diretores musicais dos coros e ensembles vocais contemporâneos - constituem obstáculos suficientes para que a prática de leitura e performance em fac-símiles se torne inviável para a maior parte dos usuários de edições modernas. Isto certamente constitui um fator determinante para que as publicações contemporâneas do repertório renascentista continuem sendo elaboradas em partitura e este formato foi também adotado pelo presente autor para as transcrições apresentadas no próximo capítulo.

he can to the music's demand for a flexible sense of meter, changing frequently throughout the piece between duple and triple time signatures. The problem is that there are still many, many passages where the voices either are in a mixture of duple and triple rhythms, or else simply have their "downbeats" at different times. No system of barring can do justice to this, and the result is a mixture of seemingly displaced accents and superfluous syncopations. Even taking a line at a time, the use of barlines, however flexible, imposes a set response in place of the wonderfully supple and expressive ambiguity of the original. Skeptics will argue that the sounding result is pretty much the same in either case, but I beg to differ. We hear the same sequence of abstract notes, certainly, and the difference may be rather subtle at any given moment, but the net result is like viewing the music through tinted glasses. Ultimately, we lose a sense of rhythmic freedom and "natural" phrasing, replaced by a kind of foursquare security borrowed from the conventions of a different age. It would be wonderful if people wanting to perform early music could use either a facsimile of the original or a transcription (known as "diplomatic") using a more readable adaptation of the original style of notation. It might be impractical to do that all the time; but it would be a very informative experience if singers would once or twice work their way through a piece in the original notation, and just learn the kinds of information that are conveyed by that notation. Sometimes the differences are very subtle; one wouldn't want to insist upon them too heavily. But then it would, I think, be possible to go back to using modern editions armed with this information and not simply having been told by someone like me that the trouble with these editions is that there are too many barlines. It's one thing to say that, and another to have the experience of singing the music without barlines." 


\section{TRANSCRIÇÕES DAS PEÇAS SELECIONADAS}

O presente capítulo consiste na apresentação do texto musical sob consideração neste trabalho - isto é, nas edições finais das 41 peças selecionadas para transcrição como parte da pesquisa. Embora as versões aqui propostas estejam apresentadas em formato de partitura e inevitavelmente reflitam nossa própria interpretação dos manuscritos estudados, procuramos adotar uma postura editorial predominantemente diplomática e minimizar intervenções, exceto nos casos em que as consideramos necessárias para que as transcrições possam ser utilizadas com fins práticos.

Apesar de não havermos reduzido os valores das figuras originais e de não havermos proposto quaisquer transposições, incluímos nas transcrições algumas sugestões editoriais de: (i) acidentes decorrentes de possíveis inflexões ficta; e (ii) equivalências métricas em peças que apresentem justaposição de trechos com subdivisões binárias e ternárias, conforme discutido ao longo do capítulo anterior. As transcrições contêm incipits que exibem os sinais de mensuração, claves e primeiras notas em notação original, possibilitando uma eventual reconsideração de aspectos relacionados à métrica, andamento e alturas por parte do intérprete, caso isso seja circunstancialmente necessário ou desejado. Nos casos supracitados em que trechos binários e ternários são justapostos, não tornamos a reproduzir na partitura os novos sinais de mensuração ocorrentes ao longo de cada peça e o leitor poderá se referir à seção 3.1 .9 (p. 111-120) para o exame detalhado dos exemplos em que tais transições ocorrem.

Eventuais inconsistências presentes nos manuscritos, assim como outras informações consideradas relevantes, foram apontadas sob a forma de notas editoriais ao final de cada peça quando necessário. Não adicionamos às transcrições qualquer indicação editorial de andamento, dinâmica ou articulação; em virtude da inegável importância da relação texto-música presente no repertório vocal do Renascimento, consideramos que estes sinais pudessem ser mais efetivamente substituídos pelos 
textos italianos e suas respectivas traduções, razão pela qual os transcrevemos imediatamente após o título de cada obra. Com o objetivo de facilitar a localização dos

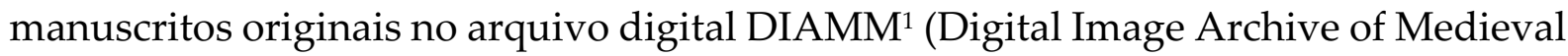
Music) por parte do intérprete interessado em sua consulta, apontamos em cada subtítulo a numeração correspondente à catalogação original do referido repositório.

${ }^{1}$ www.diamm.ac.uk 


\section{1 . \\ PACE NON TROVO}

(Winchester Partbooks, n. 4)

Texto: Francesco Petrarca (1304-1374)

anônimo

Transcrito e editado por Munir Sabag

Pace non trov' e non ho da far guerra;

E temo e spero e ardo e son un ghiaccio;

E volo sopra il cielo e giaccio in terra;

E nulla stringo e tutto il mondo abbraccio.

Tal in pregion che non m'apre né serra

Né per suo mi riten né scioglie il laccio

Et non m'ancide Amore e non mi sferra

Né mi vuol vivo né mi trae d'impaccio

Veggo senz' occhi e non ho lingua e grido;

E bramo di perir e chieggio aita;

E ho in odio me stesso e amo altrui.

Pascomi di dolor, piangendo rido;

Egualmente mi piace vita e morte.

Così vuol mia fortuna over mia sorte.
Não encontro paz, e não farei guerra;

E temo, e tenho esperança; e ardo e sou um gelo;

E voo sobre o céu, e repouso na terra;

E nada aperto, e o mundo todo abraço.

Como numa prisão que não me solta nem me prende Ném me retém para si, nem desamarra o laço

E Amor não me mata nem me liberta

Nem me quer vivo e nem me tira do embaraço.

Vejo sem olhos, e não tenho língua e grito

E clamo pela morte, e peço ajuda;

E odeio a mim mesmo, e amo outros.

Me alimento de dor, chorando rio;

Me agradam igualmente a vida e a morte.

Assim quer meu destino ou minha sorte.
[DISCANTUS]

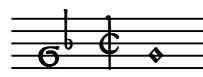

[ALTUS]

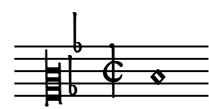

[TENOR]

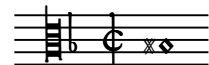

[BASSUS]

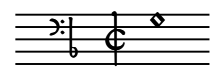

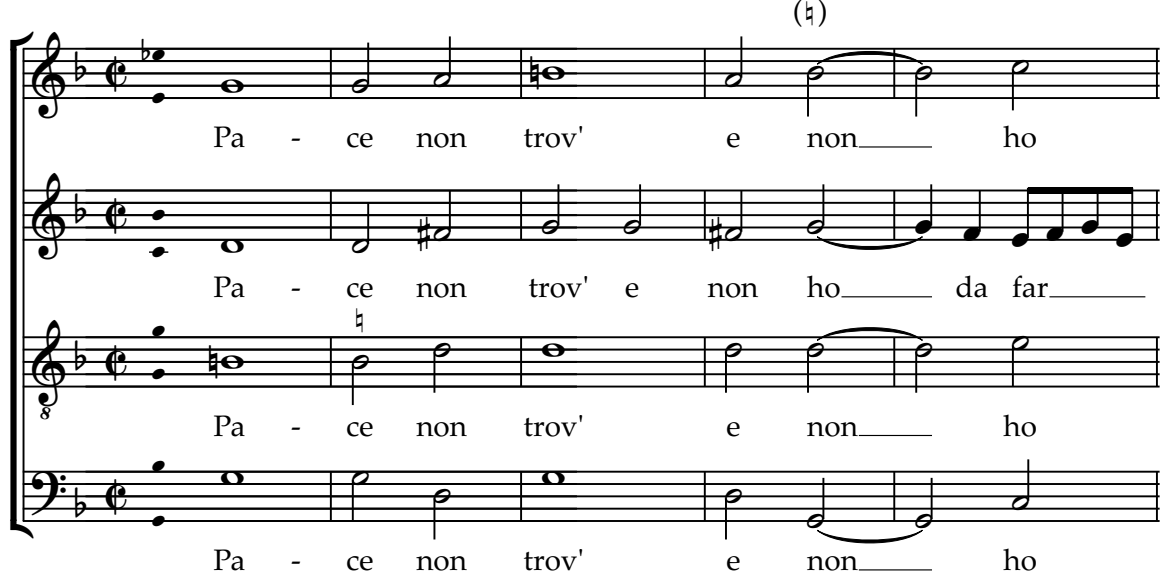

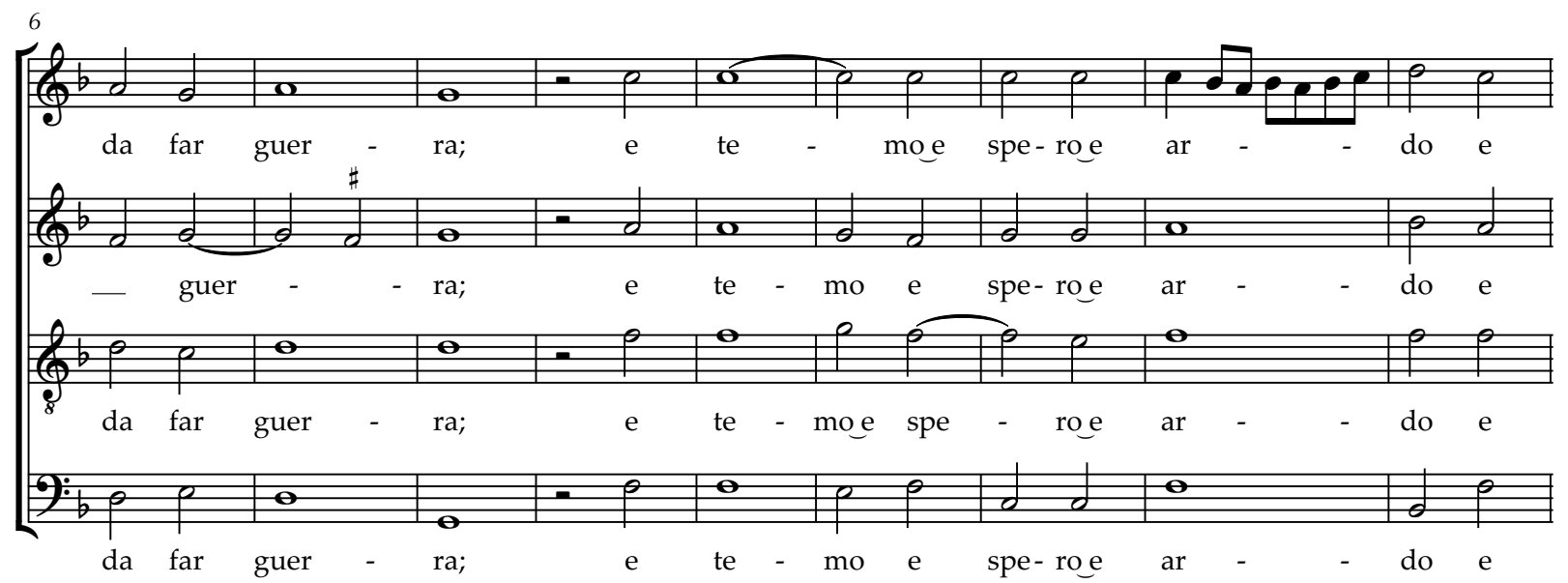



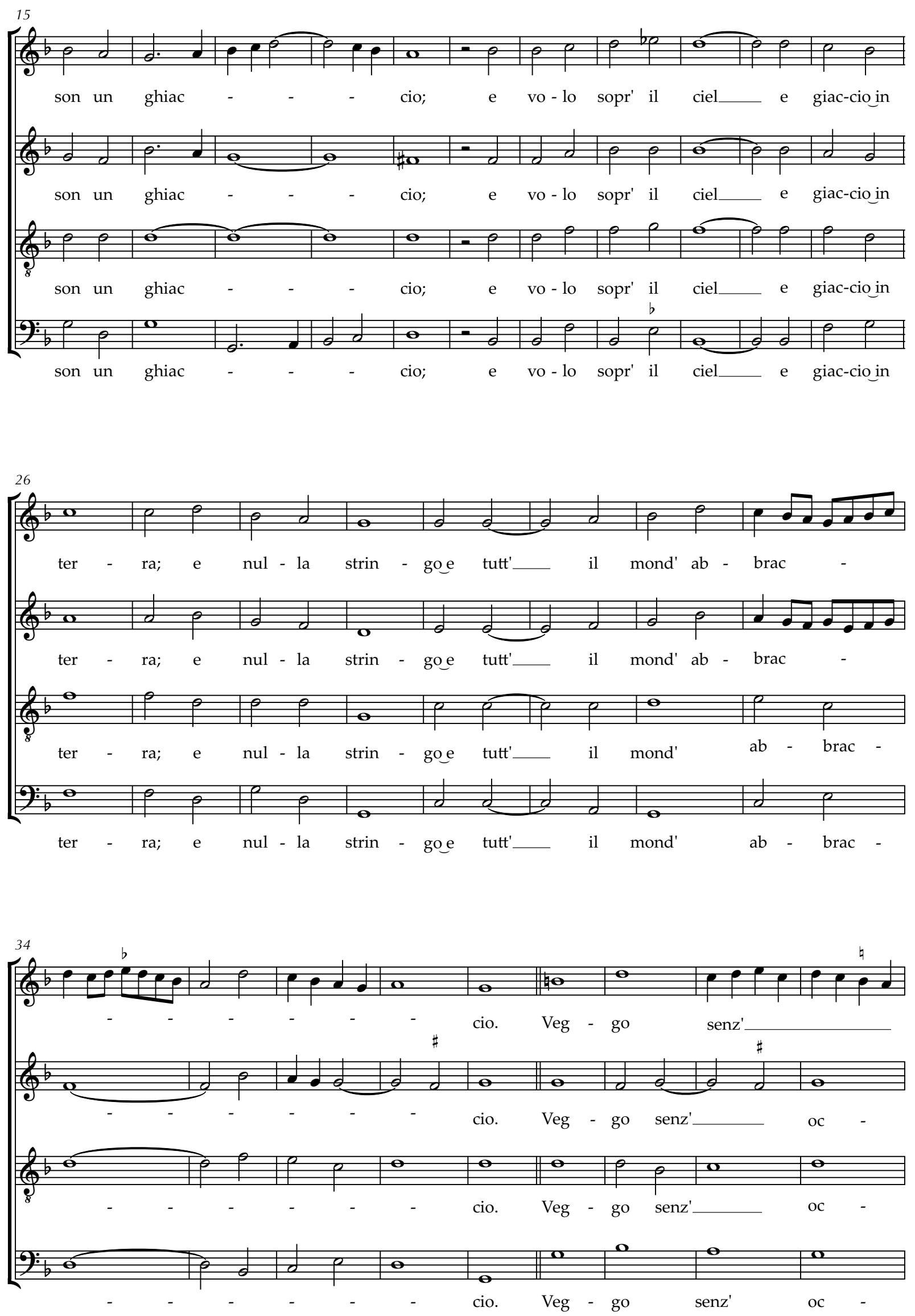

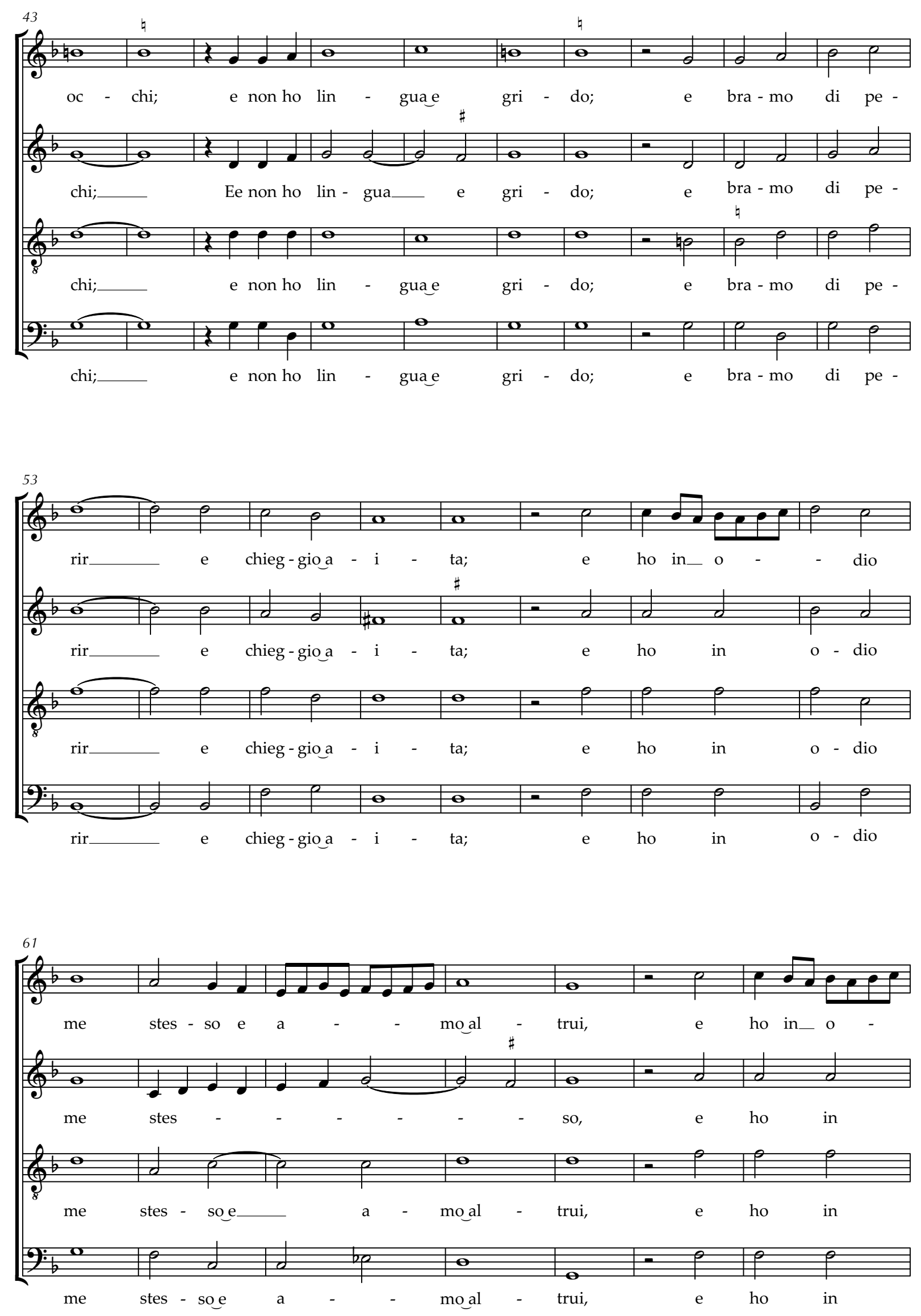

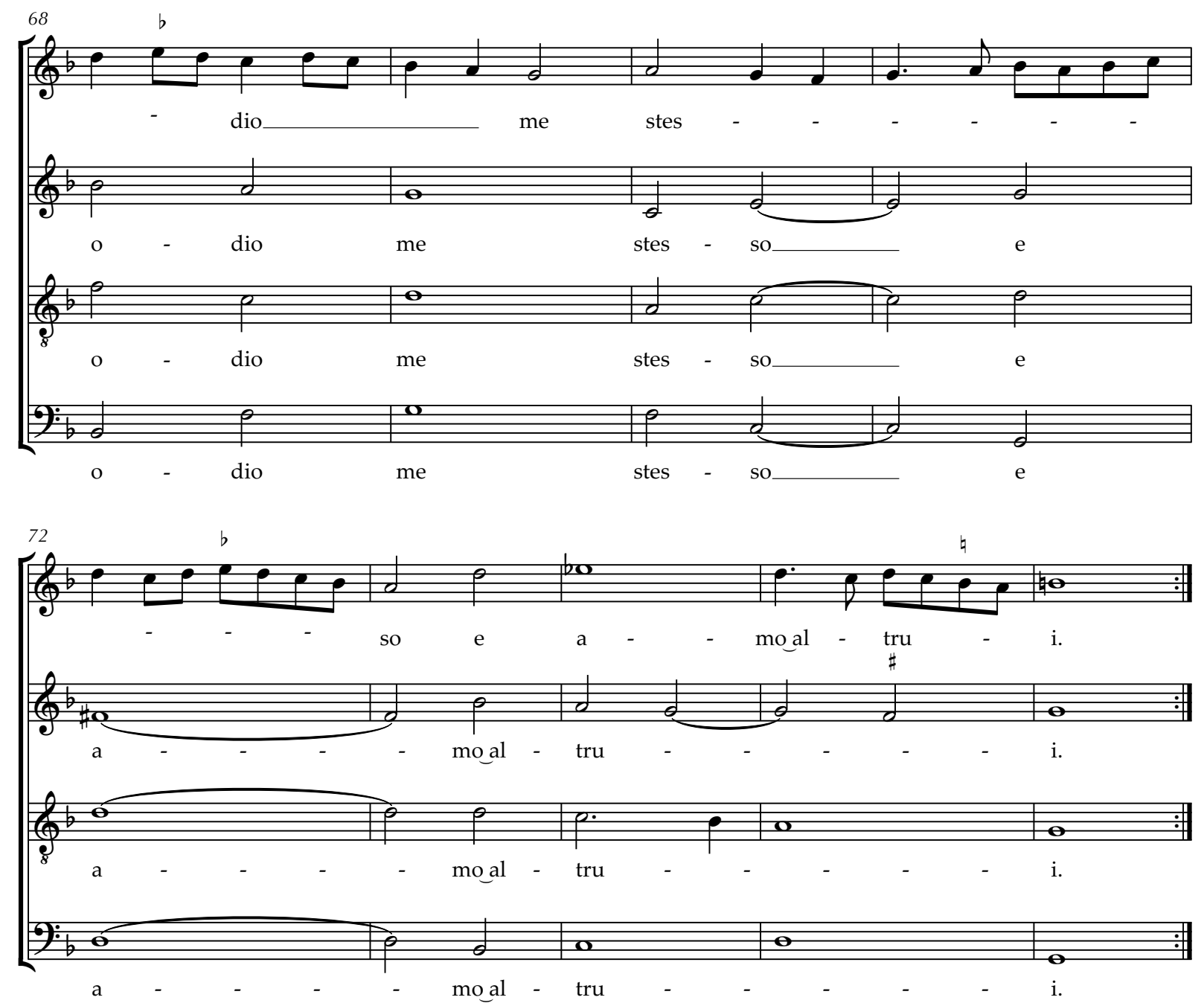

\section{NOTAS DO EDITOR:}

(1) No original de Petrarca (Canzoniere, soneto 134) o último terceto lê-se:

Pascomi di dolor, piangendo rido

Egualmente mi spiace morte e vita

In questo stato son, Donna, per vui.

(2) No manuscrito, apenas os textos do primeiro quarteto e o primeiro terceto aparecem alinhados às notas (o segundo quarteto e o segundo terceto aparecem como textos suplementares). Embora um sinal de repetição esteja anotado ao final da peça, a definição da forma (AABB ou $\mathrm{ABAB}$ ) e a colocação do texto são duvidosas (especialmente no início do segundo terceto, onde ocorreria uma pausa entre duas sílabas da palavra "dolor") e por esta razão mantivemos o texto restante como suplementar, assim como consta nas fontes originais.

(3) Discantus, compasso 58: falta a pausa de minima no manuscrito.

(4) Discantus, compassos 68-71: as figuras destacadas abaixo faltam no manuscrito; o trecho foi reconstruído pelo presente editor como uma sugestão baseada na semelhança melódica e harmônica com o compasso 62, uma vez que o trecho iniciado no compasso 66 constitui uma repetição estendida e ornamentada daquele iniciado no compasso 58.

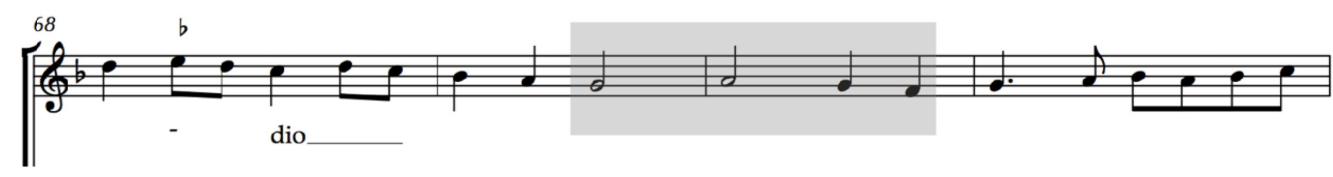




\title{
4.2. ECCO LA STAGION NOVELLA
}

\author{
(Winchester Partbooks, n. 5)
}

Texto: anônimo

Ecco la stagion novella

Ch'ogni pianta rinovella,

Ch'il suo frutto e il suo fiore;

Dimmi in cortesia pastore,

Si mai nel pett'amor fiamma te avesse.

Giovinetta son io bell'e cortese.

Sempr' il buon tempo mi piacque

Mentre passo il mio gregge per costume,

Alla riva d'un fiume

Dormir al dolce suon del mormorar dell'acque,

Hor facendo tutti i cori,

Non vedi quei biaci tori?

Come già punti e infiammati

D'amor van per verdi prati

Scherzando et fan l'altrui volgie palette?

Giovinetta son io bell' e cortese.

Sempre il buon tempo mi piacque...

Hor d'incendio et d'amor piena

Già cantando filomena

Ritorn'al suo dolce nido

E qual fanciullin cupido

Strai prepara all'amorose offese.

Giovinetta son io bell'e cortese.

Sempre il buon tempo mi piacque...

Chi d'amor sprezza la fiamma

Ch'ogni gentil cor infiamma,

Egli è sciocco indegno et vile.

Ma tu bel pastor gentile,

Se mai ti cal dell'amorose imprese,

Giovinetta son io bell' e cortese.

Sempre il buon tempo mi piacque...
Anônimo

Transcrito e editado por Munir Sabag
Eis a estação nova

Que cada planta renova,

E seu fruto, e sua flor;

Diz-me, por cortesia, pastor,

Se acaso tiveres a chama do amor no peito.

Eu sou jovenzinha, bela e cortês.

O bom tempo sempre me agrada

Enquanto passo o meu rebanho, por costume,

Pela margem de um rio,

Dormir ao doce som do murmurar das águas.

Agora, todos fazendo coro,

Não vês aqueles brancos touros?

Como já pungidos e inflamados

De amor vão pelos verdes prados,

Brincando e inspirando nos outros o desejo?

Eu sou jovenzinha, bela e cortês.

O bom tempo sempre me agrada...

Agora, plena de fogo e de amor,

Já cantando, Filomena andorinha

Retorna a seu doce ninho

E qual jovem Cupido

Prepara flechas para investidas amorosas.

Eu sou jovenzinha, bela e cortês.

O bom tempo sempre me agrada...

Quem despreza a chama do amor,

Que inflama todo coração gentil,

Ele é tolo, indigno e vil.

Mas tu, belo e gentil pastor,

Se porventura prezas investidas amorosas,

Eu sou jovenzinha, bela e cortês.

O bom tempo sempre me agrada...

[DISCANTUS]
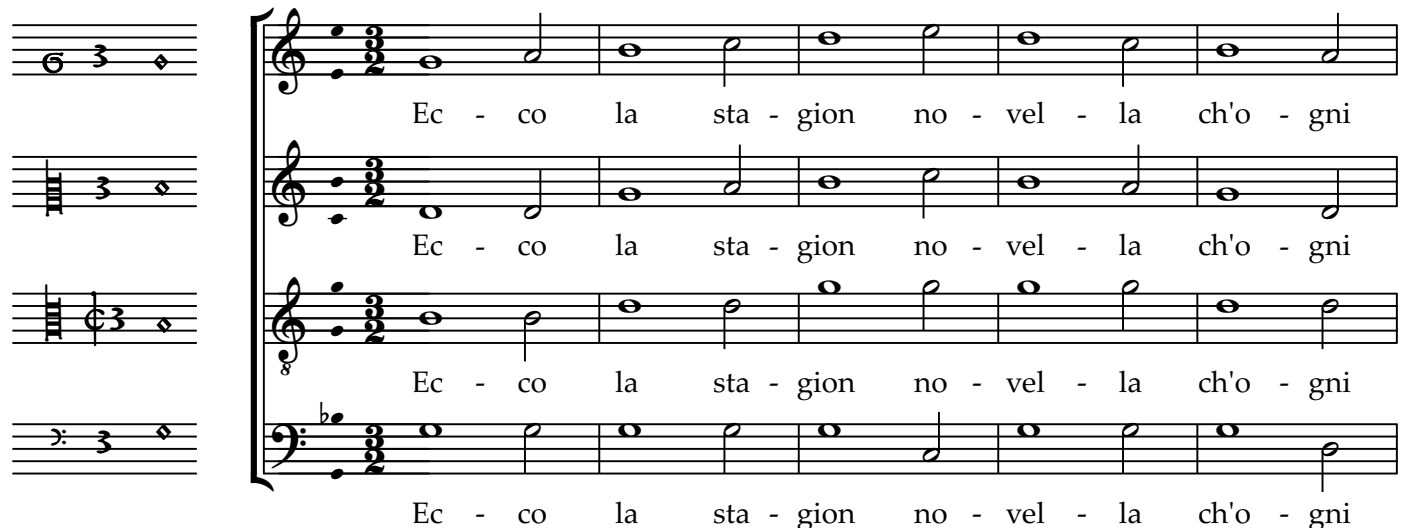

Fonte: GB-WCc MS 153 'Winchester Partbooks', 1564-6. 

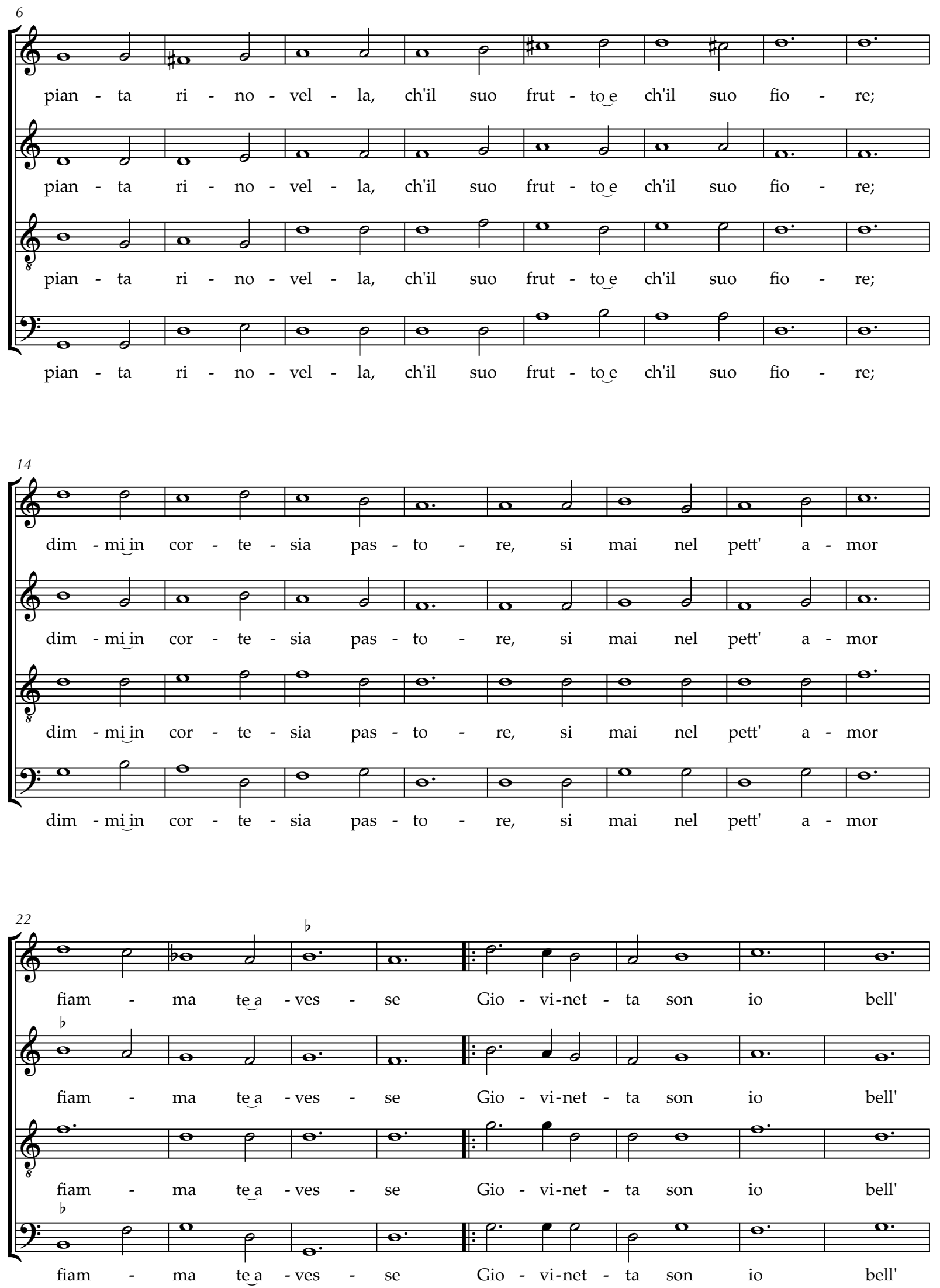

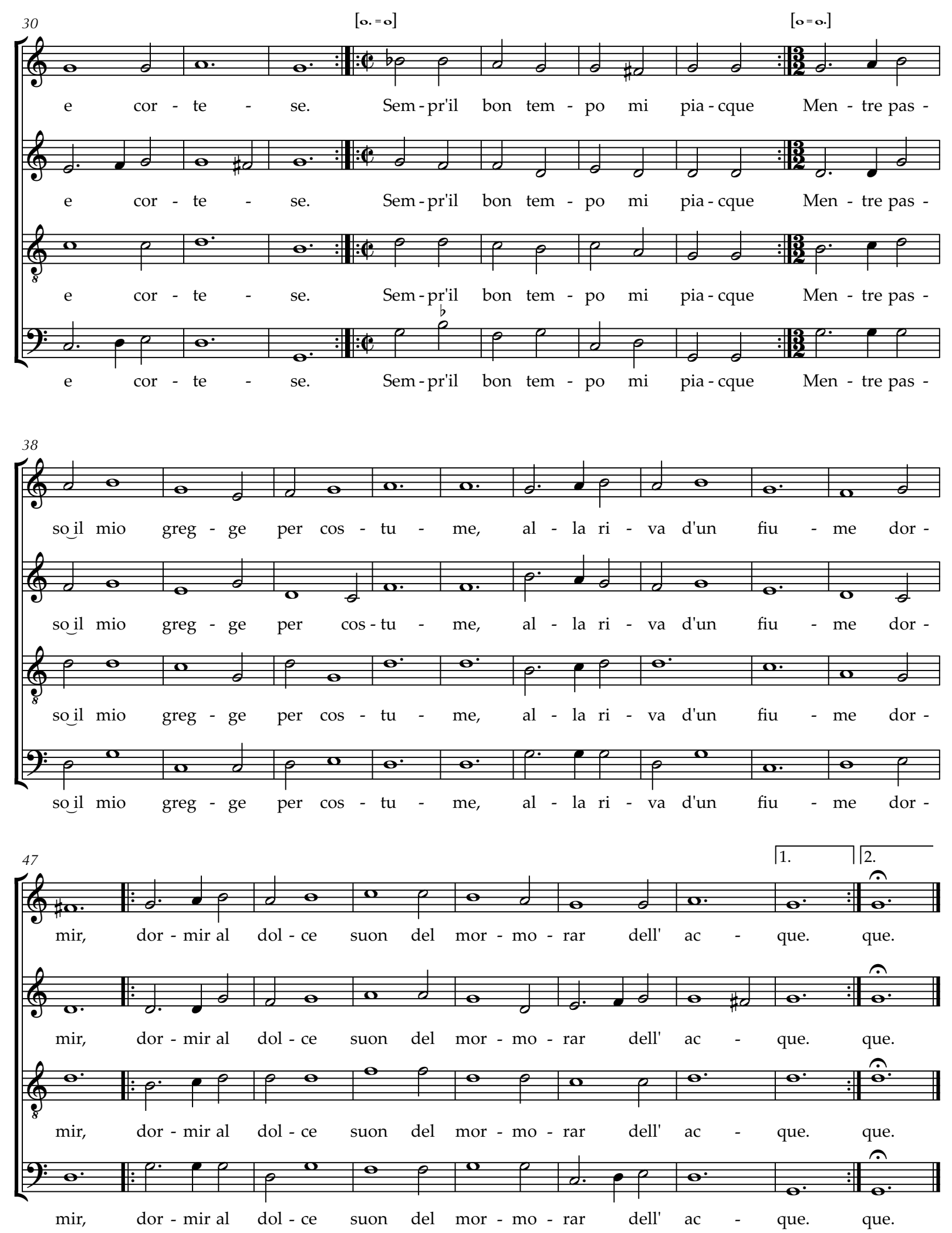

NOTA DO EDITOR:

Tenor, compassos 48-49: o manuscrito exibe apenas "al dolce". 


\title{
4.3. IO CHE TROPP' ALT' AMOR VOLSI SEGUIRE
}

\author{
(Winchester Partbooks, n. 7)
}

Texto: anônimo

anônimo

Transcrito e editado por Munir Sabag

Io che tropp' alt' amor volsi seguire

Raggion è ben ch'io pianga del mio male.

A cader va chi tropp' in alto sale.

Il giovane gentil che volse ardire

Volar vicino al Sol s'abbrucciò l'ale.

A cader va chi tropp' in alto sale.

Quand' il Gigante al ciel volse salire

Giacque ferito dal supremo strale.

A cader va chi tropp' in alto sale.

Non mi curo patir pen' e dolore

Se ben quest' alma sconsolata more

Pur ch'altamente habbia locato il core.
$\mathrm{Eu}$, que quis perseguir um amor alto demais, Devo agora chorar por meu mal.

Quem sobe muito alto acabará caindo.

O belo jovem que quis ousar

Voar perto do Sol queimou as asas.

Quem sobe muito alto acabará caindo.

Quando o gigante quis subir ao céu

Caiu ferido pelos raios celestes.

Quem sobe muito alto acabará caindo.

Não me importo padecer penas e dores

Mesmo que esta alma desconsolada morra

Desde que nas alturas eu tenha posto o coração.

[DISCANTUS]
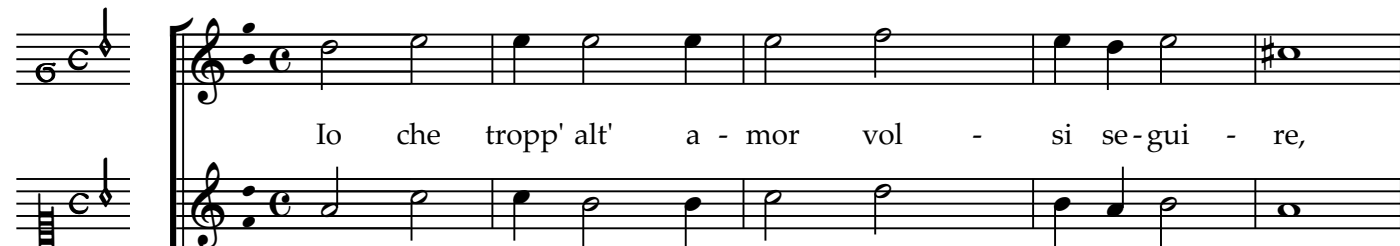

[ALTUS]

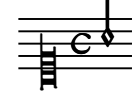

Io che tropp' alt'

a - mo

si se-gui - re,

[TENOR]

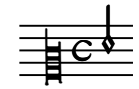

[BASSUS]
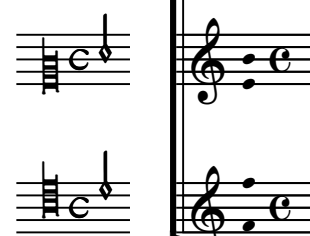

a - mor

vol

si se-gui - re,
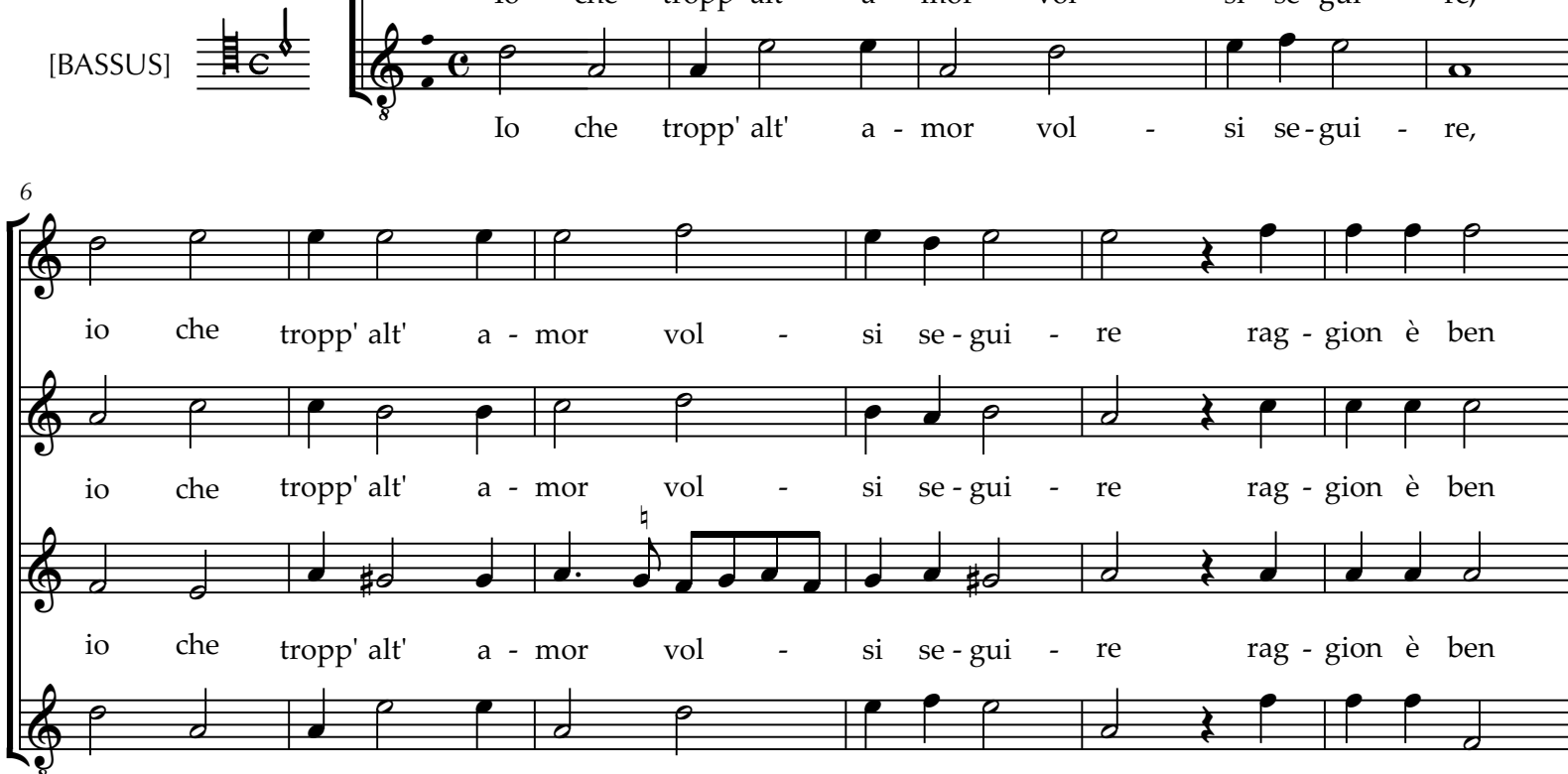

che

tropp' alt'

a - mor

vol

si se-gui - re

rag - gion' è ben

Fonte: GB-WCc MS 153 'Winchester Partbooks', 1564-6. 

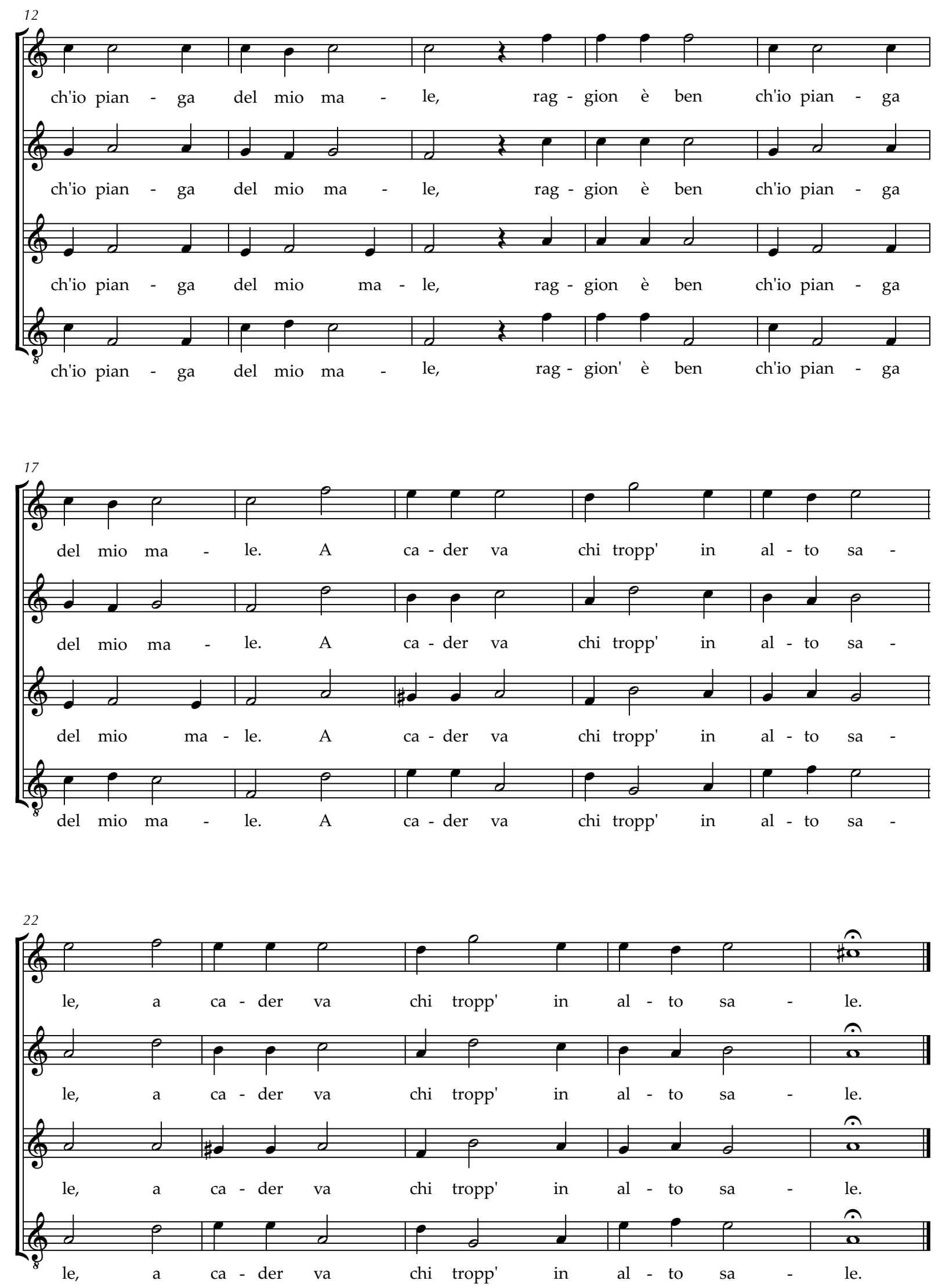


\subsection{TU SEI LA CAUSA DE LA MORTE MIA}

(Winchester Partbooks, n. 9)

Texto: anônimo

Hubert Waelrant (ca.1517-1595)

Transcrito e editado por Munir Sabag

Tu sei la causa de la morte mia,

E saccialo lo cielo con la terra,

Canazza pera, nat' in barbaria,

Tu sei la causa de la morte mia.

Tu és a causa da minha morte, E que o saibam o céu e a terra.

Cadela feroz, nascida na barbárie,

Tu és a causa da minha morte.

[DISCANTUS]
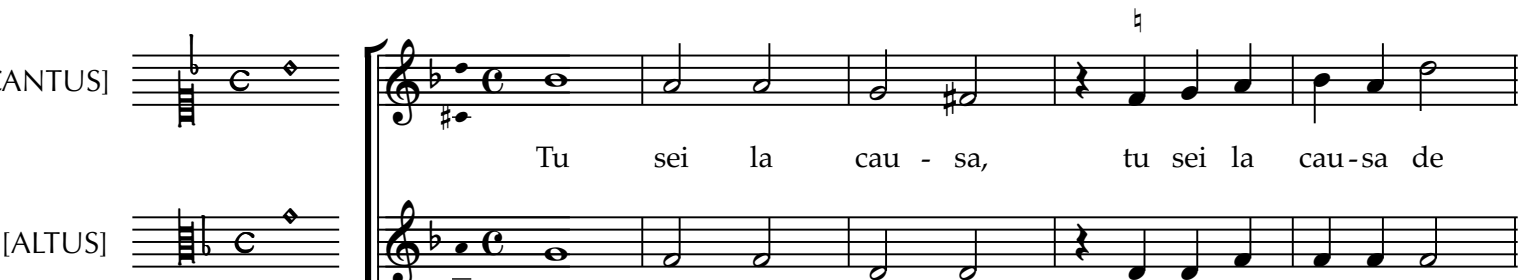

Tu sei la cau - sa,

tu sei la cau-sa de

[TENOR]

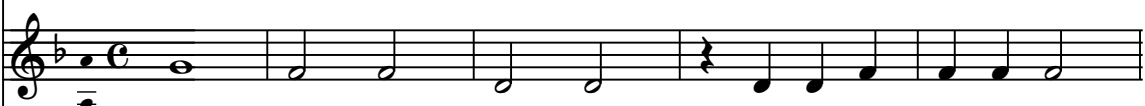

Tu sei la cau - sa, tu sei la cau-sa de

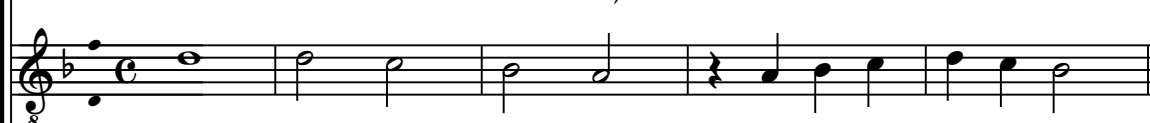

Tu sei la cau - sa, tu sei la cau-sa de

[BASSUS]
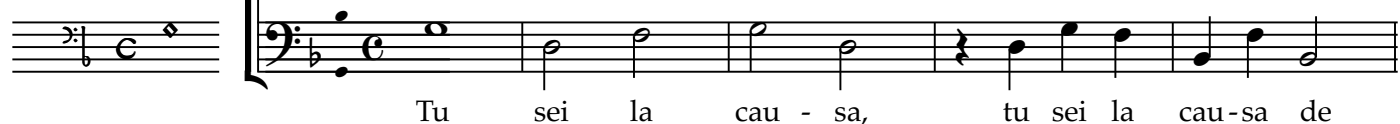

$\mathrm{Tu}$

cau - sa

tu sei la cau-sa de

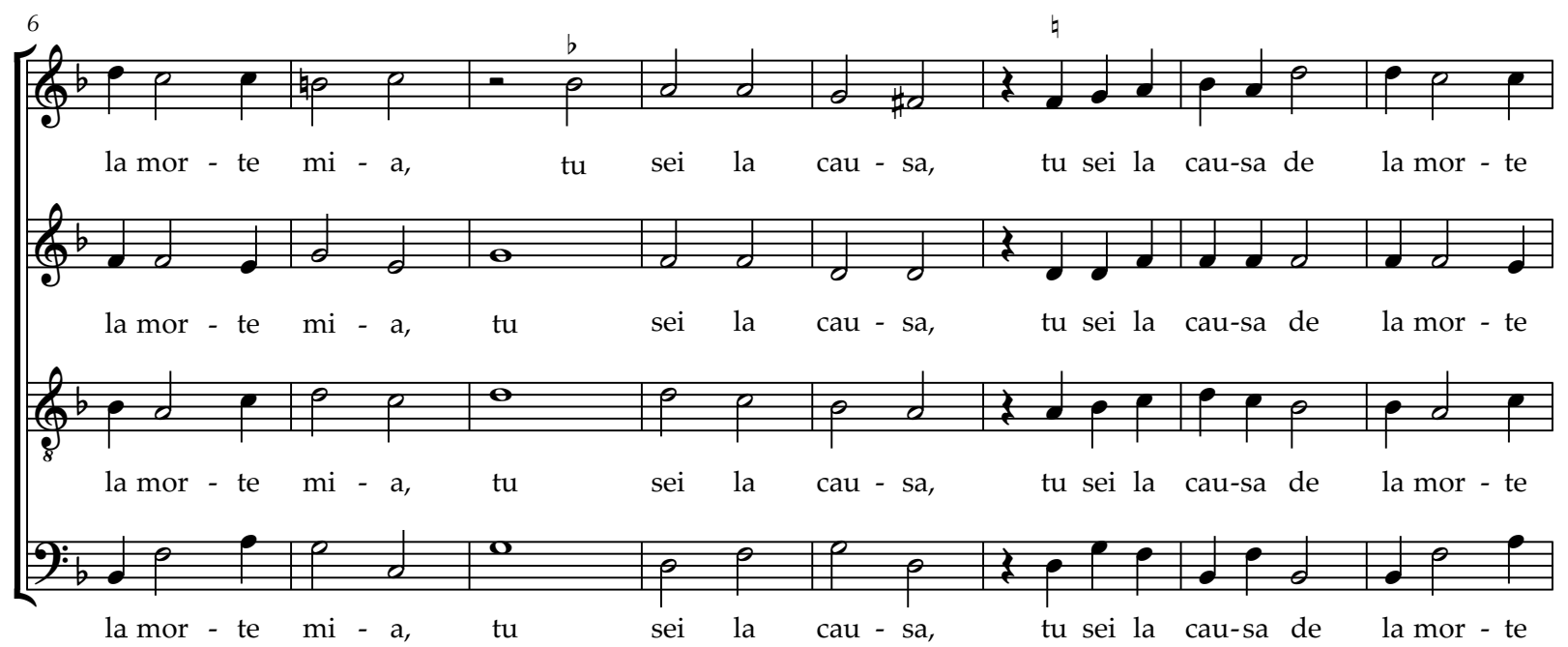



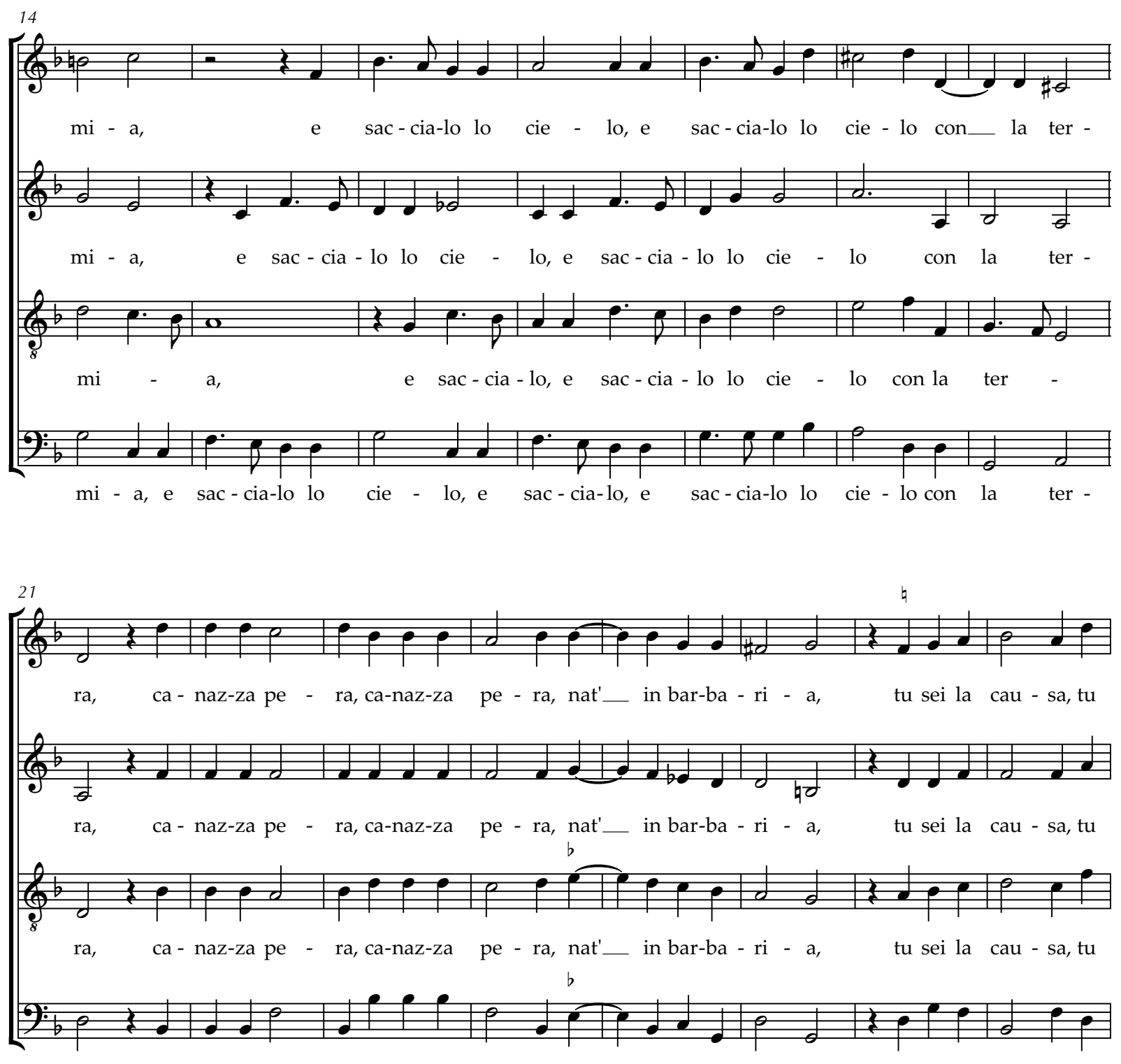

ra, ca - naz-za pe - ra, ca-naz-za pe - ra, nat'_ in bar-ba - ri - a, tu sei la cau - sa, tu

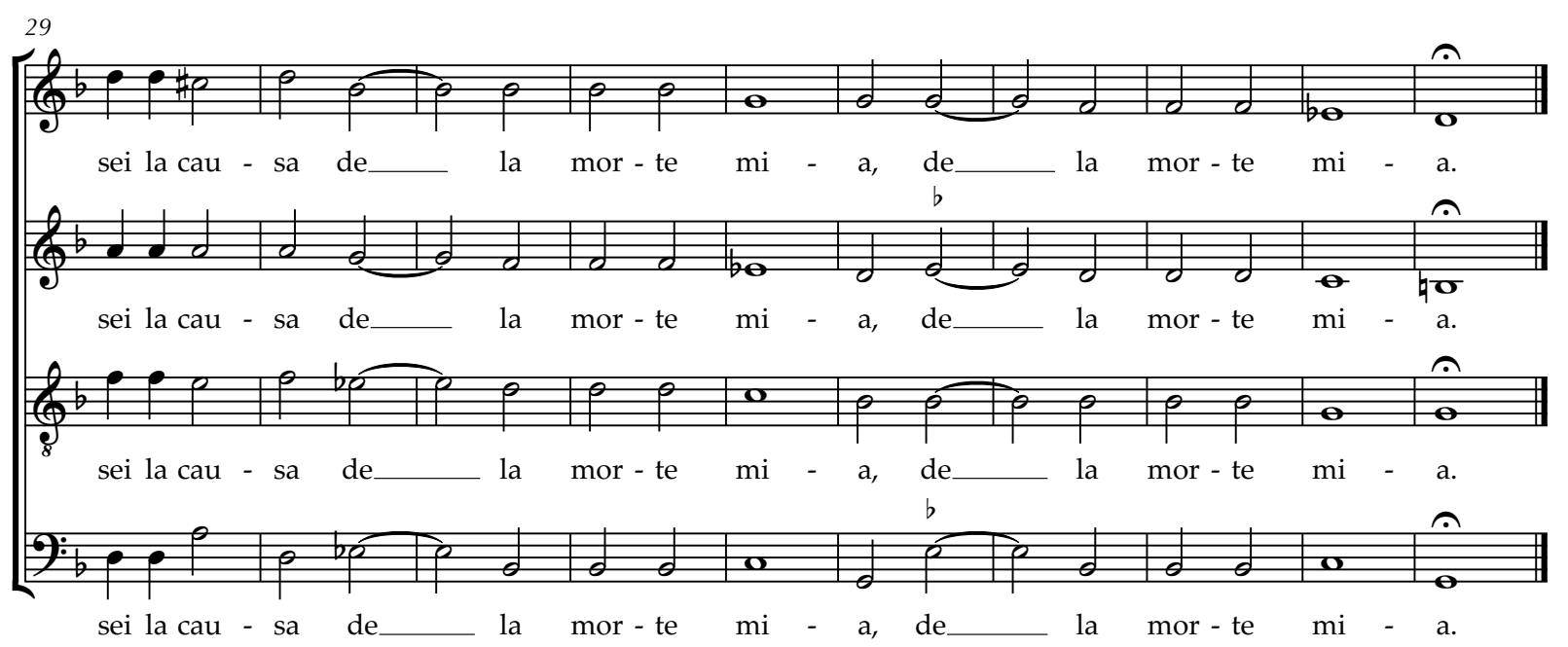




\section{5 . \\ O DIO CHE FOSSE QUELLA COSTUMANZA}

(Winchester Partbooks, n. 10)

Texto: anônimo

O Dio che fosse quella costumanza Ch'era allo tempo delle gent' antiche, Che quando s'incontravano Insieme s'abbracciavano

$\mathrm{E}$ in bocca si basciavan' a la bona.
Hubert Waelrant (ca.1517-1595) Transcrito e editado por Munir Sabag

Ó Deus, para onde foi aquele costume Que havia no tempo das pessoas antigas, Que quando se encontravam, Juntas se abraçavam

E na boca simplesmente se beijavam.

[DISCANTUS]
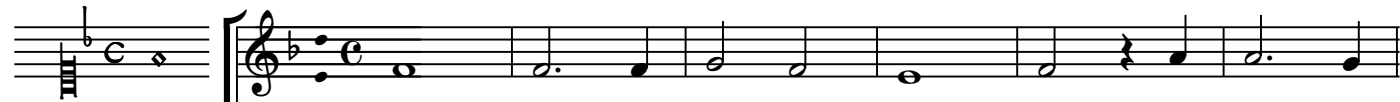

[ALTUS]

Dio che fos - se quel - la,

o Dio che

[TENOR]

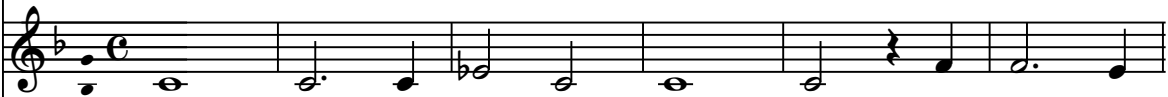

$\mathrm{O}$

Dio che fos - se

quel - la,

o Dio che
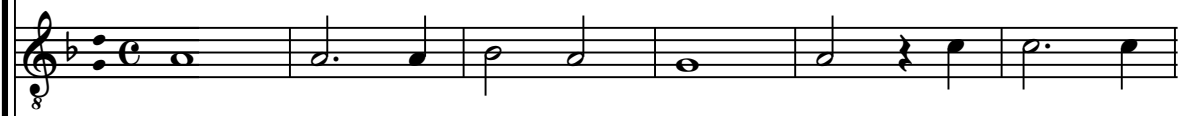

O Dio che fos - se quel - la, o Dio che

[BASSUS]
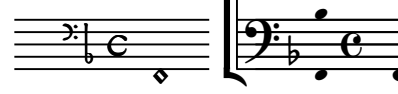

$\mathrm{O}$

Dio che fos - se

quel - la,

o Dio che

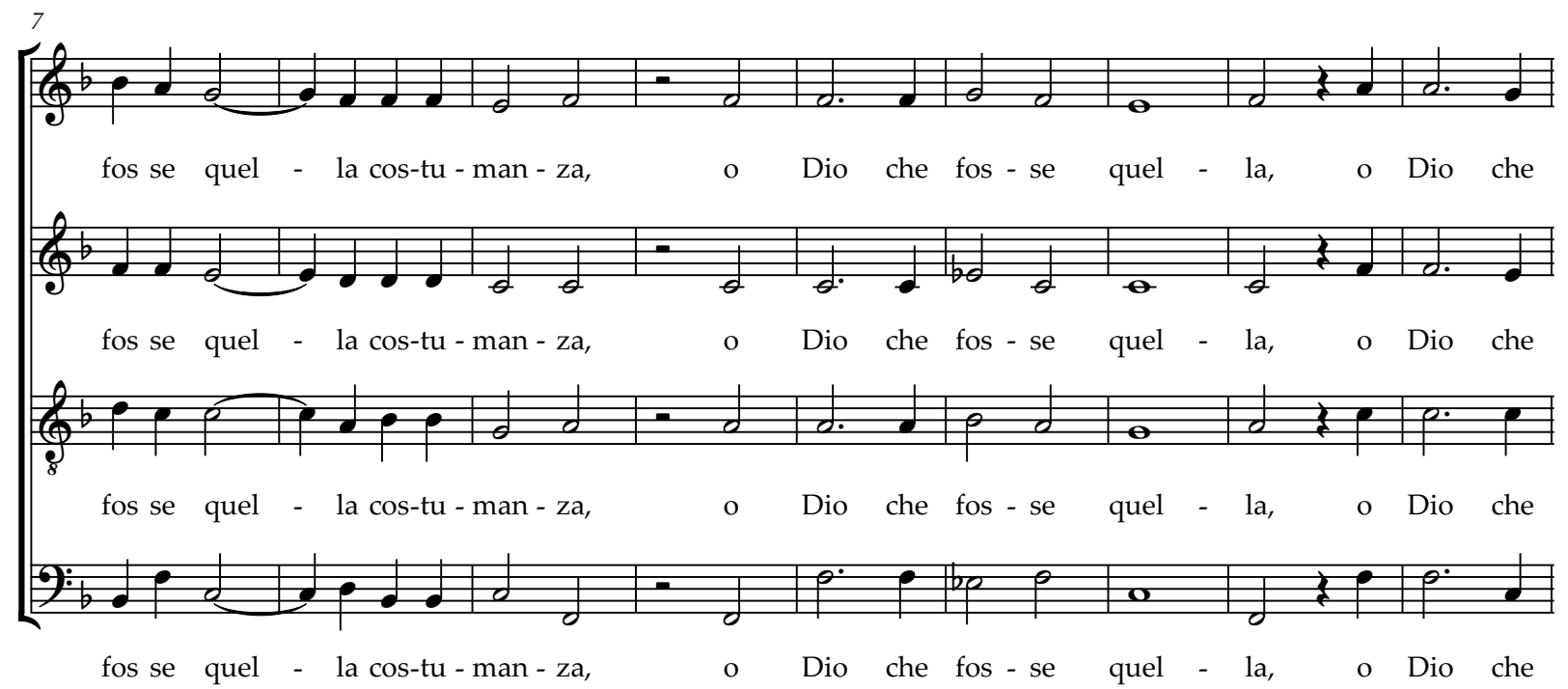




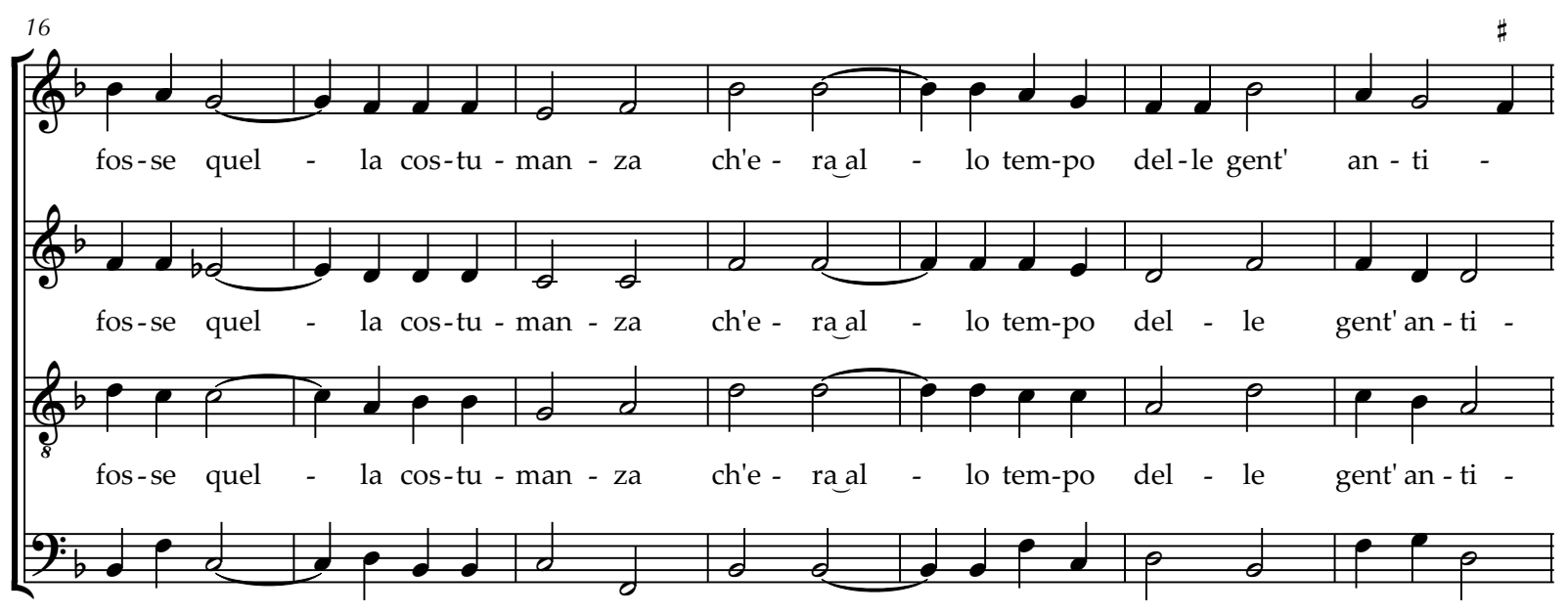

fos-se quel - la cos-tu - man - za ch'e - ra al - lo tem-po del - le gent'an - ti -
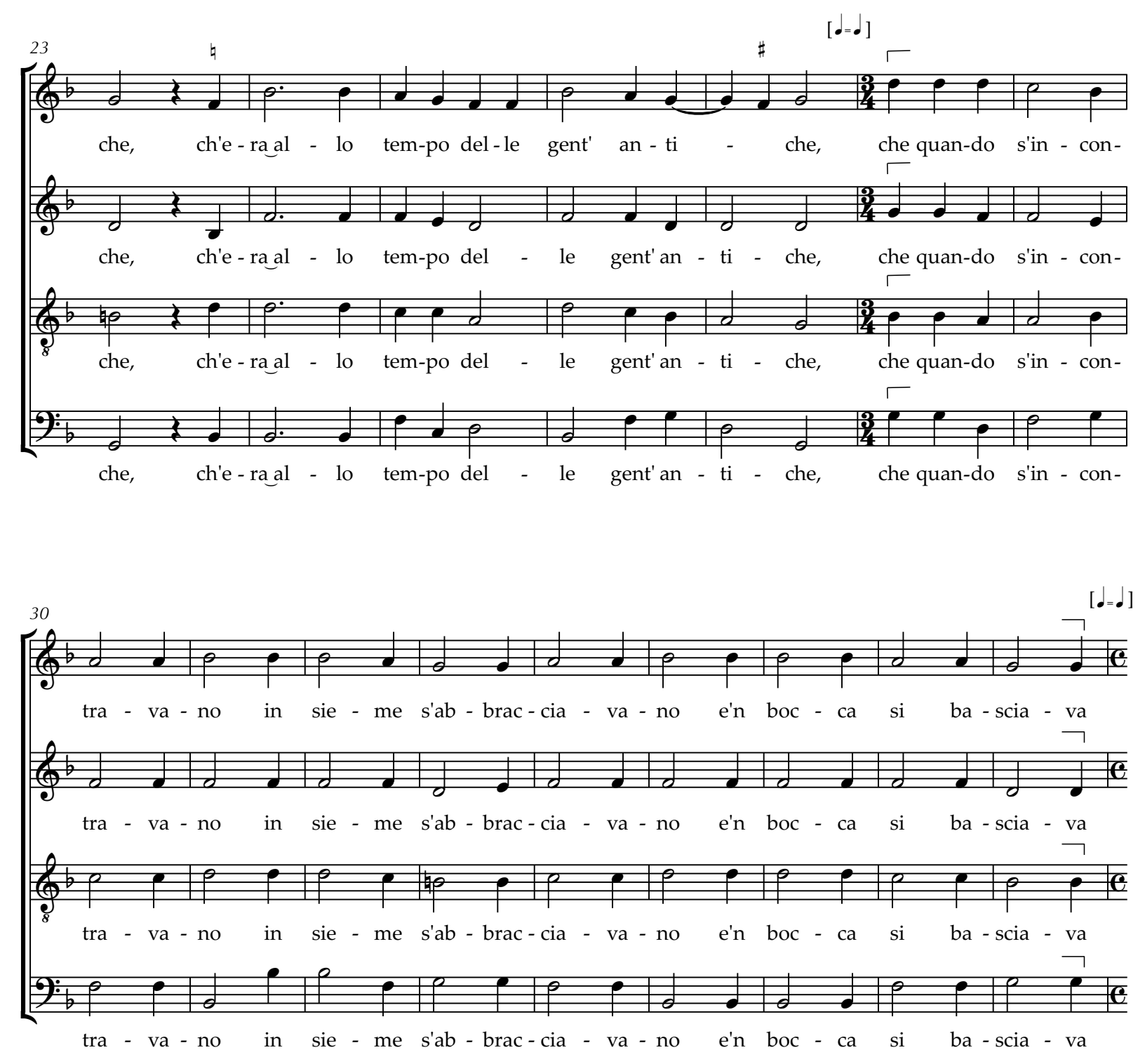

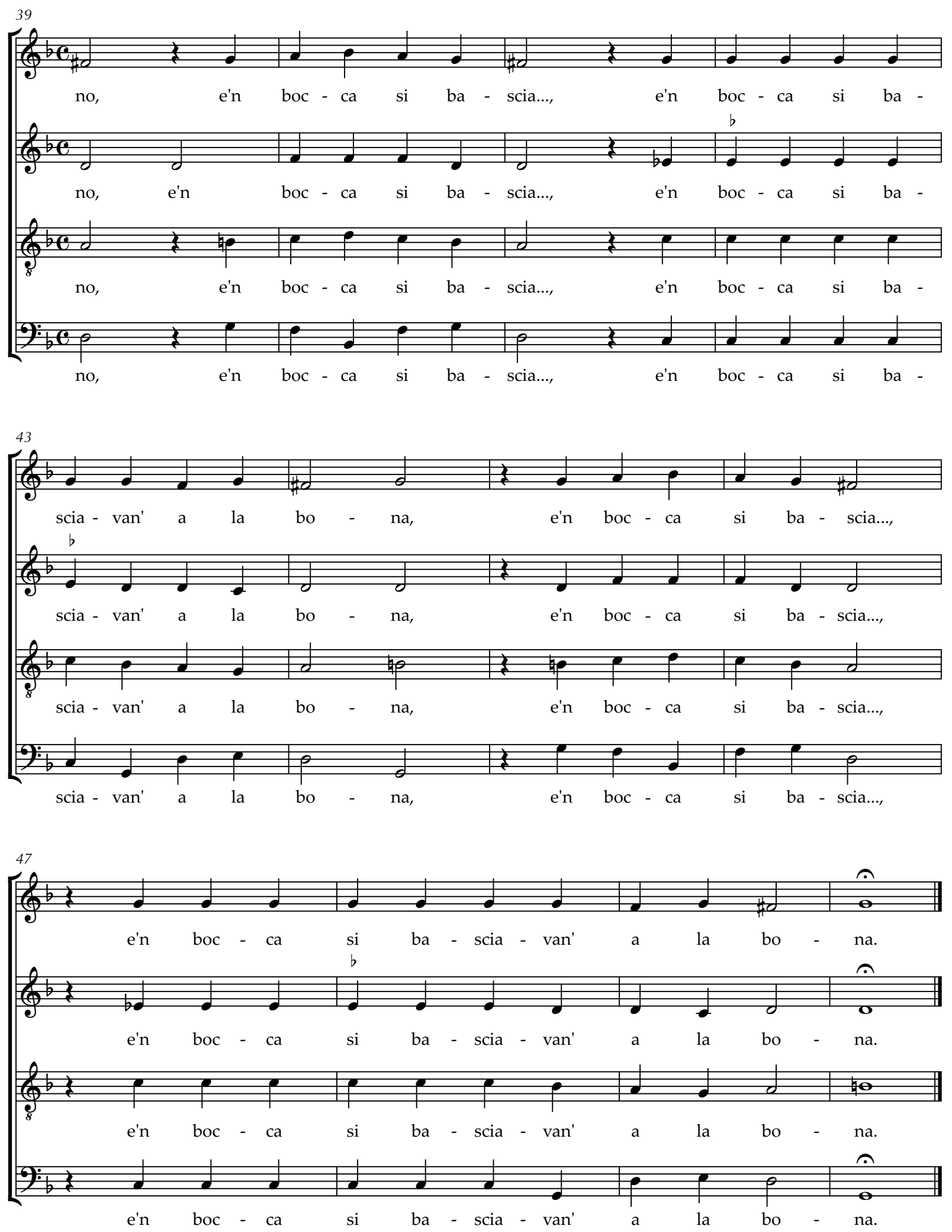

NOTA DO EDITOR:

Altus, compasso 45: o manuscrito exibe um Dó para a primeira semiminima e este foi corrigido para Ré. 


\section{6 .}

Texto: anônimo

Mort' è pietà, l'amor, la cortesia

Mort' è la fè; ben miser' è colui

Che facilmente crede

Alle ciance d'altrui

E'l suo fallir non vede.

Di queste donne ingrate,

Superb' e dispietate,

Prive d'amor, di fè,

Libera nos Domine.

\section{MORT' È PIETÀ}

(Winchester Partbooks, n. 13)

anônimo

Transcrito e editado por Munir Sabag

[DISCANTUS]

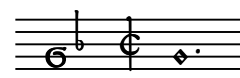

[ALTUS]

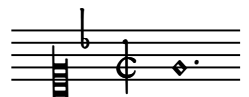

[TENOR]

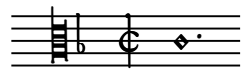

[BASSUS]
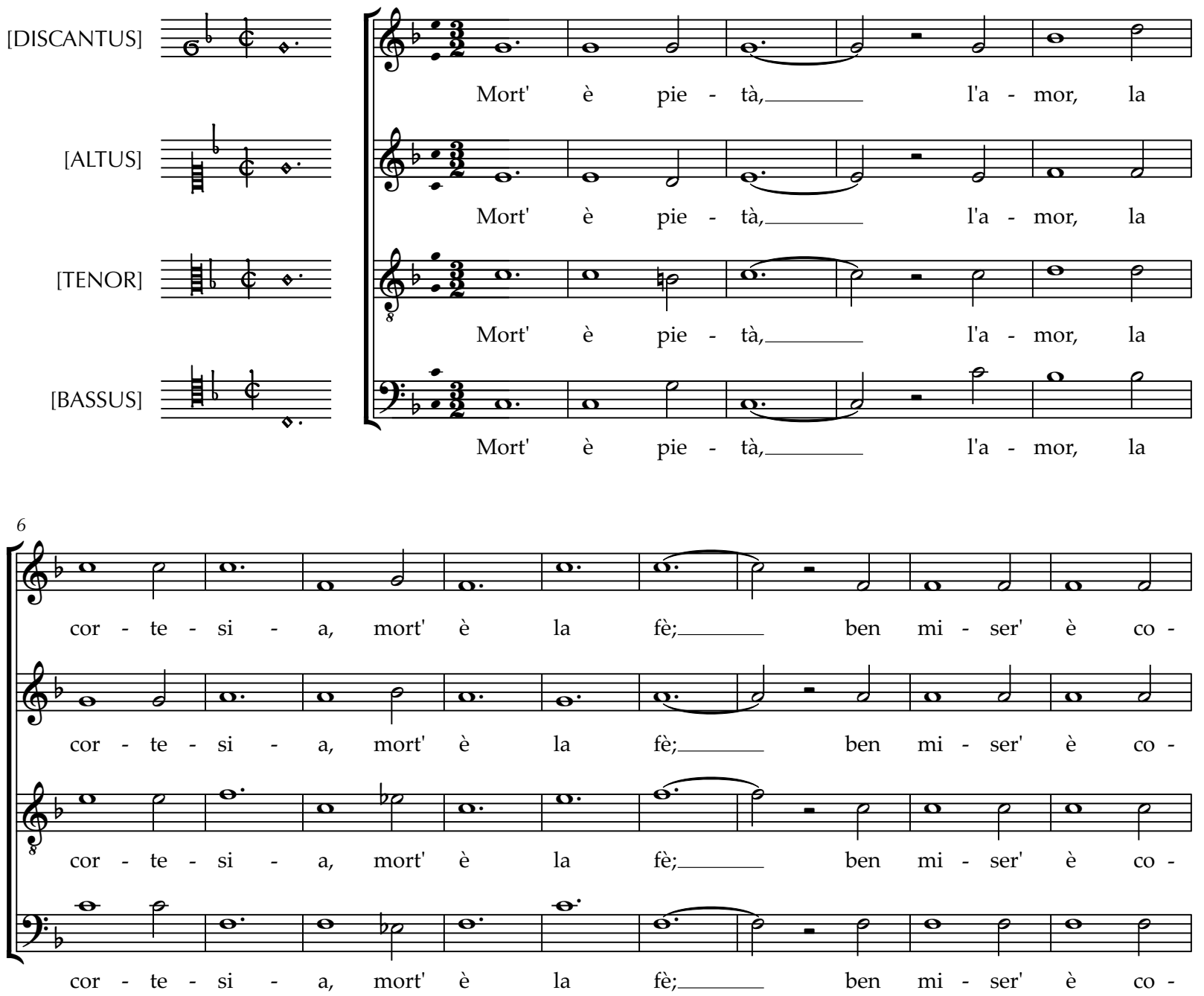

morta a piedade, o amor, a cortesia, Morta é a fé; pobre daquele

Que acredita facilmente

Nas palavras dos outros

E não percebe os enganos.

Destas mulheres ingratas,

Soberbas e impiedosas,

Desprovidas de amor, de fé,

Livra-nos, Senhor. 

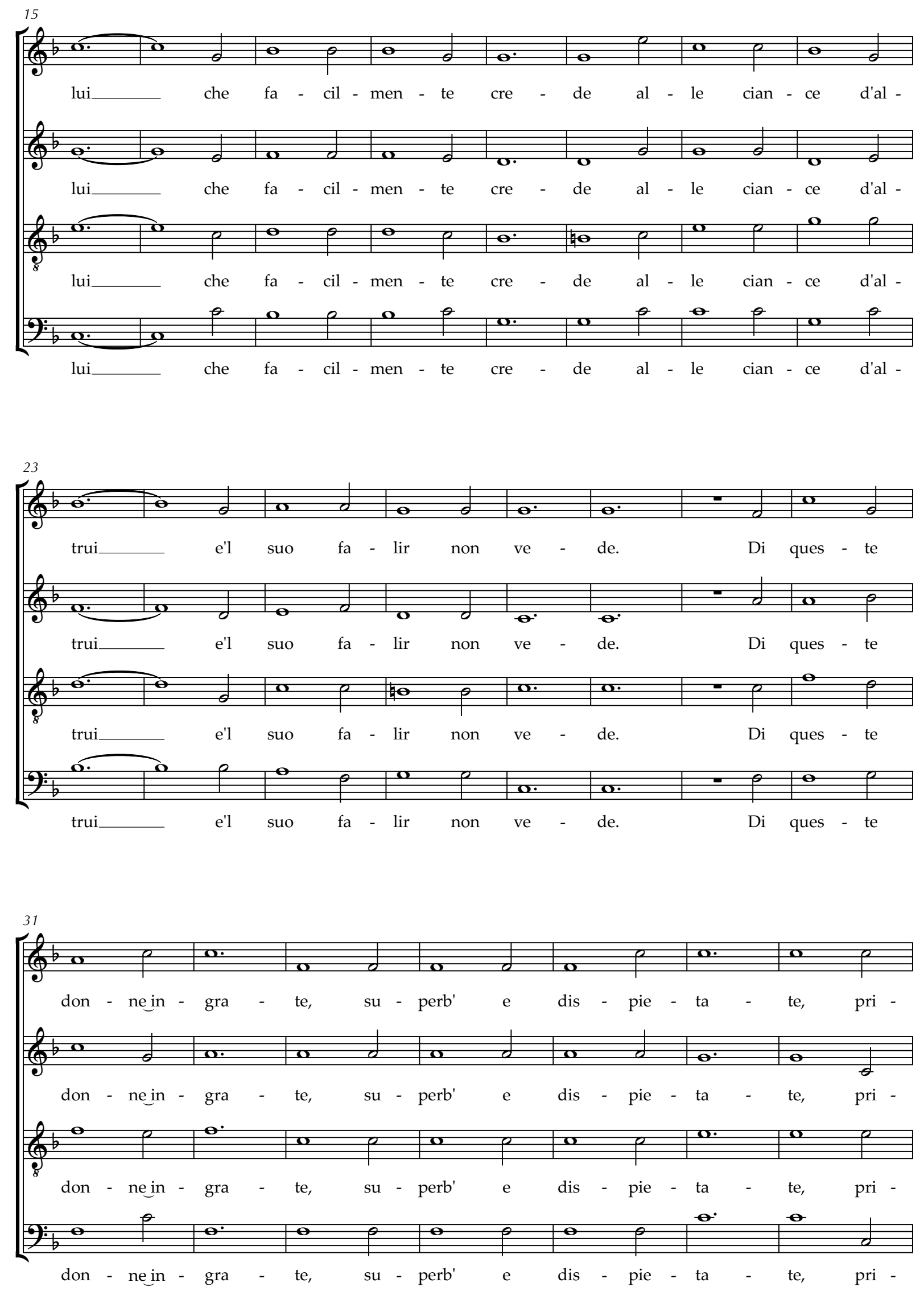


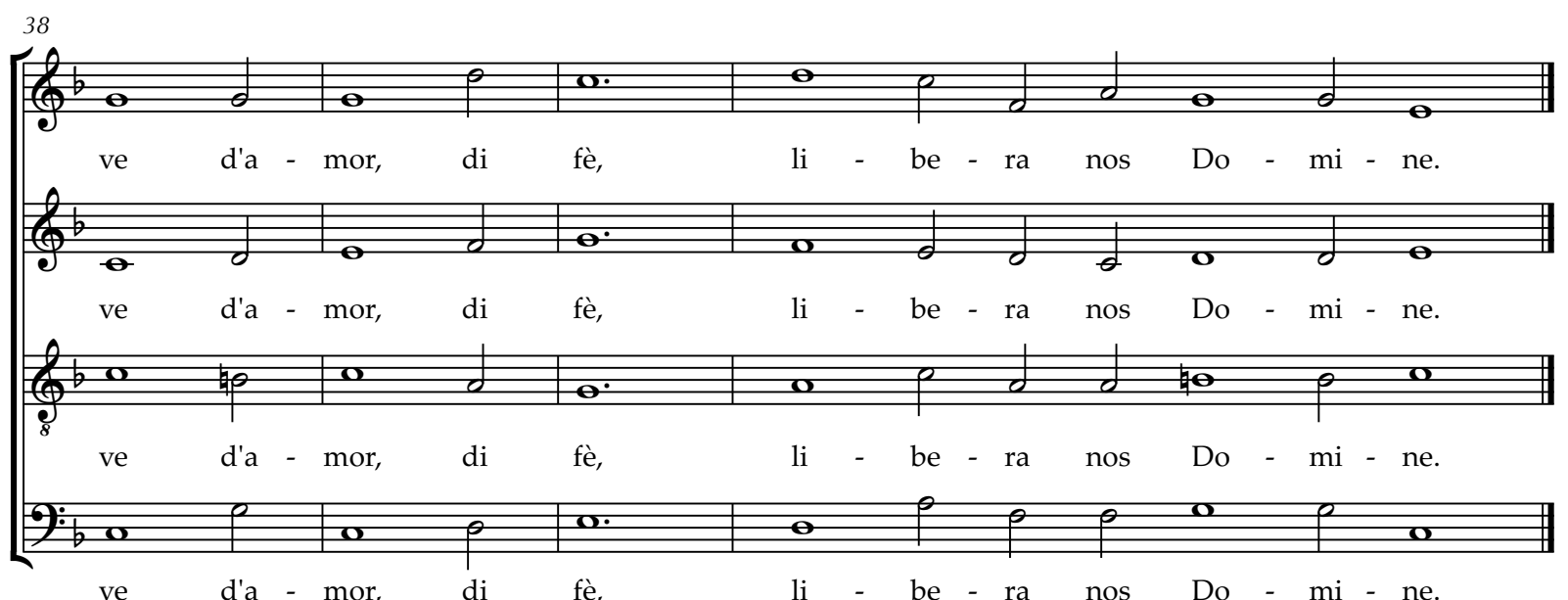

NOTAS DO EDITOR:

(1) Compasso 29: a pausa de minima é editorial e foi acrescentada para se manter o padrão anterior de acentuação, que não parece ter sido alterado; neste ponto o manuscrito exibe uma barra dupla (no discantus, altus e bassus) ou simples (no tenor).

(2) Compasso 41: A métrica da frase final (em latim) não se adapta à estrutura ternária anterior ou mesmo àquela indicada pelo sinal de mensuração inicial ( $\$$ ), fazendo uma referência jocosa à musica plana medieval - isto é, aquela em que os valores temporais não são precisamente medidos; por esta razão a notamos através de um compasso de métrica livre, onde as sílabas tônicas do texto (correspondentes aos valores mais longos - isto é, às semibreves) constituem referências seguras para a acentuação.

(3) O manuscrito da parte do bassus exibe, no espaço restante após o final desta peça, um trecho isolado (cânone?) com texto "voi crebbe 'l desio" (cresce o desejo [por] vós):

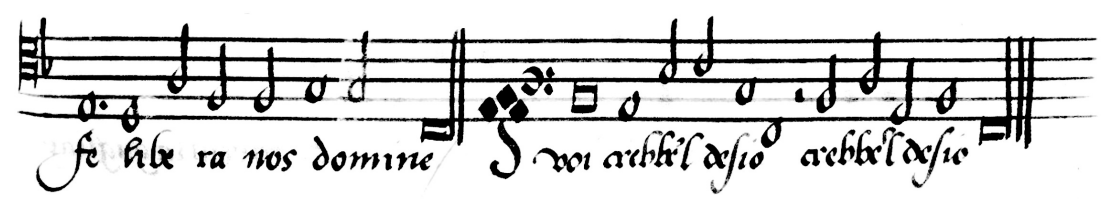

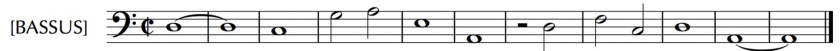

voi_ creb - be'l de - si - o, creb - be'l de si - o 


\subsection{FIAMENGA FREDDA, CORE DI DIAMANTE}

(Winchester Partbooks, n. 15)

Texto: anônimo

Fiamenga fredda, core di diamante, Petto di ghiaccio ed alma d'infedele, Ahi come sei crudele.

Rispond' al mio parlar: "niet te verstaen" E s'io ti tocco dici: "laet mij staen".

Sei cieca, sorda, cruda al tuo amante, Anzi col servo tuo tanto fedele,

Ahi come sei crudele.

Rispond' al mio parlar: "niet te verstaen"

E s'io ti tocco dici: "laet mij staen".

Ma s'io ti posso un giorno riscaldare

Tutta sta lengua ti farò imparare.

Sentendo il mio parlar.

In cambio di mi dir: "niet te verstaen"

Saccio che mi dirai: "tis wel gedaen".
Adrian Tubal (ca.1535 - ?)

Transcrito e editado por Munir Sabag

Flamenga fria, coração de diamante,

Peito de gelo e alma de infiel.

Ah, como és cruel.

Respondes à minha fala: "não se entende" E se eu te toco, dizes: "deixa-me em paz".

És cega, surda, cruel ao teu amante Ainda mais sendo teu servo tão fiel. Ah, como és cruel.

Respondes à minha fala: "não se entende" E seu te toco, dizes: "deixa-me em paz".

Mas se um dia eu te puder aquecer

Te farei aprender toda esta língua.

Ouvindo a minha fala,

Ao invés de me dizer: "não se entende"

Sei que me dirás: "está muito bom".

[DISCANTUS]
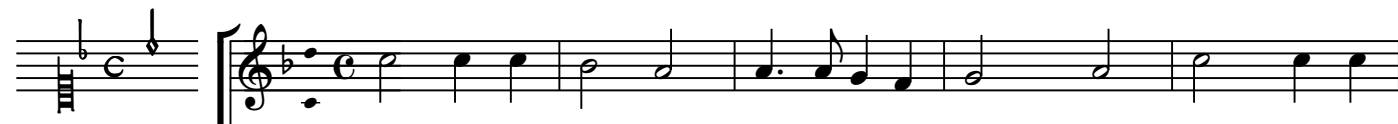

[ALTUS]

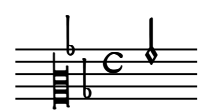

Fia -men-ga fred - da,

co - re di dia-man - te,

fia - men-ga

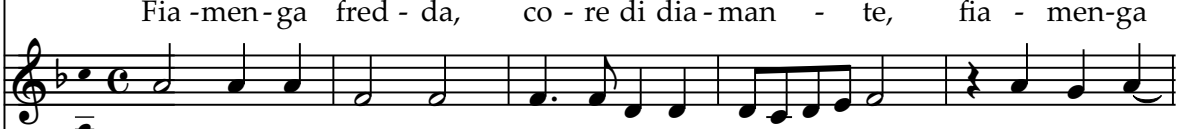

Fia -men-ga fred - da,

co - re di dia - man - te,

fia-men-ga

[TENOR]

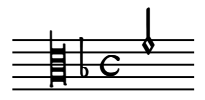

[BASSUS]
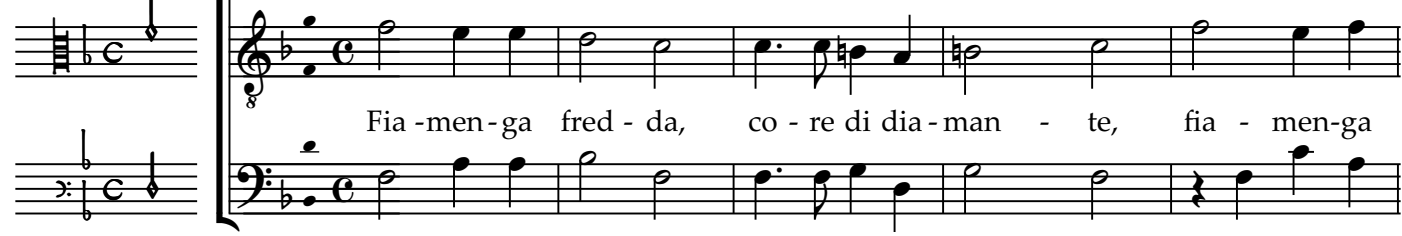

Fia -men-ga fred - da,

co - re di dia-man - te,

fia-men-ga

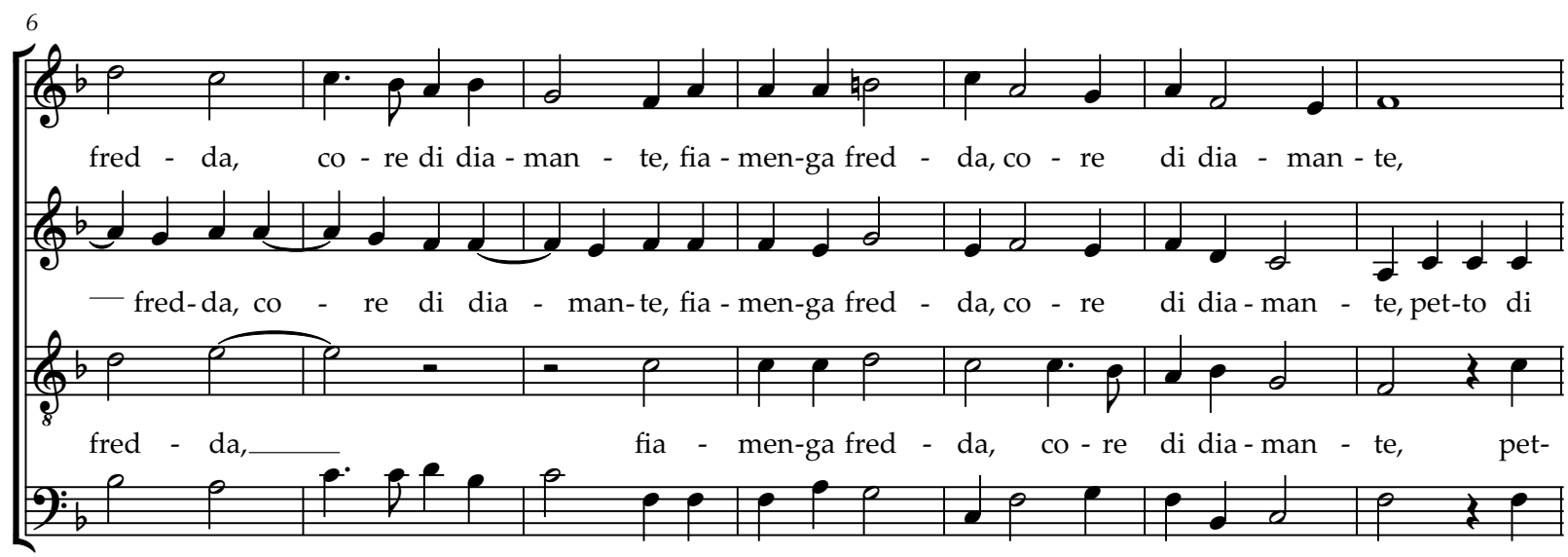

fred - da,

co - re di dia - man - te, fia - men-ga fred - da, co - re

di dia - man - te,

pet-

Fonte: GB-WCc MS 153 'Winchester Partbooks', 1564-6. 

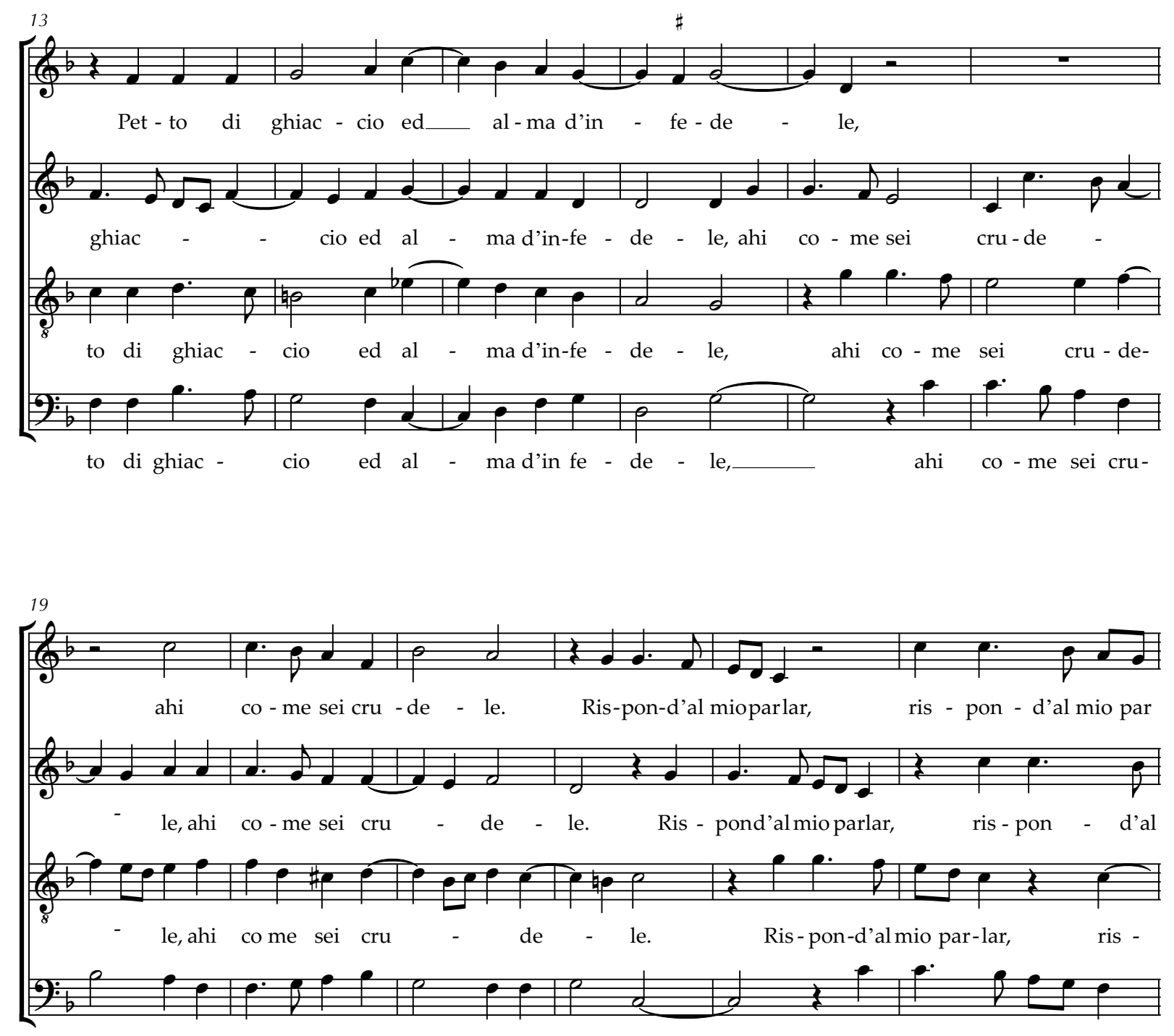

de - le, ahi co -me sei cru - de - le, cru - de - le.__ Ris - pon - d'al mio par-lar,

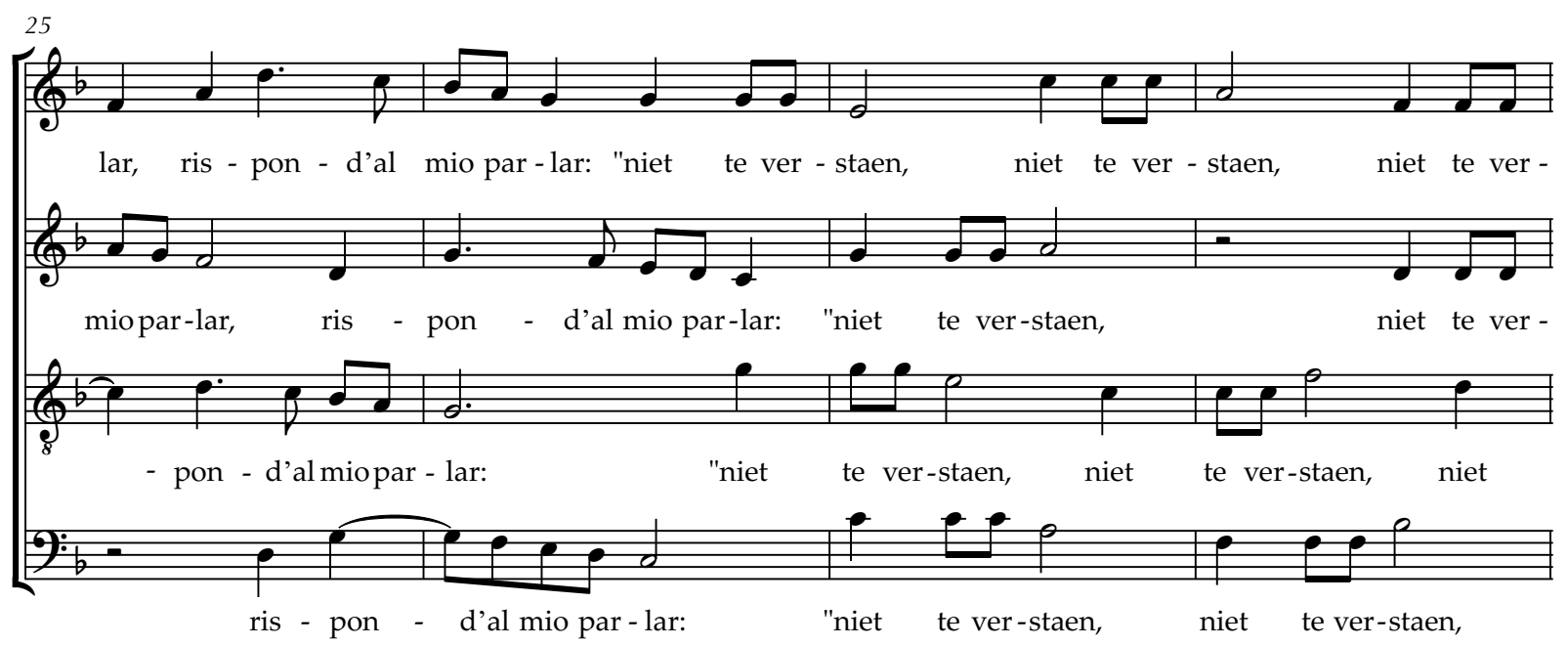



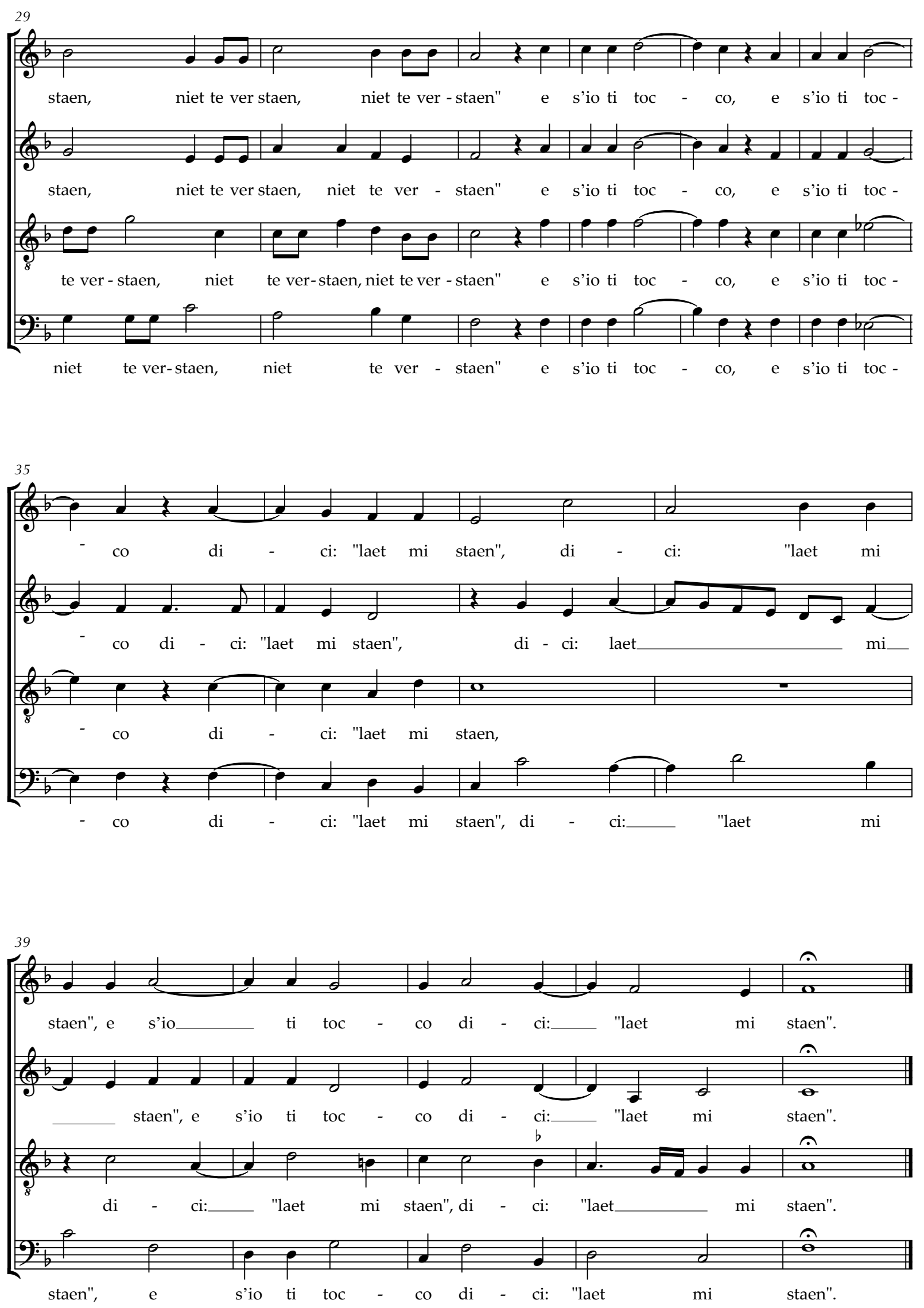


\subsection{L'AMANZA MIA SI CHIAMA SAPORITA}

(Winchester Partbooks, n. 16)

Texto: anônimo

Adrian Tubal (ca.1535 - ?)

Transcrito e editado por Munir Sabag

L'amanza mia si chiama Saporita

Ta ra ra ra ra ra ra,

Ed io ci ho fatto fare 'sta canzone

Ta ra ra ra ra ra,

O Saporita quando vien dall'orto

Portami un fico fresco per la tua fè.

O mia Saporitella,

La chi ri chi ri chi ri chi ri chella,

Quanto sei bella.

Minha amada se chama Saporita

Ta ra ra ra ra ra ra

E mandei fazer esta canção para ela

Ta ra ra ra ra ra

Ó Saporita, quando vieres do jardim Traz-me um figo fresco, por favor.

Ó minha Saporitella,

La chi ri chi ri chi ri chi ri chella

Quanto és bela.

[DISCANTUS]
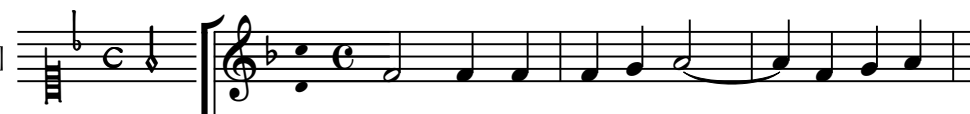

L'a - man-za mia si chia - ma Sa-po - ri - ta,___ ta ra ra ra

[ALTUS]
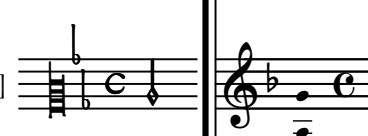

Letata

[TENOR]

L'a - man-za mia si chia - ma Sa-po - ri - ta,

ta ra ra ra

[BASSUS]
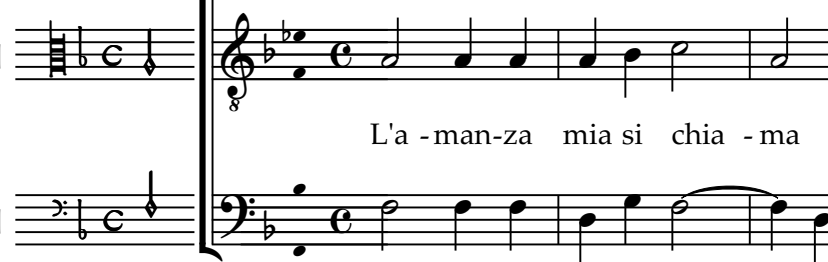

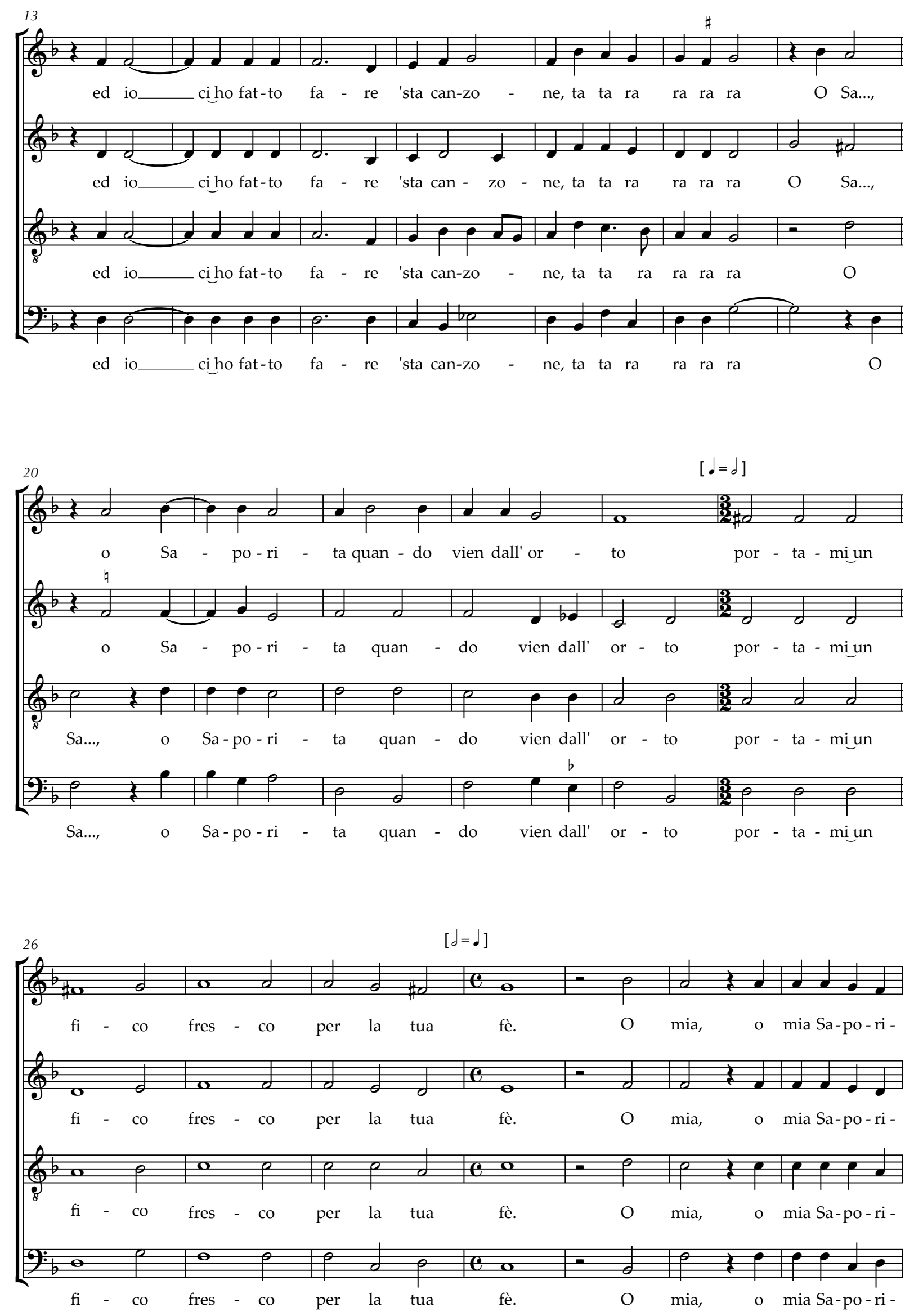

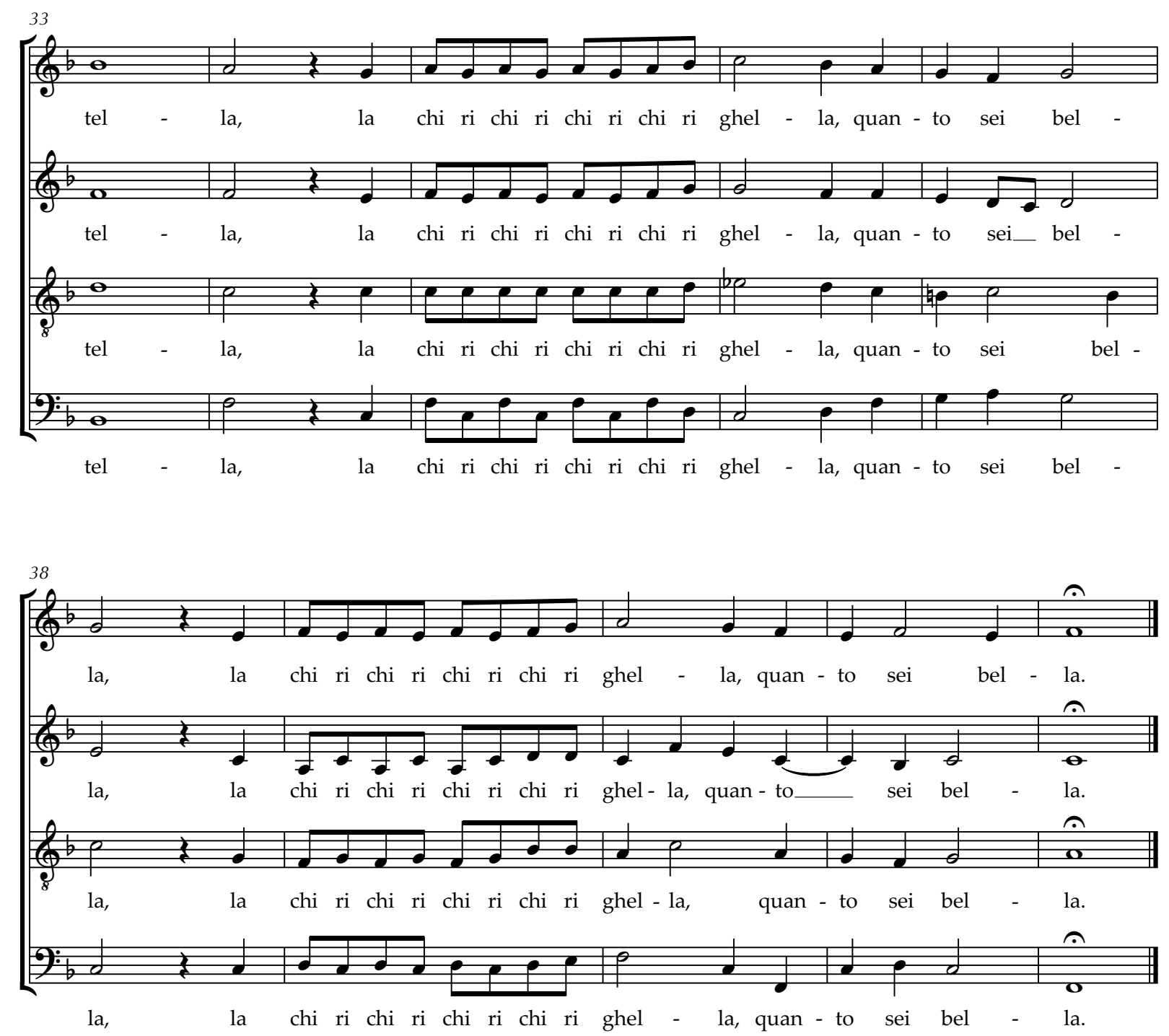

NOTA DO EDITOR:

O manuscrito exibe o texto inicial "La manza mia" (minha vaca) e não "L'amanza mia" (minha amada). Embora a pronúncia seja idêntica nos dois casos, esta situação é um dos exemplos dos jogos de palavras típicos dos textos de villanelle. 


\section{9. \\ DONNA, VOI SIETE BELLA}

(Winchester Partbooks, n. 17)

Texto: anônimo

Adrian Tubal (ca.1535 - ?)

Transcrito e editado por Munir Sabag

Donna, voi siete bella e non cortese.

Quest' è la doglia che mi fa morire.

Io pur ti vuoi seguir fin' alla morte,

Che così vuol il ciel e la mia sorte.

Dama, vós sois bela e não cortês.

Esta é a dor que me faz morrer.

Mas te quero seguir até a morte,

Pois assim quer o céu e a minha sorte.

[DISCANTUS]

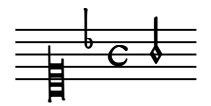

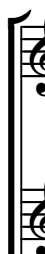

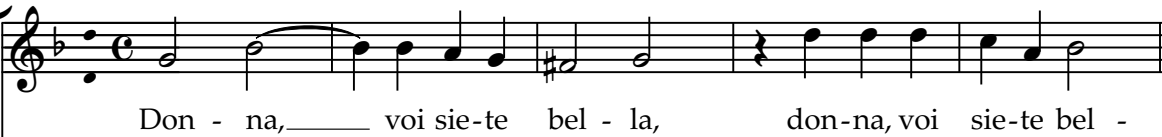

[ALTUS]

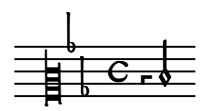

[TENOR]

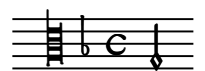

[BASSUS]
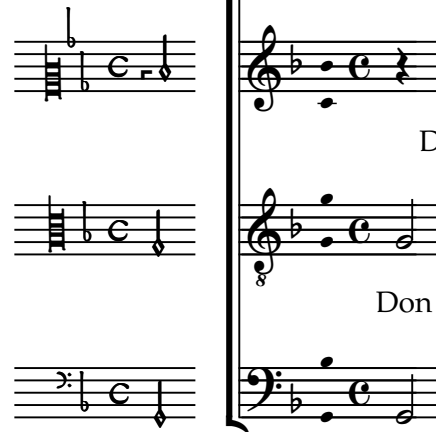

Don - na,__ voi sie-te bel - la,don - na, voi sie-te bel - la, bel

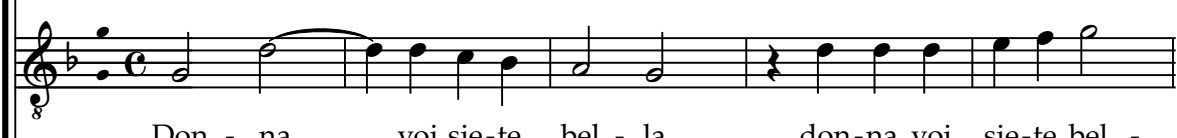

Don - na,_ voi sie-te bel - la,

don-na, voi sie-te bel -

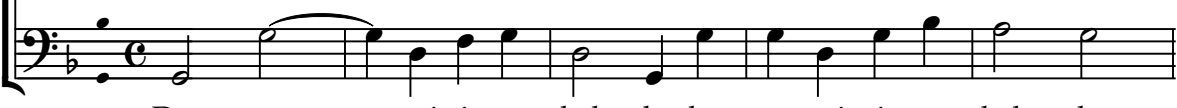

Don - na, voi sie-te bel - la, don - na, voi sie-te bel - la

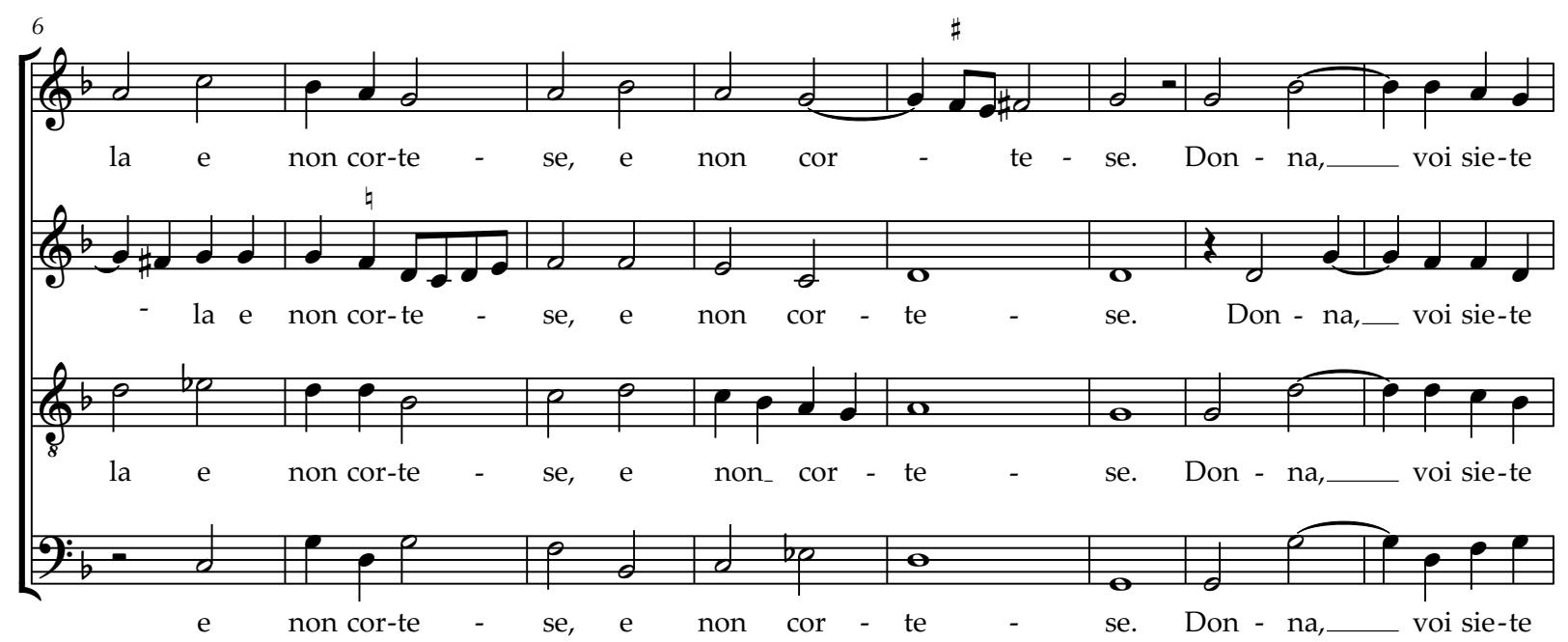



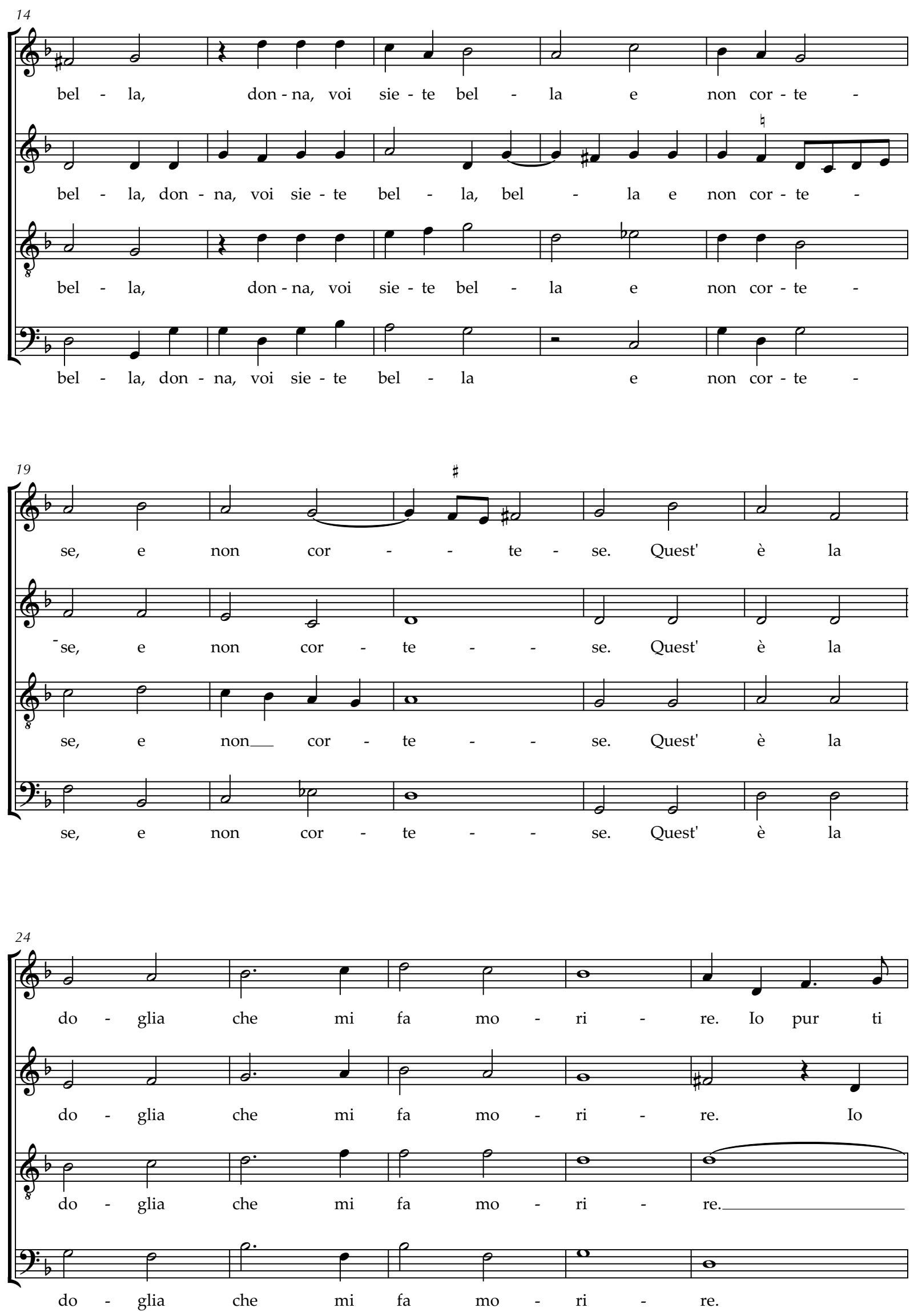

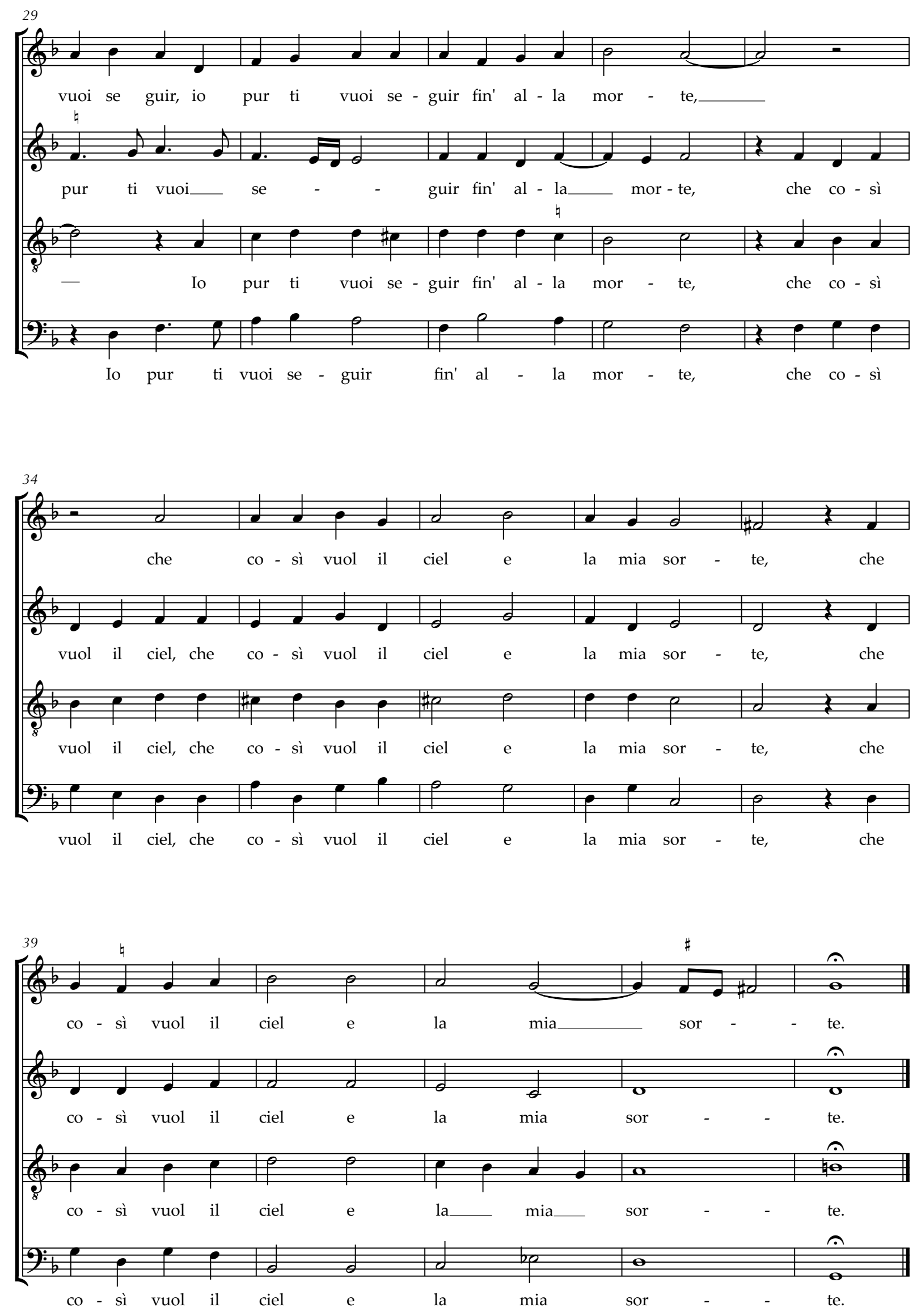


\subsection{0 .}

Texto: anônimo

Tri ciechi siamo, povr'innamorati, Privi di luc'e senz' alcun conforto. Così quel crud'Amor sia fatto torto Per esser fra gli amanti noi sgraciati. O donne belle, vengavi pietade Da far agli orbi qualche caritade. De, un'elimosina ai povri orbi.

\section{TRI CIECHI SIAMO}

(Winchester Partbooks, n. 18)
Hubert Waelrant (ca.1517-1595)

Transcrito e editado por Munir Sabag

[DISCANTUS]
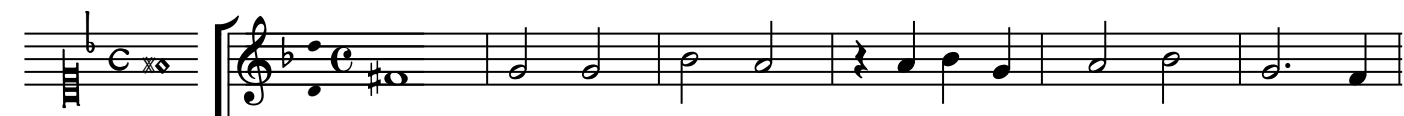

Somos três cegos, pobres apaixonados Privados de luz e sem conforto algum. Que aquele cruel Amor seja punido,

Por estarmos entre os amantes, nós, desgraçados.

Ó belas damas, que vos venha a piedade

Para fazer aos cegos alguma caridade.

Oh, uma esmola aos pobres cegos!

[BASSUS]

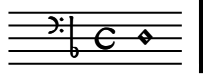

[ALTUS]

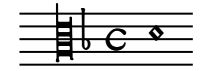

tri cie-chi sia - mo, po- vr'in-

[TENOR]
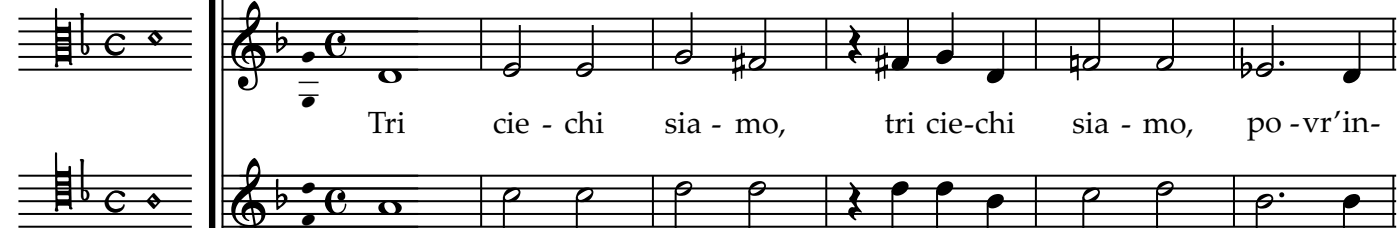

Tri cie - chi sia - mo, tri cie-chi sia - mo, po-vr'in-

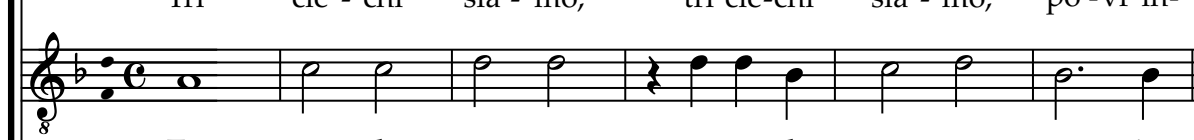

Tri cie - chi sia - mo, tri cie-chi sia - mo, po-vr'in-

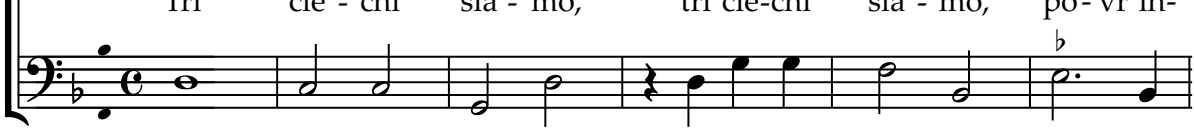

Tri

cie - chi

sia - mo,

tri cie-chi

sia - mo,

po - vr'in-

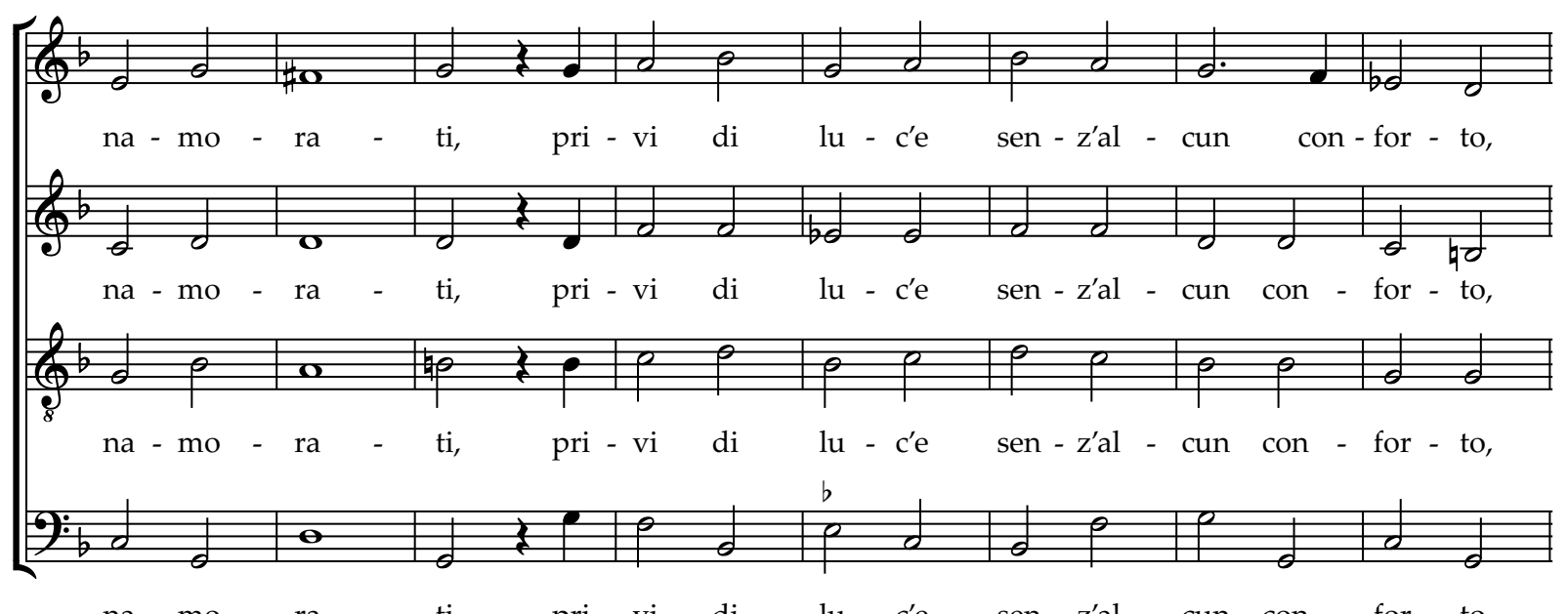

na - mo - ra - ti, pri - vi di lu - c'e sen - z'al - cun con - for - to,

Fonte: GB-WCc MS 153 'Winchester Partbooks', 1564-6. 

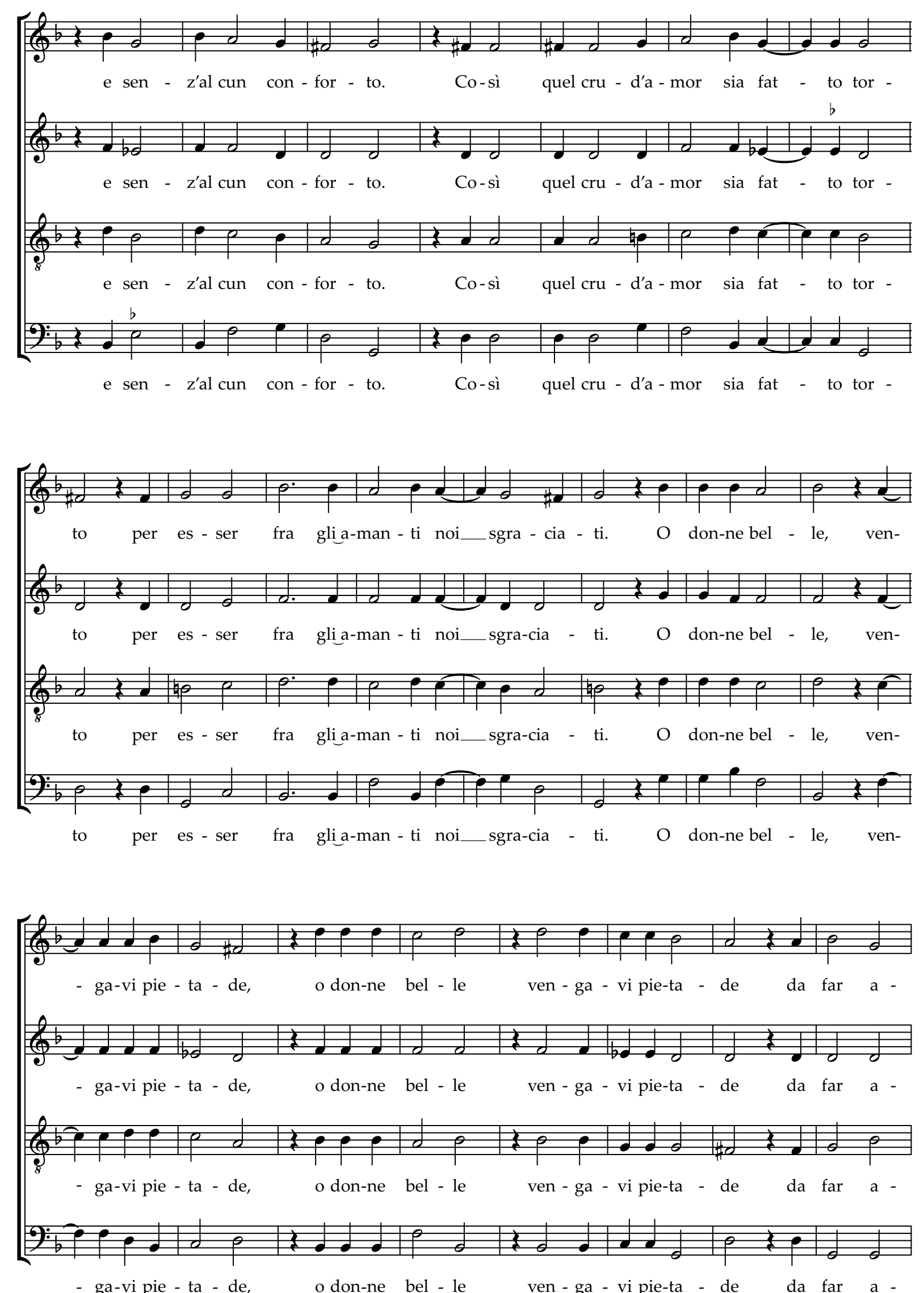
$[\cdot=d]$
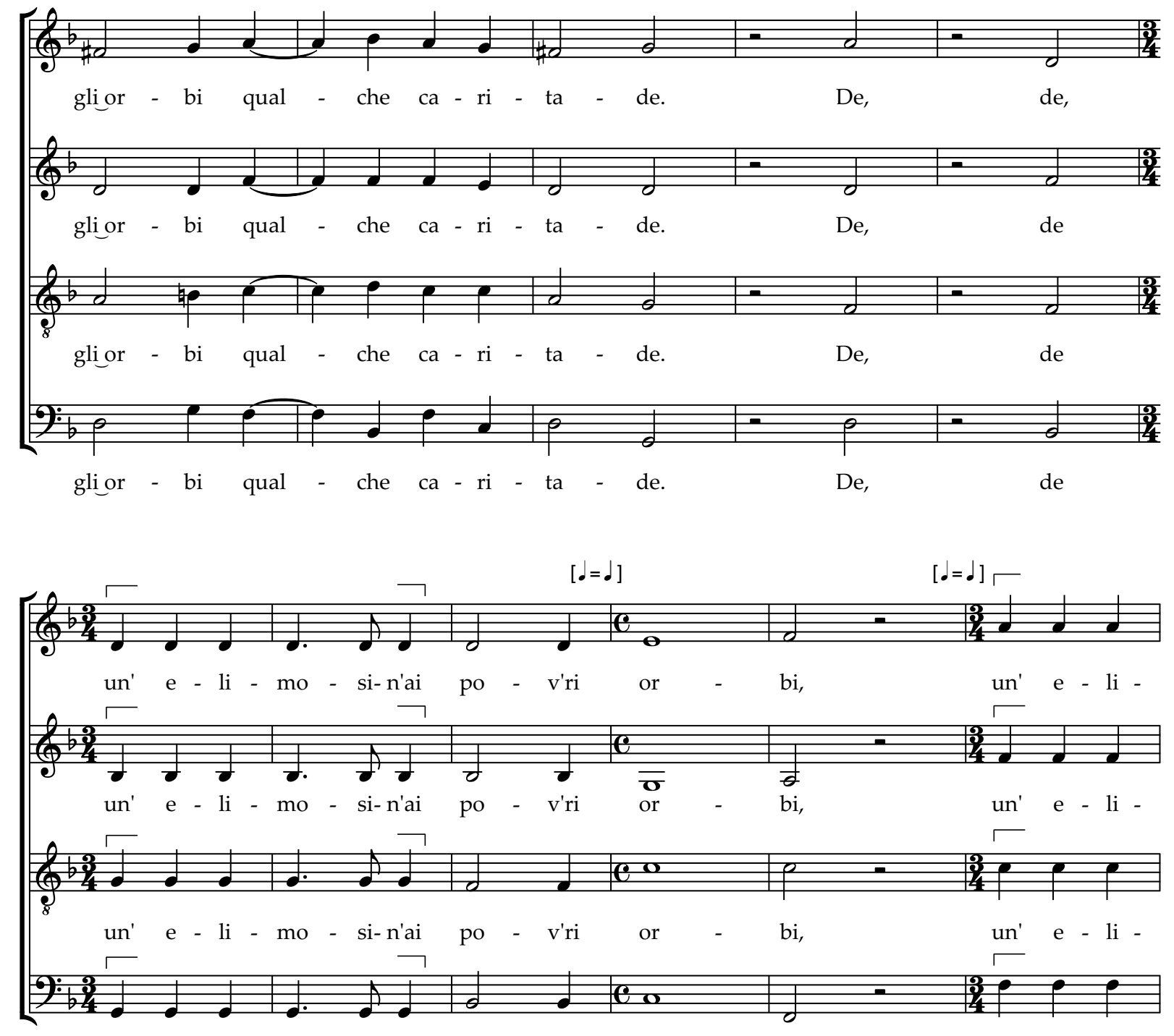
un' e - li - mo - si-n'ai po - v'ri or - bi, un' e - li -

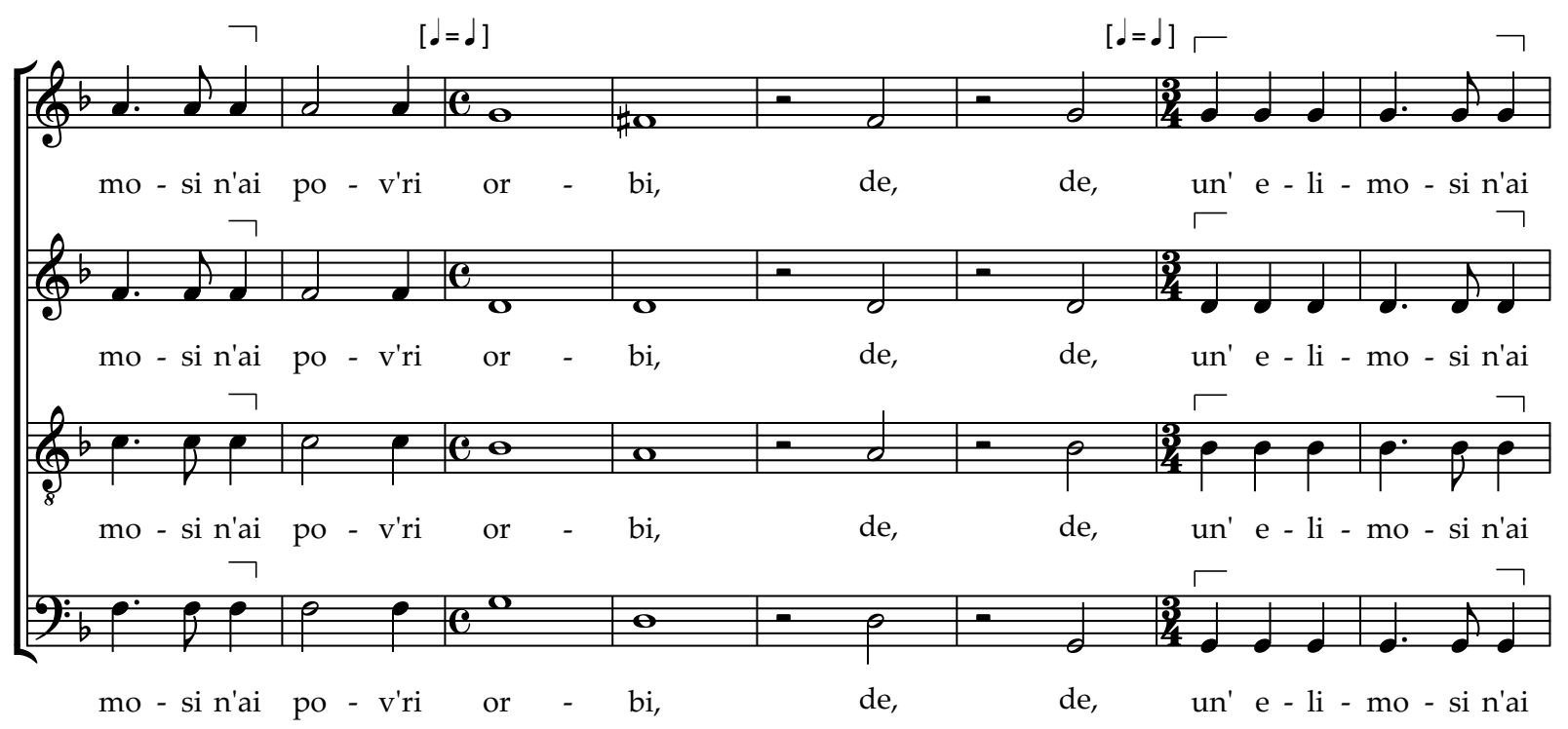




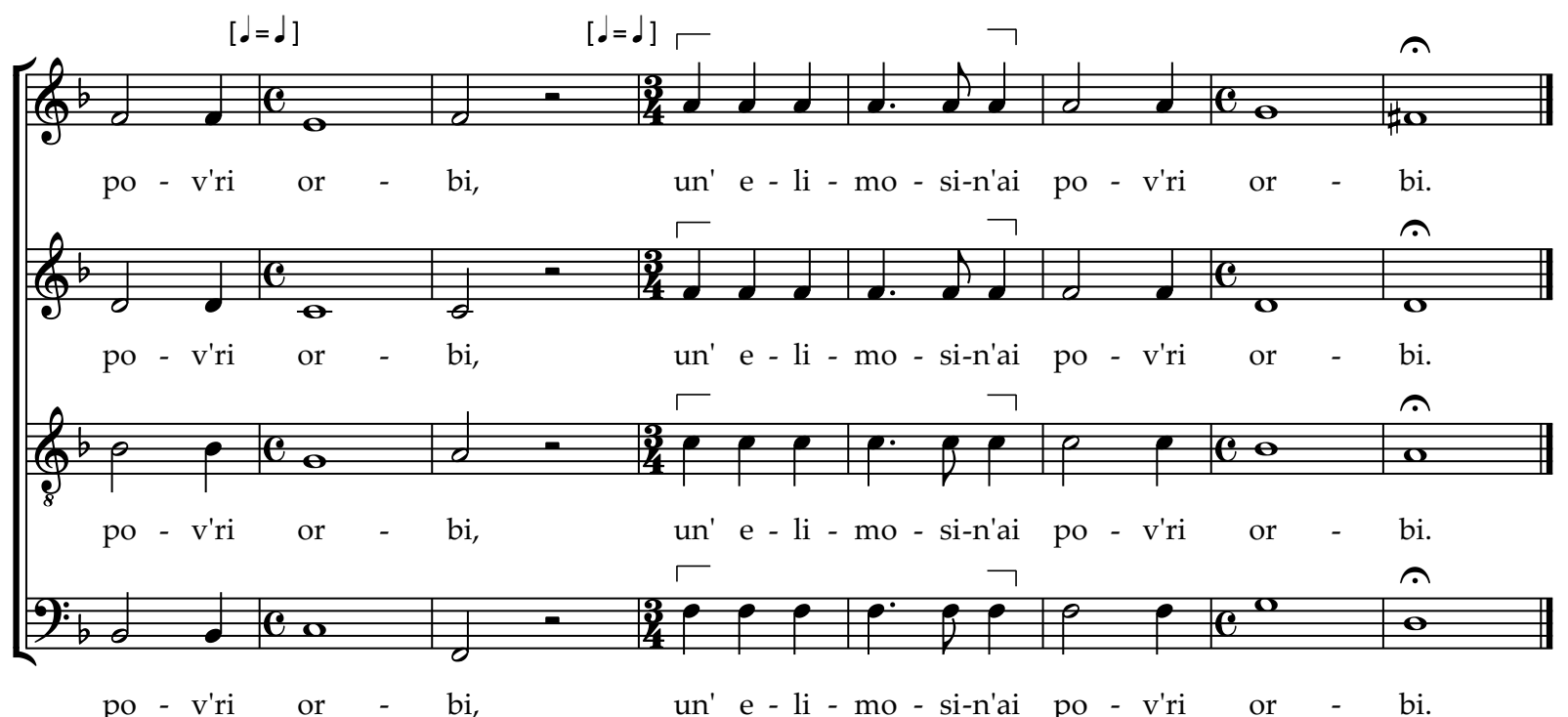




\subsection{PASCHINO, BELLO PASCHINO}

(Winchester Partbooks, n. 22)

Texto: anônimo

Paschino, bello Paschino,

Deh toccami la gamba

Che dormir non posso più.

Speranza del cor mio,

Voltat' in qua e poi voltat'in là

E lasciami dormire

Che la notte se ne va.
Hubert Waelrant (ca.1517-1595)

Transcrito e editado por Munir Sabag

Paschino, belo Paschino,

Oh, toca-me a perna,

Que não posso mais dormir.

Esperança do meu coração,

Volta-te para cá e depois volta-te para lá

E deixa-me dormir,

Que a noite já se vai.
[DISCANTUS]

[ALTUS]

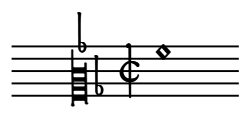

[TENOR]

[BASSUS]
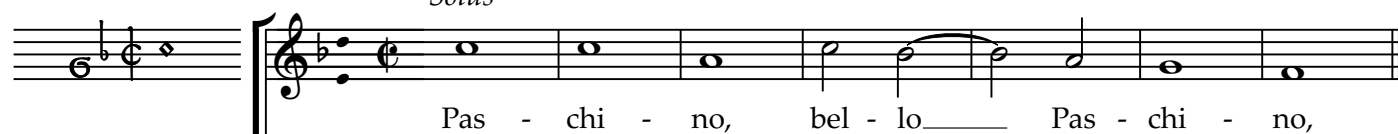

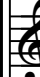

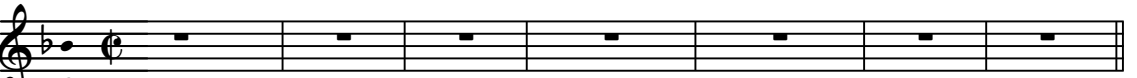

(

(

8

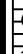

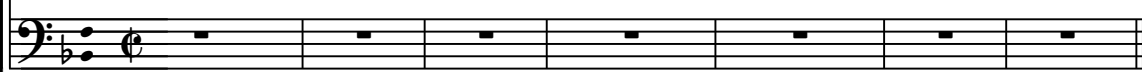

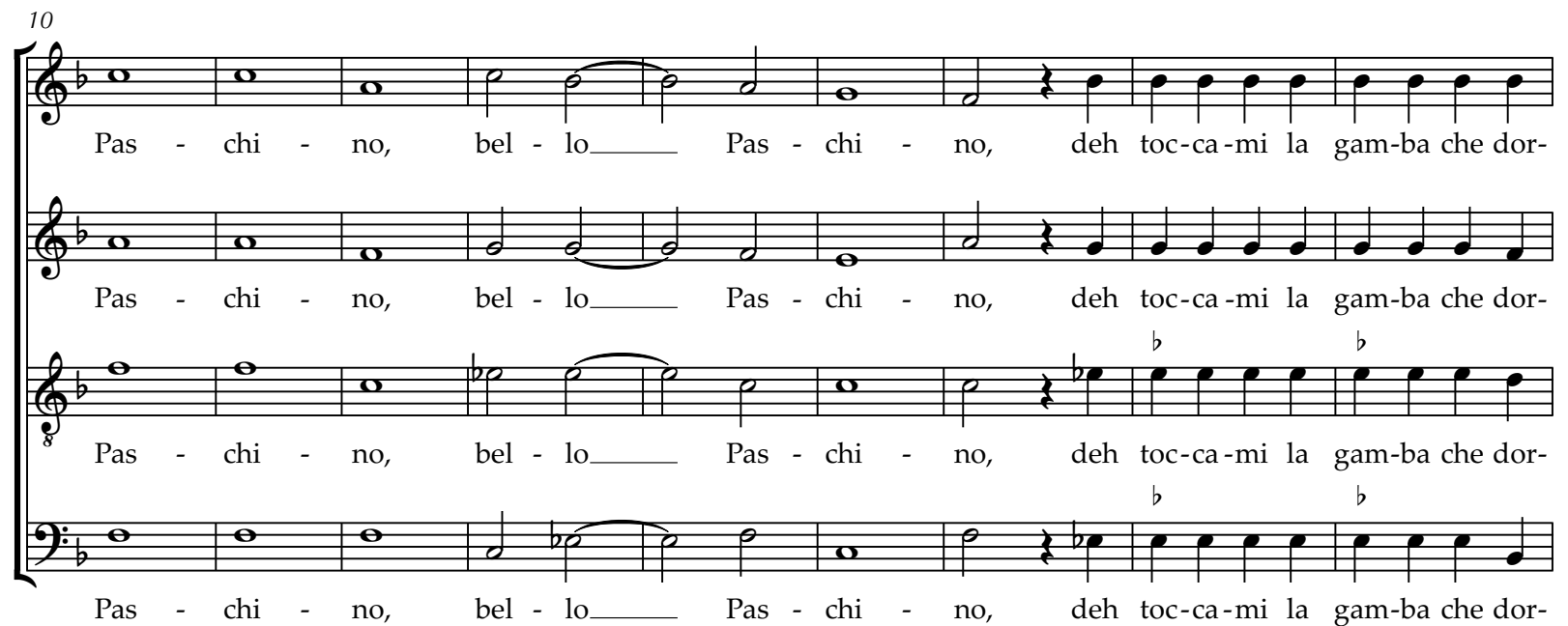



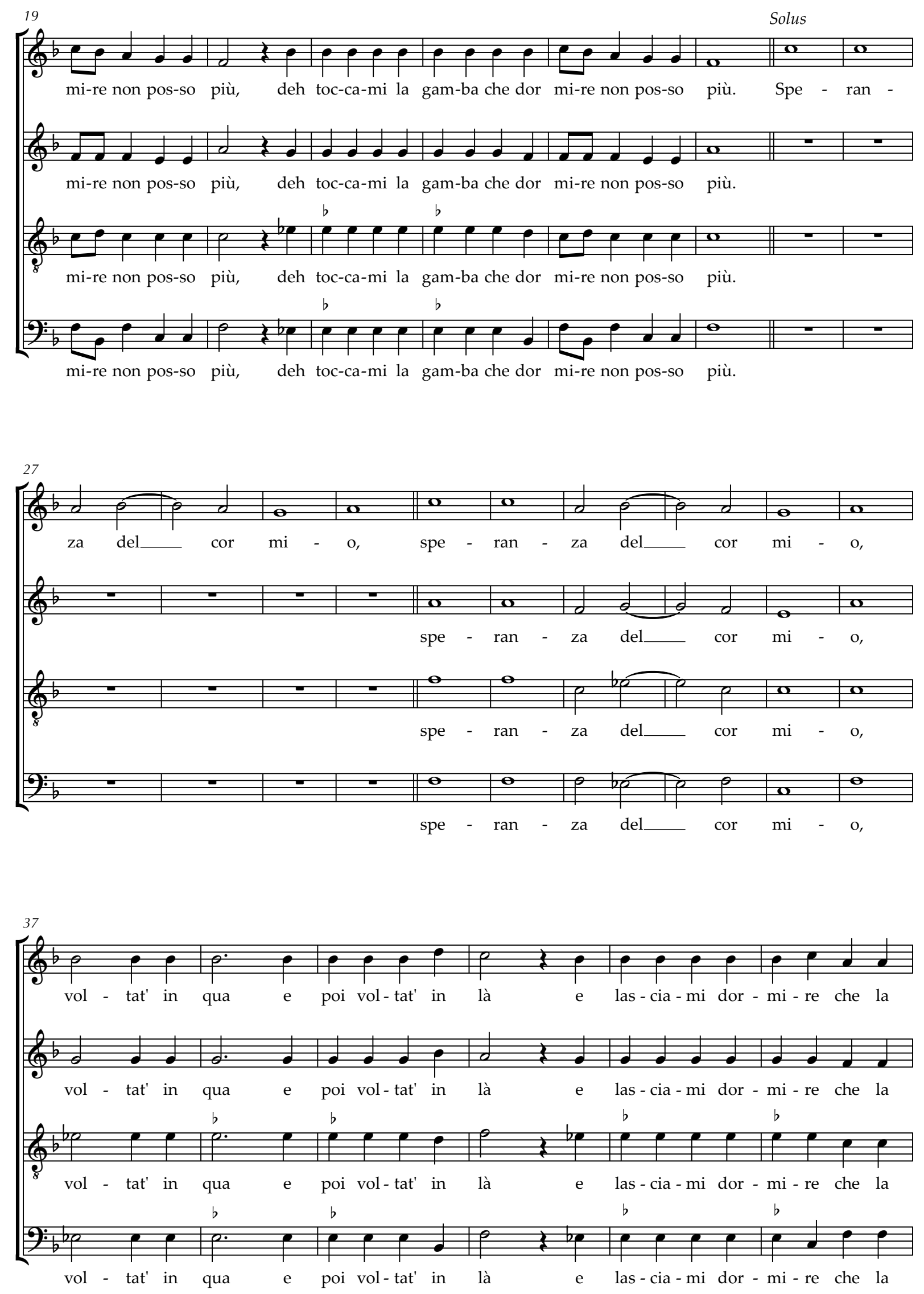


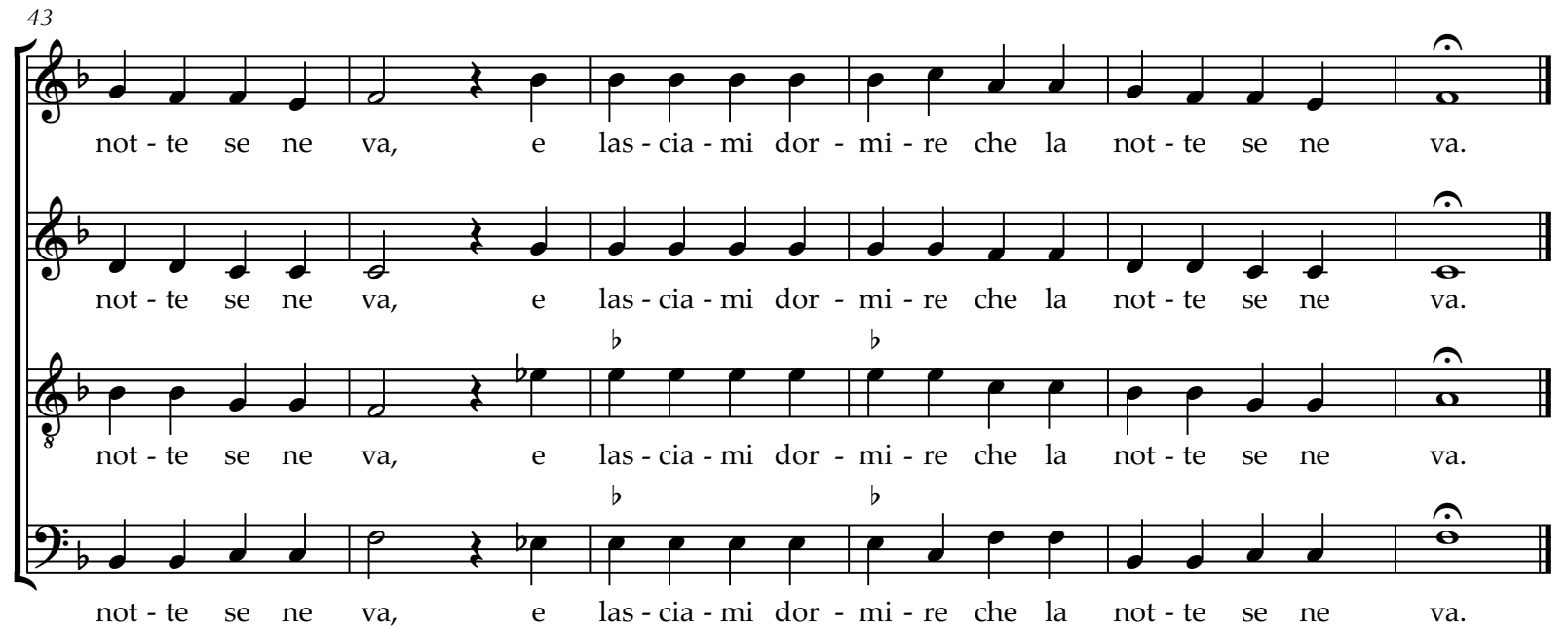




\subsection{MILL'ANNI SONO CH'IO NON T'HAGGIO VISTA}

(Winchester Partbooks, n. 29)

Texto: Vincenzo Fontana (fl. 1550)

Mill' anni sono ch'io non t'aggio vista, Lassamente non poco a rivedere. Faccio t'a sapere, faccia mia d'oro: Se non te vegg'io moro.
Hubert Waelrant (ca.1517-1595) Transcrito e editado por Munir Sabag

[DISCANTUS]
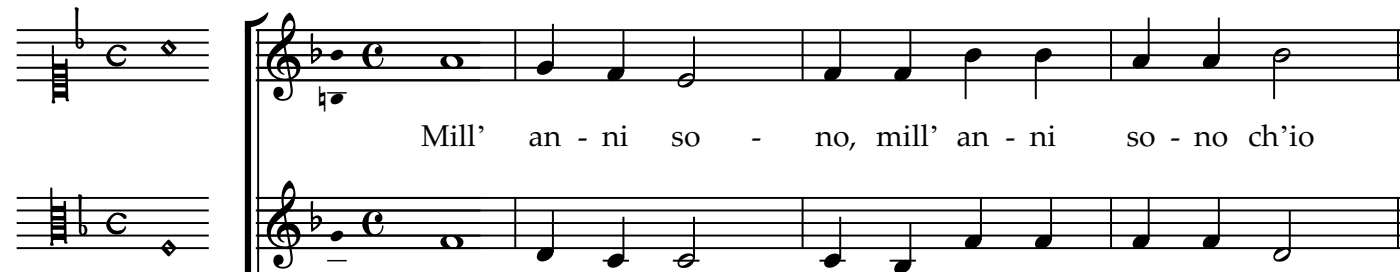

[ALTUS]
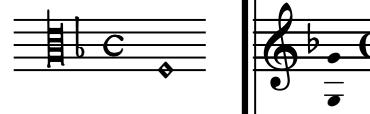

Mill'

São mil anos que não te vejo, Infelizmente não falta pouco para te rever.

Te faço saber, meu rostinho de ouro:

Se não te vejo eu morro.

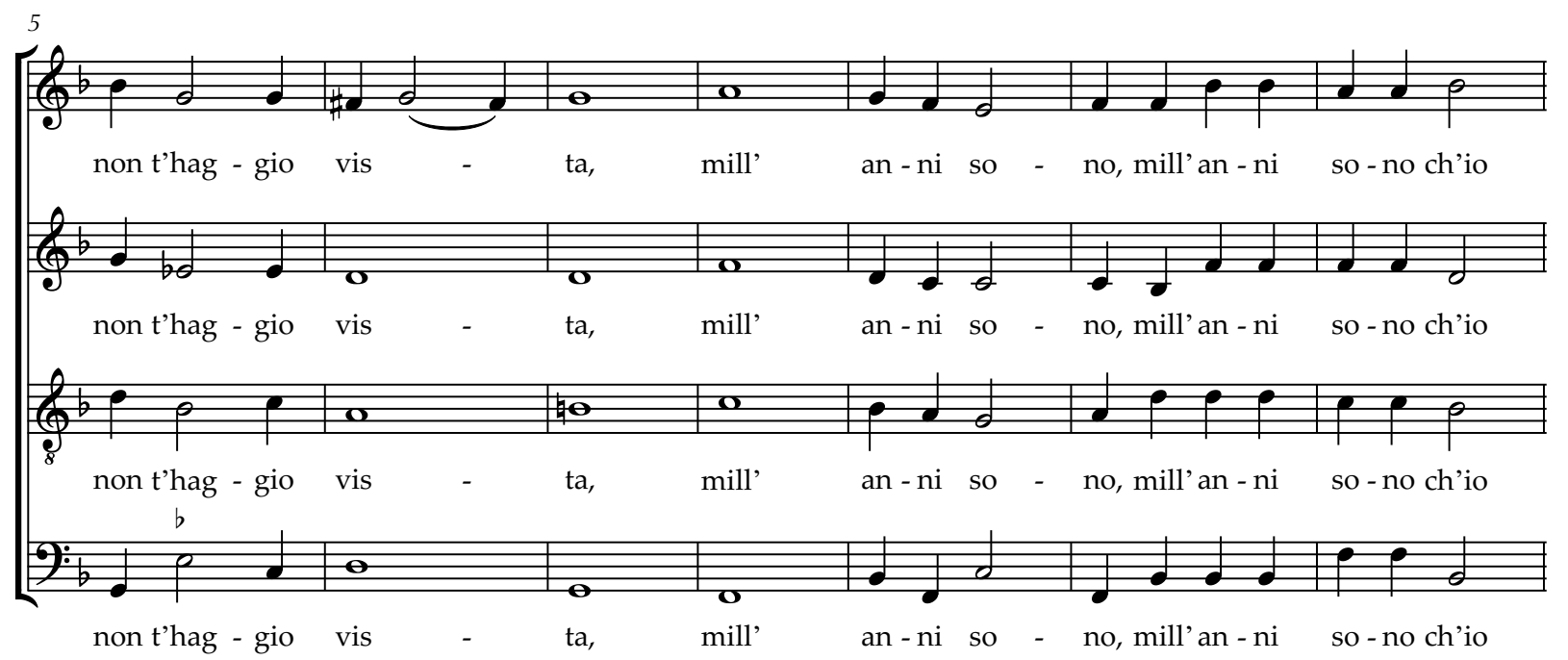



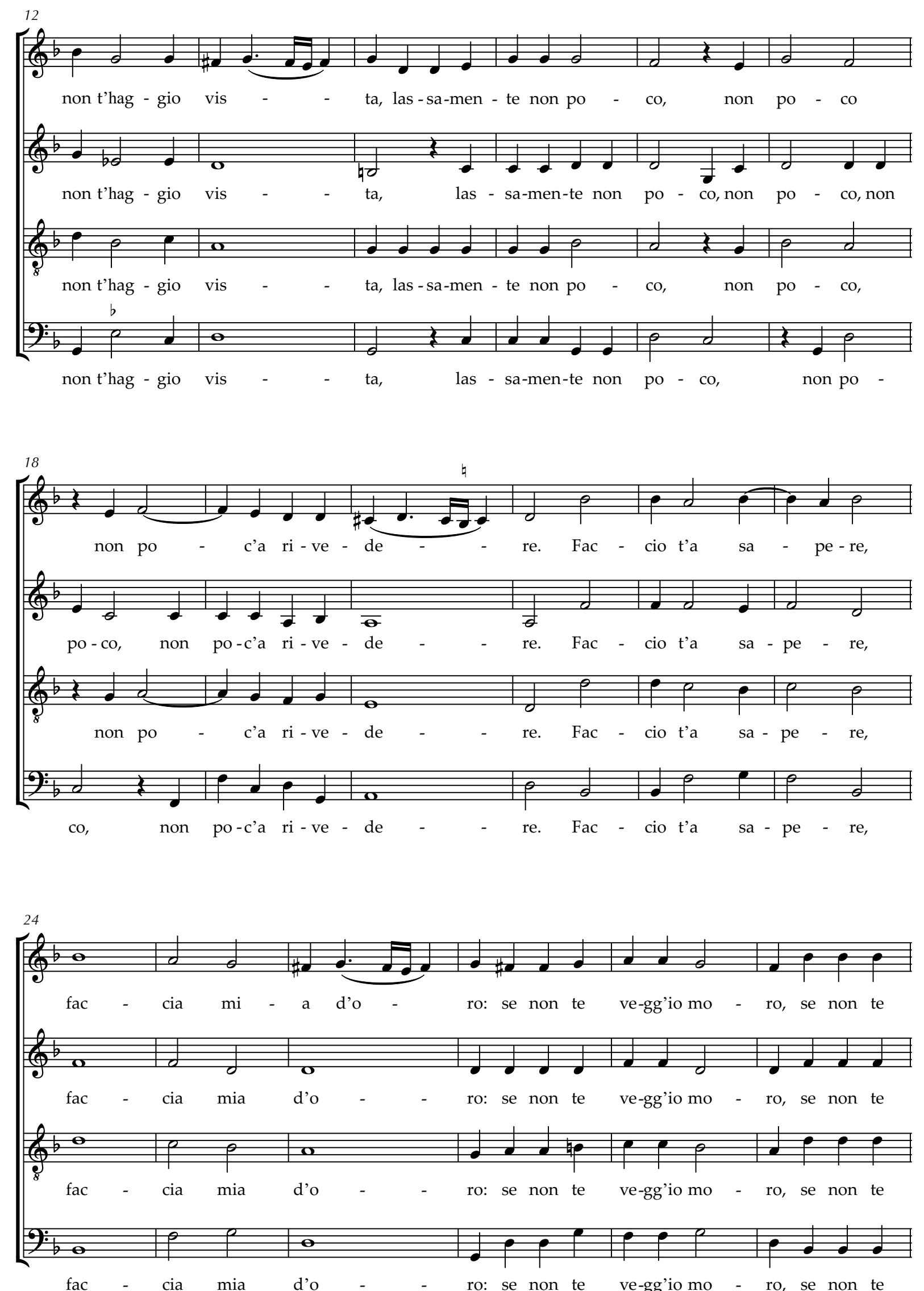


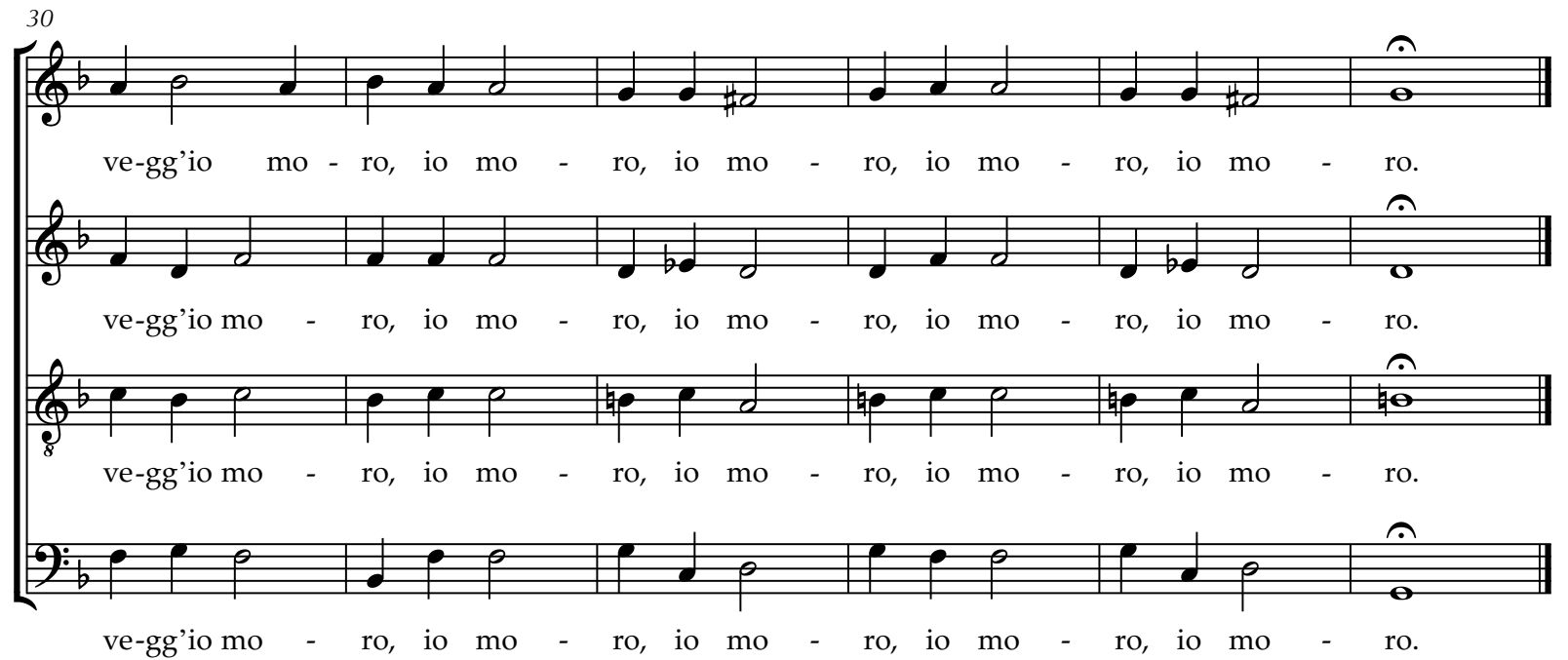




\subsection{3. \\ NON T'HO POSSUTO MAI, DONNA, MOSTRARE}

(Winchester Partbooks, n. 31)

Texto: anônimo

Non t'ho possuto mai, donna, mostrare

L'accesa fiam' e mia sincera fede.

Deh per mercede donami il loco

$\mathrm{Ch}^{\prime}$ io ti posso scoprir mio ardente foco.
Hubert Waelrant (ca.1517-1595)

Transcrito e editado por Munir Sabag

[DISCANTUS]
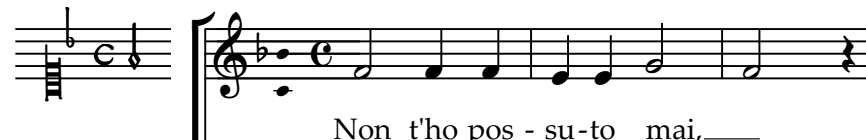

Nunca te pude mostrar, ó dama,

A chama acesa e minha sincera fé.

Oh, por piedade, dá-me o local

Em que eu possa te revelar meu ardente fogo.

[ALTUS]

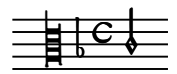

Non t'ho pos - su-to mai, non t'ho pos-su - to mai, mai, mai,

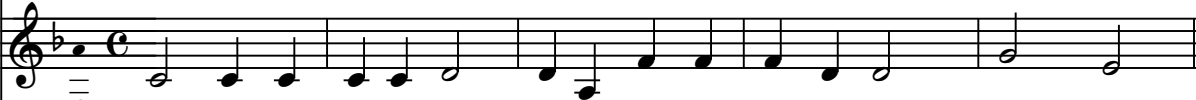

Non t'ho pos - su-to mai,__ non t'ho pos - su - to mai, mai, mai,

[TENOR]
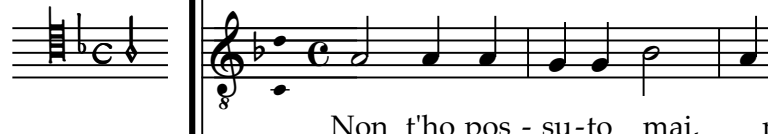

Non t'ho pos - su-to mai,__ non t'ho pos - su - to mai, mai, mai,

[BASSUS]
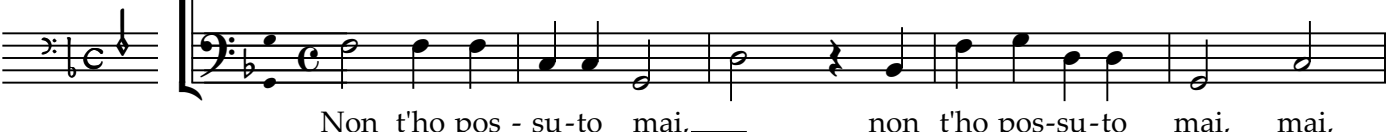

Non t'ho pos - su-to mai, non t'ho pos-su-to mai, mai,

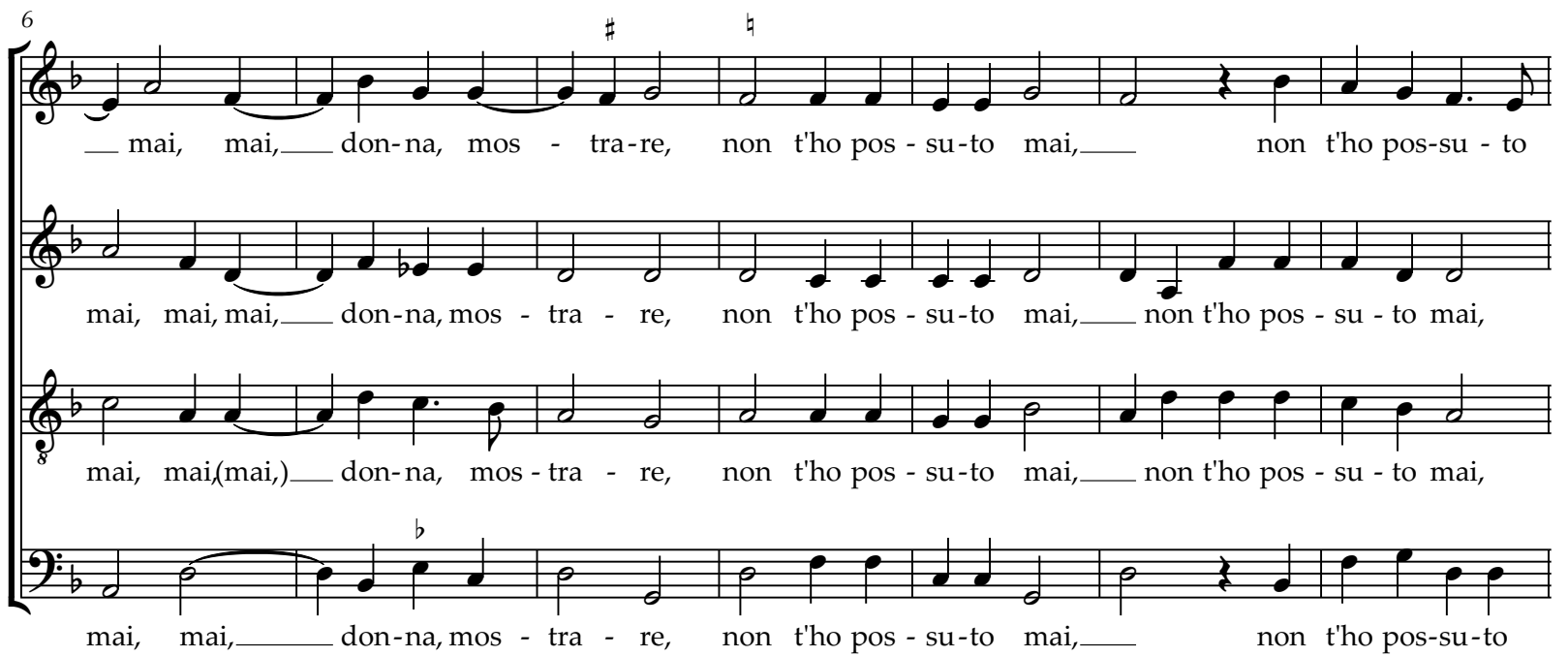



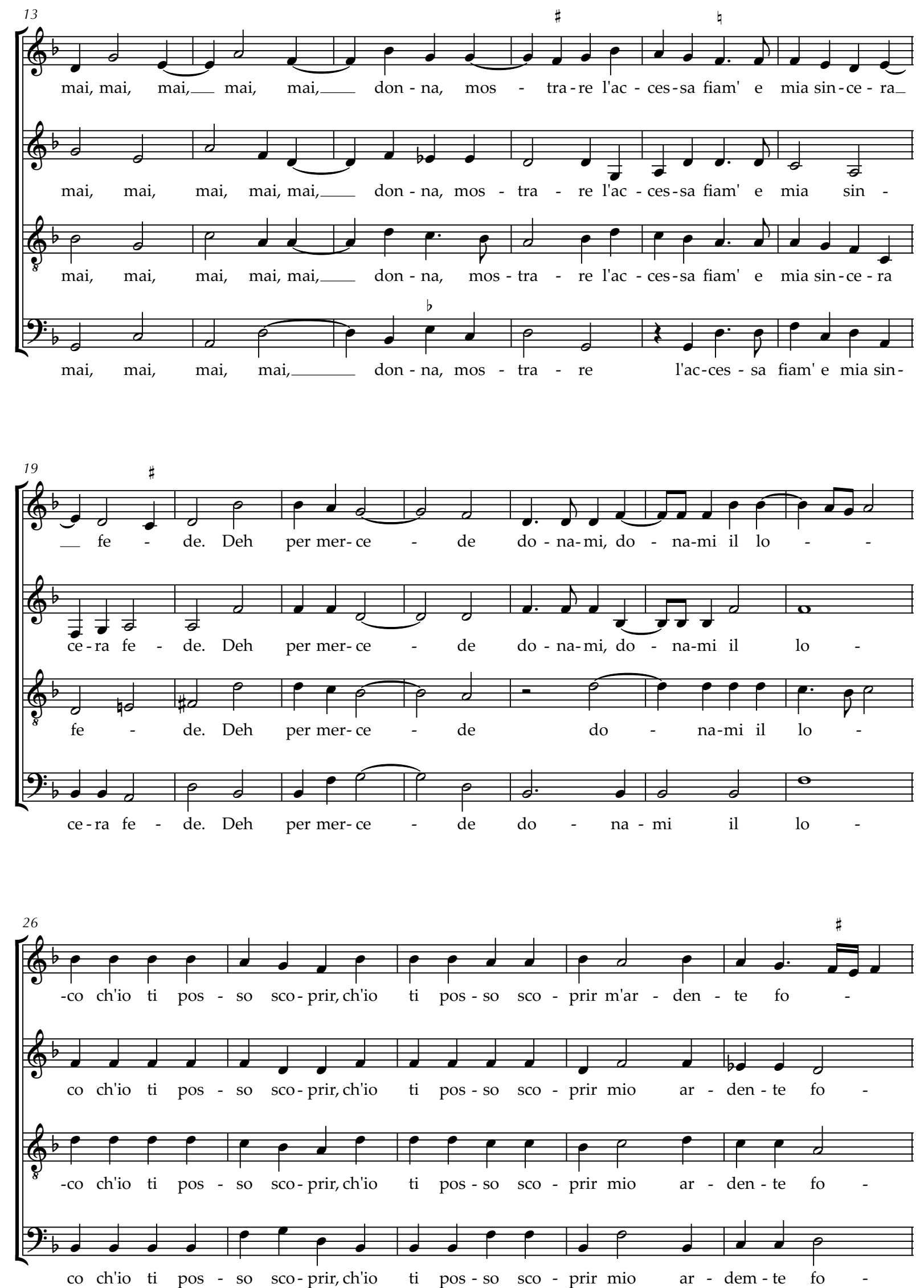


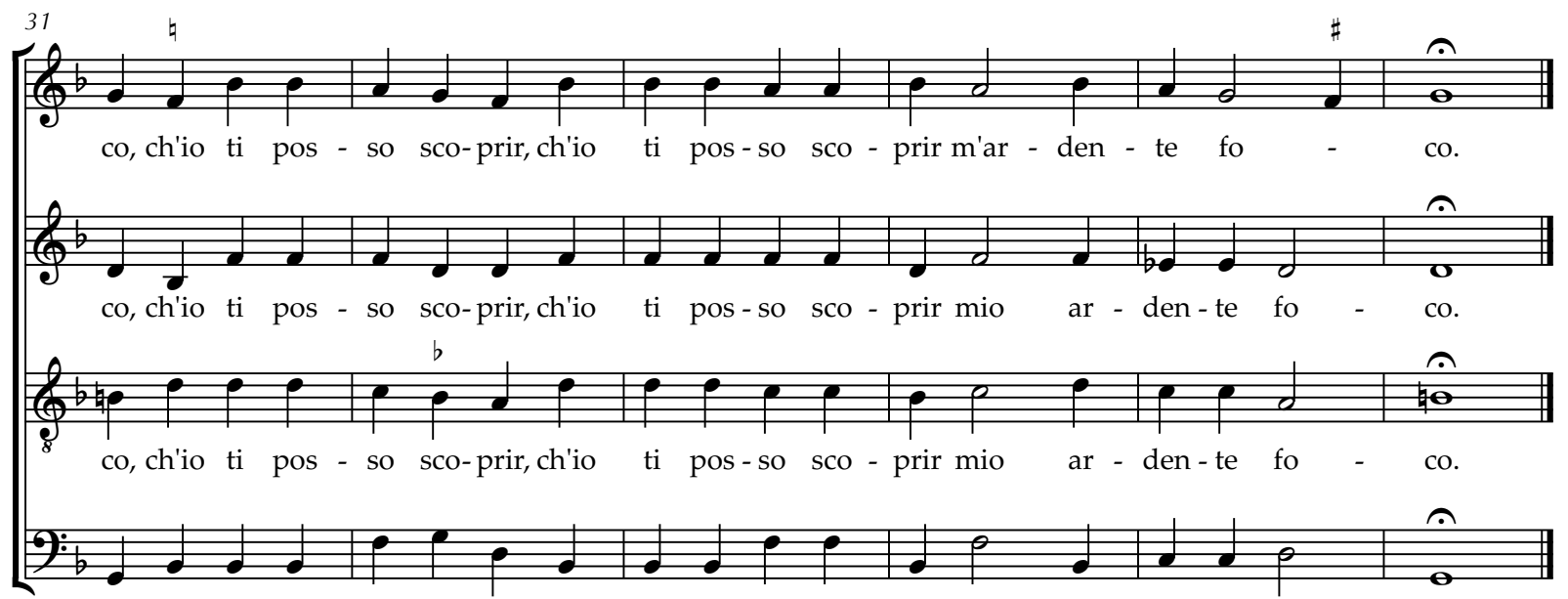

co, ch'io ti pos - so sco-prir,ch'io ti pos-so sco - prir mio ar - den - te fo - co. 


\subsection{CHIAMO LA MORT' OGN'HOR}

(Winchester Partbooks, n. 34)

Texto: anônimo

Hubert Waelrant (ca.1517-1595)

Transcrito e editado por Munir Sabag

Chiamo la mort' ogn'hor che me ne levi,

Per quest' ingrata che mi strazia tanto.

O bello vanto, o bell' honore,

A dar la mort' a chi t'ha dato il core.

Chamo sempre a morte, que me leve, Por esta ingrata que tanto me atormenta. Oh, belo orgulho, oh, bela honra,

A dar a morte a quem te deu o coração.

[DISCANTUS]
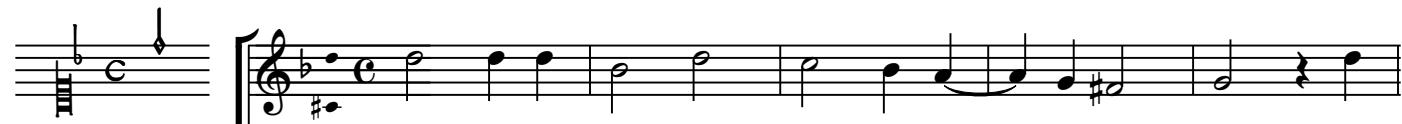

[ALTUS]

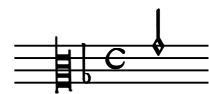

[TENOR]

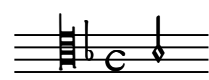

[BASSUS]

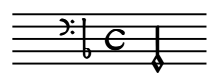

Chia - mo la mort' og

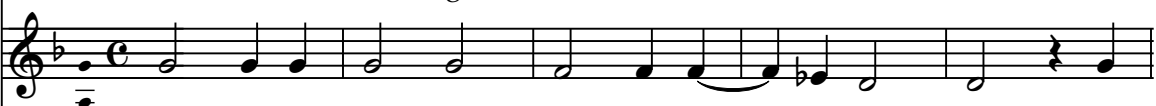

Chia - mo la mort' ogn' hor che me_ ne le - vi, chia-

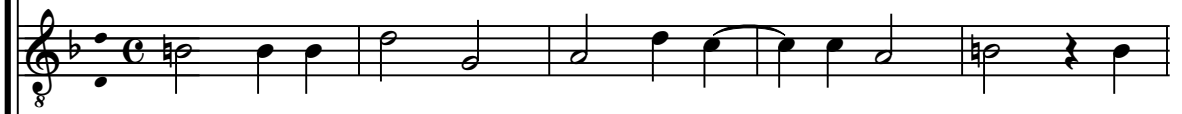

Chia - mo la mort' ogn' hor che me_ ne le - vi, chia-
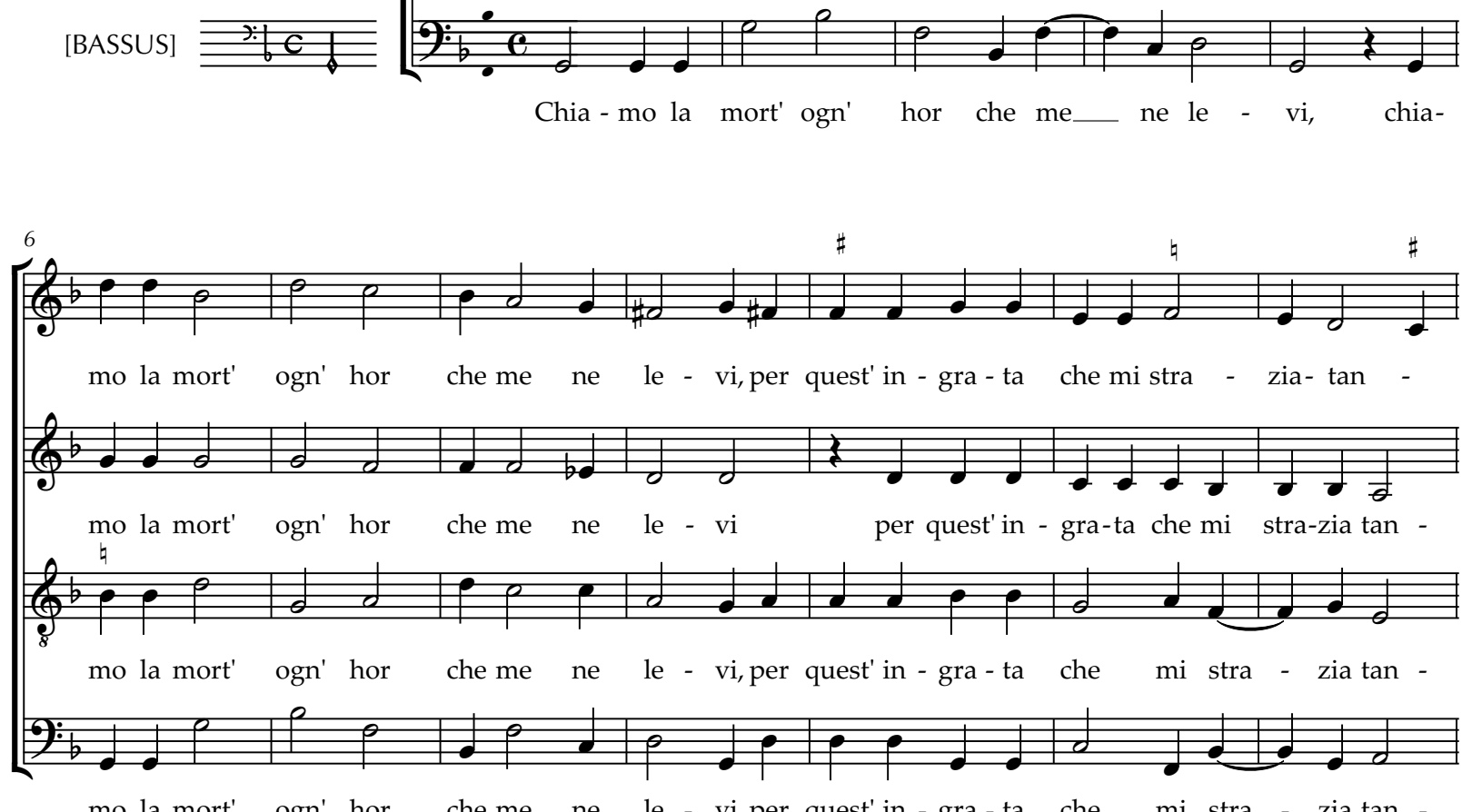

mo la mort' ogn' hor che me ne le - vi, per quest' in - gra - ta che mi stra - zia tan - 


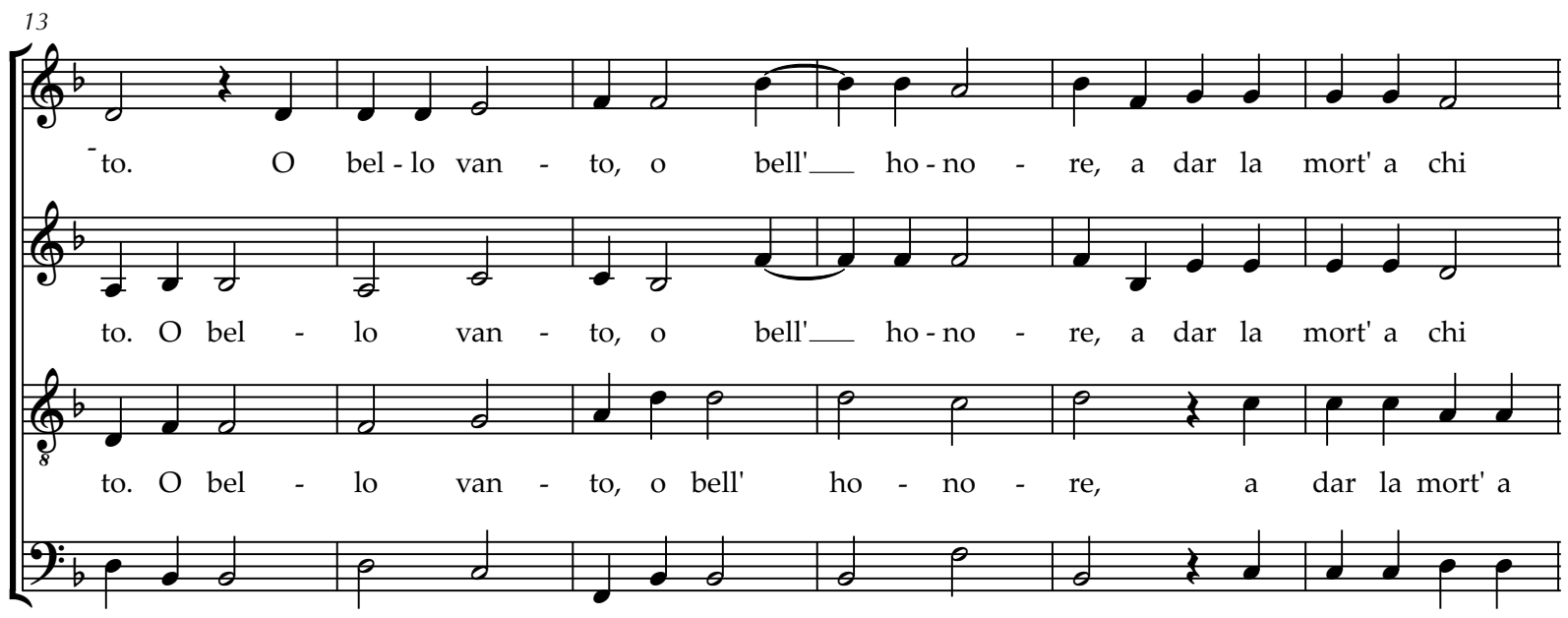
to. O bel - lo
van -
to, o bell'
ho - no - re,
a dar la mort' a

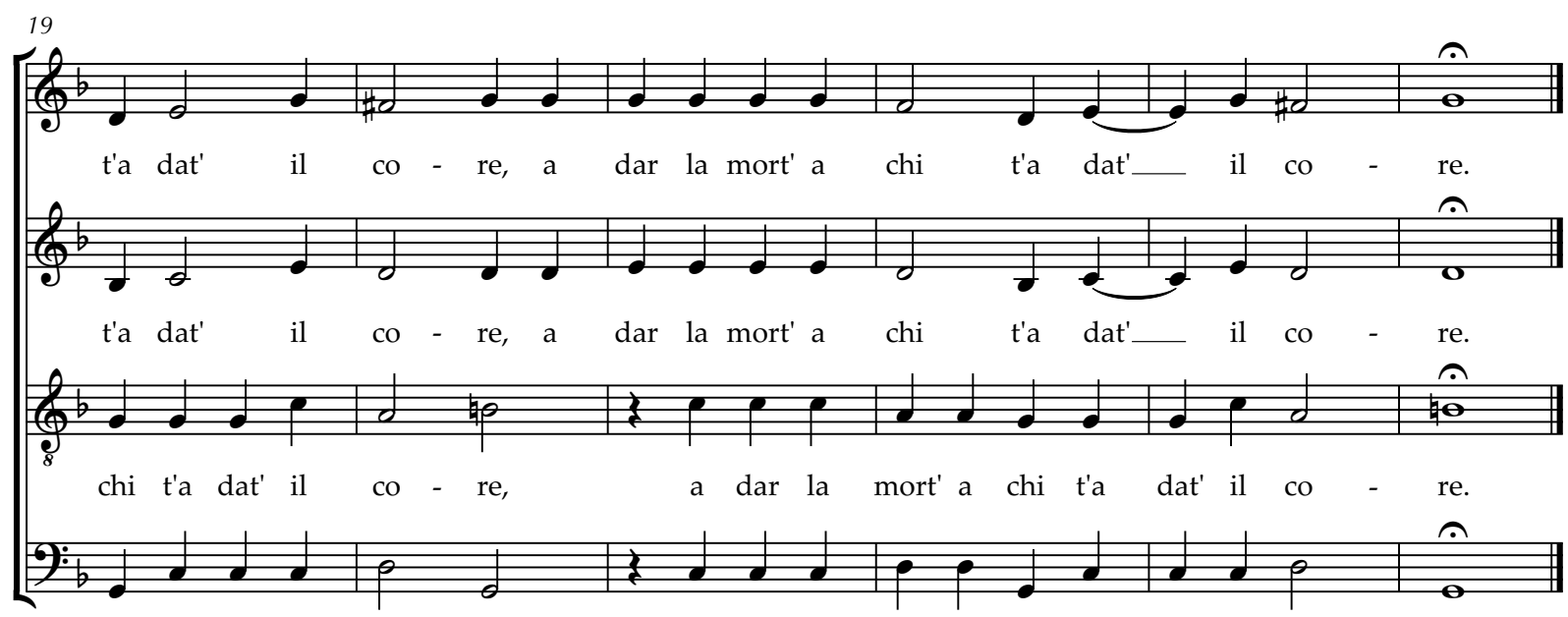

chi t'a dat' il co - re, a dar la mort' a chi t'a dat' il co - re. 


\subsection{STA' COSTANTE, COR MIO, CH'IO T'AM' OGN'HORA}

(Winchester Partbooks, n. 35)

Hubert Waelrant (ca.1517-1595)

Texto: anônimo

Transcrito e editado por Munir Sabag

Sta costante, cor mio, ch'io t'amo ogn'hora

Ed amerò per fin ch'avrò la vita,

Che tu mi tiri come calamita.

Sê constante, meu coração, que eu te amo sempre

E amarei até o fim da vida,

Pois tu me atrais como um ímã.

[DISCANTUS]
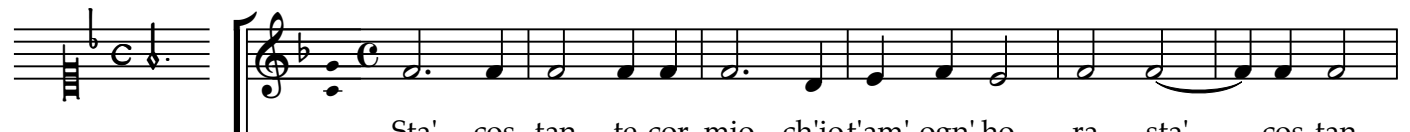

[ALTUS]

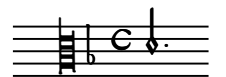

Sta' cos-tan - te cor mio ch'iot'am' ogn' ho - ra, sta'
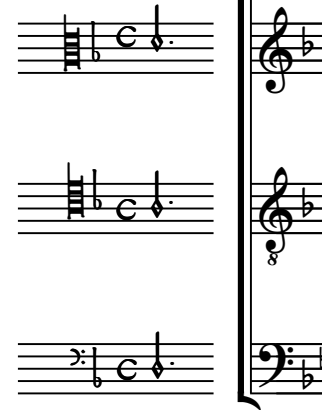

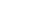
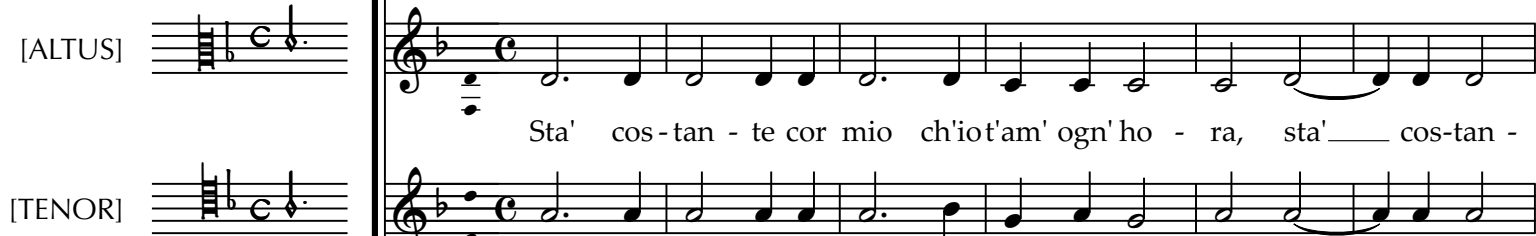

Sta' cos-tan - te cor mio ch'iot'am' ogn' ho - ra, sta' cos-tan -

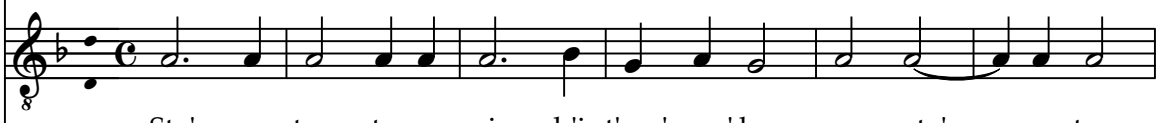

Sta' cos-tan - te cor mio ch'iot'am' ogn'ho - ra, sta'__ cos-tan -

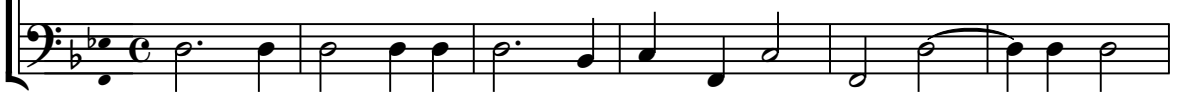

Sta' cos-tan - te cor mio ch'iot'am' ogn' ho - ra, sta' cos-tan -

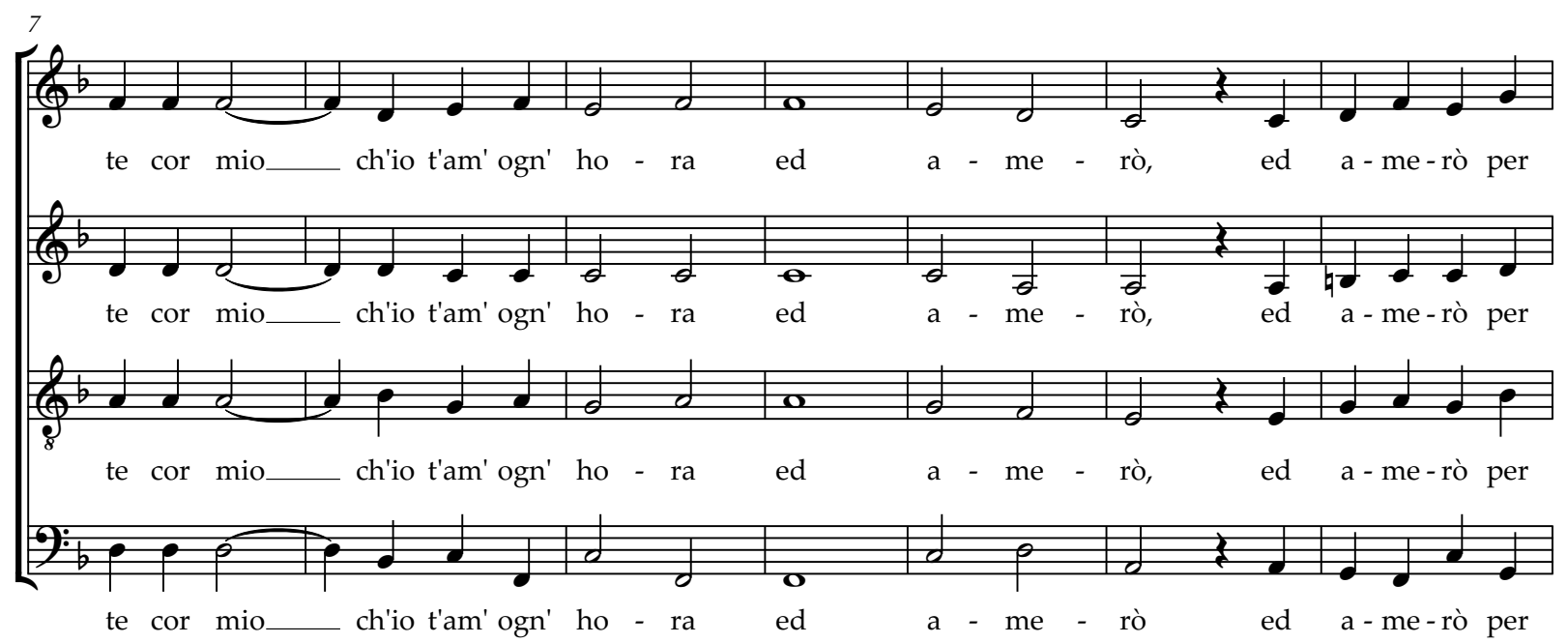



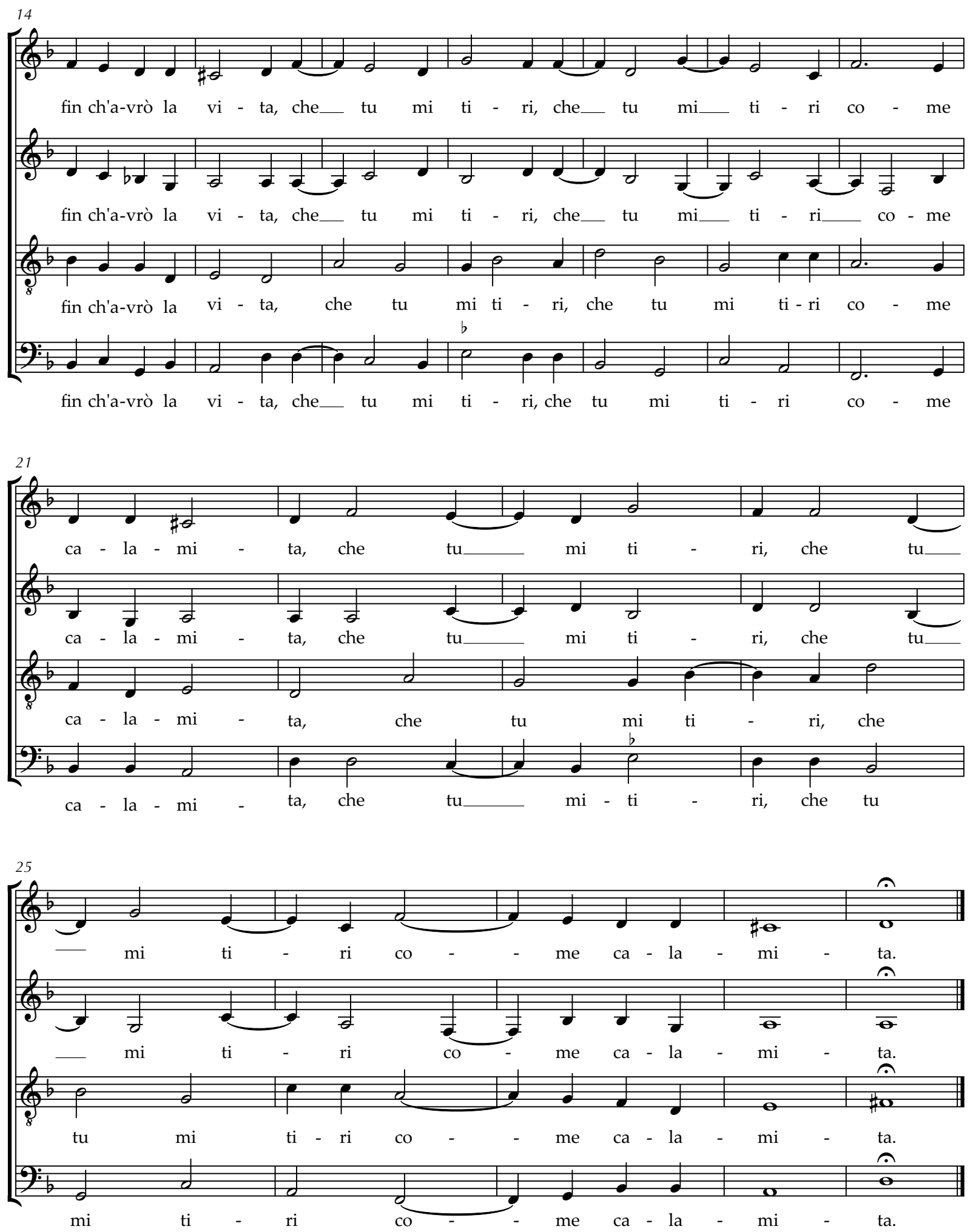

NOTA DO EDITOR:

Discantus, compasso 6: há uma minima excedente no manuscrito. 


\subsection{DOLCI SGUARDI TUOI, ALTA SIGNORA}

(Winchester Partbooks, n. 36)

Texto: anônimo

I dolci sguardi tuoi, alta signora,

Rissuscitan i morti per dolcezza.

Tu sei ‘na freccia che mi pass'il core.
Hubert Waelrant (ca.1517-1595) Transcrito e editado por Munir Sabag
[DISCANTUS]

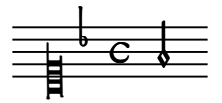

[ALTUS]

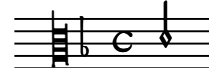

[TENOR]

[BASSUS]
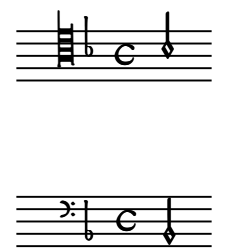
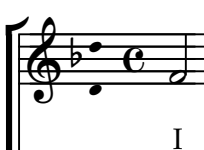

I dol

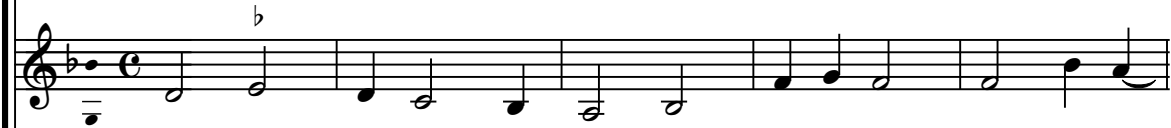

I dol - ci sguar - di tuoi al - ta sig-no - ra, al - ta

Ressuscitam os mortos pela doçura.

Tu és uma flecha que me transpassa o coração.

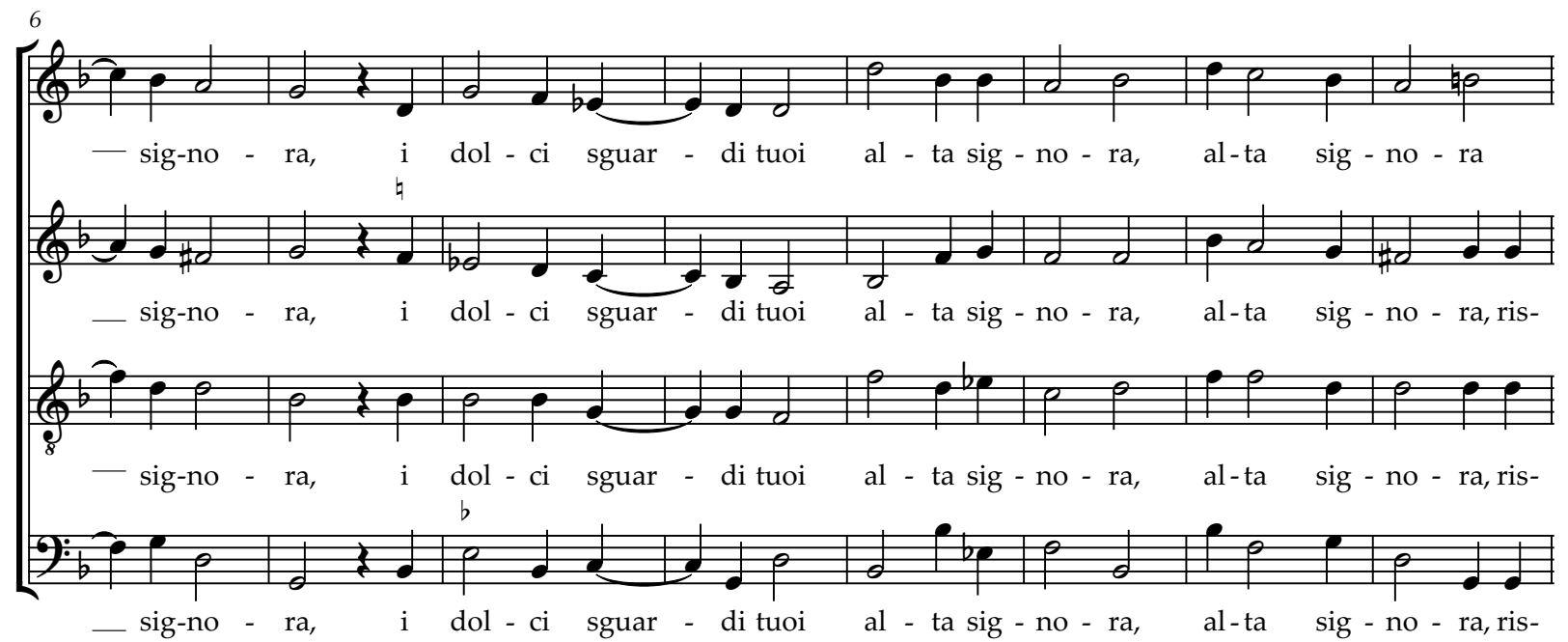






\subsection{7 . \\ SON MORT' E MORO}

(Winchester Partbooks, n. 37)

Texto: anônimo

Son mort' e moro e pur credo morire,

Nè per tanto morir perdo la vita.

O potenza d'amor sol infinita.
Hubert Waelrant (ca.1517-1595)

Transcrito e editado por Munir Sabag

[DISCANTUS]
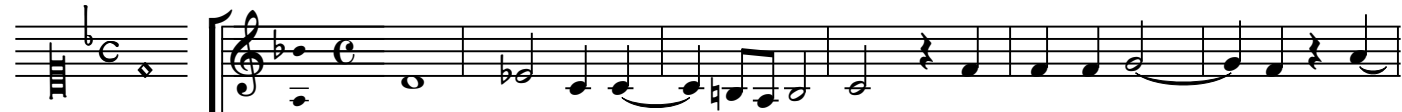

Estou morto, e morro, e ainda assim creio morrer,

E nem por tanto morrer eu perco a vida.

Ó poder do amor, único infinito.
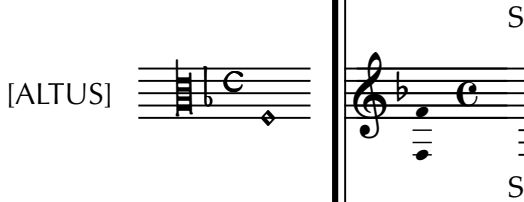

Son mort' $\mathrm{e}$ mo

ro, son mort'e mo - ro e_

[TENOR]
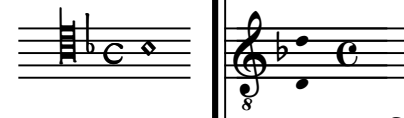

-
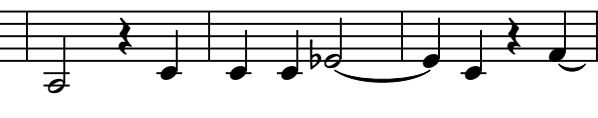

[BASSUS]
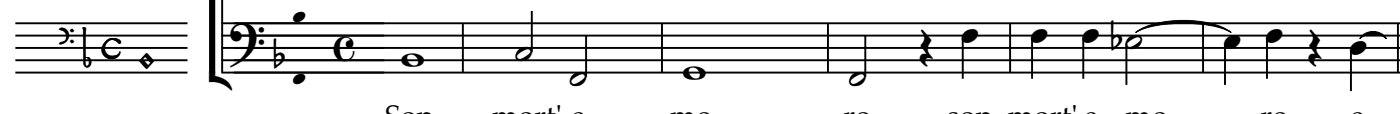

Son

ro,

son mort'e mo

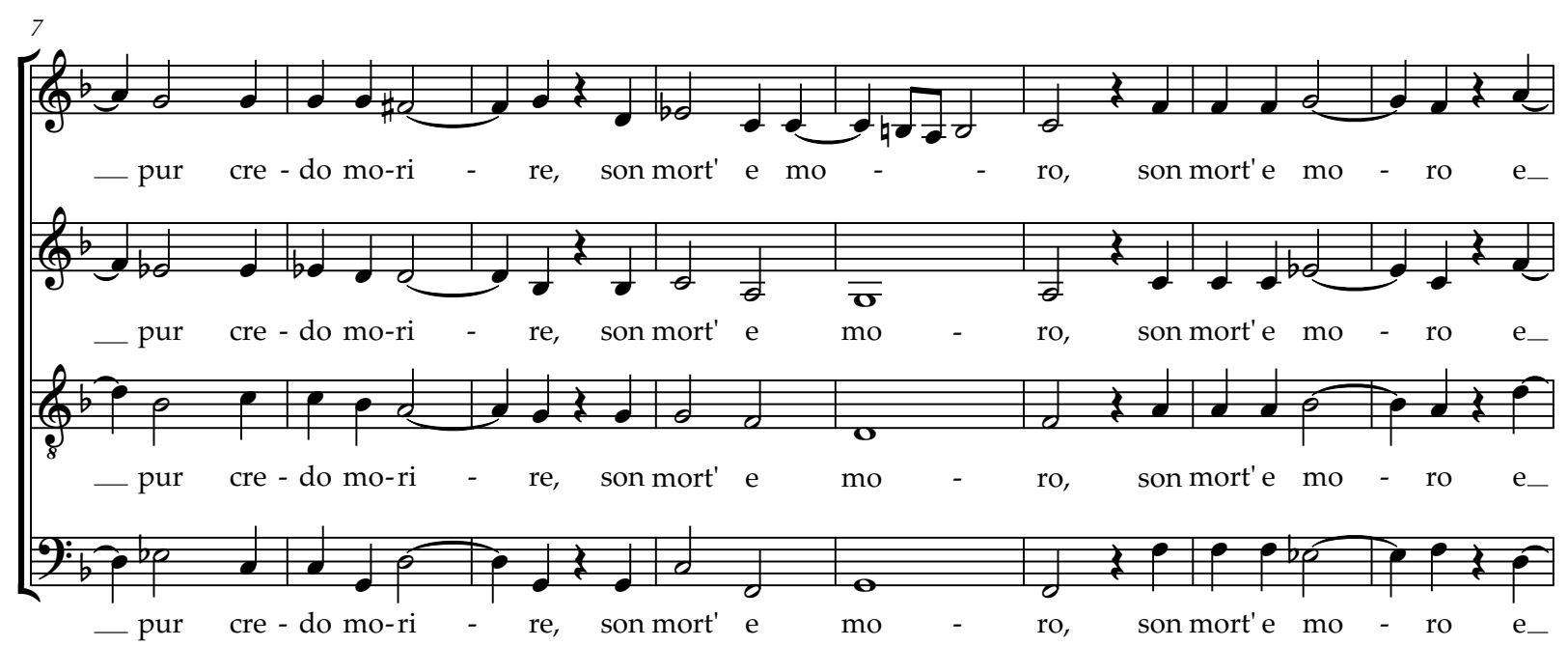



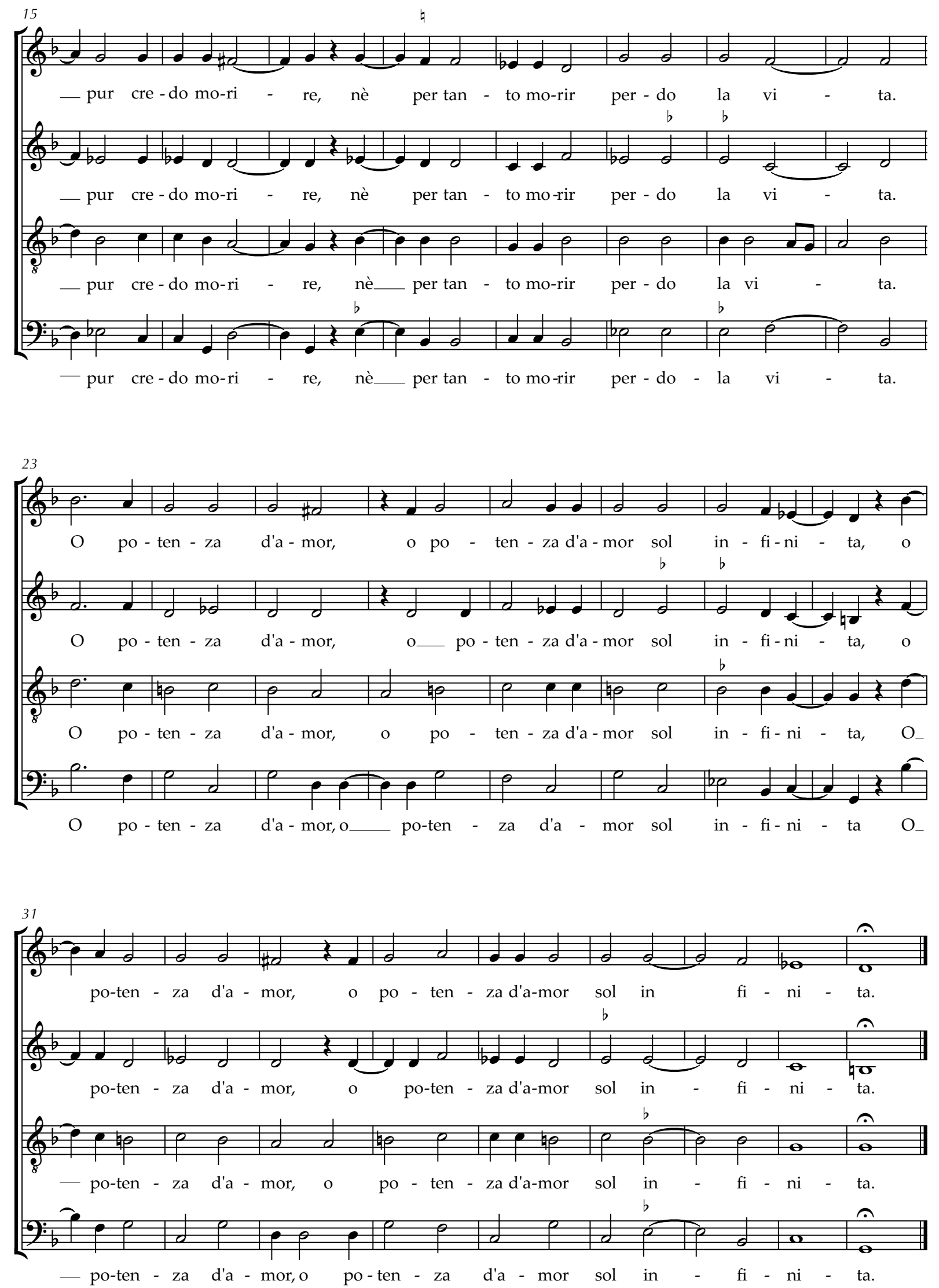


\subsection{NON POSSO FAR, COR MIO, CHE PUR NON PIANGA}

(Winchester Partbooks, n. 38)

Texto: anônimo

Non posso far, cor mio, che pur non pianga

E piangerò per fin che sarò vivo

Poichè son privo di te, ahi dura sorte.

O quanto mi saria dolce la morte.
Hubert Waelrant (ca.1517-1595) Transcrito e editado por Munir Sabag

Não posso evitar, meu coração, o pranto E chorarei enquanto estiver vivo

Porque estou sem $\mathrm{ti}$ - oh dura sorte.

Oh, quanto me seria doce a morte.

[DISCANTUS]
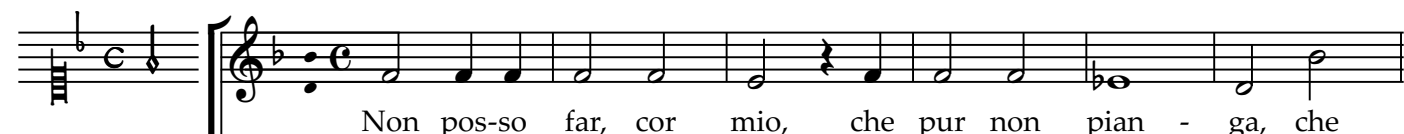

[ALTUS]

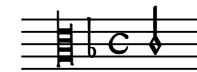

Non pos-so far, cor

che pur non

ga, che

[ALTUS]

[TENOR]
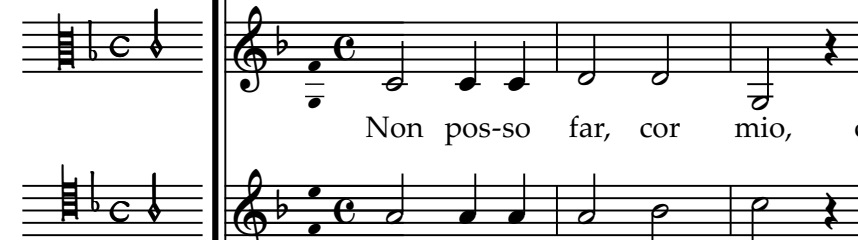

mio, che pur non pian - ga, che

[BASSUS
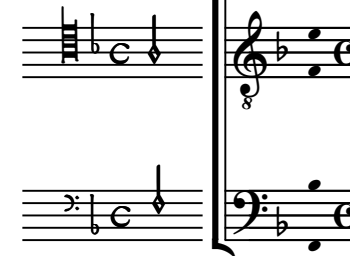

Non pos-so far, cor mio, che pur non pian - ga, che

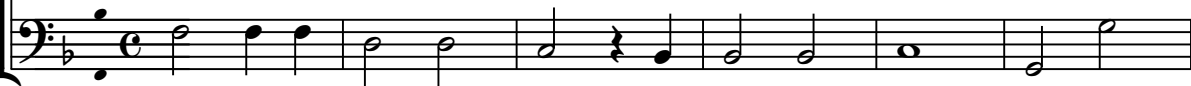

Non pos-so far, cor mio, che pur non pian - ga, che

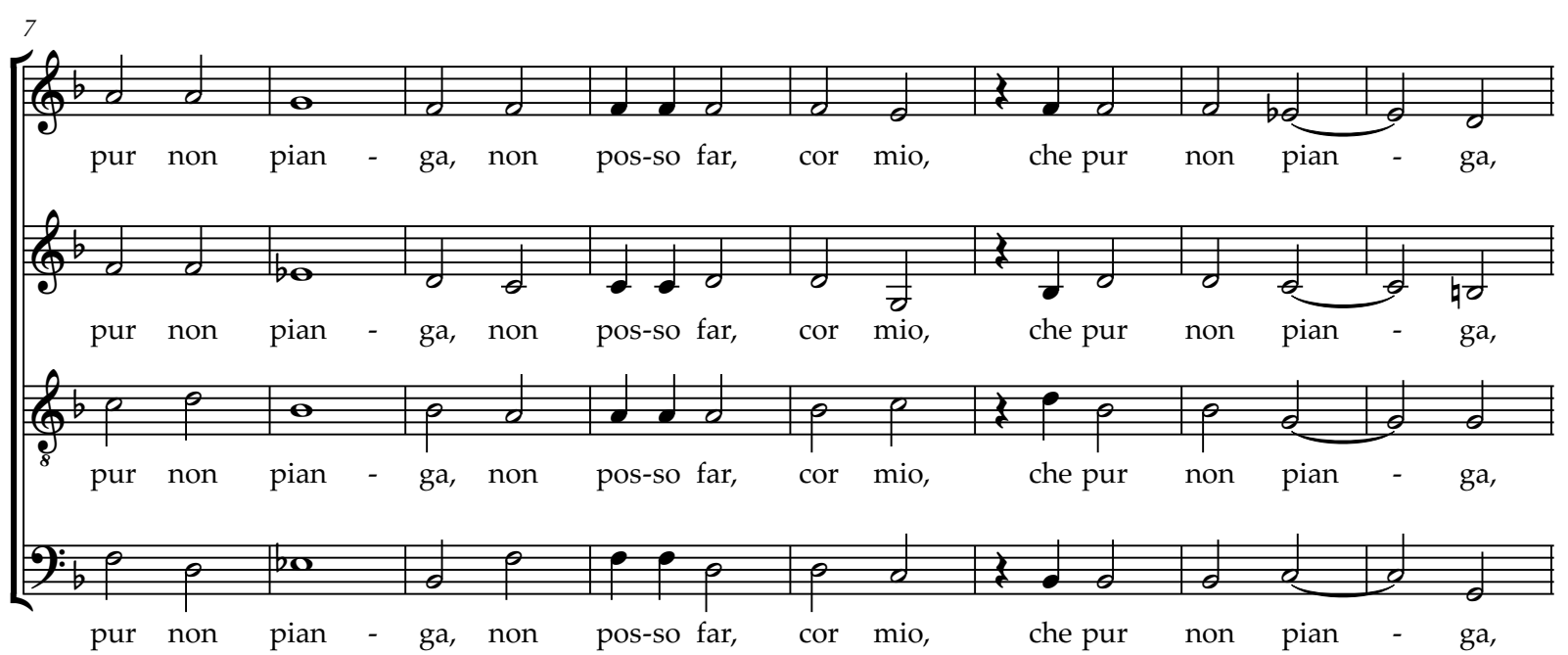



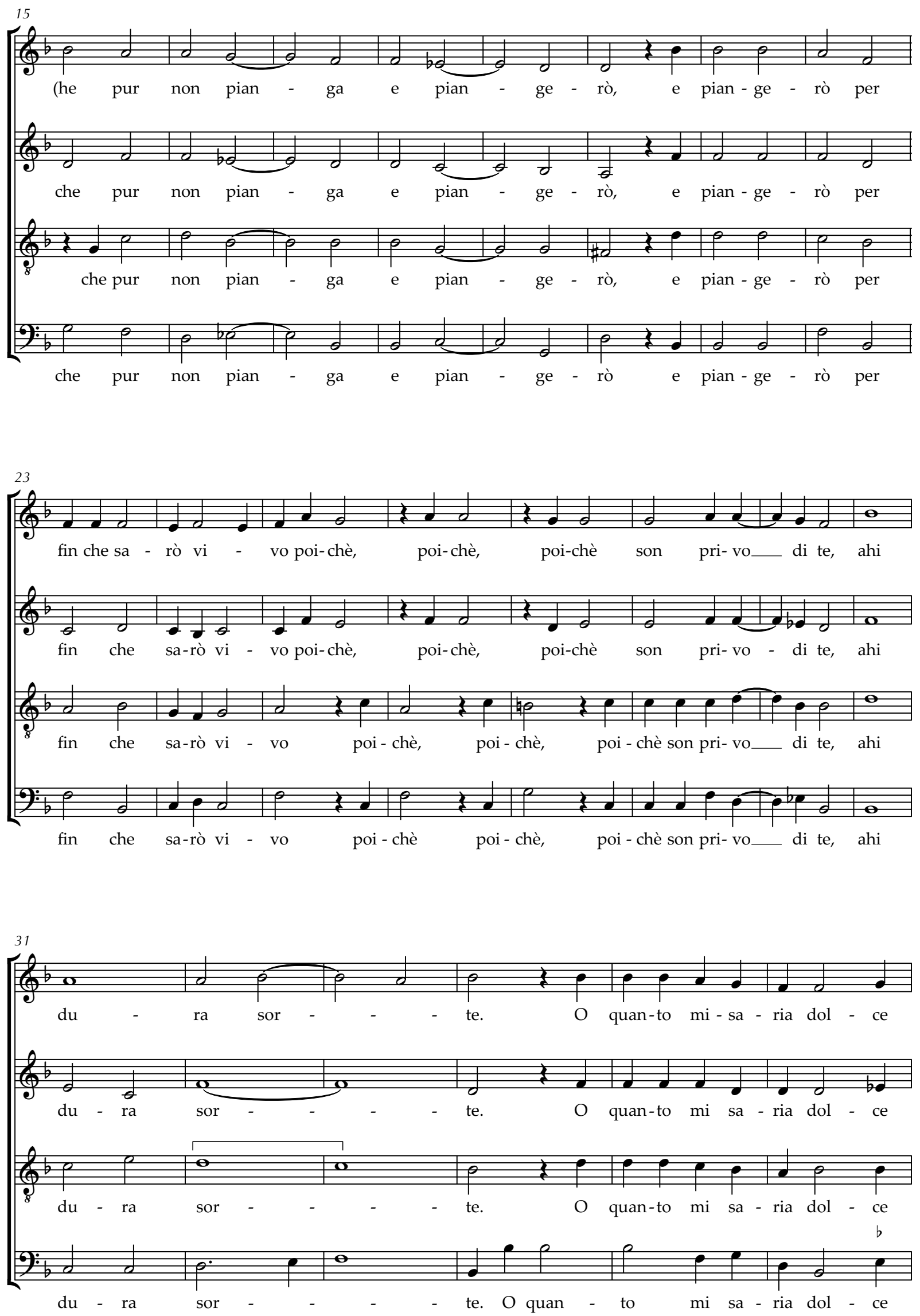


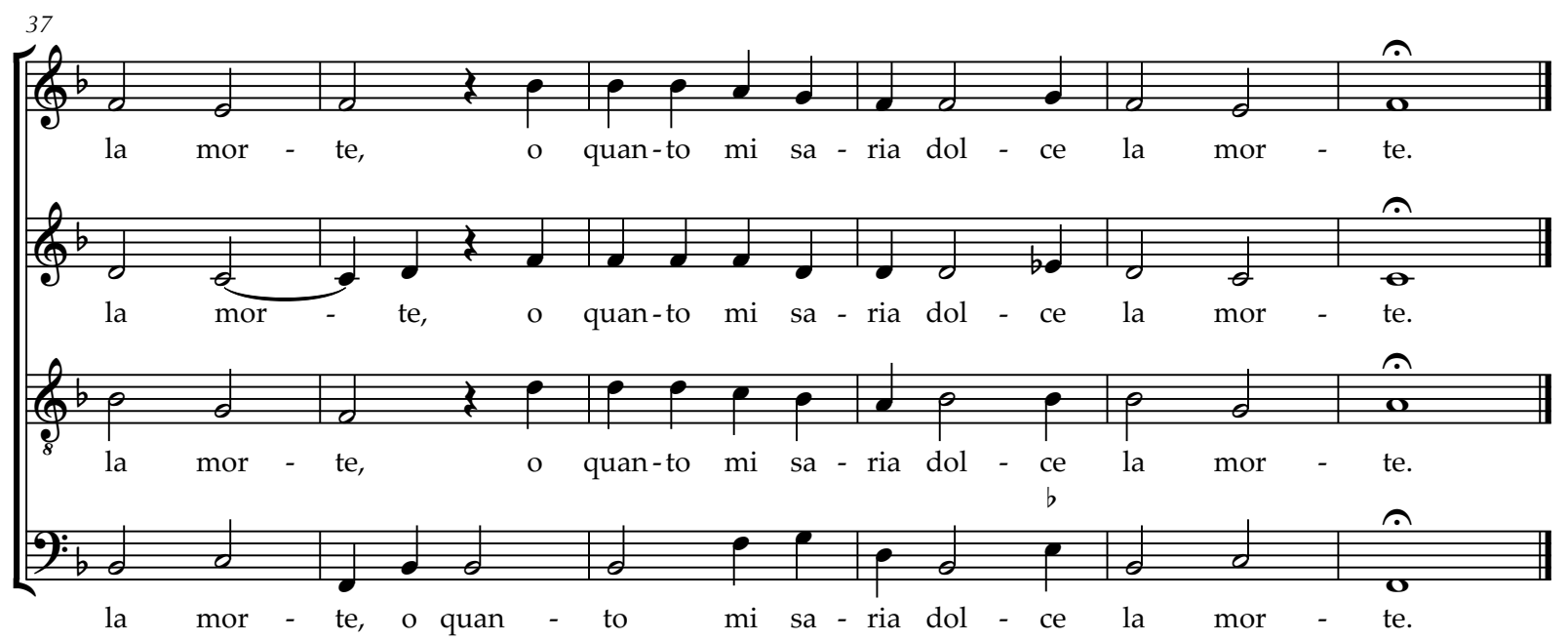




\subsection{TANTO SAI FARE CON L'INNAMORATI}

(Winchester Partbooks, n. 39)

Texto: anônimo

Tanto sai fare con l'innamorati

Che vano spersi per quest' occhi tuoi.

Deh lo vedete voi, core mio bello,

Che con quest' occhi dai tanto martello.
Adrian Tubal (ca.1535- ?)

Transcrito e editado por Munir Sabag

Tanto sabes fazer com os apaixonados Que vão dispersos por estes teus olhos. Oh, tu o vês, meu belo coração,

Como estes olhos dão tanto martírio.

[DISCANTUS]
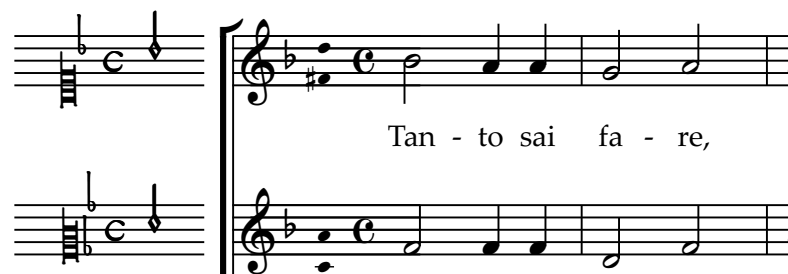

Tan - to sai fa - re,

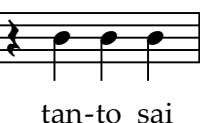

tan-to sa

[ALTUS]

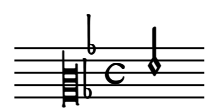

[TENOR]
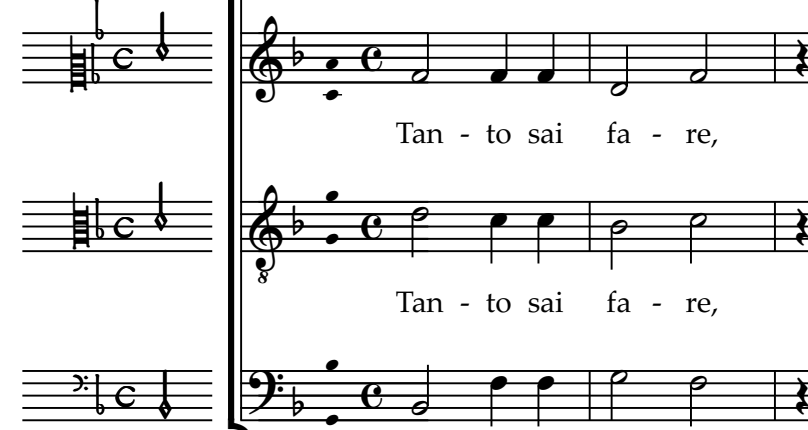

Tan - to sai fa - re,

tan-to sai

fa - re con

l'in-na - mo-

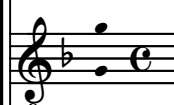

8

Tan - to sai fa - re,

tan-to sai

fa - re con

on

'in-na - mo-

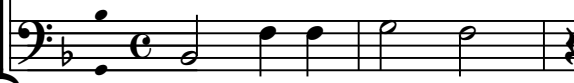

Tan - to sai fa - re,

tan-to sai fa-re con

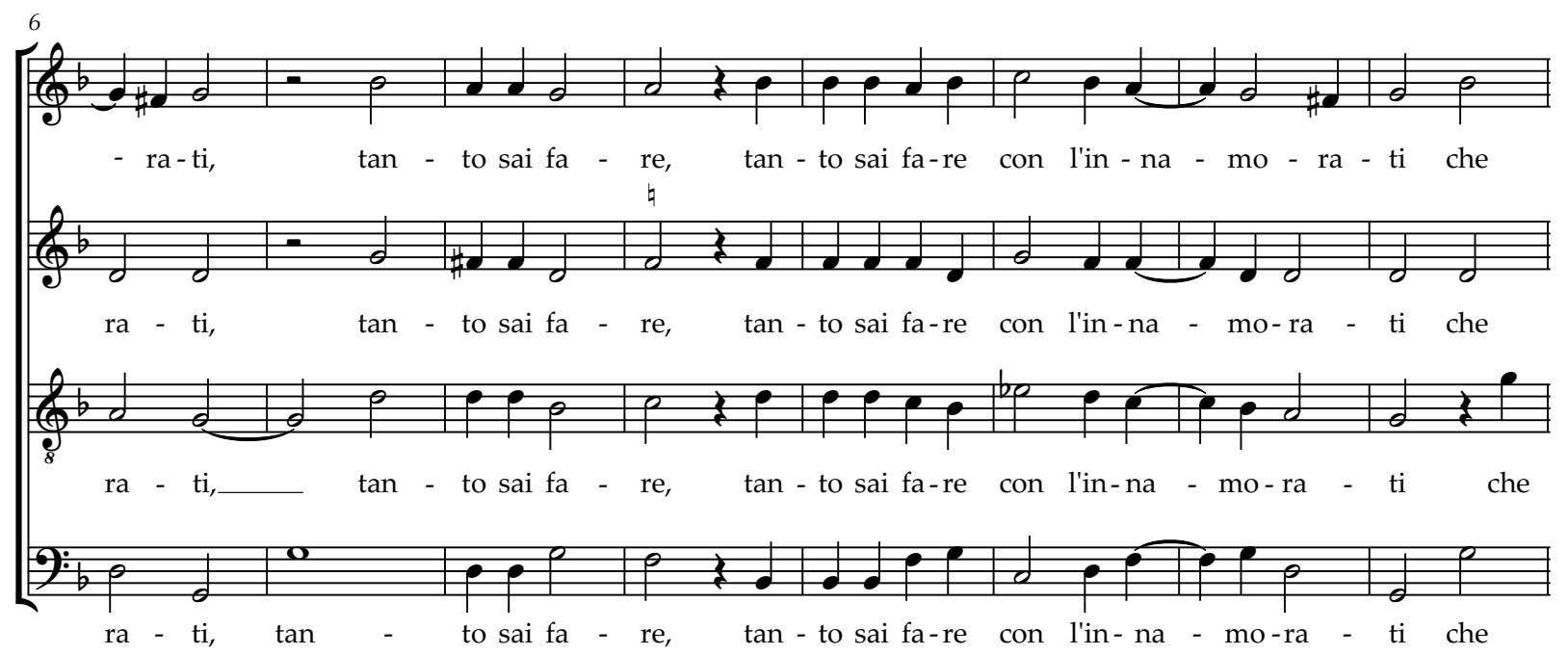



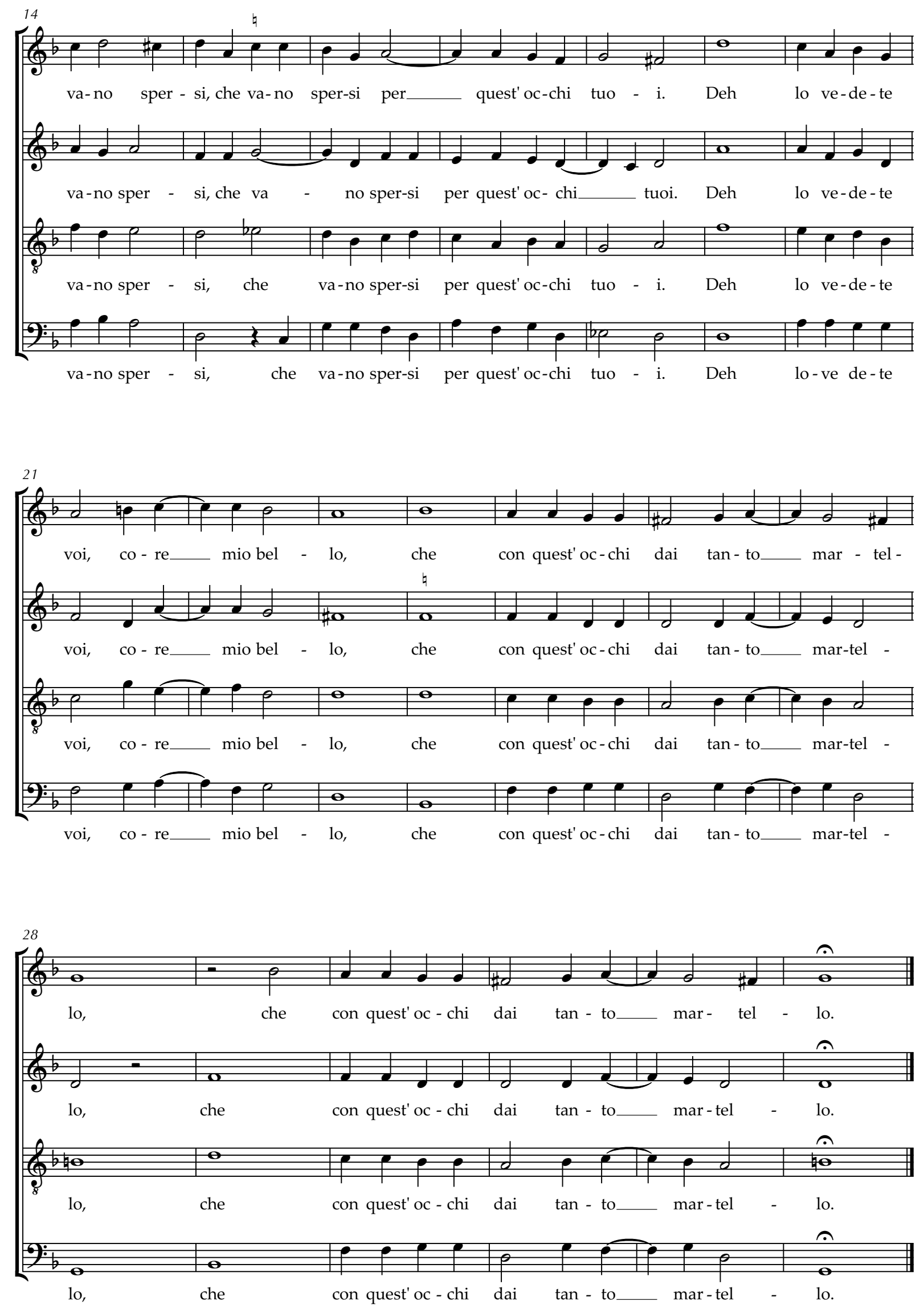


\subsection{0. \\ AMAR DIVERS' AMANTI}

(Winchester Partbooks, n. 40)

Texto: anônimo

Hubert Waelrant (ca.1517-1595)

Transcrito e editado por Munir Sabag

Amar divers' amanti è inganno aperto

Che di fint' amor nasce.

Ma chi d'un sol amor si nutr' e pasce

Come fid' amator dev' aver merto.

Donne, voi ch'a ciascuno dar solete

Guard' e risi e parole,

Ne mai d'un sol amor contente siete,

Deh non sia alcun che v'ami, perchè sola

Siete per cui d'ogn' hor si piang' e duole.
Amar muitos amantes é um evidente engano, Que vem do amor fingido.

Mas quem se nutre e se alimenta de um só amor,

Como amante fiel, deve ter mérito.

Damas, vós que costumais dar a qualquer um

Olhares, risos e palavras,

Nem estais contentes com um só amor,

Oh, que não haja alguém que vos ame, porque sois

A razão pela qual sempre se chora e sofre.
[DISCANTUS]

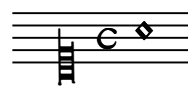

[ALTUS]

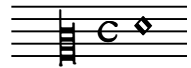

[TENOR]

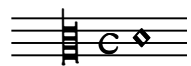

[BASSUS]

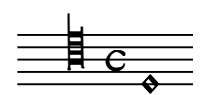

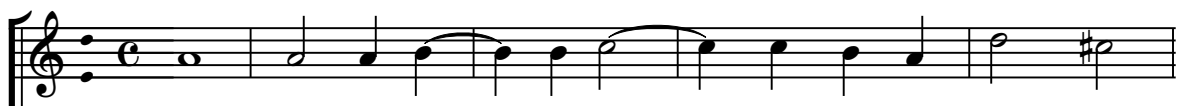

A - mar di- vers'_ a- man - tièèin-gan-noa per - to

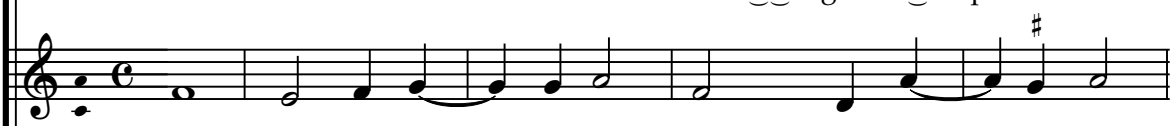

A - mar di- vers'_ a-man -tièin - gan- no a - per - to

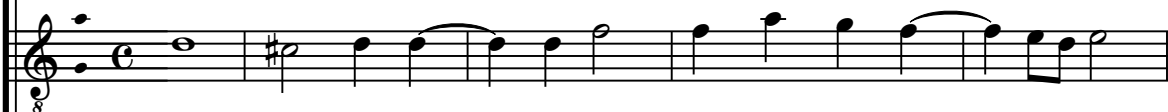

A - mar di- vers'_ a-man - tièein-gan-noa-per - to

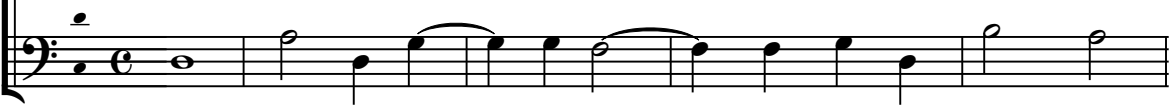

A - mar di- vers'_ a- man - tièin-gan-noa - per - to

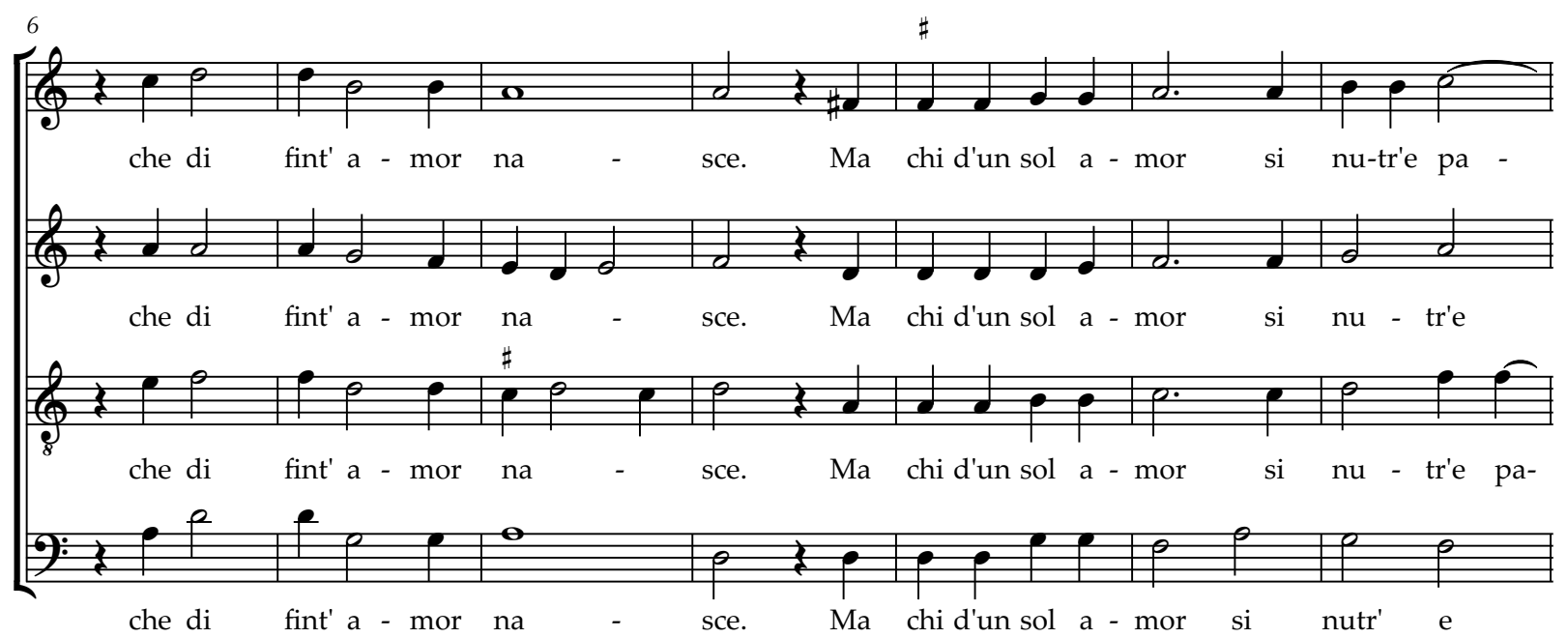



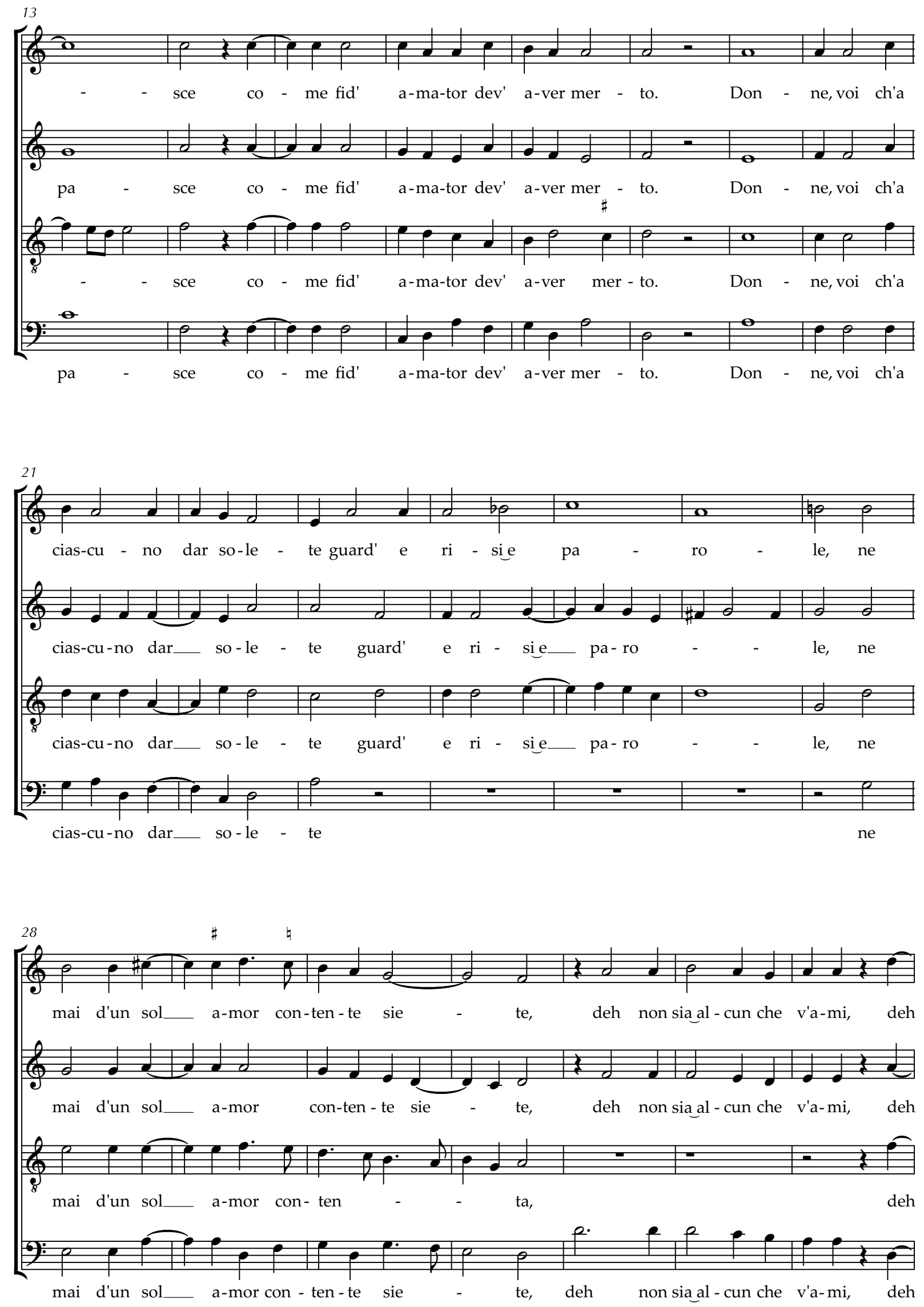

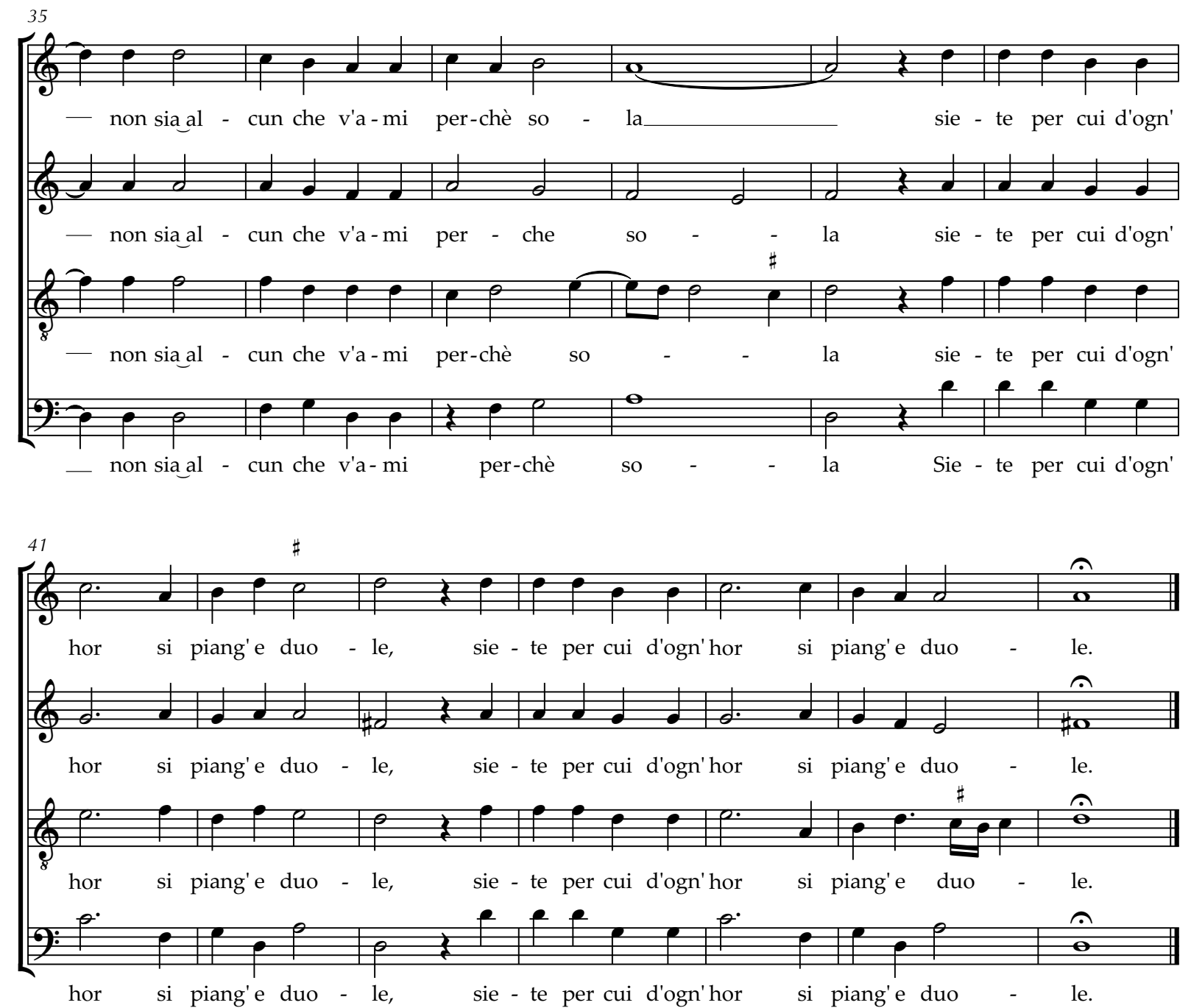


\subsection{DEH PERCHÈ ABBANDONASTI ME}

(Winchester Partbooks, n. 42)

Texto: anônimo

Adrian Tubal (ca.1535 - ?)

Transcrito e editado por Munir Sabag

Deh perchè abbandonasti me, crudel' o donna, Se stanco e sazio mai non fu d'amarti?

$O$ perfida che sei.
Oh, por que me abandonaste, ó dama cruel,

Se nunca me cansei e nunca me saciei de amar-te? Ó pérfida que és.
[DISCANTUS]

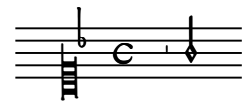

[ALTUS]

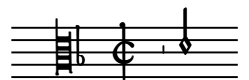

[TENOR]

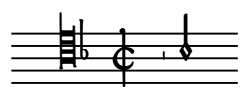

[BASSUS]

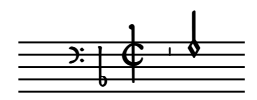

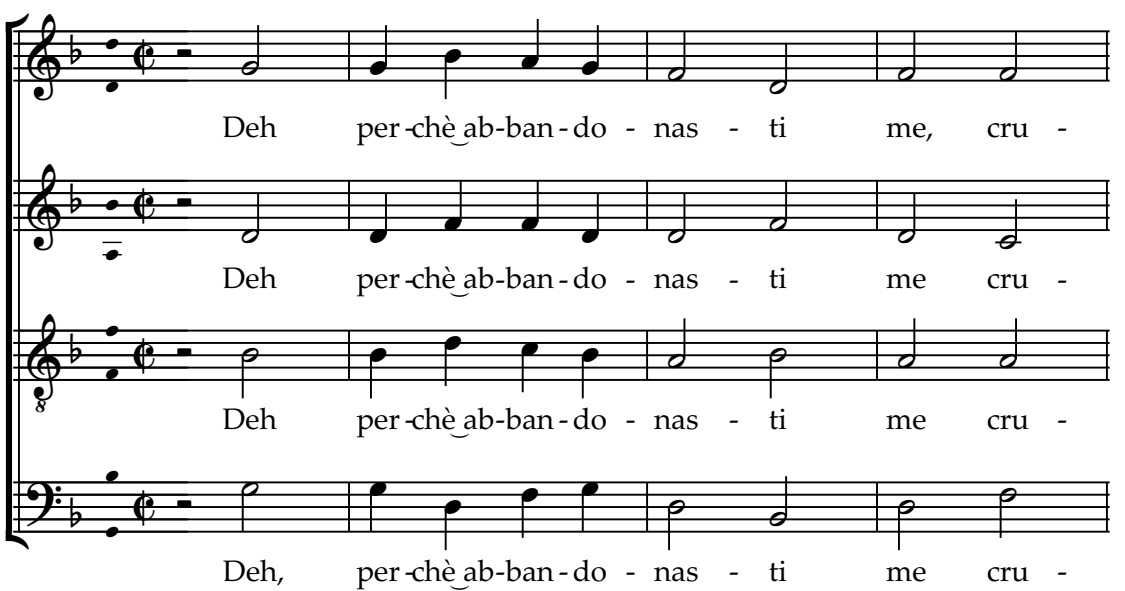

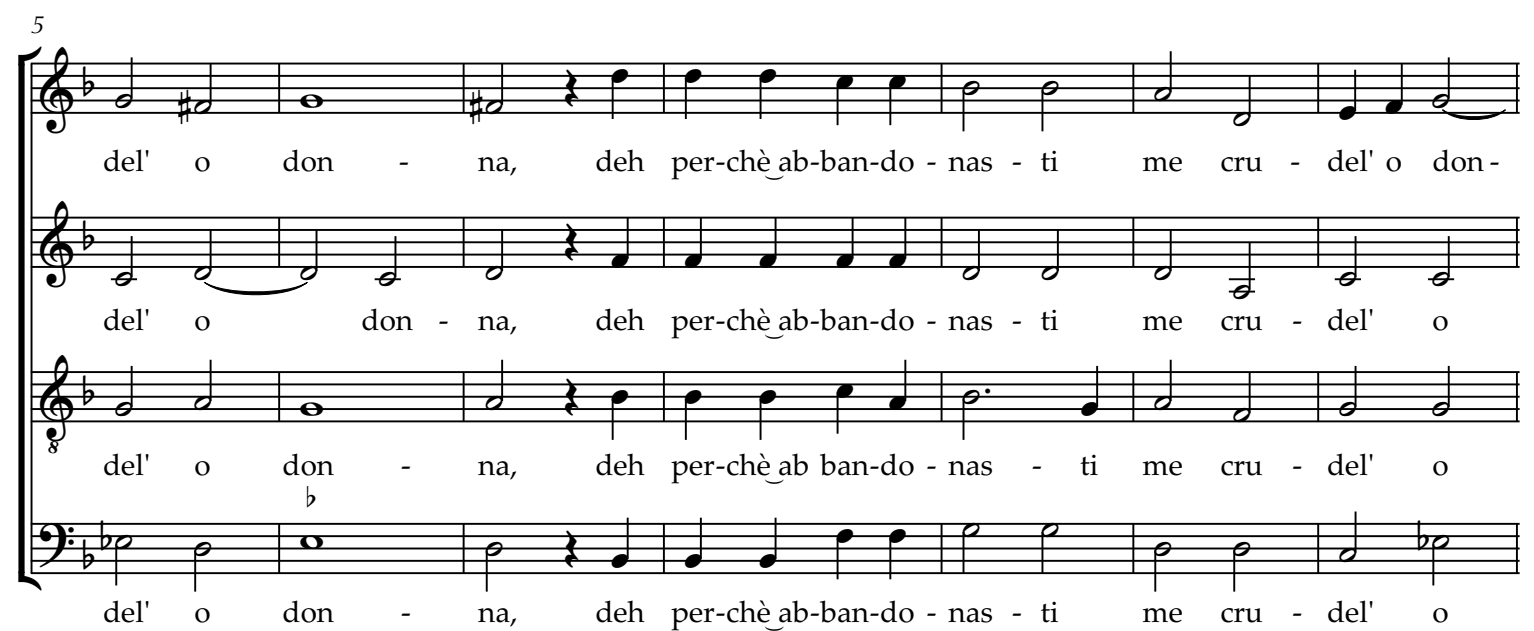



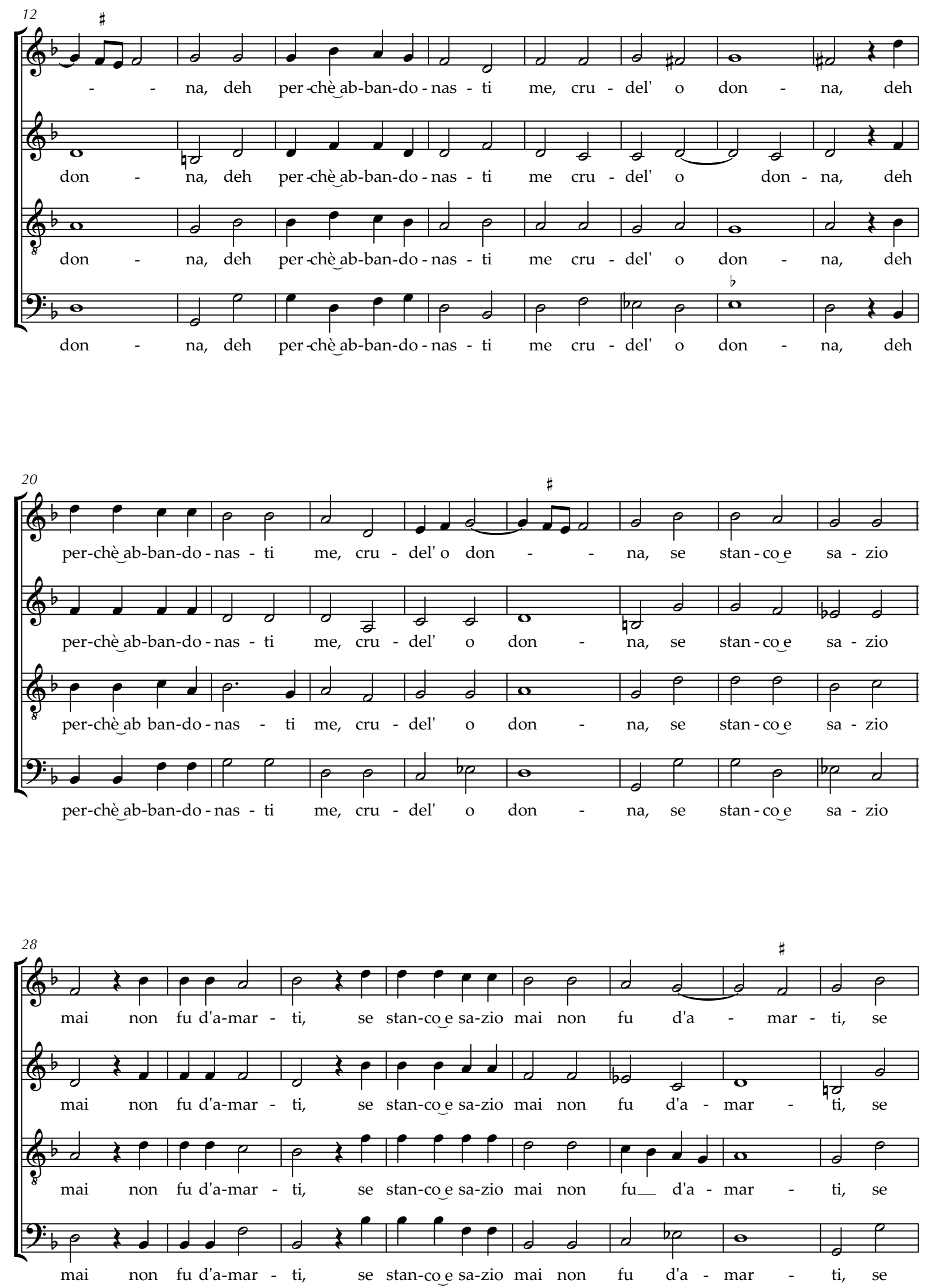

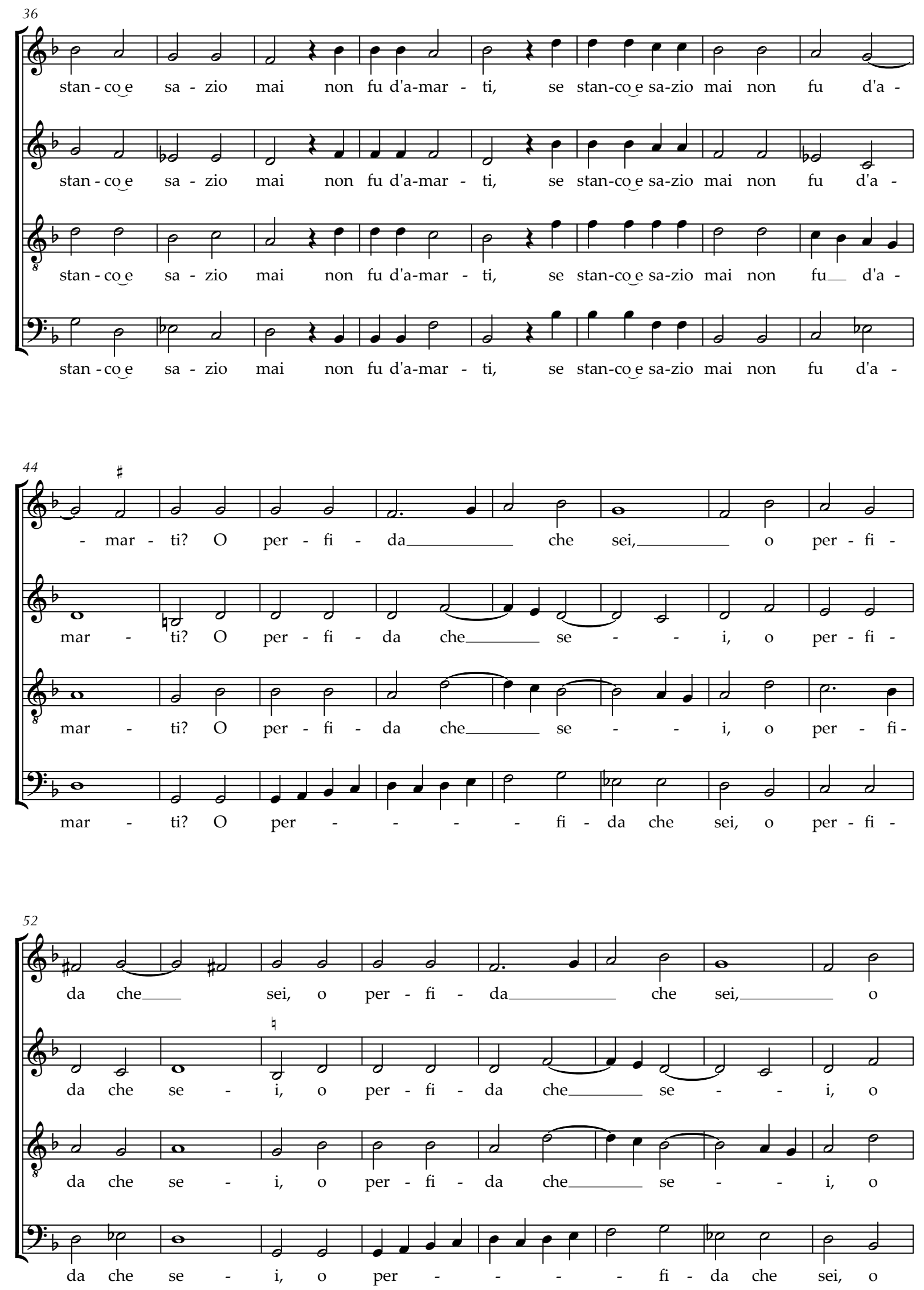


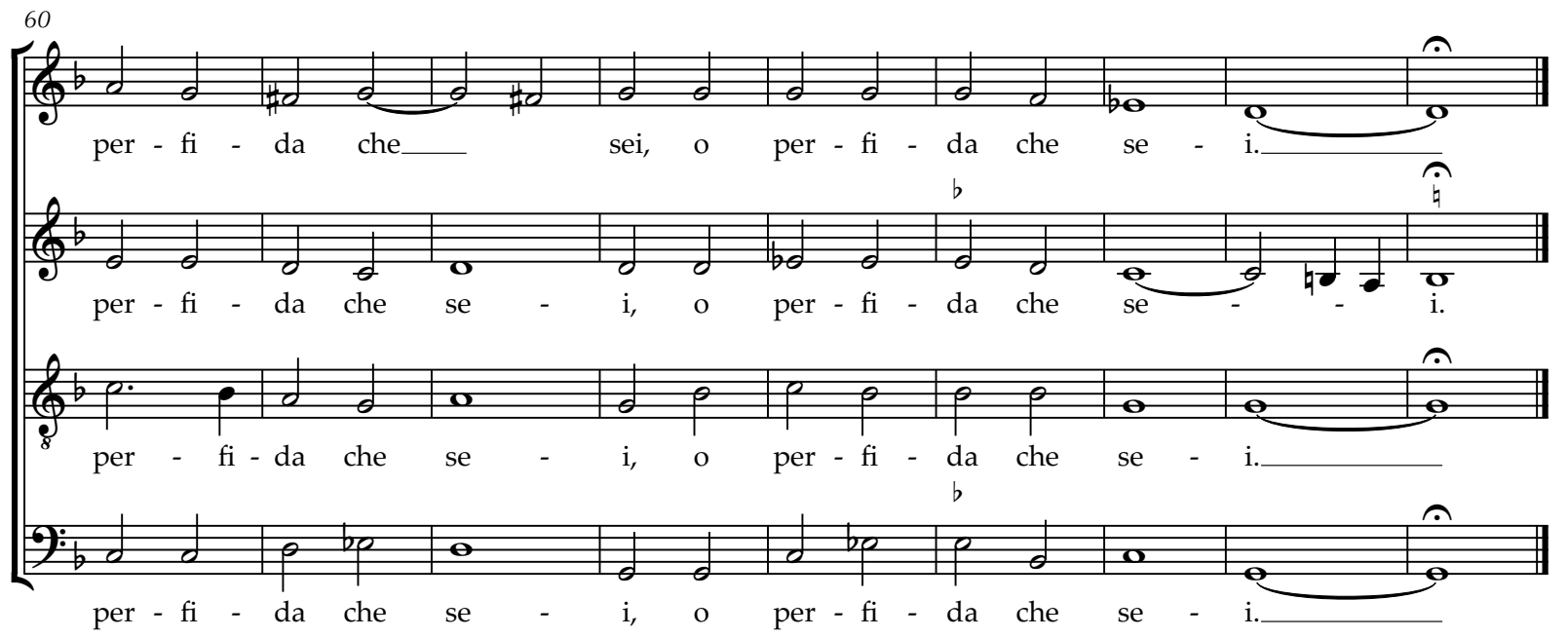




\subsection{2 . \\ CONZA LAVEZZI SIAM}

(Winchester Partbooks, n. 43)

Texto: anônimo

Hubert Waelrant (ca.1517-1595)

Transcrito e editado por Munir Sabag

Conza lavezzi siam, s'havesti rotto,

Madonna, la padell' o pertugiata.

Noi ve l'acconciarem ben e di botto.

Che sappiam far la prova l'ho mostrata.

Ponete nel in grembo, che di sotto

Dentro il martel fara natal ficcata,

Che son stupor direte per davvero:

"Mestri unichi siete in tal mestiero".

Somos consertadores de panelas, se estragaste,

Senhora, a panela, ou a furaste.

Nós a arrumaremos bem e na hora.

Que sabemos fazer, a prova te mostrei.

Coloca-a no colo, que por baixo

O martelo fará uma tal fincada dentro,

Que com surpresa dirás, em verdade:

"Sois mestres únicos neste ofício".
[DISCANTUS]

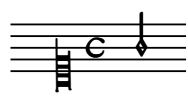

[ALTUS]

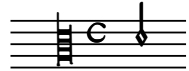

[TENOR]

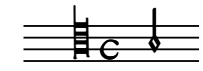

[BASSUS]

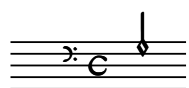

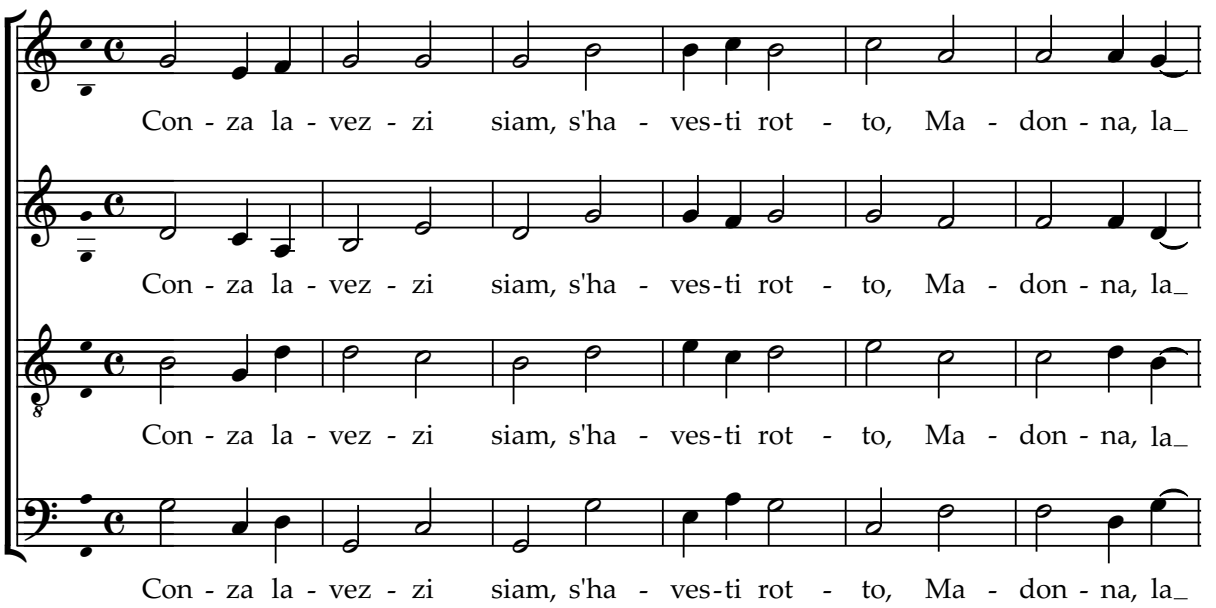

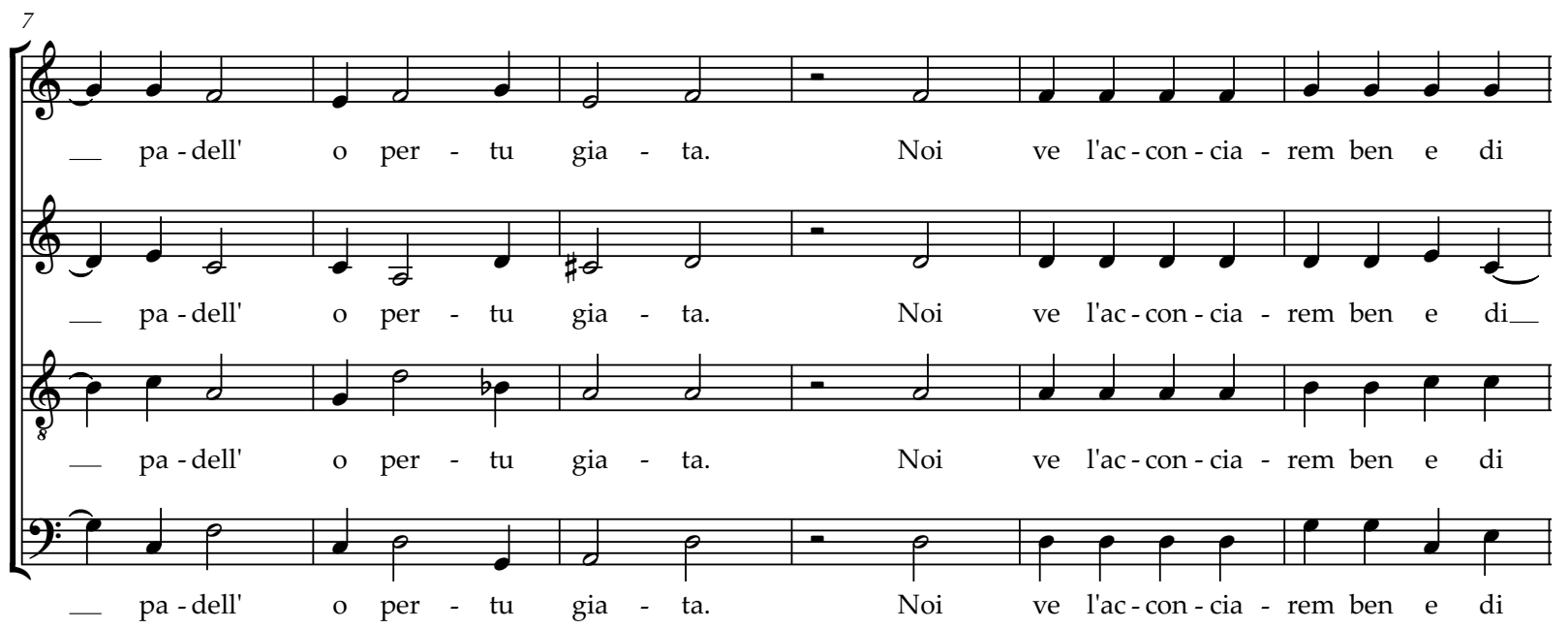

Fonte: GB-WCc MS 153 'Winchester Partbooks', 1564-6. 

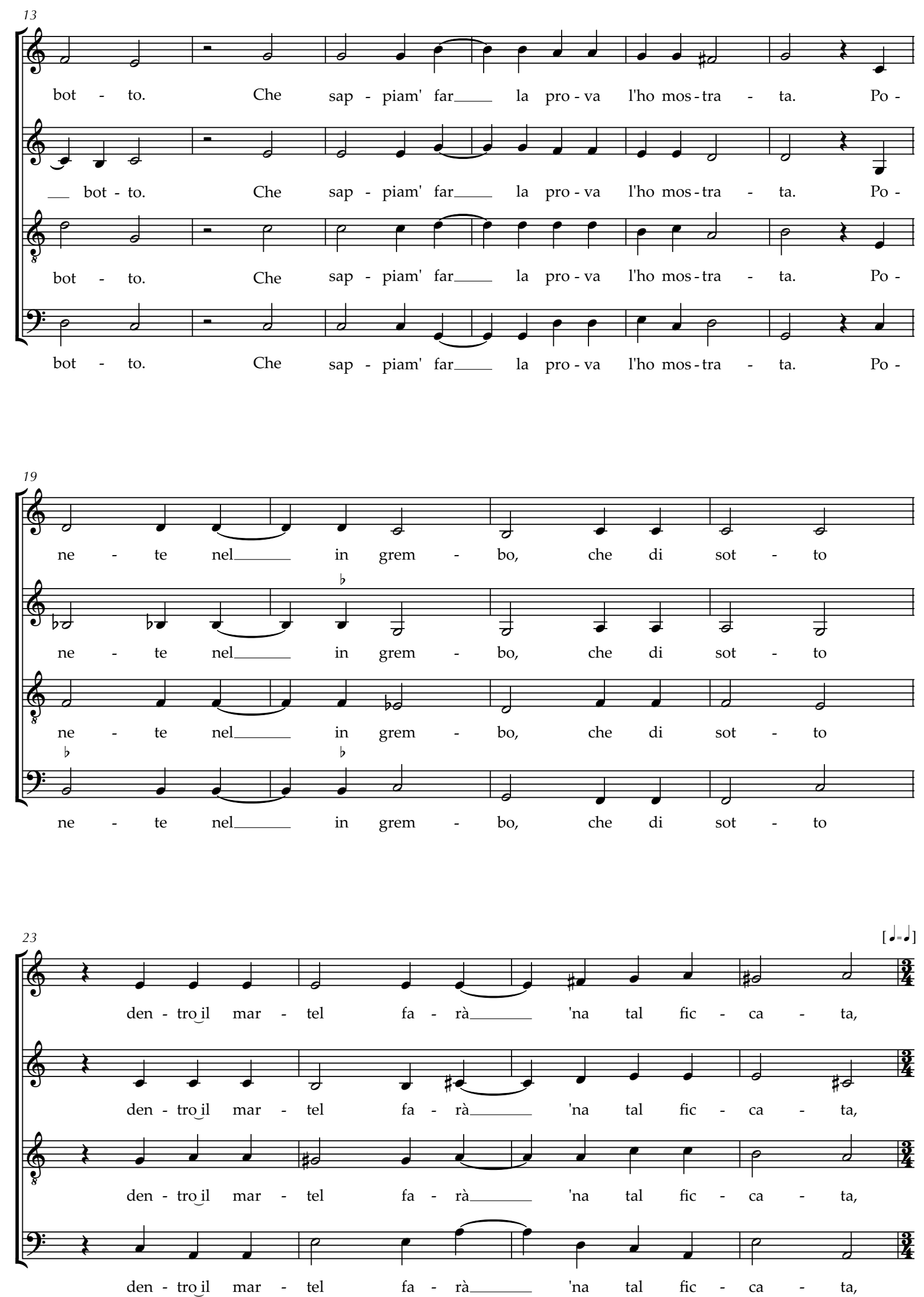

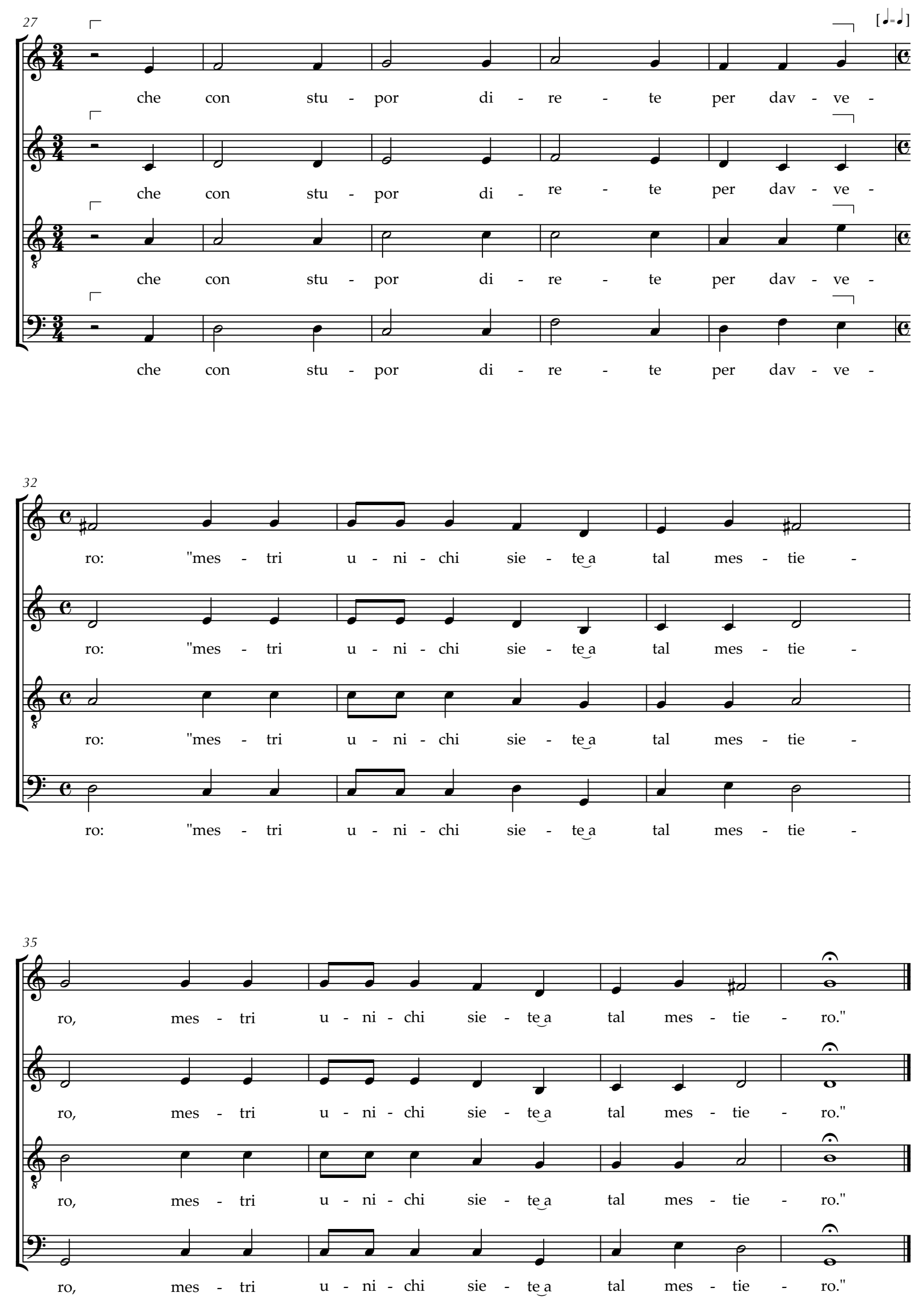


\subsection{MADONN' HABBI PIETÀ DEL MIO MARTIRE}

(Winchester Partbooks, n. 44)

Texto: anônimo

Madonn' habbi pietà del mio martire

Poi che mi vedi in tutto consumato.

Tu sola sei che mi può far beato.
Hubert Waelrant (ca.1517-1595) Transcrito e editado por Munir Sabag

Senhora, tem piedade do meu martírio, Já que me vês todo consumido.

Tu és a única que pode me fazer feliz.

[DISCANTUS]

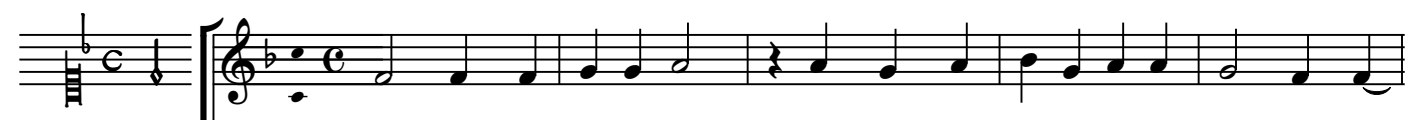

Ma-donn' hab - bi pie-tà, ma-donn' hab - bi pie-tà del mio mar - ti -

[ALTUS]
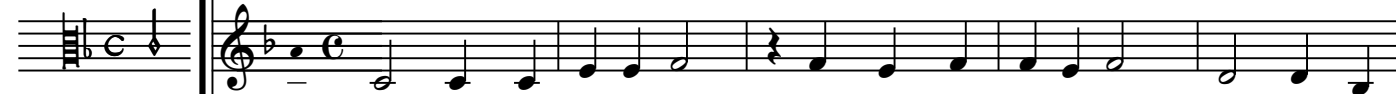

Ma-donn' hab - bi pie-tà, ma-donn' hab - bi pie-tà

del mio mar

[TENOR]

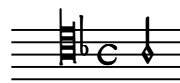

[BASSUS]
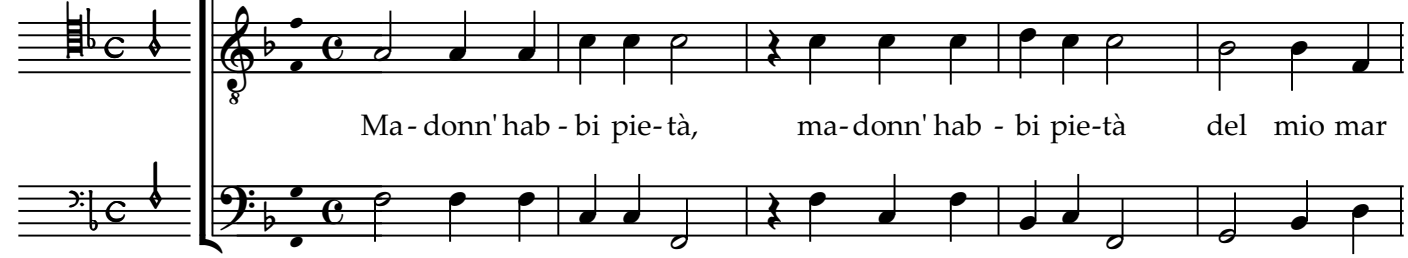

Ma - donn' hab - bi pie-tà,

ma-donn' hab - bi pie-tà

del mio mar

$\frac{6 \cdot c}{\circ \cdot 6}$

Ma-donn' hab - bi pie-tà,

ma-donn' hab - bi pie-tà

del mio mar

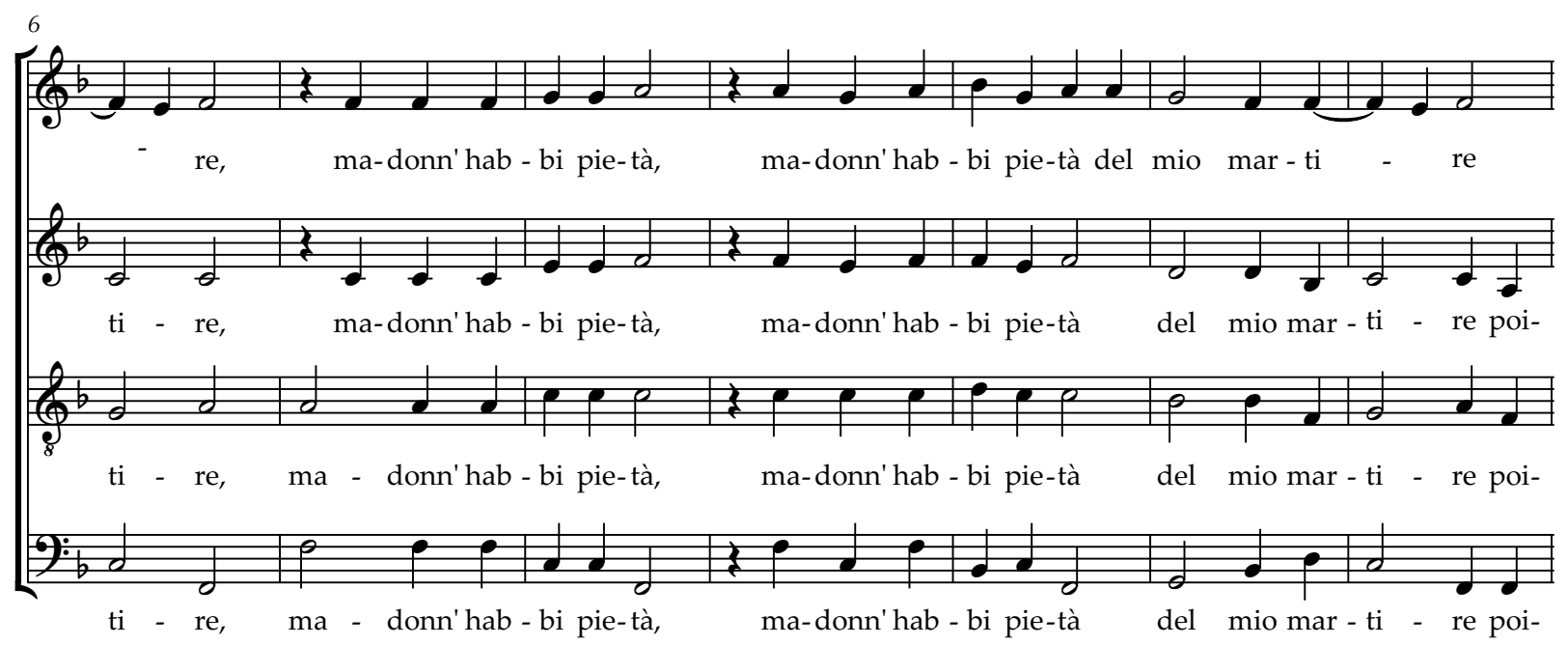



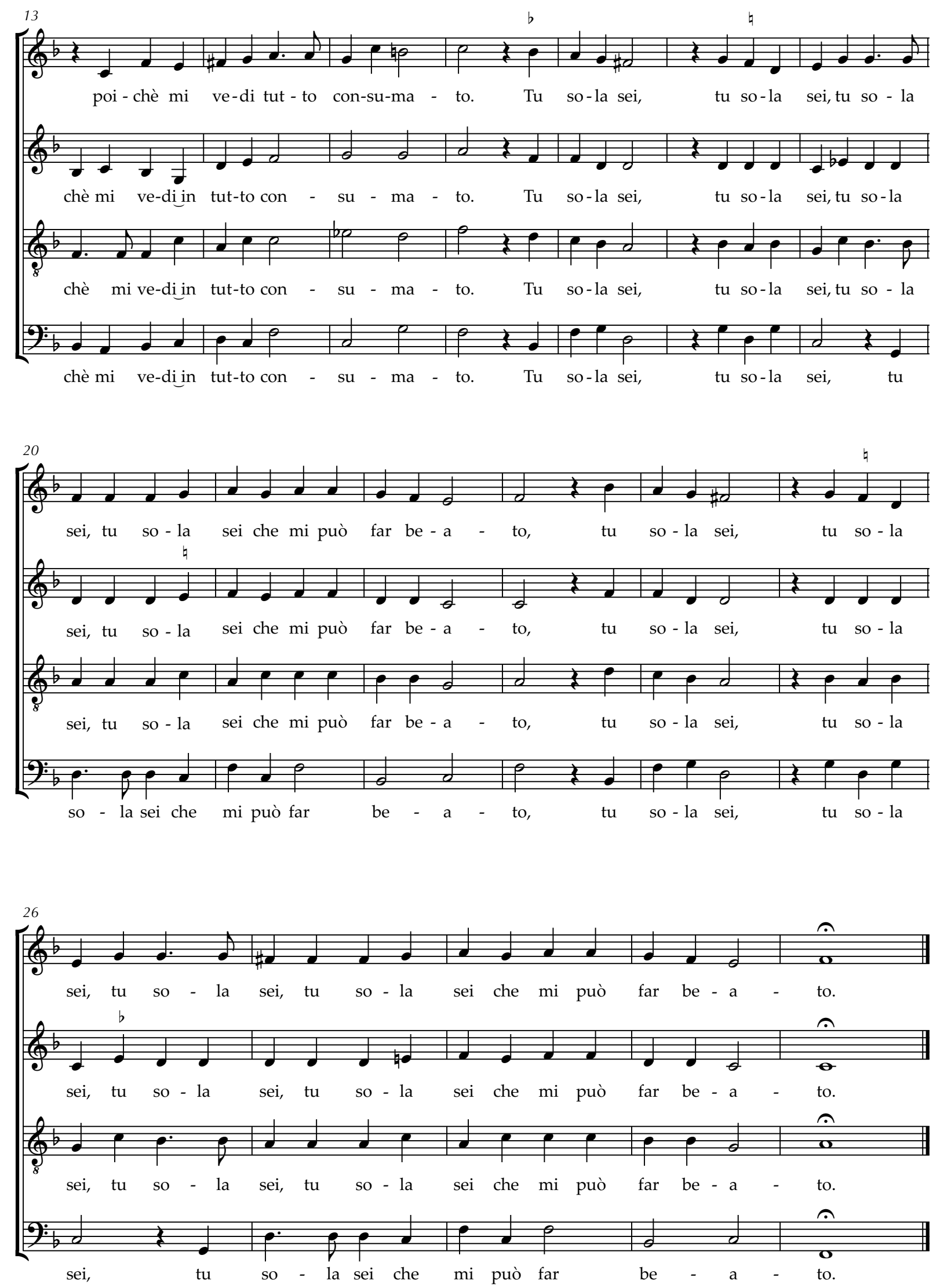


\subsection{4.}

Texto: anônimo

Non t'arricordi e quando mi dicevi

Che tu m'amavi sì perfettamente?

O d'abbraciami, giocami, stringemi,

Basciami, ridemi, traditora

O signora, o patrona,

O regina del mio core.

\section{NON T'ARRICORDI}

(Winchester Partbooks, n. 45)
Hubert Waelrant (ca.1517-1595)

Transcrito e editado por Munir Sabag
[DISCANTUS]

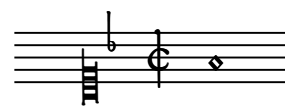

[ALTUS]

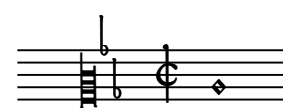

[TENOR]

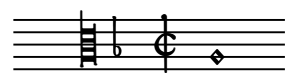

[BASSUS]

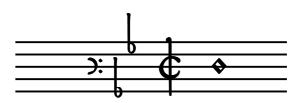

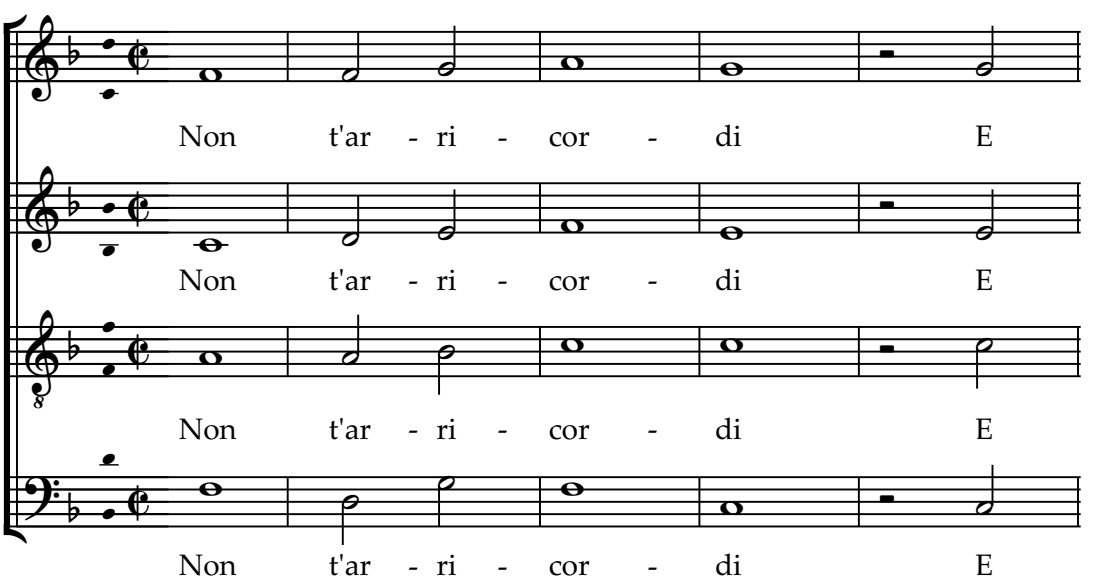

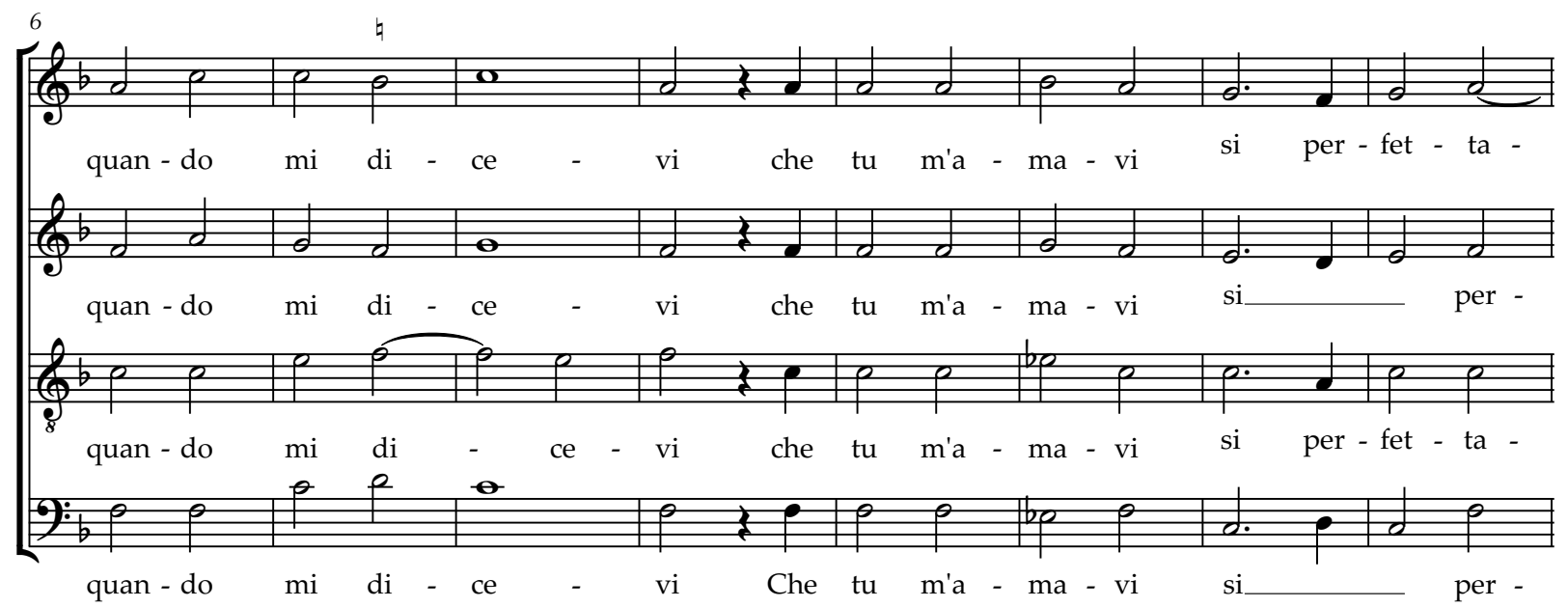

Não te lembras de quando me dizias

Que tu me amavas tão perfeitamente?

Oh, abraça-me, brinca comigo, aperta-me,

Beija-me, ri-me, traidora.

Ó senhora, ó patroa,

Ó rainha do meu coração. 

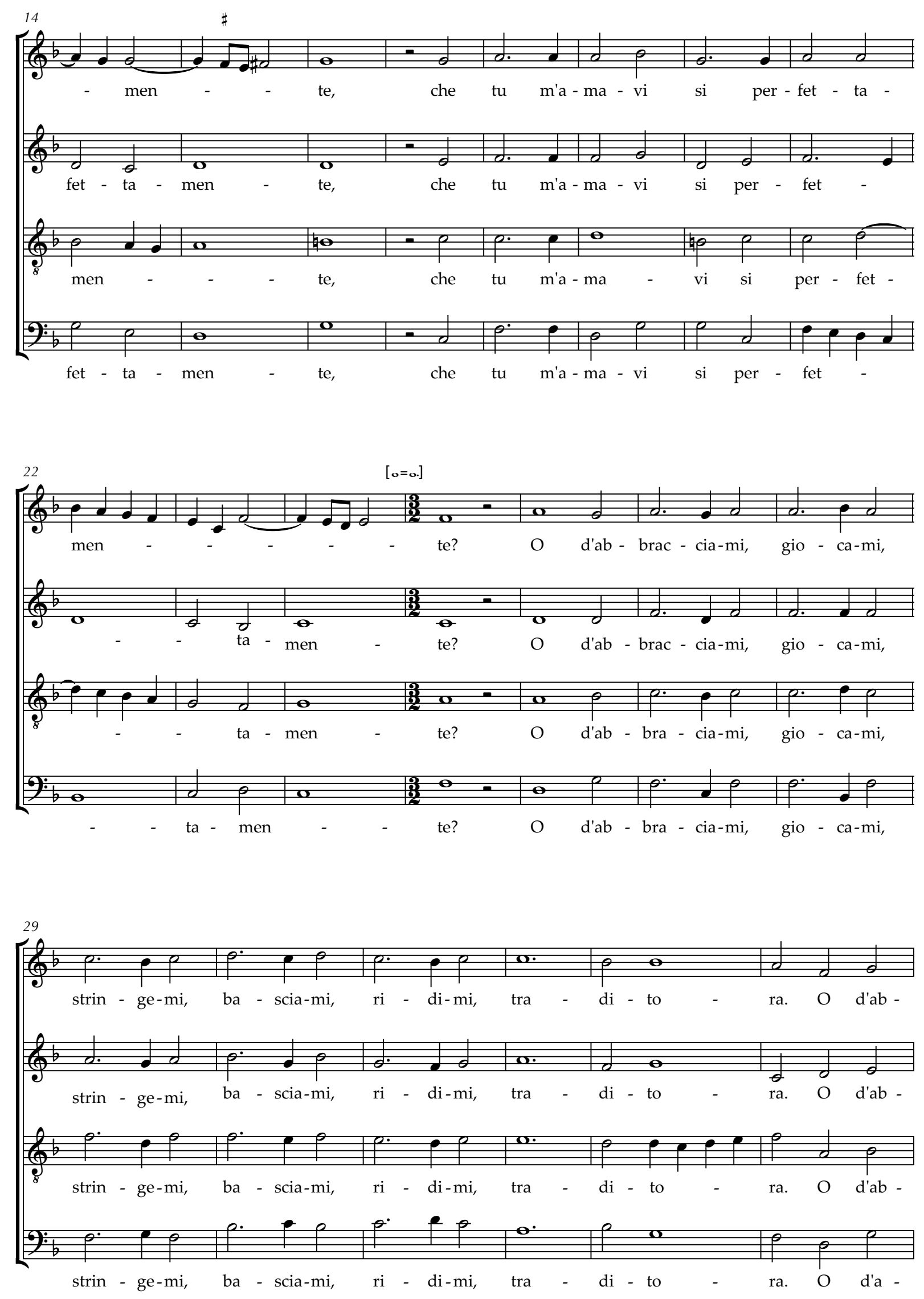

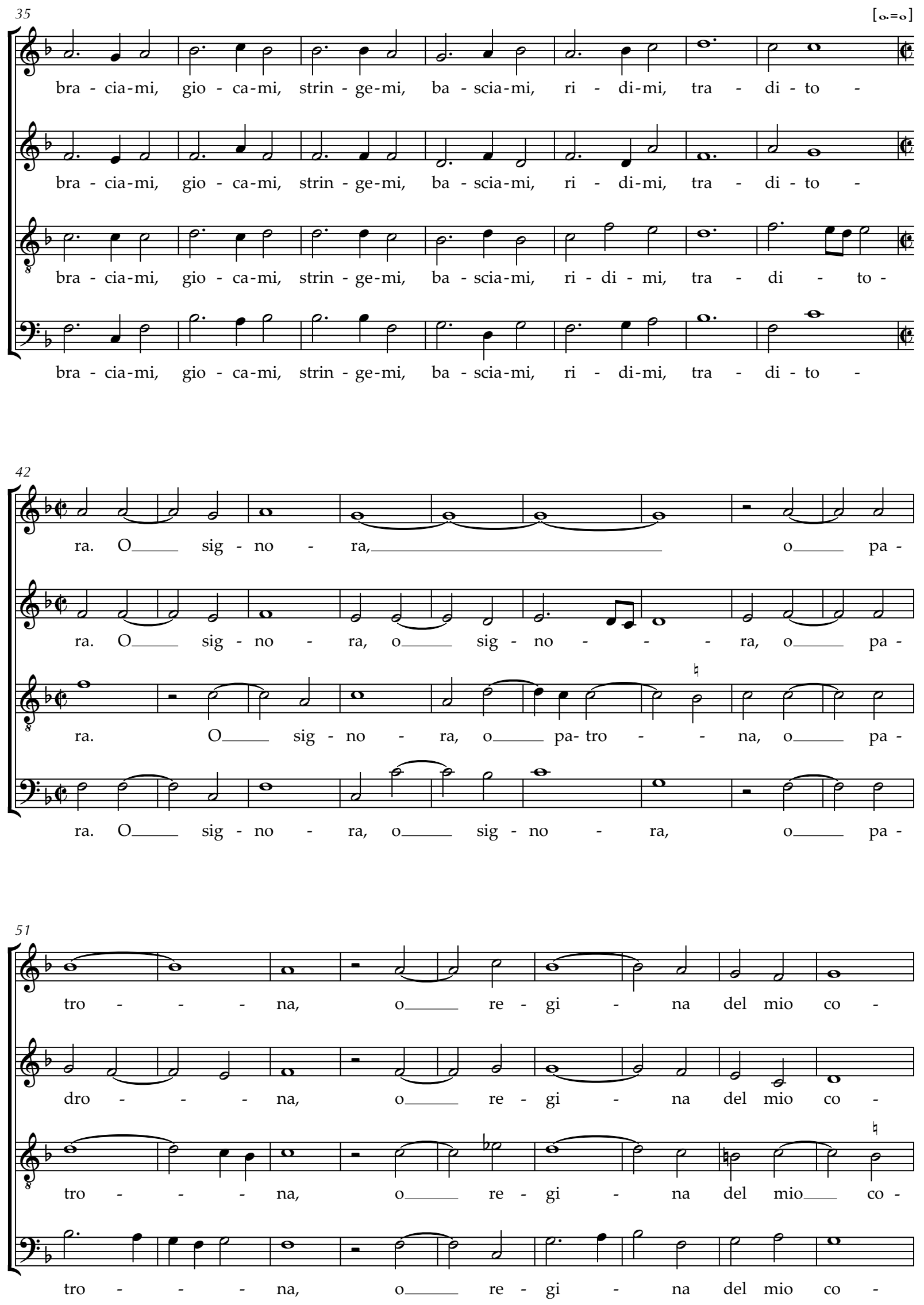

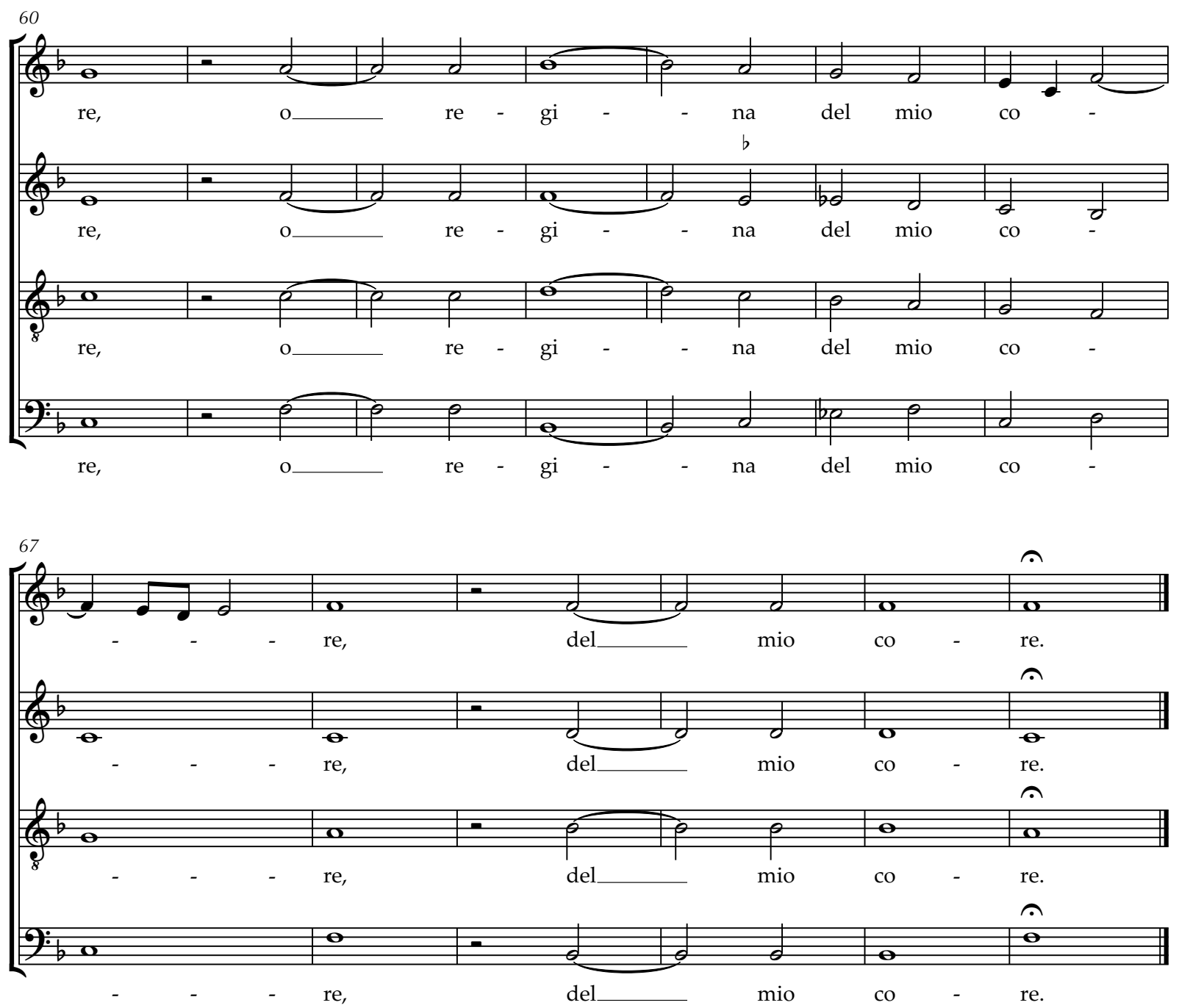
4.25

Texto: anônimo

Issa in bona fè quanto sei bella.

Pero mi ti sei post' a sa finestra.

$\mathrm{Ch}^{\prime}$ havesse 'na balestra, vecchia dannata

E ti tirasse mo una balestrata.
ISSA IN BONA FÈ

(Winchester Partbooks, n. 46)
Jan [Giovanni] Nasco (ca.1510-1561)

Transcrito e editado por Munir Sabag

[DISCANTUS]
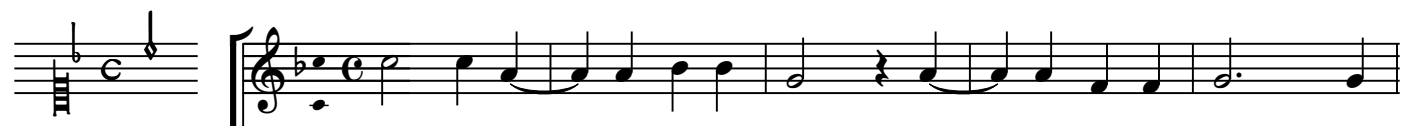

Agora, em verdade, quanto és bela.

Mas te postaste na janela.

Ah, se eu tivesse uma balestra, velha danada

$E$ te jogasse agora uma balestrada.

Is - sa, is - sa in bo-na fè, is - sa, is-sain bo - na

[ALTUS
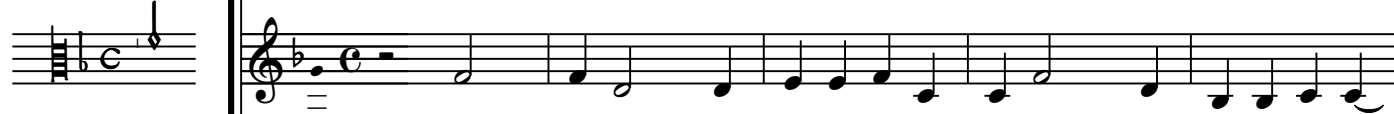

Is - sa, is - sa in bo-na fè, is - sa, is - sa in bo-na fè, is -

[TENOR]

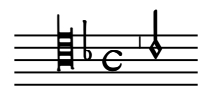

[BASSUS]

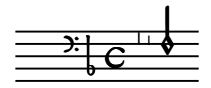

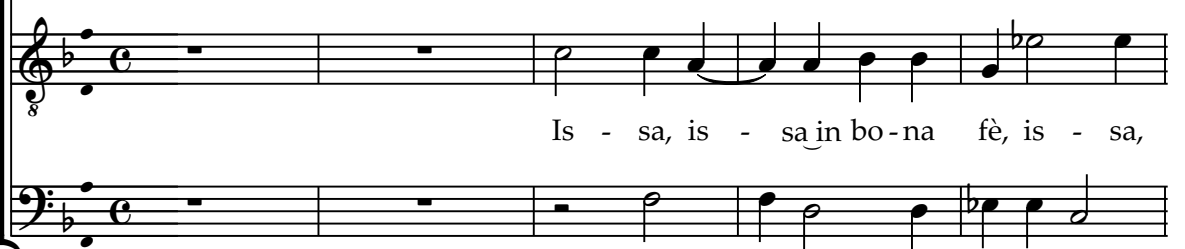

Is - sa, is - sa in bo-na fè,

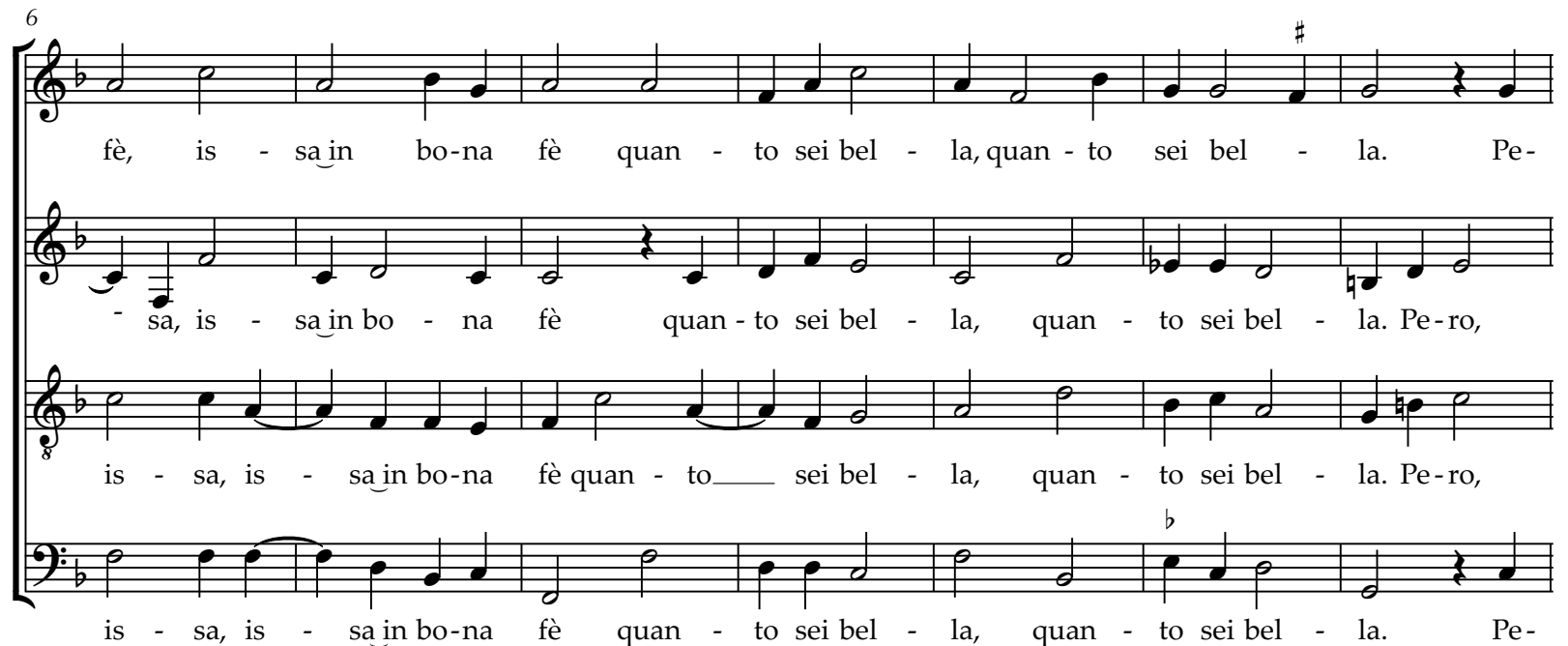



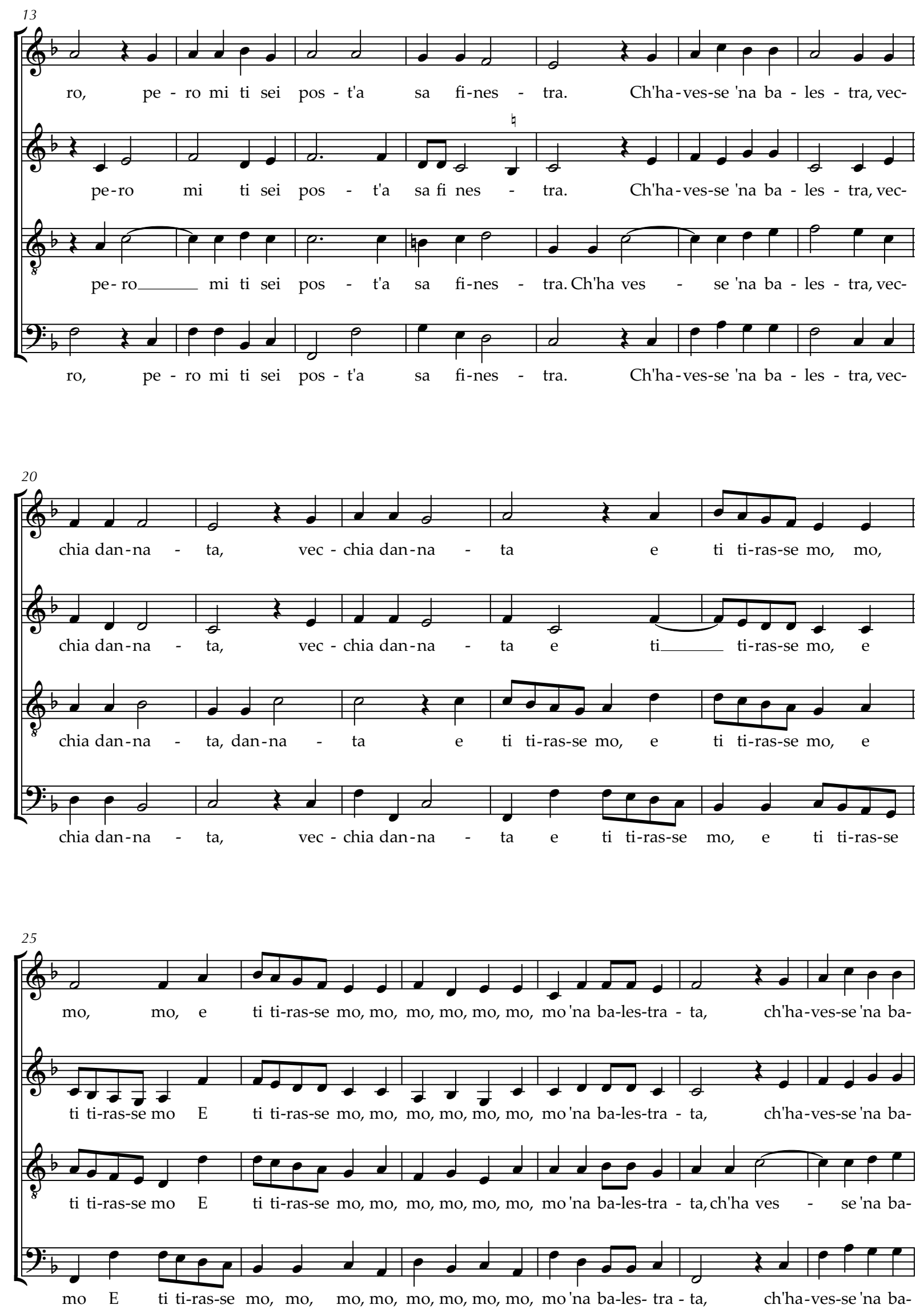

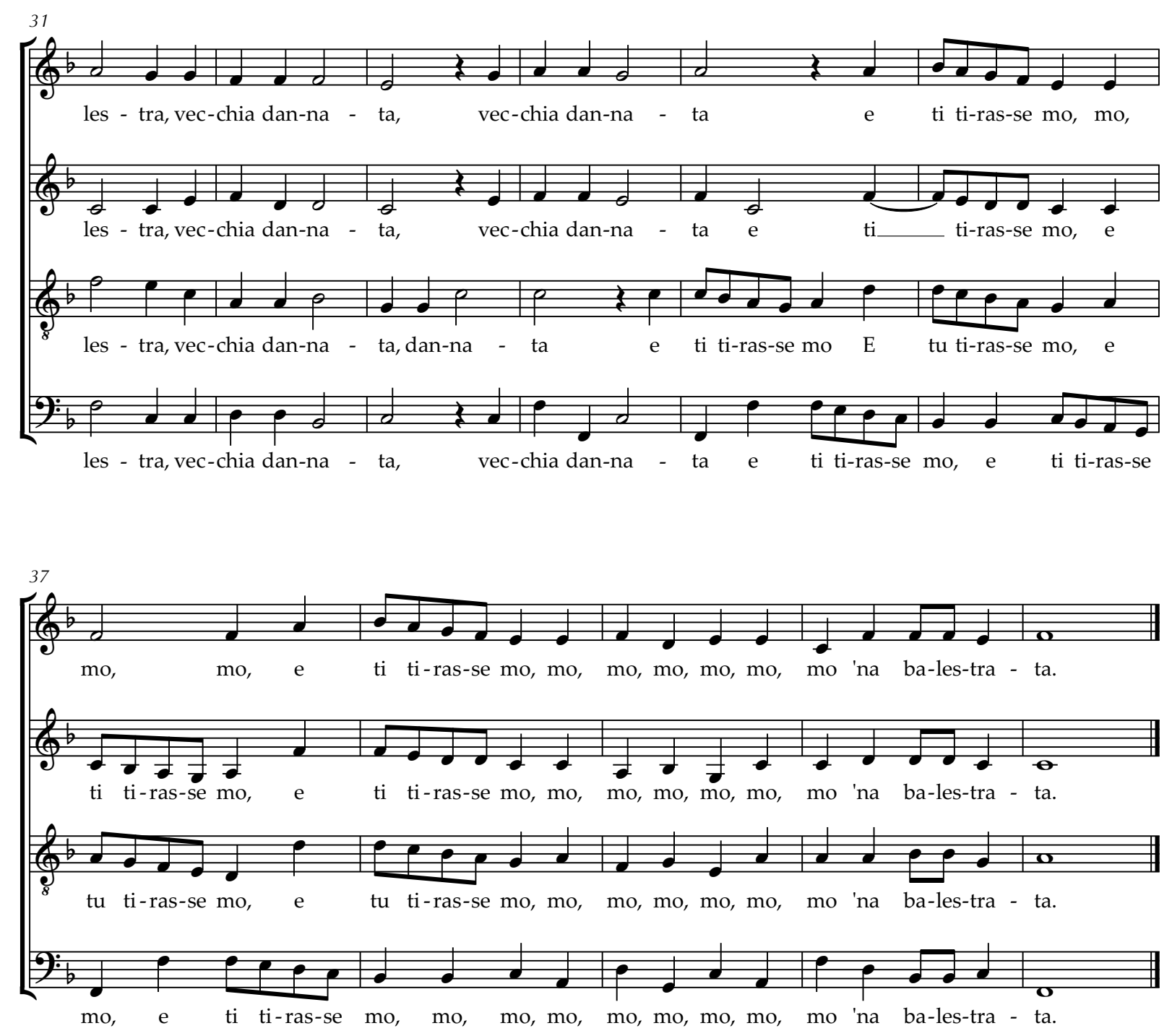

NOTA DO EDITOR:

Bassus, compasso 28: a última semiminima aparece erroneamente no manuscrito como uma minima. 


\subsection{QUANTI NE VEDI, TUTT' A TE LI TIRI}

(Winchester Partbooks, n. 50)

Texto: anônimo

Quanti ne vedi, tutt'a te li tiri

Come proprio foss' una calamita.

Dolce mia cara vita,

Habbi pietà di me se non ch'io mor' affé.
Hubert Waelrant (ca.1517-1595)

Transcrito e editado por Munir Sabag

[DISCANTUS]

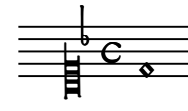

(

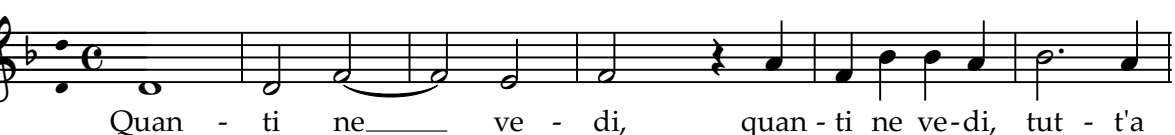

[ALTUS]

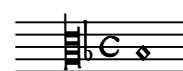

[TENOR]

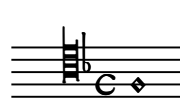

[BASSUS]
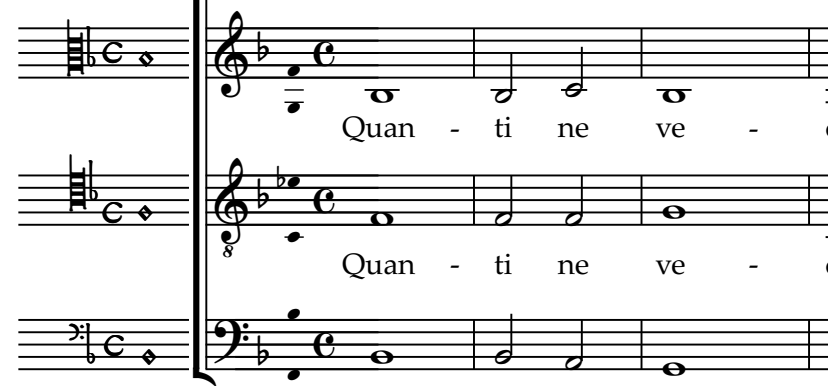

Como se fosses mesmo um ímã.

Minha cara e doce vida,

Tem piedade de mim, senão morro por certo.

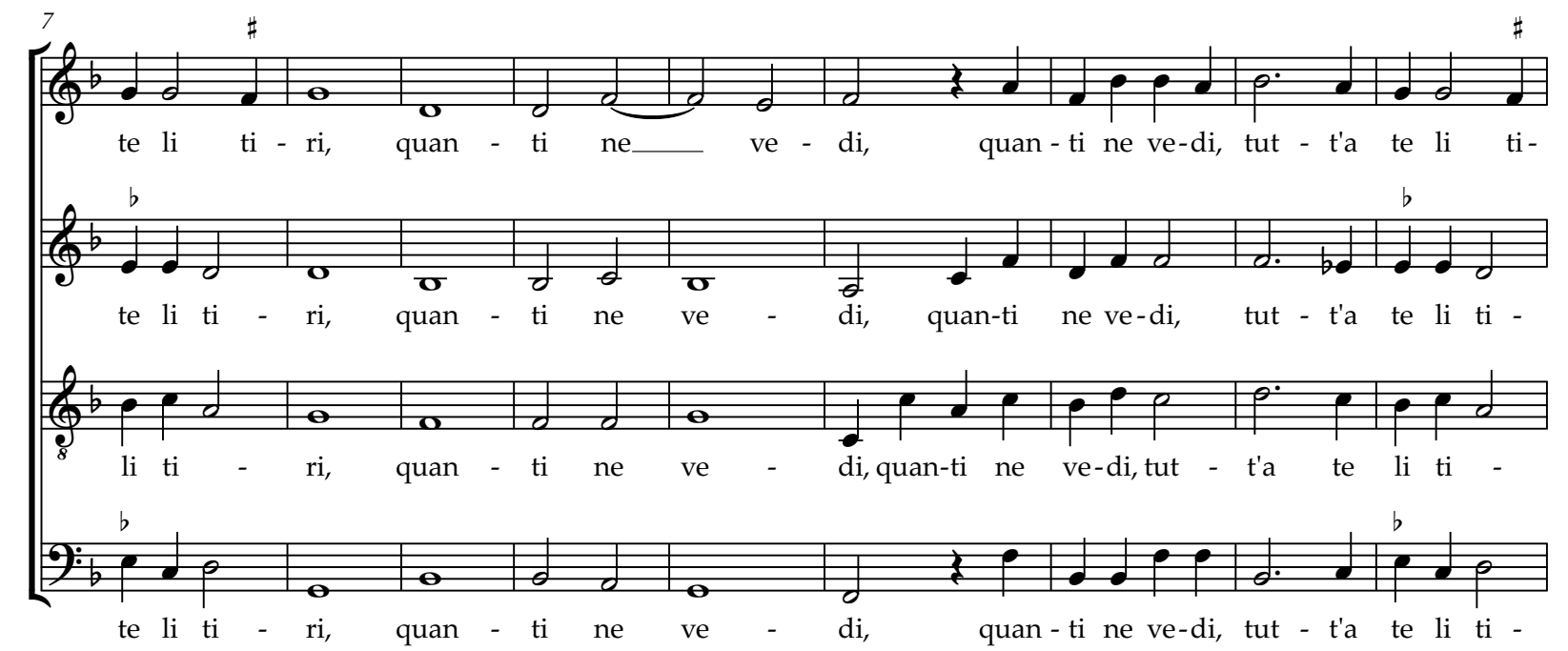



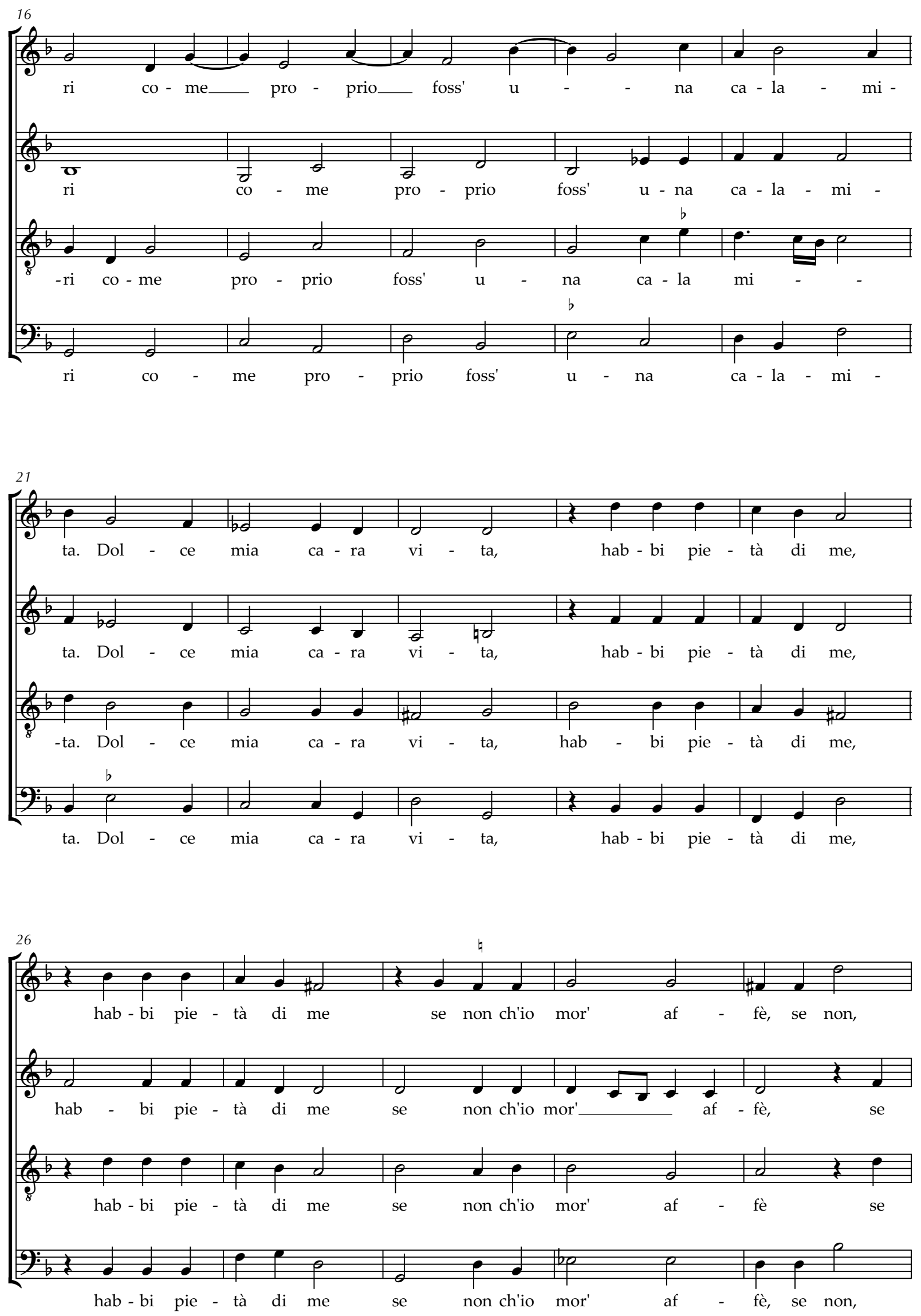

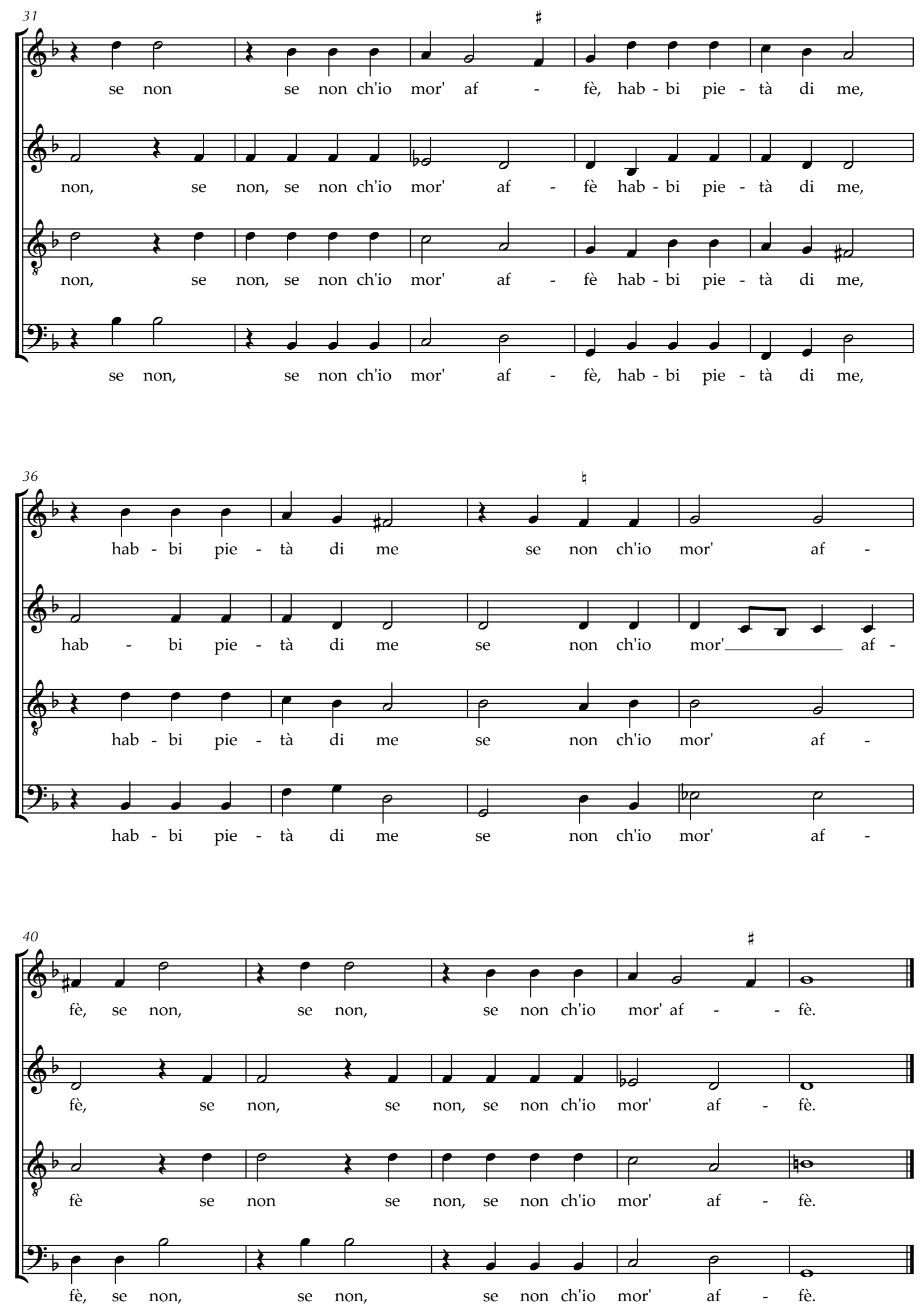


\subsection{7 . \\ MADONNA MIA, PER TE \\ SON QUASI MORTO}

(Winchester Partbooks, n. 51)

Texto: anônimo

Hubert Waelrant (ca.1517-1595)

Transcrito e editado por Munir Sabag

Madonna mia, per te son quase morto

Che m'hai donat'al cor mortal ferita.

Per ho habbi pietà, donami vita.

Senhora minha, por ti estou quase morto Porque me deste ao coração mortal ferida. Mas tem piedade, dá-me vida.
[DISCANTUS]

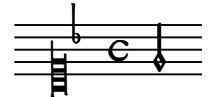

[ALTUS

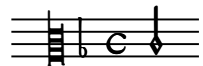

[TENOR] 勘占

[BASSUS]

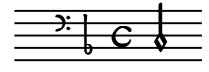

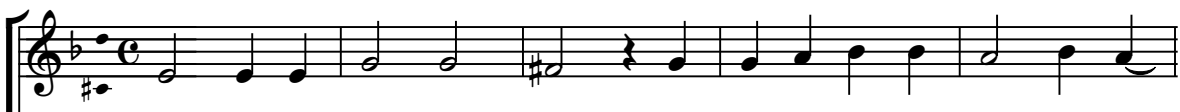

Ma - don-na mia, per te, ma-don-na mia, per te son qua

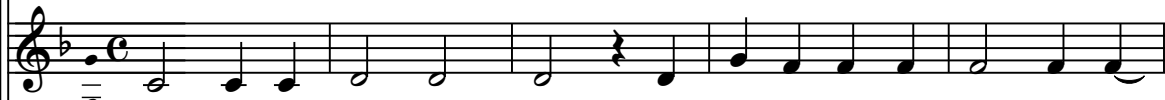

Ma - don-na mia, per te, ma-don-na mia, per te son qua

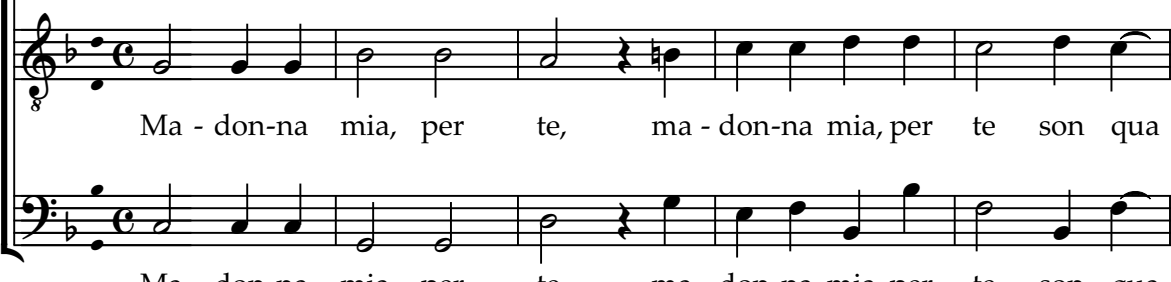

Ma - don-na mia, per te, ma-don-na mia, per te son qua

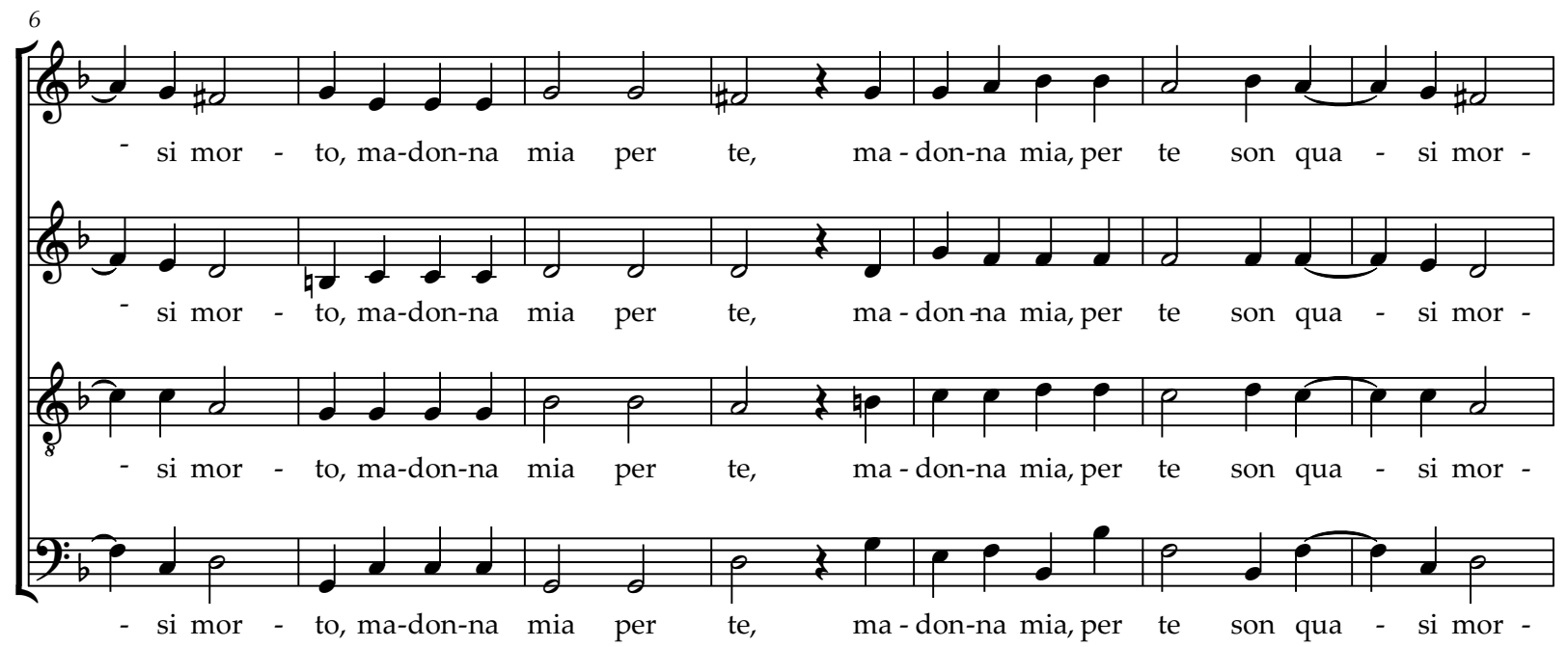



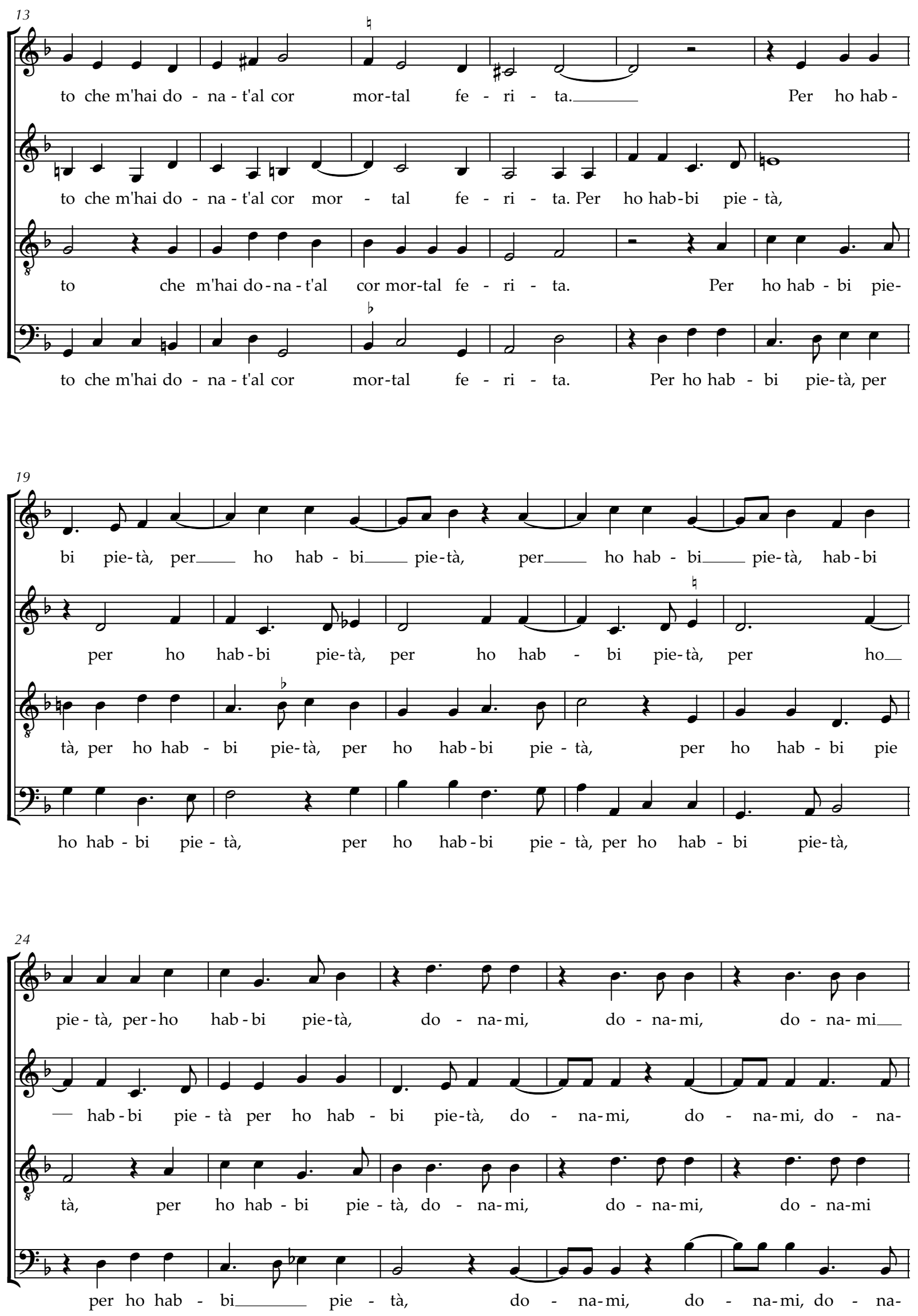

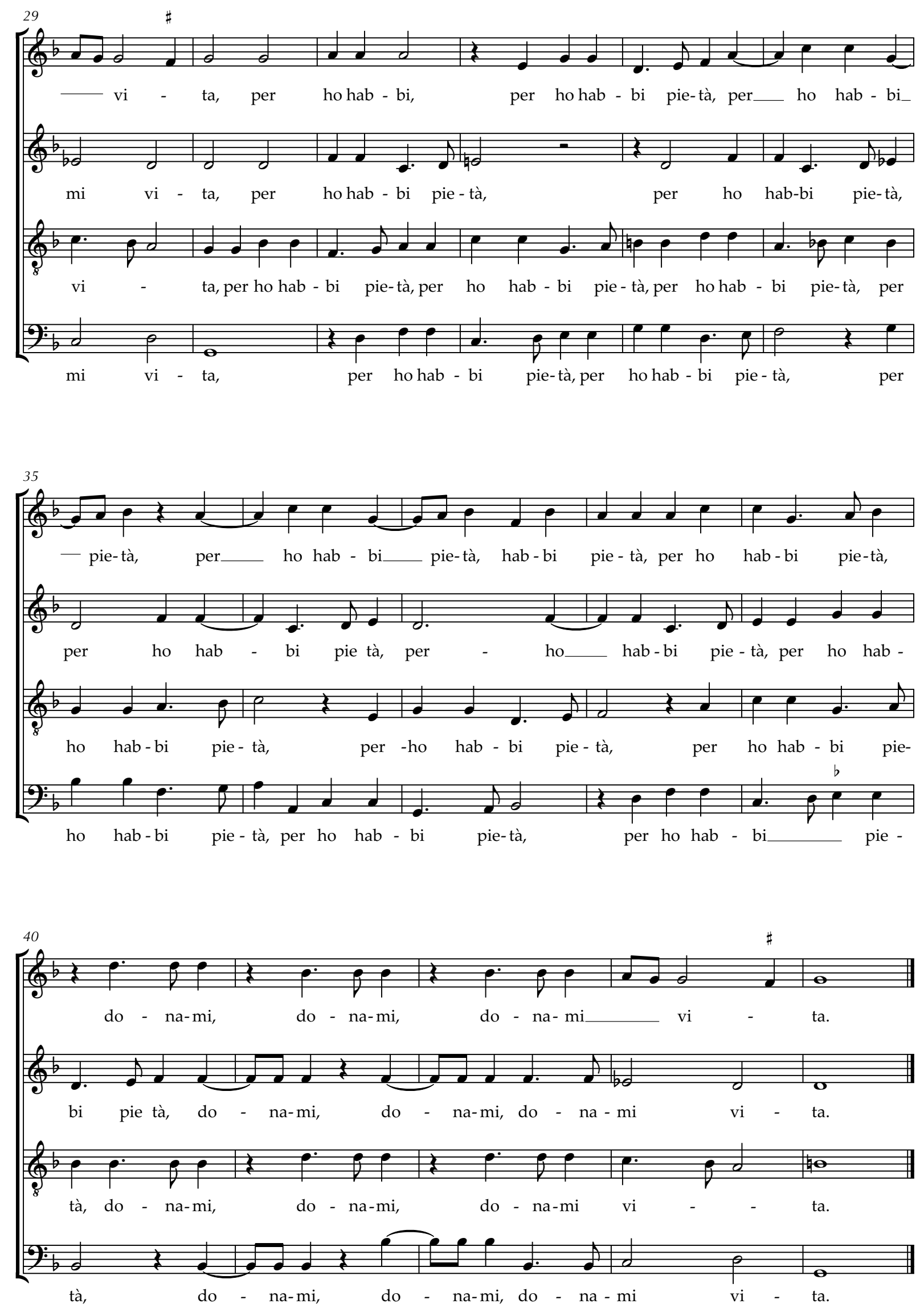


\subsection{8 . \\ IN TUTTO VUOI CH'IO \\ MOR' O TRADITORA}

(Winchester Partbooks, n. 52)

Texto: anônimo

In tutto vuoi ch'io mor' o traditora,

Che mai ti sazi di mi straziare.

Vedi ch'io moro e tu non mi vuoi amare.
Hubert Waelrant (ca.1517-1595)

Transcrito e editado por Munir Sabag

[DISCANTUS]
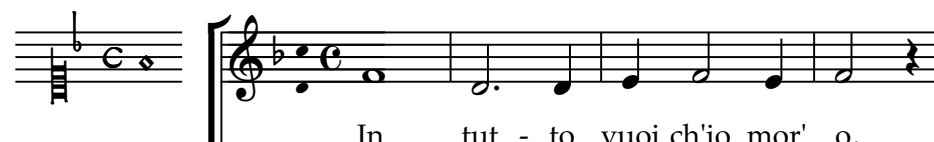

Queres mesmo que eu morra, ó traidora,

Porque nunca te sacias de atormentar-me.

Vês que eu morro e tu não me queres amar.

[ALTUS] 甚焉

[TENOR]

[BASSUS]

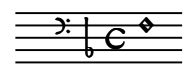

In tut - to vuoi ch'io mor' o, in tut-to vuoich'io mor' o

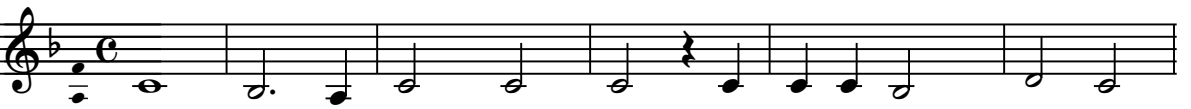

In tut - to vuoi ch'io mor', in tut-to vuoi ch'io mor'

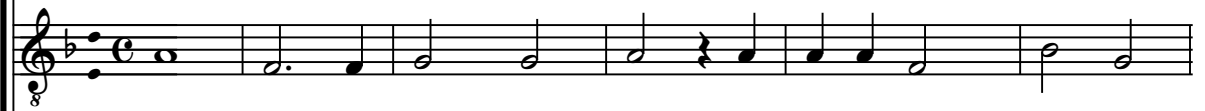

In tut - to vuoi ch'io mor', in tut-to vuoi ch'io mor'

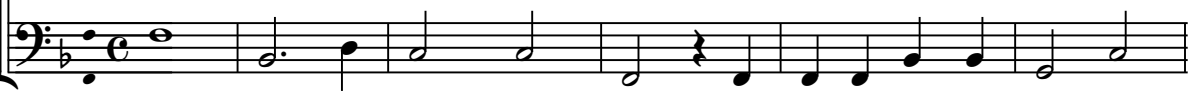

In tut - to vuoi ch'io mor', in tut-to vuoich'io mor' o

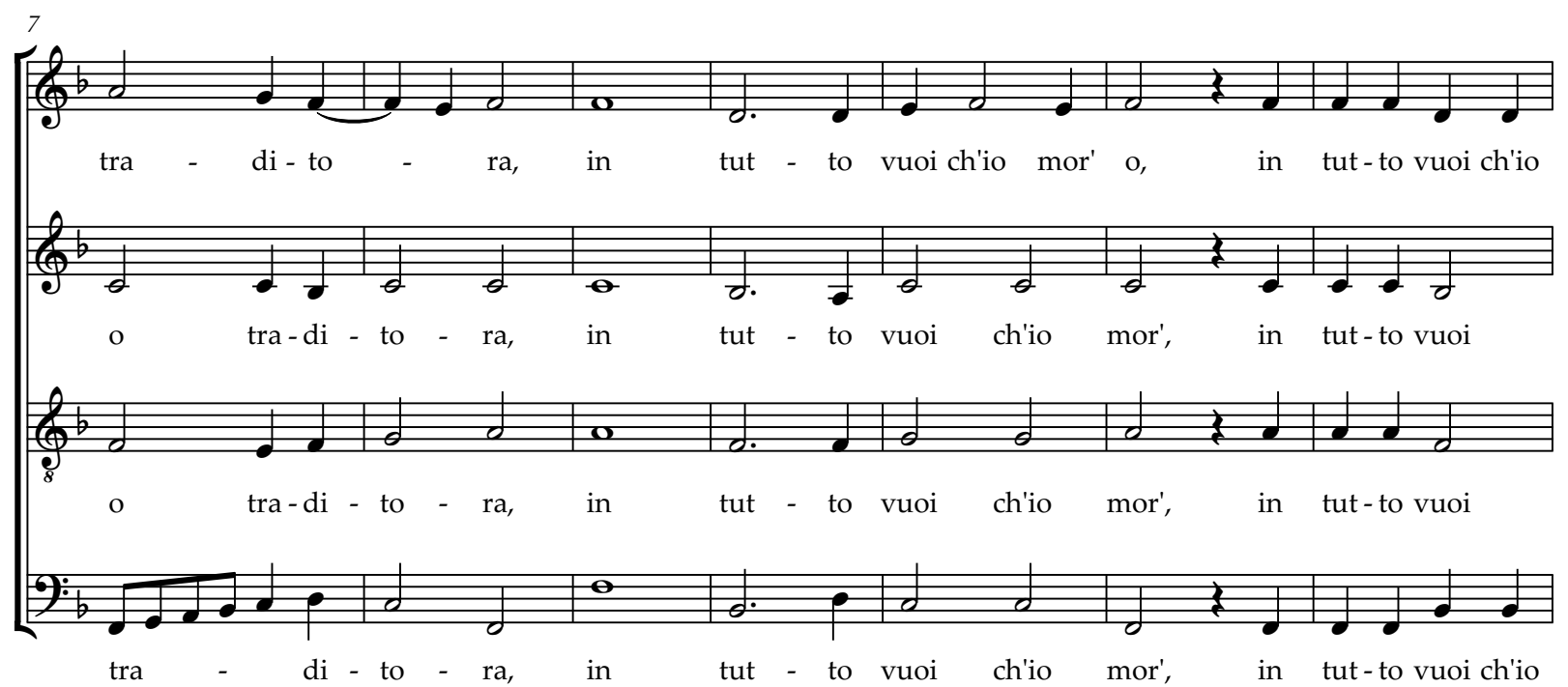



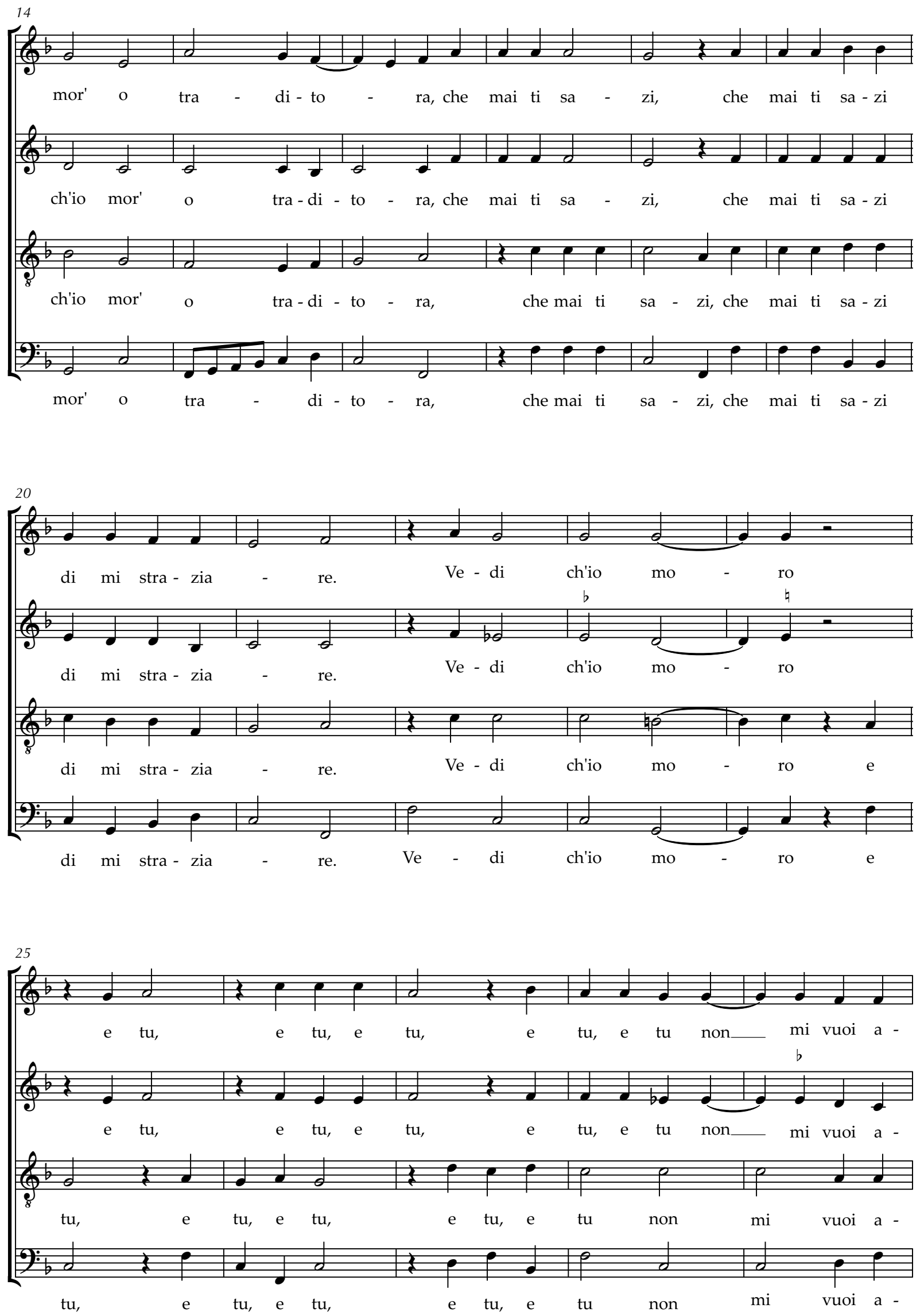

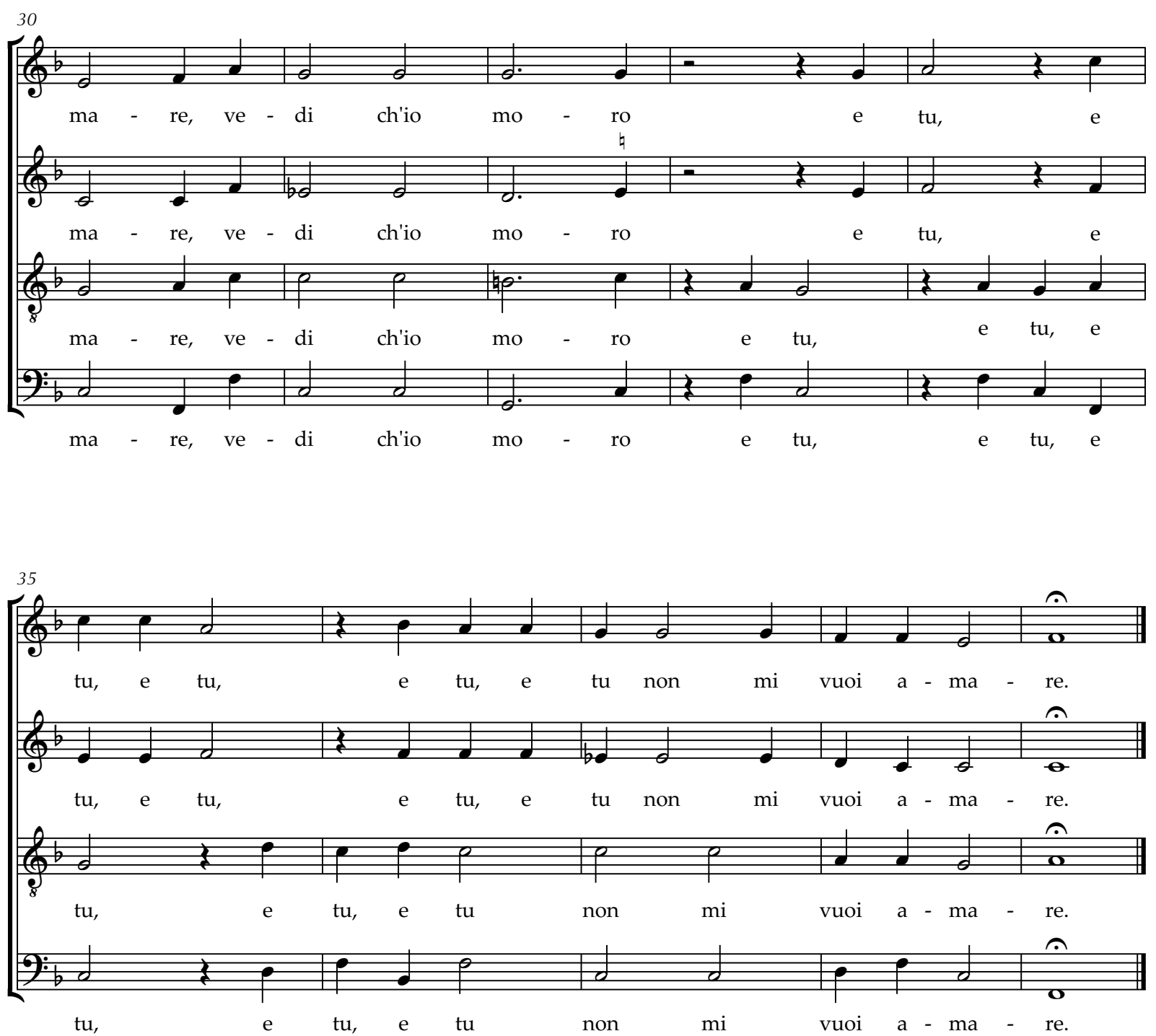


\subsection{9. \\ MEDICI NOI SIAMO}

(Winchester Partbooks, n. 53)

Texto: anônimo

Medici noi siamo o donne belle,

Con radici sanamo le ferite.

$\mathrm{Su}, \mathrm{su}, \mathrm{su}, \mathrm{su}$, hor su, su, su, citelle,

S'havet' il tempo mo non lo perdite.
Hubert Waelrant (ca.1517-1595) Transcrito e editado por Munir Sabag

Somos médicos, ó belas damas,

Com raízes curamos as feridas.

Vinde, vinde, donzelas,

Se tendes tempo, não o percam agora.

[DISCANTUS]
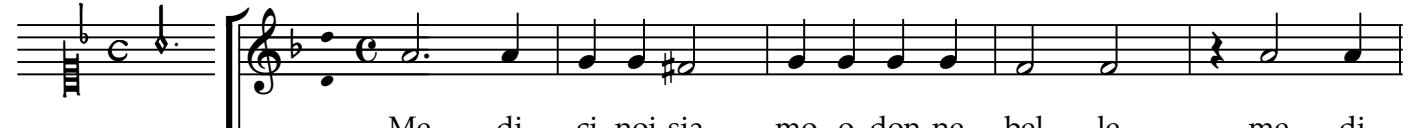
Me - di - ci noi sia - mo o don-ne bel - le, me - di -

[ALTUS]
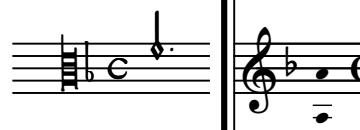

(a)

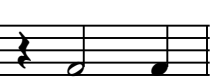

[TENOR]

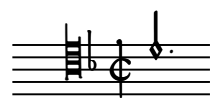

Me - di - ci noi sia - mo o don-ne bel - le,

me - di -

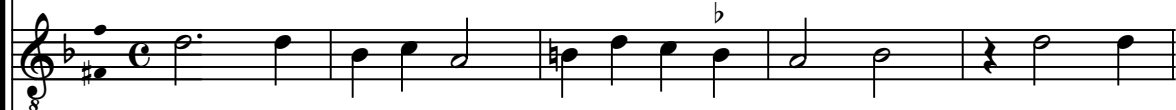

Me - di - ci noi sia - mo o don-ne bel - le, me - di -

[BASSUS]

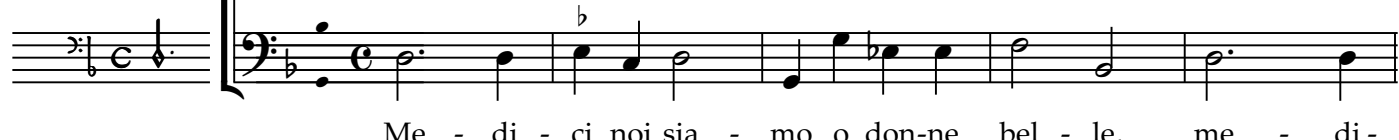

Me - di - ci noi sia - mo o don-ne bel - le, me - di -

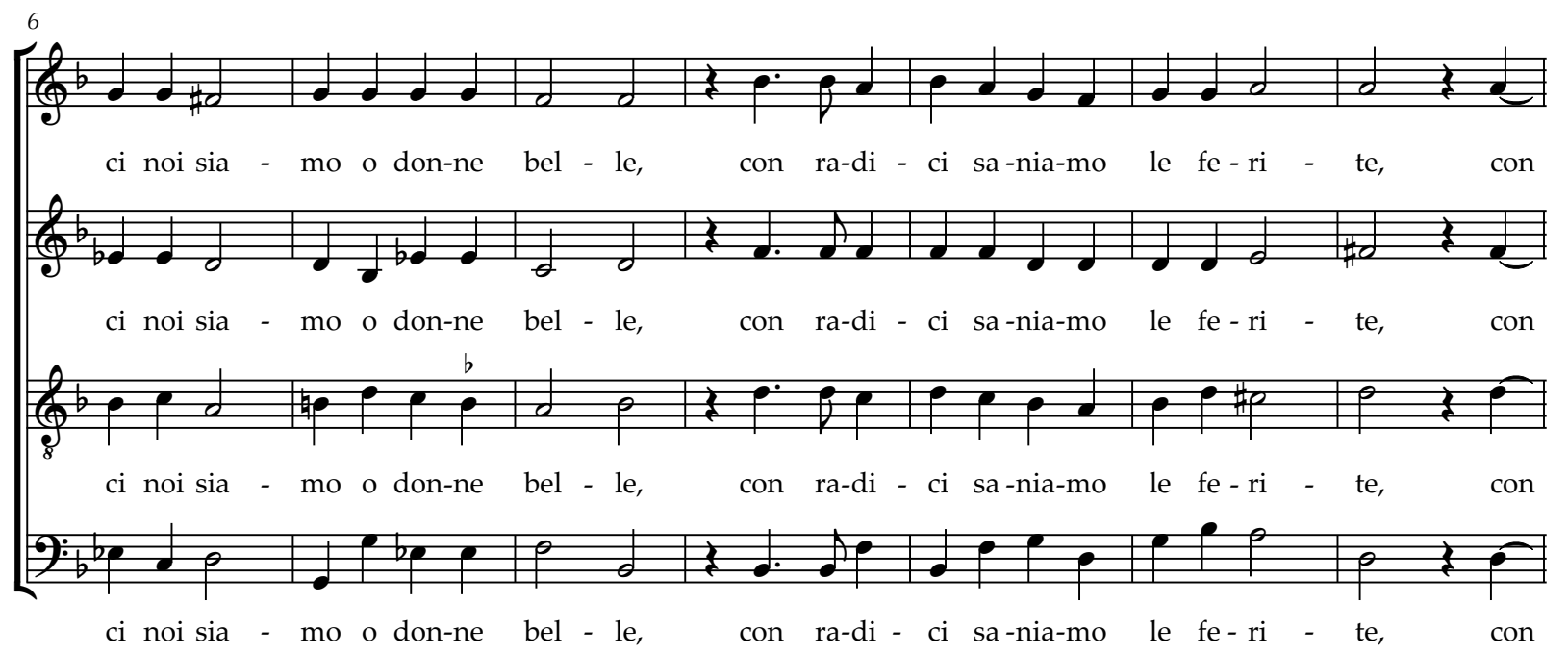



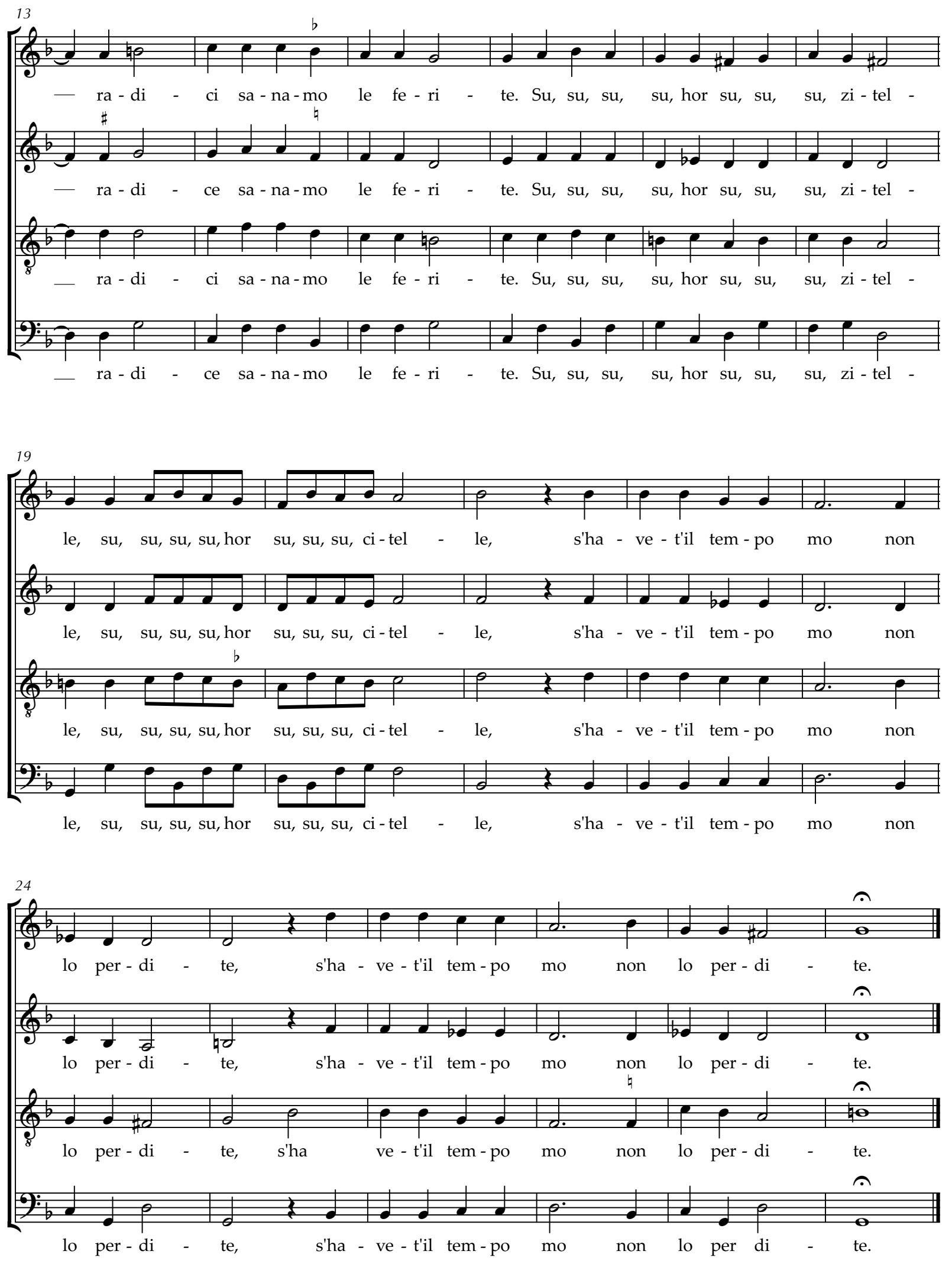

NOTA DO EDITOR:

Tenor, compasso 8: a segunda minima está marcada (erroneamente) como Bł no manuscrito. 


\subsection{PORT' ACQU' AL CRIN' E PIGLIA VENT' IN RETE}

(Winchester Partbooks, n. 54)

Texto: anônimo

Port'acqua al crin e piglia vent'in rete

Chi pens'a donna vana dar il core,

Perchè si cangia mille volte l'ore.
Hubert Waelrant (ca.1517-1595)

Transcrito e editado por Munir Sabag

[DISCANTUS]
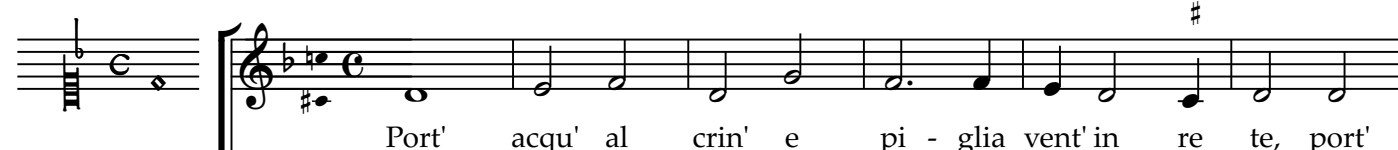

[ALTUS]

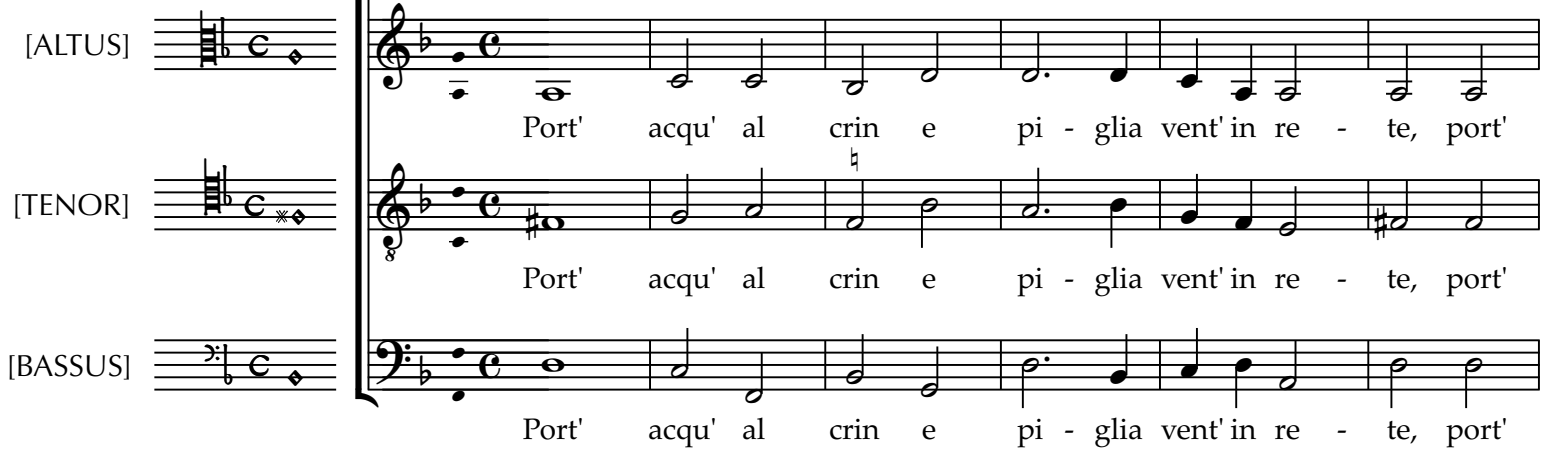

Port' acqu' al crin' e pi - glia vent'in

te, port'

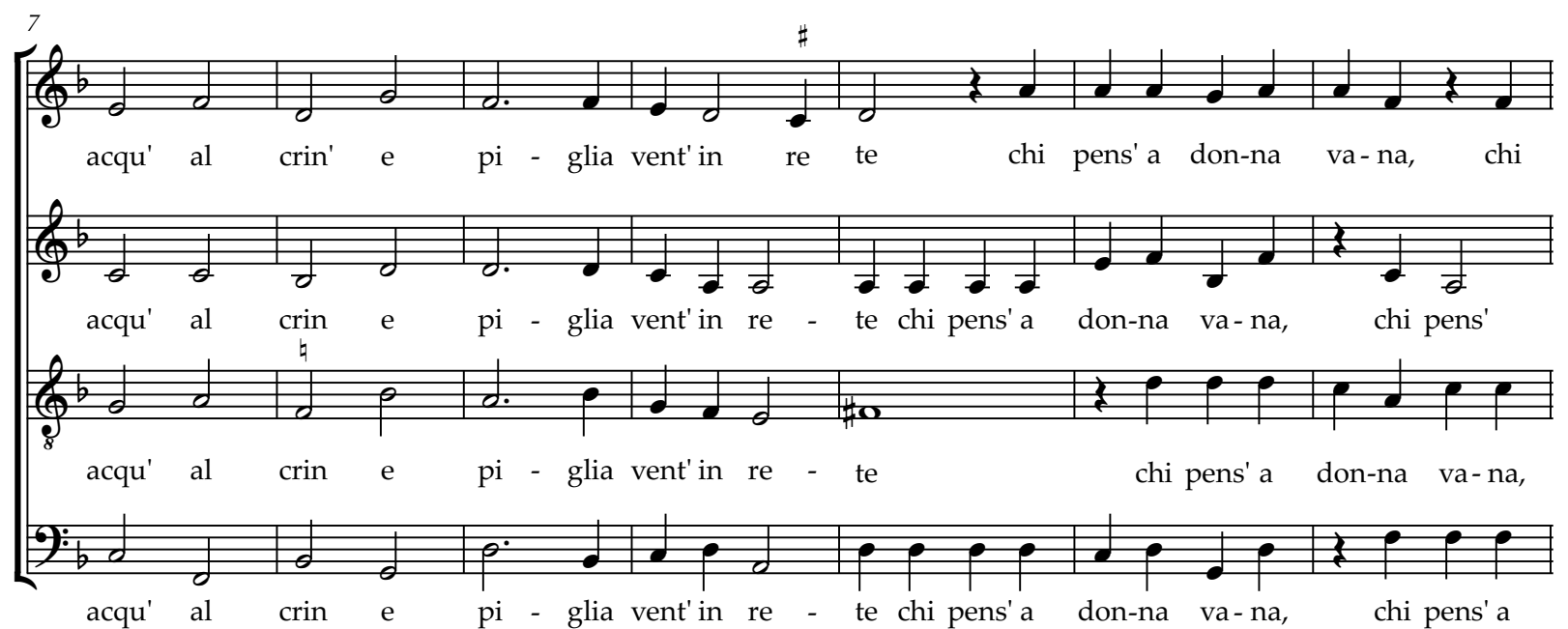



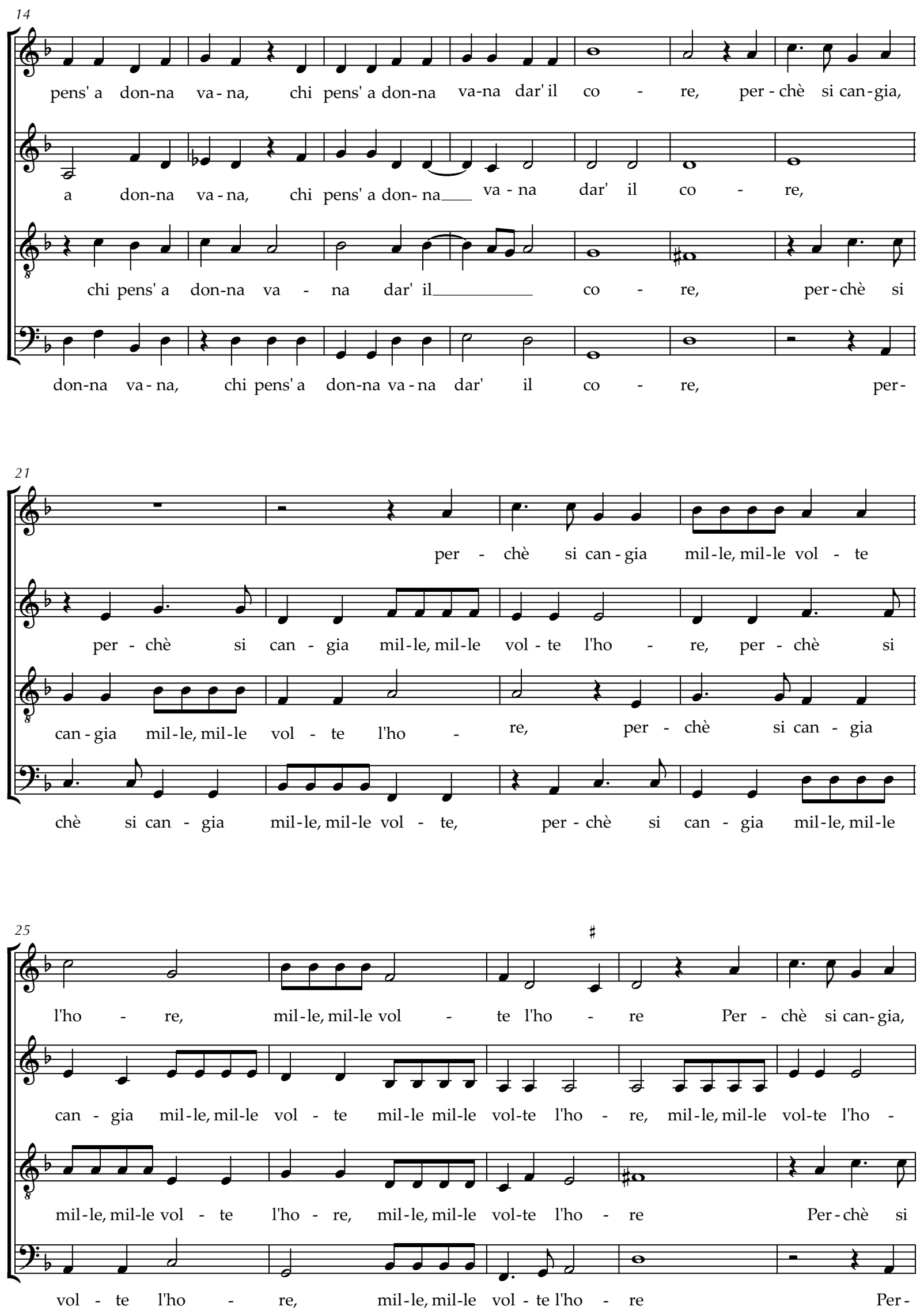

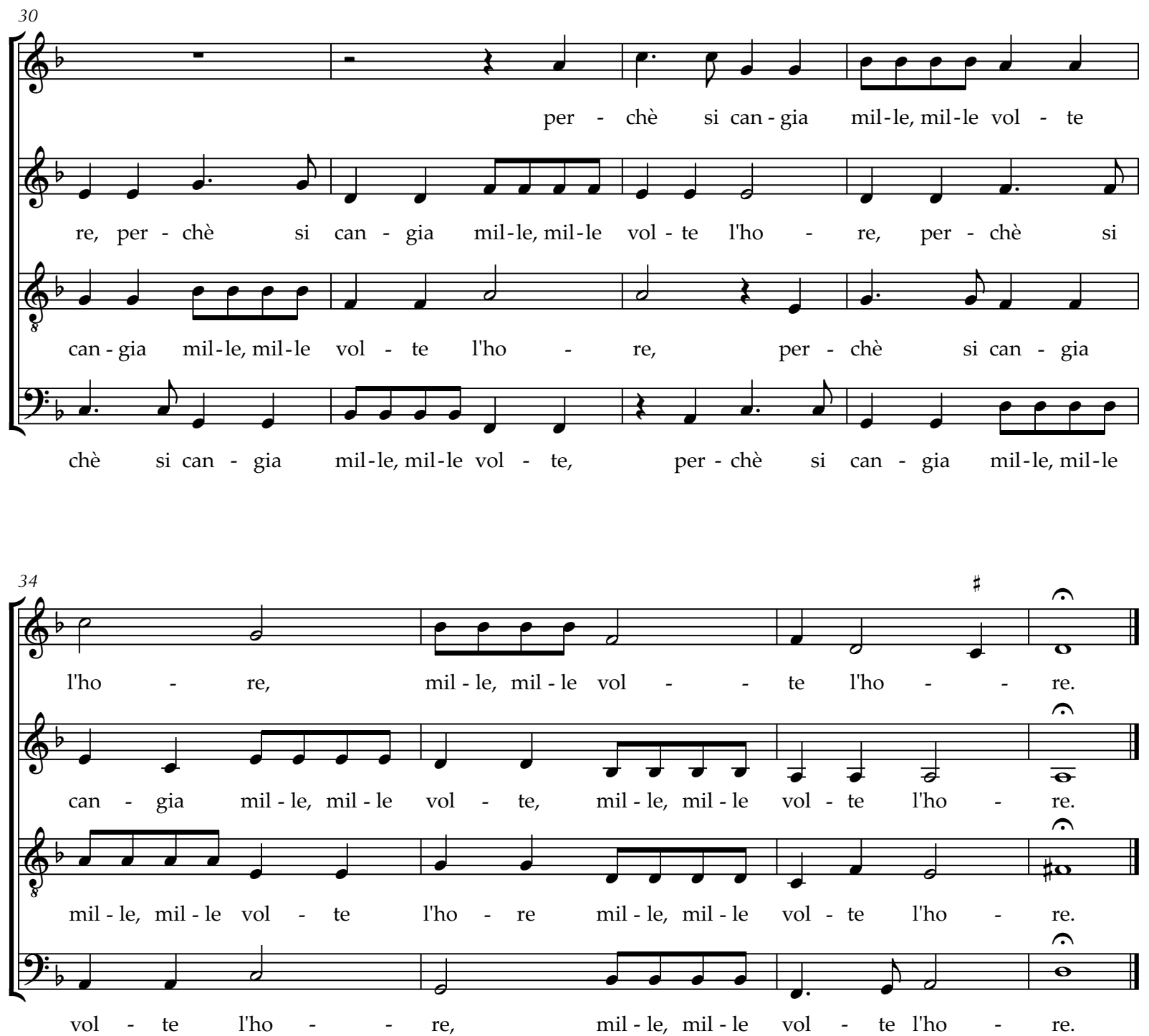


\subsection{ME BISOGNA SERVIR QUESTA CRUDELE}

(Winchester Partbooks, n. 55)

Texto: anônimo

Me bisogna servir questa crudele

Che fing' amarm' e poi dolor mi porge.

Ma lassa far a Giorge.
Hubert Waelrant (ca.1517-1595)

Transcrito e editado por Munir Sabag

[DISCANTUS]

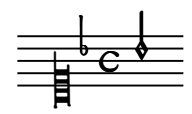

$$
\text { (E) }
$$

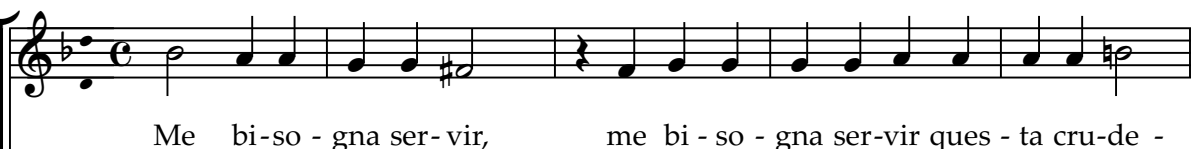

[ALTUS]

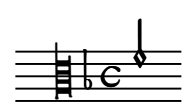

Me bi-so - gna ser-vir,

me bi - so - gna ser-vir ques - ta cru-de -

Que finge amar-me e depois me causa dor.

Mas deixa com Giorgio.

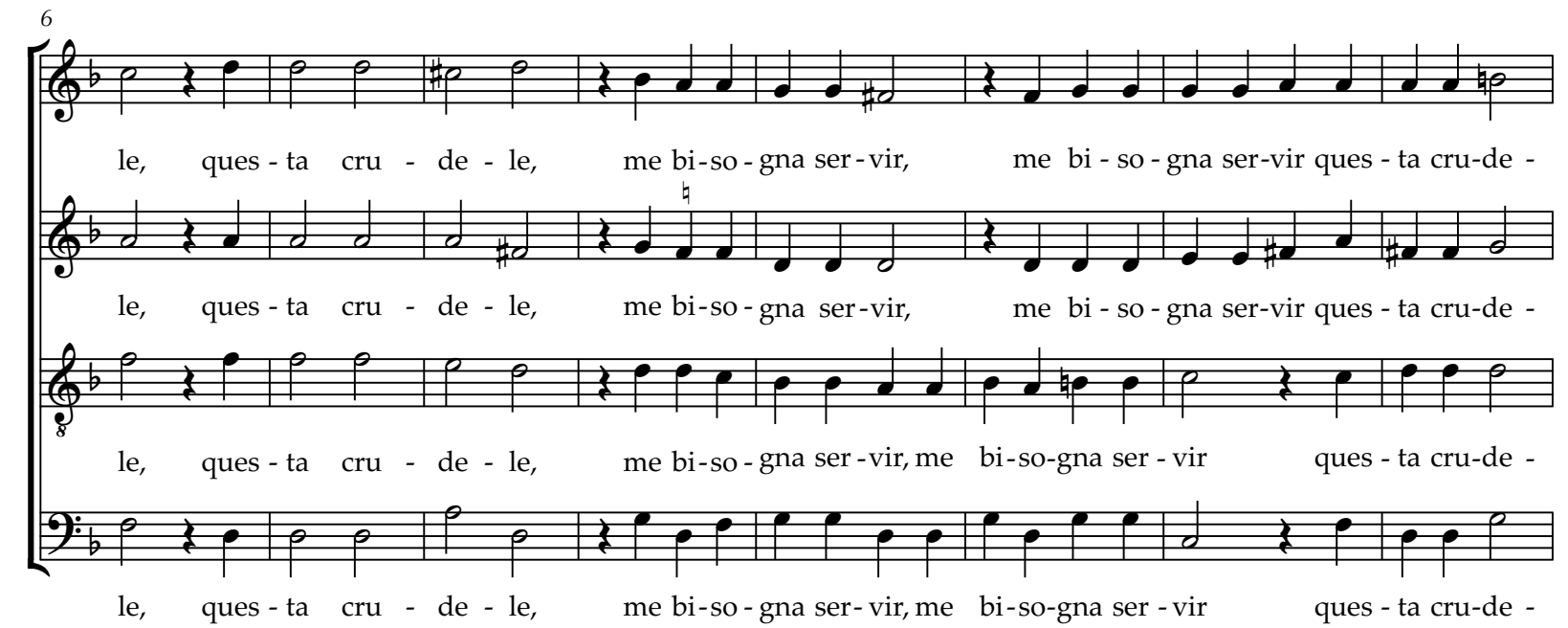



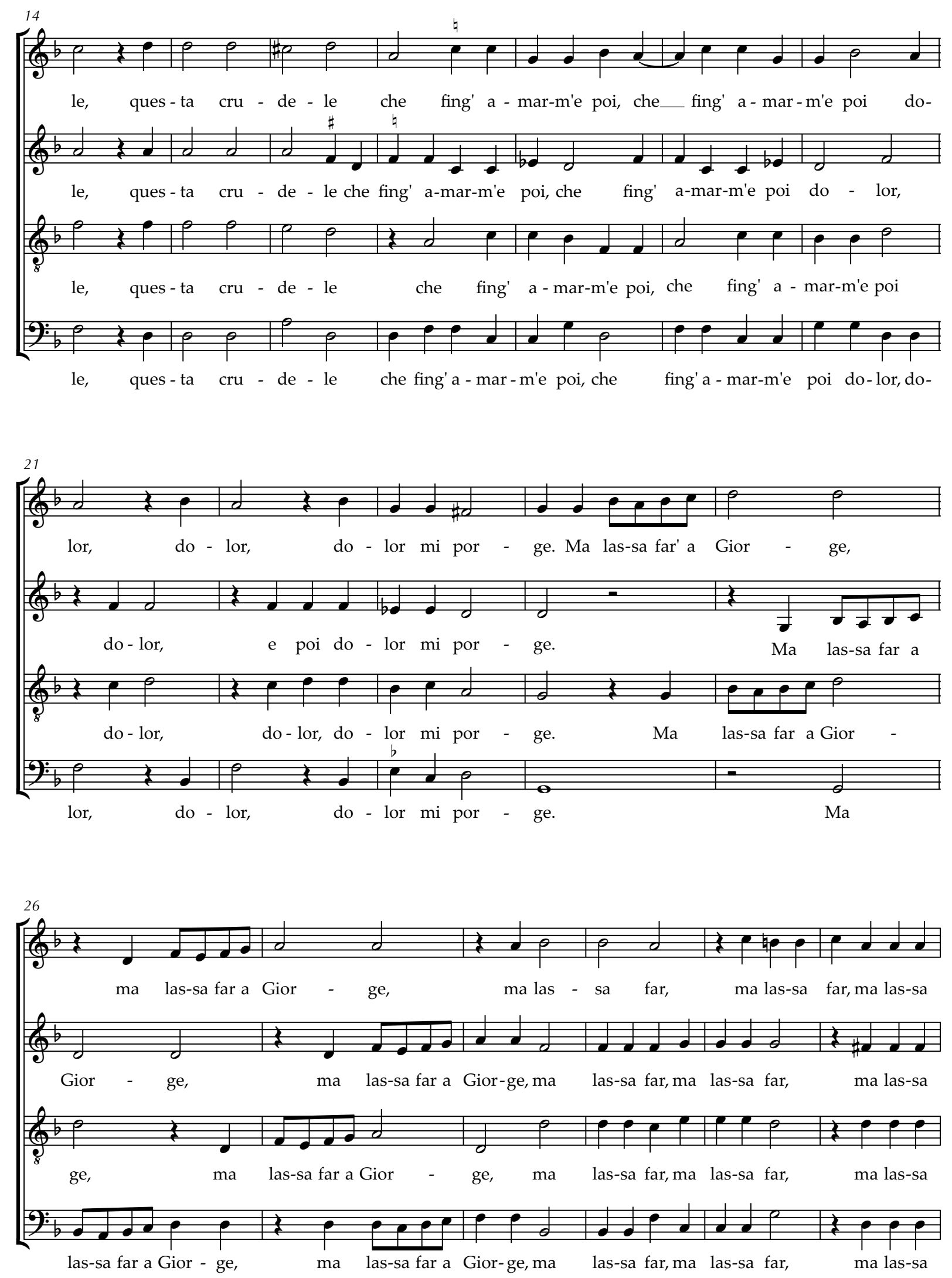

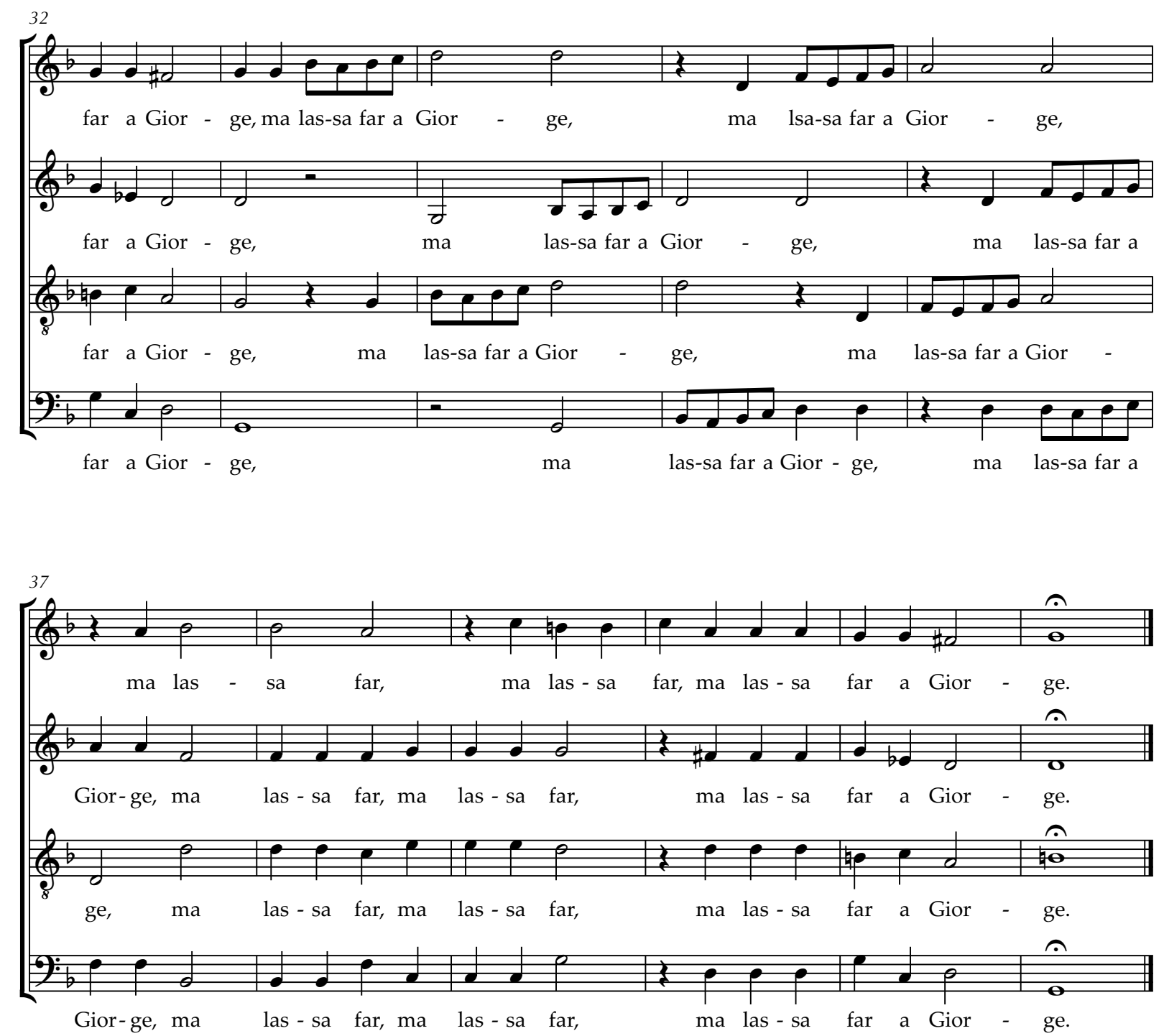

NOTAS DO EDITOR:

(1) Altus, compasso 4: a última semiminima consta no manuscrito como Fá\# e foi corrigida para Lá, da maneira como aparece na repetição do mesmo trecho (compasso 12).

(2) Agradecemos aos professores Dr. Jorge de Almeida e Dra. Maria Cecilia Casini por nos esclarecerem a expressão "lassa far a Giorgio", cunhada por Giorgio Vasari (1511-1574), cujo significado é "fique tranquilo, Giorgio vai resolver", ou "ela que se cuide". 


\subsection{LA BELLA MONICELLA VAD' A MESSA}

(Winchester Partbooks, n. 56)

Texto: anônimo

Hubert Waelrant (ca.1517-1595)

Transcrito e editado por Munir Sabag

La bella monicella vad' a messa

E sta devota per santificare.

E non te ne fidare di quanto fa,

Lo fa per $t^{\prime}$ ingannare.

A bela freirinha vai à missa

E se faz de devota para comungar.

Mas não te fies do que ela faz,

Pois o faz para te enganar.
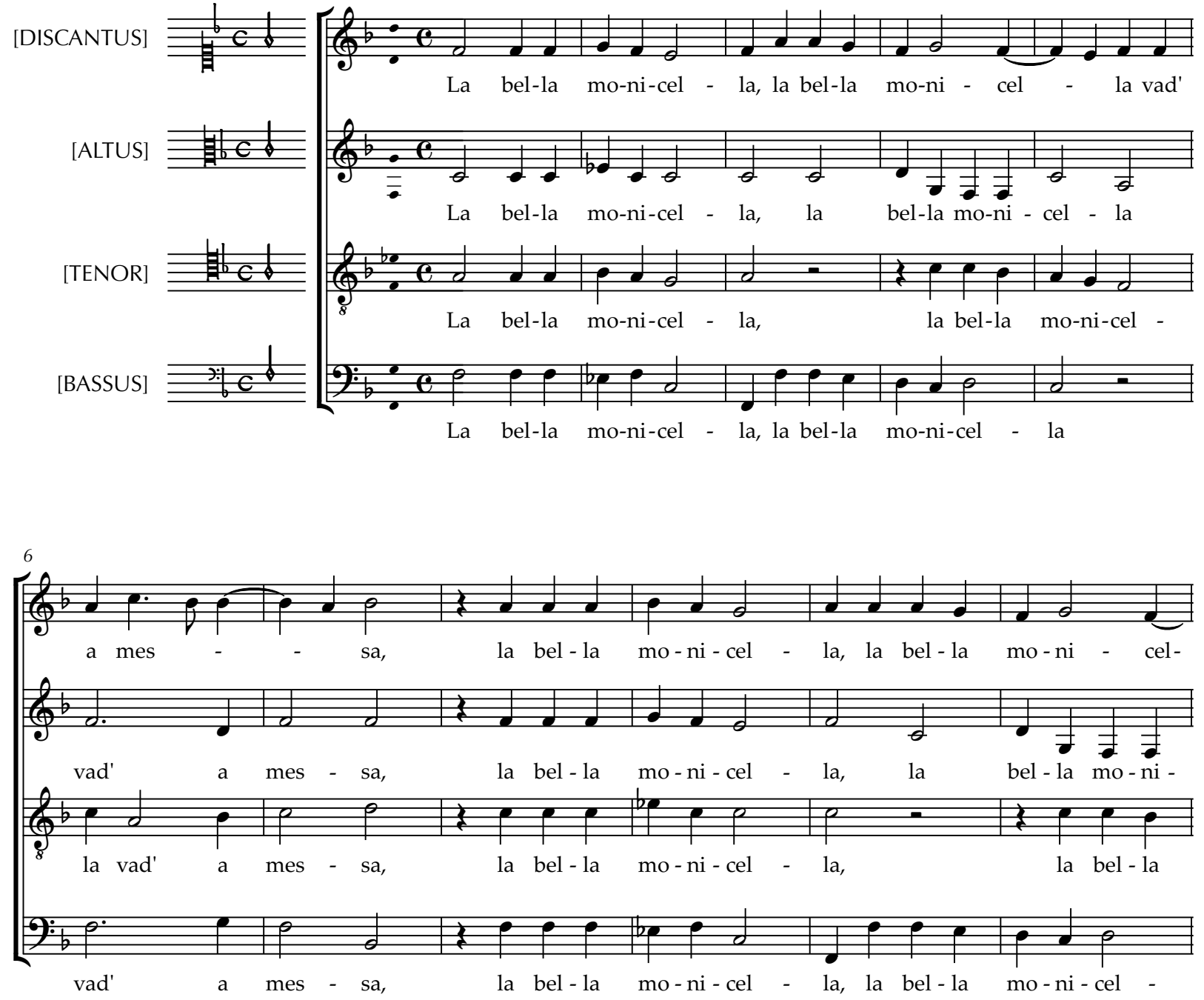

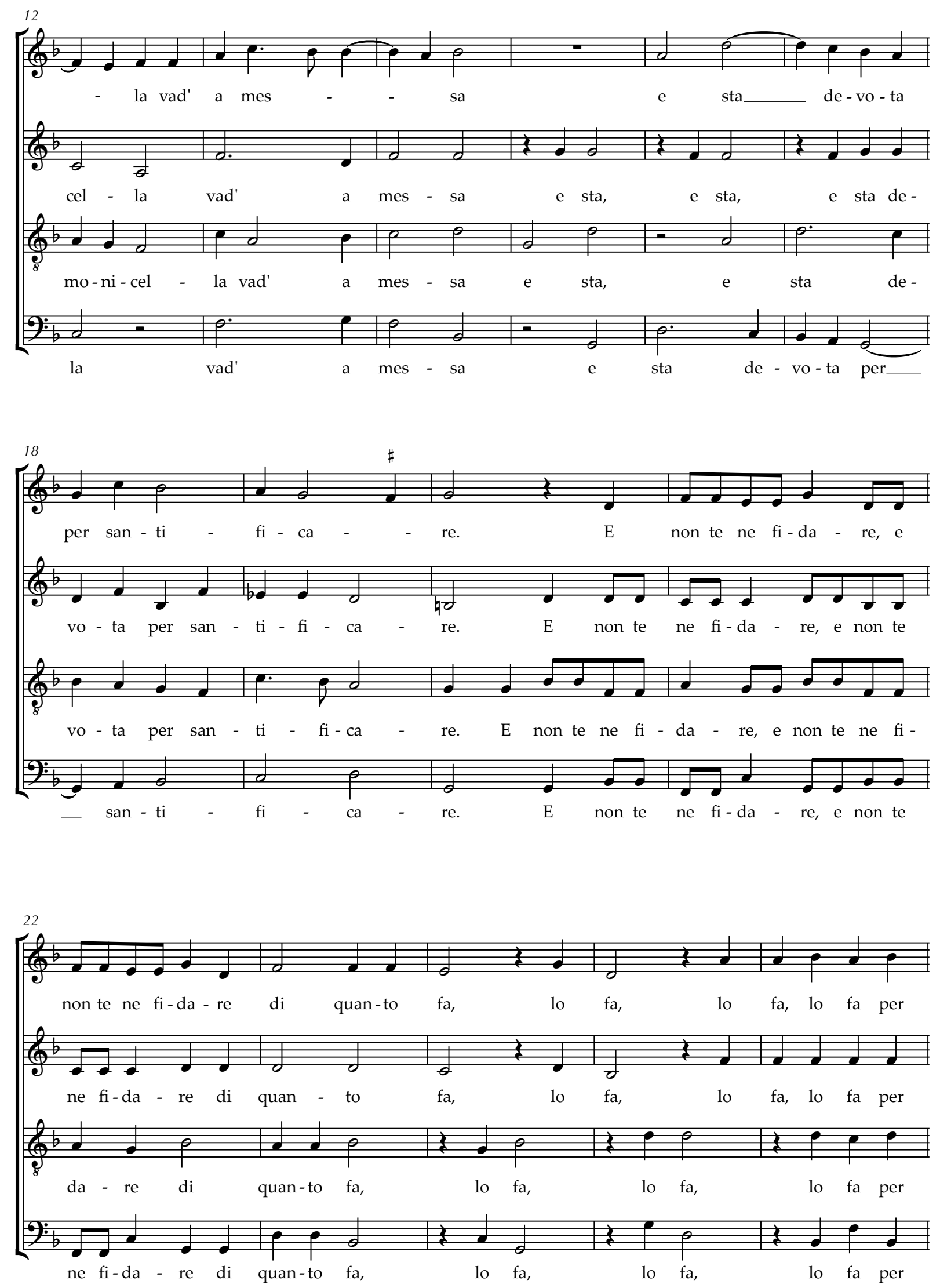

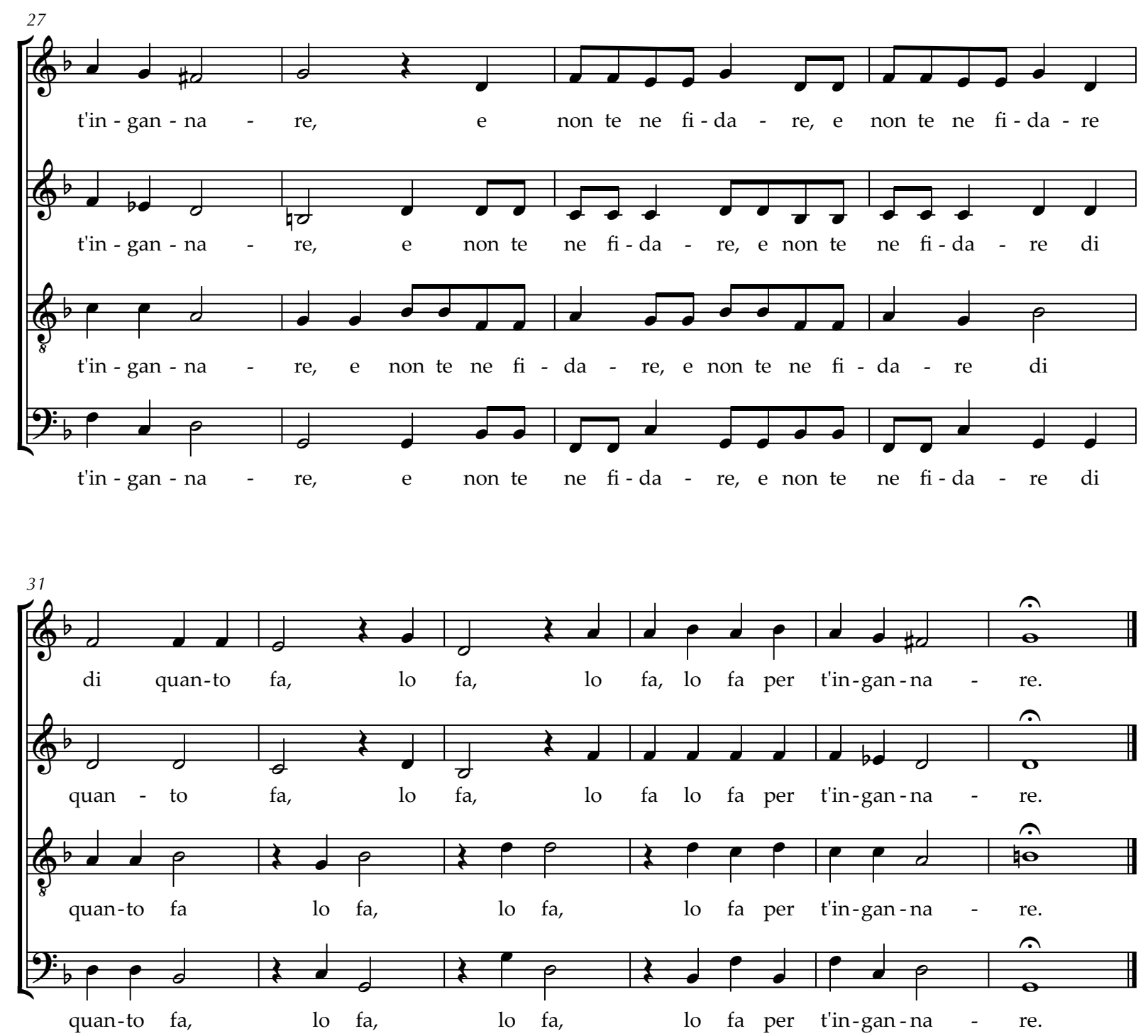


\subsection{HOR MAI SON QUASI MORTO}

(Winchester Partbooks, n. 57)

Texto: anônimo

Hubert Waelrant (ca.1517-1595)

Transcrito e editado por Munir Sabag

Hor mai son quasi morto e tu n'ol credi

Fin che l'alma del corp' uscirà fuora.

Hor di se vuoi ch'io moro,

Camo ch'io morirò senza dimora.

Já estou quase morto e tu não o crês Até que a alma saia fora do corpo.

Ora, diga se queres que eu morra,

Que eu morrerei sem demora.

[DISCANTUS]
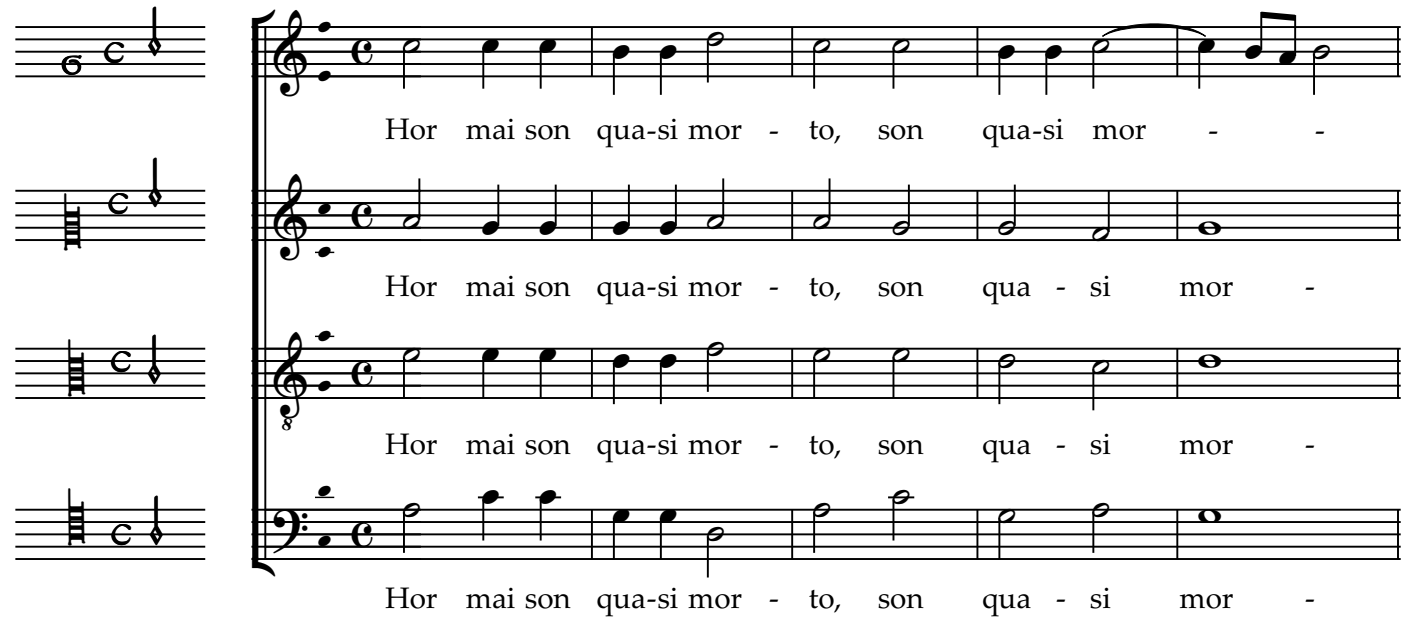

[BASSUS]

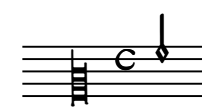

[ALTUS]

[TENOR]
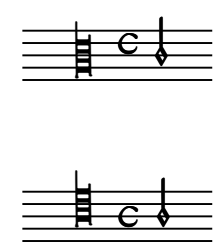

Hor mai son qua-si mor - to, son

qua - si

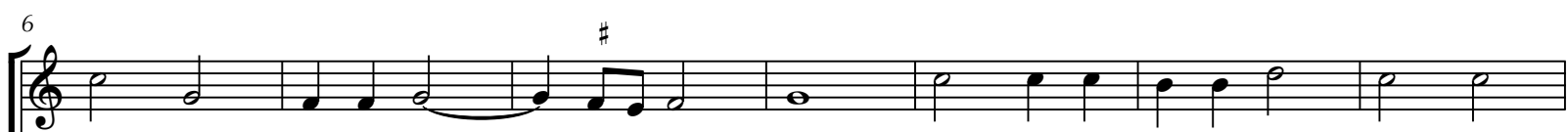

to e tu no'l cre - $\quad$ - $\quad$ - di, $\quad$ hor mai son qua-si mor - to, son
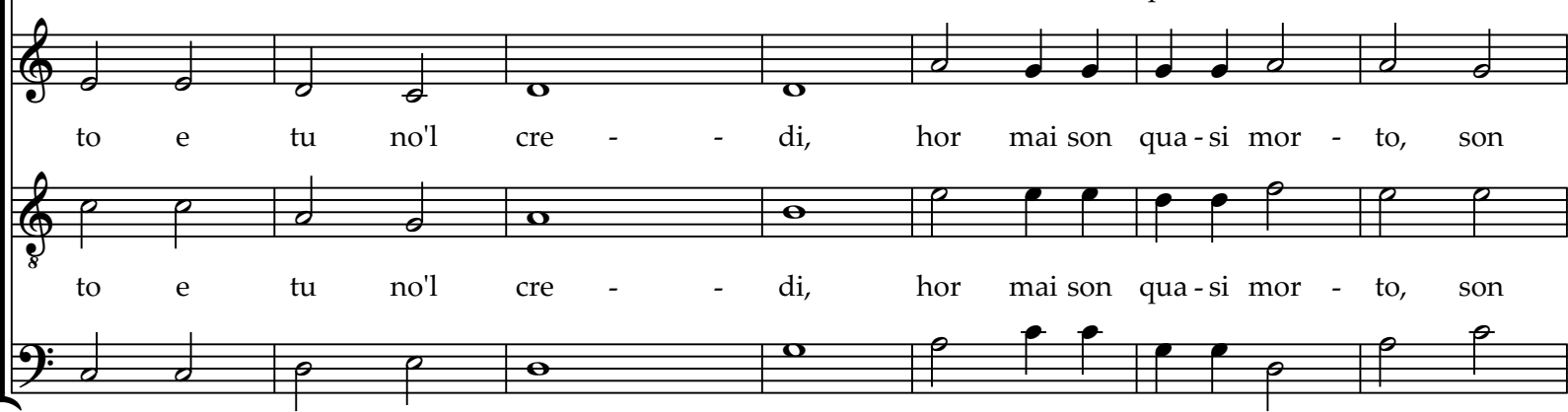

to e tu no'l cre - $\quad$ - di, hor mai son qua-si mor - to, son 

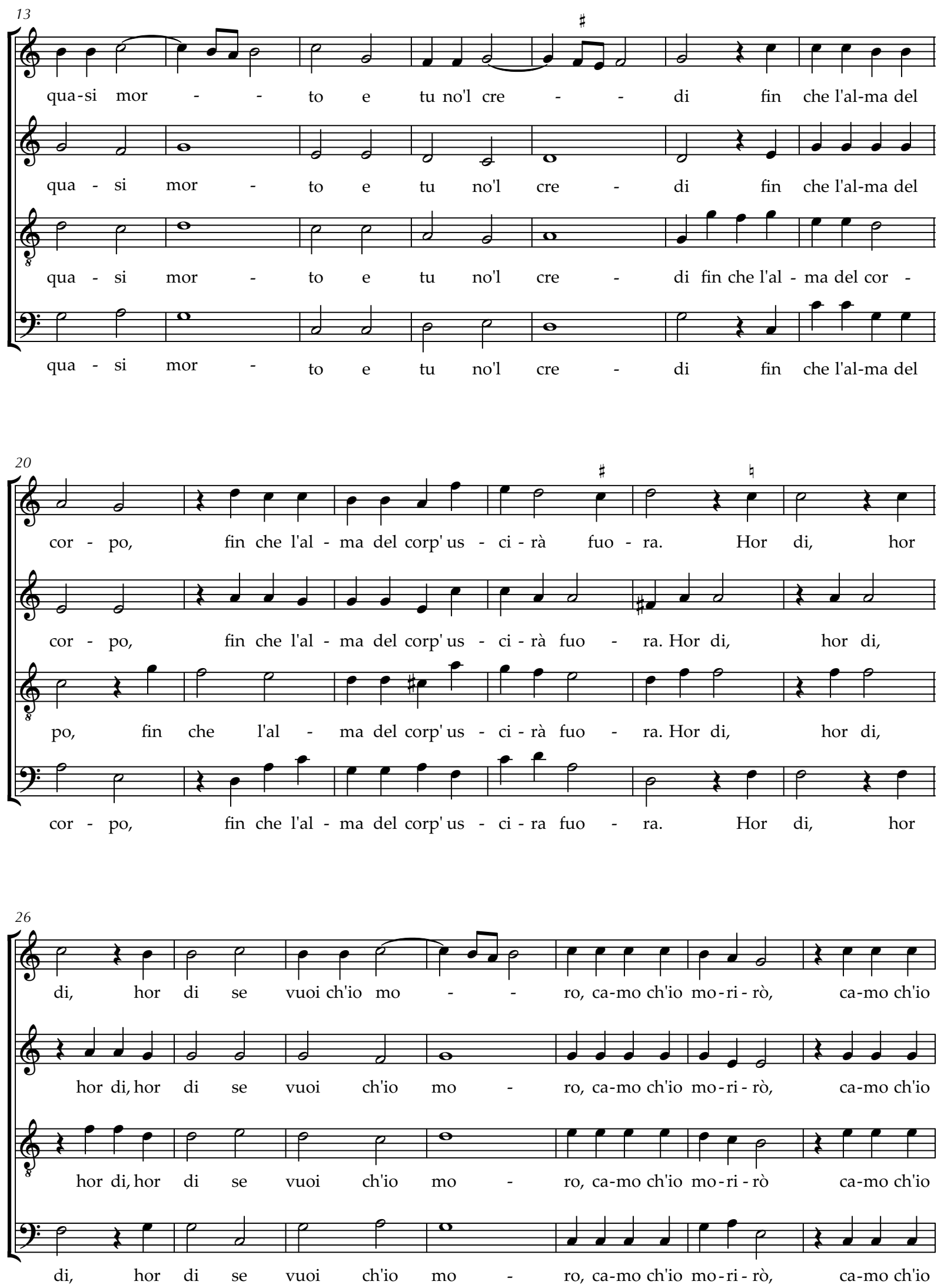

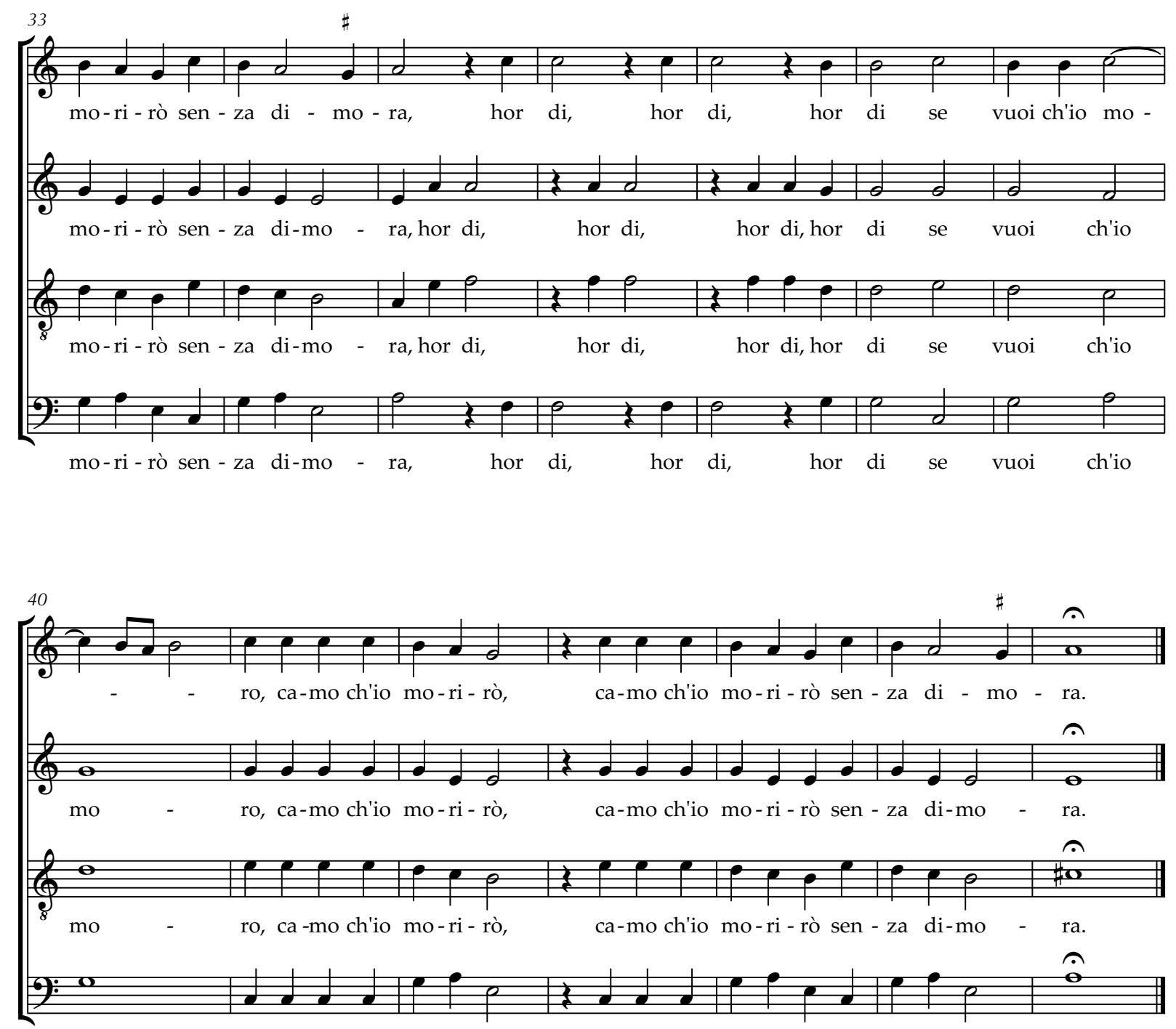

mo - ro, ca-mo ch'io mo-ri - rò, ca-mo ch'io mo-ri - rò sen - za di-mo - ra. 


\subsection{SON MOLTI GIORNI, AHIMÈ, CH'IO PERS' IL CORE}

(Winchester Partbooks, n. 58)

Texto: anônimo

Hubert Waelrant (ca.1517-1595)

Transcrito e editado por Munir Sabag

Son molti giorni, ahimè, ch'io pers' il core

E non posso trovarlo in loco nato.

Chi me l'ha furato?

Non pens' in nullo se non te o latra.
Há muitos dias, ai de mim, que eu perdi o coração E não posso encontrá-lo em seu lugar.

Quem mo roubou?

Não penso em ninguém senão [em] ti, ó ladra.

[DISCANTUS]
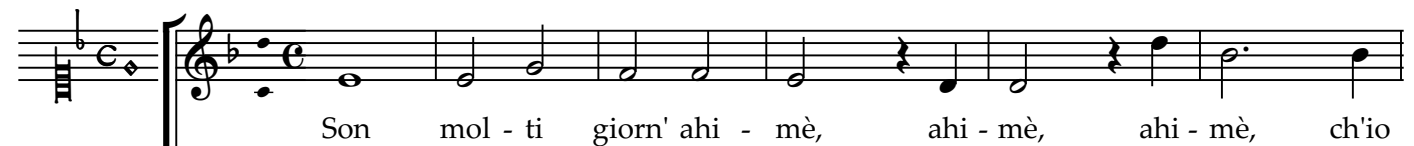

[ALTUS]
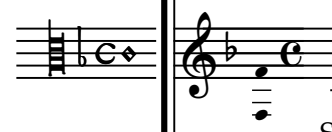

[TENOR]
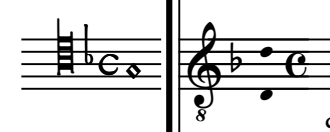

Son mol - ti giorn' ahi - mè, ahi-mè,

ani - me,

ch'io

[BASSUS]
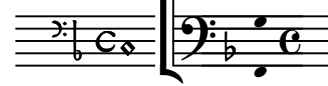

Son

mol - ti giorn' ahi - mè, ahi-mè,

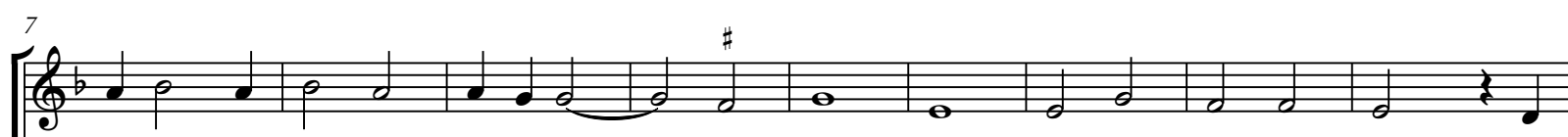

pers'il co - re, ch'io pers'il co - _ - re Son mol - ti giorn' ahi - mè, ahi-

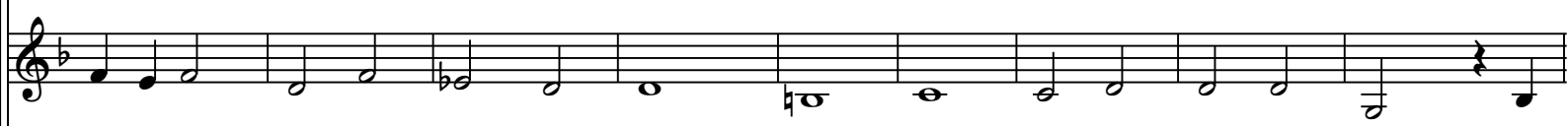

pers'il co - re, ch'io pers' il co - re Son mol - ti giorn' ahi - mè, ahi-

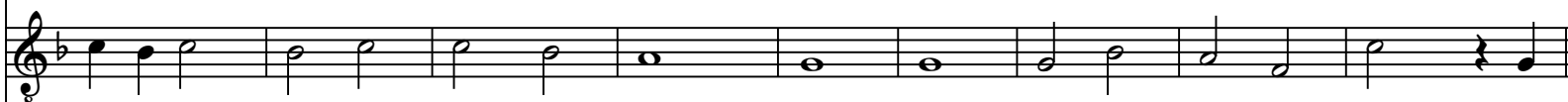

pers'il co - re, ch'io pers' il co - re Son mol - ti giorn' ahi - mè, ahi-

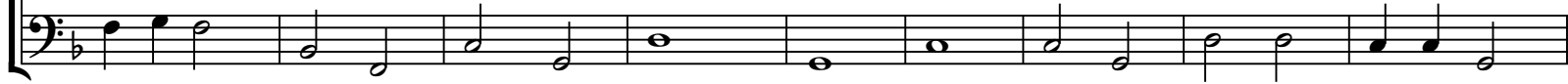

pers'il co - re, ch'io pers' il co - re Son mol - ti giorn' ahi - mè, ahi-mè, 

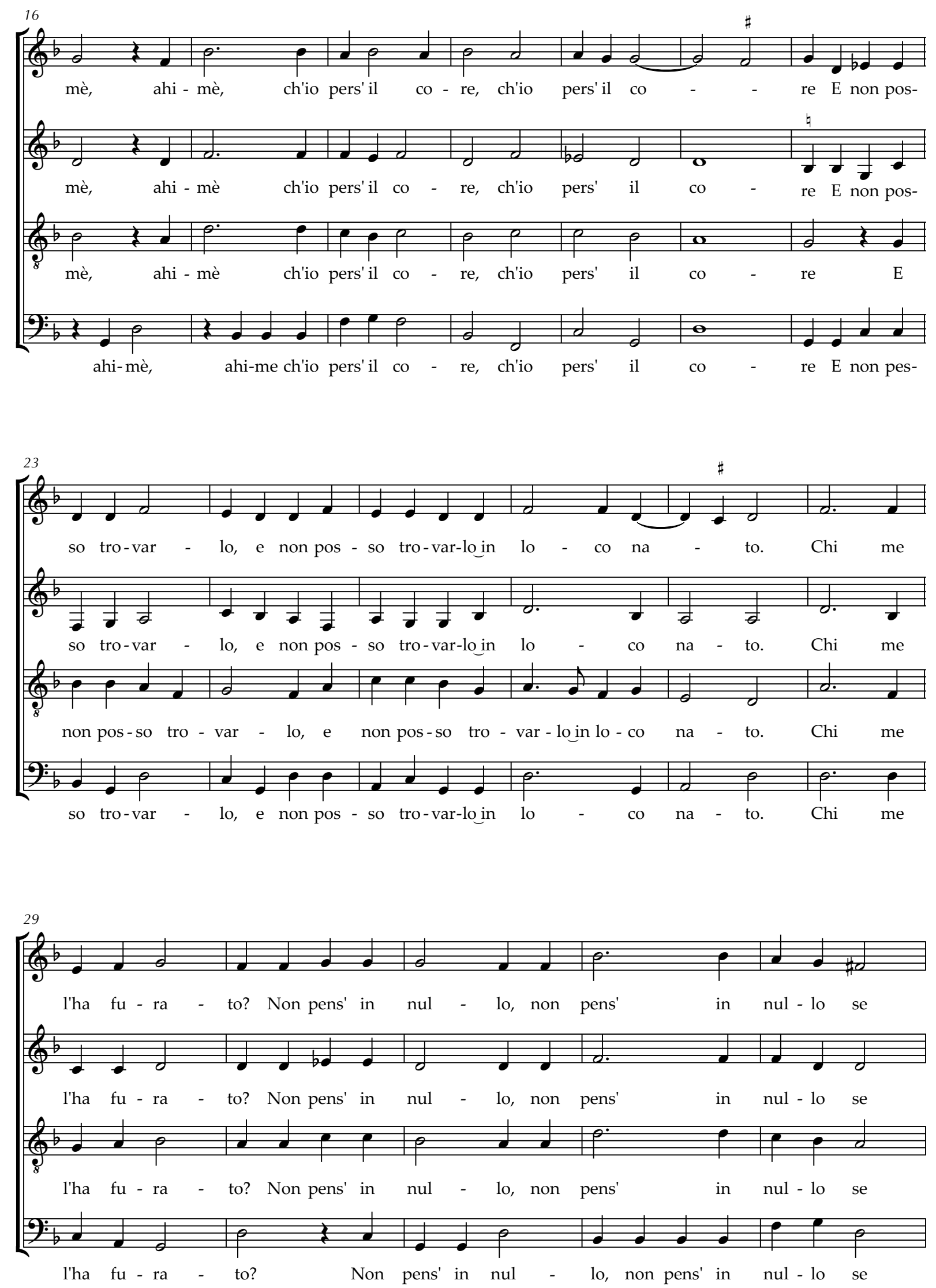

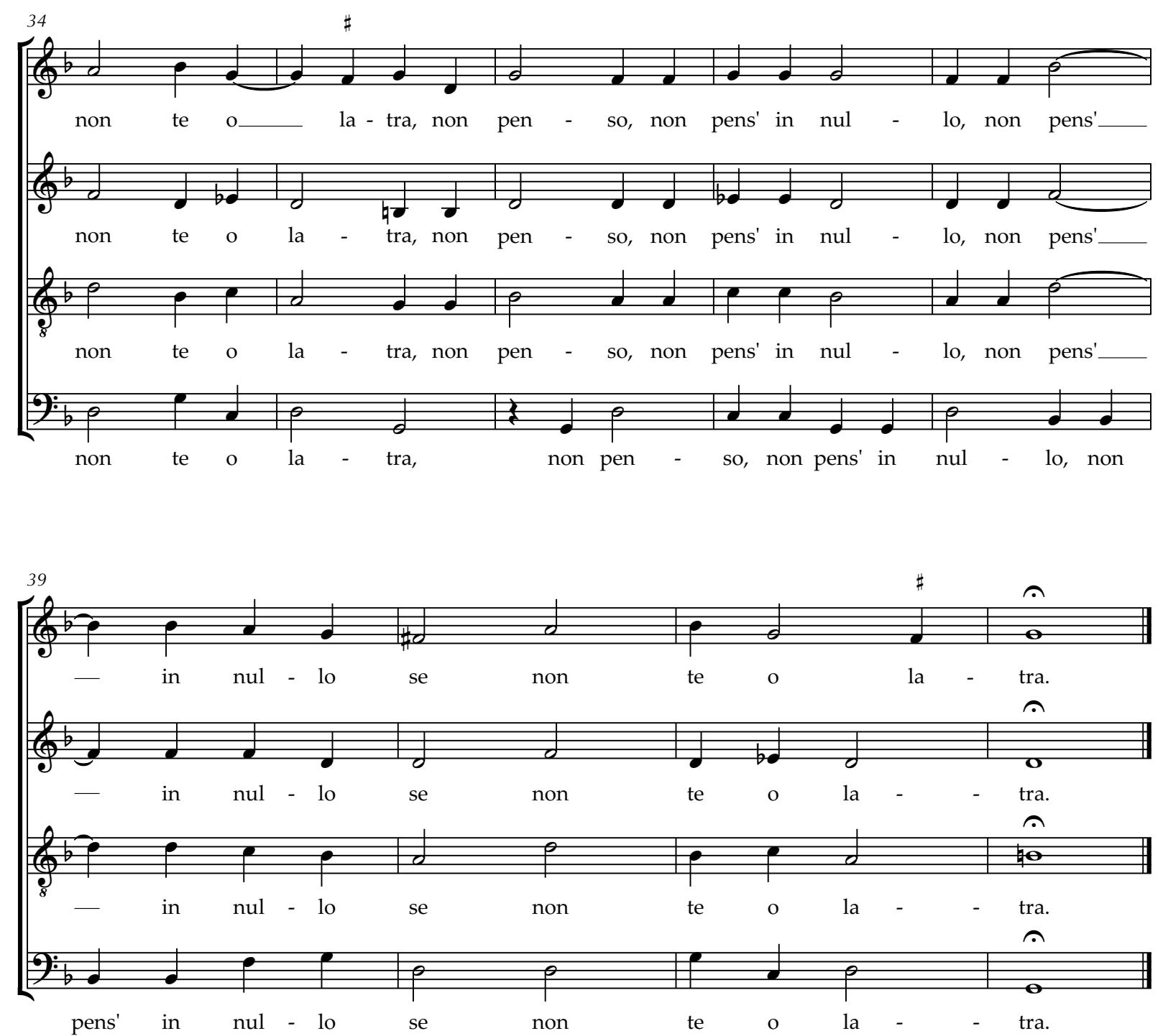


\subsection{5 . \\ VORRIA E NON VORRIA QUESTO VI DIRE}

(Winchester Partbooks, n. 62)

Texto: anônimo

Hubert Waelrant (ca.1517-1595)

Transcrito e editado por Munir Sabag

Vorria e non vorria questo vi dire:

Fate le fatti tuoi, lassa me stare,

Ch'io non ti vogli' e non te posso amare.

[DISCANTUS]
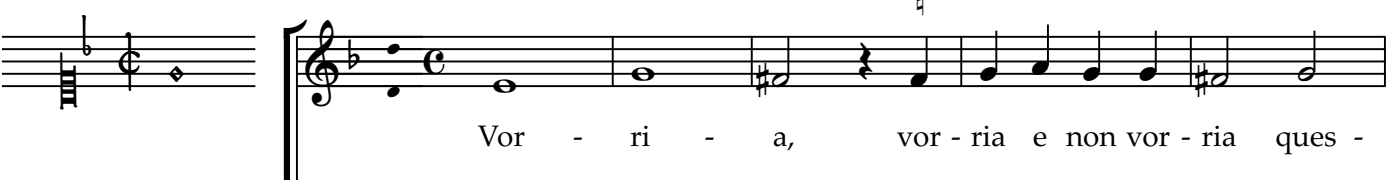

[ALTUS]
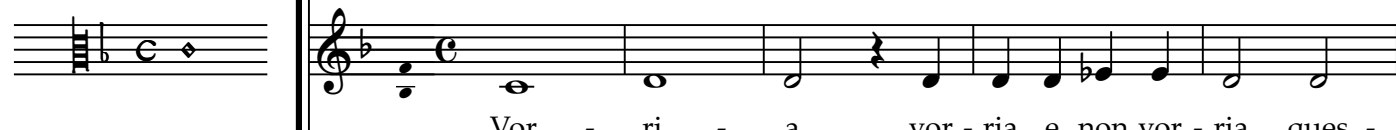

[TENOR]

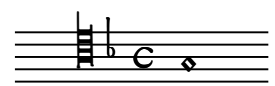

[BASSUS]
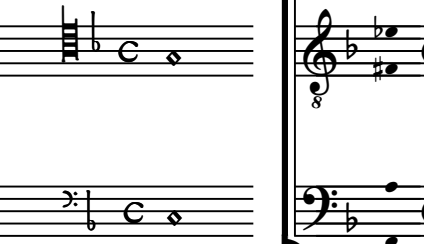

Vor - ri -

vor - ria e non vor - ria ques -
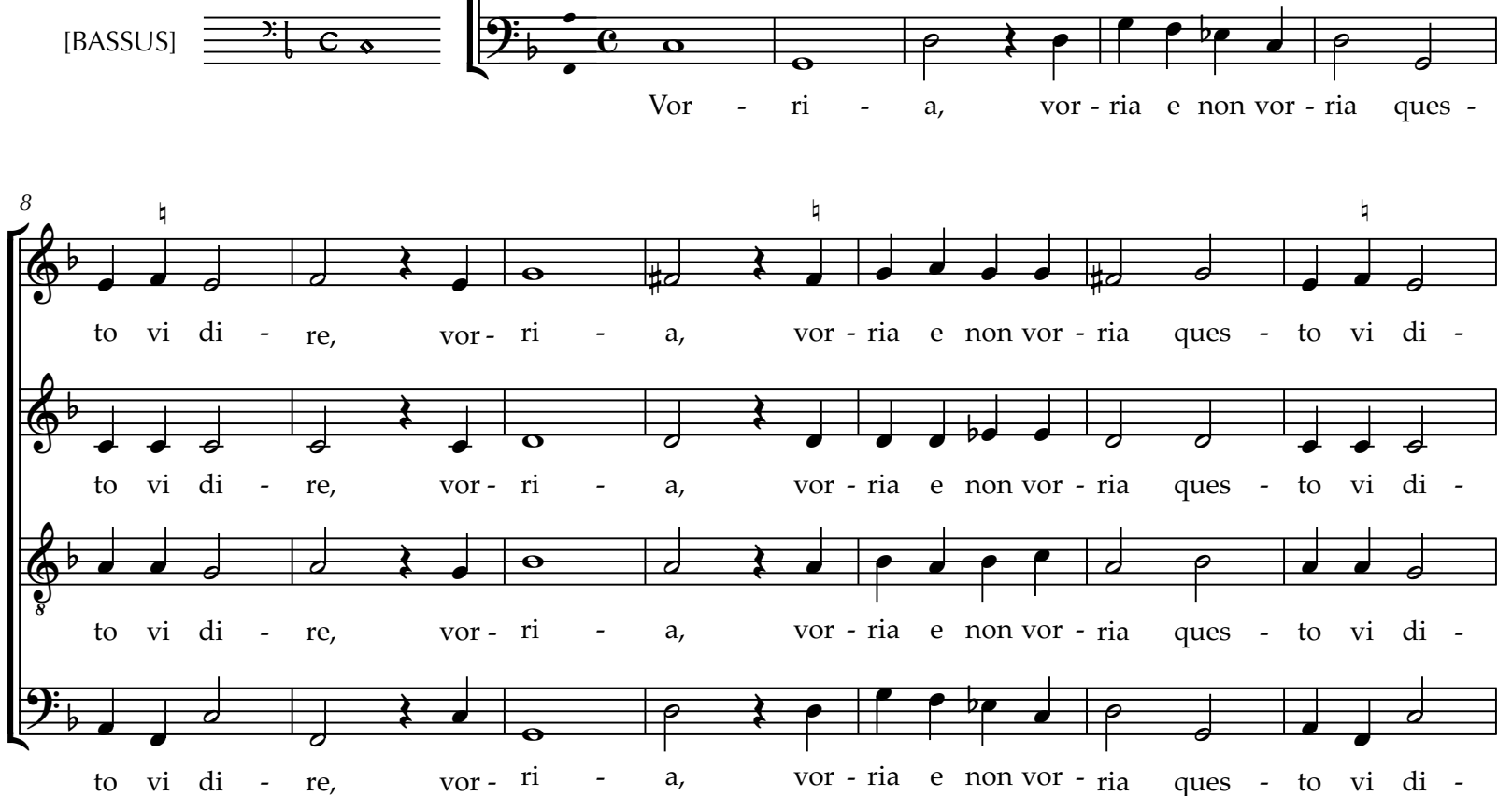

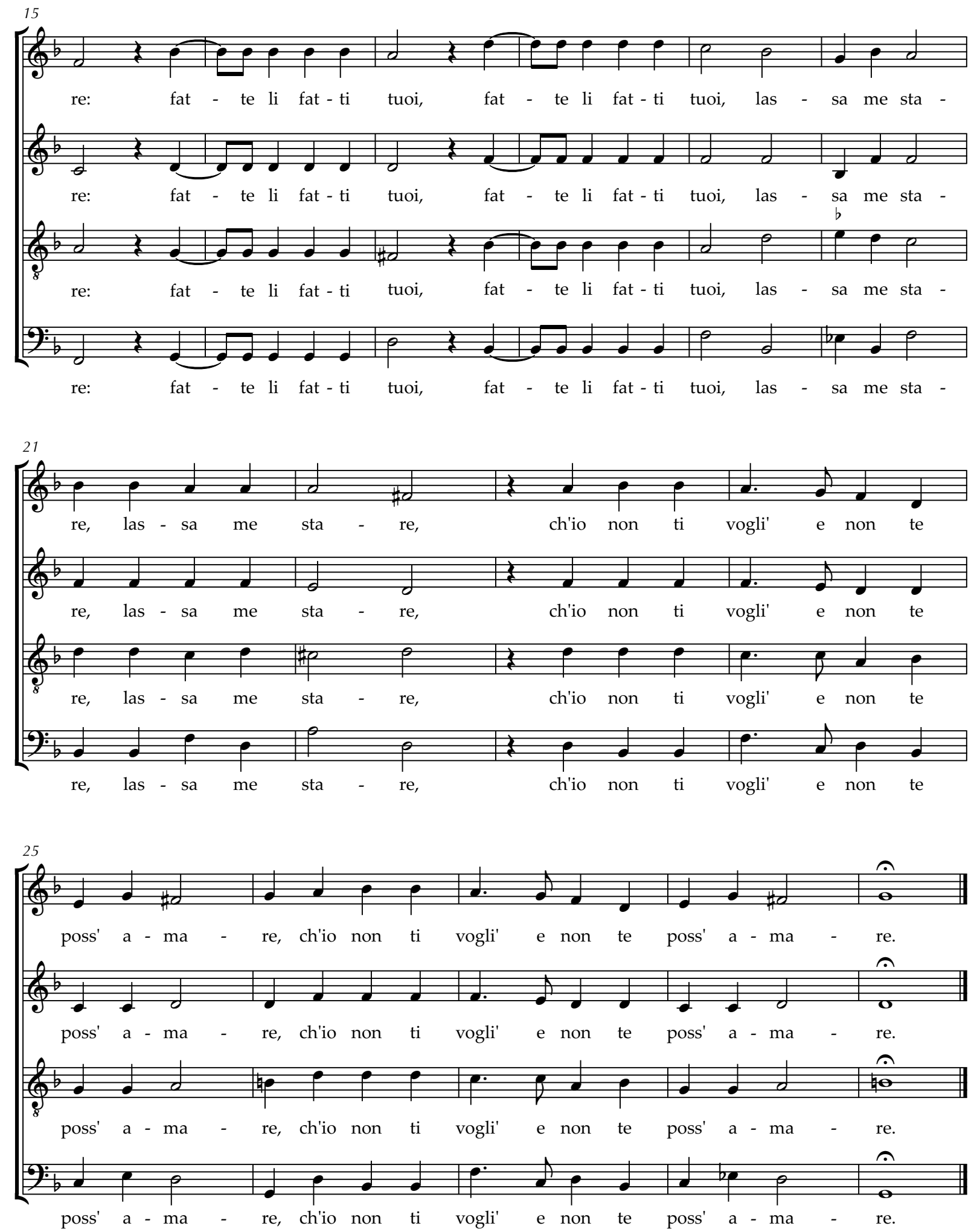

NOTA DO EDITOR:

Discantus, compasso 16: falta uma das semiminimae no manuscrito. 


\subsection{6 . \\ OGNIUNO SAPP' \\ HORMAI LA PENA MIA}

(Winchester Partbooks, n. 63)

Texto: anônimo

Ogniuno sapp' hormai la pena mia,

Madonna, se non voi, che nol' credete.

Ahimè, se lo vedete,

Perchè del mio morir pietà non havete?
Hubert Waelrant (ca.1517-1595)

Transcrito e editado por Munir Sabag

[DISCANTUS]
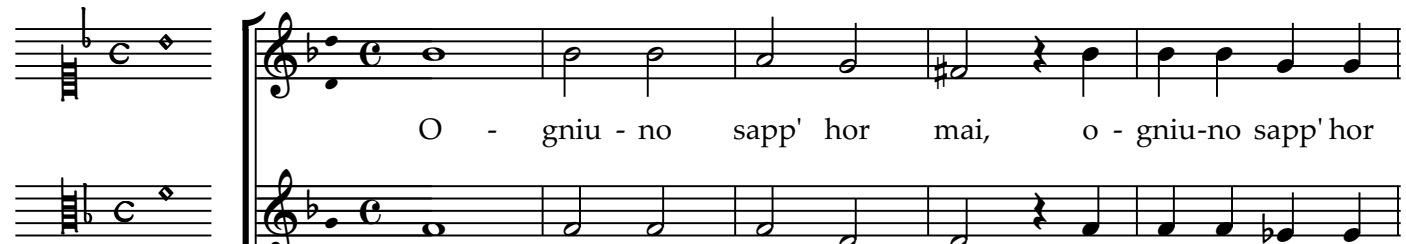

Senhora, exceto vós, que nela não credes.

Ah, se o vedes,

Porque não tendes piedade do meu morrer?

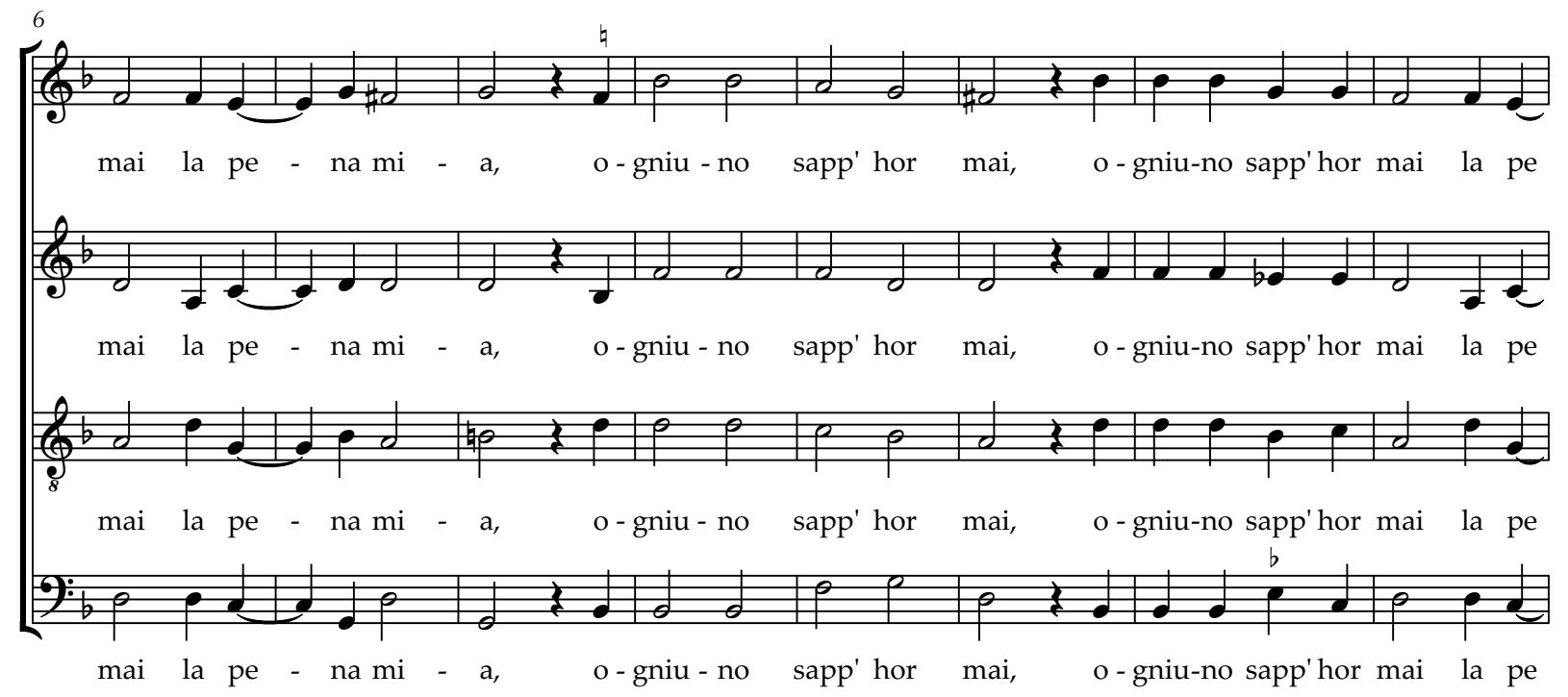




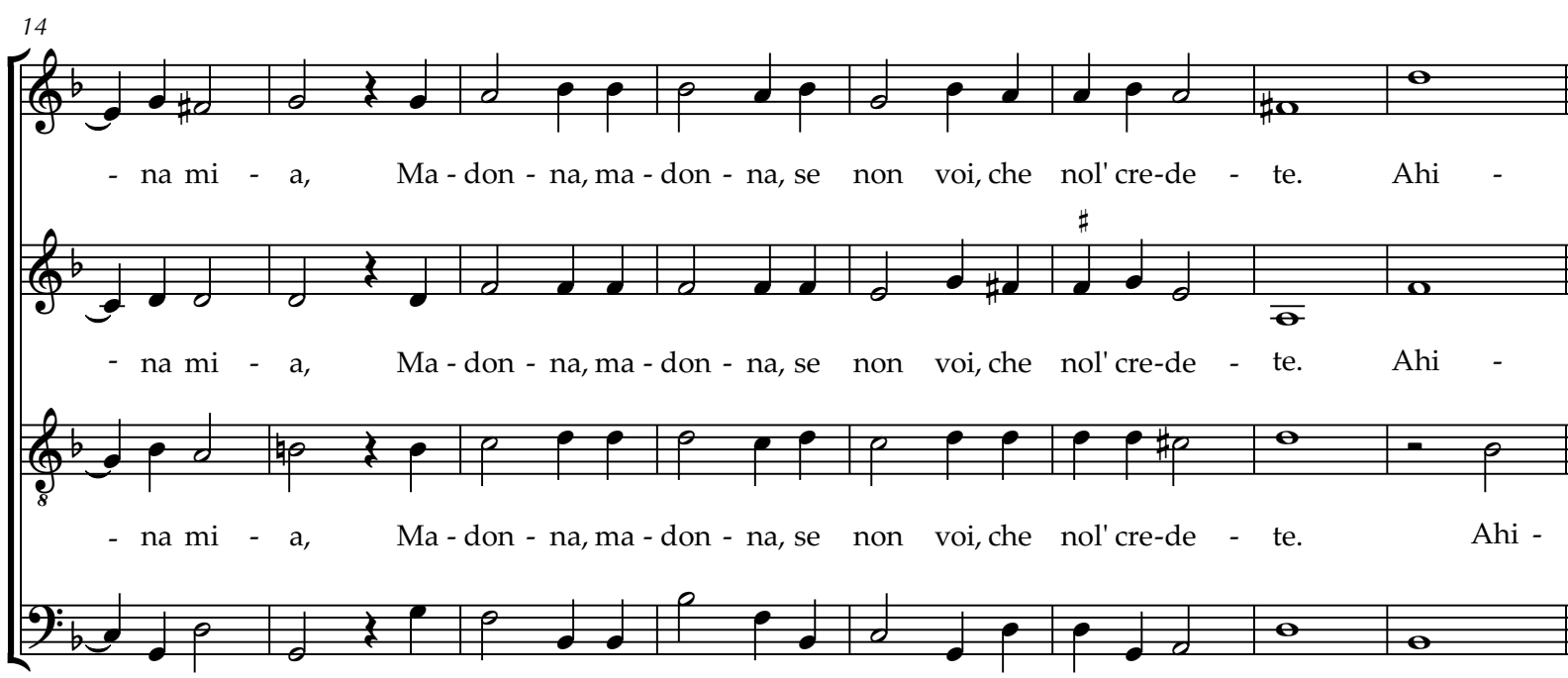

- na mi - a, Ma - don - na, ma - don - na, se non voi, che nol'cre-de - te. Ahi -
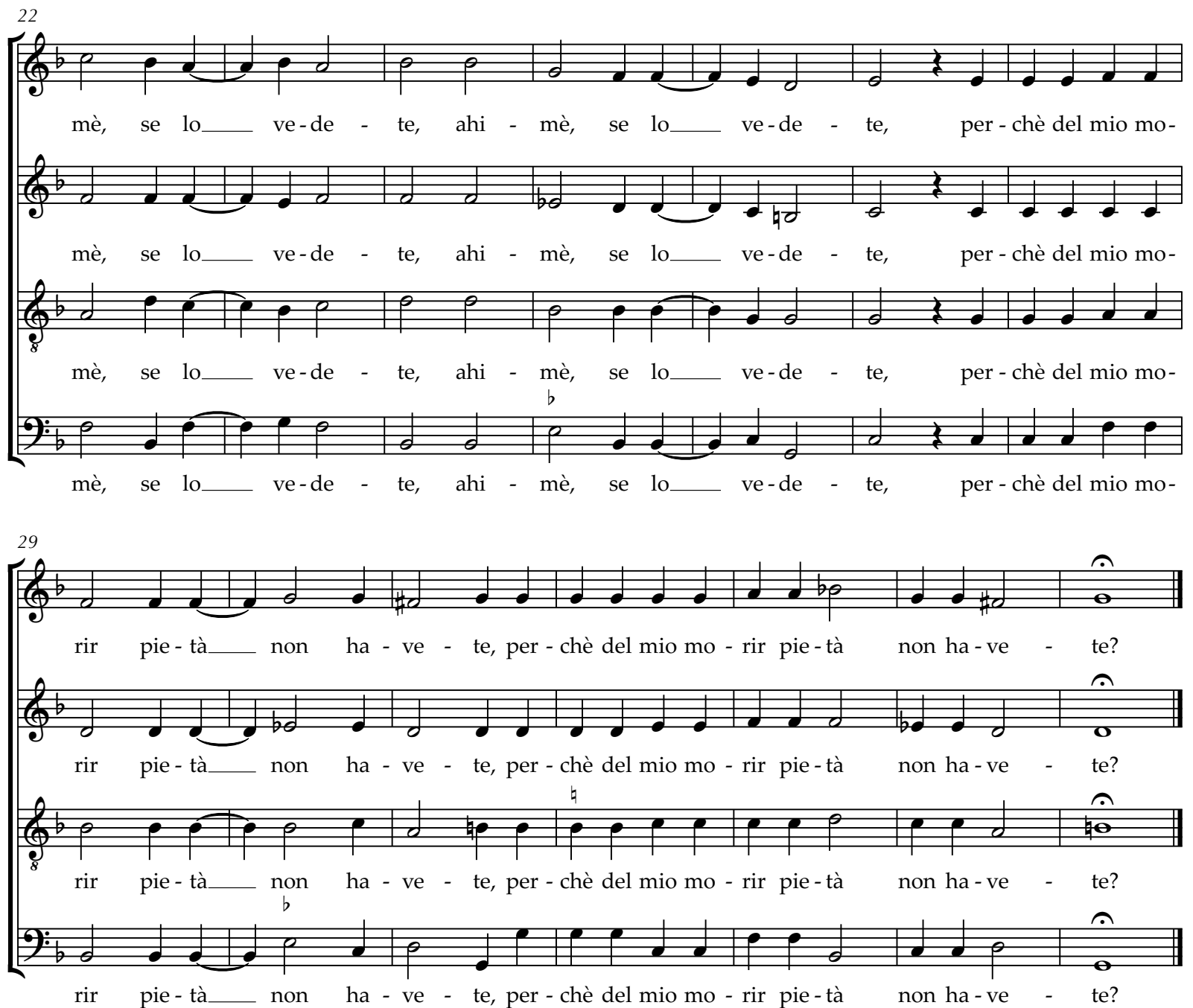

NOTA DO EDITOR:

Discantus, compasso 18: a última semiminima consta como Bb no manuscrito. 


\subsection{FORSI PERCHÈ CORE MIO BELL' AHIMÈ}

(Winchester Partbooks, n. 64)

Texto: anônimo

Forsi perchè, core mio bell' ahimè, Vorria essere re sol per havere

Sta bella faccia che l'havess' a fare.

Signora della terr' e del o mare,

Core mio bello, ahimè.
Hubert Waelrant (ca.1517-1595)

Transcrito e editado por Munir Sabag

[DISCANTUS]
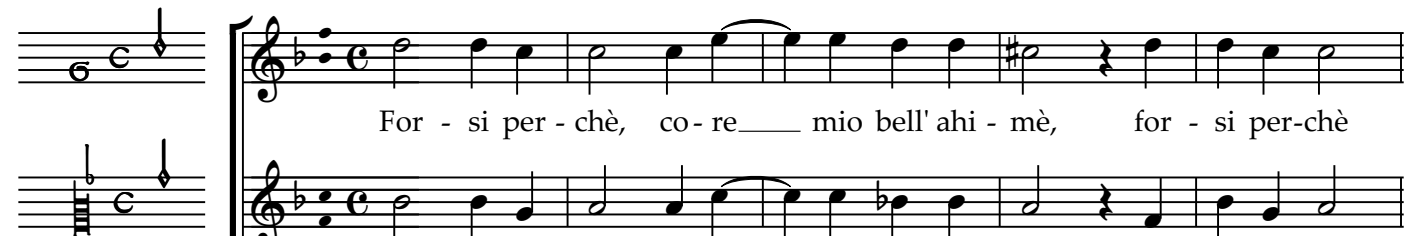

[ALTUS]

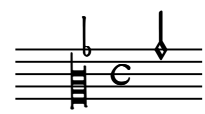

For - si per - chè, co-re mio bell' ahi - mè,

for - si per-chè

Quisera ser rei só para ter

Esta bela face só para mim.

Senhora da terra e do mar,

Meu belo coração, ai de mim.

[TENOR]

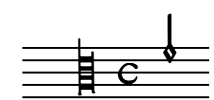

[BASSUS]
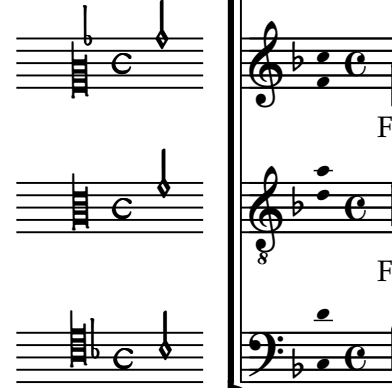

For - si per - chè, co-re

mio bell' ahi - mè,

for - si per-chè

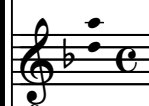

For - si per - chè, co-re

mio bell' ahi - mè,

for - si per-chè

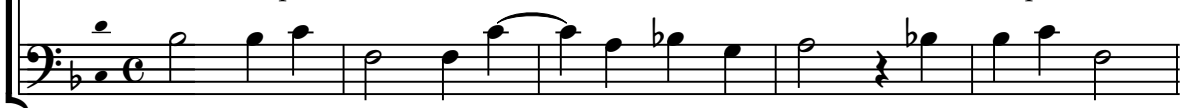

For - si per - chè, co-re

mio bell' ahi - mè,

for - si per-chè

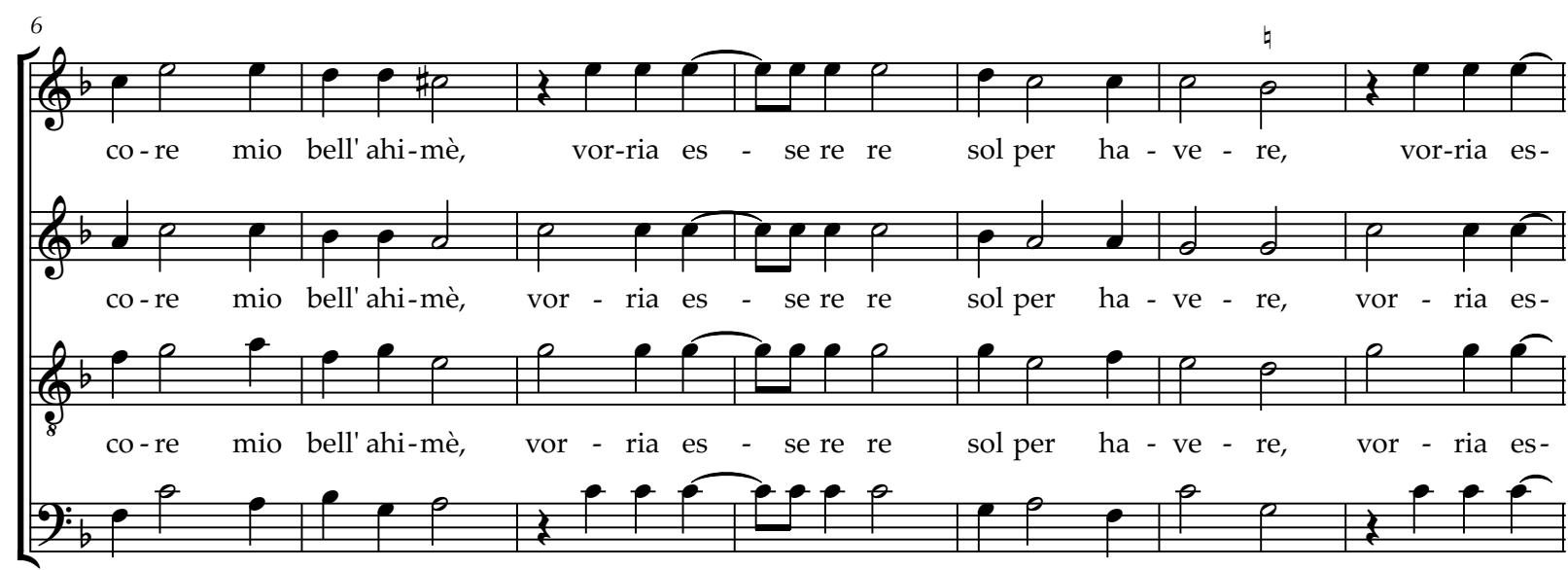

co-re mio bell' ahi-mè,

vor-ria es - se re Re

sol per ha - ve - re,

vor-ria es- 

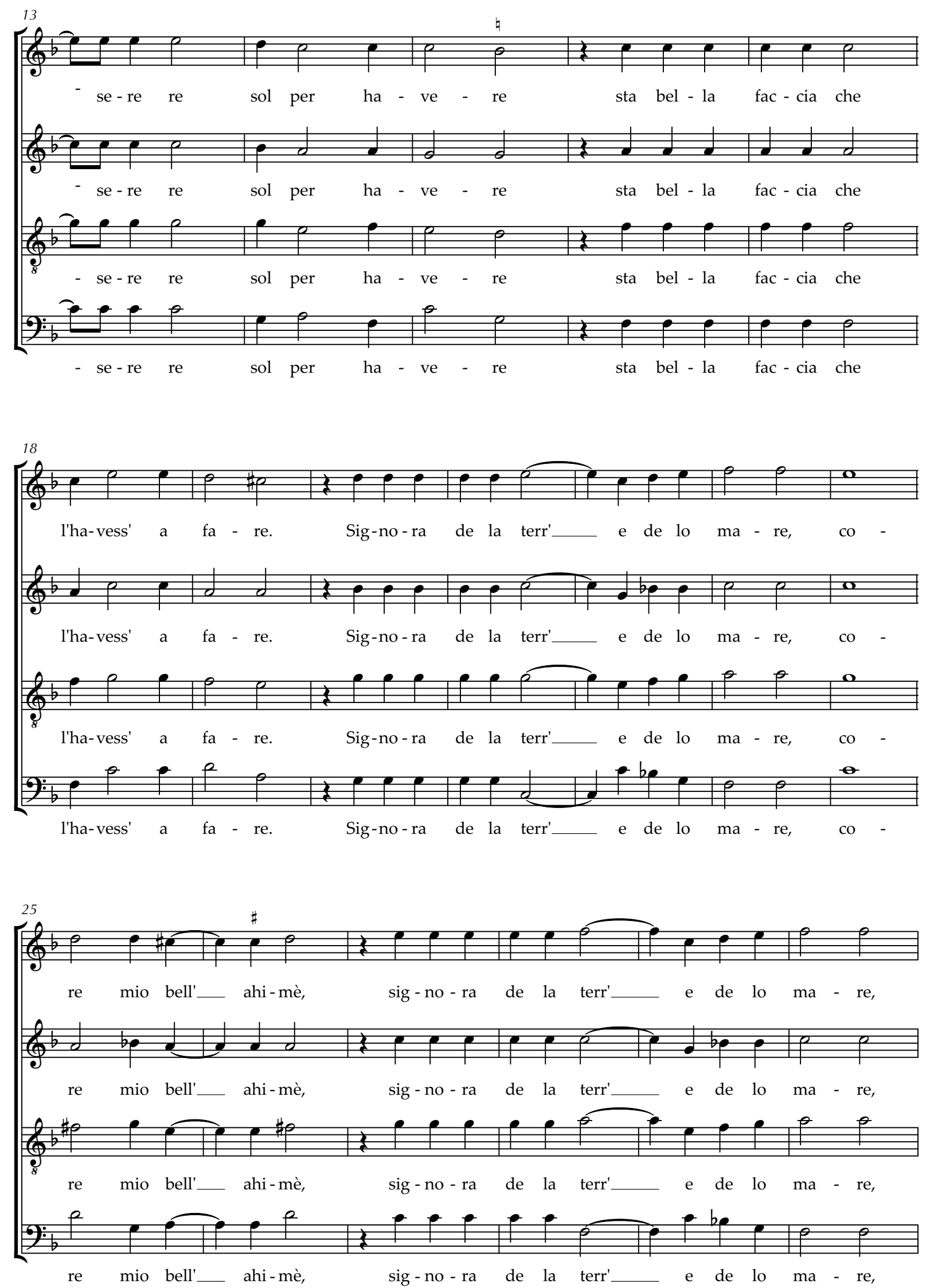


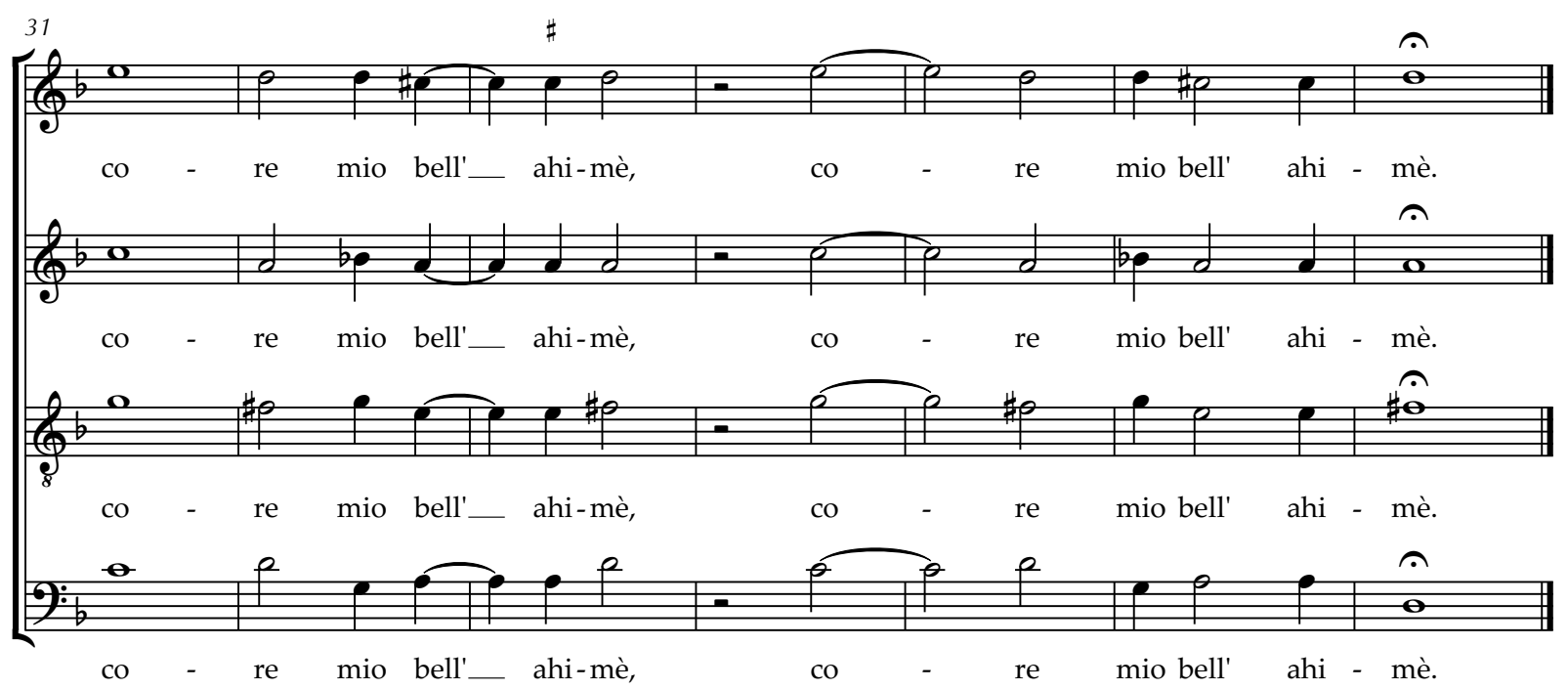




\subsection{QUELL' HORA DESIATA SEMPR' ASPETTO}

(Winchester Partbooks, n. 65)

Texto: anônimo

Hubert Waelrant (ca.1517-1595)

Transcrito e editado por Munir Sabag

Quell'hora desiata sempr'aspetto

Per te veder il giorno anima mia,

Sempre espero aquela hora desejada

E dar ripos' ad ogni penaria. para te ver de dia, alma minha,

$\mathrm{E}$ dar repouso a todo penar.

[DISCANTUS] $\frac{b}{\equiv !}$

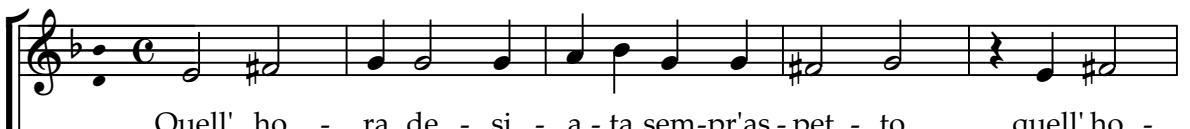

Quell' ho - ra de - si - a - ta sem-pr'as - pet - to, quell' ho -

[ALTUS] 势

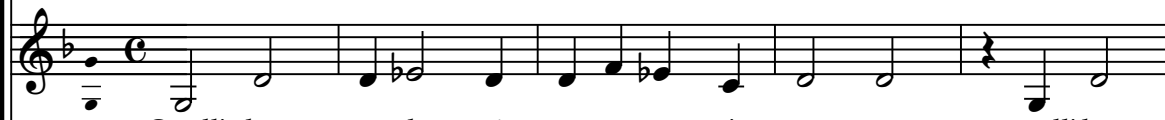

Quell' ho - ra de - si - a - ta sem-pr'as - pet - to, quell' ho -

[TENOR] 勘

[BASSUS]
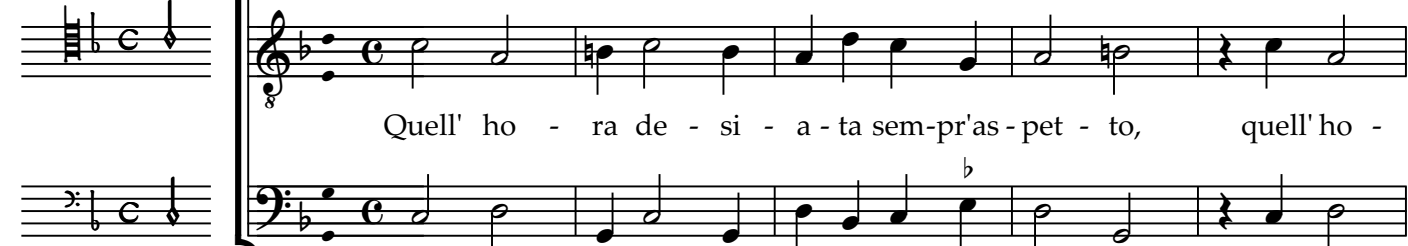

Quell' ho - ra de - si - a - ta sem-pr'as - pet - to, quell' ho -
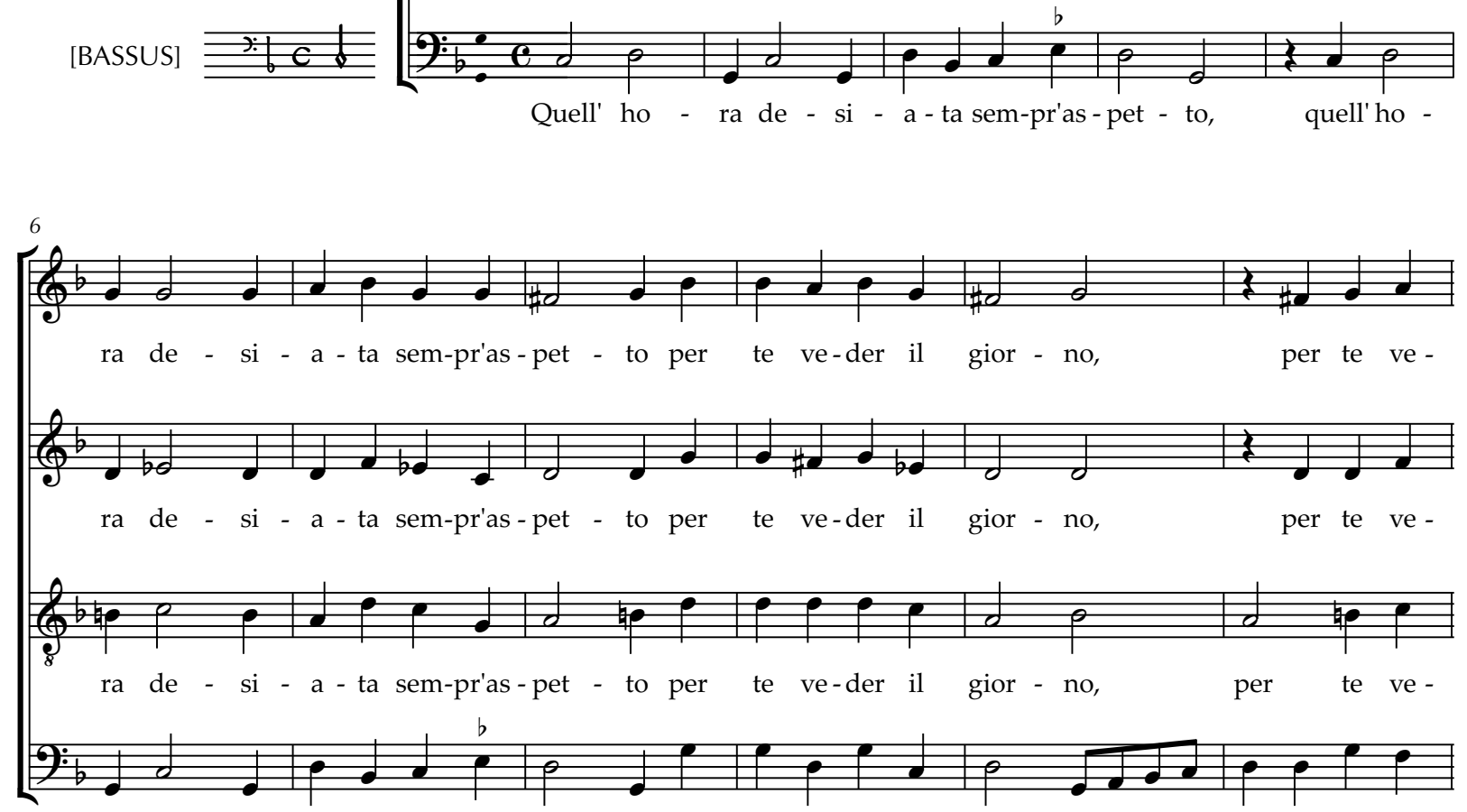

ra de - si - a - ta sem-pr'as - pet - to per te ve-der il gior - no, per te ve - 

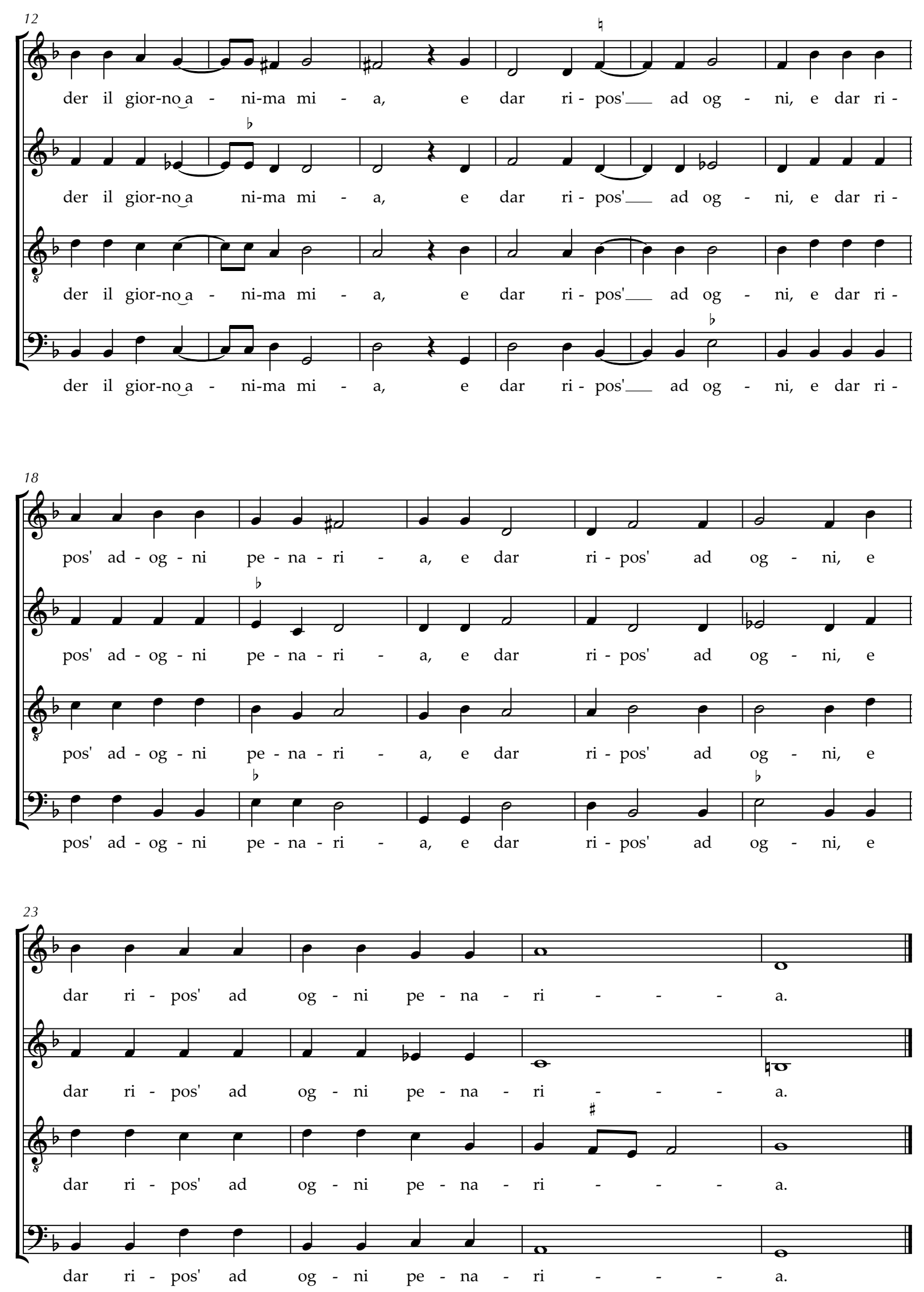


\subsection{9 \\ CON TANTO RIGUARDARE}

(Winchester Partbooks, n. 66)

Texto: anônimo

Hubert Waelrant (ca.1517-1595)

Transcrito e editado por Munir Sabag

Con tanto riguardare

Tu m'hai ucciso, ohimè,

Signora, ch'altro ben tu non mi dai.

Core crudele, perchè lo fai?

Cami moro mo.

Com tantos olhares

Tu me mataste - ai de mim -

Senhora, pois outra coisa tu não me dás.

Coração cruel, por que o fazes?

Pois assim eu vou morrer agora.

[DISCANTUS]
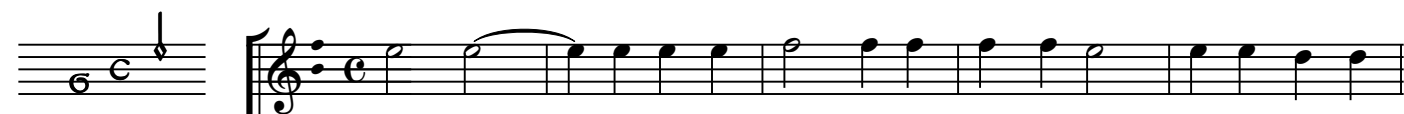

ALTUS]

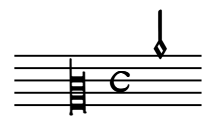

Con tan - to ri-guar-da - re tu m'hai uc-ci - so, ohi-mè, ohi-

TENOR]
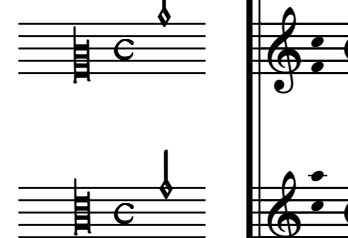

to

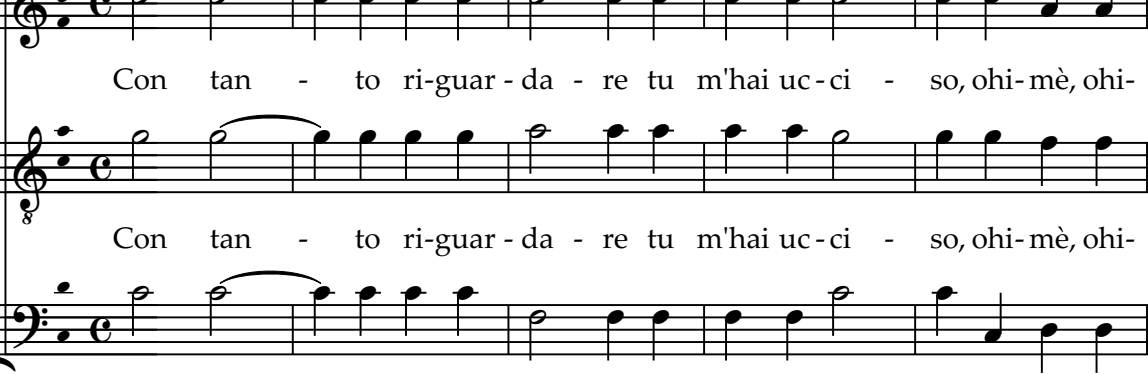

[BASSUS]

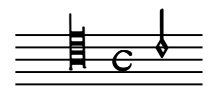

Con $\tan$

to ri-guar - da - re tu m'hai uc-ci - so, ohi-mè, ohi-

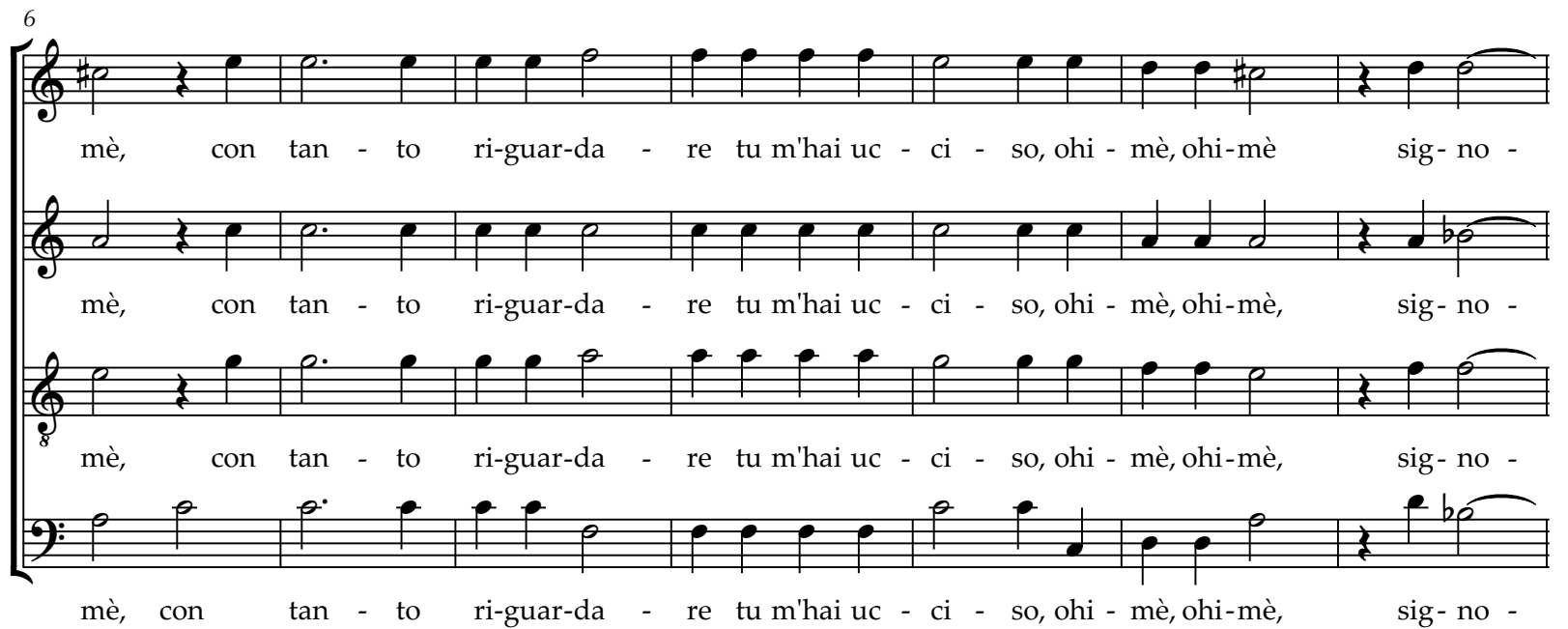



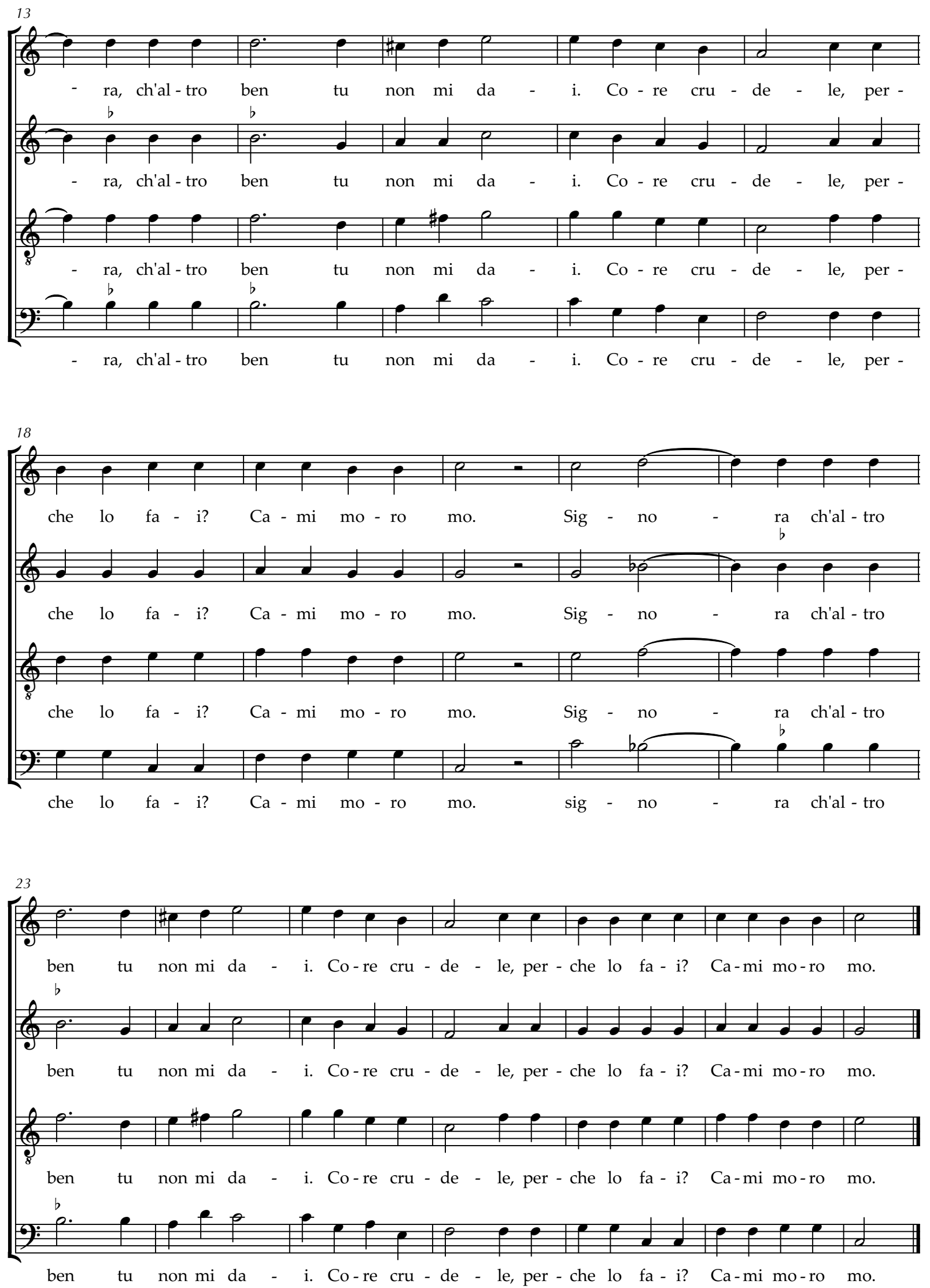


\subsection{A D'ALTRE LO VOI DARE 'STE PASSATE}

(Winchester Partbooks, n. 80)

Texto: anônimo

A d'altre lo voi dare 'ste passate

Che non con non no che voglio lo cocucco.

La trich' e trach' e trucco

Ch'altro sta dentro ed io da for' allucco.
Hubert Waelrant (ca.1517-1595)

Transcrito e editado por Munir Sabag
[DISCANTUS]

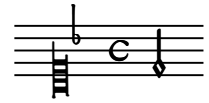

[ALTUS]

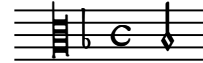

TENOR]

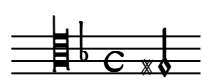

[BASSUS]

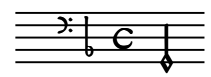

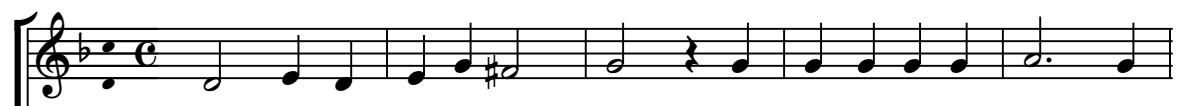

A d'al-tre lo voi da - re, a d'al-tre lo voi da - re

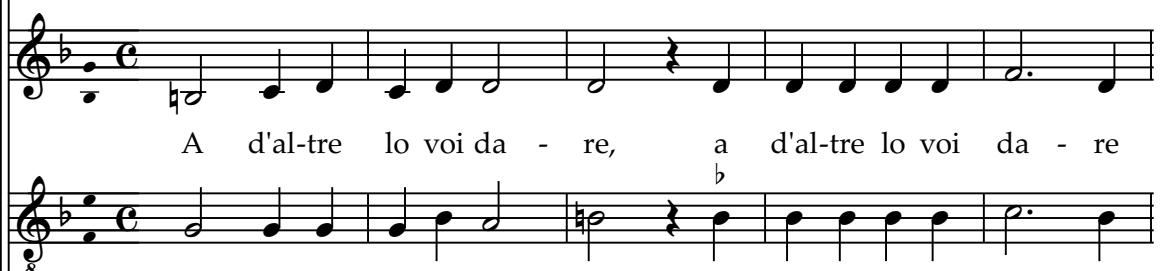

A d'al-tre lo voi da - re, a d'al-tre lo voi da - re

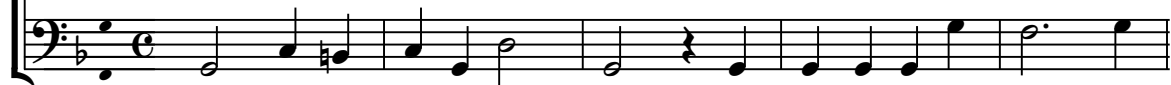

A d'al-tre lo voi da - re, a d'al-tre lo voi da - re

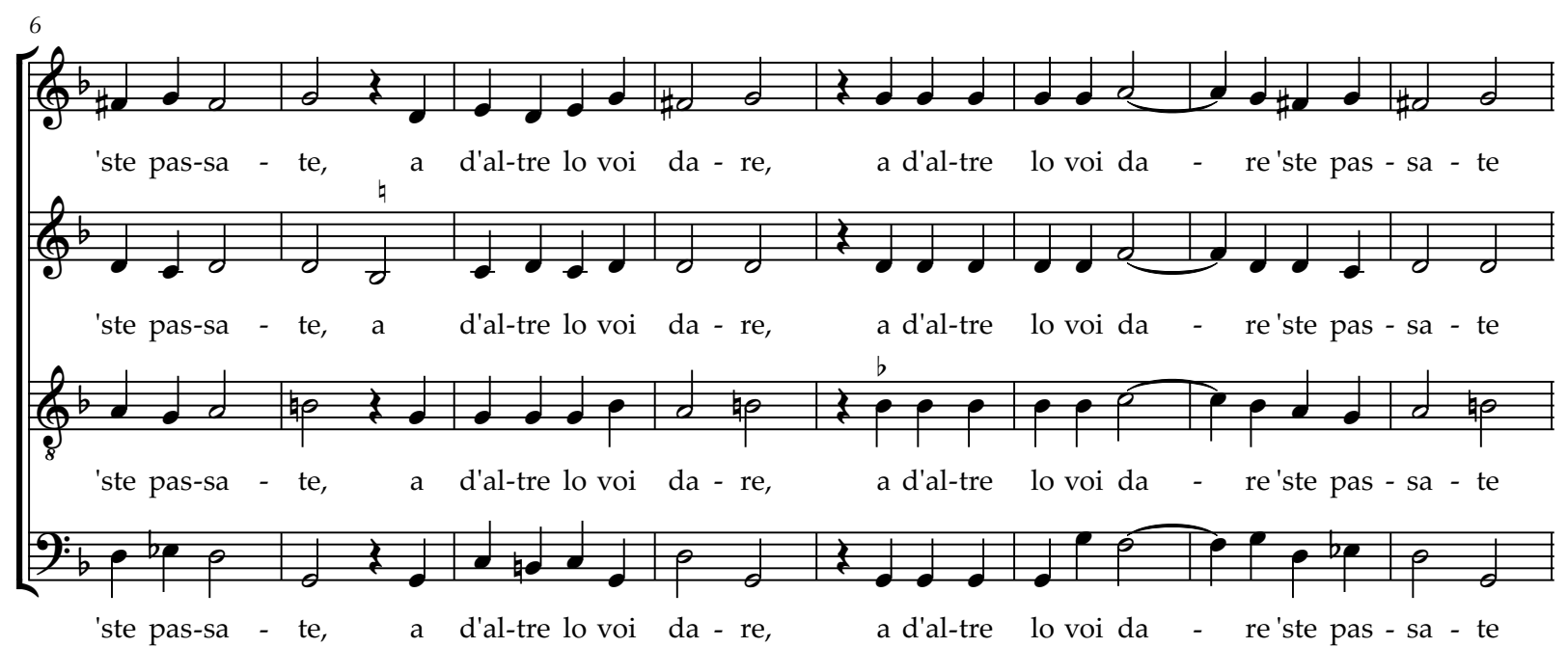




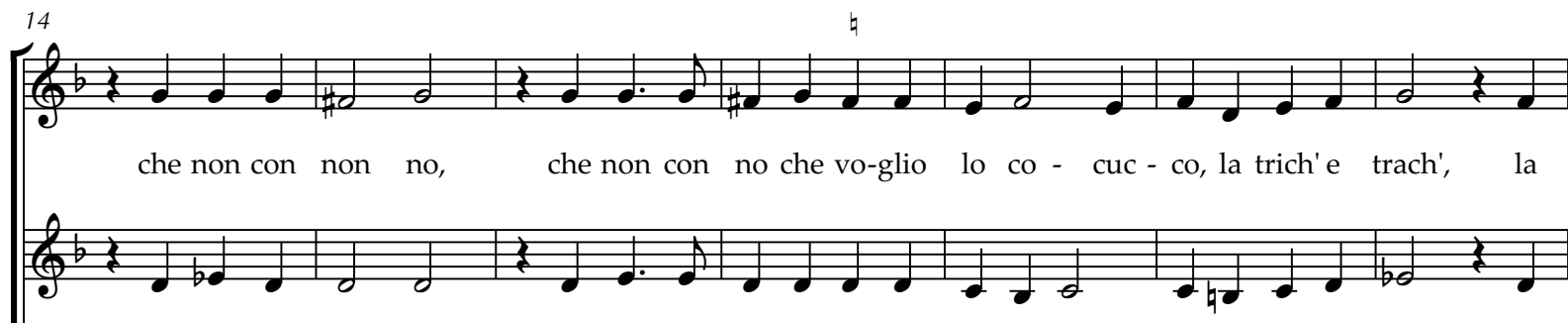

che non con non no, che non con no che vo-glio lo co-cuc - co, la trich'e trach', la

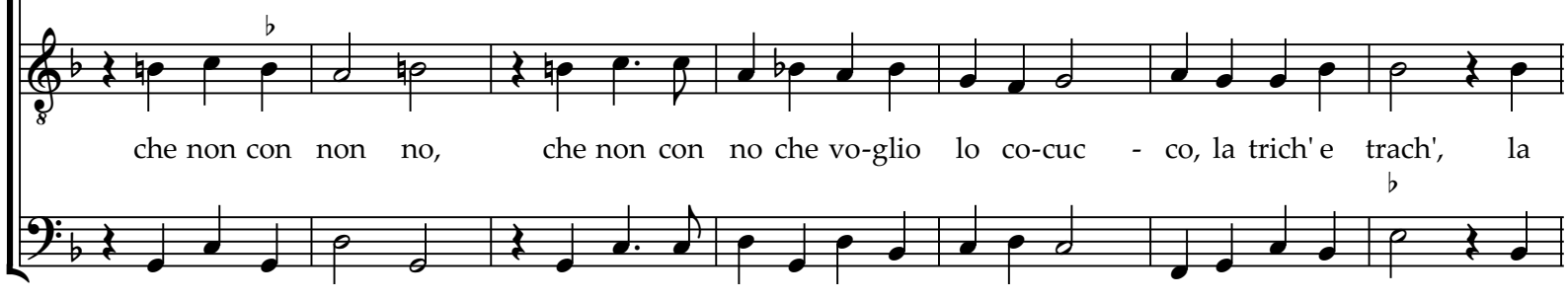

che non con non no, che non con no che vo-glio lo co-cuc - co, la trich'e trach', la
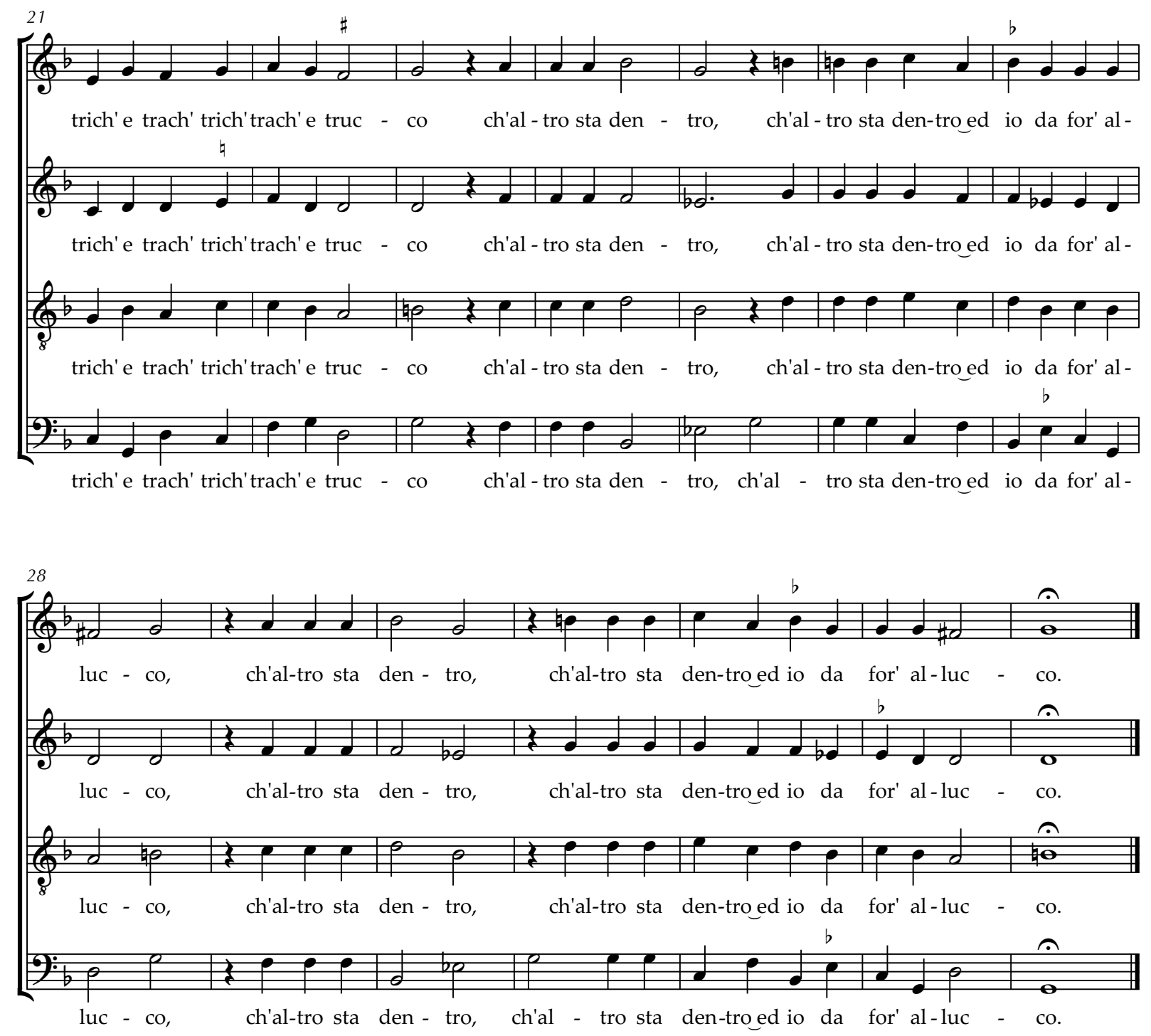


\subsection{SE BEN DA VOI MADDONN' I FIA LONTANO}

(Winchester Partbooks, n. 81)

Texto: anônimo

Hubert Waelrant (ca.1517-1595) Transcrito e editado por Munir Sabag

Se ben da voi madonn' i fia lontano, Giammai non lasserò lo vostr' amore. L'alma ch'al mio partir vi lass' in mano Lieta con voi dimor' a tutte l'hore.

Gl'occhi leggiadri vostr' ognor mi stano

Scolpiti vivi viv' in mezzo il core.

Ma se fortuna vuol vedermi privo,

Pur sempre v'amerò per fin ch'io vivo.

Ainda que eu esteja longe de vós, senhora Jamais abandonarei vosso amor.

A alma que ao meu partir vos deixo nas mãos

Permanece feliz convosco a toda hora.

Vossos olhos graciosos sempre estarão

Esculpidos vivos, vivos dentro do meu coração.

Mas se o destino quer me ver privado [de vós],

Ainda assim vos amarei enquanto eu viva.
[DISCANTUS]

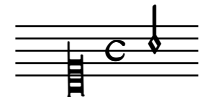

[ALTUS]

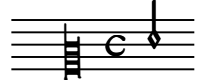

[TENOR]

[BASSUS]

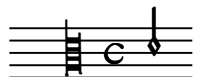

$\equiv$

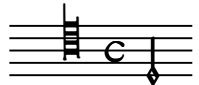

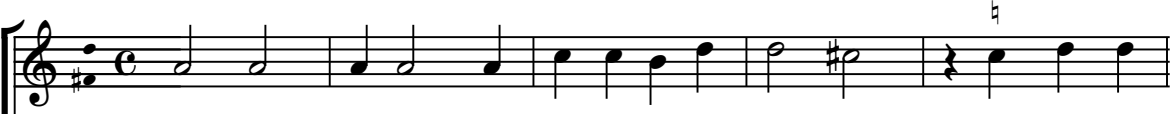

Se ben da voi ma-donn'i fia lon - ta - no, giam-mai non

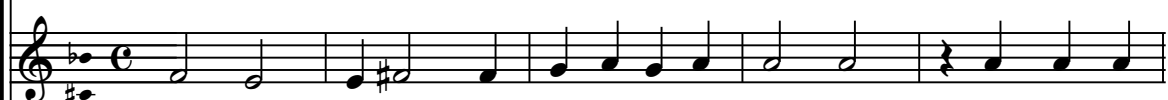

Se ben da voi ma-donn'i fia lon - ta - no, giam-mai non

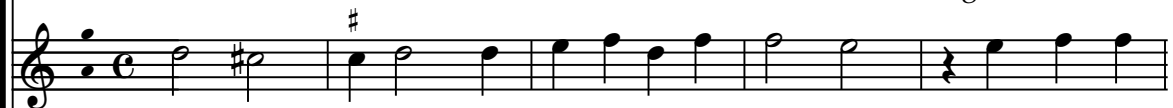

Se ben da voi ma-donn'i fia lon - ta - no, giam-mai non

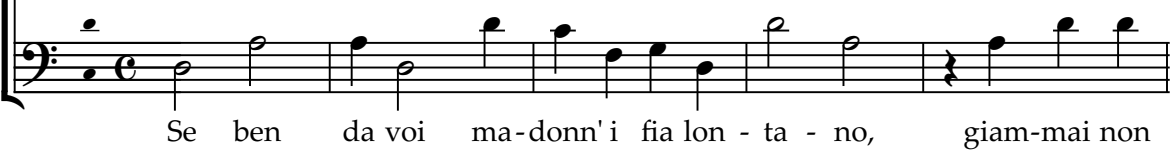

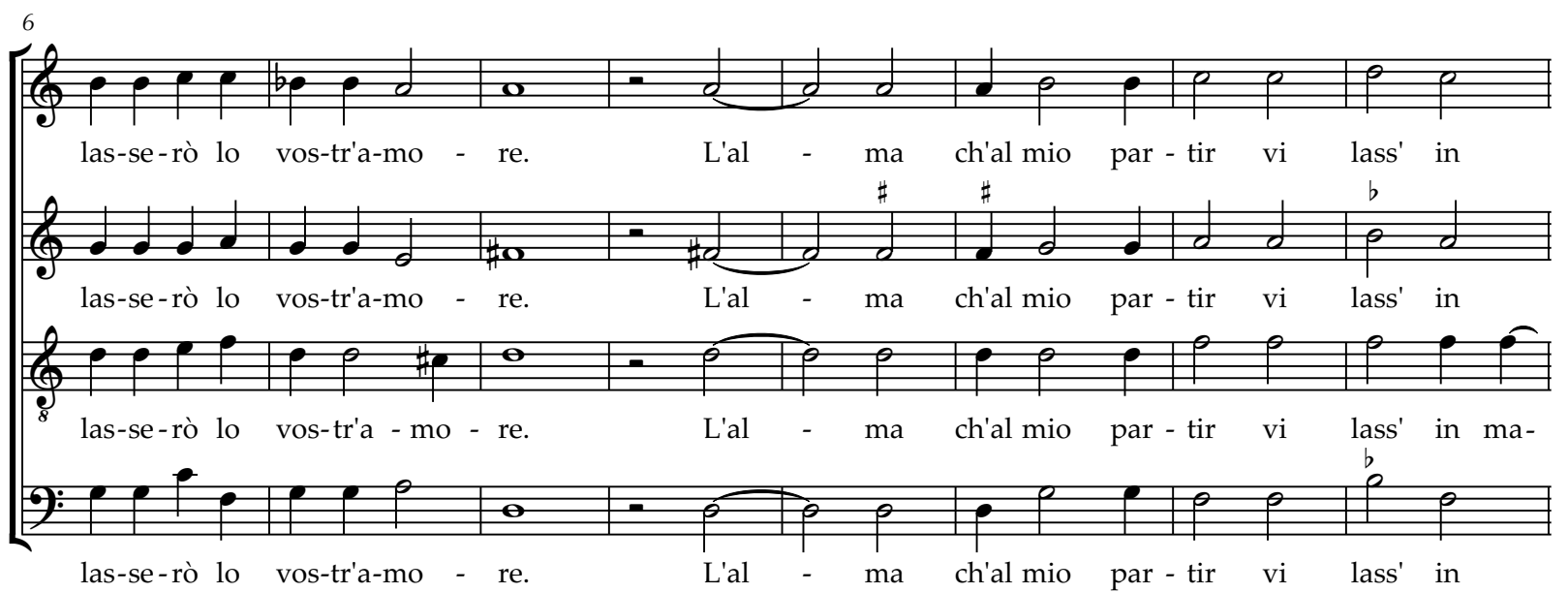



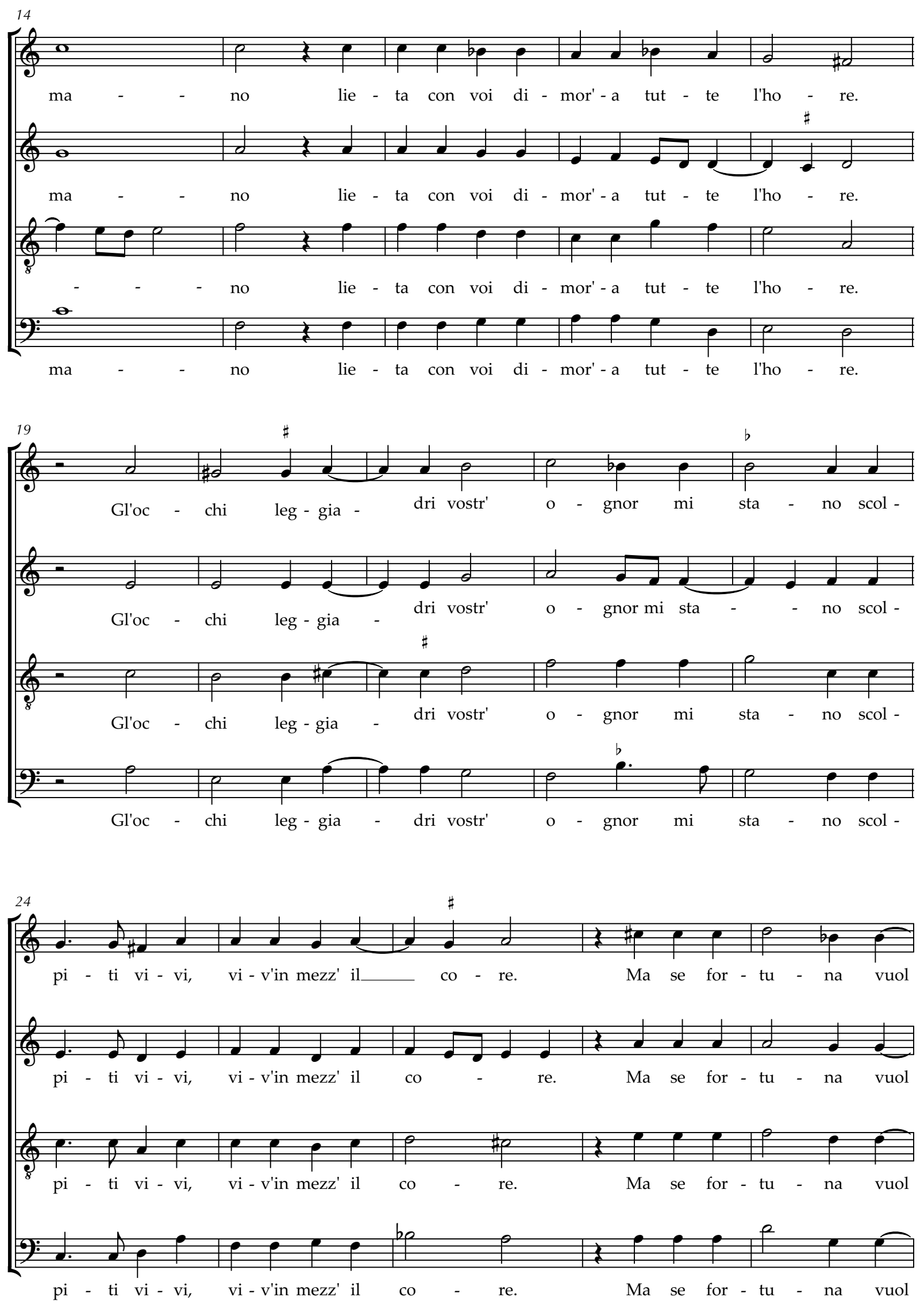

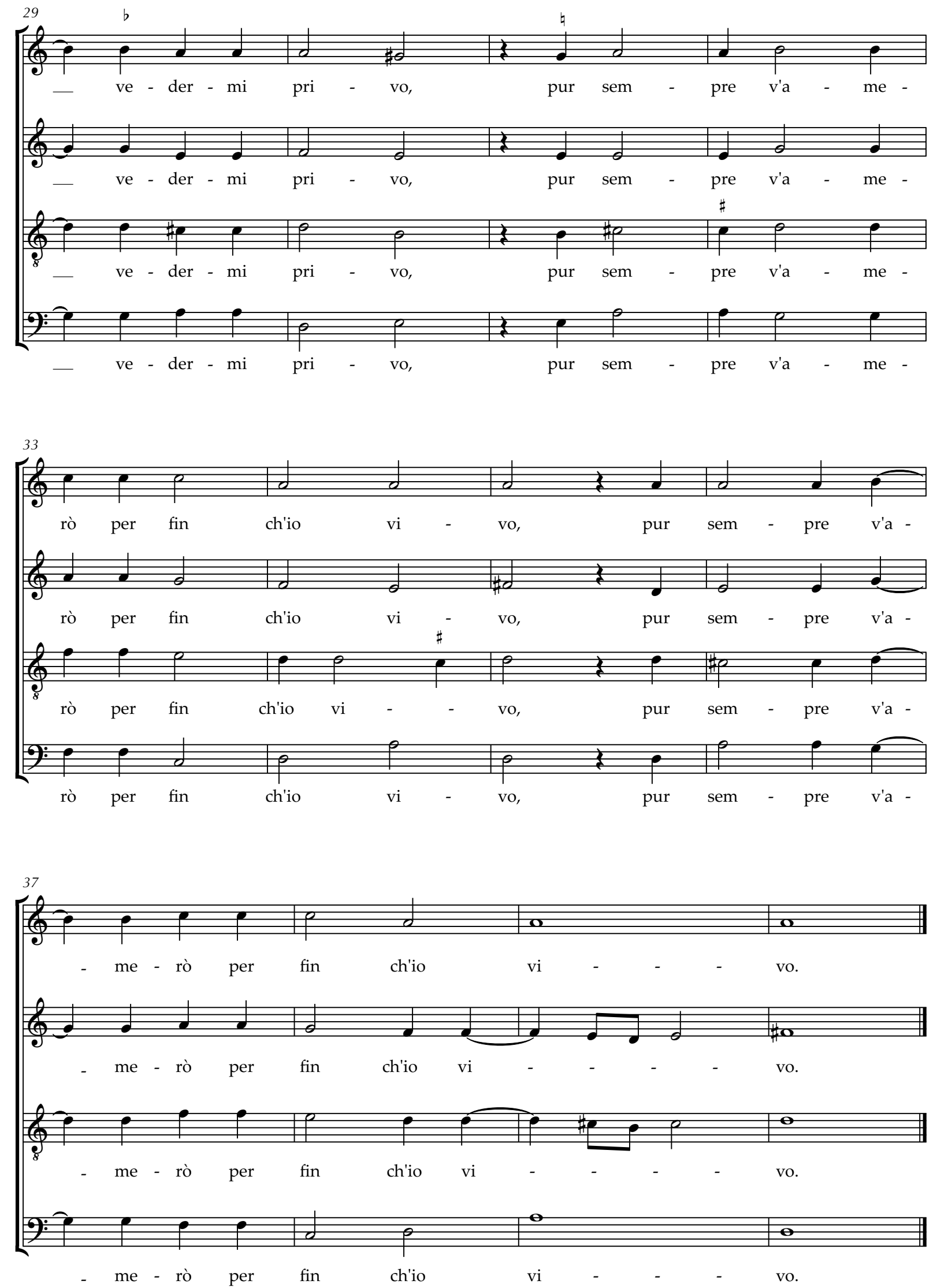


\section{CONSIDERAÇÕES FINAIS: UM ESTUDO ENTRELAÇADO}

No início deste texto, antes mesmo de havermos apresentado o objeto central de nossa pesquisa, apontamos os dois objetivos norteadores desta investigação: (i) compreender as relações entre a escrita original, a notação moderna e a performance da música vocal do Renascimento; e (ii) possibilitar, através de esforços de transcrição, o acesso dos intérpretes a peças que não tenham sido anteriormente editadas ou gravadas. Gerações de musicólogos e intérpretes têm se dedicado a estas tarefas com grande sucesso e julgamos possível fornecer, através deste texto, nossas próprias visões e respostas a estes desafios.

Pretendemos inicialmente responder aos objetivos de maneira isolada - isto é, através da discussão das relações entre notação e performance em um texto teórico formalmente desvinculado das edições que se seguiriam. Os desafios enfrentados durante os processos de transcrição, porém, tiveram papel central para nossa percepção da necessidade de contextualizar o repertório e de preparar o olhar do leitor para os problemas musicais que se apresentariam nas fontes. Isto permitiu que as discussões teóricas fossem entremeadas por exemplos extraídos das próprias peças consideradas - estabelecendo-se um efetivo diálogo entre o texto discursivo dos capítulos 2 e 3 e o texto musical apresentado no capítulo 4 - e por esta razão consideramos este trabalho como um estudo entrelaçado entre musicologia, transcrição e performance. 


\section{REFERÊNCIAS}

\section{Literatura primária}

ANÔNIMO 2. Tractatus de discantu. In: COUSSEMAKER, Edmond (Ed.).

Scriptorum de musica medii aevi novam seriem a Gerbertina alteram, 4 vols, vol. 1. Paris: Durand, 1874-76. p. 303-319.

ARON, Pietro. Toscanello in Musica. Venezia: Bernardino dei Vitali, 1531.

BANCHIERI, Adriano. Cartella musicale nel canto figurato fermo \& contrapunto. Veneza: Giacomo Vicenti, 1614. (Trabalho original publicado em 1601.)

BELDOMANDI, Prosdocimo; HERLINGER, Jan (Trad.), Contrapunctus: a New Critical Text and Translation by Jan Herlinger. Lincoln and London: University of Nebraska Press, 1984.

GUMPELZHAIMER, Adam. Compendium musicae, pro ilius artius tironibus. Augsburg: Valentini Schönigis, 1591.

HEYDEN, Sebald. De Arte Canendi. Nurnberg: Iohannes Petreium, 1540.

LANFRANCO, Giovanni. Scintille di Musica. Brescia: Lodovico Britannico, 1533.

LIBRO PRIMO DE LA CROCE. Roma: Giovanni Pasoti \& Valerio Dorico, 1526. Disponível em < https://imslp.org/wiki/Libro_primo_de_la_Croce_(Various)>.

LUSITANO, Vicente. Introduttione facilissima, et novissima, di canto fermo, figurato, contraponto semplice, et in concerto, com regole generali per far fughe differenti sopra il canto fermo, a II, III. et IIII voci, et compositioni, proportioni, generi. s. diatonico, cromatico, enarmonico. Veneza: Francesco Marcolini, 1558.

MORLEY, Thomas. A Plaine and Easie Introduction to Practicall Musicke. London: Peter Short, 1597.

A Plaine and Easie Introduction to Practicall Musicke. London: Humphrey Lownes, 1608.

MORLEY, Thomas; HARMAN, Alec (Ed.). A Plain and Easy Introduction to Practical Music. Second Edition. New York : W. W. Norton \& Company, Inc., 1952. 
NOLA, Giovan Domenico da. [CANTVS] Canzone villanesche de Don Ioan

Domenico del Giovane de Nola a tre voci novamente ristampate: libro secondo. Venezia: Antonio Gardano, 1545.

PENNA, Lorenzo. Li primi albori musicali per li principianti della musica figurata: distinti in tre libri. Dal primo spuntano li principij del canto figurato; Dal secondo le Regole del contrapunto; Dal terzo appariscono li fondamenti per suonare l'organo o clavicembalo sopra le parte. Bologna: Giacomo Monti, 1679.

QUERCU, Simon de. Opusculum musices perquam brevissimum. Viena: Johann Winterburger, 1509.

RAMIS DE PAREIA, Bartolomeo. Musica practica. Bologna: Baltasar de Hiriberia, 1482.

VANNEO, Stefano. Recanetum de musica aurea. Roma: Valerio Dorico, 1533.

WAELRANT, Hubert. [Alto] Le canzon napolitane a quattro voce di novo stampate. Veneza: Girolamo Scotto, 1565.

WINCHESTER PARTBOOKS. Winchester College Warden and Fellows Library, GBWCc MS 153, Países Baixos, [entre 1564 e 1566]. 4 partbooks manuscritos (discantus, altus, tenor e bassus). Disponíveis em <www.diamm.ac.uk $>$.

ZACCONI, Ludovico. Prattica di musica utile et necessaria per comporre i canti suoi regolatamente, si anco al cantore per assicurarsi in tutte le cose cantabili : divisa in quattro libri ; Ne i quali si tratta delle cantilene ordinarie, de tempi de prolationi, de proportioni, de tuoni, et della conve. Veneza: Bartolomeo Carampello, 1596.

ZARLINO, Gioseffo. Istitutioni Harmoniche. Venezia: Francesco de' Franceschi, 1589.

\section{Literatura secundária}

APEL, Willi. The Notation of Polyphonic Music: 900-1600. Fifth Edition. Cambridge, Massachusetts: The Mediaeval Academy of America, 1953.

BARNETT, Gregory. Tonal Organization in Seventeenth-century Music Theory. In: CHRISTENSEN, Thomas (Ed.). The Cambridge History of Western Music Theory. Cambridge: Cambridge University Press, 2002. p. 407-455. 
BENT, Margaret. Counterpoint, Composition and Musica Ficta. New York and London: Routledge, 2002.

BERGER, Anna Maria Busse. The Evolution of Rhythmic Notation. In:

CHRISTENSEN, Thomas (Ed.). The Cambridge History of Western Music Theory. Cambridge: Cambridge University Press, p. 628-656, 2002.

BERGER, Karol. Musica ficta: Theories of Accidental Inflections in Vocal Polyphony from Marchetto da Padova to Gioseffo Zarlino. Cambridge: Cambridge University Press, 1987.

BURNEY, Charles; MERCER, Frank (Ed.). A General History of Music: From the Earliest Ages to the Present Period (1789), Vol. 1. New York: Harcourt, Brance and Company, 1935.

CARDAMONE, Donna G. The Prince of Salerno and the Dynamics of Oral Transmission in Songs of Political Exile. Acta musicologica, vol. 67, n. 2. Basel: International Musicological Society, 1995. p. 77-108.

DEFORD, Ruth. Tactus, Mensuration and Rhythm in Renaissance Music. Cambridge: Cambridge University Press, 2015.

Tempo Relationships Between Duple and Triple Time in the 16th Century. Early Music History, Vol. 14, p. 1-51. Cambridge: Cambridge University Press, 1995.

DONATO, Baldassare; MACARO, Sestino (Ed.). Chi la gagliarda, donne, vo' imparare. Partitura. 2014.

DONINGTON, Robert. The Interpretation of Early Music. London: Faber and Faber, 1963.

EINSTEIN, Alfred. The Italian Madrigal: Translated by Alexander H. Krappe, Roger H. Sessions and Oliver Strunk. Princeton, NJ: Princeton University Press, 1949. 3 v.

FABRI, Frank. Sidney's Verse Adaptations to Two Sixteenth-Century Italian Art Songs. Renaissance Quarterly v. 23, n. 3. Chicago: The University of Chicago Press, 1970. p. 237-255.

FORNEY, Kristine. A Gift of Madrigals and Chansons: The Winchester Part Books and the Courtship of Elizabeth I by Erik XIV of Sweden. The Journal of Musicology, Berkeley, v. 17, n. 1. Berkeley: University of California Press, 1999. p. 50-75. 
GRIER, James. The Critical Editing of Music: History, Method and Practice. Cambridge: Cambridge University Press, 1996.

HAAR, James. Madrigal. In: . European Music: 1520-1642. Woodbridge: The Boydell Press, 2006. p. 225-245.

KERMAN, Joseph. The Elizabethan Madrigal: A Comparative Study. New York: American Musicological Society, 1962.

. Chi la gagliarda, donna, vo imparare. In: HARMAN, Alec (Ed.). The Oxford Book of Italian Madrigals. London: Oxford University Press, 1983. p. 34-35. Partitura.

. Cingari simo. In: In: WESTPHAL, Kurt; BLUME, Friedrich (Ed.).

Karnevalslieder der Renaissance: zu 3 - 4 Stimmen. Wolfenbüttel: Möseler Verlag, 1936. Partitura. p. 13 (Das Chorwerk, Heft 43)

Madonn'io non lo so. In: HERTZMANN, Erich; BLUME, Friedrich; GUDEWILL, Kurt (Ed.). Volkstümliche Italienische Lieder: Adrian Willaert und andere Meister. Wolfenbüttel: Möseler Verlag, 1930. Partitura. p. 13. (Das Chorwerk, Heft 8)

. O dolce vita mia che t'haggio fatto. In: EINSTEIN, Alfred. The Italian

Madrigal: Translated by Alexander H. Krappe, Roger H. Sessions and Oliver Strunk. Princeton, NJ: Princeton University Press, 1949. v. 3. Partitura. p. 86-87.

REESE, Gustave. Music in the Renaissance. New York: W. W. Norton \& Company, 1954.

RITTERMAN, Janet. The Winchester College Part Books: a Study of the Manuscript with a transcription of the French Chansons. Dissertação de Mestrado - King's College London, 1977.

ROCHE, Jerome. The Madrigal. Second Edition. Oxford: Oxford University Press, 1990.

ROUTLEY, Nicholas. A practical guide to musica ficta. Early Music v. 13 n. 1. Oxford: Oxford University Press, 1985. p. 59-71.

SCHMIDT-BESTE, Thomas. Editorial Text Underlay Revisited. In: DUMITRESCU, T.; KÜGLE, K.; VAN BERCHUM, M. (Ed.). Early Music Editing: Principles, Historiography, Future Directions. Turnhout: Brepols Publishers, 2013. p. 105-139. 
SHERMAN, Bernard. There is no such thing as a norm: Paul Hillier on Renaissance Sacred Music. In: . Inside Early Music: Conversations with Performers. New York: Oxford University Press, 1997. p. 100-116.

SMITH, Anne. The Performance of 16th-Century Music: Learning from the Theorists. Oxford: Oxford University Press, 2011.

STAINER, John. The Notation of Mensurable Music. Proceedings of the Musical Association. London: Taylor \& Francis Ltd. on behalf of the Royal Musical Association, 26th Sess. (1899-1900), p. 215-236, 1900.

STAINER, J. F. R.; STAINER, C. (Ed.). Dufay and his Contemporaries: Fifty Compositions. Score. London: Novello and Company Limited, 1898.

STEELE, John (Ed.). Luca Marenzio: The Complete Four Voice Madrigals for Mixed Voices. New York: Music and Arts, Inc., 1995.

THOMAS, Bernard. Renaissance Music in Modern Notation. Early Music v. 5 n. 1. Oxford: Oxford University Press, 1977. p. 4-11.

UNIVERSITY OF MINNESOTA. Faculty and Staff Directory: Donna C Jackson. Disponível em: < https://cla.umn.edu/about/directory/profile/jacks001>. Acesso em 03/03/2018.

WILLAERT, Adrian. Madonn'io non lo so. In: HERTZMANN, Erich; BLUME, Friedrich; GUDEWILL, Kurt (Ed.). Volkstümliche Italienische Lieder: Adrian Willaert und andere Meister. Wolfenbüttel: Möseler Verlag, 1930. Partitura. p. 18-19. (Das Chorwerk, Heft 8)

WILLAERT, Adrian. O dolce vita mia che t'haggio fatto. In: EINSTEIN, Alfred. The Italian Madrigal: Translated by Alexander H. Krappe, Roger H. Sessions and Oliver Strunk. Princeton, NJ: Princeton University Press, 1949. v. 3. Partitura. p. 88-89.

WILLAERT, Adrian; GARVIN, Allen (Ed.). Cingari simo venite a giocare. Dallas: Hawthorne Early Music, 2015. Partitura. 